\title{
Interpretation of Brine-Permeability Tests of the Salado Formation at the Waste Isolation Pilot Plant Site: First Interim Report
}

Richard L. Beauheim, George J. Saulnier, Jr., John D. Avis

Sandia National Laboratories

Albuquerque, New Mexico 87185 and Livermore, California 94550

for the United States Department of Energy

under Contract DE-ACO4-76DP00789 
Issued by Sandia National Laboratories, operated for the United States Department of Energy by Sandia Corporation.

NOTICE: This report was prepared as an account of work sponsored by an agency of the United States Government. Neither the United States Government nor any agency thereof, nor any of their employees, nor any of their cc.atractors, subcontractors, or their employees, makes any warranty, express or implied, or assumes any legal liability or responsibility for the accuracy, completeness, or usefulness of any information, apparatus, product, or process disclosed, or represents that its use would not infringe privately owned rights. Reference herein to any specific commercial product, process, or service by trade name, trademark, manufacturer, or otherwise, does not necessarily constitute or imply its endorsement, recommendation, or favoring by the United States Government, any agency thereof or any of their contractors or subcontractors. The views and opinions expressed herein do not necessarily state or reflect those of the United States Government, any agency thereof or any of their contractors.

Printed in the United States of America. This report has been reproduced directly from the best available copy.

Available to DOE and DOE contractors from Office of Scientific and Technical Information PO Box 62

Oak Ridge, TN 37831

Prices available from (615) 576-8401, FTS 626-8401

Available to the public from

National Technical Information Service

US Department of Commerce

5285 Port Royal Rd

Springfield, VA 22161

NTIS price codes

Printed copy: A10

Microfiche copy: A01 
SAND90-0083

Unlimited Release

SAND- $-90-0083$

Printed August 1991

\title{
INTERPRETATION OF BRINE-PERMEABILITY TESTS OF THE SALADO FORMATION AT THE WASTE ISOLATION PILOT PLANT SITE: FIRST INTERIM REPORT
}

\author{
Richard L. Beauheim \\ Fluid Flow and Transport Division \\ Sandia National Laboratories \\ Albuquerque, New Mexico 87185 \\ George J. Saulnier, Jr. and John D. Avis \\ INTERA Inc. \\ 6850 Austin Center Blvd., Suite 300 \\ Austin, Texas 78731
}

\begin{abstract}
Pressure-pulse tests have been performed in bedded evaporites of the Salado Formation at the Waste Isolation Pilot Plant (WIPP) site to evaluate the hydraulic properties controlling brine flow through the Salado. Hydraulic conductivities ranging from about $10^{-14}$ to $10^{-11} \mathrm{~m} / \mathrm{s}$ (permeabilities of about 10-21 to $10^{-18} \mathrm{~m}^{2}$ ) have been interpreted from nine tests conducted on five stratigraphic intervals within eleven meters of the WIPP underground excavations. Tests of a pure halite layer showed no measurable permeability. Pore pressures in the stratigraphic intervals range from about 0.5 to $9.3 \mathrm{MPa}$. An anhydrite interbed (Marker Bed 139) appears to be one or more orders of magnitude more permeable than the surrounding halite. Hydraulic conductivities appear to increase, and pore pressures decrease, with increasing proximity to the excavations. These effects are particularly evident within two to three meters of the excavations. Two tests indicated the presence of apparent zero-flow boundaries about two to three meters from the boreholes. The other tests revealed no apparent boundaries within the radii of influence of the tests, which were calculated to range from about four to thirty-five meters from the test holes. The data are insufficient to determine if brine flow through evaporites results from Darcy-like flow driven by pressure gradients within naturally interconnected porosity or from shear deformation around excavations connecting previously isolated pores, thereby providing pathways for fluids at or near lithostatic pressure to be driven towards the low-pressure excavations. Future testing will be performed at greater distances from the excavations to evaluate hydraulic properties and processes beyond the rarge of excavation effects.
\end{abstract}

\section{MASTER}




\section{ACKNOWLEDGEMENTS}

The authors wish to thank Lee Jensen, Wayne Stensrud, Jeff Palmer, Randy Roberts, Paul Domski, Kent Lantz, and Michael Bame for their efforts in fielding the tests discussed in this report. We would also like to thank Chris Neuzil, Susan Howarth, John Stormont, Dave McTigue, Dave Borns, Wolfgang Wawersik, Darrell Munson, and John Pickens for their helpful review comments. Tim Dale performed a valuable consistency review of the manuscript and assisted with figure preparation. Bob Jones' and Darcy Pulliam's efforts in preparing the camera-ready version of the manuscript are also appreciated. 


\section{TABLE OF CONTENTS}

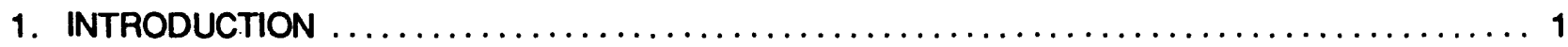

2. GEOLOGIC SETTING AND LOCAL STRATIGRAPHY $\ldots \ldots \ldots \ldots \ldots \ldots \ldots \ldots \ldots \ldots \ldots$

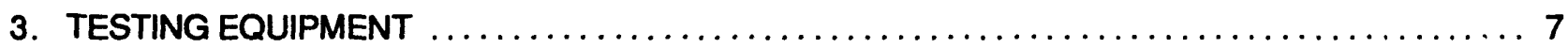

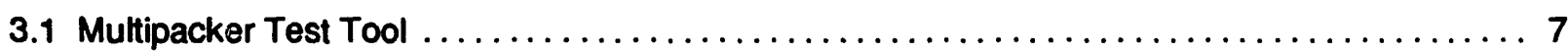

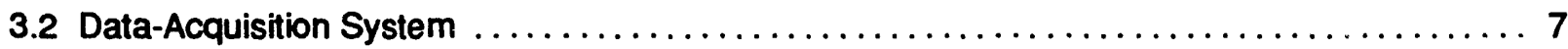

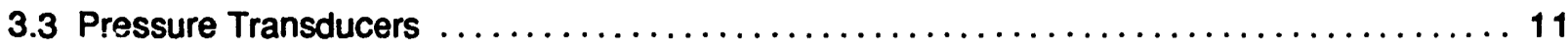

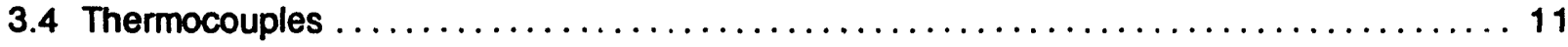

3.5 Linear Variable-Differential Transformers $\ldots \ldots \ldots \ldots \ldots \ldots \ldots \ldots \ldots \ldots \ldots \ldots \ldots \ldots \ldots$

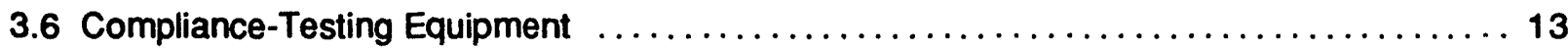

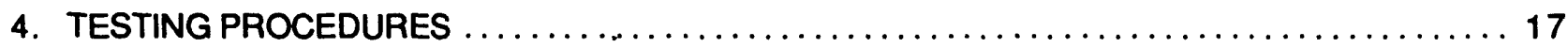

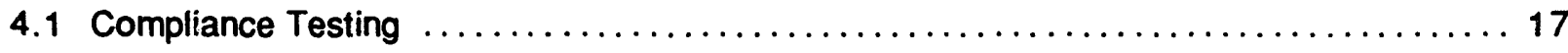

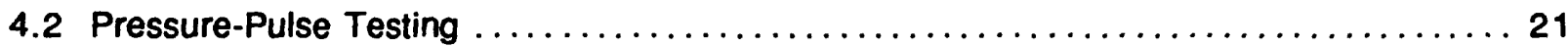

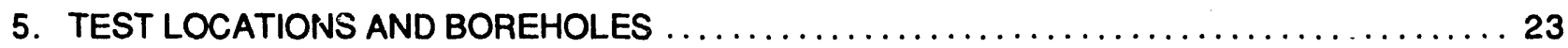

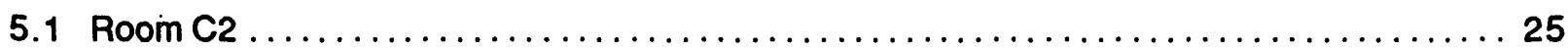

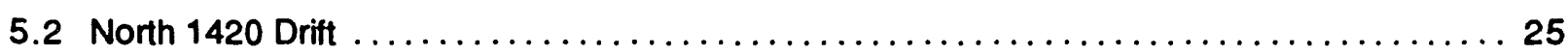

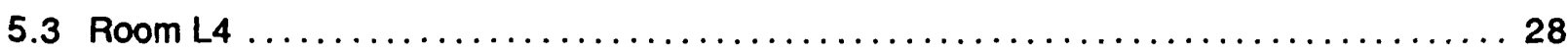

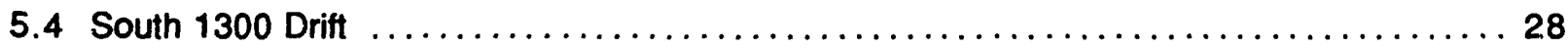

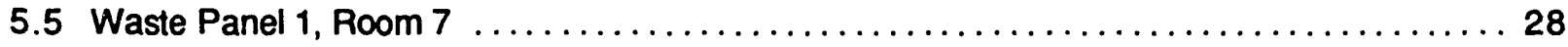

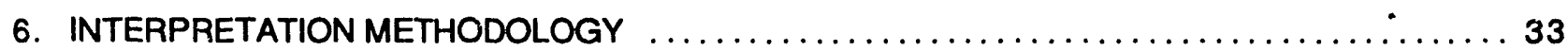

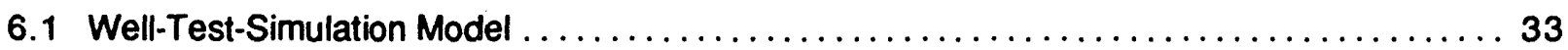

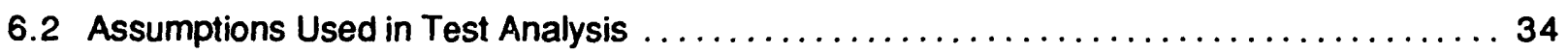

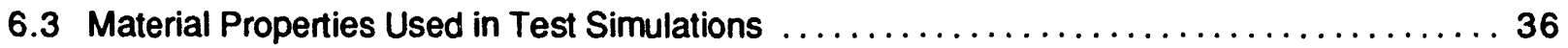

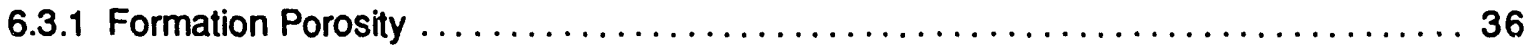

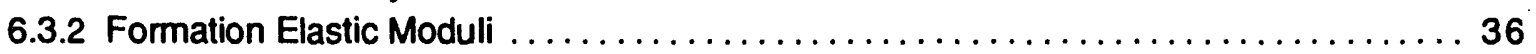

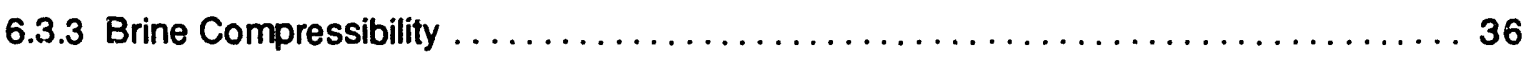

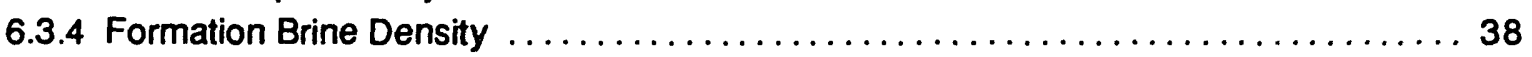

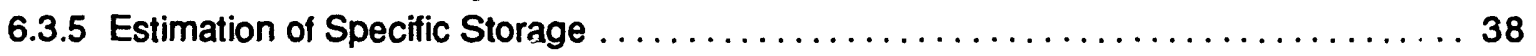

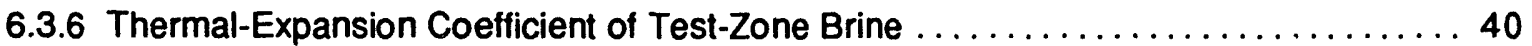

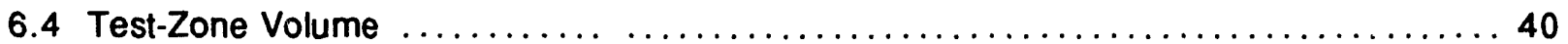

6.4 .1 Initial Test-Zone Volume ...................................... 41

6.4.2 Compensation for Changes in Test-Zone Volume .................. 42

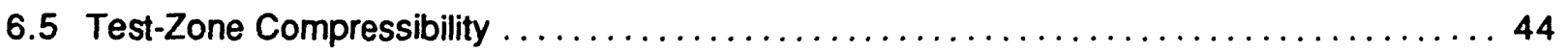

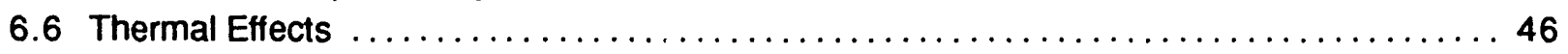

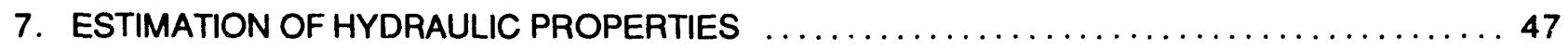

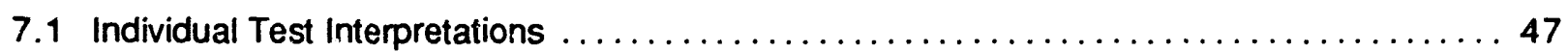

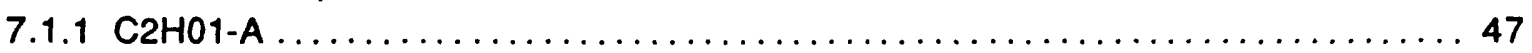

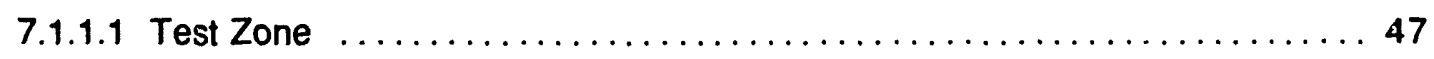




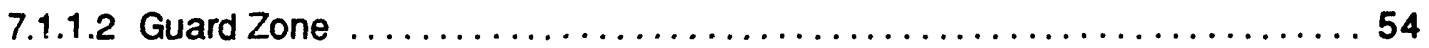

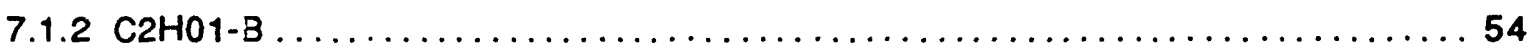

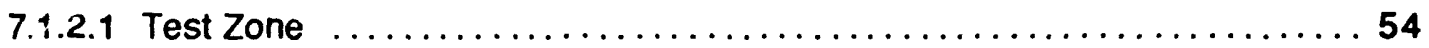

7.1.2.2 Guard Zone .............................................. 59

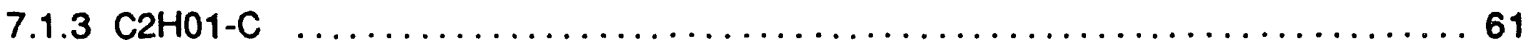

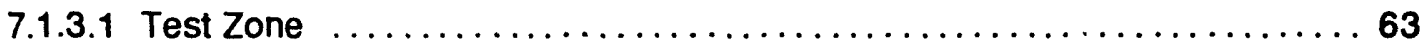

7.1.3.2 Guard Zone ..................................... 64

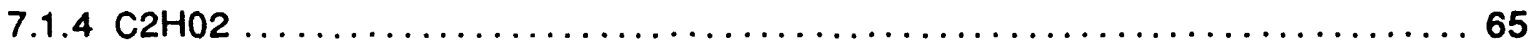

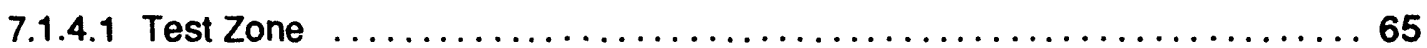

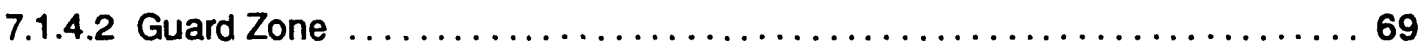

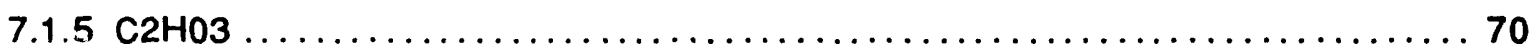

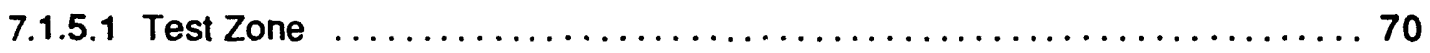

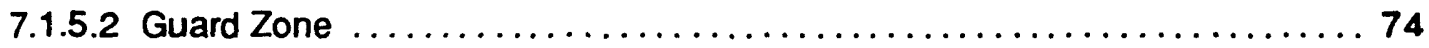

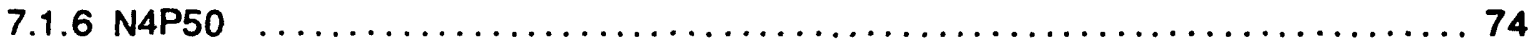

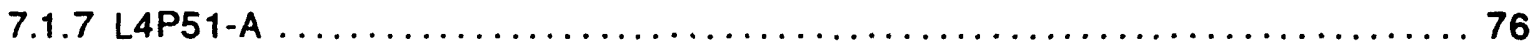

7.1.7.1 Test Zone ............................................... 76

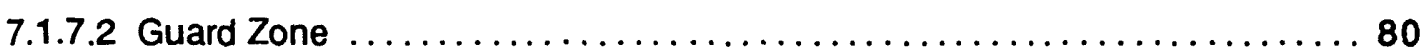

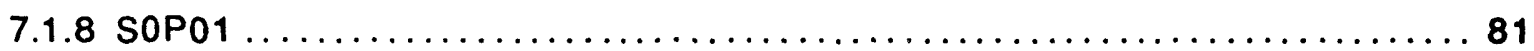

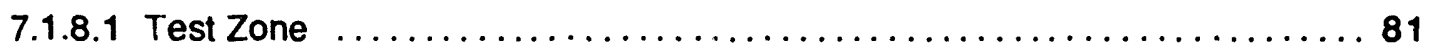

7.1.8.2 Guard Zone ......................................... 84

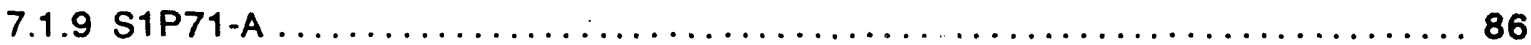

7.1.9.1 Test Zone ......................................... 86

7.1.9.2 Guard Zone ....................................... 88

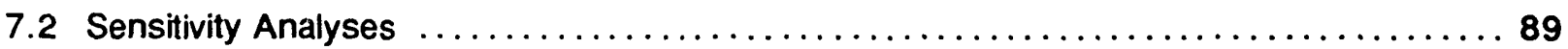

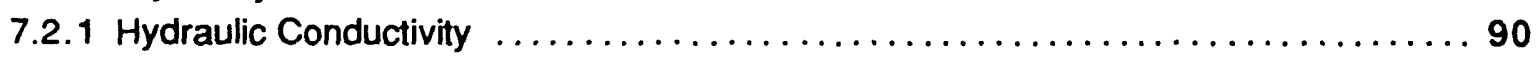

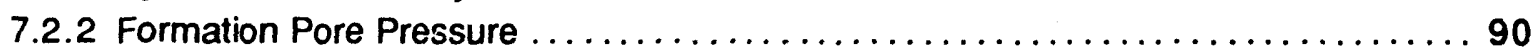

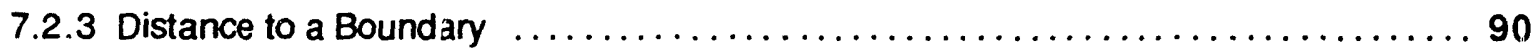

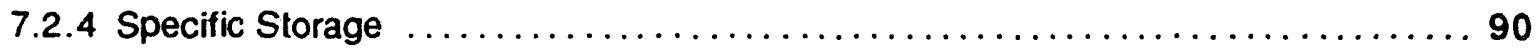

7.2.5 Test-Zone Compressibility ...................................... 110

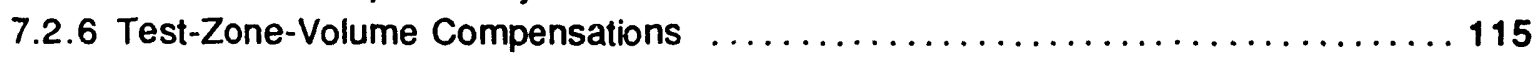

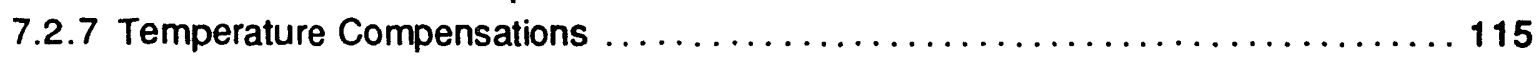

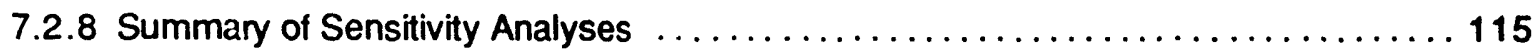

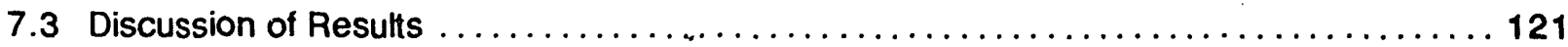

7.3.1 Effects of Disturbed-Rock Zone .............................. 121

7.3.1.1 Comparison of Results from L4P51-A, S0P01, and S1P71-A ......... 122

7.3.1.2 Comparison of Results from $\mathrm{C}_{2} \mathrm{H} 01-\mathrm{C}$ and $\mathrm{C} 2 \mathrm{H} 02 \ldots \ldots \ldots \ldots \ldots . . . . . .123$

7.3.1.3 Relationship Between Hydraulic Conductivity and Distance

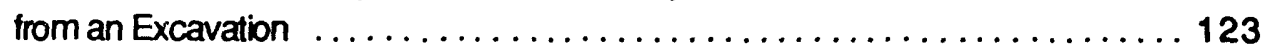

7.3.1.4 Relationship Between Formation Pore Pressure and Distance from an Excavation .................................. 124

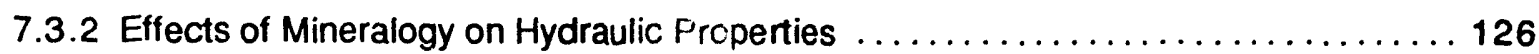

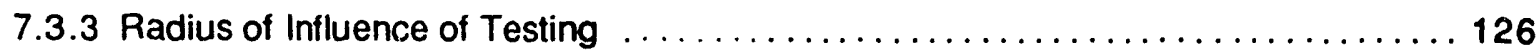

7.3.4 Evaluation of Porous-Medium Assumption ...................... 127

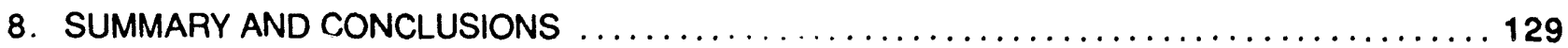

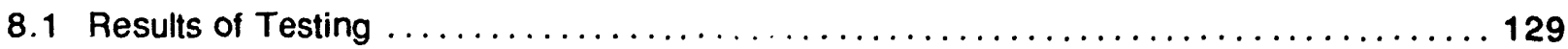




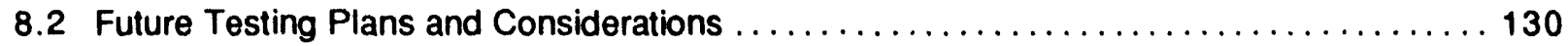

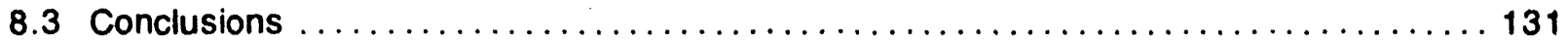

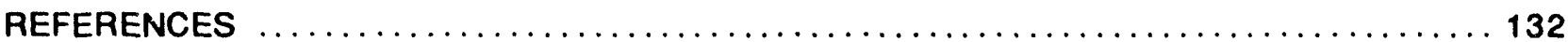

APPENDIX A: Summary of Surface-Based Hydraulic Testing of the Salado Formation $\ldots \ldots \ldots \ldots 137$

APPENDIX B: Stratigraphic Units (Map Units) Near the WIPP Facility Horizon $\ldots \ldots \ldots \ldots \ldots \ldots \ldots 141$

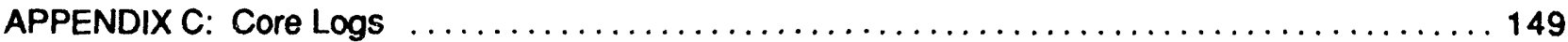

APPENDIX D: Factors Affecting Test-Zone Compressibility ..................... 177

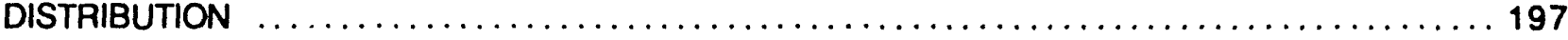




\section{FIGURES}

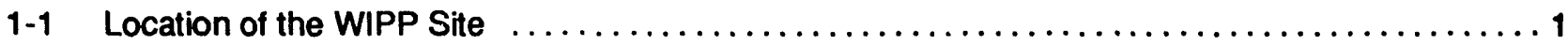

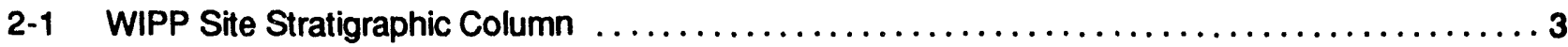

2-2 Detailed Stratigraphy Near the WIPP Underground Facility $\ldots \ldots \ldots \ldots \ldots \ldots \ldots \ldots \ldots \ldots$

2-3 Schematic of Typical WIPP Underground Rooms Showing Stratigraphic Positions $\ldots \ldots \ldots \ldots 5$

3-1 Multipacker Test Tool \#1 Used in C2H01-A and C2H01-B Testing and in

Waste-Handling Shatt Festing $\ldots \ldots \ldots \ldots \ldots \ldots \ldots \ldots \ldots \ldots \ldots \ldots \ldots \ldots$

3-2 Typical Configuration of the Multipacker Test Tools Designed for Underground Testing ....... 9

3-3 Detail of Test- and Guard-Zone Sections of the Multipacker Test Tool ................. 10

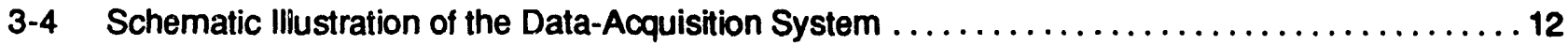

3-5 Movement of Sliding-End Sub in Guard Zone During Packer Inflation . . . . . . . . . . . . . 14

3-6 Cross-Section View of Stainless-Steel Compliance-Testing Chamber in Borehole P4P30 . . . . 15

4-1 Zone Pressures for Compliance Test COMP 16, Multipacker Test Tool \#5, Borehole C2H03 ... 19

4-2 Packer Pressures for Compliance Test COMP 16, Multipacker Test Tool \#5, Borehole C2H03 . 19

4-3 Zone Temperatures for Compliance Test COMP 16, Multipacker Test Tool \#5,

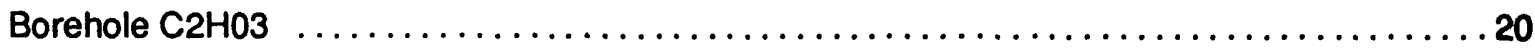

4-4 Radial-LVDT Data for Compliance Test COMP 16, Multipacker Test Tool \#5, Borehole C2H03 .. 20

4-5 Axial-LVDT Data for Compliance Test COMP 16, Multipacker Test Tool \#5, Borehole C2H03 ..21

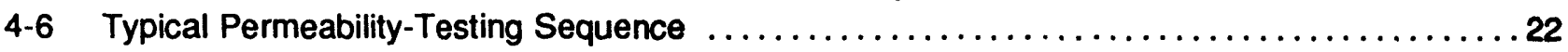

5-1 Map of the WIPP Underground Facility Showing Test Locations $\ldots \ldots \ldots \ldots \ldots \ldots \ldots \ldots 24$

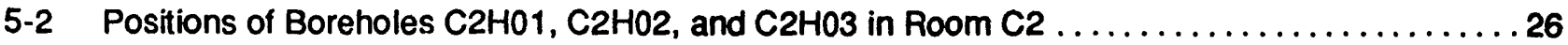

5-3 Position of Borehole N4P50 in the North 1420 Drift ............................ 27

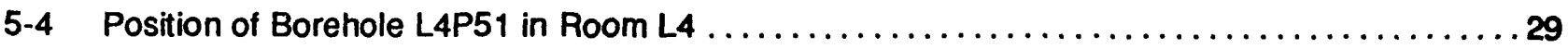

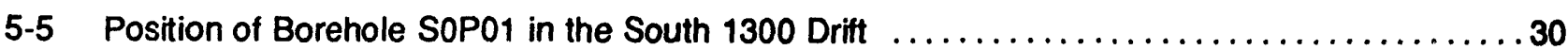

5-6 Position of Borehole S1P71 in Waste Panel 1, Room $7 \ldots \ldots \ldots \ldots \ldots \ldots \ldots \ldots \ldots \ldots \ldots \ldots \ldots \ldots . \ldots \ldots$

7-1 Configuration of Multipacker Test Tool \#1 in Borehole $\mathrm{C} 2 \mathrm{HO} 01$ for C2H01-A Testing ........49

7-2 Test- and Guard-Zone Fluid-Pressure Data irom $\mathrm{C}_{2} \mathrm{H} 01-\mathrm{A}$ Testing $\ldots \ldots \ldots \ldots \ldots \ldots \ldots$

7-3 Best-Fit Model Simulation of the Test-Zone Fluid-Pressure Response During

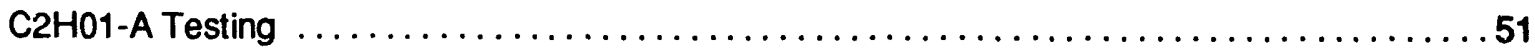

7-4 Simulated Formation Pore Pressures at Selected Radial Distances from the Test

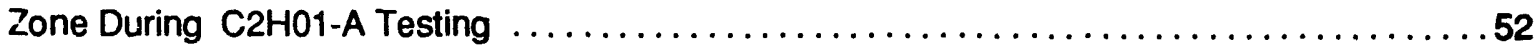

7-5 Best-Fit Model Simulation of the Test-Zone Fluid-Pressure Response During

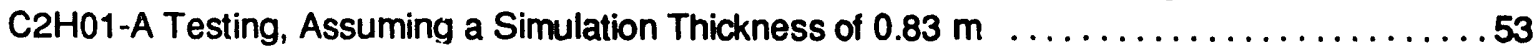

7-6 Simulated Formation Pore Pressures at Selected Radial Distances from the Test Zone During C2H01-A Testing, Assuming a Simulation Thickness of $0.83 \mathrm{~m} \mathrm{\ldots ....53}$

7-7 Configuration of Multipacker Test Tool \#1 in Borehole $\mathrm{C}_{2} \mathrm{H} 01$ for $\mathrm{C} 2 \mathrm{H} 01-\mathrm{B}$ Testing ........55

7-8 Test- and Guard-Zone Fluid-Pressure Data from C2H01-B Testing $\ldots \ldots \ldots \ldots \ldots \ldots \ldots \ldots$

7-9 Best-Fit Model Simulation of the Test-Zone Fluid-Pressure Response During

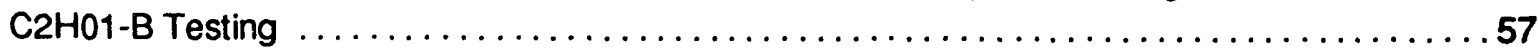


7-10 Best-Fit Model Simulation of Pulse-Injection \#1 During C2H01-B Testing Showing

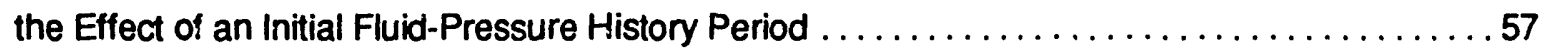

7-11 Best-Fit Model Simulation of Pulse-Withdrawal \#1 During C2H01-B Testing Showing

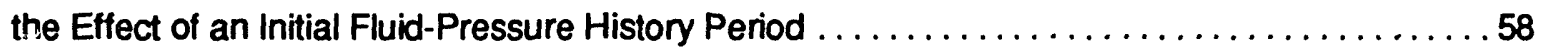

7-12 Best-Fit Model Simulation of Pulse-Withdrawal \#2 During C2H01-B Testing Showing the Effect of an Initial Fluid-Pressure History Feriod $\ldots \ldots \ldots \ldots \ldots \ldots \ldots \ldots \ldots \ldots \ldots$

7-13 Simulated Formation Pore Pressures at Selected Radial Distances from the Test

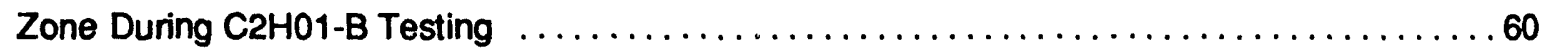

7-14 Best-Fit Model Simulation of the Guard-Zone Fluid-Pressure Response During

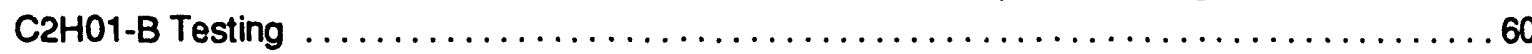

7-15 Simulated Formation Pore Pressures at Selected Radial Distances from the

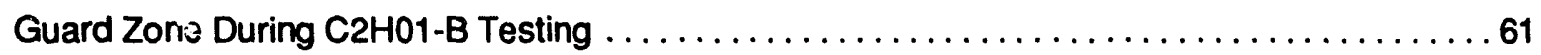

7-16 Configuration of Multipacker Test Tool \#5 in Borehole $\mathrm{C} 2 \mathrm{H} 01$ for $\mathrm{C} 2 \mathrm{H} 01-\mathrm{C}$ Testing ........62

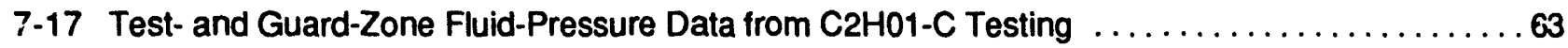

7-18 Best-Fit Model Simulation of the Test-Zone Fluid-Pressure Response During

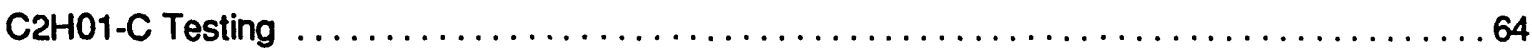

7-19 Simulated Formation Pore Pressures at Selected Fadial Distances from the

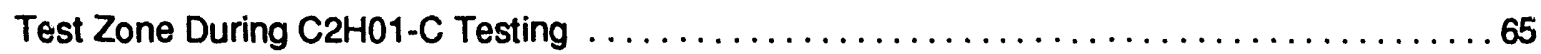

7-20 Configuration of Multipacker Test Tool \#4 for Permeability Testing in Borehole C2HO2 . . . . .66 66

7-21 Test- and Guard-Zone Fluid-Pressure Data from $\mathrm{C}_{2} \mathrm{HO} 02$ Testing $\ldots \ldots \ldots \ldots \ldots \ldots \ldots \ldots$

7-22 Schematic Illustration of the Actual and Idealized Test-Zone Geometry Used for the

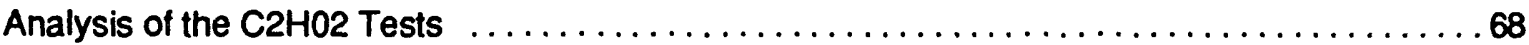

7-23 Best-Fit Model Simulation of the Test-Zone Fluid-Pressure Response During C2H02 Testing . . 68

7-24 Simulated Formation Pore Pressures at Selected Radial Distances from the Test

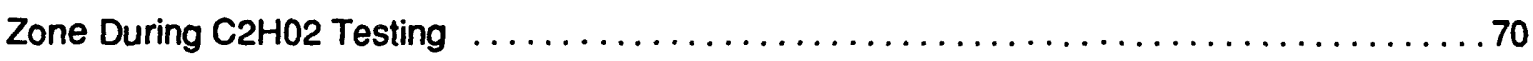

7-25 Configuration of Multipacker Test Tool \#5 for Permeability Testing in Borehole C2HO3 .......71

7-26 Test- and Guard-Zone Fluid-Pressure Data from $\mathrm{C}_{2} \mathrm{H} 03$ Testing $\ldots \ldots \ldots \ldots \ldots \ldots \ldots \ldots 72$

7-27 Simulated Test-Zone Fluid-Pressure Response in Borehole $\mathrm{C} 2 \mathrm{H} 03$ Using a Formation Pore Pressure of $11 \mathrm{MPa}$, a Test-Zone Compressibility of $6 \times 10^{-6} \mathrm{~Pa}^{-1}$,

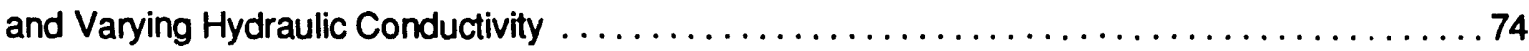

7-28 Configuration of Multipacker Test Tools \#3 and \#4 for Permeability Testing in Borehole N4P50 .75

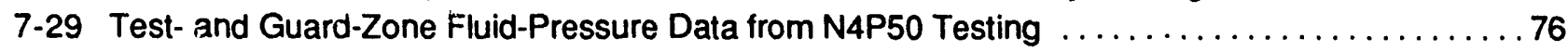

7-30 Configuration of Multipacker Test Tool \#3 in Borehole L4P51 for L4P51-A Testing . . . . . . . . .77

7-31 Test- and Guard-Zone Fluid-Pressure Data from L4P51-A Testing $\ldots \ldots \ldots \ldots \ldots \ldots \ldots .79$

7-32 Best-Fit Model Simulation of the Test-Zone Fluid-Pressure Response During L4P51-A Testing ............................................ 79

7-33 Configuration of Multipacker Test Tool \#3 for Permeability Testing in Borehole SOP01 . . . . 82

7-34 Test- and Guard-Zone Fluid-Pressure Data from S0P01 Testing $\ldots \ldots \ldots \ldots \ldots \ldots \ldots \ldots 83$

7-35 Best-Fit Model Simulation of the Test-Zone Fluid-Pressure Response During SOP01 Testing . . 83

7-36 Simulated Formation Pore Pressures at Selected Radial Distances from the

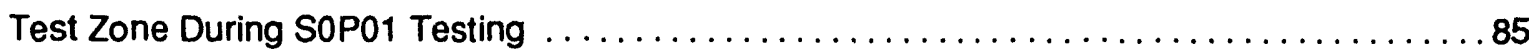

7-37 Best-Fit Model Simulation of the Guard-Zone Fluid-Pressure Resporise During

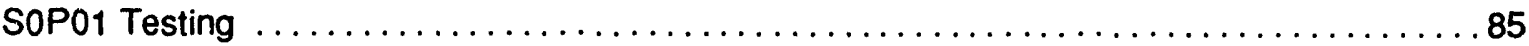

7-38 Configuration of Multipacker Test Tool \#2 in Borehole S1P71 for S1P71-A Testing ........87

7-39 Test- and Guard-Zone Fluid-Pressure Data from S1P71-A Testing $\ldots \ldots \ldots \ldots \ldots \ldots . \ldots 8$ 
7-40 Best-Fit Model Simulation of the Test-Zone Fluid-Pressure Response During

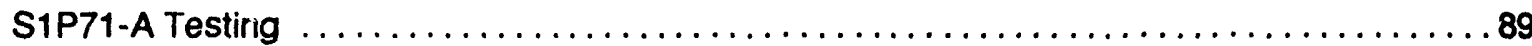

7-41 Simulation of the Test-Zone Fluid-Pressure Response During C2H01-A

Testing Showing the Simulation's Sensitivity to Hydraulic Conductivity ...............91

7-42 Simulation of the Test-Zone Fluid-Pressure Response During C2H01-B

Testing Showing the Simulation's Sensitivity to Hydraulic Conductivity ..............91

7-43 Simulation of the Guard-Zone Fluid-Pressure Response During C2H01-B

Testing Showing the Simulation's Sensitivity to Hydraulic Conductivity ...............92

7-44 Simulation of the Test-Zone Fluid-Pressure Response During C2H01-C

Testing Showing the Simulation's Sensitivity to Hydraulic Conductivity $\ldots \ldots \ldots \ldots \ldots \ldots \ldots 92$

7-45 Simulation of the Test-Zone Fluid-Pressure Response During C2H02

Testing Showing the Simulation's Sensitivity to Hydraulic Conductivity $\ldots \ldots \ldots \ldots \ldots \ldots .93$

7-46 Simulation of the Test-Zone Fluid-Pressure Response During L4P51-A

Testing Showing the Simulation's Sensitivity to Hydraulic Conductivity ..............93

7-47 Simulation of the Test-Zone Fluid-Pressure Response During SOP01

Testing Showing the Simulation's Sensitivity to Hydraulic Conductivity ..............94

7-48 Simulation of the Test-Zone Fluid-Pressure Response During S1P71-A

Testing Showing the Simulation's Sensitivity to Hydraulic Conductivity . . . . . . . . . . . 94

7-49 Simulation of the Test-Zone Fluid-Pressure Response During C2H01-A

Testing Showing the Simulation's Sensitivity to Formation Pore Pressure . . . . . . . . . 95

7-50 Simulation of the Test-Zone Fluid-Pressure Response During C2H01-B

Testing Showing the Simulation's Sensitivity to Formation Pore Pressure ............. 95

7-51 Simulation of the Guard-Zone Fluid-Pressure Response During C2H01-B

Testing Showing the Simulation's Sensitivity to Formation Pore Pressure . . . . . . . . . 96

7-52 Simiulation of the Test-Zone Fluid-Pressure Response During C2H01-C

Testing Showing the Simulation's Sensitivity to Formation Pore Pressure $\ldots \ldots \ldots \ldots \ldots .96$

7-53 Simulation of the Test-Znone Fluid-Pressure Response During $\mathrm{C}_{2} \mathrm{HO} 2$

Testing Showing the Simulation's Sensitivity to Formation Pore Pressure .............97

7-54 Simulation of the Test-Zone Fluid-Pressure Response During L4P51-A

Testing Showing the Simulation's Sensitivity to Formation Pore Pressure $\ldots \ldots \ldots \ldots \ldots . . .97$

7-55 Simulation of the Test-Zone Fluid-Pressure Response During SOP01

Testing Showing the Simulation's Sensitivity to Formation Pore Pressure $\ldots \ldots \ldots \ldots \ldots \ldots 98$

7-56 Simulaticri oi the Tesi-Zone Fluid-Pressure Response During S1P71-A

Testing Showing the Simulation's Sensitivity to Formation Pore Pressure ............98

7-57 Simulation of the Test-Zone Fluid-Pressure Response During L4P51-A

Testing Showing the Simulation's Sensitivity to Distance to the Zero-Flow Boundary .......99

7-58 Simulation of the Test-Zone Fluid-Pressure Response During S1P71-A

Testing Showing the Simulation's Sensitivity to Distance to the Zero-Flow Bouridary ........99

7-59 Simulation of the Test-Zone Fluid-Pressure Response During C2H01-A

Testing Showing the Simulation's Sensitivity to Specific Storage ................. 101

7-60 Simulation of the Test-Zone Fluid-Pressure Response During C2H01-B

Testing Showing the Simulation's Sensitivity to Specific Storage $\ldots \ldots \ldots \ldots \ldots \ldots \ldots 101$

7-61 Simulation of the Guard-Zone Fluid-Pressure Response during C2H01-B

Testing Showing the Simulation's Sensitivity to Specific Storage ................. 102

7-62 Simulation of the Test-Zone Fluid-Pressure Response during C2H01-C

Testing Showing the Simulation's Sensitivity to Specific Storage ................. 102 
7-63 Simulation of the Test-Zone Fluid-Pressure Response During $\mathrm{C}_{2} \mathrm{HO} 2$

Testing Showing the Simulation's Sensitivity to Specific Storage ................. 103

7-64 Simulation of the Test-Zone Fluid-Pressure Response During L4P51-A

Testing Showing the Simulation's Ser.sitivity to Specific Storage ................. 103

7-65 Simulation of the Test-Zone Fluid-Pressure Response During SOP01

Testing Showing the Simulation's Sensitivity to Specific Storage .................. 104

7-66 Simulation of the Test-Zone Fluid-Pressure Response During S1P71-A

Testing Showing the Simulation's Sensitivity to Specific Siorage .................. 104

7-67 Best-Fit Model Simulation of the Test-Zone Fluid-Pressure Response

During L4P51-A Testing Using the Maximum Estimated Value for Specific Storage ....... 105

7-68 Best-Fit Model Simulation of the Test-Zone Fluid-Pressure Response During

L4P51-A Testing Using the Minimum Estimated Value for Specific Storage ............ 105

7-69 Best-Fit Model Simulation of the Test-Zone Fluid-Pressure Response During

S1P71-A Testing Using the Minimum Estimated Value for Specific Storage . . . . . . . . 107

7-70 Best-Fit Model Simulation of the Test-Zone Fluid-Pressure Response During S0P01 Testing Using the Minimum Estimated Value for Specific Storage ............ 107

7-71 Simulated Formation Pore Pressures at Selected Radial Distances from the Test

Zone During S0P01 Testing Using the Minimum Estimated Value for Specific Storage .... 108

7-72 Best-Fit Model Simulation of the Test-Zone Fluid-Pressure Response During SOP01

Testing Using a Specific Storage of $4.1 \times 10^{-5} \mathrm{M}^{-1} \ldots \ldots \ldots \ldots \ldots \ldots \ldots \ldots \ldots \ldots \ldots . \ldots \ldots$

7-73 Simulated Formation Pore Pressures at Selected Radial Distances from the Test

Zone During SOP01 Testing Using a Specific Storage of $4.1 \times 10^{-5} \mathrm{M}^{-1} \ldots \ldots \ldots \ldots \ldots \ldots 109$

7-74 Best-Fit Model Simulation of the Test-Zone Fluid-Pressure Response During

S1P71-A Testing Using a Specific Storage of $4.1 \times 10^{-5} \mathrm{M}^{-1} \ldots \ldots \ldots \ldots \ldots \ldots \ldots \ldots . \ldots 109$

7-75 Simulation of the Test-Zone Fluid-Pressure Response During C2H01-A Testing

Showing the Simulation's Sensitivity to Test-Zone Compressibility $\ldots \ldots \ldots \ldots \ldots \ldots \ldots 111$

7-76 Simulation of the Test-Zone Fluid-Pressure Response During C2H01-B Testing

Showing the Simulation's Sensitivity to Test-Zone Compressibility $\ldots \ldots \ldots \ldots \ldots \ldots \ldots 111$

7-77 Simulation of the Guard-Zone Fluid-Pressure Response During C2H01-B Testing

Showing the Simulation's Sensitivity to Guard-Zone Compressibility ............... 112

7-78 Simulation of the Test-Zone Fluid-Pressure Response During C2H01-C Testing

Showing the Simulation's Sensitivity to Test-Zone Compressibility $\ldots \ldots \ldots \ldots \ldots \ldots \ldots 112$

7-79 Simulation of the Test-Zone Fluid-Pressure Response During C2H02 Testing

Showing the Simulation's Sensitivity to Test-Zone Compressibility $\ldots \ldots \ldots \ldots \ldots \ldots \ldots 113$

7-80 Simulation of the Test-Zone Fluid-Pressure Response During L4P51-A Testing

Showing the Simulation's Sensitivity to Test-Zone Compressibility ................ 113

7-81 Simulation of the Test-Zone Fluid-Pressure Response During S0P01 Testing

Showing the Simulation's Sensitivity to Test-Zone Compressibility .................. 114

7-82 Simulation of the Test-Zone Fluid-Pressure Response During S1P71-A Testing

Showing the Simulation's Sensitivity to Test-Zone Compressibility $\ldots \ldots \ldots \ldots \ldots \ldots \ldots 114$

7-83 Simulation of the Test-Zone Fluid-Pressure Response During C2H01-A Testing

Showing the Simulation's Sensitivity to Test-Zone-Volume Compensation ........... 116

7-84 Simulation of the Test-Zone Fluid-Pressure Response During C2H01-B Testing

Showing the Simulation's Sensitivity to Test-Zone-Volume Compensation ............ 116

7-85 Simulation of the Guard-Zone Fluid-Pressure Response During C2H01-B Testing

Showing the Simulation's Sensitivity to Guard-Zone-Volume Compensation 
7-86 Simulation of the Test-Zone Fluid-Pressure Response During C2H01-C Testing Showing the Simulation's Sensitivity to Test-Zone-Volume Compensation ........... 117

7-87 Simulation of the Test-Zone Fluid-Pressure Response During C2H02 Testing Showing the Simulation's Sensitivity to Test-Zone-Volume Compensation

7-88 Simulation of the Test-Zone Fluid-Pressure Response During L4P51-A Testing Showing the Simulation's Sensitivity to Test-Zone-Volume Compensation

7-89 Simulation of the Test-Zone Fluid-Pressure Response During S0P01 Testing

Showing the Simulation's Sensitivity to Test-Zone-Volume Compensation ............ 119

7-90 Simulation of the Test-Zone Fluid-Pressure Response During S1P71-A Testing

Showing the Simulation's Sensitivity to Test-Zone-Volume Compensation ............. 119

7-91 Simulation of the Test-Zone Fluid-Pressure Response During L4P51-A Testing

Showing the Simulation's Sensitivity to Temperature Compensation ............... 120

7-92 Simulation of the Test-Zone Fluid-Pressure Response During S0P01 Testing

Showing the Simulation's Sensitivity to Temperature Compensation ...

7-93 Interpreted Hydraulic Conductivities Versus Distances From Excavations to the

Centers of Tested Intervals

7-94 Interpreted Formation Pore Pressures Versus Distances From Excavations to the

Centers of Tested Intervals

7-95 Interpreted Formation Pore Pressures Versus Depths Below Excavation fr, the

Tested Intervals in Borehole $\mathrm{C} 2 \mathrm{H} 01$ 


\section{TABLES}

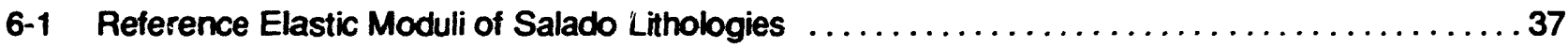

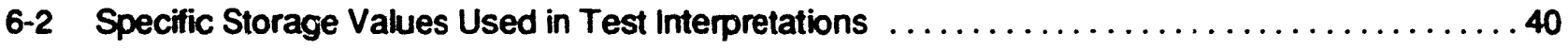

6-3 Test-Zone Compressibilities Calculated from Fluid Volumes Measured During

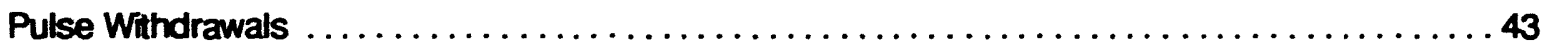

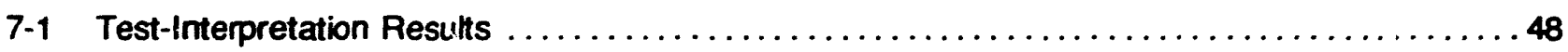




\section{INTRODUCTION}

This report presents preliminary interpretations of hydraulic tests conducted in bedded evaporites of the Salado Formation from 1988 through early 1990 at the Waste Isolation Pibt Plant (WIPP) site in southeastern New Mexico (Figure 1-1). The WIPP is a U.S. Department of Energy research and development facility designed to demonstrate safe disposal of transuranic wastes resulting from the nation's defense programs. The WIPP disposal horizon is located in the lower portion of the Permian Salado Formation. The hydraulic tests discussed in this report were performed in the WIPP underground facility s;; INTERA Inc., Austin, Texas, under the technical direction of Sandia National Laboratories, Albuquerque, New Mexico.

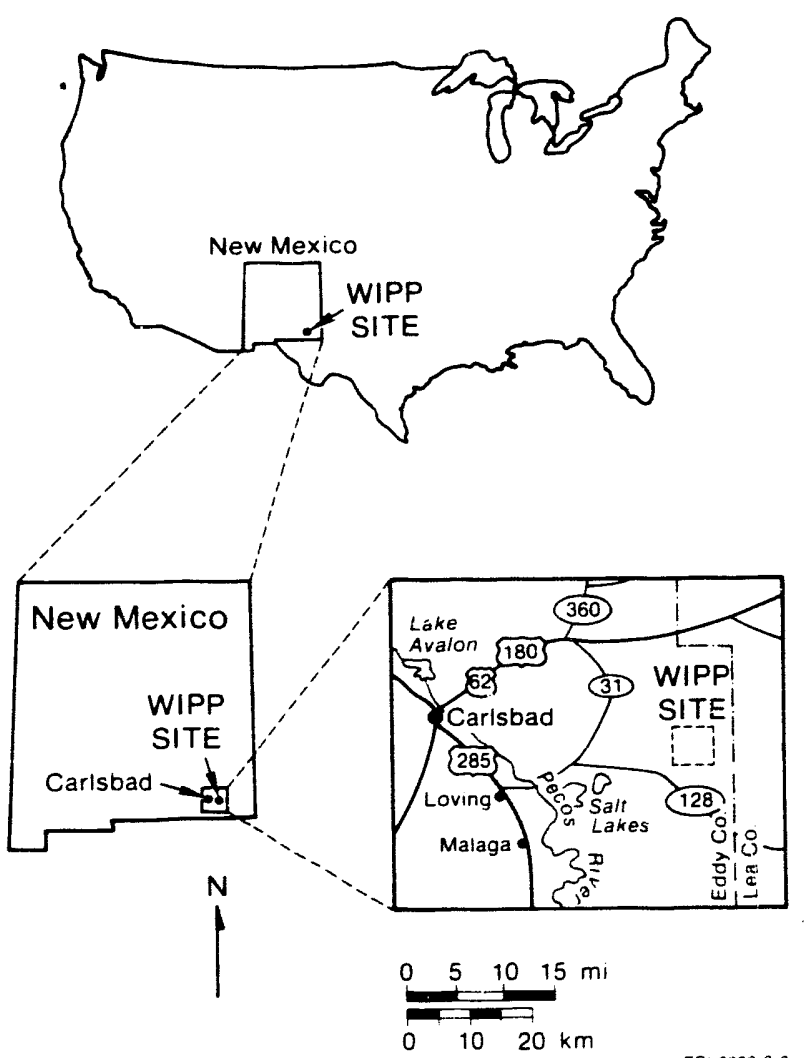

Figure 1-1. Location of the WIPP Site.
Hydraulic testing is being performed in the Salado Formation to provide quantitative estimates of the hydraulic properties controlling brine flow through the Salado Formation. The specific objectives of the tests are:

- Todeterminepermeabilities of different stratigraphic intervals in the Salado Formation around the WIPP facility;

- To determine formation pore pressures within different stratigraphic intervals in the Salado Formation around the facility;

- To determine whether or not hydraulic boundaries are encountered within the Salado on the scale of testing;

- To define the distance(s) to which the presence of the WIPP facility has affected hydraulic properties and/or formation pore pressures in the surrounding rock; and

- To provide data which may allow discrimination between different conceptual models that attempt to explain flow through evaporites, such as a Darcyflow model in which flow is driven by pore-pressure gradients, and a stress- or creep-driven flow model in which brine is squeezed out of the formation by plastic deformation of the rock.

From 1976 to 1985, a number of hydraulic tests of the Salado Formation were performed in boreholes drilled from the surface. Drillstem tests (DSTs), air-injection tests, and/or pressure-pulse tests were performed in boreholes ERDA-9, ERDA-10, AEC-7, AEC-8, Cabin Baby-1, DOE-2, and WIPP-12, but none provided data that could be interpreted to yield reliable estimates of formation permeability and/or pore pressure (Appendix A). In 1986, permeability tests of portions of the Salado were performed in several holes drilled from within the WIPP underground facility using both air and brine as test fluids. Peterson et al. (1987) interpreted 
hydraulic conductivities ranging from $7 \times 10^{-15}$ to $3 \times$ $10^{-12} \mathrm{~m} / \mathrm{s}$ from these tests. In 1987, permeability testing was performed at two depths in the Salado in holes drilled from within the waste-handling shaft at the WIPP site (Stensrud et al., 1988). Interpretation of the data from these tests indicated hydraulic conductivities ranging from $2 \times 10^{-14}$ to $1 \times 10^{-13} \mathrm{~m} / \mathrm{s}$ (Saulnier and Avis, 1988). Following these experiences, testing in holes drilled from within the WIPP underground facility was considered to have a greater likelihood of success than continued attempts at surface-based testing, leading to the development of the testing program discussed in this report.

The hydraulic testing reported herein consists of pressure-pulse tests of five stratigraphic intervals within eleven meters of the WIPP excavations. The stratigraphic intervals tested include halite (both pure and impure), anhydrite, and clay. From September 1988 through February 1990, nine sets of pulse tests were completed in five different boreholes. Testing of a sixth stratigraphic interval consisting entirely of relatively pure halite was attempted in anotherborehole, but no interpretable response was observed. Testing of a seventh stratigraphic interval was begun, but had to be terminated prematurely because of conflicts with other activities in that part of the WIPP underground facility.

Unike porous media such as sandstones, halite exhibits creep behavior that may complicate the interpretation of hydraulic tests. Creep causes borehole dimensions to change during tests and may also cause timedependent changes in the permeability and specific storage of the region undergoing creep. Compensating for these changes is complicated by the dependence of creep rates around a borehole on the fluid pressure in the borehole. In addition, because halite and other evaporites tend to have extremely low permeabilities, temperature changes and equipment-related factors that have negligible effects on tests in higher permeability media may significantly affect observed fluid-pressure responses in evaporites. Thus, the effects of temperature changes, pressure-dependent test-tool-volume changes (compliance), andmovement of the testtoolduring testing also need to be incorporated into the test interpretation.

Other factors specific to the tests of the Salado Formation, which bear on test interpretation, are borehole orientation (in some cases the holes were not drilled perpendicular to bedding), possible partialpenetration effects (test intervals may not have been fully confined), the effect of trapped gas within test intervals on test-zone compressibility, and possible two-phase flow caused by gas having exsolved from the Salado brine in the relatively depressurized nearborehole region of the surrounding rock.

The interpretations presented in this report are termed "preliminary" because they do not fully incorporate all of the complexities discussed above. In particular, formation creep, partial-penetration effects, pressuredependent test-zone compressibility resulting from the presence of gas, and two-phase flow are not quantitatively addressed in this report. Additional experimentation, study, and model development will be required before many of these complexities can be incorporated into the test interpretations. 


\section{GEOLOGIC SETTING AND LOCAL STRATIGRAPHY}

The WIPP site is located in the northern part of the Delaware Basin in southeastem New Mexico. WIPP. site geologic investigations have concentrated on the upper seven formations typically found in that part of the Delaware Basin. These are, in ascending order, the Bell Canyon Formation, the Castile Formation, the Salado Formation, the Rustler Formation, the Dewey Lake Red Beds, the Dockum Group, and the Gatuna Formation (Figure 2-1). All of these formations are of Permian age, except for the Dockum Group, which is of Triassic age, and the Gatuna, which is a Quatemary deposit.

The WIPP underground facility lies in the lower part of the Salado Formation at an approximate depth of $655 \mathrm{~m}$ below ground surface. The Salado Formation

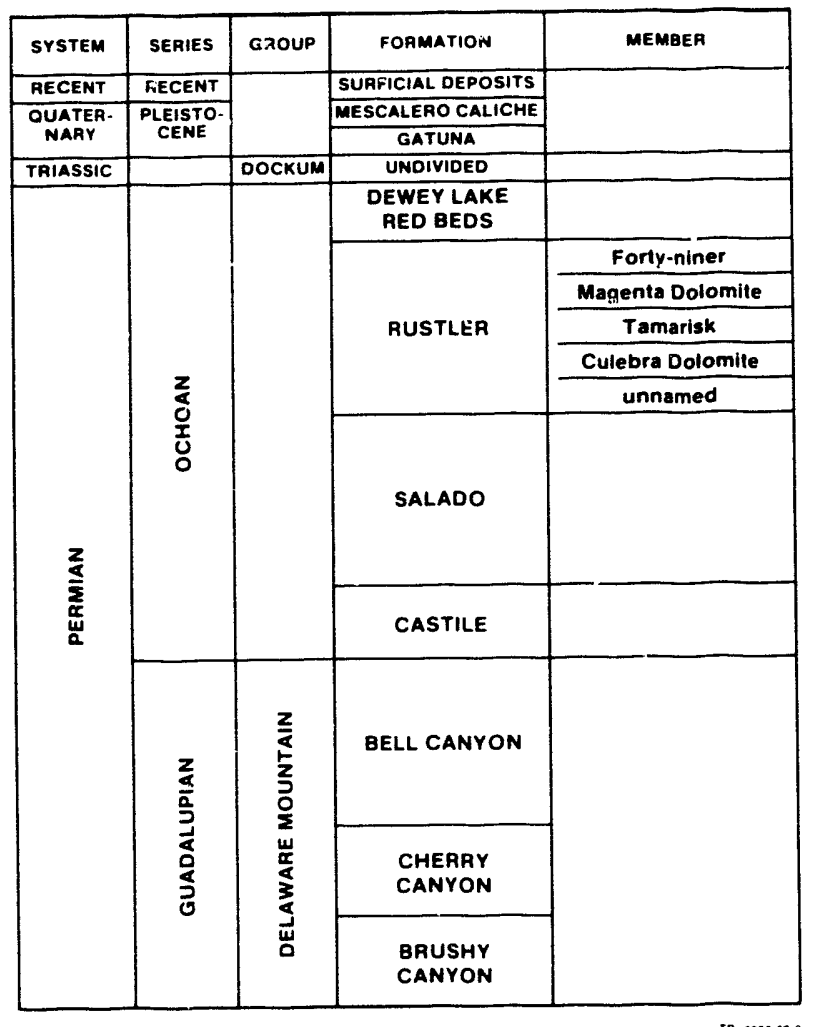

Figure 2-1. WIPP Site Stratigraphic Column. is approximately $600 \mathrm{~m}$ thick at the WIPP site and is composed largely of halite with minor amounts of interspersed clay and polyhalite. The Salado also contains interbeds of anhydrite, polyhalite, clay, and siltstone. Many of these interbeds are traceable over mcst of the Delaware Basin. Jones et al. (1960) designated 45 of the anhydrite and/or polyhalite interbeds as "Marker Beds", and numbered these "Marker Beds", from 100 to 144, increasing downward. The WIPP facility horizon (the stratigraphic location of the underground excavations from which the boreholes for the brine-permeability program were drilled) lies between Marker Beds 138 and 139.

A typical stratigraphic section of the Salado Formation in the vicinity of the WIPP underground facility, adapted from Westinghouse (1989), is shown in Figure 2-2. Westinghouse (1989) presents a detailed description of stratigraphic units that correlate throughout most of the underground facility (Appendix B). The description covers a 37.5-m interval of the Salado, centered approximately at the stratigraphic midpoint of the excavations. This description delineates 16 "map units," numbered 0 to 15, and 20 unnumbered units. The majority of the map units are composed primarily of halite, and are differentiated principally on the basis of differing clay and polyhalite contents. The remainder of the map units are anhydrite interbeds such as Marker Beds 138 and 139. Thinner anhydrite interbeds and a number of the more continuous clay seams have also been given letter designations to facilitate consistent referencing. These units are shown on Figure 2-2. The stratigraphic positions of the WIPP excavations with respect to the designated map units are shown in Figure 2-3. The testing and guard-zone monitoring discussed in this report were carried out in map unit 9 and in all of the strata from map unit 6 to the halite underlying anhydrite "c." 


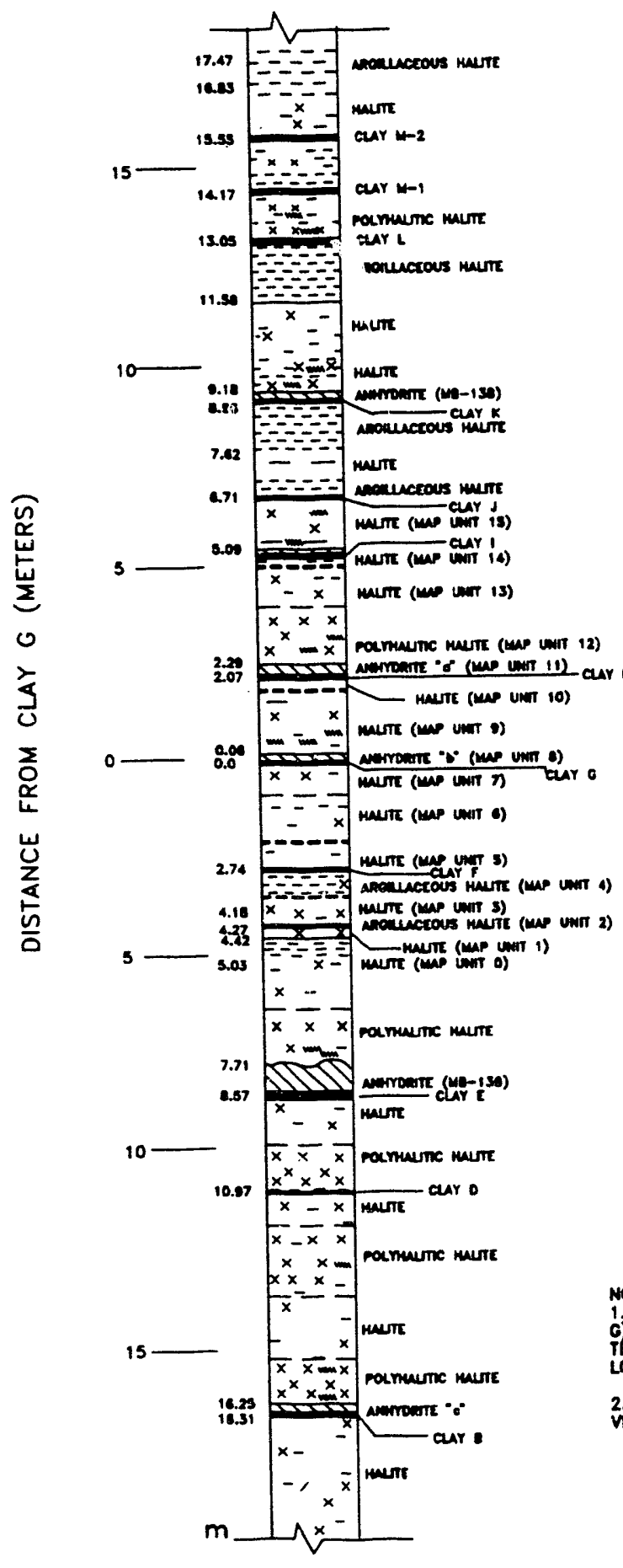

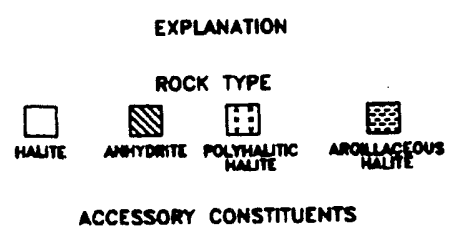

区xy

E minuctous

$\equiv$ stimetres

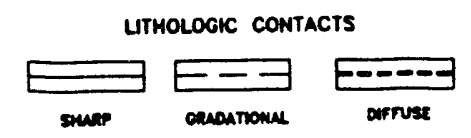

NOTES: C) AND ARE AVERACED TROM REPRESENTATIVE COREHOU LOOS, SHAFT AND LOCALYY FROM THOSE SHOWM.

2. OESCRIPTIONS Of UNTS ARE BASED ON COREHOLE DATA. SHAFT MAPPING AND VISUAL INSPECTION OF EXPOSURES IN UNDERGROUND DRITTS' AND ROOMS.

ADAPTED FROM WESTINCHOUSE (1989)

Figure 2-2. Detalled Stratigraphy Near the WIPP Underground Facility. 


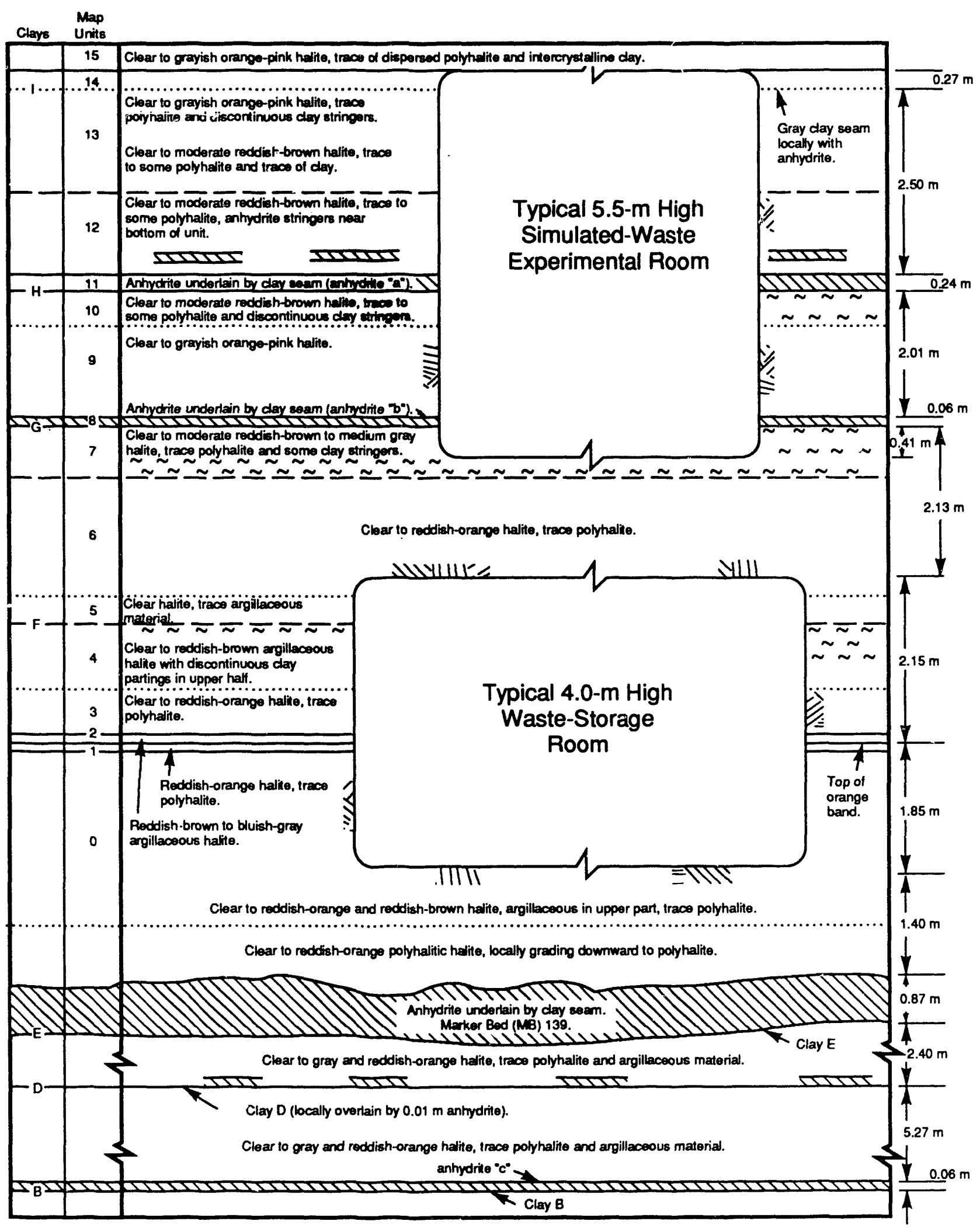

TRI-6334-257-1

Figure 2-3. Schematic of Typlcal WIPP Underground Rooms Showing Stratigraphic Positions. 
The stratigraphic units described by Westinghouse (1989) are not encountered by all boreholes, however. As shown in detailed geologic maps of drift and room ribs (walls) throughout the underground facility (e.g., Westinghouse, 1989, 1990), the halitic map units are locally crosscut by syndepositional dissolution pits (Powers and Hassinger, 1985). These pits range in depth and width from a few centimeters to a few meters and may completely crosscut one or several map units at any given location. The pits are typically filled by relatively pure, coarsely crystalline halite.

As mentioned above, the halitic map units designated by Westinghouse (1989) were defined on the basis of relatively consistent differences in clay content and/or color and polyhalite content that are apparent in macroscopic examination, rather than on sedimentological differences. The local absence of map units can be attributed to depositional processes. Holt and Powers (1990) present a detailed discussion of the sedimentology of the Salado Formation. They provide descriptions of lithofacies commonly found within the Salado and discuss syndepositional alteration processes. Salado textures and lithofacies distributions are highly variable both laterally (at a local scale) and vertically, as they are the products of repeated episodes of dissolution and alteration over a large areal scale. 


\section{TESTING EQUIPMENT}

The following sections briefly describe the equipment used in the permeability-testing program in the WIPP underground facility. The equipment includes multipacker test tools, data-acquisition systems, instruments to measure borehole deformation, pressure transducers, and thermocouples. More detailed descriptions of the testing equipment and the procedures and methods used to calibrate the equipment are presented in Saulnier et al. (1991).

NOTE: The use of brand names in this report is for identification only, and does not imply endorsement of specific products by Sandia National Laboratories.

\subsection{Multipacker Test Tool}

The first two sets of tests performed under this program, in borehole $\mathrm{C} 2 \mathrm{H} 01$, employed the multipacker test tool used for permeability tests in the wastehandling shaft as described in Stensrud et al. (1988) and Saulnier and Avis (1988). This tool (Figure 3-1) is in principle very similar to the multipacker test tool designed specifically for the underground permeability-testing program, but lacks borehole-deformation measuring devices. All other permeability tests were conducted using the multipacker test tool described below.

The multipacker test tool designed for this testing program, shown on Figures 3-2 and 3-3, has two sliding-end, 9.5-cm outside diameter (O.D.) inflatable packers mounted on a $4.83-\mathrm{cm}$ O.D. mandrel and oriented with the packers' fixed ends toward the bottom-hole end of the test tool. The packers have 0.92 $\mathrm{m}$ long inflatable elastic elements composed of natural rubber and synthetic materials. The packer elements have approximately $0.81-\mathrm{m}$ seal lengths when inflated in 10.2-cm diameter boreholes. The tool is anchored to the wall or floor of the underground facility during testing by bolting a mandrel clamp to the flange of a $0.51-\mathrm{m}$ long borehole collar grouted into the top of the hole. For sometests, the test tool is also secured using a cross made of 1 -m lengths of $5.08-\mathrm{cm}$ square tubular steel, which is clamped onto the mandrel or its extension and anchored to the floor or wall using $61-\mathrm{cm}$ long rock bolts.

Each multipacker test tool is equipped with three sets of ports to the bottom-hole test zone and the guard zone between the packers. One set of ports is used to transmit fluid pressures from the test and guard zones to the transducers, which are mounted outside of the boreholes. A second set of ports is used to dissipate "squeeze" pressures created during packer inflation and to vent fluid from the isolated intervals to initiate pulse-withdrawal tests. These two sets of ports are accessed by continuous lengths of $0.48-\mathrm{cm}(3 / 16-$ inch) O.D. stainless-steel tubing. The third set of ports provides access for $0.32-\mathrm{cm}$ (1/8-inch) diameter Type $E$ thermocouples to measure temperatures in the test and guard zones. Packer-inflation pressures are monitored with transducers attached to the packerinflation lines.

The test-interval section of each test tool is equipped with linear variable-differential transformers (LVDTs) to measure borehole deformation and test-tool movement during the testing period. Three radially oriented LVDTs are located below the test-interval packer, and one axially oriented LVDT is mounted at the bottom end of the multipacker test tool (Figure 3-3) to measure tool movement relative to the bottom of the hole during testing.

\subsection{Data-Acquisition System}

A computer-controlled data-acquisition system (DAS) monitors the progress of each test and records 


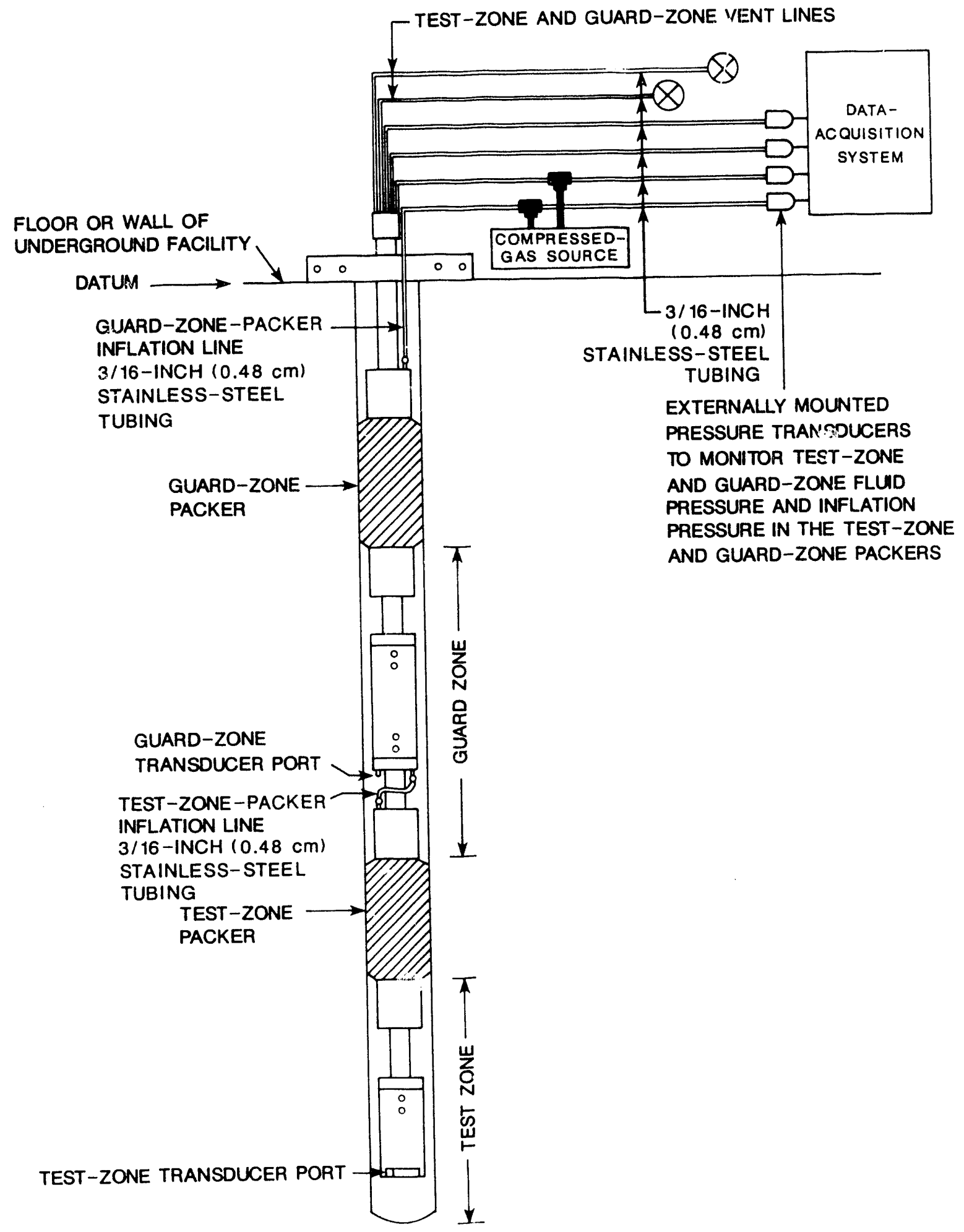

Figure 3-1. Multipacker Test Tool \#1 Used in C2H01-A and C2H01-B Testing and in Waste-Handling Shaft Testing. 


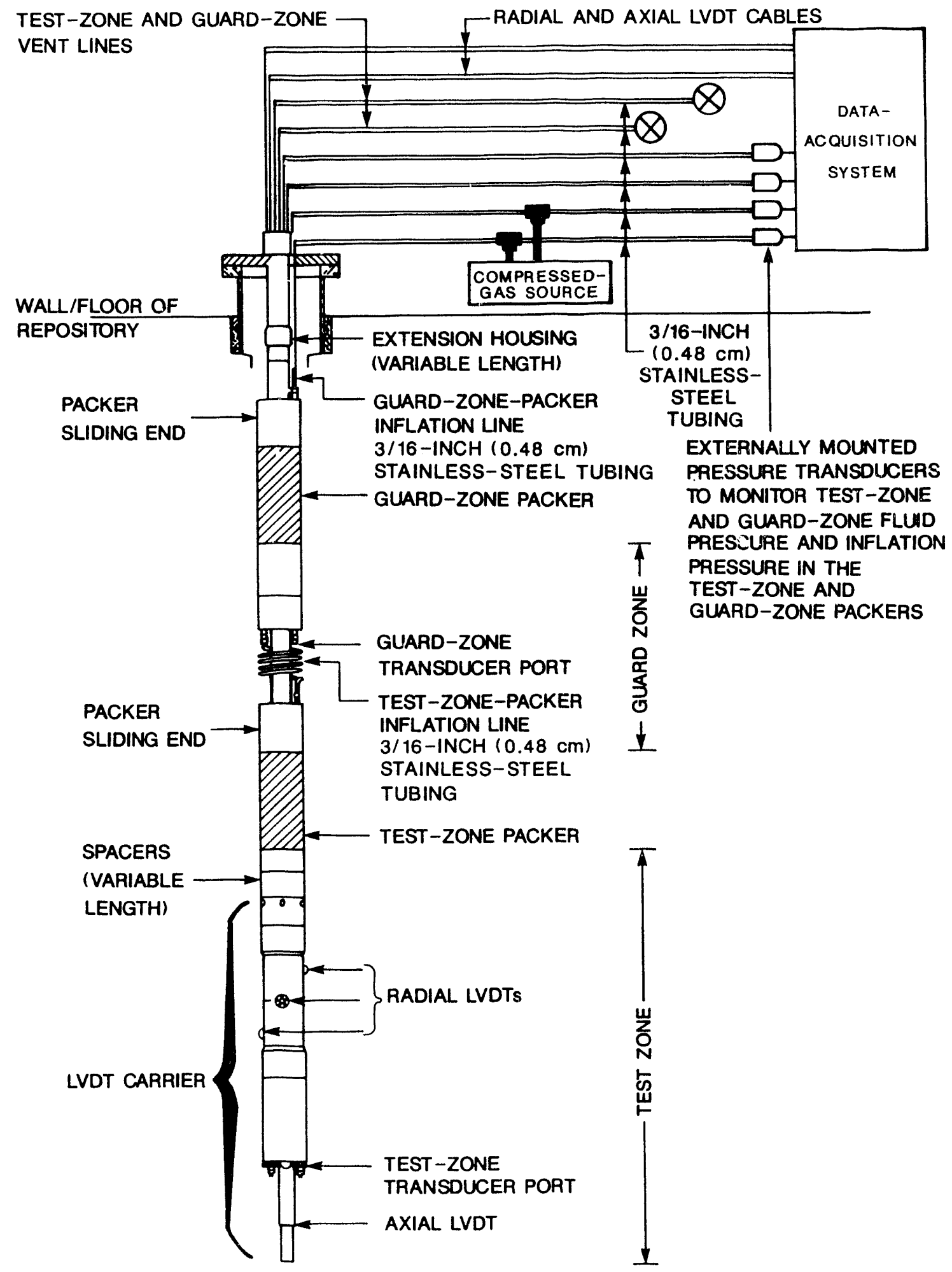

Figure 3-2. Typical Configuration of the Multipacker Test Tools Designed for Underground Testing. 


\section{TEST ZONE}

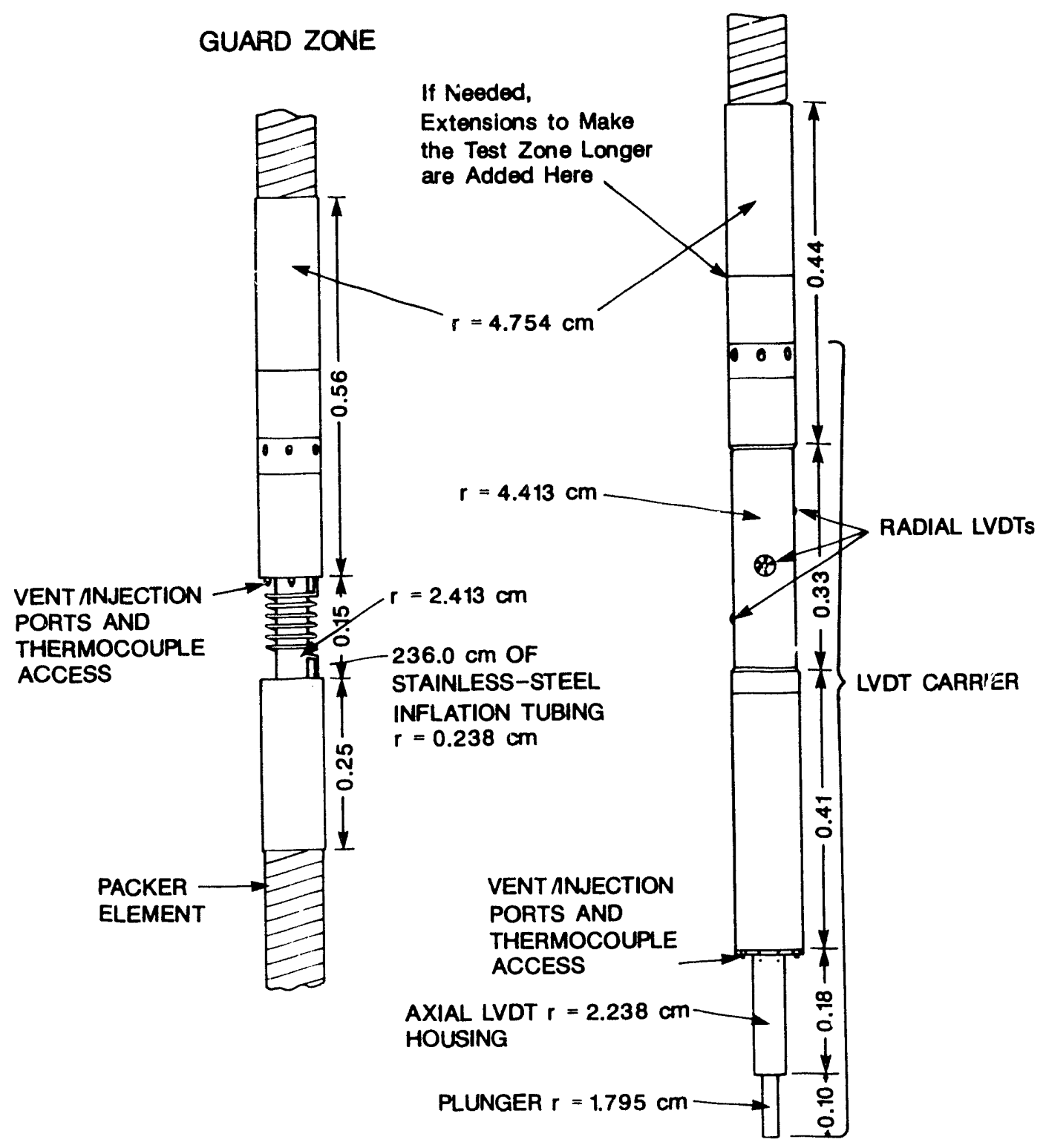

Typical Lengths of Test-Tool

Segments Shown in Meters

Figure 3-3. Detall of Test- and Guard-Zone Sections of the Multipacker Test Tool. 
fluic-pressure, fluid-temperature, and boreholedeformation data (Figure 3-4). Each DAS consists of an IBM PS/2 Model 50 desktop computer for system control and data storage, and a Hewlett Packard (HP) 3497A Data-Acquisition/Control Unit containingpower supplies to excite the transducers, thermocouples, and LVDTs, a signal scanner to switch and read channels, and a 5-1/2 digit voltmeter to measure the output from the transducers, thermocouples, and LVDTs. The data-acquisition software allows sampling of the sensors' outputs at user-specified time intervals ranging from 15 seconds to 24 hours. As the data are acquired, they are stored both on the computer's hard disk and on either 3.5-inch or 5.25inch diskettes. Real-time listing of the data on an auxiliary printer and screen and/or printer plots of the accumulated data are also possible.

\subsection{Pressure Transducers}

Fluid pressures in the test and guard zones and in the packers are monitored with Druck PDCR-830 straingage pressure transducers rated to monitor pressures from 0 to $14 \mathrm{MPa}$. The manufacturer's stated accuracy of the transducers is $\pm 0.1 \%$ of full scale, or $\pm 0.014 \mathrm{MPa}$. Transducers are calibrated before and after each installation of a multipacker test tool according to procedures described in Saulnier et al. (1991). The transducers are mounted outside the boreholes and are connected to the isolated zones and the packers through $0.48-\mathrm{cm}$ (3/16 inch) O.D. stainlesssteel tubing, which passes into and through the packer mandrels (Figure 3-2). Calibration data for the transducers used during the permeability testing discussed in this report are tabulated in Saulnier et al. (1991).

\subsection{Thermocouples}

Pickens et al. (1987) have shown that the thermal expansion or contraction of fluid in an isolated test zone in a borehole can have a significant effect on the measured fluid-pressure response during testing in low-permeability media. Therefore, Type E ChromelConstantan thermocouples are used to monitor temperatures within the test and guard zones during the permeability tests, and these data are incorporated in test interpretation. The thermocouples used are $0.32 \mathrm{~cm}$ ( $1 / 8 \mathrm{inch}$ ) in diameter, are sheathed in Inconel 600 , and are manufactured by ARI Industries. The thermocouples are reported to be accurate to within $\pm 0.006^{\circ} \mathrm{C}$. The thermocouples are calibrated by Sandia National Laboratories, and the calibration data are stored at the WIPP-site Sandia office.

\subsection{Linear Variable-Differential Transformers}

Open boreholes, rooms, and drifts in the underground facility exhibit closure, deformation, and differential movement between halite and anhydrite beds (Bechtel, 1936). Measureable borehole closure (on the order of a few tenths-of-a-millimeter change in borehole diameter) in a shut-in, fluid-filled test interval could raise the fluid pressure to higher levels than would occur without this closure. Axial movement of the multipacker test tool can be caused by packer inflation, fluiv-pressure buildup or withdrawal in the isolated intervals, and hole elongation resulting from creep closure of the excavations. (The rate of rock creep decreases with increasing distance from an excavation (Westinghouse, 1990), causing boreholes drilled from an excavation to elongate.) Axial movement of the test tool can change the test-zone volume, which, in low-permeability media, can affect the observed fluid-pressure response in an isolated borehole interval. Three Trans-Tek Model 241 LVDTs are radially mounted, with $120^{\circ}$ separation, on the test-interval part of the multipacker test tool to measure radial borehole deformation (Figures 3-2 and 3-3). These LVDTs can each measure a range of motion of $0.5 \mathrm{~cm}$. An axially mounted Trans-Tek Model 245 LVDT on the bottom of the test tool measures tool movement along the borehole axis (Figures 3-2 and 3-3). This LVDT has a range of motion of $10 \mathrm{~cm}$. The 


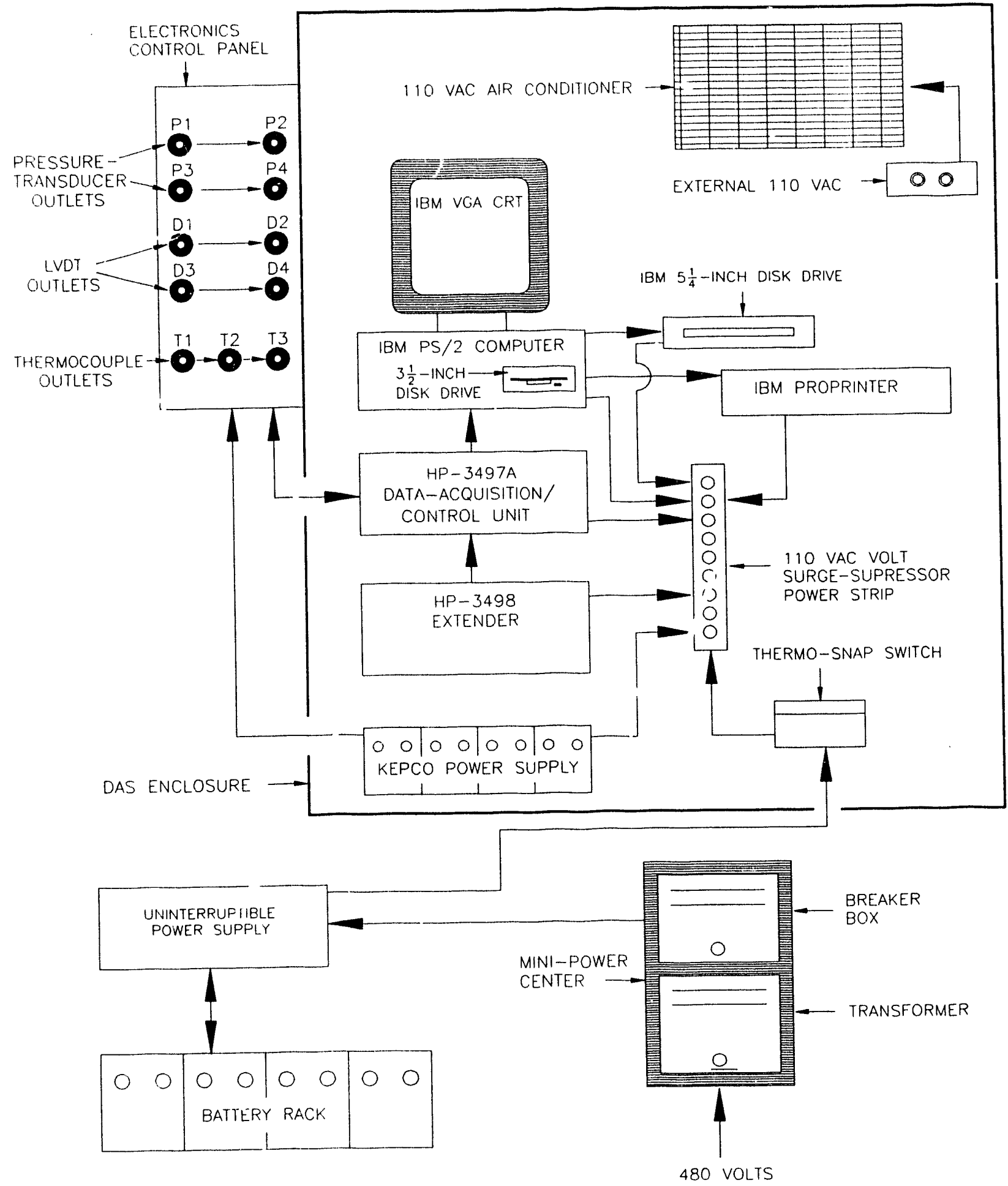

Figure 3-4. Schematic Illustration of the Data-Acquisition System. 
LVDT responses are reported by Trans-Tek to be linear within $\pm 0.5 \%$ over their working ranges. Jensen (1990) discusses in detail the design, calibration, and use of the LVDTs.

\subsection{Compliance-Testing Equipment}

Pickens et al. (1987) have shown that test-tool movement in response to packer inflation and fluid injection or withdrawal can affect fluid-pressure responses in isolated intervals in boreholes in low-permeability media. Figure 3-5 illustrates how packer movement due to packer inflation can cause the packer element to displace fluid in isolated intervals, causing changes in fluid pressure. Changes in the shape, volume, or position of the test tool that affect fluid-pressure responses during testing are referred to as compliance. To evaluate the magnitude of compliance for the multipacker test tool, preinstallation compliance tests were conducted in the underground facility on all test tools according to procedures outlined in Section 4.1. Compliance tests were conducted in sealed and pressure-tested sections of $11 .+3-\mathrm{cm}$ (4.5 inch) O.D. steel or stainless-steel casing to differentiate test-tool-related phenomena from fluid-pressure responses observed in drilled boreholes. The casing was intended to simulate a borehole with effectively zero permeability. Early compliance tests were conducted in the test rooms with the compliance chamber mounted on a jackstand from August 1988 through June 1989. Because the magnitude of diurnal temperature changes monitored during early compliance tests in the steel casing appeared to cause thermally induced fluidpressure responses, a stainless-steel chamber for subsequent compliance tests was placed in a borehole drilled into the Salado Formation from the underground facility as shown on Figure 3-6. 

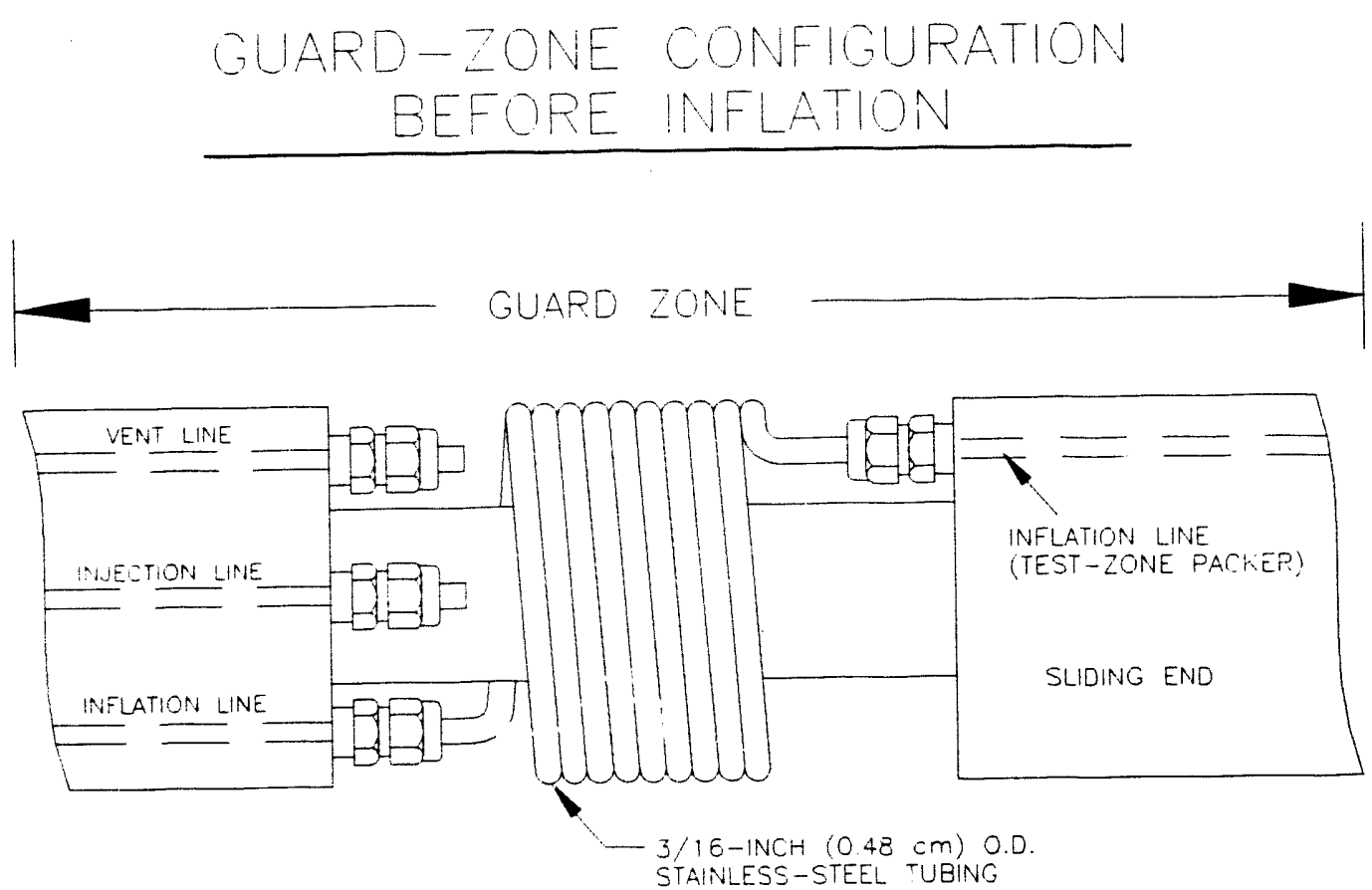

AFTER INFLATION

SLIONG END OF TEST-ZONE PACKER MOVES INTO BOREHOLE WHEN INFLATED
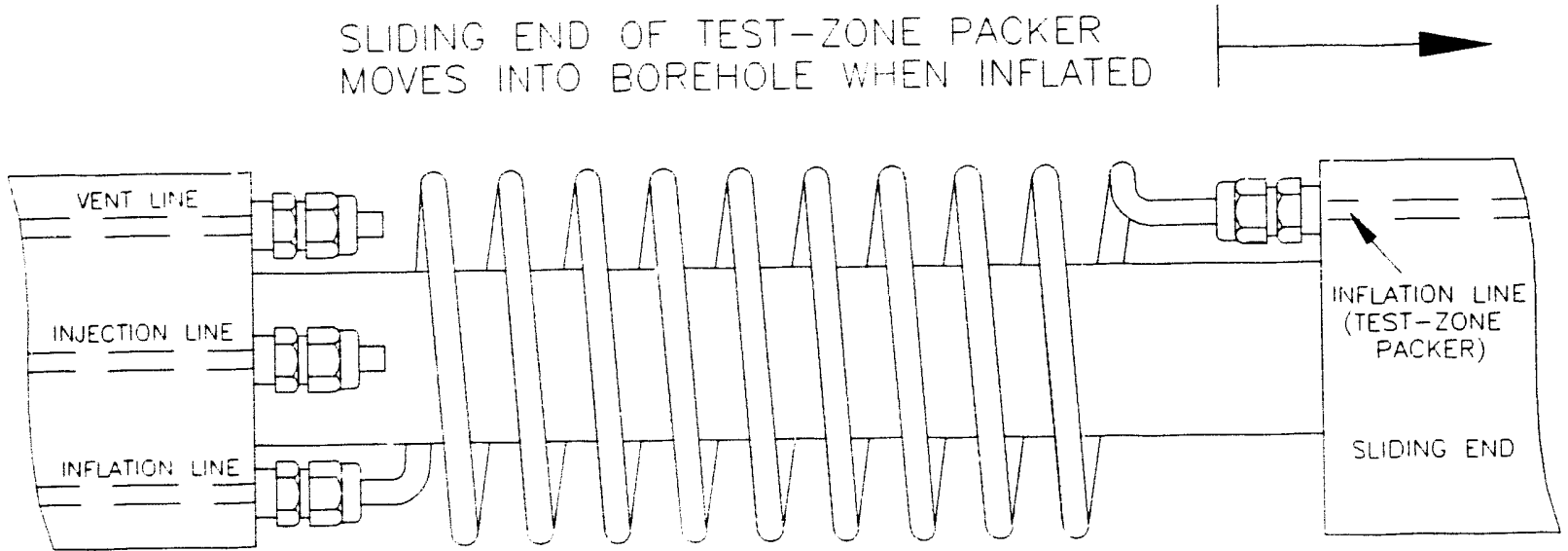

Figure 3-5. Movement of Sliding-End Sub in Guard Zone During Packer Inflation. 


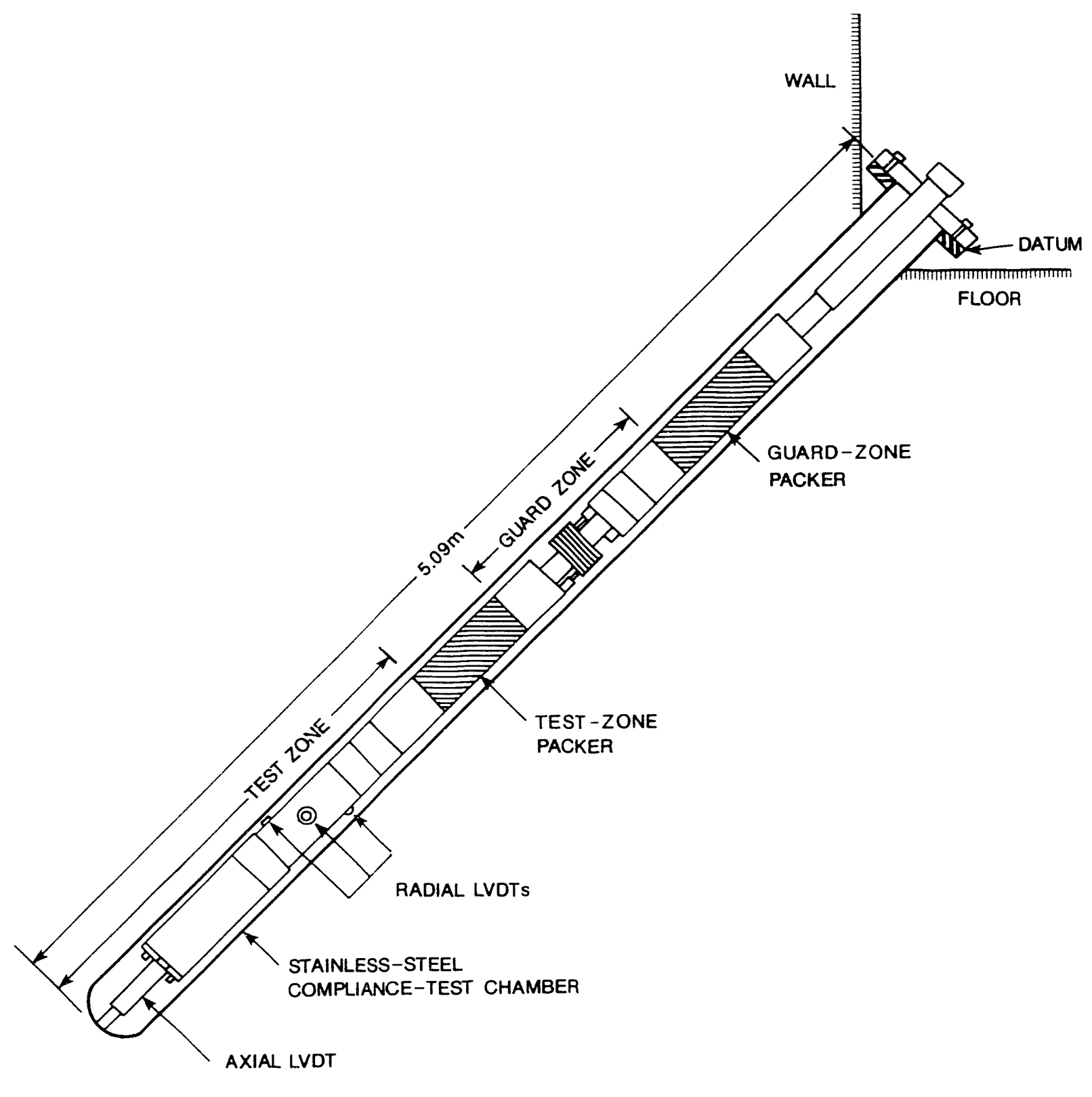

Figure 3-6. Cross-Section View of Stainless-Steel Compliance-Testing Chamber in Borehole P4P30. 


\section{TESTING PROCEDURES}

The multipacker test tools are used to conduct permeability tests in boreholes drilled from the underground excavations. In low-permeability formations such as the Salado, changes in the volume or temperature of the test-zone fluid and/or the test tool can materially affect observed fluid-pressure responses, as described in Pickens et al. (1987). In addition, changes in fluidpressure conditions in isolated sections of boreholes in low-permeability media can cause physical movement of the test tool. Changes in fluid-pressure conditions can occur in response to temperature changes affecting the test-zone and/or packer-inflation fluids. Fluid pressures in test intervals may also be affected by changes in packer-inflation pressures, and vice versa, as when a pulse injection in a test zone increases the forces acting against the outside of the test-zone packer, causing the packer-inflation pressure to increase.

Changes in the volume and pressure of the test-zone fluid that are not due to the formation's hydraulic response but instead to charges in the position of the test tool or deformation of the test tool or borehole are included under the term "compliance." Pickens et al. (1987) showed that compliance-related fluid-pressure changes during permeability tests of formations with hydraulic conductivities less than $10^{-12} \mathrm{~m} / \mathrm{s}$ can obscure and/or dominate actual formation-related fluidpressure changes and result in incorrect estimates of the formation's hydraulic properties. Test-tool-related compliance can be empirically estimated by subjecting the testing equipment to simulated test conditions and observingthe resultingfluid-pressure responses. These "compliance tests" provide data to understand and/or compensate fluid-pressure changes resulting from compliance during actual permeability testing.
The multipacker test tool to be used for permeability testing in any borehole undergoes compliance testing in a compliance-test chamber (Section 3.6) before being installed in the test borehole. Compliance testing quantifies the response of the test tool to the types and magnitudes of pressure changes anticipated during permeability testing. After compliance testing is completed, the test tool is installed in the test borehole, and a testing sequence consisting of a shut-in pressure buildup followed by pressure-pulse tests is initiated to evaluate the formation's hydraulic properties. Compliance- and pulse-testing procedures are discussed below.

\subsection{Compliance Testing}

Compliance tests are performed for each test tool before the tool is installed in a test borehole. The purposes of the compliance testing are to (1) establish that the test tools have been properly assembled and that all seals and fittings are performing as designed; and (2) evaluate test-tool responses to packer inflation and applied pressure pulses in the intervals isolated by the inflated packers. During compliance tests, the test tools with all monitoring instruments are installed in steel or stainless-steel chambers sealed at one end in the same manner employed when installing the test tool in a borehole. The DAS is used to monitor and record the results of the compliance testing.

The test tool's packers are then sequentially inflated, starting with the test-zone packer. Both packers are inflated to between 8 and $10 \mathrm{MPa}$, after which the pressures are monitored for 24 to 48 hours for evidence of leaks or improper performance. Packer pressures usually decrease during this period due to the elasticity of the packer-element material, possible 
- air entrapped during inflation going into solution, and other compliance-related phenomena. After monitoring this pressure decline for the initial 24- to 48-hour period, packer-inflation pressures are usually increased to 8 to $10 \mathrm{MPa}$ and monitored for an additional 24 to 48 hours.

After the leak-check/packer-pressure-adjustment periods, the test zone is subjected to a pressure-injection pulse of at least 3.5 MPa. The fluid-pressure responses of both the test and guard zones are then monitored for evidence of leaks, and the associated packer-pressure responses are also monitored. After evaluation of test-zone integrity is completed, the same procedure is followed to evaluate the integrity of the guard zone.

In some instances, the test- and guard-zone pressures are increased andior decreased in a series of step pressure-injection and/or -withdrawal pulses to provide a range of test-zone and packer-pressure responses to pressure changes in neighboring zones and packers. During the withdrawals, the volume of fluid released during each pressure drop is measured to provide data with which to evaluate test-tool or system compressibility.

Figures 4-1 to 4-5 display the results of a typical compliance-test sequence. Figure 4-1 shows the fluid pressures in the test and guard zones; Figure 4-2 shows the pressures in the test-zone and guard-zone packers; Figure 4-3 shows the fluid temperatures in the test and guard zones; Figure 4-4 shows the relative movement of the radial LVDTs; and Figure 4-5 shows the relative movement of the axial LVDT.

During the compliance test depicted on Figures 4-1 to 4-5, the pressure in the test zone was increased from approximately 0 MPato 7 MPa on Day 223 by injecting a small quantity of brine. The peak pressure quickly dissipated to about $4 \mathrm{MPa}$ and then slowly decreased due to compliance effects such as packer readjustment and/or axial test-tool movement. Figure 4-1 also shows that the guard zone received a pulse injection on Day 227 when the pressure was increased from $0 \mathrm{MPa}$ to $5 \mathrm{MPa}$. The guard-zone pressure displayed similar behavior to that of the test zone. The pulse injections into the test and guard zones caused pressure changes throughout the system. As the pressure in a zone is increased, the adjacent packer(s) is compressed, causing its internal pressure to increase. The packer(s) also deforms slightly away from the zone being pressurized, which cancause the pressure in the adjacent zone to rise slightly. This pressure increase can in turn be transmitted to another packer.

Figure 4-3 shows the temperatures measured in the test and guard zones during compliance testing. Temperatures were stable throughout the testing period except for short-lived increases in the guard-zone temperature following the pulse injections.

Figures 4-4 and 4-5 show the LVDT responses during compliance tests. The radial LVDTs (Figure 4-4) show that the test chamber's diameter in the test zone increased by about $0.04 \mathrm{~mm}$ during the pulse injection. This increase is consistent with the predicted diameter increase calculated from the material properties of the test chamber. Note that because of the LVDTs' orientation (see Section 3.5), the actual increase in diameter must be estimated by integrating the responses of all three radial LVDTs. Figure 4-5 shows that the axial LVDT was compressed (shortened) when the test-zone packer was inflated, but tended to lengthen as the test-zone-packer pressure declined. This response is probably due to some elastic response of the packer element. During the pulse injection in the test zone, the axial LVDT lengthened as 


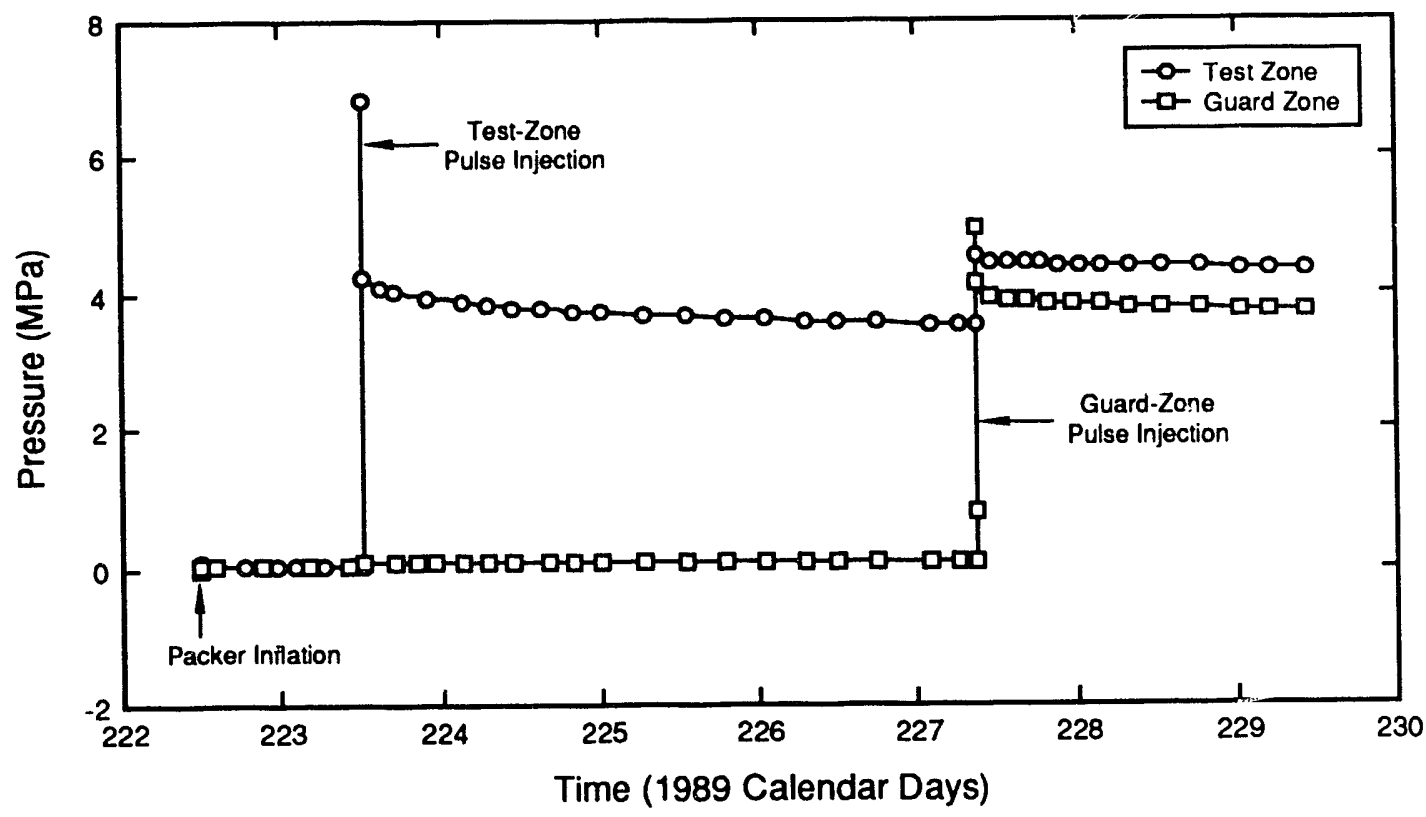

TR1-6344-556-0

Figure 4-1. Zone Pressures for Compllance Test COMP 16, Multipacker Test Tool \#5, Borehole C2H03.

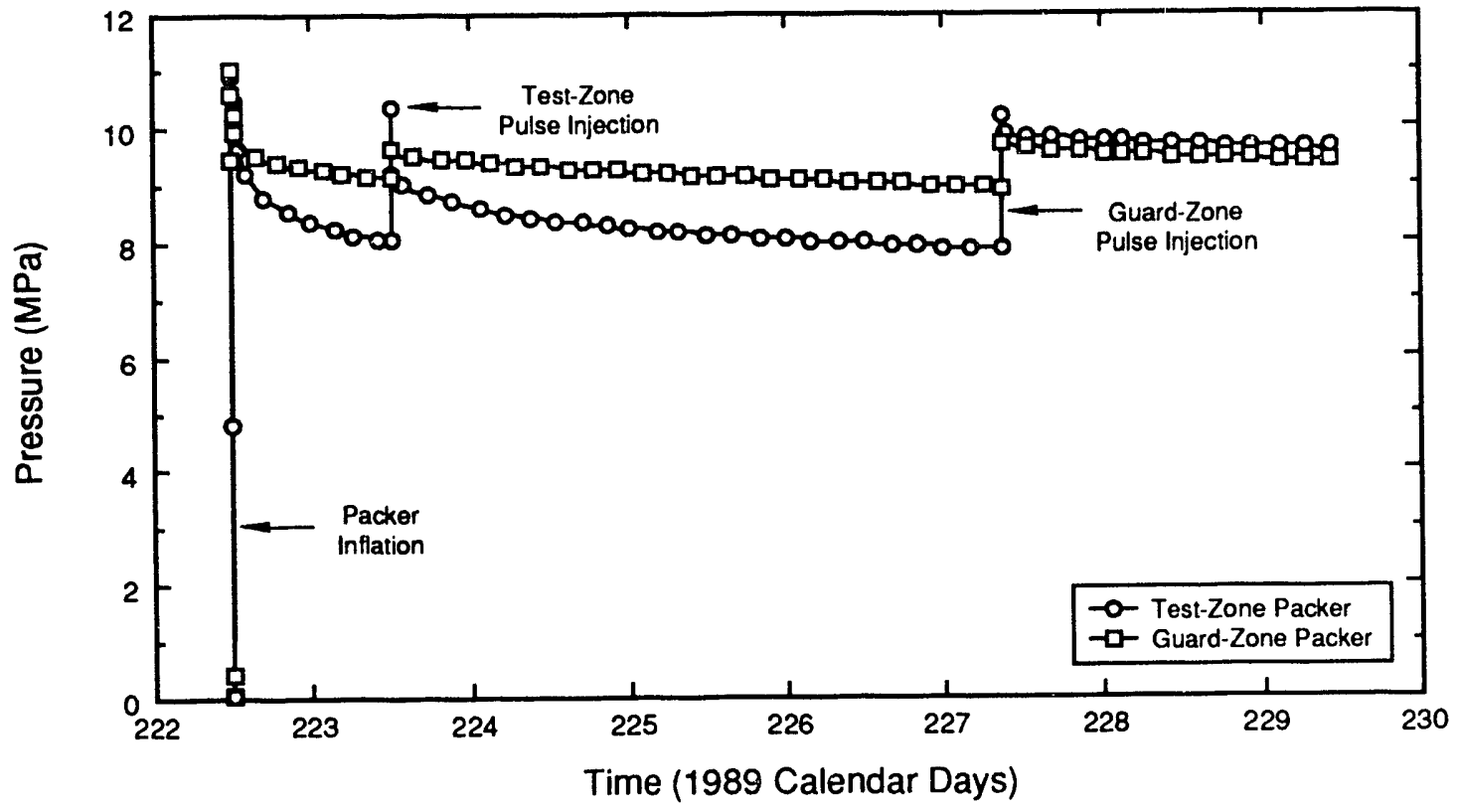

Figure 4-2. Packer Pressures for Compliance Test COMP 16, Multipacker Test Tool \#5, Borehole C2HO3. 


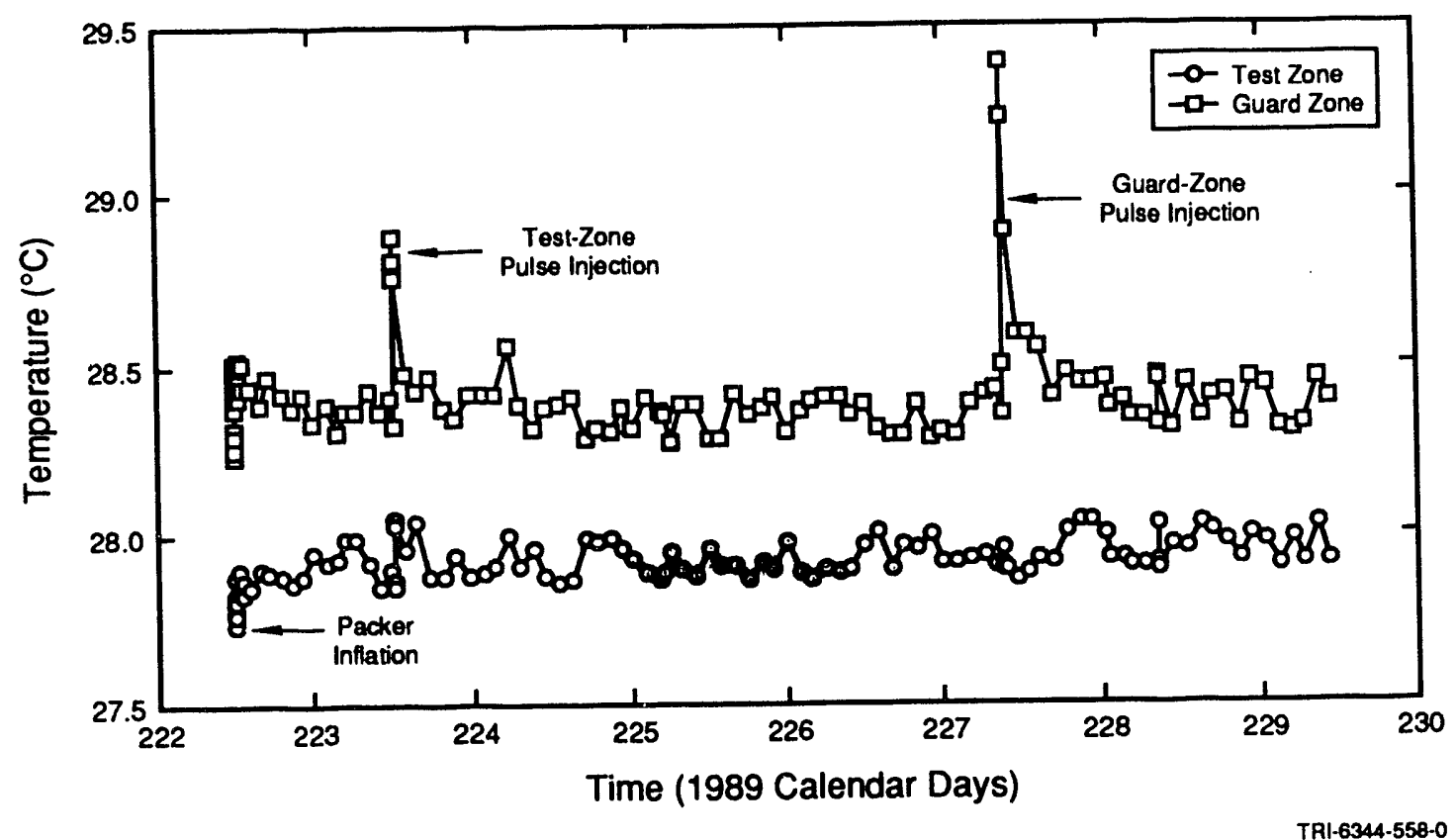

Figure 4-3. Zone Temperatures for Compliance Test COMP 16, Multipacker Test Tool \#5, Borehole C2HO3.

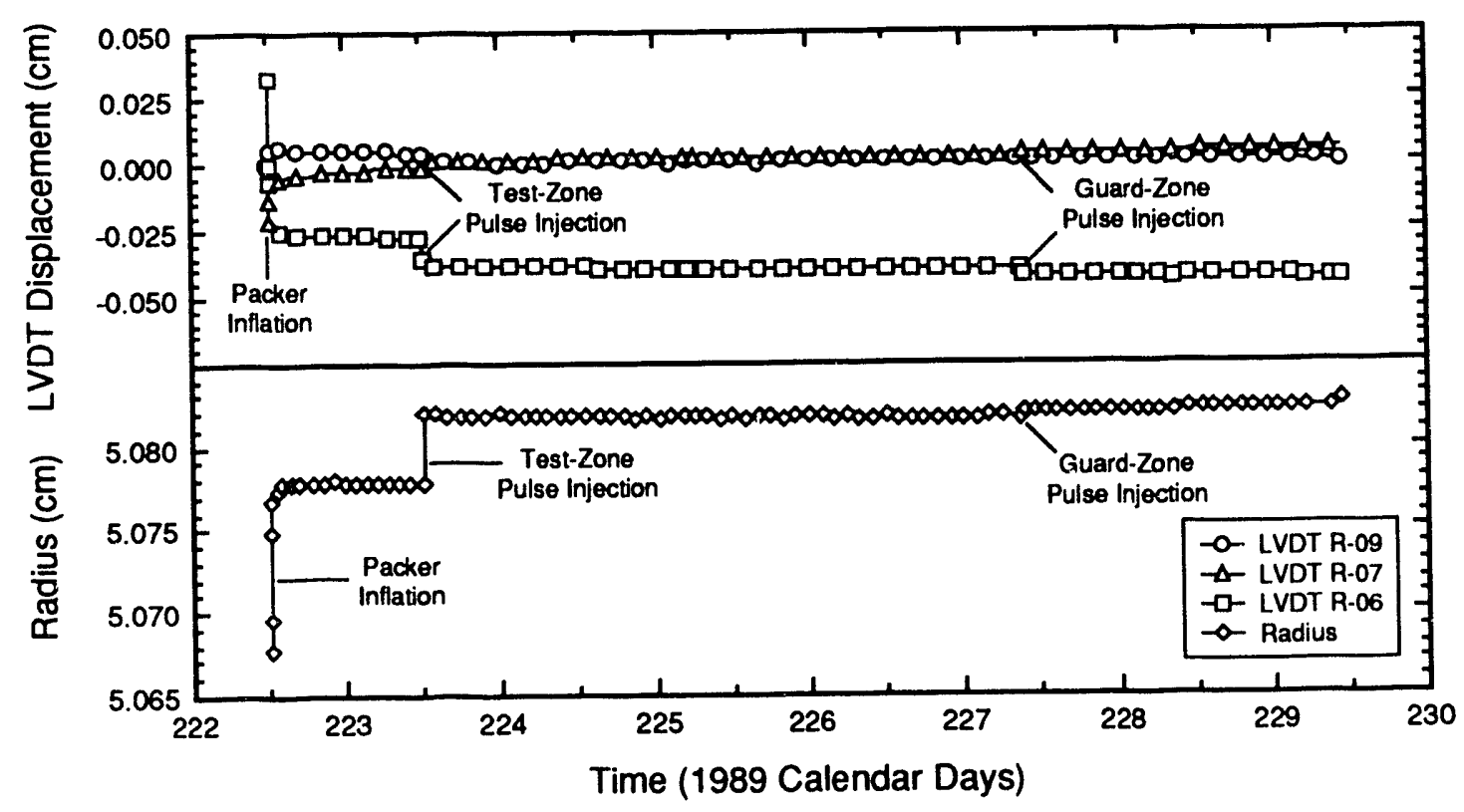

Figure 4-4. Radial-LVDT Data for Compliance Test COMP 16, Multipacker Test Tool \#5, Borehole C2H03. 


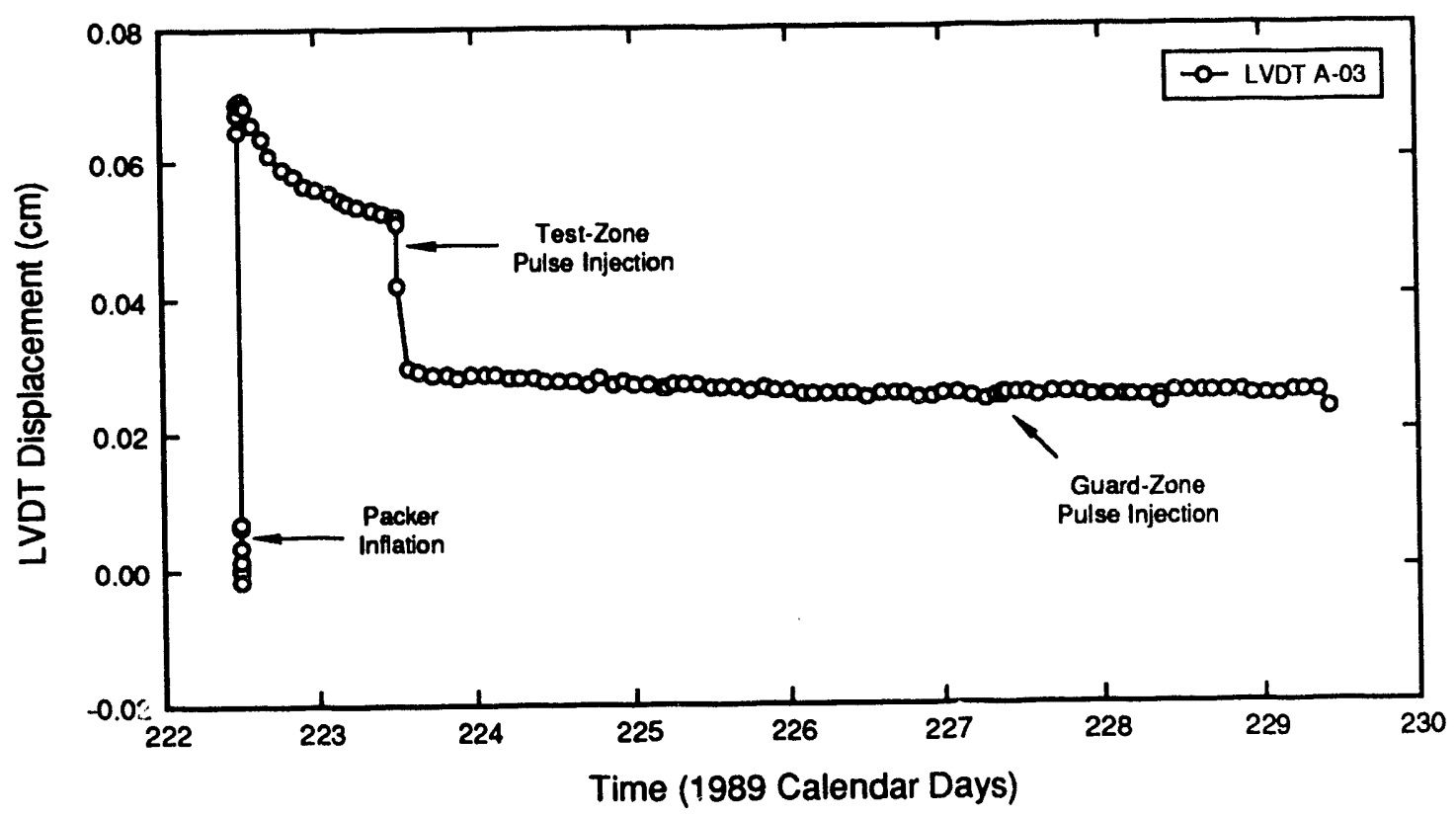

TRI-6344-560-0

Figure 4-5. Axlal-LVDT Data for Compliance Test COMP 16, Multipacker Test Tool \#5, Borehole C2HO3.

the increase in test-zone pressure forced the test tool upward in the compliance-testing chamber. The guardzone pulse injection did not have the same effect on the axial LVDT response. Saulnier et al. (1991) present complete plots and tabulated data for the compliance tests performed before the permeability tests analyzed in this report.

\subsection{Pressure-Pulse Testing}

A permeability-testing sequence begins with the drilling of a nominal 10.2-cm (4-inch) diameter borehole. A multipacker test tool is installed in each test borehole as soon after drilling as possible in an attempt to minimize pretest borehole history under non-shut-in conditions. The test boreholes are filled with brine saturated with sodium chloride, simulating the formation fluid, either immediately after drilling, or by injecting brine through the injection lines after the packers are inflated. The fluid pressures and temperatures in the isolated zones are monitored after test-tool installation until the readings stabilize. The packers are then sequentially inflated to approximately $11 \mathrm{MPa}$, starting with the test-zone packer. The packers are inflated with fresh water using a positive-displacement pressure-intensifier pump. The packer-inflation pressures are monitored closely for $\mathbf{2 4}$ to $\mathbf{4 8}$ hours after inflation. If compliance-related reductions in the packer-inflation pressures of greater than $3 \mathrm{MPa}$ are observed, the packer-inflation pressures are increased to $11 \mathrm{MPa}$ and observed for an additional 24 hours. After the initial transient decreases in packer pressures occur and the packer-inflation pressures approach relative stability, valves on the test- and guard-zone vent lines are closed to shut in the test and guard zones.

Once the test and guard zones are shut in, the fluid pressures in the two zones increase as they equilibrate with the formation pore pressure in the vicinity of the 
borehole. Pressure-pulse testing of the type described by Bredehoeft and Papadopulos (1980) is initiated after the rate of pressure increase in the test zone decreases and the pressure-recovery curve appears to be on an asymptotic trend (Figure 4-6). Pulsewithdrawal rather than pulse-injection tests were generally chosen for the Salado Formetion permeability testing because: they do not force fluids into the formation that may not be in chemical equilibrium with the rock; they do not overpressurize the formation, a procedure which could potentially open existing fractures or create new fractures by hydrofracture; and they more closely represent the hydraulic conditions expected shortly after closure of the WIPP underground facility when brine may be flowing from the host rock towards the relatively underpressurized rooms.

Pulse-withdrawal tests are initiated in a test or guard zone by opening the zone's vent valve and allowing fluid to flow from the zone until the desired fraction of the shut-in pressure has dissipated. After the desired pressure decrease has been achieved, the valve is then closed to shut in the zone. The volume of fluid released from the vent line during each pulse withdrawal is measured and recorded. Following the pulse withdrawal, the reequilibration of the zone's fluid pressure and the formation pore pressure is monitored with the DAS. After the zone's fluid pressure has recovered to approximately its pre-pulse value, the test is usually repeated (Figure 4-6) to provide assurance that the observed fluid-pressure responses are reproducible and are representative of formation responses. After testing in the test zone (and guard zone if desired), the pressures in both the guard and test zones are vented and the volumes of fluid produced during the depressuring are measured before removing the test tool from the borehole. For the latertests, the pressure was decreased in steps, measuring the volume released during each step, to provide data with which to estimate the post-testing test-zone compressibility.

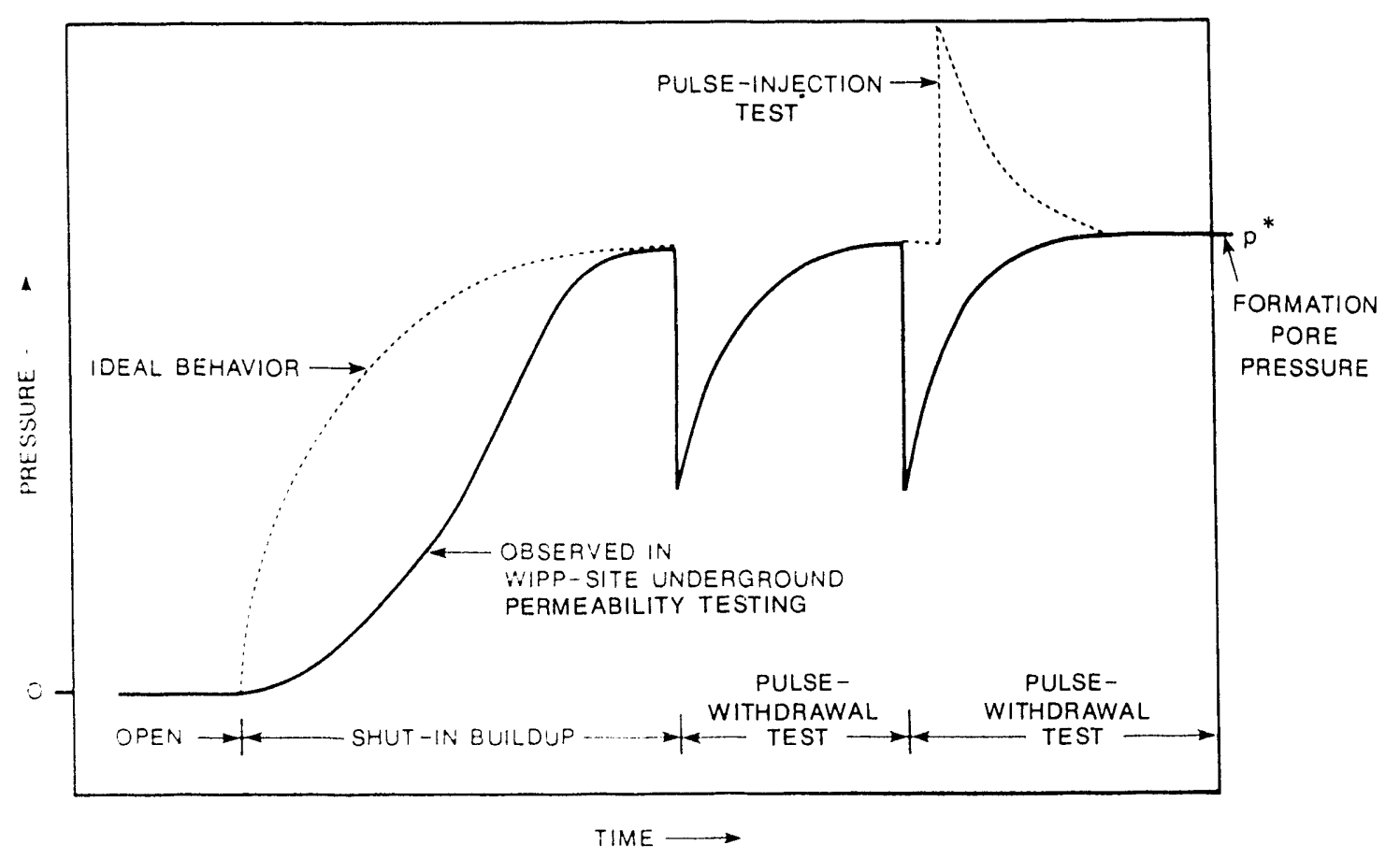

Figure 4-6. Typical Permeability-Testing Sequence. 


\section{TEST LOCATIONS AND BOREHOLES}

Figure 5-1 shows the locations of the boreholes drilled for the underground permeability-testing program. Boreholes were drilled in the experimental area, the operations area, and the waste-storage area. Borehole locations were chosen to provide access to different Salado Formation lithclogies (Figure 2-3), to investigate whether or not the ages of excavations affect permeability in similar stratigraphic intervals, and to provide a representative distribution of data from a wide area of the underground facility. The testing discussed in this report was performed in boreholes $\mathrm{C} 2 \mathrm{H} 01, \mathrm{C} 2 \mathrm{HO2}, \mathrm{C} 2 \mathrm{HO} 3, \mathrm{~N} 4 \mathrm{P} 50$, L4P51, SOPO1, and S1P71.

Borehole locations in the underground experimental area (C2HOx, N4P50, and L4P51) were chosen to investigate three aspects of Salado Formation hydrology. First, holes drilled from Room $\mathrm{C2}$, which was excavated stratigraphically above the waste-disposal horizon, were used to test the waste-disposal horizon in downward-oriented boreholes. Second, boreholes drilled from the stratigraphically higher parts of the experimental area (Room C2) were used to test Marker Bed 139 under conditions where it lies about seven meters below an excavation. (In contrast, Marker Bed 139 is encountered about two meters below the excavations in the operations and waste-storage areas.) Third, testing in the experimental area was conducted in boreholes drilled from excavations both older (Room C2, North 1420 Drift) and younger (Room L4) than those in the waste-storage area.

A borehole location in the operations area (SOP01) was chosen to allow testing of the strata in immediate proximity to the waste-disposal horizon from an excavation (South 1300 Drift) older than those available in the waste-storage area, as well as to increase the areal distribution of Salado hydraulic data.

\begin{abstract}
A borehole location in the waste-storage area (S1P71 in Room 7 of Waste Panel 1) was chosen to provide hydraulic information for those portions of the Salado Formation directly affected by the excavations scheduled for waste storage (Figure 2-3). These areas generally have been exposed to excavation effects for less time than excavations in the experimental and operations areas.
\end{abstract}

In some instances, test tools are repositioned after the initial testing is completed to allow testing of different segments of holes. In other instances, holes are deepened and additional testing is performed after testing of the initial borehole configuration has been completed. In both cases, the first testing sequence performed in a borehole is given an " $A$ " suffix, as in $\mathrm{C} 2 \mathrm{H} 01-\mathrm{A}$, and subsequent testing sequences are given " $B$," " $C$," etc. suffixes, as in $\mathrm{C} 2 \mathrm{H} 01-\mathrm{B}$ and $\mathrm{C} 2 \mathrm{H} 01-\mathrm{C}$. Note that only the "A" testing for boreholes L4P51 and S1P71 is discussed herein; later testing in these holes was not ccmpleted by the data-cutoff deadline for this report (February 1990).

Permeability tests were not completed successfully in all boreholes drilled for the testing program. The extremely slow fluid-pressure response observed in borehole $\mathrm{C}_{2} \mathrm{H} 03$ in Room $\mathrm{C} 2$ was considered unsuitable for the continuation of testing activities. Borehole N4P50, in the North 1420 Drift, had to be abandoned during the shut-in period that normally precedes testing because of construction activities.

A compressed-air drilling apparatus was used to drill the boreholes for the permeability-testing program in the floors and ribs (walls) of the test rooms. All of the boreholes were cored and/or drilled to a nominal $10.2-\mathrm{cm}$ (4 inch) diameter. The boreholes were cored 


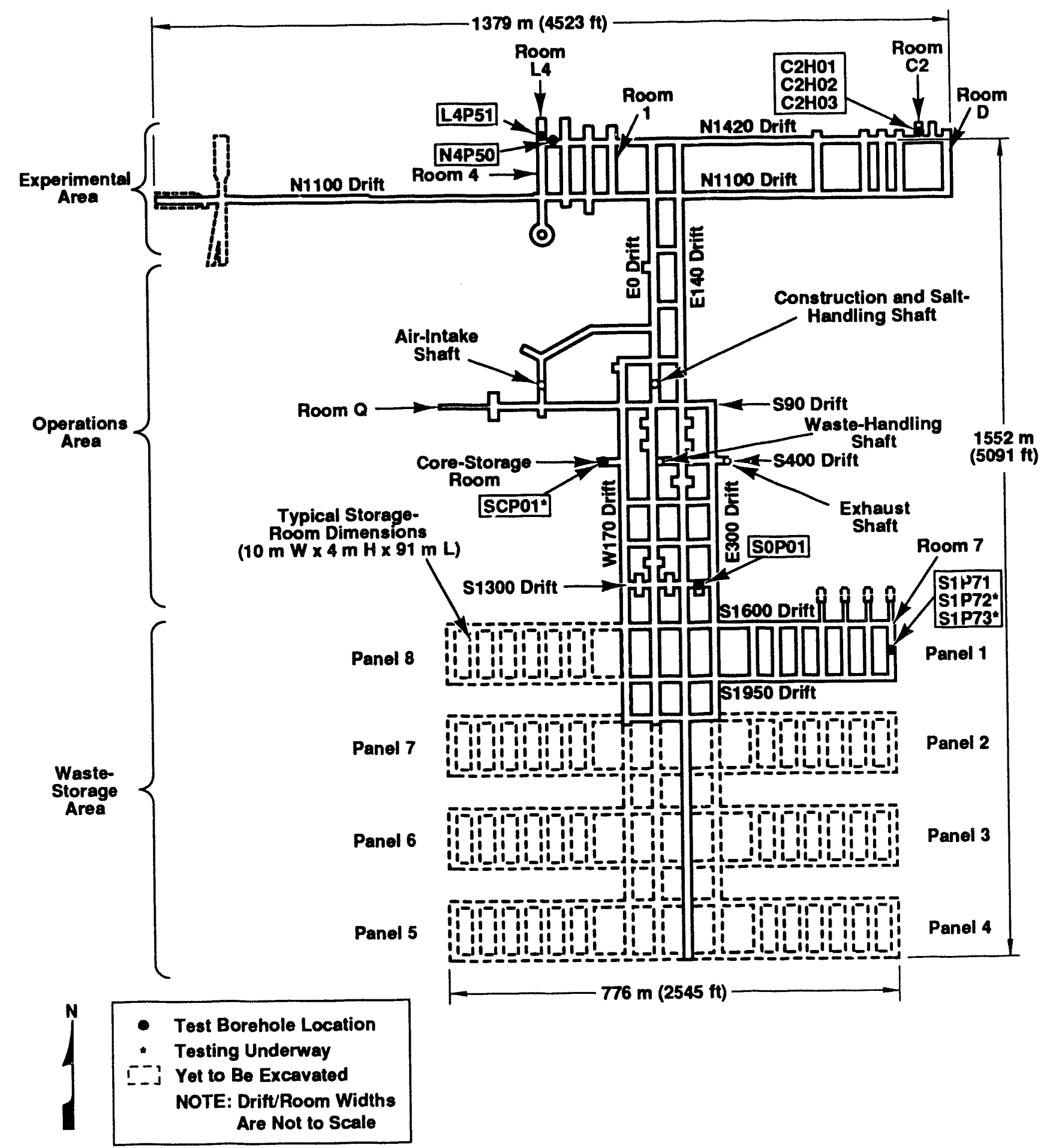

TRI-6330-129-2

Figure 5-1. Map of the WIPP Underground Facility Showing Test Locations. 
when possible to allow sample recovery. When visible quantities of formation brine were encountered in association with clay and/or anhydrite layers, brine saturated with respect to sodium chloride was used as the drilling fluid and conventional, non-coring drill bits were used. For testing of $\mathrm{C}_{2} \mathrm{HO} 1-\mathrm{C}, \mathrm{C} 2 \mathrm{H} 02, \mathrm{C}_{2} \mathrm{HO}$, and L4P51, $12.7-\mathrm{cm}$ (5 inch) I.D., $51-\mathrm{cm}$ (20 inch) long, steel borehole collars were grouted to the formation in the tops of the holes. The multipacker test tools were then bofted to the collars to help eliminate test-tool movement in response to packer inflation and pressure buildup in the guard and test zones. Borehole collars were not used for earlier tests $\mathrm{C} 2 \mathrm{H} 01-\mathrm{A}, \mathrm{C} 2 \mathrm{H} 01-\mathrm{B}$, N4P50, S0P01, or S1P71-A.

Core samples were recovered from 95 percent of the drilled lengths of the test boreholes. The lithologies, fracturing, penetration times, and occurrences of fluid were recorded on the core sample logs (see Appendix C, and Saulnier et al., 1991). The lithologies are referenced to the standard WIPP map units listed in Appendix B. Descriptions of the drilling locations and individual boreholes are presented below.

\subsection{Room C2}

Room C2 was excavated in March and April 1984 to nominal dimensions of $5.5 \mathrm{~m}$ wide, $5.5 \mathrm{~m}$ high, and $34.8 \mathrm{~m}$ long (Bechtel, 1986). Figure 5-2 shows crosssection and plan sketches of the borehole array drilled for permeability testing in Room C2. Both the initial and deepened configurations for borehole $\mathrm{C} 2 \mathrm{HO} 1$ are shown. Borehole $\mathrm{C} 2 \mathrm{H} 01$ was drilled vertically downward to an initial depth of $5.58 \mathrm{~m}$ below the floor of Room C2 on August 4, 1988 (Calendar Day 217). The floor of Room C2 lies within map unit 7 (Figure 2-2), and the hole bottomed in map unit 0 . Thus, the hole penetrated all of the strata in which the waste-disposal rooms are located (Figure 2-3). The hole was deepened to 8.97 mon February 13 and 15, 1989 (Calendar Days 44 and 46) to allow testing of Marker Bed 139. which was encountered from 6.80 to $7.76 \mathrm{~m}$. A description of the core samples recovered from borehole $\mathrm{C} 2 \mathrm{H} 01$ during both drilling periods is presented in Appendix C.

Borehole $\mathrm{C} 2 \mathrm{H} 02$ was drilled to allow testing of Marker Bed 139 beneath the rib (wall), rather than the floor, of Room C2. Borehole $\mathrm{C}_{2} \mathrm{H} 02$ was drilled westward, at a downward angle of $45^{\circ}$ from the horizontal, to a depth of $10.86 \mathrm{~m}$ from the intersection of the west rib and floor of Room C2 (Figure 5-2). The drilled depth corresponds to a vertical depth of $7.68 \mathrm{~m}$ below the floor of the room. Borehole $\mathrm{C} 2 \mathrm{H} 02$ was cored on April 12, 13, and 17, 1989 (Calendar Days 102, 103, and 107). Marker Bed 139 was encountered from 9.20 to $10.68 \mathrm{~m}$ (Figure 5-2). The section of the hole from $10.3 \mathrm{~m}$ to the bottom-hole depth of $10.86 \mathrm{~m}$ was cored using sodium-chbride-saturated brine to remove drilling cuttings because formation brine was encountered when drilling this interval. A description of the core samples recovered from borehole $\mathrm{C} 2 \mathrm{H} 02$ is presented in Appendix $C$.

Borehole $\mathrm{C}_{2} \mathrm{H} 03$ was drilled to test a bed of relatively pure halite between anhydrites "a" and "b" (Figure 5-2). The hole was cored horizontally, $2.1 \mathrm{~m}$ above the floor, into the west rib of Room C2 to a distance of $9.14 \mathrm{~m}$. The drilling was performed on August 22 and 23, 1989 (Calendar Days 234 and 235). A description of the core samples recovered from borehole $\mathrm{C}_{2} \mathrm{H} 03$ is presented in Appendix C.

\subsection{North 1420 Drift}

The location of borehole N4P50 in the North 1420 Drift is shown in Figure 5-1. This portion of the North 1420 Drift was excavated in March 1983 to nominal dimensions of $6.1 \mathrm{~m}$ wide and $3.7 \mathrm{~m}$ high (Bechtel, 1985). Borehole N4P50 was cored vertically downward to a depth of $10.87 \mathrm{~m}$ below the floor of the drift (Figure 5-3) on December 15 and 16, 1988 (Calendar 


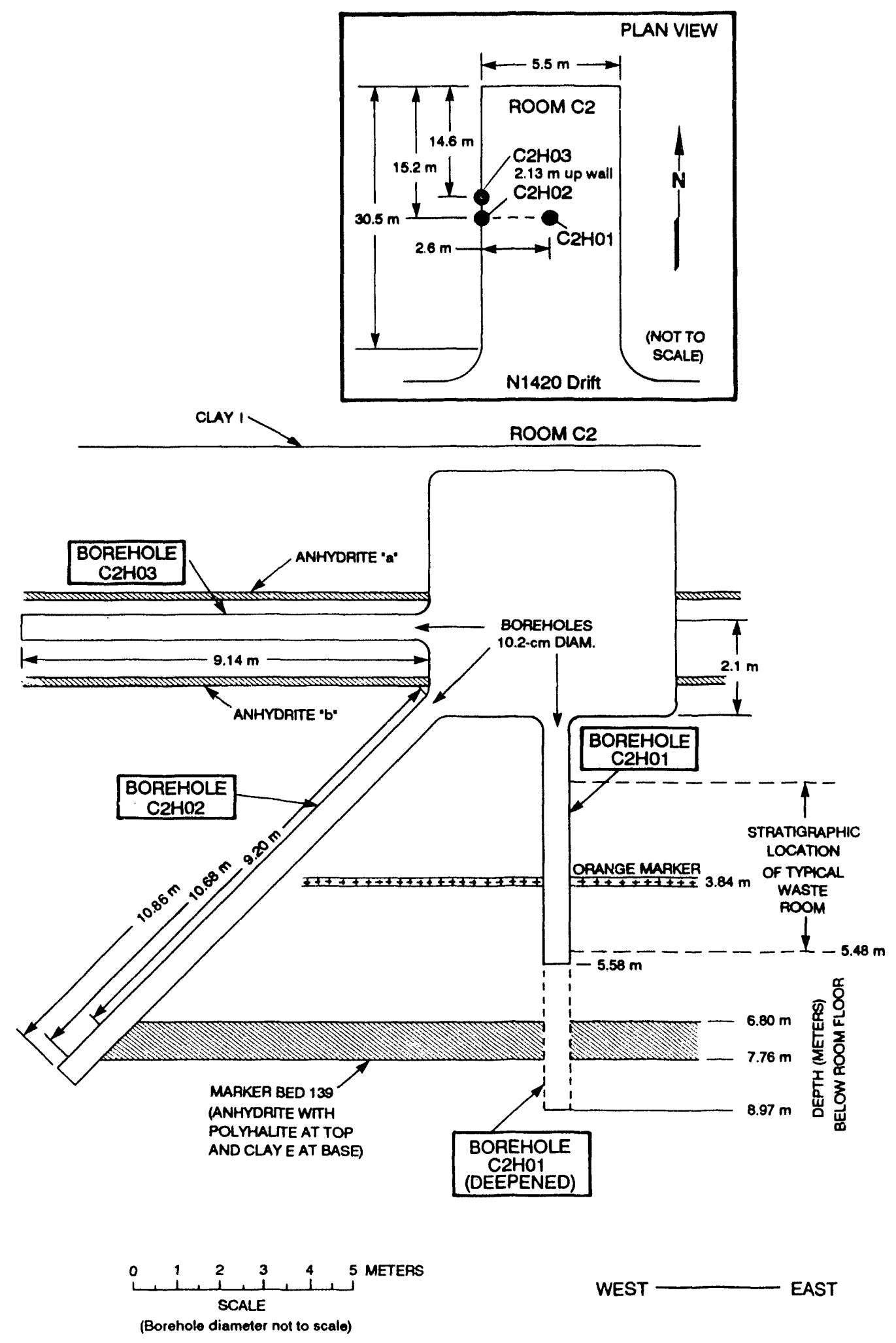

Figure 5-2. Positions of Boreholes $\mathrm{C}_{2} \mathrm{HO1}, \mathrm{C} 2 \mathrm{HO2}$, and $\mathrm{C}_{2} \mathrm{HO}$ in RoOm C2. 

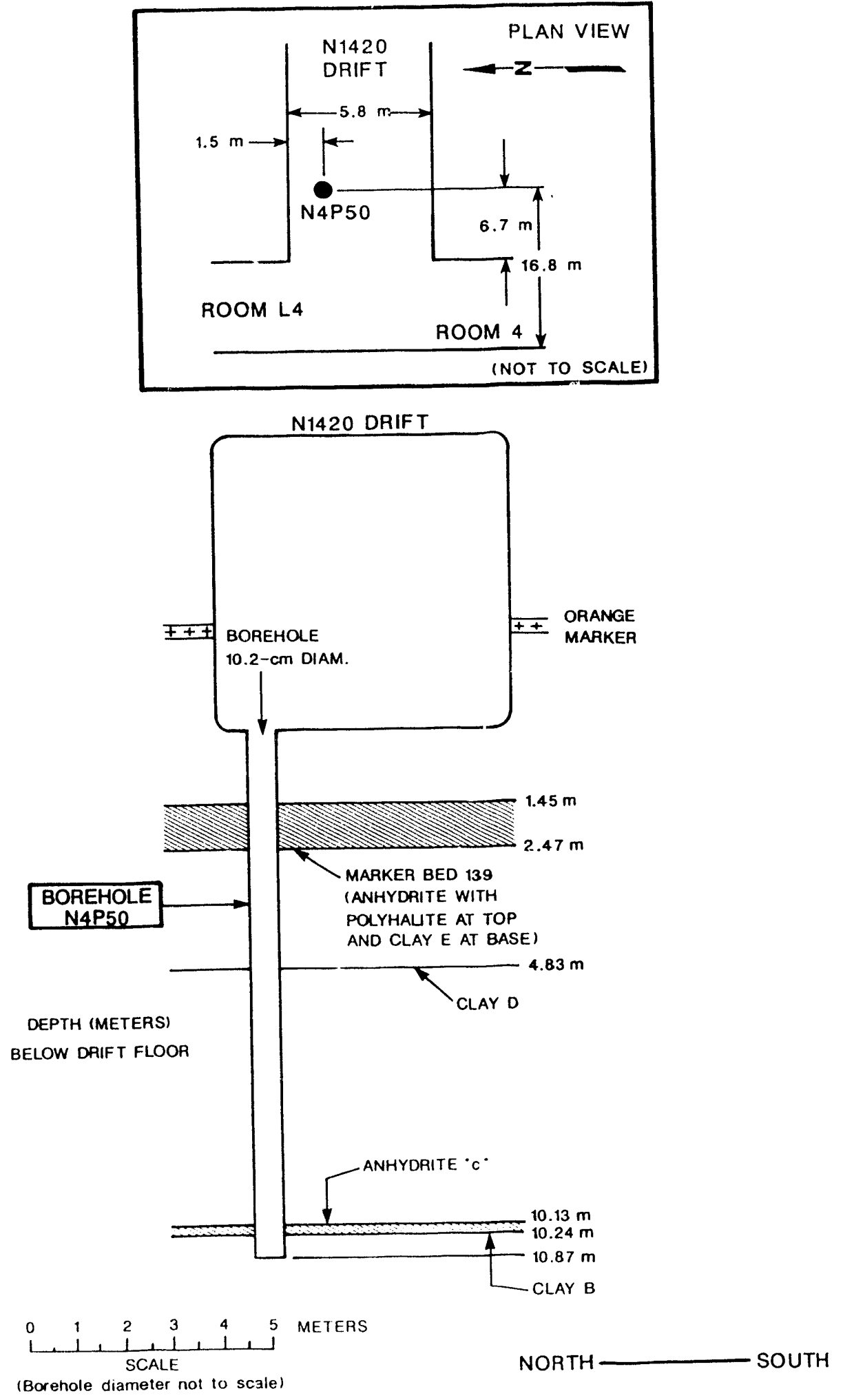

Figure 5-3. Position of Borehole N4P50 in the North 1420 Drift. 
Days 350 and 351). The borehole was drilled to aliow testing of anhydrite "c," which was encountered from 10.13 to $10.24 \mathrm{~m}$ deep. A description of the core samples recovered from borehole N4P50 is presented in Appendix C.

\subsection{Room L4}

Room L4 was excavated in February 1989 (Westinghouse, 1990) and provided an opportunity to irstall and test a borehole shortly after a room had been excavated. The room is nominally $10.1 \mathrm{~m}$ wide, $3.7 \mathrm{~m}$ high, and $59.7 \mathrm{~m}$ long. Borehole L4P51 was $d$ iflied and cored vertically downward to a depth of $4.75 \mathrm{~m}$ below the floor of the room (Figure 5.4 ) from October 18 to 19, 1989 (Calendar Days 290 and 291). The borehole was drilled to investigate the properties of Marker Bed 139 and the underlying halite, poiyhalitic halite, and clay D. Marker Bed 139 (including clay E) was encountered from 1.50 to $2.36 \mathrm{~m}$ below the floor of the room, and clay D was encountered from 4.55 to $4.57 \mathrm{~m}$ deep (Figure 5-4). A description of the core samples recovered from borehole L4P51 is presented in Appendix $\mathrm{C}$.

\subsection{South 1300 Drift}

Figure 5-1 shows the location of borehole SOPO1 in the South 1300 Drift. This portion of the South 1300 Drift was excavated in June and July 1984 to nominal dimensions of $6.1 \mathrm{~m}$ wide and $3.7 \mathrm{~m}$ high (Bechtel,
1985). Borehole SOP01 was drilled on January 11 and 12, 1989 (Calendar Days 11 and 12) to investigate Marker Bed 139 and the underlying halite, polyhalitic halite, and $c$ ay $D$ in a location between the experimental area and the waste-storage area. The hole was drilled vertically downward to a depth of $5.17 \mathrm{~m}$ below the floor of the drift (Figure 5-5). The hole encountered Marker Bed 139 from 1.80 to $2.76 \mathrm{~m}$ below the floor of the drift. Clay D was encountered at the bottom of the borehole, from 5.155 to $5.170 \mathrm{~m}$ (Figure 5-5). A description of the core samples recovered from borehole SOP01 is presented in Appendix C.

\subsection{Waste Panel 1, Room 7}

Room 7 in Waste Panel 1 was excavated in March 1988 to nominal dimensions of $10.1 \mathrm{~m}$ wide, $4.1 \mathrm{~m}$ high, and $91.4 \mathrm{~m}$ long (Westinghouse, 1989). Borehole S1P71 was drilled vertically downward into the floor of Room 7 (Figure 5-6) on November 10, 1988 (Calendar Day 315) to a depth of $4.56 \mathrm{~m}$. The purpose of the hole was to allow testing of Marker Bed 139 and underlying halite, polyhalitic halite, and clay $D$ in the waste-storage area. Borehole S1P71 encountered Marker Bed 139 and clay E from 1.40 to 2.25 m below the floor of Room 7 (Figure 5-6). Clay D was encountered at the bottom of the borehole. Adescription of the core samples recovered from borehole S1P71 during drilling is presented in Appendix C. 

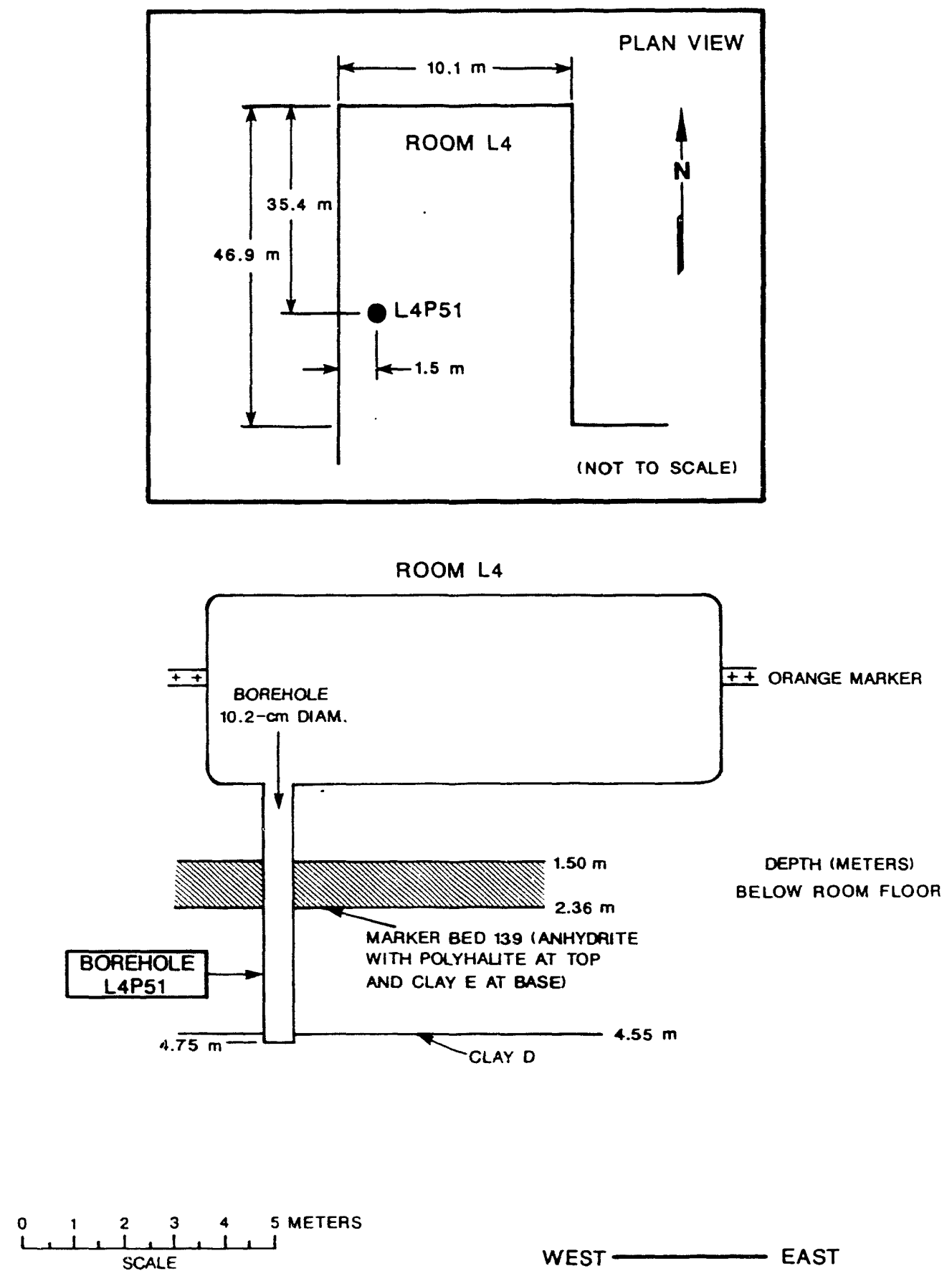

WEST $\longrightarrow$ EAST

(Borehole diameter not to scale)

Figure 5-4. Position of Borehole L4P51 in Room L4. 

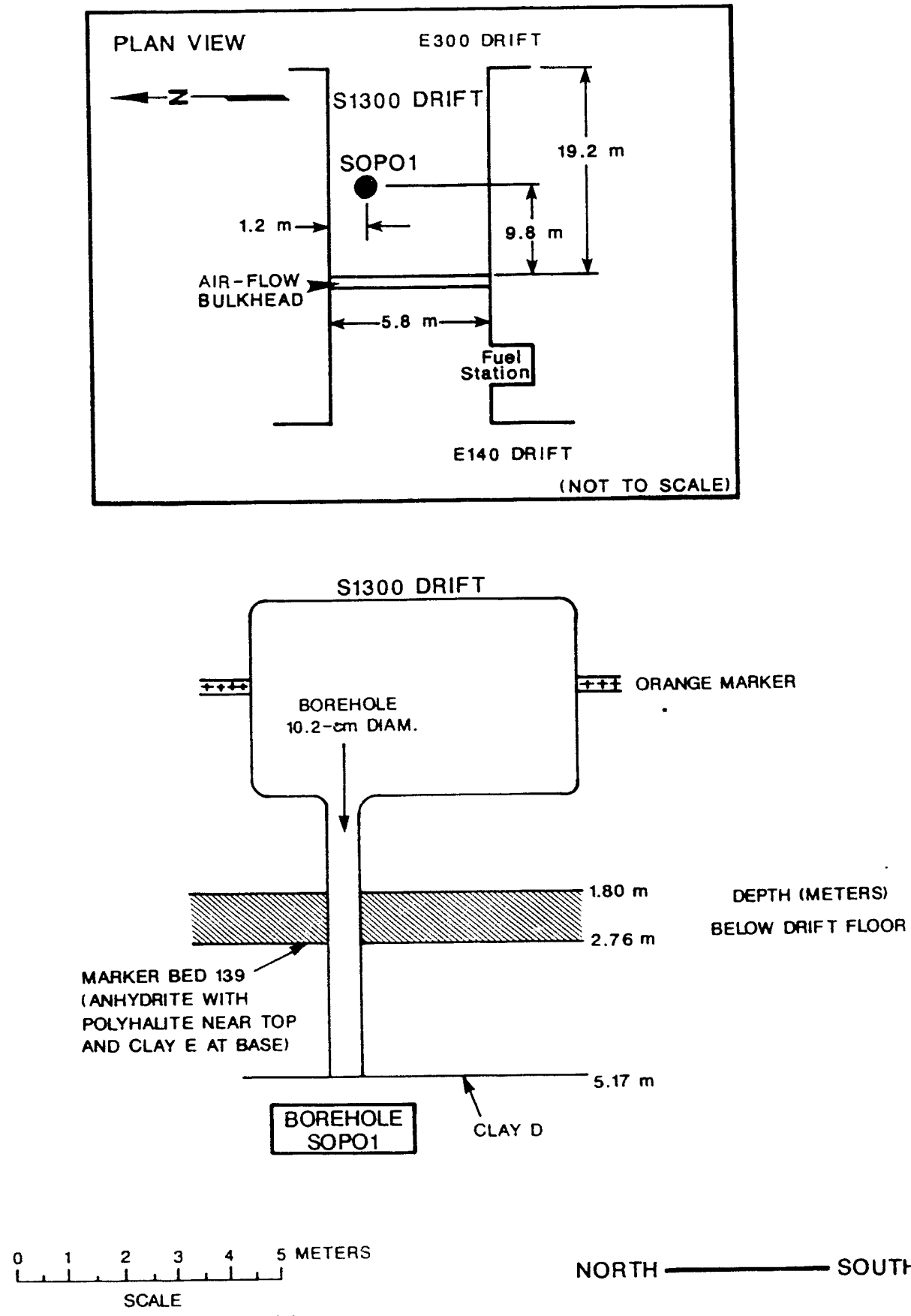

NORTH SOUTH

(Borehole diameter not to scale)

Figure 5-5. Position of Borehole SOP01 in the South 1300 Drift. 

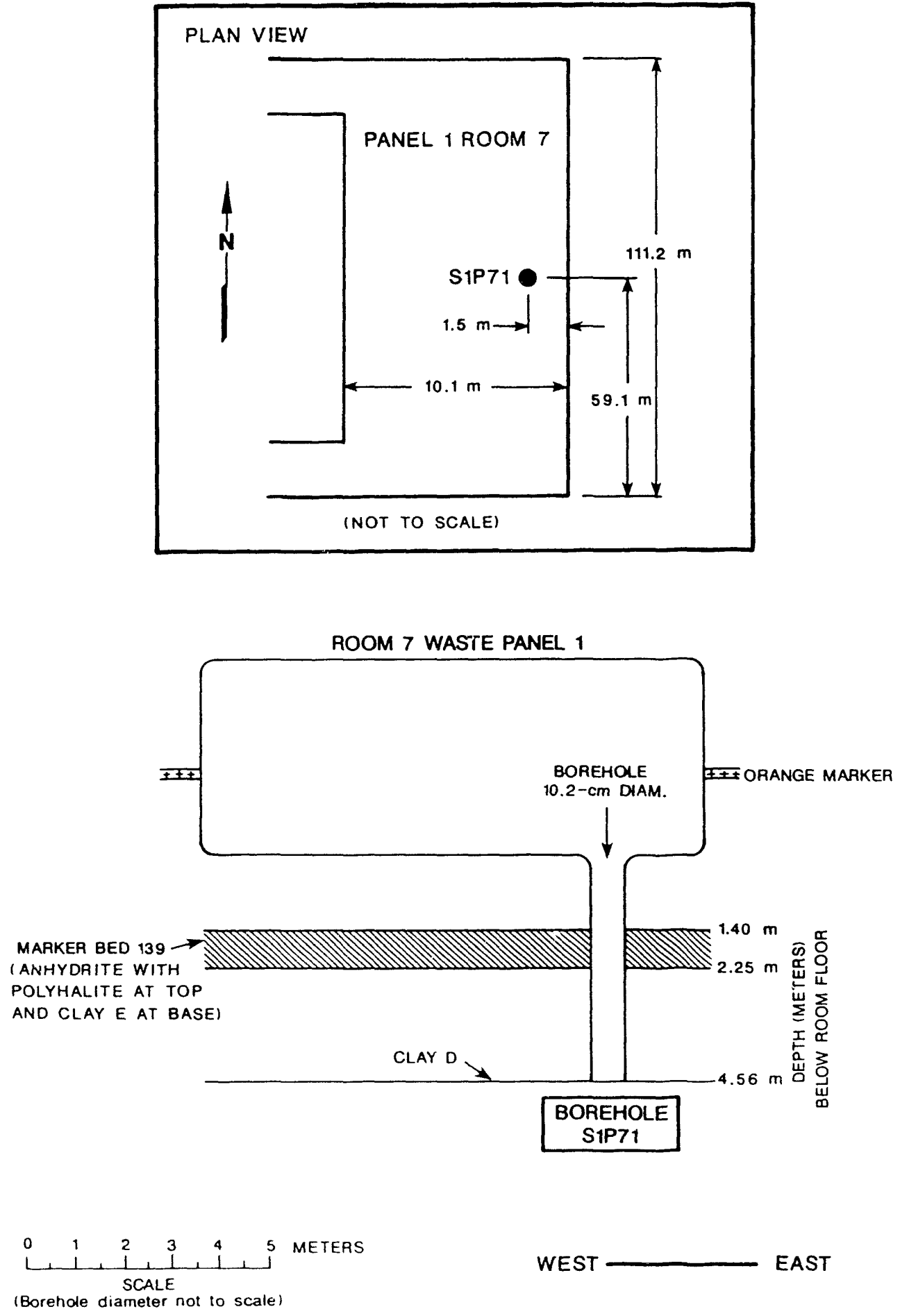

Figure 5-6. Position of Borehole S1P71 in Waste Panel 1, Room 7. 


\section{INTERPRETATION METHODOLOGY}

Interpretation of the permeability tests in the WIPP underground facility was performed with the well-testsimulation model GTFM (Graph Iheoretic Eield Model; Pickens et al., 1987). GTFM was used to simulate the fluid-pressure responses observed during permeability testing of the Salado Formation. Different combinations of the most uncertain formation parameters, hydraulic conductivity and pore pressure, were used in the simulations. Estimates of the actual values of these parameters were determined by graphically comparing the simulated and observed fluid-pressure responses. The parameter combinations that yielded the simulated responses that most closely matched the observed fluid-pressure responses were considered to be representative estimates of the actual formation parameters. The simulation model was also used to conduct sensitivity analyses of the most important model and formation parameters to quantify the uncertainties of the formation-parameter estimates.

The well-test-interpretation model is discussed in Section 6.1. Section 6.2 summarizes some of the salient assumptions underlying the test interpretations. Section 6.3 discusses the values of the tested formations' material properties that were used in the simulations and how those values were selected.

The primary parameters used by the analysis model to simulate the formation's fluid-pressure responses during pulse tests are the formation's hydraulic parameters, the test-zone volume, and the test-zone compressibility. The test-zone volume and test-zone compressibility are used to calculate the wellbore boundary conditions for the pulse-test simulations. Section 6.4 presents the initial test-zone volumesused for each interpreted test and the procedure used to compensate the simulations for variations in test-zone volume during testing. Section 6.5 discusses the procedures and rationale used for determining testzone compressibility. Section 6.6 discusses incorporation of the observed test- and guard-zone temperature data in the simulations.

\subsection{Well-Test-Simulation Model}

GTFM is a numerical model that simulates the hydraulic response of a single-phase, one-dimensional, radial-flow regime to boundary conditions applied at a borehole located at the center of the modeled flow system. The problem domain is discretized by dividing the radial-flow system into a series of concentric rings centered on the borehole, with each ring represented by a node. A constant multiplicative factor is used to increase the spacing between nodes with increasing distance from the origin (borehole). For the simulations presented in this report, 250 radial nodes were used. The model assumes that the formation has a constant thickness with vertically homogeneous hydraulic propenties. Formations may be single or double porosity, and may include a single radially centered heterogeneity to simulate the presence of a "skin" zone adjacent to the borehole. The skin zone may have properties different from those of the remainder of the formation.

The GTFM model can be used with assigned conditions of either fixed pressure or zero flow at the extemal boundary of the model. Selection between the two boundary conditions is made on a test-specific basis, depending on whether or not the test data show boundary effects. If no boundary effects are indicated by the test data, a fixed-pressure boundary condition is specified at a distance from the borehole such that the type of boundary has no effect on the calculated fluid-pressure response in the borehole. The adequacy of the specified distance is verified by ensuring that the pressure in the portion of the simulated formation 
adjacent to the boundary does not change over the duration of the test-interpretation simulation. In cases where boundary effects are indicated, the type of, and distance to, the boundary are parameters selected and fitted as part of the test interpretation.

The model has wellbore boundary conditions which can be used to simulate pulse-injection/withdrawal tests, specified borehole-pressure conditions, specified formationflow rates, and slug-irjection/withdrawaltests. The effects of consecutive tests are incorporated in the simulations. The model can also incorporate test-zone pressure changes resulting from temperature variations in the test zone as well as test-equipment- and/or formation-induced changes in the test-zone volume. The model output consists of simulated fluid-pressure responses in the borehole and at selected radial distances from the borehole. The model can also calculate formation flow-rate data and cumulativeproduction data based on the formation's estimated hydraulic properties.

For the interpretations presented in this report, the individual testing periods were subdivided into discrete time intervals, called sequences. Sequences were differentiated by the wellbore boundary conditions in effect during these time periods. History sequences were used to represent the test intervals' pretest borehole-pressure history during the open-borehole period between drilling and initial shut-in of the test zone, and also to represent time periods when nonideal behavior characterized the fluid-pressure responses. During history sequences, the pressure conditions in the isolated test intervals were specified directly using the fluid pressures recorded by the DAS. Pulse sequences were used to simulate the fluidpressure buildups observed after shutting in the test zones and also the fluid-pressure-recovery responses to individual pulse-injection and pulse-withdrawaltests.
A complete description of the methodology, appropriate boundary conditions, and governing equations of the model can be found in Pickens et al. (1987). GTFM was verified by comparing its results to analytical solutions for pulse tests, slug tests, constant-pressure flow tests, and constant-flow-rate pumping tests (Pickens et al., 1987). Application of GTFM to the simulation of pressure-pulse testing in low-permeability formations is described in Saulnier and Avis (1988). Assumptions inherent in the formulation of GTFM and application of the model to the Salado permeabilitytesting program are described in Section 6.2 below.

\subsection{Assumptions Used in Test Analysis}

The analysis of the Salado Formation permeability tests assumed a one-dimensional radial-flow regime on the scale of testing. For the majority of the tests discussed in this report, the boreholes were vertical, and therefore radial flow was the same as horizontal flow. Radial flow was also assumed for the analysis of the tests in the nonvertical holes $\mathrm{C} 2 \mathrm{HO} 2$ and $\mathrm{C}_{2} \mathrm{H} 03$. The implications of this assumption for the nonvertical holes are discussed with the relevant test interpretations in Sections 7.1.4.1 (C2HO2) and 7.1.5.1 (C2H03).

The assumption of one-dimensional radial flow requires justification with respect to the flow dimension included (horizontal, or parallel to bedding) and to the flow dimension excluded (vertical, or perpendicular to bedding). With respect to the horizontal dimension, an assumption of radial flow implies that the formation is homogeneous and isotropic in the horizontal plane over the volume tested. Even though no medium is ever truly homogeneous or isotropic on a microscopic scale, this is nevertheless a standard assumption underlying most analytical methods for single-well-test analysis. The assumption of horizontal homogeneity means that the permeability of the volume being tested 
will not change appreciably if the volume is increased or decreased slightly. The assumption of horizontal isotropy is acceptable in a horizontally anisotropic medium if the interpreted permeability is recognized as being an effective permeability (i.e., the square root of the product of the minimum and maximum permeability [Hantush, 1966]).

With respect to a potential vertical flow direction, an assumption of one-dimensional radial flow implies that vertical flow is either nonexistent or is of such low magnitude that it has no appreciable effect on the radial flow field. For either of these conditions to exist, the vertical permeabilities of the strata above and below the test interval must be much less than the horizontal permeability within the test interval, to prevent (or minimize) vertical flow from above and below into the test interval. Most of the tests discussed in this report were performed over intervals with arbitrarily defined tops and bottoms which did not coincide with lithologic discontinuities but were instead defined by the physical dimensions of the test tools. Thus, the potential for vertical flow is limited solely by the anisotropy in permeability of the host rock between the horizontal and vertical directions. Unfortunately, no information is available on the presence or absence of horizontal-to-vertical permeability anisotropy in evaporites. In most sedimentary porous media, this type of anisotropy is imparted to the rock by the stratification of clastic material. For example, when tabular clay minerals are oriented with their long axes parallel to bedding and their short axes perpendicular to bedding, the resulting arrangement of overlapping plates tends to reduce permeability in the direction perpendicular to bedding (Freeze and Cherry, 1979). Whether or not a similar mechanism is effective at producing anisotropy in evaporites is unclear, however, because the permeability of the evaporites may already be as low or lower than the permeability of clays perpendicular to bedding. The permeability of clays parallel to bedding, however, is probably higher than that of evaporites, in which case clays may still impart anisotropy to the overall medium, at least on the scale at which the clays forma continuous interconnected layer. Given the lack of quantitative information on anisotropy in evaporites, the potential effects of vertical flow were excluded from the preliminary analyses presented in this report. In general, ignoring potential vertical flow, which contributes to observed pressure-recovery rates, should result in overestimates of horizontal permeability. Sensitivity analyses will be performed at a later date to evaluate the potential errors associated with this exclusion as a function of the magnitude of anisotropy.

Another model assumption is that the hydraulic head in the test horizon is static (constant with time), and radially and longitudinally (parallel to the borehole axis) invariant before drilling begins. Preliminary evidence from a limited number of holes indicates that the pressures under the floor of a room are less than the pressures under the ribs (walls). The resulting pressure gradients may reflect dilatation of the rock beneath rooms as a result of the excavation of the rooms (see Section 7.3.1) or flow to the rooms. These gradients appear to persist over longer time scales than those of the permeability tests. Thus, the pressure responses to the permeability tests may be superimposed on a relatively static pressure field. In any case, lacking reliable two-dimensional definition of the pressure distribution over time within a tested horizon, our initial assumption in modeling will be that a single constant pressure exists throughout a tested horizon when testing begins. As more data on pressure distributions become available, two-dimensional modeling will be performed to evaluate the influence of this assumption on the test interpretations.

Consiclering the proximity of excavations at atmospheric pressure to the test intervals, longitudina! pressure gradients through the test intervals toward 
the excavations should be present. The fluid pressures obsenved during testing, therefore, probably represent the average pore pressures (heads) over the entire tested intervals. Treating these average pressures as if they were uniformly distributed over the tested 1- to 2-m thicknesses is not expected to lead to significant errors during test interpretation.

Cther assumptions specific to the interpretation of individual tests are discussed in Section 7.1 under the headings of the individual tests.

\subsection{Material Properties Used in Test Simulations}

To simulate permeability tests using GTFM, a number of material properties must be specified. These properties include the porosity, elastic moduli, and permeability (hydraulic conductivity) of the lithology(ies) being tested; the compressibility and density of the formation brine; and the thermal-expansion coefficient of the test-zone brine. Porosity, elastic moduli, and brine compressibility and density are used to calculate the specific storage of the formation. The thermalexpansion coefficient is used to incorporate the effects of variations in test-zone temperatures on test-zone pressures.

Most of the values of these material properties can be reliably estimated to within an order of magnitude or less. Permeability is the most uncertain of the parameters and, therefore, permeability is used as one of the primary fitting parameters during the model simula. tions. Other, more certain, parameters are simply specified as constants. The values used in the simulations for the different material properties are presented below along with discussions of the methods used to determine or to estimate those values. Sensitivity calculations performed to evaluate the significance of uncertainties in both the specified and fitted parameters are presented in Section 7.2.
6.3.1 FORMATION POROSITY. A review of the SNL testing of samples from the formations at the WIPP site, as presented in Touloukian et al. (1981), Powers et al. (1978), Black et al. (1983), and Skokan et al. (1989), indicates that a porosity of 0.01 is representative of the Salado Formation halite and anhydrite interbeds. Porosities presented in the references listed above range from 0.001 to 0.03 . Although fracturing and/or diagenetic changes may have locally added secondary porosity to anhydrite interbeds such as Marker Bed 139, this added secondary porosity probably does not alter the range of porosities presented above.

6.3.2 FORMATIONELASTIC MODULI. Elastic moduli of the halite and anhydrite lithologies tested have been reported by Wawersik and Hannum (1980), Pfeifle and Senseny (1981), Teufel (1981), Gevantman (1981), Krieg (1984), and Desai and Varadarajan (1987). These moduli are summarized in Table 6-1. No Salado-specific data on the elastic moduli of claystone are available. The claystone moduli presented in Table 6-1 are reported by Pfeifle et al. (1983) for mudstones from the Palo Duro Basin in Texas. The values presented by Krieg (1984) and the averages of the values from Pfeifle et al. (1983) were taken as base-case values, with the other sources or individual values providing the ranges of values to be used in sensitivity analyses (see Section 7.2.4).

6.3.3 BRINE COMPRESSIBILITY. The compressibility of brine depends on pressure, temperature, fluid composition, and gas saturation. In general, fluid compressibility decreases with increased pressure and dissolved-solids concentration, and increases with temperature and the amount of dissolved gas.

Two brines were used as the test-zone fluid for the testing in the WIPP underground facility. Brine for the testing in $\mathrm{C} 2 \mathrm{H} 01-\mathrm{A}, \mathrm{C} 2 \mathrm{H} 01-\mathrm{B}$, and S1P71-A was 


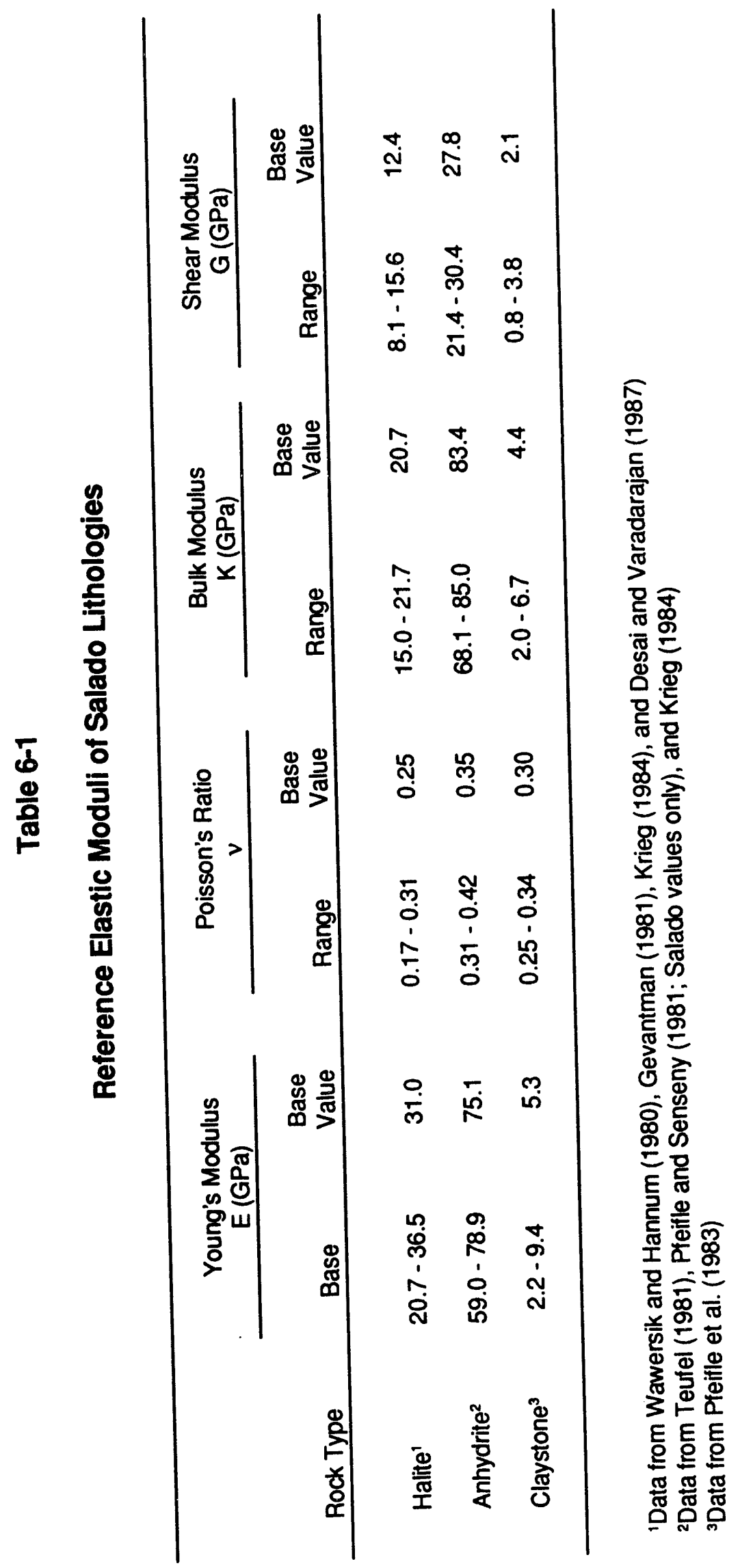


obtained from Rowland Trucking of Carlsbad, who use Carlsbad city water to dissolve Salado halite to as close to saturation as possible. The total-dissolvedsolids (TDS) concentration of this brine is approximately $320,000 \mathrm{mg} / \mathrm{L}$ (Data supplied by B\&E, Inc., Carlsbad). The brine used in all other test boreholes was supplied by the WIPP Brine Sampling and Evaluation Program (BSEP). Brine for testing in SOP01, $\mathrm{C} 2 \mathrm{H} 01-\mathrm{C}, \mathrm{C}_{2} \mathrm{HO}_{2}, \mathrm{C}_{2} \mathrm{HO}_{3}$, and $\mathrm{N} 4 \mathrm{P} 50$ was obtained from borehole DHP-402A in Room 7, Waste Panel 1. The brine used in testing in borehole L4P51-A was obtained from boreholes drilled in the entryway of the underground core library. The dissolved-solids concentration of brine supplied by the BSEP was about $380,000 \mathrm{mg} / \mathrm{L}$ (Deal et al., 1989).

The compressibility of saturated sodium-chloride brine with dissolved-solids concentrations approximately equal to those collected under the BSEP was estimated using Figure D.19 in Earlougher (1977), which plots fluid compressibility versus temperature for brines containing 300,000 parts per million (ppm) $\mathrm{NaCl}$ dissolved in distilled water at various pressures and assuming no solution gas. For the limited temperature range of $26^{\circ}$ to $29^{\circ} \mathrm{C}$ observed during the underground-permeability-testing program at WIPP, the formation-brine compressibility can be assumed to be essentially invariant and insensitive to temperature. For the pressure ranges observed during testing, fluid compressibility at $27^{\circ} \mathrm{C}$ interpolated from the curves shown on the figure ranges from $2.75 \times 10^{-10} \mathrm{~Pa}^{-1}$ at $9.8 \mathrm{MPa}$ to $3.1 \times 10^{-10} \mathrm{~Pa}^{-1}$ at $2.5 \mathrm{MPa}$.

The fluid compressibility derived from Earlougher(1977) assumes brine with no dissolved gas. Earlougher (1977) further shows that the compressibility of water saturated with methane at $25^{\circ} \mathrm{C}$ is about 5 to 12 percent higher over a pressure range from 2.5 to 9.8 MPa than that of the same water with no dissolved gas.
Gas present in the Salado Formation is largely nitrogen, rather than methane (U.S. DOE, 1983). However, Cygan (1991) showed that nitrogen solubility in brine is slightly lower than that of methane. Therefore, the effect of dissolved nitrogen on brine compressibility should be slightly less than the effect of dissolved methane. Based on these data, we estimate that the amount of gas potentially in solution at the pressures observed during the permeability tests might increase the compressibility of the gas-brine solution by a maximum of about ten percent.

After consideration of the foregoing information, a single formation-fluid-compressibility value of $3.1 \mathrm{x}$ $10^{-10} \mathrm{~Pa}^{-1}$ was selected for use in all test interpretations presented in this report. This value was considered to be representative of actual in situ formation brine given the limited range of variability of the density and dissolved-solids concentration of formation brine and the lack of quantitative data regarding solution-gas constituents.

6.3.4 FORMATION BRINE DENSITY. Salado brine densities reported by the WIPP BSEP range from 1.215 to $1.224 \mathrm{~kg} / \mathrm{L}$ (Deal et al., 1987). For this study, formation brine density was approximated as $1.22 \mathrm{~kg} / \mathrm{L}$.

\subsubsection{ESTIMATION OF SPECIFIC STORAGE.} Specific storage is defined as the volume of water released from storage by a unit volume of aquifer because of expansion of water and compression of the aquiferunder a unit decline in hydraulic head (Hantush, 1964). The expression for specific storage most commonly used in groundwater hydrology is as given by Domenico (1972):

$$
S_{s}=\rho_{1} g(\alpha+\phi B)
$$


where:

$$
\begin{aligned}
& \rho_{1}=\text { fluid density } \\
& g=\text { acceleration of gravity } \\
& \alpha=\text { vertical formation compressibility } \\
& \phi=\text { formation porosity } \\
& B=\text { fluid compressibility }
\end{aligned}
$$

Implicit in this equation is an assumption that the compressibility of the rock solids is a negligible component of the bulk formation compressibility compared to the compressibility of the pores. This assumption is valid for most aquifer materials, which have porosities on the order of a few tens of percent and low-compressibility solids. This assumption may not be valid for halite, however.

Green and Wang (1990) present a rigorous expression for specific storage that includes the bulk modulus (inverse of compressibility) of the rock solids:

$$
S_{S}=\rho_{19}\left[\left(\frac{1}{K}-\frac{1}{K_{s}}\right)\left(1-\frac{4 G\left(1-K / K_{s}\right) / 3}{K+4 G / 3}\right)+\phi\left(\frac{1}{K_{f}}-\frac{1}{K_{s}}\right)\right]
$$

where:

$$
\begin{aligned}
\rho_{f}= & \text { fluid density } \\
g= & \text { acceleration of gravity } \\
K= & \text { drained bulk modulus of rock } \\
K_{s}= & \text { unjacketed bulk modulus of rock (grain or } \\
& \text { solids modulus) } \\
G= & \text { drained shear modulus of rock } \\
\phi= & \text { porosity } \\
K_{f}= & \text { bulk modulus of fluid }
\end{aligned}
$$

When the $\mathrm{K}_{\mathrm{s}}$ term in Eq. 6-2 is much greater than the $K$ term $\left(K / K_{s} \approx 0\right.$ ), Eq. 6-2 reduces to Eq. 6-1 (Green and Wang, 1990) with:

$$
\alpha=1 /(K+4 G / 3)
$$

Few data are available on the bulk modulus of halite solids, and those data that are available are not specific to Salado halite. Carmichael (1984) lists 15 values, ranging from 22.8 to $24.0 \mathrm{GPa}$, for the bulk modulus of halite solids. These values are only slightly higher than the values for the drained bulk modulus $(K)$ of Salado halite given in Table 6-1 (15.0 to 21.7 GPa). Thus, if the data from Carmichael (1984) are also representative of Salado halite, $K / K_{s} \neq 0$, and the specific storage of Salado halite is probably better represented by Eq. 6-2 than by Eq. 6-1.

Using Eq. 6-1 and the base-case mechanical properties of halite given in Table 6-1, the specific storage of halite with a porosity of one percent is about $3.6 \times 10^{-7} \mathrm{~m}^{-1}$. Using the same parameters in Eq. 6-2, along with a bulk modulus of halite solids $\left(\mathrm{K}_{\mathrm{s}}\right)$ of $23.4 \mathrm{GPa}$, produces a specific-storage estimate of about $9.5 \times 10^{-8} \mathrm{~m}^{-1}$. Thus, the specific storage calculated using Eq. 6-2 is about a factor of four smaller than the specific storage calculated using Eq. 6-1.

No data were available on the bulk modulus of anhydrite solids. Consequently, the specif ...... of anhydrite was evaluated using Eq. 6-1 and the base-case mechanical properties presented in Table 6-1. The specific storage of anhydrite with a porosity of one percent is about $1.4 \times 10^{-7} \mathrm{~m}^{-1}$.

Palciauskas and Domenico (1989) note that pore compressibility accounts for 95 to 100 percent of the bulk compressibility of mudstone and clay. Accordingly, the specific storage of claystone was evaluated using Eq. 6-1 and the base-case elastic moduli presented in Table 6-1. The specific storage of claystone with a porosity of 30 percent was thereby calculated to be about $2.8 \times 10^{-6} \mathrm{~m}^{-1}$. 
In cases where the tested interval included several lithological intervals having different elastic moduli, a length-weighted average was used for specific storage. Table 6-2 lists the estimated specific-storage values for the formations tested and shows the weighting used to arrive at those estimates.

\subsubsection{THERMAL-EXPANSION COEFFICIENT OF} TEST-ZONE BRINE. The thermal-expansion coefficient of the test-zone brine was estimated from data showing the density of pure water as a function of temperature (Weast, 1983) and data showing the relationship of sodium-chloride solution density as a function of salt concentration and temperature (Perry and Chilton, 1973). These data were used to calculate the thermal-expansion coefficient of water for a range of temperatures and solution concentrations. For the brines used and the range of temperatures observed during the brine-permeability testing program, the coefficient of thermal expansion $\left(C_{T}\right)$ was estimated to be $4.6 \times 10^{-4}{ }^{\circ} \mathrm{C}^{-1}$. This value of $C_{T}$ was also used by Nowak et al. (1988) in modeling brine inflow to the WIPP underground facility.

\subsection{Test-Zone Volume}

Accurate knowledge of the volume of fluid contained within a test zone is important in the interpretation of permeability tests in packer-isolated test intervals.

Table 6-2

\section{Specific Storage Values Used in Test Interpretations}

\begin{tabular}{lccccc}
\hline & & \multicolumn{3}{c}{ Lithologies and Lengths $(\mathrm{cm})$} & \\
\cline { 3 - 5 } Test ID & $\begin{array}{c}\text { Test-Zone } \\
\text { Length }(\mathrm{cm})\end{array}$ & Halite & Anhydrite & Clay & $\begin{array}{c}\text { Average } \\
\text { Specific Storage }\left(\mathrm{m}^{-1}\right)^{\mathbf{a}}\end{array}$ \\
\hline C2H01-A & 349 & 349 & 0 & 0 & $9.5 \times 10^{-8}$ \\
C2H01-B & 108 & 108 & 0 & 0 & $9.5 \times 10^{-8}$ \\
C21 101-B-GZ & 110 & 110 & 0 & 0 & $9.5 \times 10^{-8}$ \\
C2H01-C & 234 & 138 & 96 & 0 & $1.4 \times 10^{-7 b}$ \\
C2H02 & 139 & 51 & 88 & 0 & $1.4 \times 10^{-7 b}$ \\
C2H03 & 138 & 138 & 0 & 0 & $9.5 \times 10^{-8}$ \\
L4P51-A & 142 & 140 & 0 & 2 & $1.3 \times 10^{-7}$ \\
SOP01 & 143 & 142 & 0 & 1 & $1.1 \times 10^{-7}$ \\
SOP01GZ & 105 & 15 & 90 & 0 & $1.4 \times 10^{-7 b}$ \\
S1P71-A & 144 & 141 & 0 & 3 & $1.5 \times 10^{-7}$ \\
\hline
\end{tabular}

average specific storage

'Halite sections ignored

Average is length-weighted average based on lithology, except as noted:

\begin{tabular}{lc}
\multicolumn{1}{c}{ Lithology } & $\begin{array}{c}\text { Specific Storage } \\
\left(\mathrm{m}^{-1}\right)\end{array}$ \\
Halite & $9.5 \times 10^{-8}$ \\
Anhydrite & $1.4 \times 10^{-7}$ \\
Clay seams (claystone) & $2.8 \times 10^{-6}$
\end{tabular}


Together with the test-zone compressibility (Section 6.5), the test-zone volume controls the amount of fluid that must flow into or out of the test zone to create a given fluid-pressure change. The techniques used to estimate the test-zone volume at the start of each test and the changes in test-zone volumes that occurred during the tests are discussed below.

6.4.1 INITIAL TEST-ZONE VOLUME. The initial testzone volume, $V_{t z}(0)$, refers to the volume of fluid in the test zone when the test zone was isolated at the start of the initial fluid-pressure build-up period after packer inflation. $V_{t}(0)$ plus $\Delta V_{t z}(t)$, the volume-cornpensation factor discussed in Section 6.4.2, are used to calculate $V_{12}(t) . V_{12}(t)$ and test-zone compressibility are used to calculate the wellbore boundary condition applied during the simulation of pulse tests.

The test-zone volume used for each simulation was estimated by subtracting the test-tool volume from the volume of the isolated length of the borehole:

$$
V_{t}(0)=V_{\text {hole }}(0)-V_{1001}(0)
$$

where:

$$
\begin{aligned}
& V_{\Delta}(0)=\text { initial test-zone volume } \\
& V_{\text {hole }}(0)=\text { initial borehole volume } \\
& V_{\text {tool }}(0)=\text { initial test-tool volume }
\end{aligned}
$$

To calculate an initial test-zone volume, the length and radius of the test zone must be known. The test-toolconfiguration diagrams presented in Chapter 5 indicate the lengths of the test and guard zones after the test tools have been installed in the boreholes, but before the packers have been inflated. Two corrections must be made to these lengths to represent actual test conditions. First, based on a cast made of the end of a packer when it was inflated in steel casing, approximately one cmat the end of the packer elements does not seal against the wall of the casing. Accordingly, all test zones were considered to be one $\mathrm{cm}$ longer, and all guard zunes were considered to be two $\mathrm{cm}$ longer, than the lengths indicated on the test-toolconfiguration diagrams. Second, the sliding end of a packer was observed to move $5.7 \mathrm{~cm}$ during inflation in slotted steel casing. On multipacker test tool \#1, used for the $\mathrm{C} 2 \mathrm{H} 01-\mathrm{A}$ and $\mathrm{C} 2 \mathrm{H} 01-B$ testing, the sliding end of the test-zone packer is in the test zone, while the sliding end of the guard-zone packer is on the side away from the guard zone. Thus, the test zone for multipacker test tool \#1 is about six cm longer after packer inflation, while the guard-zone length does not change. For multipacker test tools \#2-5, used for all other testing, the sliding end of the test-zone packer is in the guard zone. Thus, the guard zones for these other test tools lengthen by about six cm during packer inflation, while the test-zone lengths remain unchanged.

Initial borehole-radius values were calculated from the data derived from the radial LVDTs when the borehole test intervals were first shut in. (The initial shut-in values of the radial LVDTs were assumed to reflect the actual borehole radius because they were obtained before fluid-pressure buildup in the test intervals could compress the O-rings of the LVDTs, as described in Section D.2 of Appendix D). The radii calculated from the radial-LVDT data range from 5.119 to $5.225 \mathrm{~cm}$, which are larger than the $5.08-\mathrm{cm}$ nominal radii of the core bits used in drilling the test boreholes. The apparent entargement of the boreholes is probably due to the impact of the drill rods on the borehole walls after the core bits had exposed the relatively soft evaporite minerals in the boreholes. For the $\mathrm{C} 2 \mathrm{H} 01-\mathrm{A}$ and $\mathrm{C} 2 \mathrm{H} 01-\mathrm{B}$ tests, where no radial LVDT data were available, aborehole radius of $5.2 \mathrm{~cm}$ was used in all calculations.

The test-tool volumes were estimated from data obtained by immersing multipackertest tool \#3 in water in a length of sealed and volumetrically calibrated 
transparent casing. The volumes of muttipacker test tools \#2, \#4, and \#5 were estimated using the volumedisplacement data from multipacker test tool \#3, and compensating for different lengths of the various tcol components of the different tools.

Table 6-3 presents calculated borehole volumes, testtool volumes, and initial test-zone volumes used in the permeability-test simulations presented in this report. The calculated borehole volumes, and therefore testzone volumes, must be considered uncertain because we have assumed perfectly cylindrical holes with radii exactly as indicated by the radial LVDTs. This uncertainty is unimportant because the product of testzone volume and test-zone compressibility (which includes test-zone volume in the denominator; see Eq. 6-9) affects pressure responses in a test zone, and the volume terms cancel as the product is taken.

\subsubsection{COMPENSATION FOR CHANGES IN TEST-}

ZONE VOLUME. The volume of a test zone does not remain constant throughout a permeability-testing sequence. Creep closure of a borehole could cause the test-zone volume to decrease. The radial LVDTs on the test tools were designed to measure borehole closure directly. Unfortunately, for the tests discussed in this report, the data from the radial LVDTs are consideredunreliable (see Section D.2 of Appendix D). The potential closure of a typical borehole was calculated and found to have an insignificant effect on test-zone volume on the time scale of the tests (see Section D.6 of Appendix D). Accordingly, creep closure was not included in the test-zone volume compensations used for the test simulations presented in this report. As reliable radial-LVDT data become available for future tests, howevir, the measured borehole-radius changes will be incorporated directly into the test-zone-volume compensations.

The volume of a test zone carl also change in response to changes in the fluid pressure within the test zone.
Fluid-pressure changes in the test zone can cause: 1) changes in the volumes of the non-packer components of the test-tool; 2) borehole-radius changes; and 3) test-zone volume changes due to axial test-tool movement. The net effect of these three changes can be combined to give the total change in test-zone volume $\left(\Delta V_{t}\right)$ as follows:

$$
\Delta V_{t}(t)=\Delta V_{\text {tool }}(t)+\Delta V_{r a d}(t)+\Delta V_{a x}(t)
$$

\section{where:}

$$
\begin{aligned}
\Delta \mathrm{V}_{\text {wol }}(t)= & \text { test-tool-volume change at time } t \\
\Delta \mathrm{V}_{\text {red }}(t)= & \text { borehole-radius-volume change at } \\
& \text { time } t \\
\Delta \mathrm{V}_{\mathrm{ux}}(\mathrm{t})= & \text { test-tool-volume change due to axial } \\
& \text { test-tool movement at time } t
\end{aligned}
$$

As discussed in Section D-1 of Appendix D, the three terms of Eq. 6-5 can be expressed as:

$$
\begin{aligned}
& \Delta V_{\text {wol }}(t)=C_{\text {tool }} P(t) \\
& \Delta V_{\text {rod }}(t)=C_{\text {rad }} P(t) \\
& \Delta V_{e x}(t)=C_{2 x}\left[L_{2 x}(t)-L_{2 x}(0)\right]
\end{aligned}
$$

where:

$$
\begin{array}{ll}
C_{\text {bot }}= & \text { test-tool volume constant } \\
C_{\text {tad }}= & \text { borehole-radius volume constant } \\
C_{2 x}= & \text { axial test-tool-movement } \\
& \text { volume constant } \\
P(t)= & \text { test-zone pressure at time } t \\
L_{2 x}(0)= & \text { initial axial LVDT measurement } \\
L_{2 x}(t)= & \text { axial LVDT measurement at time } t
\end{array}
$$

The volume constant $C_{2 x}$ includes the test-zone and test-tool-specific constants for borehole radius, testzone-packer end-sub radius, and the radius of the axial-LVDT actuator rod. The borehole radius is assumed to be constant for the calculation of $\mathrm{C}_{\mathrm{ax}}$. The minor changes in radius determined from Eq. D-9 were determined to have negligible influence on the calculated volume change $\Delta \mathrm{V}_{\mathrm{s}}$. 


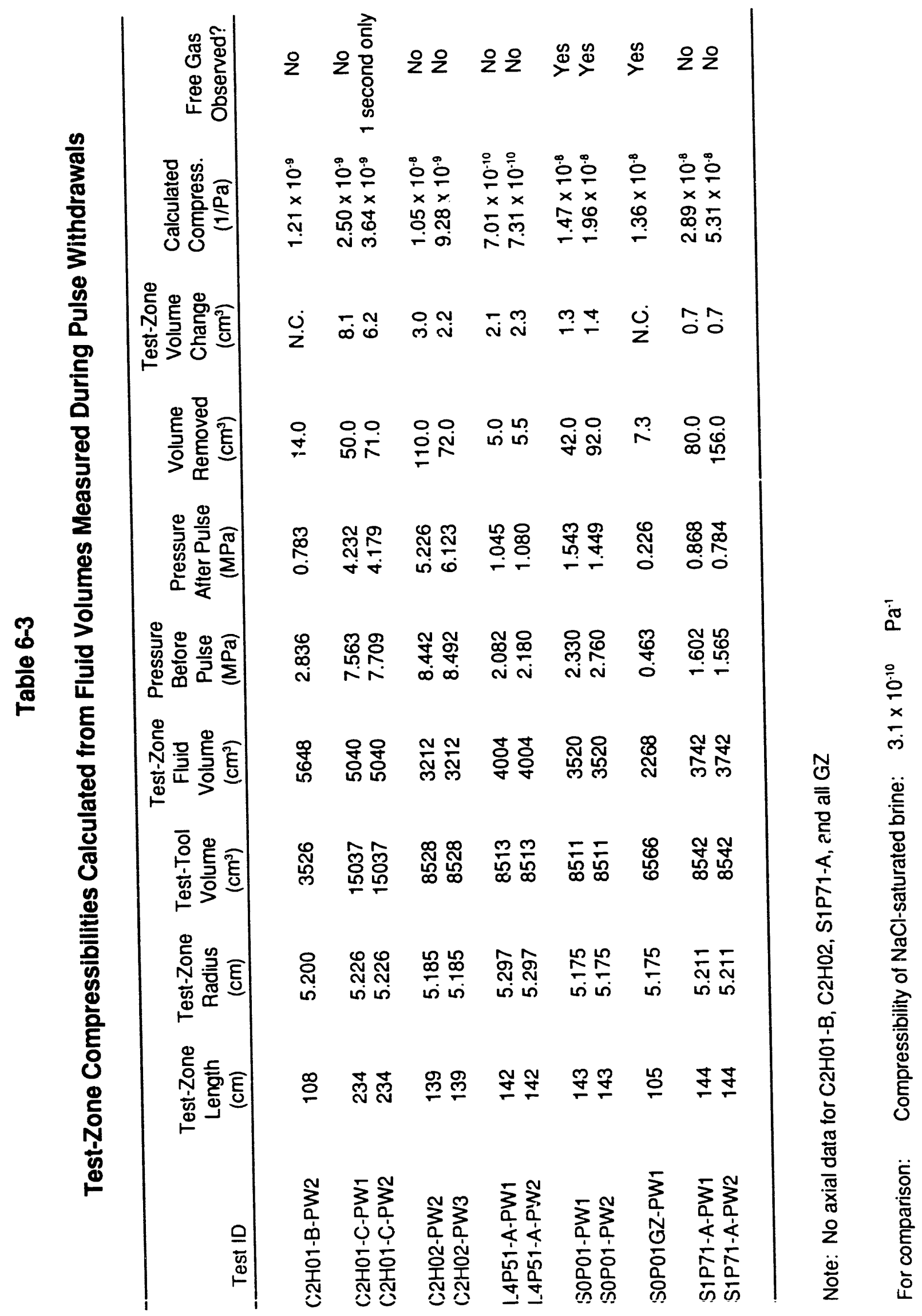


Eqs. 6-5 through 6-8 were applied to the test-zonepressure and axial-LVDT data recorded during the tests. Fortests where axial-LVDT datawere unavailable or unreliable, the $\Delta \mathrm{V}_{\mathrm{ax}}(t)$ term was not included. The $\Delta \mathrm{V}_{\mathrm{t}}$-versus-time data were then used to determine a functional representation of the data which was incorporated directly into the test-interpretation simulations. The methods used to incorporate these data in the simulations include both the effect of testzone volume on the pulse-test boundary condition, and the effect of induced flow rates due to changes in test-zone volume versus time.

\subsection{Test-Zone Compressibility}

Test-zone compressibility is an important factor in permeability testing performedunder shut-in conditions because, given the volume of a test zone, the test-zone compressibility govems the amount of fluid that must flow into or out of the test zone to create a given pressure change. In an ideal system, characterized by a pressure-invariant test-zone volume completely filled with a homogeneous fluid, the test-zone compressibility would be equal to that of the test-zone fluid. However, the fluid-pressure responses observed during pulse withdrawals indicate that the test-zone compressibilities in the permeability-testing program were considerably greater than the compressibility of the test-zone brine alone.

Neuzil (1982) observed test-zone compressibilities a factor of six larger than water compressibility during pressure-pulse testing of the Pierre Shale. He evaluated the possible factors that could be responsible for the apparently high test-zone compressibilities, and concluded that test-tool compliance and air entrapment were probably most important. He also emphasized the importance of measuring test-zone compressibility rather than simply assuming that it would be equal to fluid compressibility, because of the proportionality between test-zone compressibility and interpreted hydraulic conductivity. Hsieh et al. (1983) also report test-zone compressibilities higher by a factor of five than water compressibility and relate the higher compressibilities to test-tool compliance.

Six factors were identified that could be contributing to high test-zone compressibilities in the Salado permeability-testing program:

1) non-packer test-tool-componentcompressibility The volumes of the various metal components of the test tool, specifically the transducer carriers, mandrels, and transducer and vent lines, vary in response to changes in test-zone fluid pressure.

2) borehole compressibility - The radius of the borehole varies in response to. splied test-zone fluid pressure.

3) axialtest-tool movement - The test tool moves into and out of the test boreholes in response to applied test-zone fluid pressure. The movement is particularly noticeable during pulse withdrawals and was observed during all tests conducted with test tools equipped with axial LVDTs.

4) test-zone-packer deformation - Both long-term and short-term variations in the test-zone-packer inflation pressure were observed in all of the permeability tests. Assuming that the packer and the associated packer-inflation tubing form a closed system and that pressure changes are not due to fluid leakage, then the changes in packer-inflation pressure imply a concomitant change in the internal volume of the packer system. The assumption can then be made that the external volume of the packer system is varying, which in turn implies a time-varying impact on the test-zone volume. 
5) entrapped/created gas in the test-zone - Gas was observed during the venting of the test zones for some of the pulse-withdrawal tests. Fourpotential gas sources have been identified: air entrapped in the test zone during test-tool installation; gas created as a result of the reaction of the metal tool components with the test-zonebrine; gas exsolved from the formation fluid; and gas created through anaerobic bacterial degradation of hydrocarbons that might be contaminating the test zone.

The test-zone gas may be either fully dissolved in the test-zone fluid, exsolving during the sudden pressure drop caused by zone venting, or the gas may occur as a separate phase at testing pressures. A substantial increase in test-zone compressibility would be expected if the gas were present as a separate phase.

6) creep closure of the borehole - Halite and argillaceous halite undergo plastic steady-state creep in underground openings (Krieg, 1984; Van Sambeek, 1987). Therefore, the potential exists for borehole volume to change due to creep closure of the boreholes during permeability testing.

Appendix $D$ presents a thorough discussion of these six factors, and, where possible, quantifies their potential impacts on the observed fluid-pressure responses. All of these factors except for the last one, creep closure, could have a significant potential impact on test-zone compressibility. Creep closure occurs too slowly to affect test-zone compressibility.

The effects of the first three factors listed above are incorporated in the model simulations as discussed in Section 6.4.2. The impact of factors 4) and 5), testzone-packer deformation and test-zone gas, are impossibie to quantify separately at this time. The effects of both factors are expected to be nonlinear with respect to pressure. However, the bulk effect of these two factors over specific pressure ranges, as well as any other unaddressed factors, can be estimated using the compressibility equation and data collected when venting the test zones to start pulse-withdrawal tests.

Zone-compressibility values for some individual test analyses were calculated using the brine volumes removed from the test or guard zones during pulse withdrawals and the test- or guard-zone fluid pressures observed immediately before and immediately after the withdrawals. In the case of the tests in borehole SOP01, volumes of gas that were produced along with brine during the pulse withdrawals were not measured, and were not, therefore, included in the test-zone-compressibility calculations. Volume compensation as described in Section 6.4.2 was included in these calculations. The test-zone compressibility was calculated using the following form of the equation for fluid compressibility:

$$
C_{b}=\frac{1}{V_{b}(0)} \frac{V_{w}-V_{c}}{P_{1}-P_{1}}
$$

where:

$$
\begin{array}{ll}
C_{\square} & =\text { test-zone compressibility } \\
V_{\square}(0) & =\text { initial test-zone volume } \\
V_{w} & =\text { volume of brine withdrawn } \\
V_{c} & =\text { compensated volume } \\
P_{i} & =\begin{array}{l}
\text { test-zone pressure before the pulse } \\
\text { withdrawal }
\end{array} \\
P_{t} & =\begin{array}{l}
\text { test-zone pressure after the pulse } \\
\text { withdrawal }
\end{array}
\end{array}
$$

The compensated volume term in Eq. 6-9 is required to account for changes in the test-zone volume caused by the pressure change during the pulse. These changes would not otherwise be included in the simulations because the actual pulse is a discontinuity that is not simulated. $V_{c}$ for each pulse withdrawal was the 
difference in test-zone volumes $\left(V_{t z}(t)\right)$ immediately before and after the pulse, calculated using Eq. 6-5 as described in Section 6.4.2.

Equation 6-9 does not take into account variation in test-zone compressibility as a function of pressure. However, the equation can be viewed as representing the average test-zone compressibility over the particularpressure range used in the calculation, which is also the pressure range of interest in the test interpretations. Use of this equation to calculate test-zone compressibility should not, therefore, result in significant error in the test interpretations. The $C_{t z}$ values used in the test interpretations presented in this report can be found in Table 6-3 along with the measured fluid volumes removed during pulse withdrawals, the observed pressures, and the volume compensations used. The calculated volume compensations were insignificant in the calculation of test-zone compressibilities, being less than $0.2 \%$ of the test-zone volume in all cases. The calculated test-zone compressibilities ranged from $7.01 \times 10^{-10} \mathrm{~Pa}^{-1}$ to $5.31 \times 10^{-8} \mathrm{~Pa}^{-1}$, as compared to the compressibility of the test-zone fluid, which was approximately $3.1 \times 10^{-10} \mathrm{~Pa}^{-1}$. These high values of test-zone compressibility reflect the importance of the factors that could not be independently quantified, packer deformation and test-zone gas.

As mentioned in Appendix $D$, a number of modifications have been made to the multipacker test tools test-tool materials, and test-tool installation procedures to help minimize the impact of packer deformation and entrapped gas on test-zone compressibility. The test-zone compressibilities calculated from pulsewithdrawal tests in L4P51, which were performed after modifying test procedures and test-tool materials, were one-half order of magnitude lower than those calculated from the pulse-withdrawal tests performed in other boreholes before these changes were enacted
(Table 6-3). In addition, packer-inflation pressures were more stable after implementing these procedures (Saulnier et al., 1991).

When more than one test-zone-compressibility value was calculated for a sequence of tests, as in tests in borehole S1P71-A, a log-average value of $C_{12}$ was used in the interpretations. The calculated $C_{t z}$ values used in the test interpretations do not incorporate potential non-linearities and time-varying behavior that may have occurred.

\subsection{Thermal Effects}

Analysis of permeability tests in low-permeability media have shown that the thermal expansion or contraction of the test-zone fluid can produce significant fluidpressure responses in isolated test zones (Pickens et al., 1987). Changes in test-zone-fluid temperature must be included in test analysis to account for fluidpressure changes due to the thermal expansion of the test-zone fluid. GTFM accounts for the influence of test-zone temperature changes in test analyses. Observed fluctuations in test-zone and packer-inflation pressures were apparently due in part to the temperature changes. Assuming that the in situ formation temperature is constant, the source of the observed temperature variations appears to be changes in the ambient air temperature in the rooms and drifts, which were communicated to the boreholes through the metallic cores of the test tools.

Thermocouples were used to monitor test-zone and guard-zone temperatures during permeability testing. The analysis model was used to create a functional representation of the temperature-versus-time data, which was then incorporated directly into the testinterpretation simulations as a wellbore flux equal to the calculated fluid expansion or contraction. 


\section{ESTIMATION OF HYDRAULIC PROPERTIES}

This chapter presents individual interpretations of the pressure-pulse tests conducted in the boreholes discussed in Chapter 5. The interpretations given in Section 7.1 include GTFM simulations of the tests and estimates of the hydraulic parameters of the tested intervals. Section 7.2 presents sensitivity analyses of the interpreted results and addresses the quantitative effects of hydraulic- and material-property uncertainties on the interpreted hydraulic parameters. Section 7.3 summarizes the overall uncertainties in the test interpretations.

\subsection{Individual Test Interpretations}

The tests performed in the individual boreholes are discussed and interpreted below. The fluid-pressure responses observed in the guard zones during the testing in the test zones are also examined to see if any conclusions can be drawn about the hydraulic properties of the guard-zone intervals. A summary of the interpreted results is presented in Table 7-1.

7.1.1 C2H01-A. Borehole $\mathrm{C} 2 \mathrm{H} 01$ was the first borehole drilled for the Salado permeability-testing program (see Section 5.1). As described in Chapter 3, the $\mathrm{C} 2 \mathrm{H} 01-\mathrm{A}$ testing was performed with the multipacker test tool used in the waste-handling shaft, which has neither radial nor axial LVDTs (see Figure 3-1). Figure 7-1 shows the configuration of the test tool in $\mathrm{C} 2 \mathrm{HO} 1$ for the C2H01-A testing, and indicates the lengths and stratigraphic locations of the guard and test zones. The guard zone for the $\mathrm{C} 2 \mathrm{H} 01-\mathrm{A}$ testing extended from about 0.50 to $1.64 \mathrm{~m}$ below the floor of Room C2 and included the lower part of map unit 7 (argillaceous halite) and most of map unit 6 (halite). The test zone extended from about 2.09 to $5.58 \mathrm{~m}$ below the floor of the room and included most of map unit 5 (argillaceous halite), all of map units 4 (argillaceous halite), 3 (halite), and 1 (polyhalitic halite), and a portion of map unit 0 (argillaceous halite). Map unit 2 was not recognizable in $\mathrm{C} 2 \mathrm{H} 01$.

The C2H01-A testing consisted of a shut-in period followed by two pulse-injection tests. The fluid-pressure responses to the pulse injections were so rapid that the test period was terminated earlier than normal so that the test tool could be removed from the hole and tested for leaks. Leak testing revealed no problems with the tool and, therefore, the fluid-pressure responses observed during testing are believed to be representative of the formation tested. The fluidpressure data from the test and guard zones during the C2H01-A testing are shown in Figure 7-2.

7.1.1.1 Test Zone. As described in Saulnier et al. (1991), the C2H01-A testing period was preceded by a 21-day period during which the borehole was at or near atmospheric pressure. The multipacker test tool was first installed immediately after drilling with a length of $10.16-\mathrm{cm}$ (4-inch) O.D. seamless pipe fixed to the end of the tool to reduce the fluid volume of the test zone. Because of a leak in the volumereduction device, no fluid-pressure buildup was observed in the test zone after the test zone was shut in. This period, which included attempts to increase the test- and guard-zone pressures by injection, was included in the test analysis as a specified-pressure borehole-history sequence.

The multipacker test tool was removed from the hole and reinstalled without the volume-reduction device on August 24, 1988 (Calendar Day 237). The test and guard zones were shut in on August 25 (Calendar Day 238), and testing began later that same day. The testing consisted of two pulse-injection tests. The first test lasted about five days, and the second test lasted about two days (Figure 7-2). 


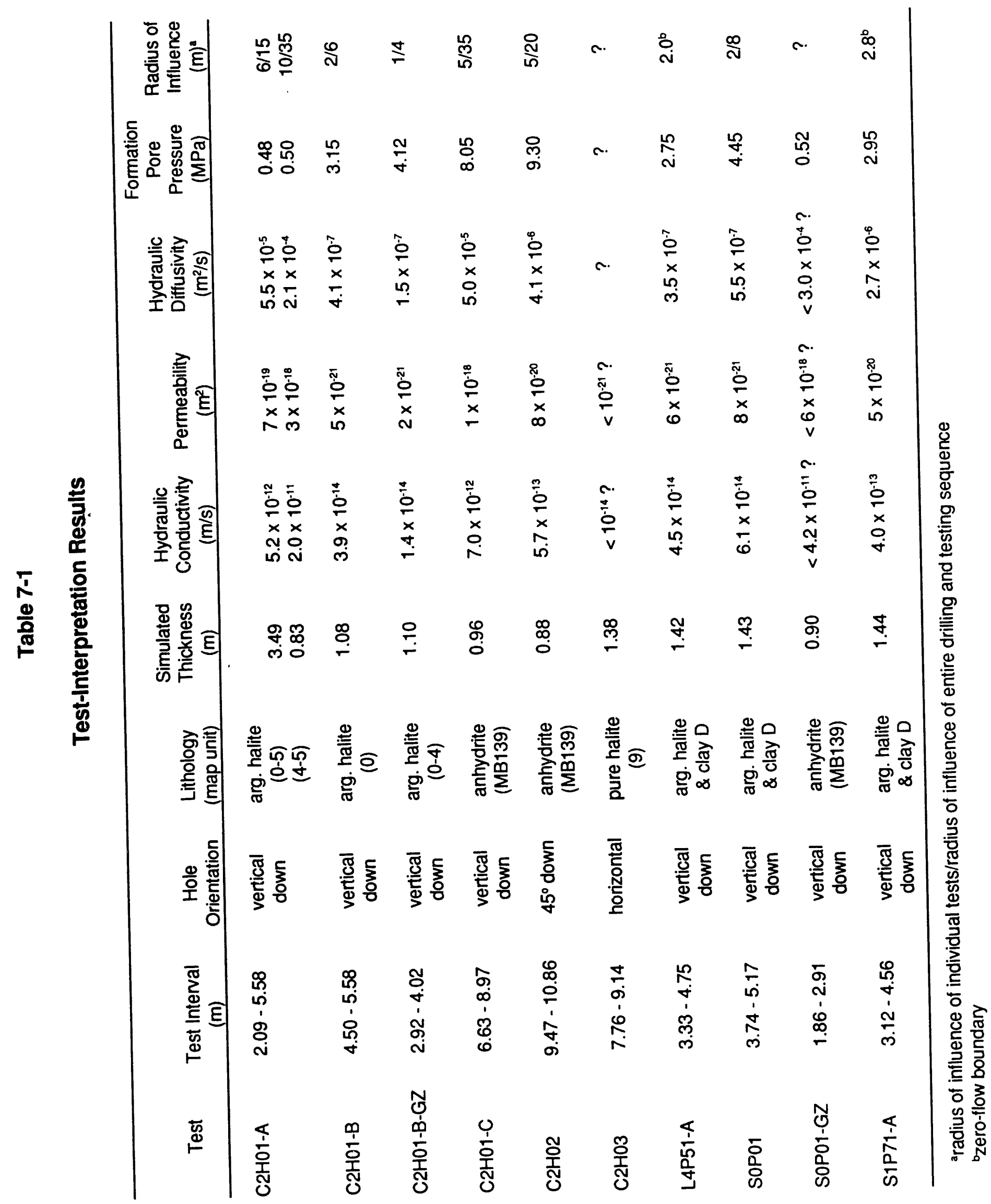




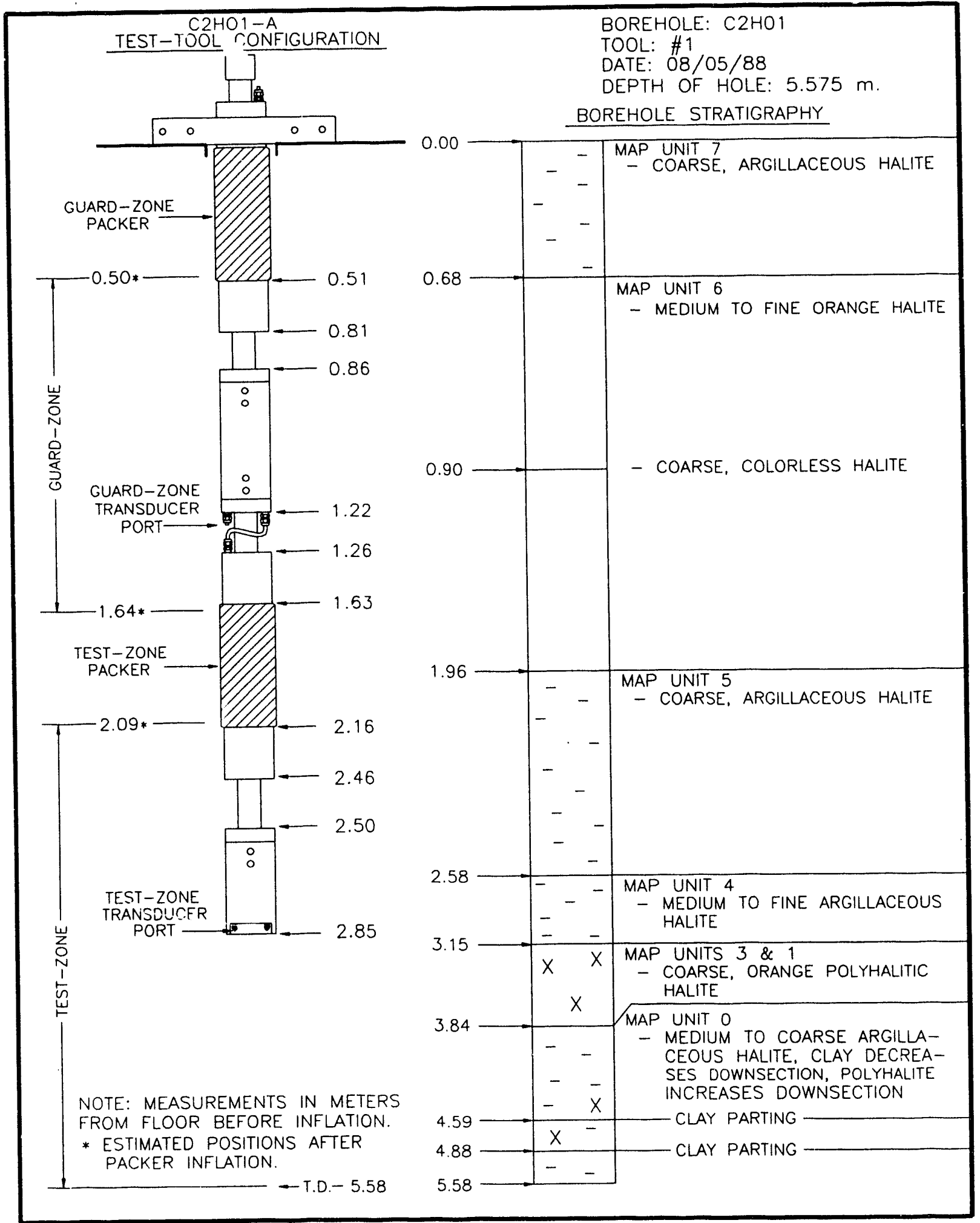

Figure 7-1. Configuration of Multipacker Test ToOl \#1 in Borehole C2H01 for C2H01-A Testing. 


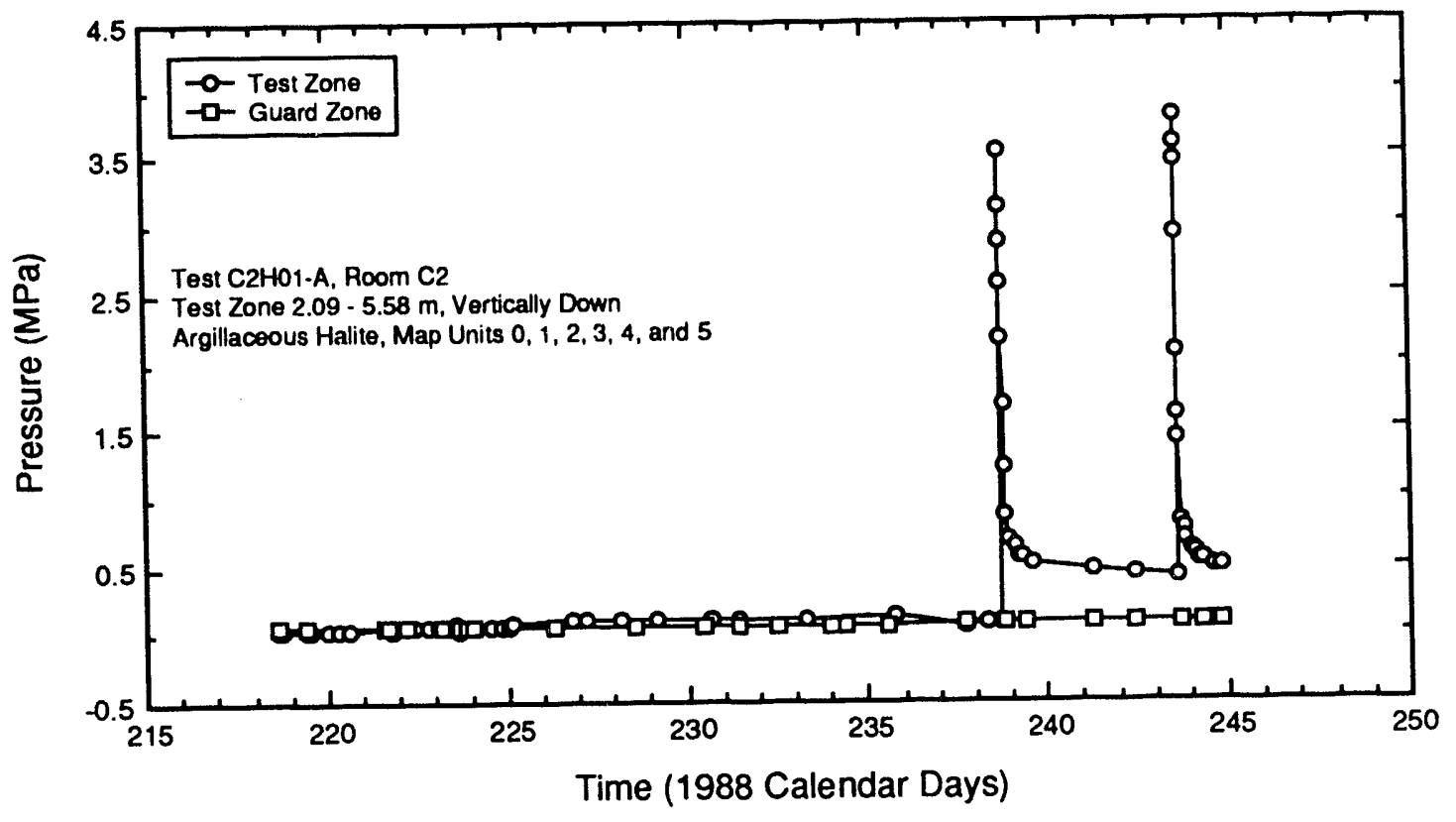

Figure 7-2. Test- and Guard-Zone Fluld-Pressure Data from C2H01-A Testing.

Figure 7-2 shows that the test-zone fluid pressure responded very rapidly immediately after the pulse injections were shut in, recovering from a significant fraction of each induced pulse in a period of minutes while the remainder of the recovery occurred over a period of days. This early-time response is too rapid to be representative of the true formation response. Similar rapid partial recoveries from pulse injections and withdrawals have also been observed during compliance testing in steel casing (Saulnier et al., 1991) and during the other tests discussed in this report. These rapid recoveries are therefore believed to be primarily related to tool-compliance effects. Some portion of the early-time response might also reflect the presence of a damaged zone, or skin, around the borehole with permeability and porosity increased relative to that of the undamaged formation. This damage could be caused by dilation of the rock around the borehole immediately after drilling. Whether the early-time response observed during testing is related to tool compliance, a skin around the borehole, or both, it is not considered to reflect the properties of the formation outside of the hypothesized skin. Therefore, the post-pulse early-time pressure responses observed during all testing discussed in this report were treated as periods of specified pressure in the simulations. The effects of this treatment on interpretation of formation properties are discussed in Section 7.1.2.1.

Figure 7-3 shows the best-fit model simulation of the $\mathrm{C} 2 \mathrm{H} 01-\mathrm{A}$ pulse-injection tests along with the observed fluid-pressure data from the test zone. Compared to all other tests, much larger percentages of the $\mathrm{C} 2 \mathrm{H} 01-\mathrm{A}$ post-pulse pressure responses had to be included as specified-pressure history periods to obtain any reasonable agreement between the simulations and the observed data. Even so, the match between the simulation and the observed data is not as good as might be hoped, particularly for the first pulse test. All modifications made to the fitted parameters to improve the fit to the first pulse test, however, had the effect of degrading the fit to the 


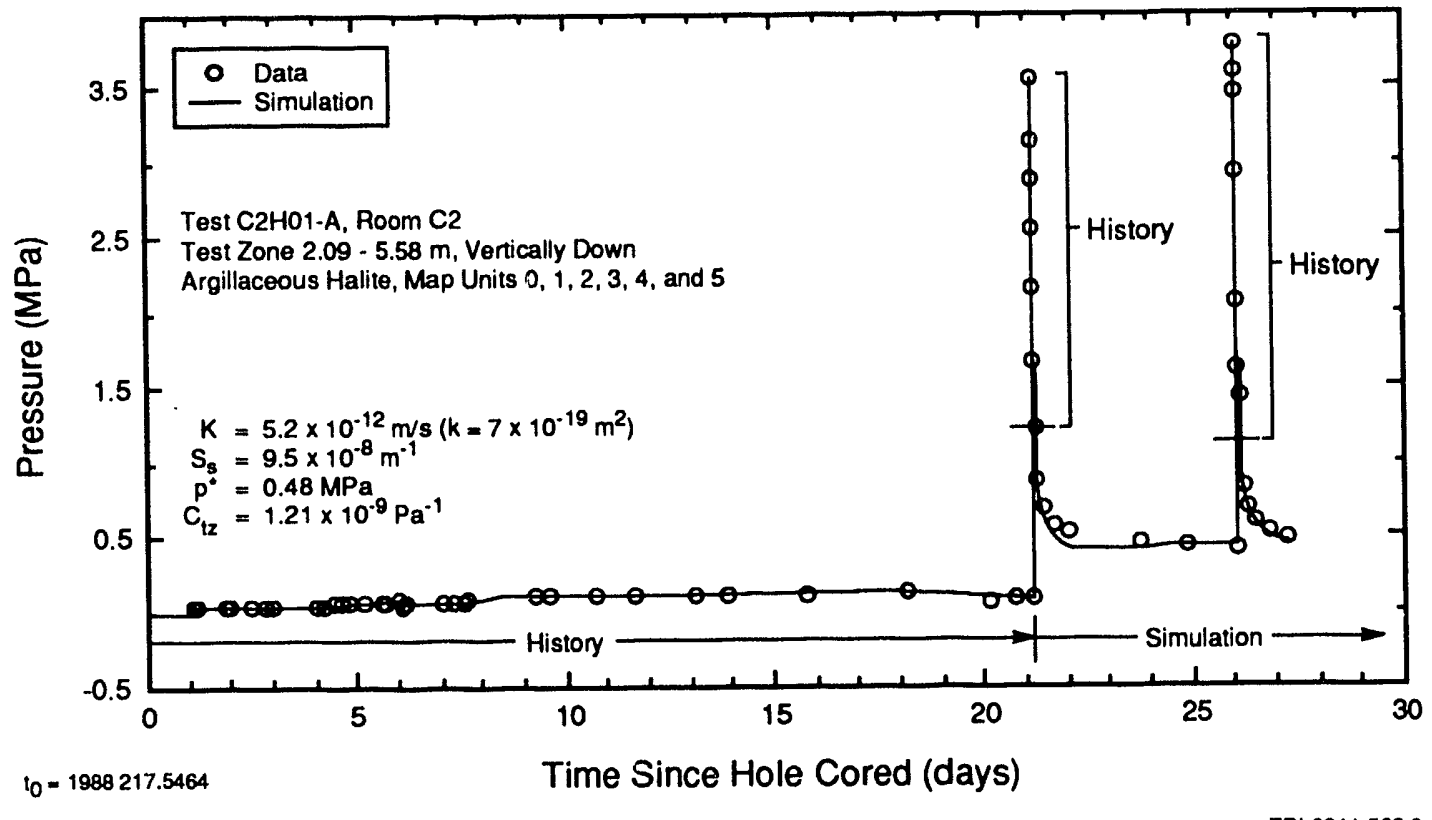

Figure 7-3. Best-Fit Model Simulation of the Test-Zone Fiuid-Pressure Response During C2H01-A Testing.

second pulse test. The specified parameters for the simulation were a formation thickness of $3.49 \mathrm{~m}$, a specific storage of $9.5 \times 10^{-8} \mathrm{~m}^{-1}$, and a test-zone compressibility of $1.21 \times 10^{-9} \mathrm{~Pa}^{-1}$. The test-zone compressibility value used was determined during the $\mathrm{C} 2 \mathrm{H} 01-\mathrm{B}$ testing (see Section 7.1.2.1) because no data were provided by the $\mathrm{C} 2 \mathrm{H} 01-\mathrm{A}$ testing that would allow calculation of that parameter. The fitted parameters for the simulation shown in Figure 7-3 were a hydraulic conductivity of $5.2 \times 10^{-12} \mathrm{~m} / \mathrm{s}$ (permeability of $7 \times 10^{-19} \mathrm{~m}^{2}$ ) and a formation pore pressure of $0.48 \mathrm{MPa}$. Additional simulations showing the sensitivity of the best-fit model to slight changes in hydraulic conductivity, formation pore pressure, specific storage, and test-zone compressibility, as well as to the presence or absence of testzone-volume compensations, are presented in Section 7.2 .
The well-test-analysis model was used to examine the radius of influence of the $\mathrm{C} 2 \mathrm{H} 01-\mathrm{A}$ testing. Figure 7-4 shows the simulated pressure response at different radial distances from the borehole throughout the entire $\mathrm{C} 2 \mathrm{H} 01-\mathrm{A}$ testing period. The longest duration, highest magnitude response was caused by the initial 21-day period during which the hole was depressurized. The simulated effects of this depressurization had propagated to a distance of more than $15 \mathrm{~m}$ from the hole by the end of the monitoring period. The effects of the individual pulse tests can be seen to a distance of about $6 \mathrm{~m}$ from the hole. That is, the slopes of the pressure curves out to 6-m distance change visibly after each pressure pulse in the test zone. In the case of the 6-m pressure curve, these changes in slope occur about one day after the pulses. 


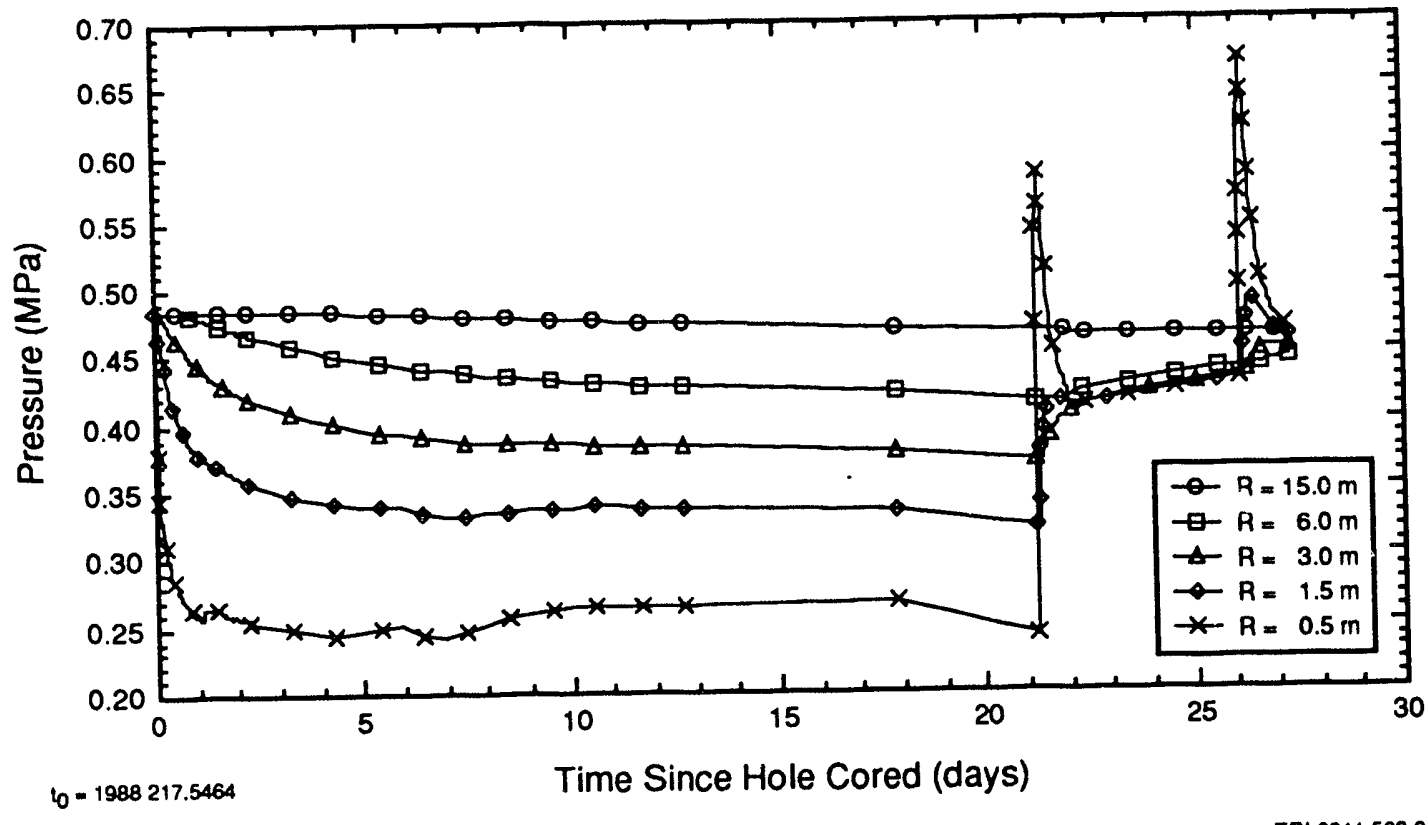

\section{Figure 7-4. Simulated Formation Pore Pressures at Selected Radial Distances from the Test Zone During C2H01-A Testing.}

During the $\mathrm{C} 2 \mathrm{H} 01-\mathrm{B}$ tests, which followed the $\mathrm{C} 2 \mathrm{H} 01-$ A tests, most of the $\mathrm{C} 2 \mathrm{H} 01-\mathrm{A}$ test zone was contained in eitherthe $\mathrm{C} 2 \mathrm{H} 01-\mathrm{B}$ guard zone or test zone. Excluding the interval covered by the $\mathrm{C} 2 \mathrm{H} 01-\mathrm{B}$ test-zone packer, only the portion of the $\mathrm{C} 2 \mathrm{H} 01-\mathrm{A}$ test zone from 2.09 to $2.92 \mathrm{~m}$ below the floor of Room C2 was not included in either the $\mathrm{C} 2 \mathrm{H} 01-\mathrm{B}$ guard ortest zone. The responses observed in the $\mathrm{C} 2 \mathrm{H} 01-\mathrm{B}$ test and guard zones during testing were qualitatively different from the responses observed during the $\mathrm{C} 2 \mathrm{H} 01-A$ testing, with lower interpreted hydraulic conductivities and higher interpreted formation pore pressures (see Section 7.1.2). The behavior observed during the $\mathrm{C} 2 \mathrm{H} 01-\mathrm{A}$ testing may, therefore, largely reflect the hydraulic properties of only the upper $0.83 \mathrm{~m}$ (or less) of the test zone.

The $\mathrm{C} 2 \mathrm{H} 01-\mathrm{A}$ tests were resimulated assuming a testzone thickness of $0.83 \mathrm{~m}$. Figure 7-5 shows the match between the observed data and the best simulation obtained. The simulation matches the observed data no better than did the simulation using the full test-zone thickness (Figure 7-3). The specified parameters for the simulation were a formation thickness of $0.83 \mathrm{~m}$, a specific storage of $9.5 \times 10^{-8} \mathrm{~m}^{-1}$, and a test-zone compressibility of $1.21 \times 10^{-9} \mathrm{~Pa}^{-1}$. The fitted parameters were a hydraulic conductivity of $2.0 \times 10^{-11} \mathrm{~m} / \mathrm{s}$ (permeability of $3 \times 10^{-18} \mathrm{~m}^{2}$ ) and a formation pore pressure of $0.50 \mathrm{MPa}$. Using these properties, the radius of influence of the entire testing period was about $35 \mathrm{~m}$, while the effects of each pulse could be observed to a distance of about $10 \mathrm{~m}$ from the borehole (Figure 7-6).

In summary, the interpretation of the $\mathrm{C} 2 \mathrm{H} 01-\mathrm{A}$ tests is uncertain. The portion of the test zone that actually contributed to the observed responses cannot be determined, and none of the simulations matched the observed data satisfactorily. However, later testing in both borehole $\mathrm{C} 2 \mathrm{HO} 1$ and other 


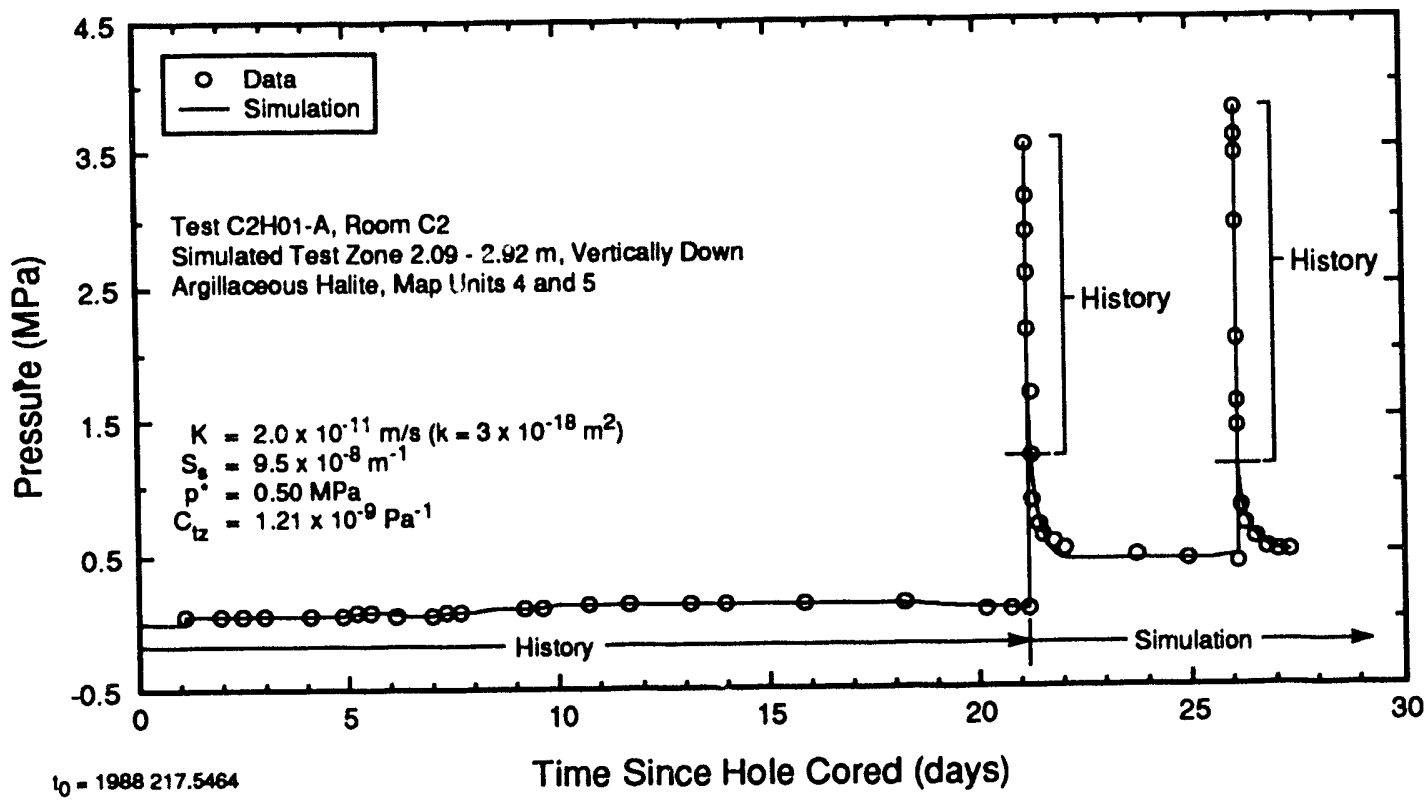

Figure 7-5. Best-Fit Model Simulation of the Test-Zone Fluid-Pressure Response During C2H01-A Testing, Assuming a Simulation Thickness of $0.83 \mathrm{~m}$.

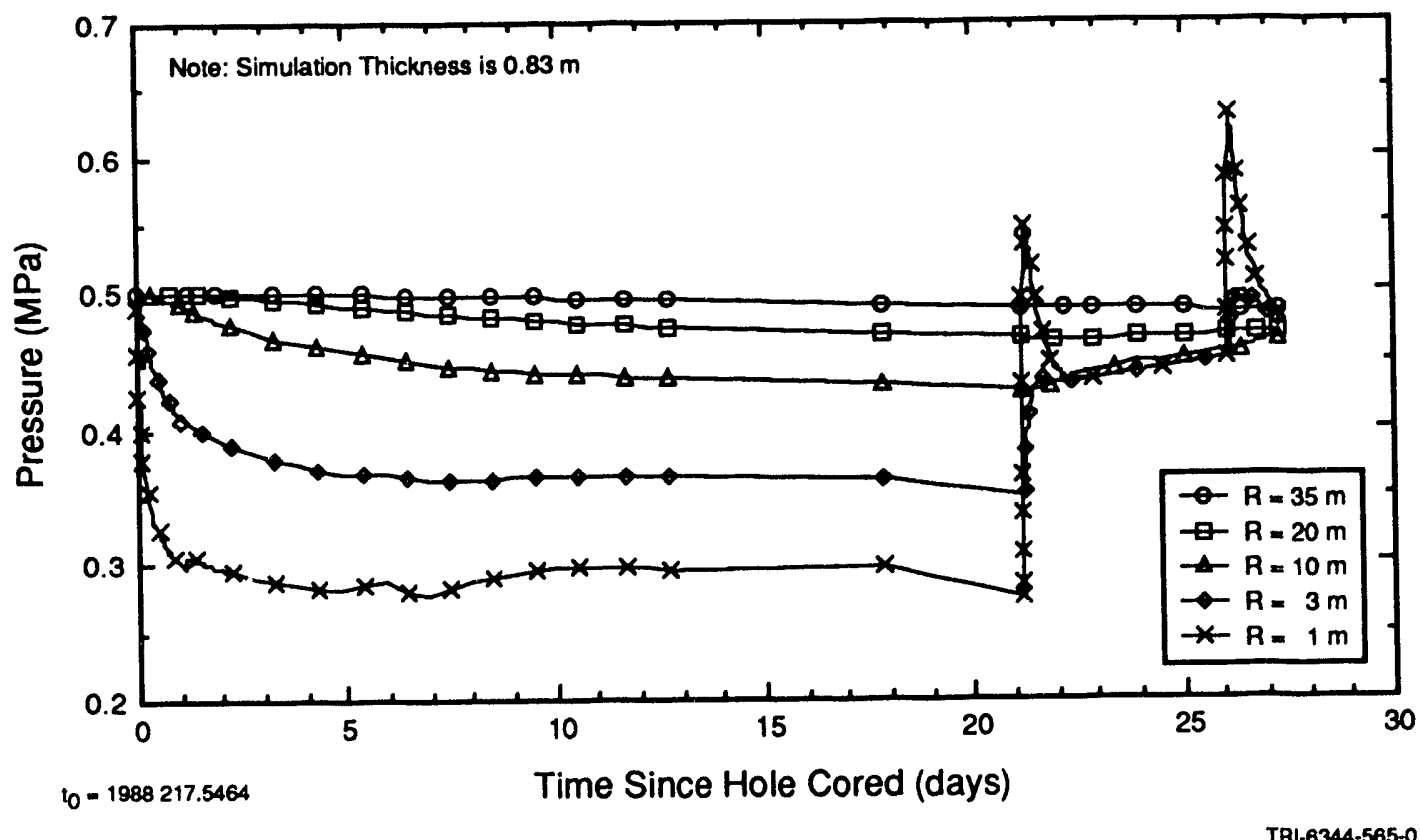

Figure 7-6. Simulated Formation Pore Pressures at Selected Radial Distances from the Test Zone During C2H01-A Testing, Assuming a Simulation Thickness of $0.83 \mathrm{~m}$. 
holes, discussed below, has provided additional insight into the $\mathrm{C}_{2} \mathrm{H} 01-\mathrm{A}$ test responses. Further discussion of the $\mathrm{C} 2 \mathrm{H} 01-\mathrm{A}$ tests is deferred, therefore, to Section 7.3.1.

7.1.1.2 Guard Zone. No pressure buildup was observed in the guard zone during the $\mathrm{C} 2 \mathrm{H} 01-\mathrm{A}$ testing (Figure 7-2). The guard zone may have been connected to the atmospheric pressure in Room C2 through fractures in the rock near the excavation. Borns and Stormont (1988) report the development of a disturbed rock zone (DRZ) within one to two meters of the WIPP excavations. This DRZ is characterized by fracturing and an increase in permeability (see Section 7.3.1). Considering that Room C2 was more than four years old at the time of the $\mathrm{C} 2 \mathrm{H} 01-\mathrm{A}$ testing, some fracturing in the floor was to be expected.

7.1.2 C2H01-B. After the C2H01-A testing was completed, the multipacker test tool was removed from the hole, tested for leaks, and reinstalled at a greater depth in the hole for the C2H01-B testing. The configuration of the test tool in the borehole for the $\mathrm{C} 2 \mathrm{H} 01-\mathrm{B}$ testing is shown in Figure 7-7. The test zone extended from 4.50 to $5.58 \mathrm{~m}$ below the floor of Room C2, and was contained entirely within map unit 0 (argillaceous halite). The guard zone extended from 2.92 to $4.02 \mathrm{~m}$ below the floor of the room, and included all of map units 3 (halite) and 1 (polyhalitic halite), and portions of map units 4 (argillaceous halite) and 0 (argillaceous halite). Thus, the test and guard zones for the $\mathrm{C} 2 \mathrm{H} 01-\mathrm{B}$ testing isolated different portions of what had been the test zone for the C2H01-A testing (compare Figures 7-1 and 7-7).

Figure 7-8 is a plot of the test- and guard-zone fluidpressure data collected by the DAS during the $\mathrm{C} 2 \mathrm{H} 01-\mathrm{A}$ and $\mathrm{C} 2 \mathrm{H} 01-\mathrm{B}$ monitoring periods. The $\mathrm{C} 2 \mathrm{H} 01-\mathrm{B}$ testing sequence consisted of an initial buildup period, followed by a pulse injection to increase the test-zone pressure and bring it closerto the formation porepressure, and two pulsewithdrawal tests in the test zons (Figure 7-8). Interpretations of the tests performed in the test zone, as well as of the fluid-pressure responses observed in the guard zone, are discussed below.

7.1.2.1 Test Zone. The multipacker test tool was reinstalled in borehole $\mathrm{C} 2 \mathrm{H} 01$ on September 1 , 1988 (Calendar Day 245) for the C2H01-B testing. The test and guard zones were shut in the next day. The fluid-pressure buildup in the test zone was monitored until September 28 (Calendar Day 272). The test zone for the $\mathrm{C} 2 \mathrm{H} 01-\mathrm{B}$ testing was subjected to the entire borehole-pressure history leading up to and including the $\mathrm{C}_{2} \mathrm{H} 01-\mathrm{A}$ testing. Therefore, the fluid-pressure data collected by the DAS from the time the hole was drilled until the end of the C2H01-B buildup period were used to specify the test-zone pressure during the period preceding the pulse tests.

Figure 7-8 shows that the fluid-pressure buildup after shut in for the $\mathrm{C} 2 \mathrm{H} 01-\mathrm{B}$ testing on Calendar Day 246 was not characteristic of a typical shut-in buildup as shown on Figure 4-6. The ideal buildup response shown on Figure 4-6 is representative of an incompressible test interval containing a constantcompressibility fluid recovering from an episode of depressurization. The slope of the buildup curve continually decreases as the pressure differential between the test interval and the surrounding formation decreases. In contrast, Figure 7-8 shows a buildup curve whose slope increases with time. This type of response could be caused by a testzone compressibility that decreased with increasing pressure. As long as the test-zone compressibility was decreasing faster than the pressure differential between the test interval and the surrounding formation, the slope of the pressure-buildup curve could increase. As discussed in Section 6.5, the 


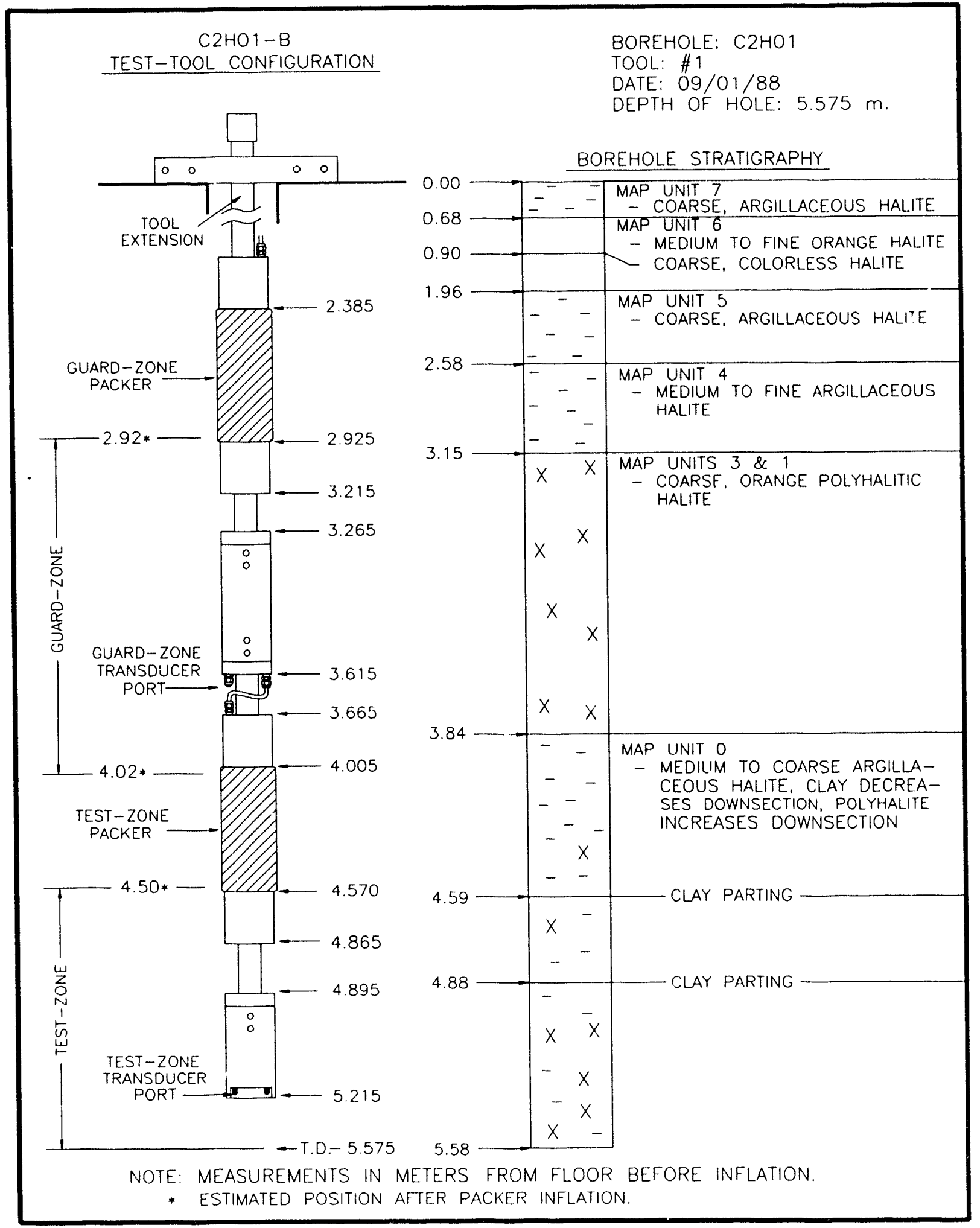

Figure 7-7. Configuration of Multipacker Test Tool \#1 in Borehole C2H01 for C2H01-B Testing. 


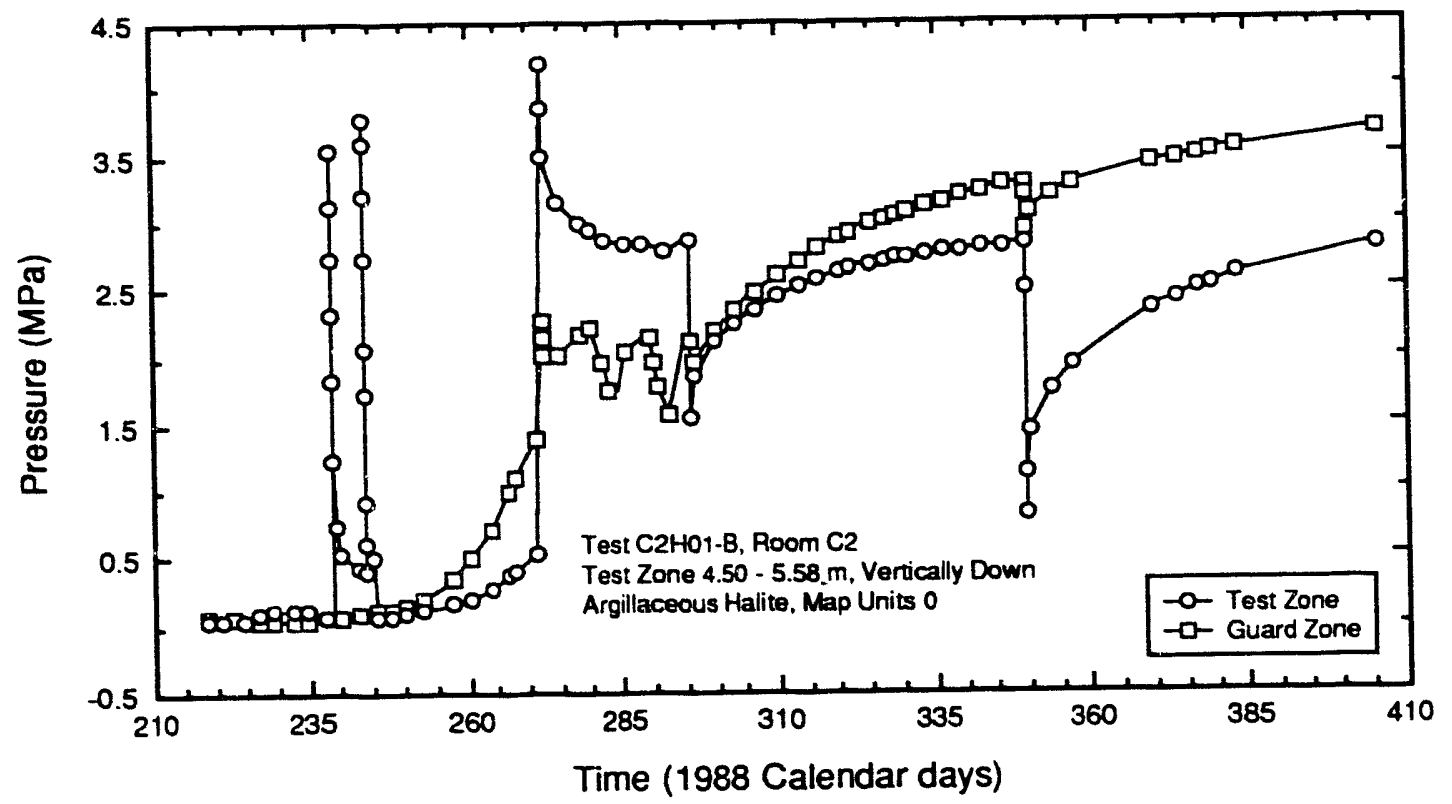

Figure 7-8. Test- and Guard-Zone Fluid-Pressure Data from C2H01-B Testing.

combination of test-tool compliance, packer deformation, and/or gas in the test zone could cause the compressibility of the test zone to have a nonlinear dependence on pressure.

Figure 7-9 shows the best-fit model simulation of the C2H01-B testing period compared to the observed fluid-pressure data. As noted on the figure, the time from the drilling of the test zone to the pulse injection was included as specified-pressure history. The specified parameters used in the simulation of the pulse-injection and two pulse-withdrawal tests were a formation thickness of $1.08 \mathrm{~m}$, a specific storage of $9.5 \times 10^{-8} \mathrm{~m}^{-1}$, and a test-zone compressibility of $1.21 \times 10^{-9} \mathrm{~Pa}^{-1}$. The fitted parameters were a hydraulic conductivity of $3.9 \times 10^{-14} \mathrm{~m} / \mathrm{s}$ (permeability of $5 \times 10^{-21} \mathrm{~m}^{2}$ ) and a formation pore pressure of 3.15 MPa. Additional simulations showing the sensitivity of the best-fit model to slight changes in

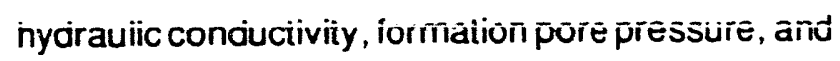
specitic storage, as well as to the presence or absence of test-zone-volume compensations, are presented in Section 7.2.

Figure 7-8 shows that the te: $\cdot$ zune fluid pressure responded very rapidly immedia. : after the pulse injection and two pulse withdrawals wer, 'it in, recovering from a significant fraction of each induced pulse in a period of minutes while the remainder of the recovery took week:. As discussed in Section 7.1.1.1, these early-time responses are believed to be primarily related to tool-compliance effects. Thus, a portion of the early-time response observed during testing was treated as a specified-pressure history in the simulations. Figures $7-10$ through $7-12$ show the data from the three $\mathrm{C} 2 \mathrm{H} 01-\mathrm{B}$ pulse tests with simulations performed including and noc including an early-time specified-pressure history, using the hydraulic parameters defined for the best-fit simulation shown in Figure 7-9. In all cases, the simulatior including an eariy specified-pressure history fits the complete data set better than the simulation with no history. The 


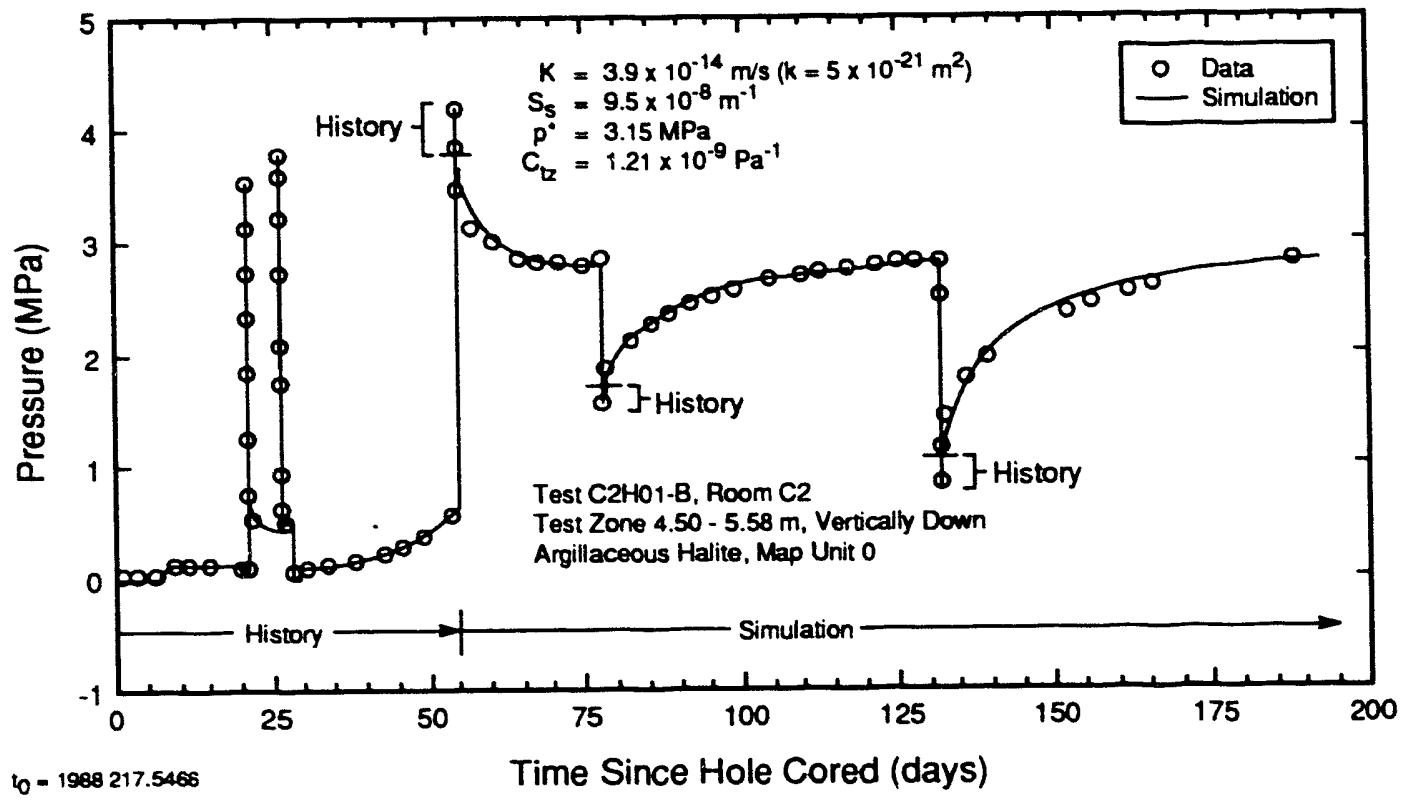

TRI-6344-567-0

Figure 7-9. Best-Fit Model Simulation of the Test-Zone Fluid-Pressure Response During C2H01-B Testing.

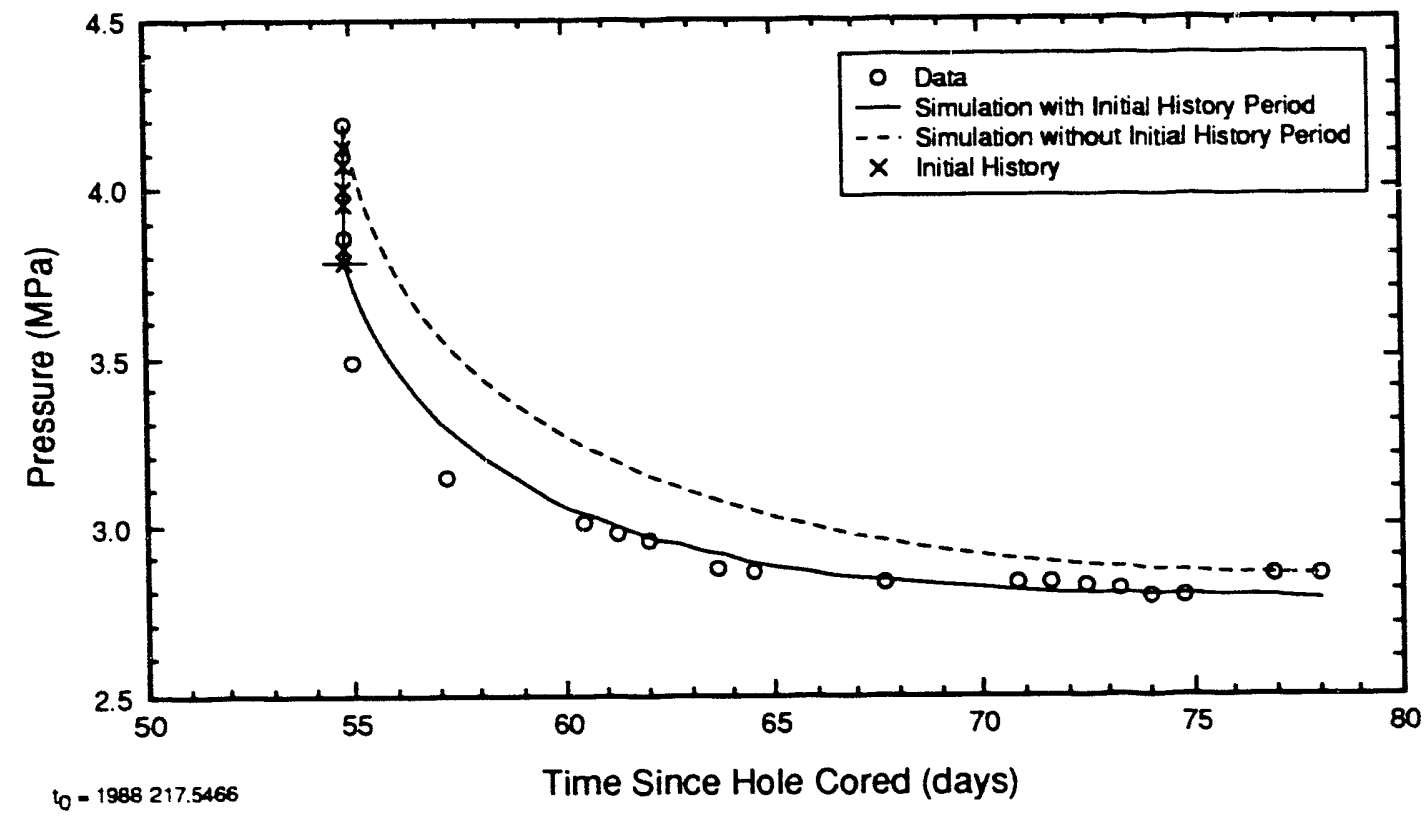

Figure 7-10. Best-Fit Model Simulation of Pulse-Injection \#1 During C2H01-B Testing Showing the Effect of an Initial Fluid-Pressure History Period. 


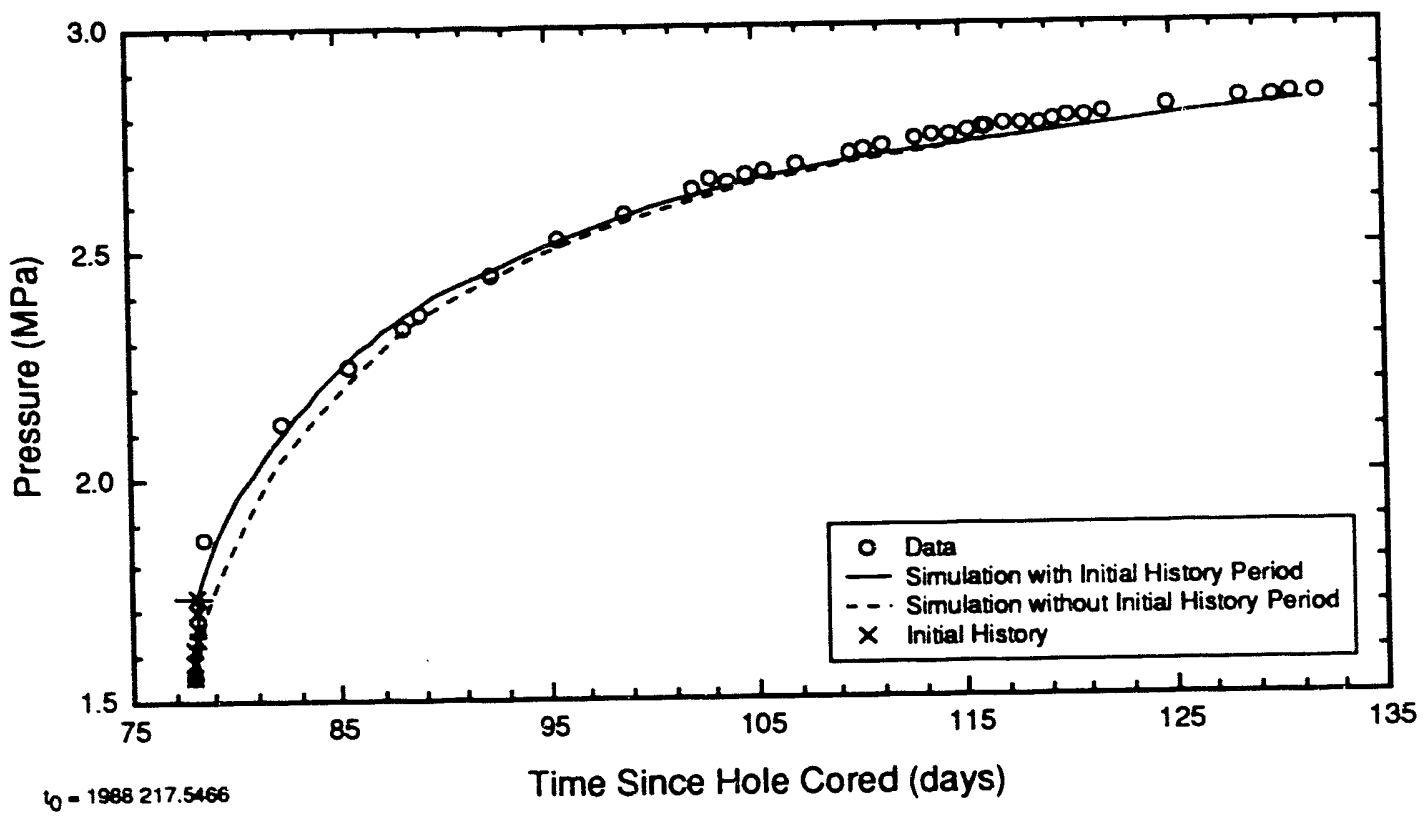

Figure 7-11. Best-Fit Model Simulation of Pulse-Withdrawal \#1 During C2H01-B Testing Showing the Effect of an Initial Fluld-Pressure History Period.

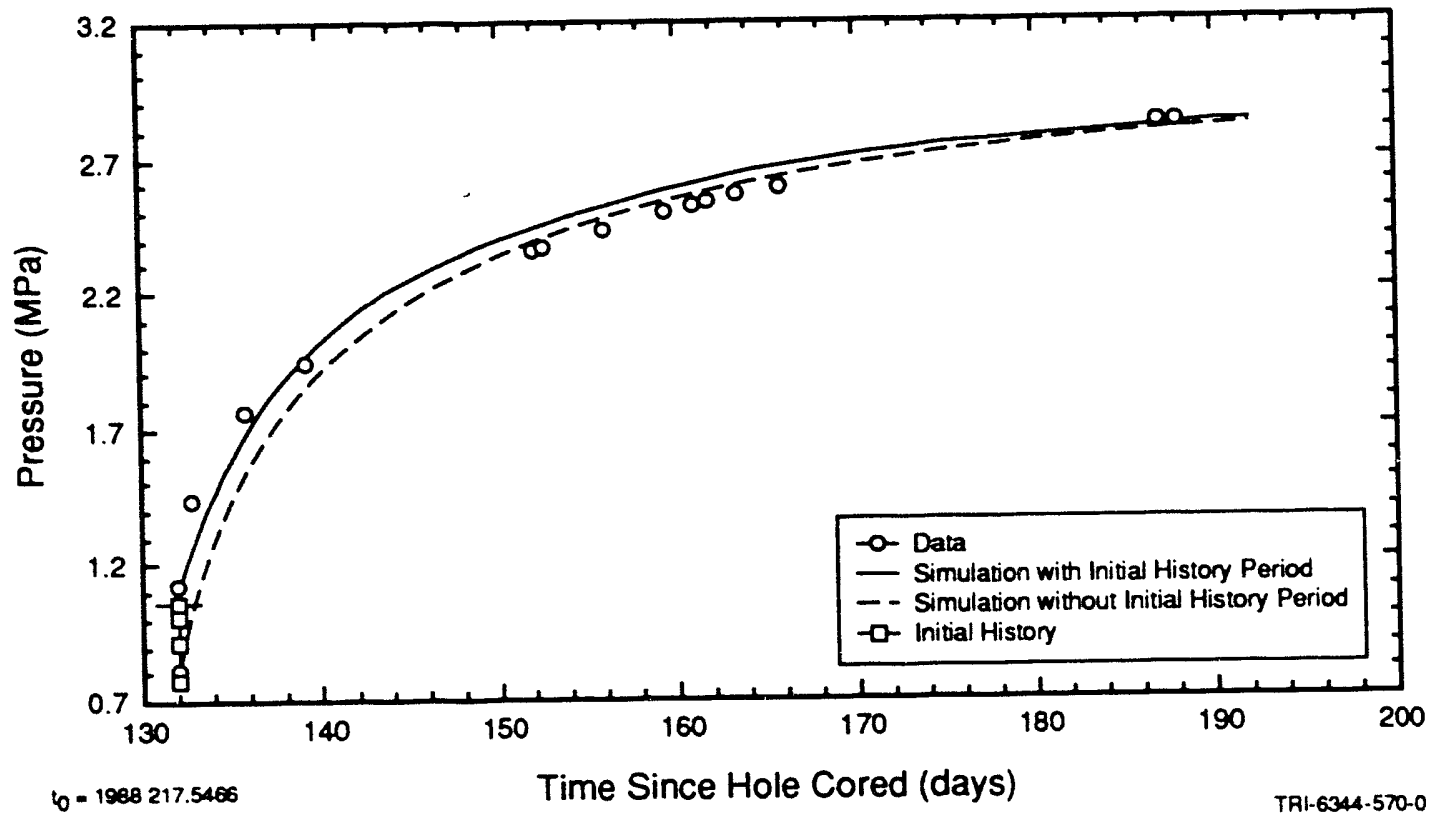

Flgure 7-12. Rest-Fit Model Simulation of Pulse-Withdrawal \#2 During C2H01-B Testing Showing the Effect of an Initial Fluid-Pressure History Period. 
simulation lacking an early specified-pressure history invariably shows an early-time recovery less rapid than that actually observed, in keeping with the time scales of actual formation responses. Significantly, however, the pairs of simulations become increasingly similar with time, showing the overriding influence of the formation-parameter estimates on the late-time pressure behavior. Thus, questions about the exact delineation of the period that should appropriately be included as history are moot.

The well-test-analysis model was used to examine the radius of influence of the $\mathrm{C} 2 \mathrm{H} 01-\mathrm{B}$ testing. Figure 7-13 shows the simulated formation-fluid pressures at different radial distances from the borehole throughout the entire $\mathrm{C} 2 \mathrm{H} 01-\mathrm{B}$ testing period. The longest duration, highest magnitude response was caused by the initial 55-day period during which the hole was either completely depressurized or at relatively low pressure ( $<1 \mathrm{MPa})$. The effects of this depressurization had propagated to a distance of about $6 \mathrm{~m}$ from the hole by the end of the monitoring period. The effects of the individual pulse tests can be seen to a distance of about $2 \mathrm{~m}$ from the hole. That is, the slopes of the simulated pressure curves out to 2-m distance change visibly after each pressure pulse in the test zone. In the case of the 2-m pressure curve, these changes in slope occur 10 to 15 days after the pulses.

7.1.2.2 Guard Zone. Although no testing was specifically performed in the guard zone during the C2H01-B testing, tool compliance transmitted a portion of each test-zone pulse to the guard zone (Figure 7-8). The two pulse withdrawals in the test zone, in particular, produced responses in the guard zone that could be used to estimate formation hydraulic parameters.
Figure 7-14 shows the best-fit model simulation of the $\mathrm{C} 2 \mathrm{H} 01-\mathrm{B}$ guard-zone response compared to the observed fluid-pressure data. As noted on the figure, the time from the drilling of the guard zone to the first pulse withdrawal in the test zone was included as specifiedpressure history. Brief specified-pressure history segments were also used at the start of each pulse recovery. Because the pressure pulses in the guard zone were created by tool responses to pressure changes in the test zone, the pressure buildups following the pulses were probably also caused, in part, by tool compliance. Specifically, recovery to the prepulse pressure could be due entirely to tool compliance if the test-zone pressure were recovering to its prepulse value over the same time period. Increases in the guard-zone pressure beyond the pre-pulse pressure, particularly if the test-zone pressure was still below its pre-pulse value, must reflect formation response. Thus, the response observed in the guard zone during the first "pulse test" shown on Figure 7-14 probably includes a greater component of formation response than does the response during the second "pulse test." This conclusion appears to be borne out by the simulation shown on Figure 7-14, which matches the observed data well during the first pulse test, but falls below the observed data during the second pulse test.

The specified parameters used to create the simulation of the two pulse-withdrawal tests shown on Figure 7.14 were a formation thickness of $1.10 \mathrm{~m}$, a specific storage of $9.5 \times 10^{-8} \mathrm{~m}^{-1}$, and a guard-zone compressibility. Lacking any independent estimate of the guard-zone compressibility, the calculated compressibility of the test zone $\left(1.21 \times 10^{-9} \mathrm{~Pa}^{-1}\right)$ was also used to approximate the guard-zone compressibility. The fitted parameters were a hydraulic conductivity of $1.4 \times 10^{-14} \mathrm{~m} / \mathrm{s}$ (permeability of $2 \times 10^{-21} \mathrm{~m}^{2}$ ) and a 


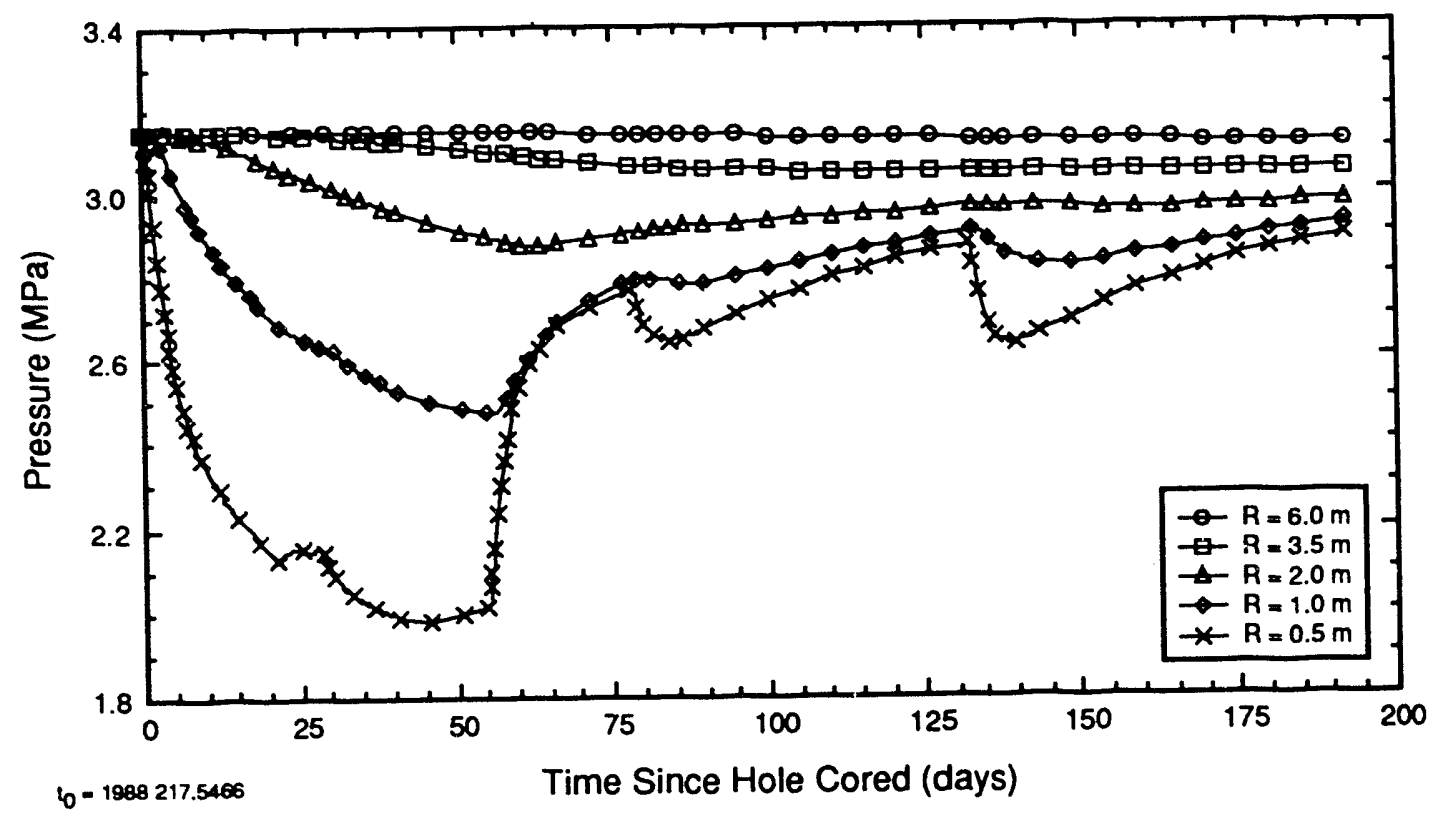

TRI-6344-571-0

Figure 7-13. Simulated Formation Pore Pressures at Selected Radial Distances from the Test Zone During C2H01-B Testing.

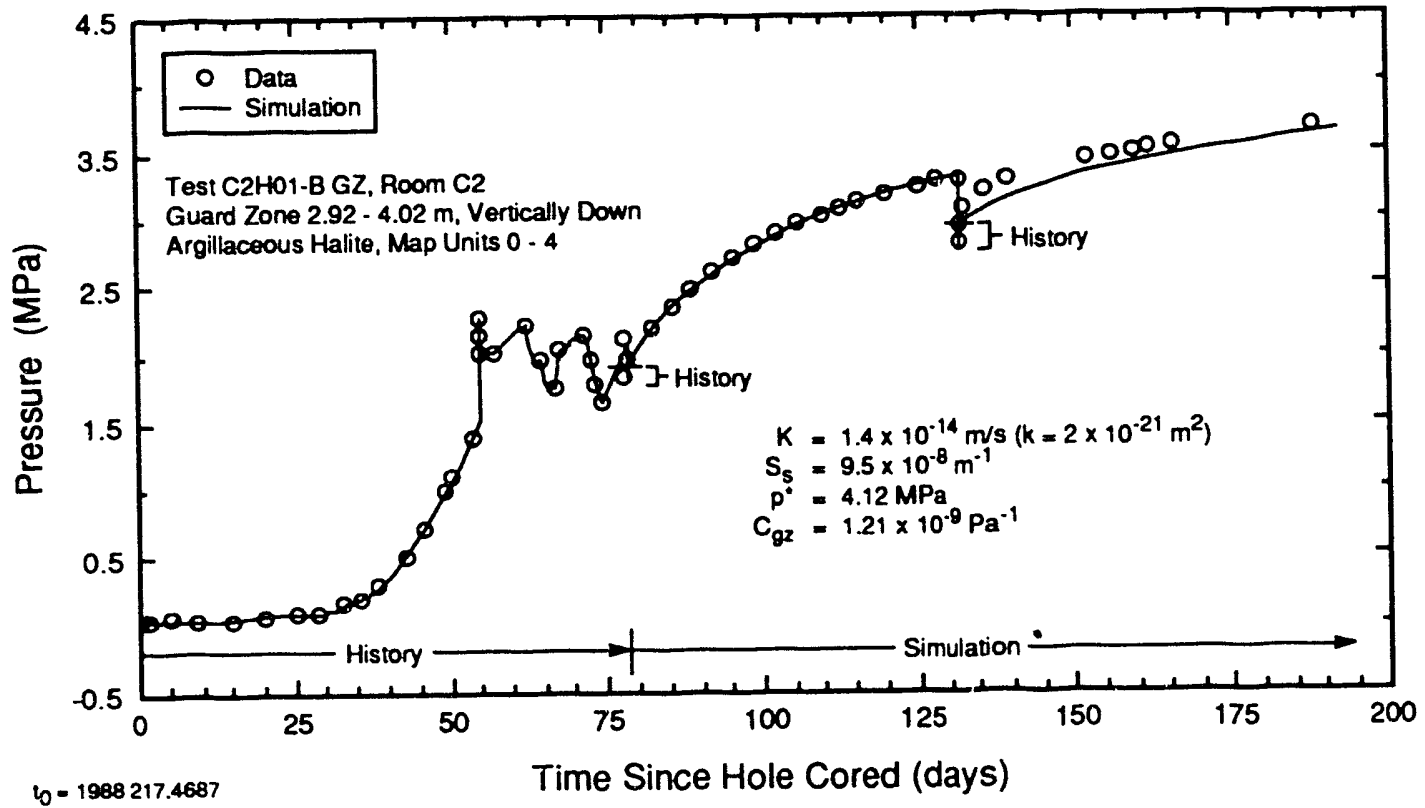

Figure 7-14. Best-FH Model Simulation of the Guard-Zone Fluid-Pressure Response During C2H01-B Testing. 
formation pore pressure of $4.12 \mathrm{MPa}$. Additional simulations showing the sensitivity of the best-fit model to slight changes in hydraulic conductivity, formation pore pressure, and specific storage, as well as to the presence or absence of guard-zone-volume compensations, are presented in Section 7.2.

The radius of influence of the C2H01-B guard-zone "testing" was investigated by using the model to calculate pressure histories at different radial distances from the borehole. Figure 7-15 shows that depressurization effects extended to a distance of about $4 \mathrm{~m}$ during the testing period. The effects of the individual pulse tests can be seen to a distance of about $1 \mathrm{~m}$ from the hole.

7.1.3 C2HO1-C. C2H01-C is the designation applied to the testing in the deepened segment of borehole $\mathrm{C} 2 \mathrm{H} 01$. Borehole $\mathrm{C} 2 \mathrm{H} 01$ was deepened from 5.58 to $8.97 \mathrm{~m}$ below the floor of Room C2 on February 10 and 11, 1989 (Calendar Days 41 and 42). The hole was deepened to allow testing of Marker Bed 139 in a location where this unit was deeper than 1 to $2 \mathrm{~m}$ below an excavation. Figure 7-16 shows the configuration of the test tool in $\mathrm{C}_{2} \mathrm{H} 01$ during the $\mathrm{C} 2 \mathrm{H} 01-\mathrm{C}$ testing, and indicates the lengths and stratigraphic locations of the guard and test zones. The test zone included Marker Bed 139 and halite and polyhalitic halite above and below the marker bed, while the guard zone included argillaceous halite of map unit 0 .

Figure 7-17 is a plot of the test- and guard-zone fluidpressure data collected during the testing period. The testing sequence consisted of an initial pressurebuildup period and two pulse-withdrawal tests in the test zone. The $\mathrm{C} 2 \mathrm{H} 01-\mathrm{C}$ testing period was preceded by an initial 5-day buildup period as shown on Figure 7-17. The multipacker test tool was removed from the hole after this short buildup period and reconfigured to shorten the length of the test zone. On February 24, 1989 (Calendar Day 55), the test zone was shut in to

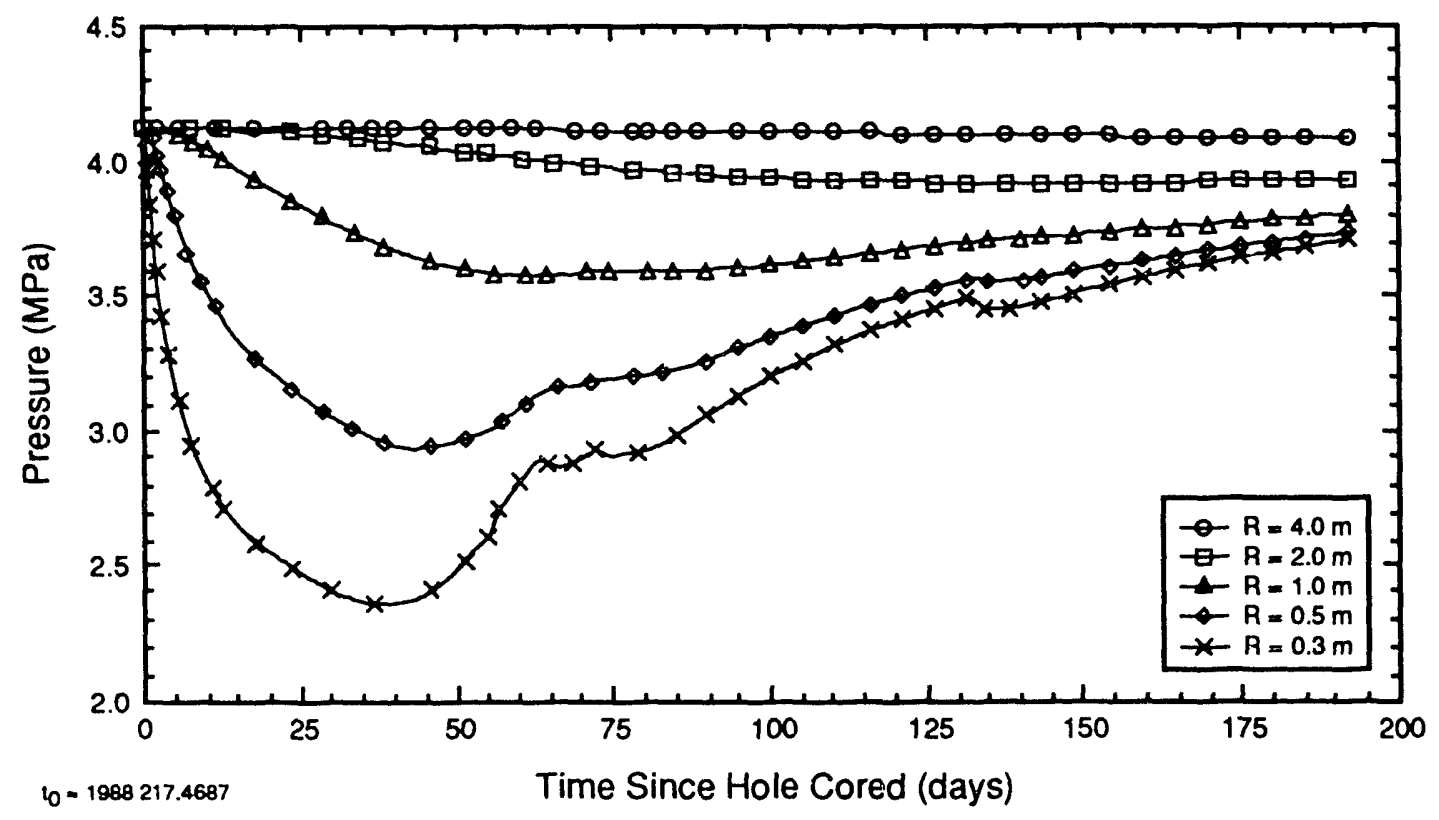

TRI-6344-573-0

Figure 7-15. Simulated Formation Pore Pressures at Selected Radial Distances from the Guard Zone During C2H01-B Testing. 


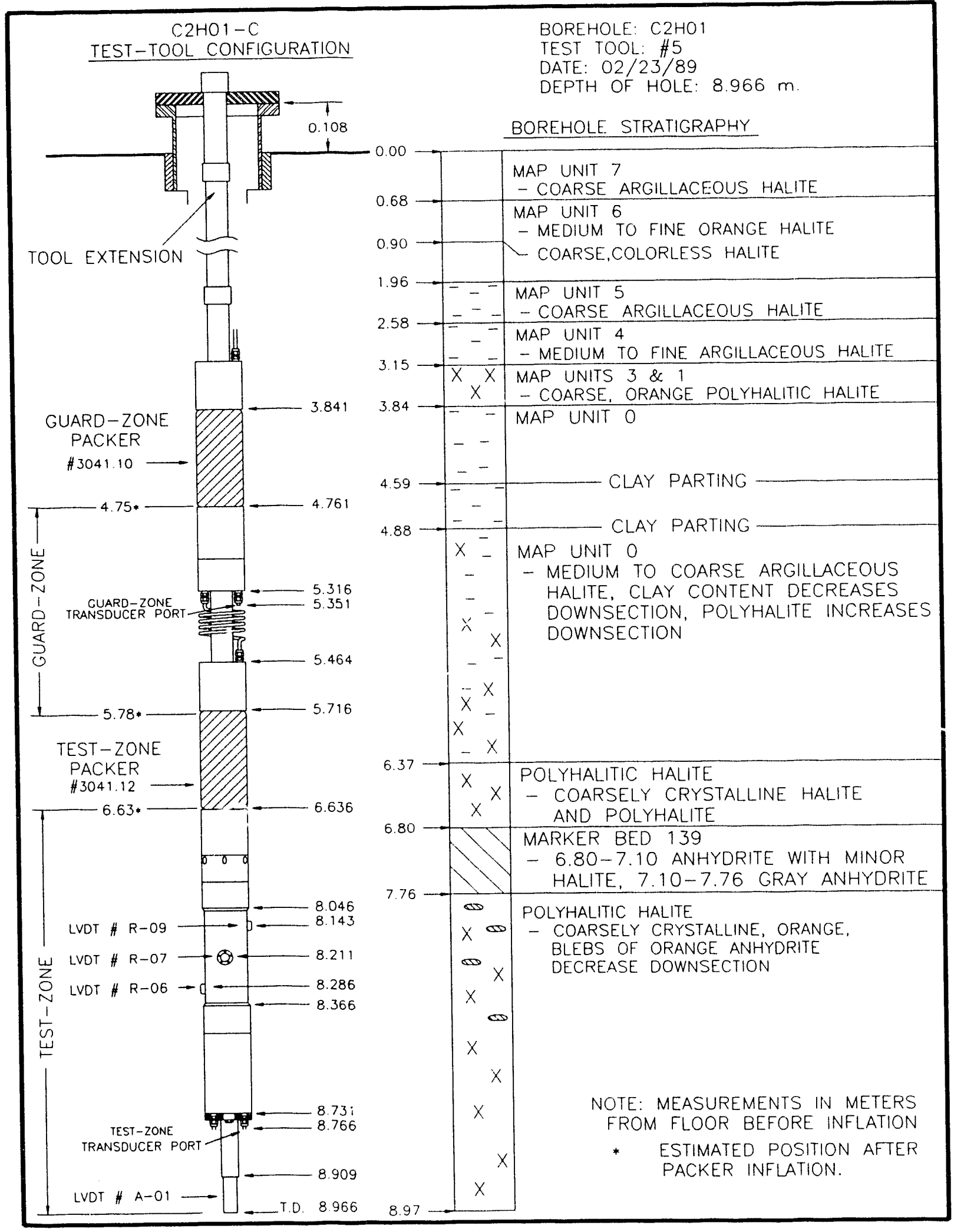

Figure 7-16. Configuration of Multipacker Test Tool \#5 in Borehole C2H01 for C2H01-C Testing. 


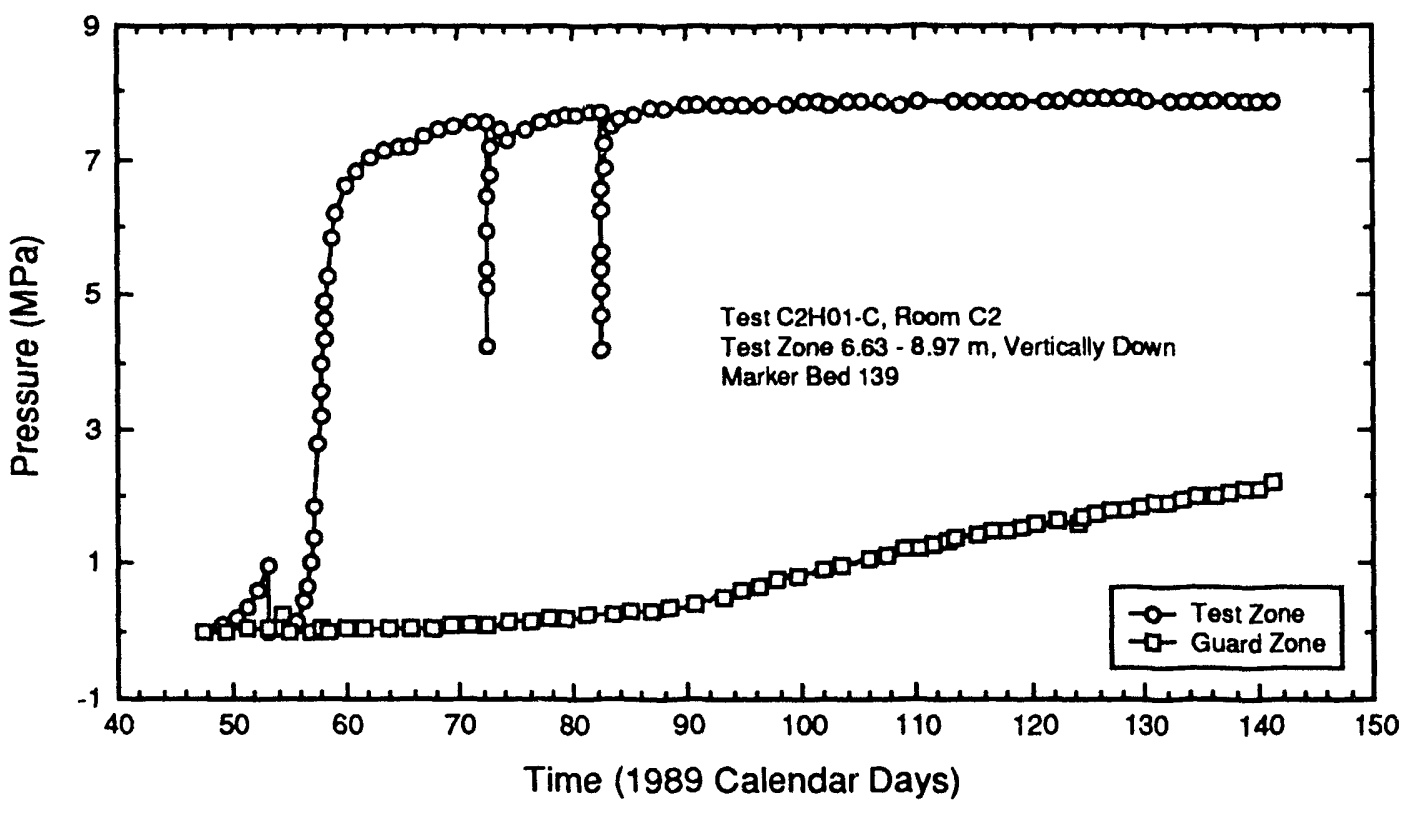

TRI-6344-574-0

Figure 7-17. Test- and Guard-Zone Fluid-Pressure Data from C2H01-C Testing.

start the second buildup period, which continued until the test-zone-fluid pressure reached relative stability at $7.65 \mathrm{MPa}$ in mid-March 1989.

7.1.3.1 Test Zone. The pressure-buildup period in $\mathrm{C} 2 \mathrm{H} 01-\mathrm{C}$ produced a non-characteristic buildup curve (Figure 7-17) similar to that described for the $\mathrm{C} 2 \mathrm{H} 01-\mathrm{B}$ test zone in Section 7.1.2.1. The same factors that could have led to a pressure-dependent compressibility in that case might also have been operative in this case. The test-zone compressibilities calculated for the two $\mathrm{C} 2 \mathrm{HO}-\mathrm{C}$ pulse withdrawals, $2.50 \times 10^{-9}$ and $3.64 \times 10^{-9} \mathrm{~Pa}^{-1}$ (Table 6-3), are, however, higher than the test-zone compressibility calculated for $\mathrm{C} 2 \mathrm{H} 01-\mathrm{B}$, perhaps indicating a greater amount of gas in the C2H01-C test zone. A onesecond burst of gas from the test-zone vent line was in fact observed during the second $\mathrm{C} 2 \mathrm{H} 01-\mathrm{C}$ pulse withdrawal (Saulnier et al., 1991).

Figure 7-18 shows the best-fit model simulation of the $\mathrm{C} 2 \mathrm{H} 01-\mathrm{C}$ pulse-withdrawal tests along with the observed fluid-pressure data from the test zone. The data from the time of penetration of the center of the test zone by drilling to the first pulse withdrawal were included as specified-pressure history, as were the data collected during the first minutes following the pulse withdrawals. The specified parameters used to simulate the two pulse-withdrawal tests were a formation thickness of $0.96 \mathrm{~m}$ (corresponding only to the Marker Bed 139 portion of the test interval), a specific storage of $1.4 \times 10^{-7} \mathrm{~m}^{-1}$, and a test-zone compressibility of $3.02 \times 10^{-9} \mathrm{~Pa}^{-1}$. The fitted parameters were a hydraulic conductivity of $7.0 \times 10^{-12} \mathrm{~m} / \mathrm{s}$ (permeability of $1 \times 10^{-18} \mathrm{~m}^{2}$ ) and a formation pore pressure of $8.05 \mathrm{MPa}$. Additional simulations showing the sensitivity of the best-fit model to slight changes in hydraulic conductivity, formation pore pressure, specific storage, and test-zone compressibility, as well as to the presence or absence of test-zone-volume compensations, are presented in Section 7.2.

The well-test-analysis model was used to examine the radius of influence of the $\mathrm{C} 2 \mathrm{H} 01-\mathrm{C}$ testing. 


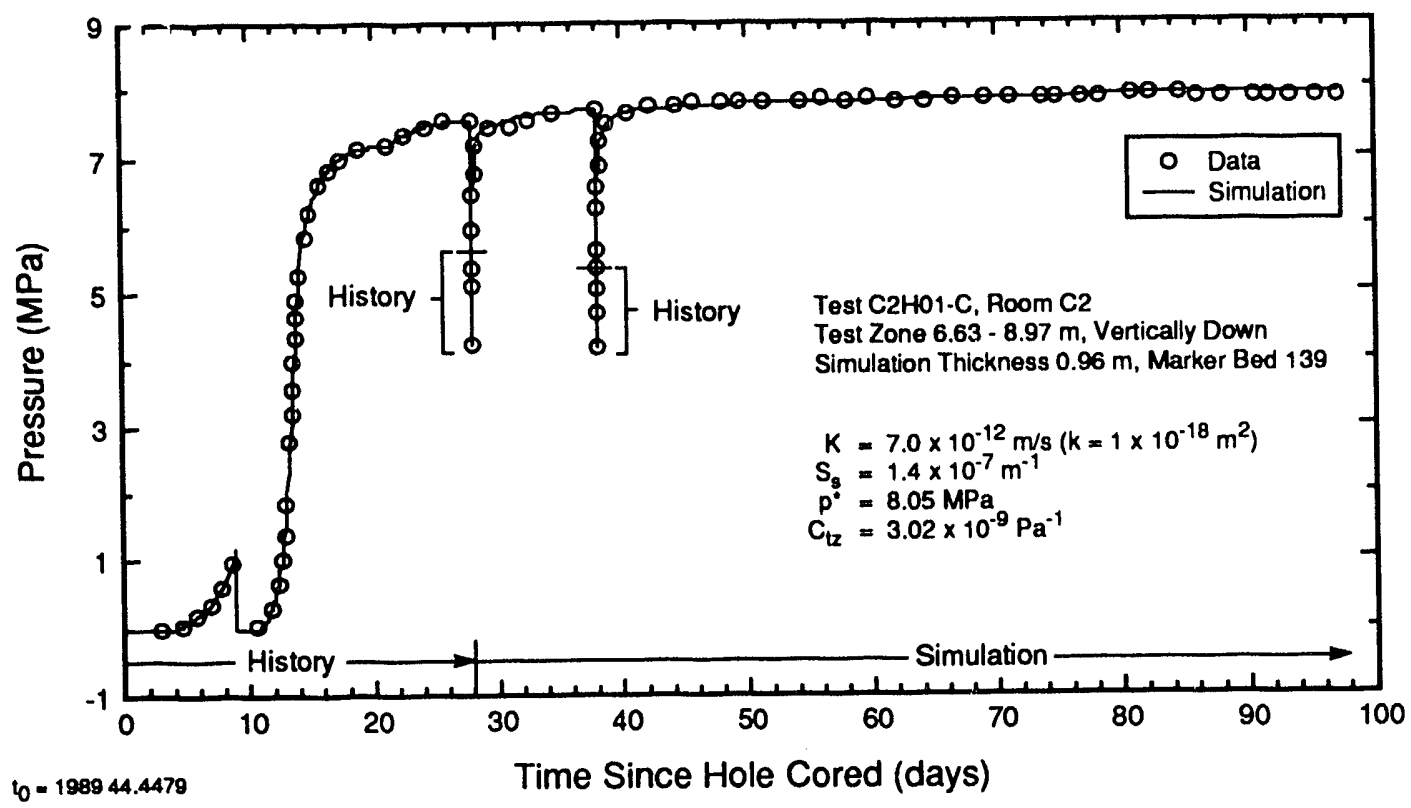

TRI-6344-575-0

Figure 7-18. Best-Fit Model Simulation of the Test-Zone Fluid-Pressure Response During C2H01-C Testing.

Figure 7-19 shows the simulated formation-fluid pressures at different radial distances from the borehole throughout the entire $\mathrm{C} 2 \mathrm{H} 01-\mathrm{C}$ testing period. The longest duration, highest magnitude response was caused by the initial open-hole and buildup periods. The simulated effects of this depressurization had propagated to a distance of about $35 \mathrm{~m}$ from the hole by the end of the monitoring period. The effects of the individual pulse tests can be seen as minor changes in the slopes of the pressure curves to a distance of about $5 \mathrm{~m}$ from the hole. In the case of the 5-m pressure curve, these changes in slope occur a few days after the pulses.

This analysis assumes that Marker Bed 139 behaves hydraulically as a porous, rather than fractured, medium. Borns (1985) reported that Marker Bed 139 is typically fractured. If Marker Bed 139 is in fact fractured at borehole $\mathrm{C} 2 \mathrm{H} 01$, and if brine flow is confined to the fractures, then the hydraulic conductivity of the fractures must be greater than $7.0 \mathrm{x}$ $10^{-12} \mathrm{~m} / \mathrm{s}$, which is the average hydraulic conductivity over the full 96-cm thickness of Marker Bed 139. In addition, the radius of influence of the tests would be greater than is indicated by Figure 7-19, because the fractures would have less storage capacity than the full thickness used in the simulations.

7.1.3.2 Guard Zone. The guard zone during the $\mathrm{C} 2 \mathrm{H} 01-\mathrm{C}$ testing included very nearly the same stratigraphic interval as the test zone during the $\mathrm{C} 2 \mathrm{H} 01-\mathrm{B}$ testing (compare Figures 7-7 and 7-16). Thus, we expected to observe a buildup in pressure towards the $3.35 \mathrm{MPa}$ indicated by the $\mathrm{C} 2 \mathrm{H} 01-\mathrm{B}$ test interpretation as the formation pore pressure for that interval. A very slow increase in pressure was observed between the time the guard zone was shut in on February 24, 1989 (Calendar Day 55) and late March (approximately Calendar Day 90), after which time the pressure rose considerably more rapidly (Figure 7-17). The reasons for the originally slow rate of pressure buildup and later increase are unknown. Failure to achieve complete shut in until approximately Calendar Day 90 could 


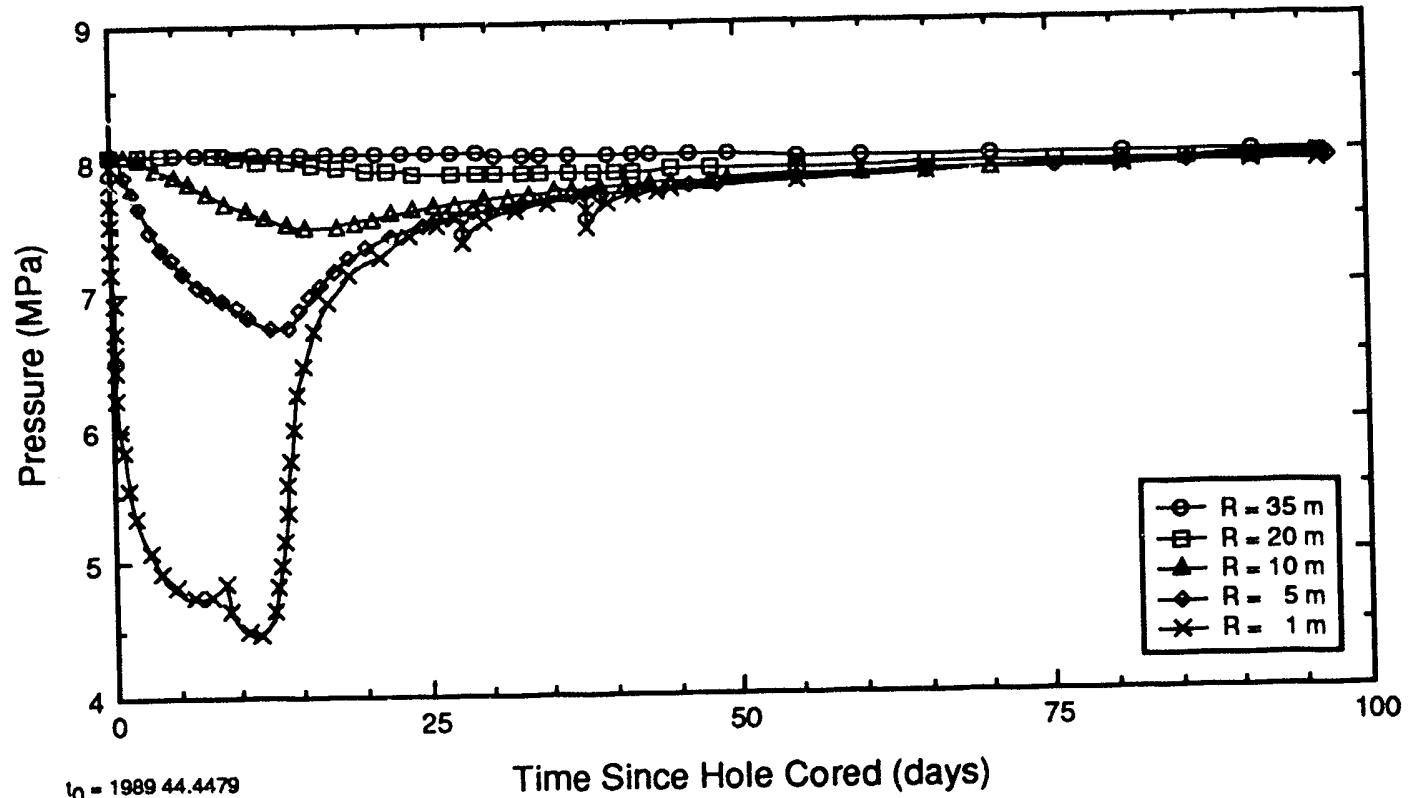

TRI-6344-576-0

\section{Figure 7-19. Simulated Formation Pore Pressures at Selected Radial Distances from the Test Zone During C2H01-C Testing.}

account for the observed response, but how or why this could have occurred is unknown. At the end of the monitoring period, the guard-zone pressure was 2.22 MPa and increasing.

\subsubsection{C2H02. Borehole $\mathrm{C} 2 \mathrm{HO} 2$ was drilled at a} downward angle of $45^{\circ}$ to allow testing of Marker Bed 139 beneath the west rib of Room C2 (Figure 5-2). Figure 7-20 shows the configuration of the test tool in $\mathrm{C} 2 \mathrm{HO2}$, and indicates the lengths and stratigraphic locations of the guard and test zones. The test zone included all but the upper $27 \mathrm{~cm}$ of Marker Bed 139, as well as $18 \mathrm{~cm}$ of the underlying halite. The guard zone included the lower part of map unit 0 (halite) and the upper part of the polyhalitic halite overlying Marker Bed 139.

Figure 7-21 is a plot of the test- and guard-zone fluidpressure data collected by the DAS during the monitoring period. The testing sequence consisted of an initial buildup period, followed by a pulse-withdrawal test that was aborted after the valves on the zone vent lines were accidentally opened, a pulse injection to accelerate the equilibration between the borehole and formation pore pressures, and two pulse-withdrawal tests (Figure 7-21). Following the second successful pulsewithdrawal test, the pressure in the test zone was decreased during a gas-sampling exercise. A second gas sample was collected six days later, after which monitoring was discontinued (Saulnier et al., 1991). Interpretations of the tests performed in the test zone, as well as of the fluid-pressure responses observed in the guard zone, are discussed below.

7.1.4.1 Test Zone. The model used in the analysis of the pulse-withdrawal tests assumes radial flow in the horizontal plane as described in Sections 6.1 and 6.2. Cinco et al. (1975) showed that standard radial-flow solution techniques could be applied to the interpretation of tests performed in slanted wells by considering the vertical, rather than slanted, penetration distance of the well as the production thickness. 


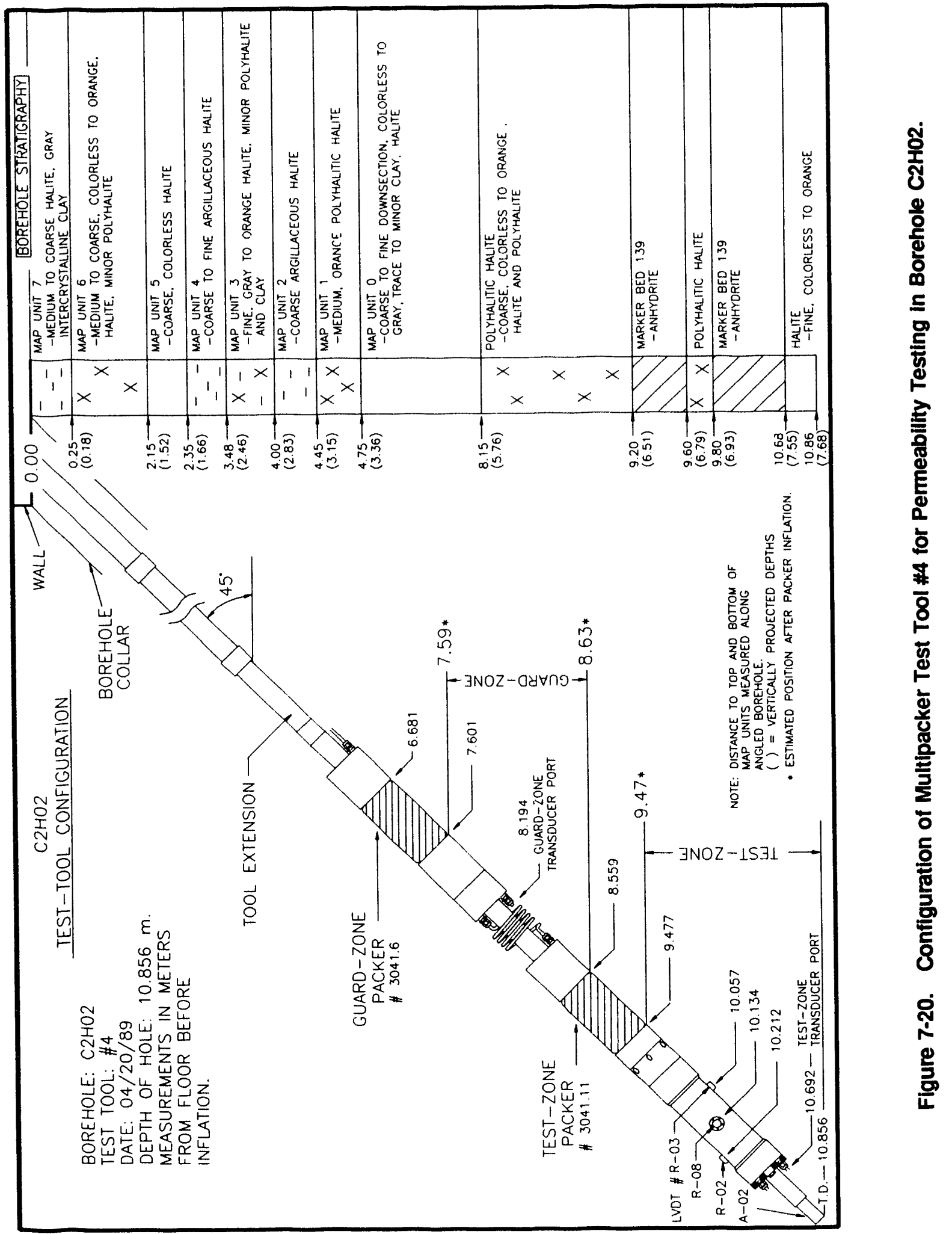




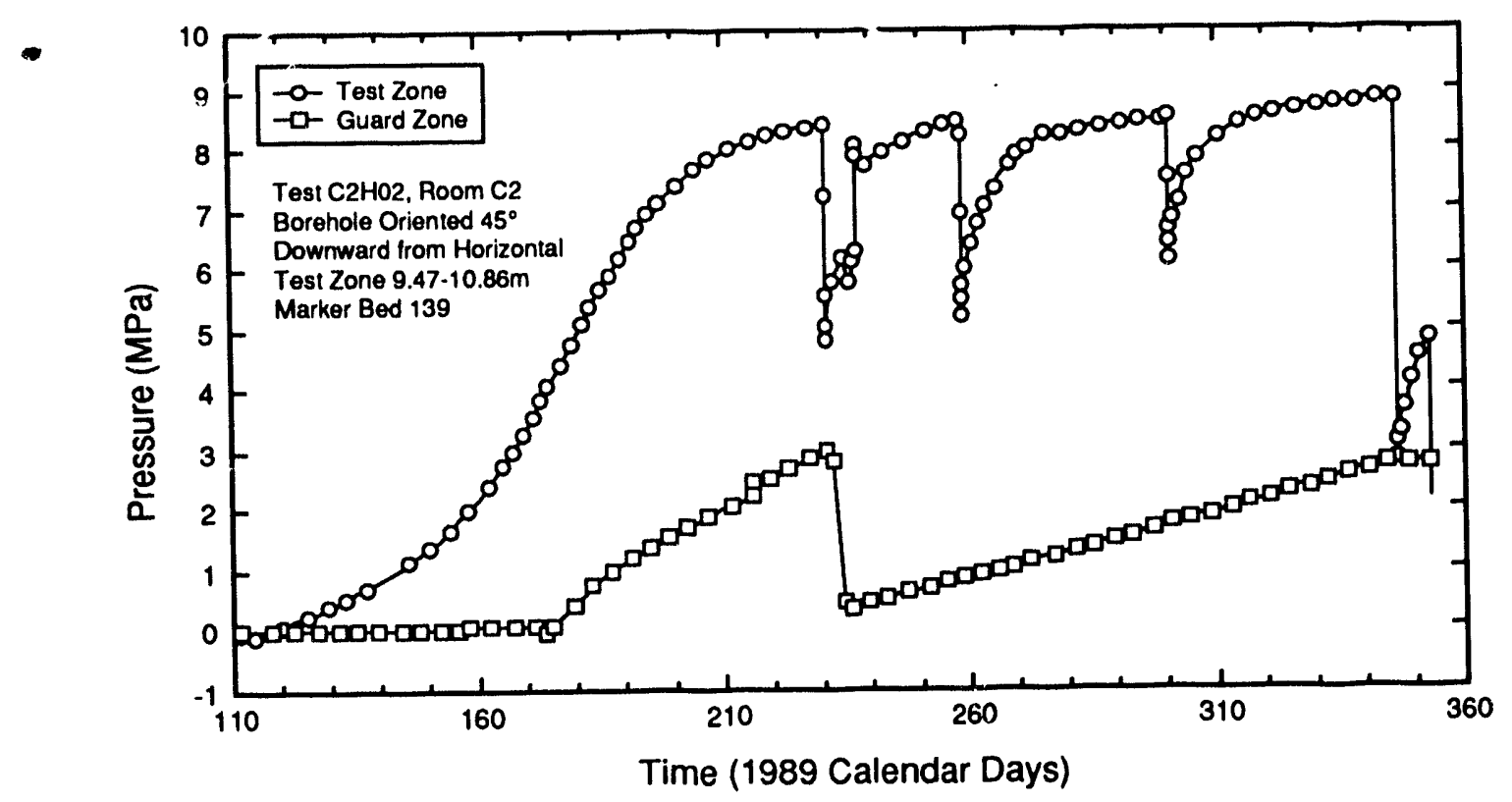

TR1-6344-577.0

Figure 7-21. Test- and Guard-Zone Fluld-Pressure Data from C2H02 Testing.

Because $\mathrm{C} 2 \mathrm{H} 02$ was drilled at a downward angle of $45^{\circ}$ and included most of the essentially horizontal Marker Bed 139 in the test zone, tests of this interval were analyzed using an idealized test-zone geometry. Flow from Marker Bed 139 to the borehole was assumed to be horizontal only, and the test zone was modeled as a vertical cylindrical borehole with a circumference equivalent to that of the ellipse formed by the intersection of the $45^{\circ}$ borehole and the horizontal marker bed, and with a height equal to the vertical thickness of that portion of the marker bed contained within the test interval (Figure 7-22). The test-interval volume was maintained at its actual value by adding an appropriate "dead volume" to the test-interval volume calculated by the model from the specified idealized dimensions. This procedural step satisfies the model test-interval-compressibility boundary condition.

During each pulse withdrawal, more fluid was removed from the test zone to produce a given pressure reduction than the amount predicted based on the compressibility of brine. Thetest-zone compressibilities calculated from the data collected during the second and third pulse withdrawals were $1.05 \times 10^{-8}$ and 9.28 $\times 10^{-9} \mathrm{~Pa}^{-1}$, respectively (Table 6-3). The brine produced during the pulse withdrawals degassed visibly in the collection vessel. At the conclusion of the $\mathrm{C} 2 \mathrm{HO} 2$ testing, samples of the gas from the test zone were collected and analyzed. As reported in Saulnier et al. (1991), the gas was determined to be $91 \%$ hydrogen, $6.5 \%$ nitrogen, and minor amounts of oxygen, methane, argon, and carbondioxide. The aluminumcomponents of the test tool were found to be severely corroded when the tool was removed from the hole. The hydrogen gas was apparently generated during the corrosion of the tool.

Figure 7-23 shows the best-fit model simulation of the $\mathrm{C} 2 \mathrm{H} 02$ pulse-withdrawaltests assuming porous, rather than fracture, flow. The observed fluid-pressure data from the test zone are also presented on the figure. The data from the time of penetration of the center of 
Actual

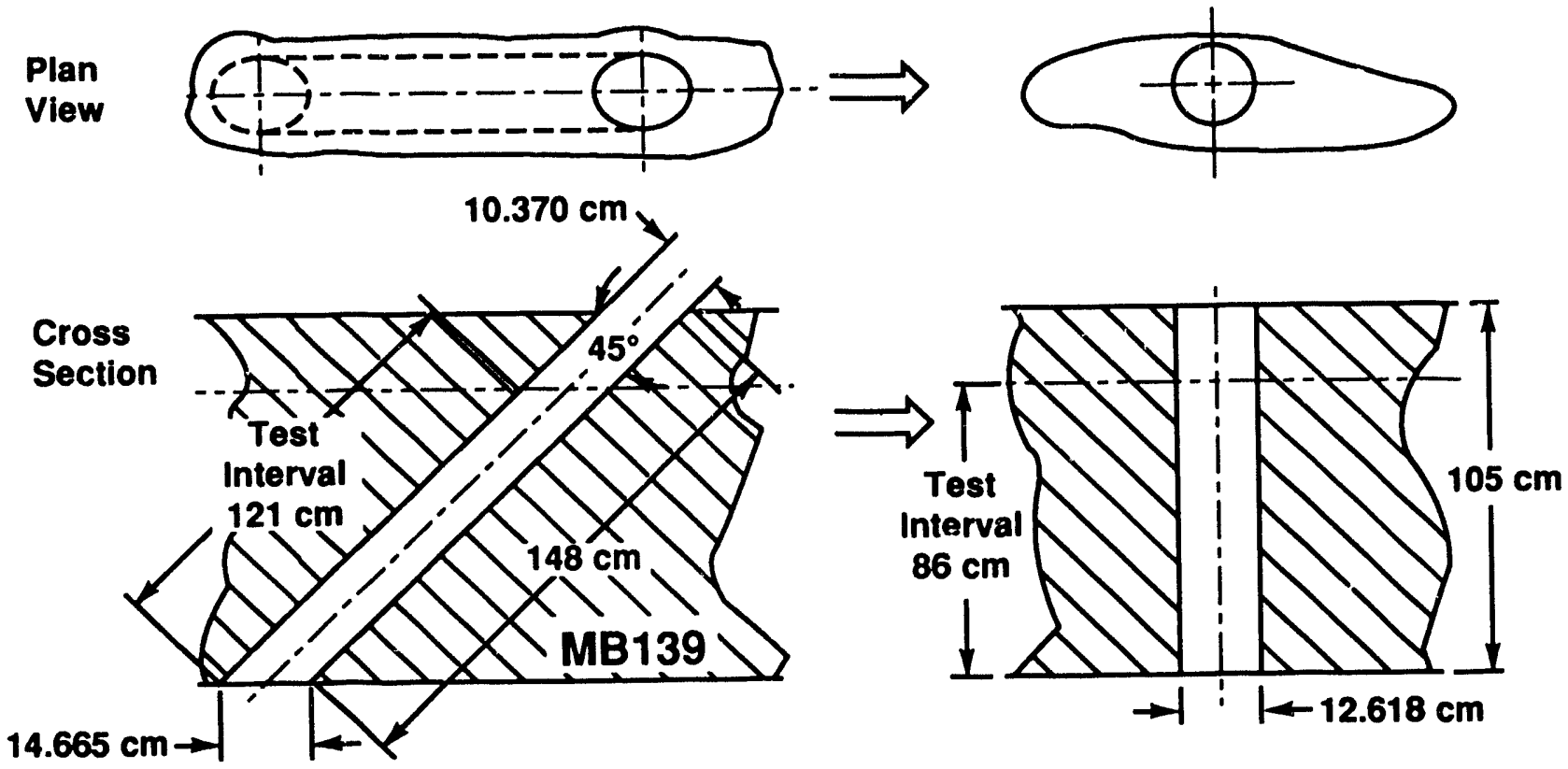

TRI-6344-121-0

Figure 7-22. Schematic Illustration of the Actual and Idealized Test-Zone Geometry Used for the Analysis of the C2H02 Tests.

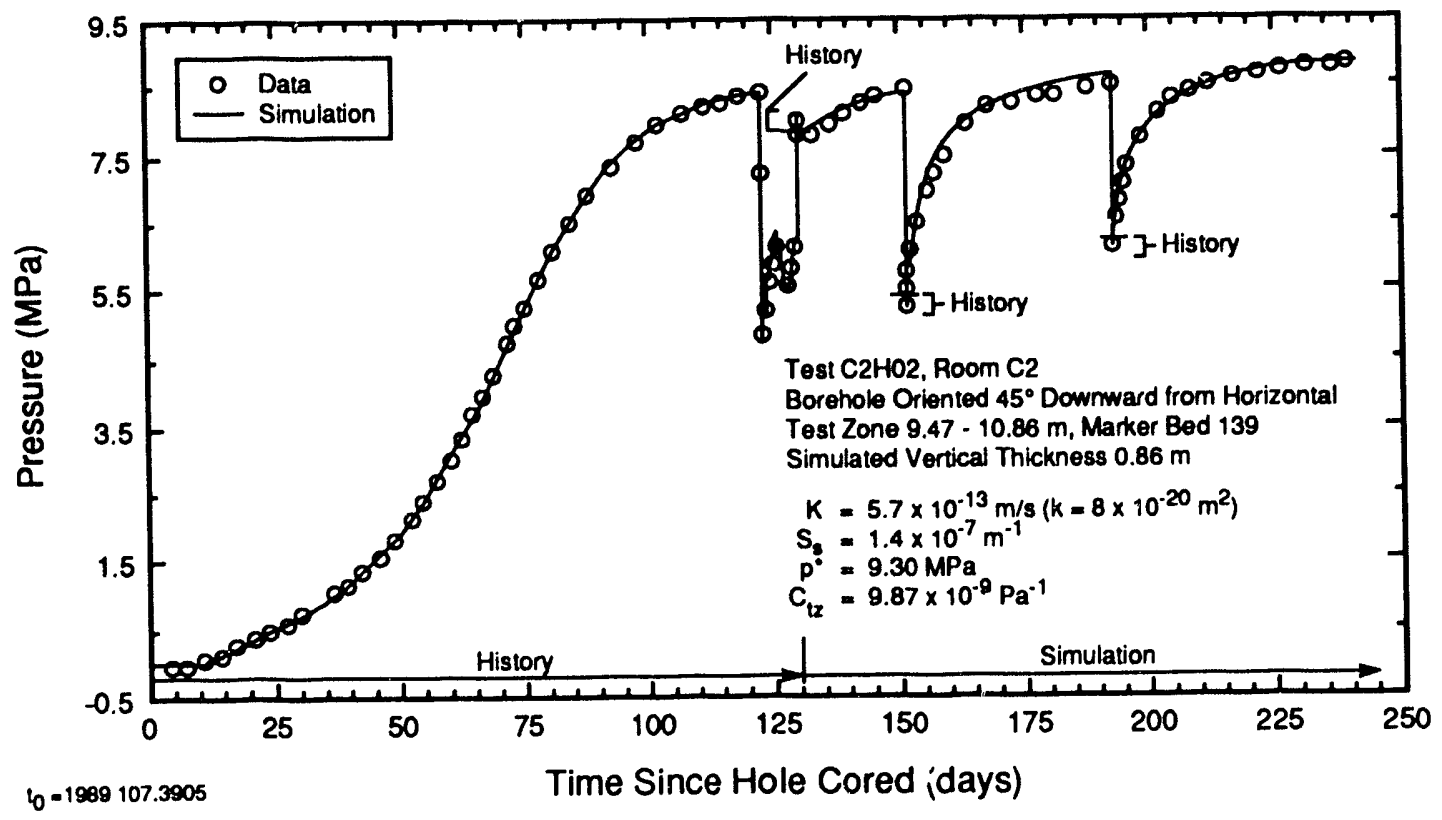

Figure 7-23. Best-Fit Model Simulation of the Test-Zone Fluid-Pressure Response During C2HO2 Testing. 
the test zone by drilling through the first minutes following the pulse injection were included as specifiedpressure history, as were the data collected during the first minutes following each pulse withdrawal. The specified parameters used to simulate the last two pulse-withdrawal tests were a formation thickness of $0.86 \mathrm{~m}$ (corresponding to the vertical thickness of only the marker bed portion of the test interval), a specific storage of $1.4 \times 10^{-7} \mathrm{~m}^{-1}$, and a test-zone compressibility of $9.87 \times 10^{-9} \mathrm{~Pa}^{-1}$. The fitted parameters were a hydraulic conductivity of $5.7 \times 10^{-13} \mathrm{~m} / \mathrm{s}$ (permeability of $8 \times 10^{-20} \mathrm{~m}^{2}$ ) and a formation pore pressure of $9.30 \mathrm{MPa}$. Additional simulations showing the sensitivity of the best-fit model to slight changes in hydraulic conductivity, formation pore pressure, specific storage, and testzone compressibility, as well as to the presence or absence of test-zone-volume compensations, are presented in Section 7.2.

The well-test-analysis model was used to examine the radius of influence of the $\mathrm{C} 2 \mathrm{H} 02$ testing, again assuming porous flow. Figure 7-24 shows the simulated pressures at different radial distances from the borehole throughout the entire testing period. The longest duration, highest magnitude response was caused by the initial open-hole and buildup periods. The simulated effects of this depressurization had propagated to a distance of about $20 \mathrm{~m}$ from the hole by the end of the monitoring period. The effects of the individual pulse tests can be seen as minor changes in the slopes of the pressure curves to a distance of at least $5 \mathrm{~m}$ from the hole. In the case of the 5-m pressure curve, these changes in slope occur a few days after the pulses. As discussed with respect to the testing of Marker Bed 139 in $\mathrm{C} 2 \mathrm{H} 01-\mathrm{C}$ (Section 7.1.3.1), the radius of influence of the $\mathrm{C} 2 \mathrm{H} 02$ tests would be greater if flow through Marker Bed 139 is confined to fractures.

7.1.4.2 Guard Zone. After first being shut in on April 24, 1989 (Calendar Day 114), the guard zone failed to pressurize as expected (Figure 7-21). The tubing from the control panel to the guard zone was replaced on May 17 (Calendar Day 137), but the guard zone still did not pressurize as expected. On June 22 (Calendar Day 173), the guard zone was vented and the guard-zone packer was deflated. Brine was circulated through the guard-zone vent and injection lines, and the packer was reinflated. After the guard zone was shut in on June 23 (Calendar Day 174), a typical pressure buildup was observed. An increase in the guard-zone-packer pressure on August 3 (Calendar Day 215) caused a slight increase in the fluid pressure in the guard zone, and the pulse withdrawal from the test zone on August 18 (Calendar Day 230) caused the guard-zone pressure to decrease slightly. Three days later, the test- and guard-zone vent valves of the test tool were inadvertently opened during preparations for the drilling of borehole $\mathrm{C} 2 \mathrm{H} 03$, causing the guard-zone pressure to decrease. After the valves were closed, the guard-zone pressure began to rise again, but at a lower rate than that observed after the June 23 shut-in. The guard-zone fluid pressure continued to rise at a relatively constant rate for the remainder of the monitoring period.

The relatively constant rate at which the guard-zone fluid pressure increased between August 22, 1989 (Calendar Day 234) and December 12, 1989 (Calendar Day 346) is anomalous (Figure 7-21). A steadily decreasing rate of pressure rise, such as that observed after the shut-in on June 23 (Calendar Day 174), is the expected response following a shut-in (Figure 4-6). Some type of equipment :ailure, perhaps a leak from the guard-zone packer (Figure D-8), may have been responsible for the observed behavior. No quantitative interpretation can be made from the fluid-pressure responses observed in the guard zone during the $\mathrm{C} 2 \mathrm{H} 02$ testing. The formation pore pressure of the guard-zone interval, however, must be greater than 3 $\mathrm{MPa}$, the highest pressure observed during the monitoring period. 


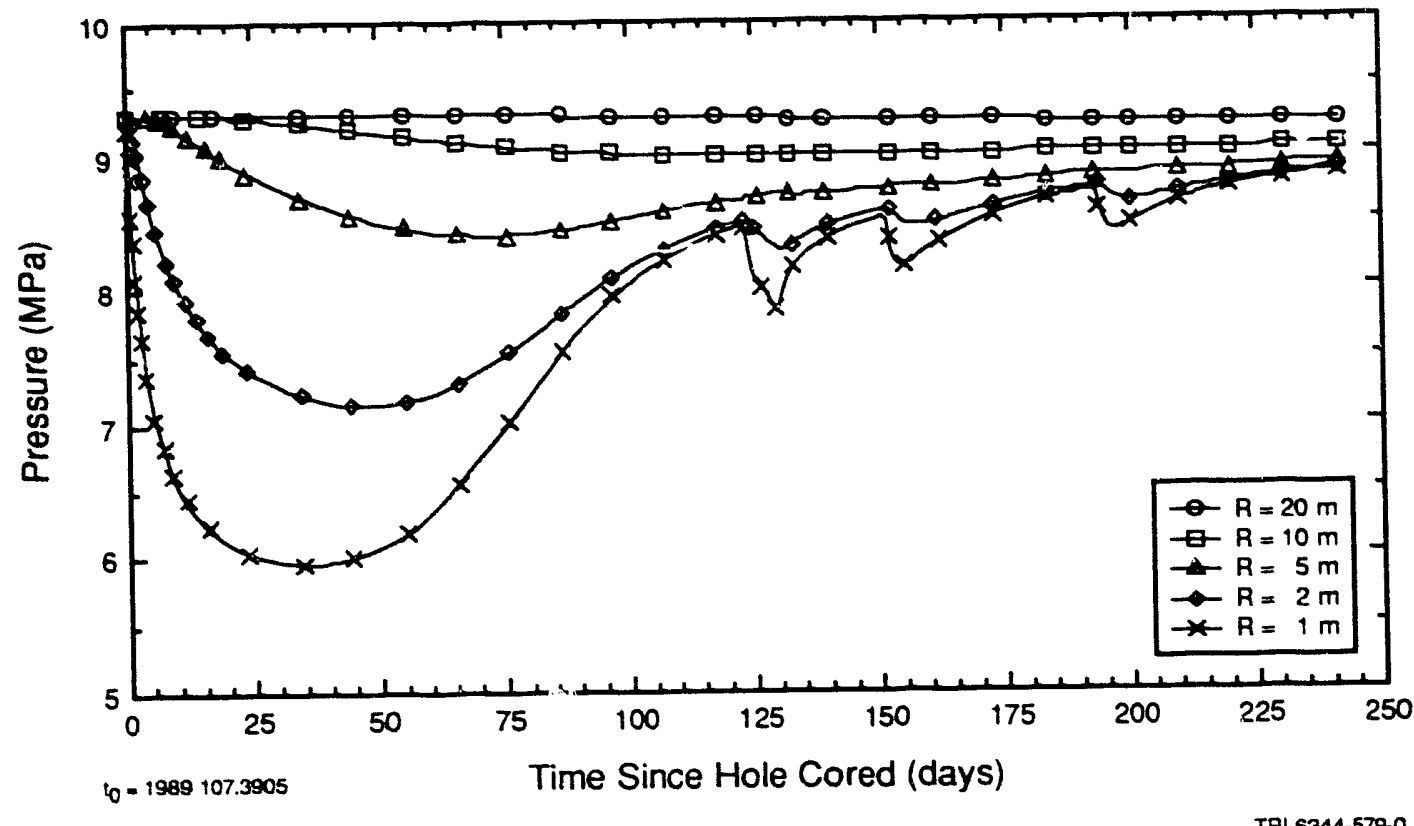

Figure 7-24. Simulated Formation: Pore Pressures at Selected Radial Distances from the Test Zone During C2HO2 Testing.

7.1.5 C2H03. Borehole $\mathrm{C} 2 \mathrm{HO}$ is a horizontal borehole drilled $2.1 \mathrm{~m}$ above the floor of Room $\mathrm{C} 2$ between anhydrites "a" and "b" on August 22 and 23, 1989 (Calendar Days 234 and 225). Figure 7-25 shows the configuration of the test tool in $\mathrm{C} 2 \mathrm{HO} 3$ as installed on August 24 and 25, 1989 (Calendar Days 236 and 237). The test zone in $\mathrm{C} 2 \mathrm{HO}$ extended from 7.76 to $9.14 \mathrm{~m}$ from the rib of the room, while the guard zone extended from 5.90 to $6.92 \mathrm{~m}$. $\mathrm{C} 2 \mathrm{H} 03$ was drilled entirely in map unit 9 , which consists of pure halite with only trace quantities of clay and polyhalite (Appendix C).

Figure 7-26 is a plot of the test- and guard-zone fluidpressure data collected by the DAS during the 30-day monitoring period following the shut in of the test and guard zones on August 29, 1989 (Calendar Day 241). Before the test and guard zones were shut in, their fluid pressures were 0.054 and $0.056 \mathrm{MPa}$, respectively. These väiues were rôt expected to te zero, bocause the hole was higher than the transducers, which were mounted outside the hole on the instrumentation trailer.
The elevation head between the hole and the transducers was calculated to be only about $0.01 \mathrm{MPa}$, however. The difference between the observed and calcuiated values probably reflects the difficulty in achie ving accurate transducer readings near the lower limit of a transducer's range rather than actual pressures or pressure differences. As the intervals were shut in, the test- and guard-zone pressures increased to 0.067 and $0.101 \mathrm{MPa}$, respectively, as the fluid in the zones was compressed slightly. After shut in, the testand gud-zone pressures were monitored for 30 days. ine zones' fluid pressures decreased slightly during the shut-in period. Because of the lack of any pressure buildup during the shut-in period, testing was ended and the test tool was removed from $\mathrm{C}_{2} \mathrm{HO}_{3}$ on September 29, 1989 (Calendar Day 272).

7.1.5.1 Test Zone. As shown on Figure 7-26, the fluid pressure in the C.2Hn3 tost zone did not increase during the 30-day shut-in period, but instead decreased by about $0.01 \mathrm{MPa}$. Testing of multipacker 
BOREHOLE: C2HO3

TEST TOOL: \#5

DATE: $08 / 28 / 89$

DEPTH OF HOLE: $9.144 \mathrm{~m}$

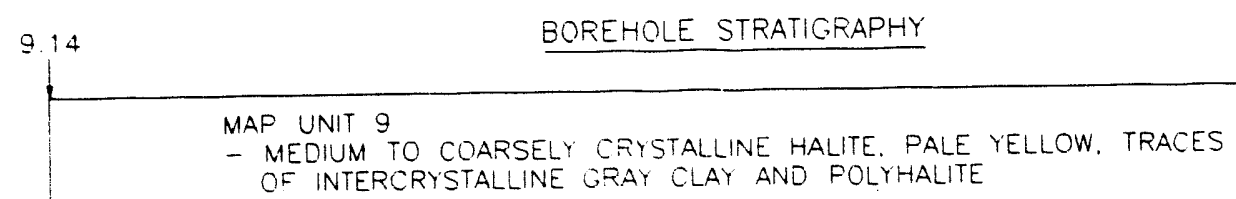

$\mathrm{C} 2 \mathrm{HO} 3$

TEST-TOOL CONFIGURATION

7.76* 6.92* $5.90 *$

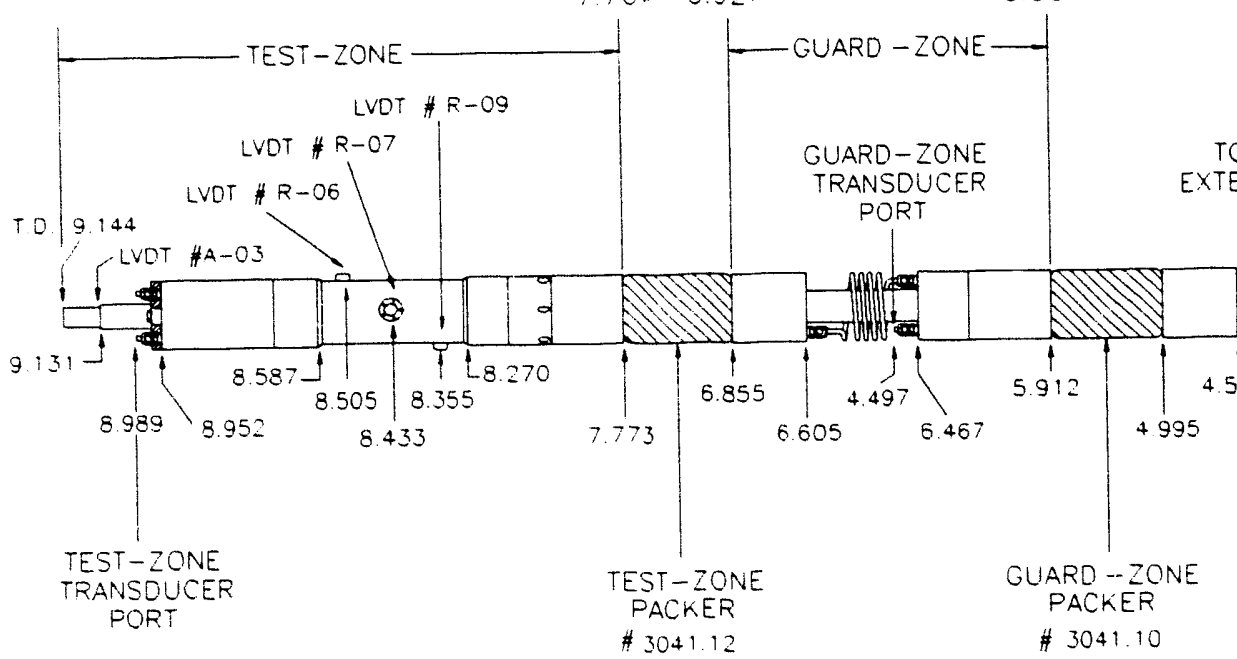

NOTE MEASUREMENTS N METERS fROM WALL BEFORE NFLATION

- estmated fustron after hiflation

Figure 7-25. Configuration of Multipacker Test Tool \#5 for Permeability Testing in Borehole C2H03. 


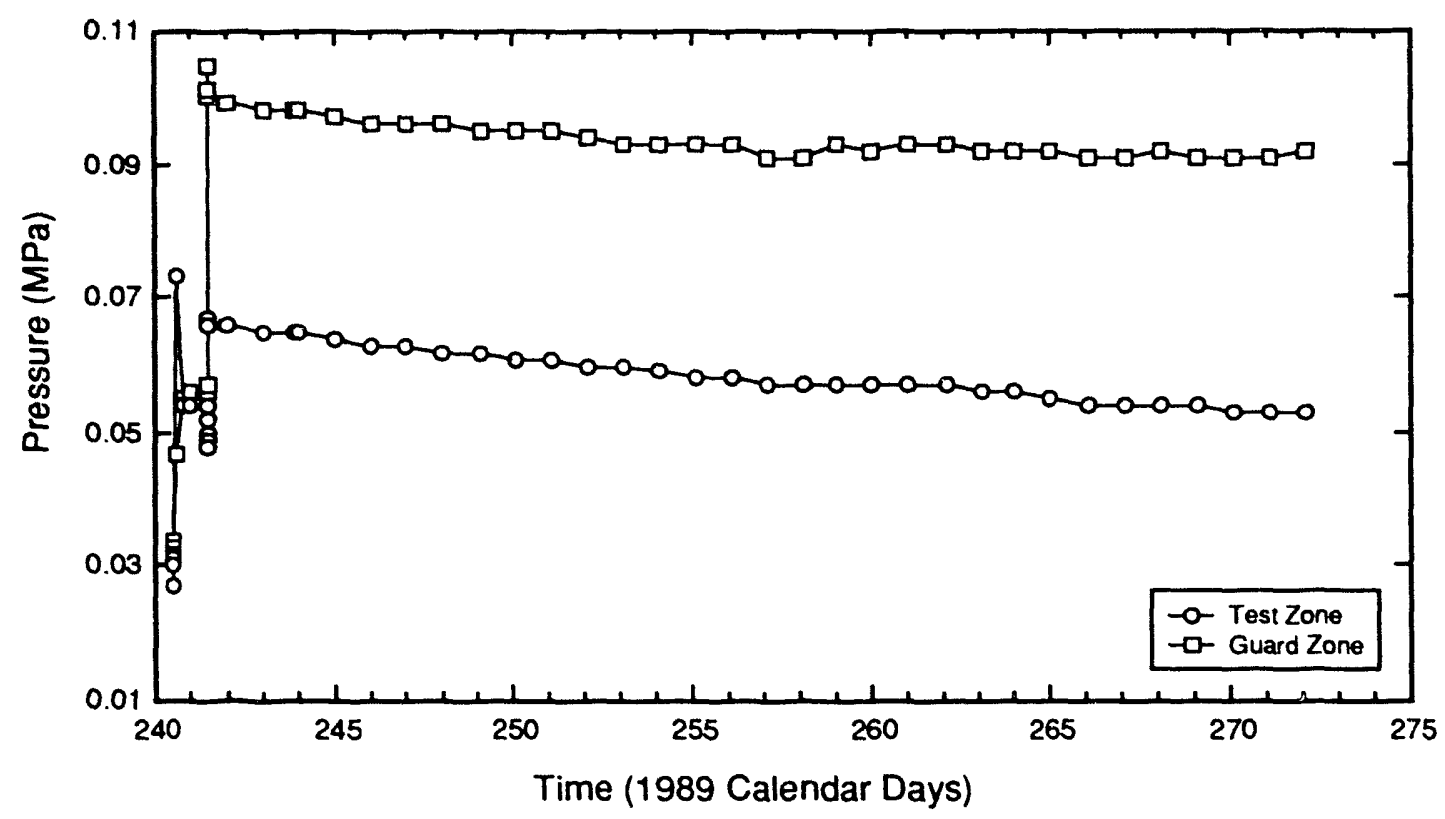

TRI-6344-580-0

Figure 7-26. Test- and Guard-Zone Fluid-Pressure Data from C2H03 Testing.

test tool \#5 before and after the $\mathrm{C} 2 \mathrm{HO}$ testing revealed no problems that could have caused the tool to fail to hold pressure during the testing. Therefore, the observed behavior is thought to be representative of the formation response to the testing conditions.

For the shut-in pressure to decrease, a combination of events would have to occur. First, the test-zone volume would have to increase slightly. This could occur in response to packer readjustment or hole elongation. Second, little or no inflow from the formation would also be required, implying very low formation permeability. Two possible conditions could explain a lack of inflow to the borehole. First, the relatively pure halite of map unit 9 may not have continuous interconnected porosity that would lead to permeability. Second, map unit 9 may have continuous interconnected porosity, but the permeability may be so low that no observable pressure response could occur on the time scale of the monitoring period. The first possibility cannot be evaluated with the available data; a much longer monitoring period and perhaps a different type of testing would be required to establish the complete absence of permeability. The second possibility can be evaluated, at least qualitatively, by considering the pressure responses that would be expected to occur given a range of permeability (hydraulic conductivity) values.

Before simulations can be performed showing what the formation response might be given different values of hydraulic conductivity, a value for test-zone compressibility must be specified. No pulse withdrawals were performed in $\mathrm{C} 2 \mathrm{HO} 3$ that would have provided data with which to evaluate test-zone compressibility, so a value must be estimated. Air may have been entrapped in $\mathrm{C}_{2} \mathrm{H} 03$ during test-tool installation because of the hole's orientation. Different procedures were followed to install the test tool in the horizontal $\mathrm{C} 2 \mathrm{H} 03$ borehole than those used in downward-angled holes. The tool was installed in the empty borehole and the guard-zone packer was inflated. The hole was 
then evacuated with a vacuum pump, after which the hole was filled with brine and the test-zone packer was inflated. Brine was then circulated through the guard and test zones using the vent and transducer lines to try to remove residual trapped air. Recent testing in transparent Lexan casing has shown these procedures to be inadequate in removing entrapped air. After following these procedures, approximately one percent of the test-zone volume and three percent of the guard-zone volume may still be occupied by air. The presence of this amount of air would make the compressibility of the test zone considerably higher than that of brine alone. The actual value of test-zone compressibility for the $\mathrm{C} 2 \mathrm{HO} 3$ testing, however, cannot be evaluated with the available data.

An upper bound on the compressibility of the test zone can be approximated by considering the compressibility of an ideal gas. The compressibility of an ideal gas is given by the inverse of the absolute pressure of the gas (Craft and Hawkins, 1959). At the start of the shutin period, the test-zone pressure in $\mathrm{C} 2 \mathrm{H} 03$ was 0.067 MPa (0.167 MPa absolute pressure). The theoretical maximum compressibility of the test zone, therefore, was $6.0 \times 10^{-6} \mathrm{~Pa}^{-1}$. This value was used to evaluate the fluid-pressure responses that might have been observed during the $\mathrm{C}_{2} \mathrm{H}_{0} 3$ testing given a range of hydraulic-conductivity values.

A suite of simulations was performed showing the responses that would have been expected during the $\mathrm{C} 2 \mathrm{HO} 3$ testing, given the test-zone compressibility presented above and a range of hydraulic conductivity values and other formation parameters. These simulations were obtained by assuming that the formation pore pressure was $11 \mathrm{MPa}$. This pressure was selected because it is approximately the highest pressure yet observed during this testing program and may, if the Salado is truly a porous medium with coniinuousiy iniercominected porosity, represent the pressure to be expected at the WIPP facility horizon in the absence of excavation-related depressurization. Presumably, if the permeability of map unit 9 is so bw as to preclude any observable pressure response during the $\mathrm{C} 2 \mathrm{HO} 3$ testing, then that same low permeability should have prevented significant depressurization at the test-zone depth from the excavation of Room C2. Specific storage for the simulations was assumed to be $9.5 \times 10^{-8} \mathrm{~m}^{-1}$. The simulations assume radial flow to the borehole, which in the case of the horizontal borehole $\mathrm{C}_{2} \mathrm{H} 03$, may be a questionable assumption. Given the lack of an observed pressurebuildup response, however, use of a more complex model designed specifically for tests in horizontal holes appears unwarranted at this time.

Figure 7-27 shows the results of these simulations. At a hydraulic conductivity $\leq 10^{-14} \mathrm{~m} / \mathrm{s}$, less than $0.01 \mathrm{MPa}$ pressure buildup would have occurred during the monitoring period. At a hydraulic conductivity of $10^{-13}$ $\mathrm{m} / \mathrm{s}$, a few hundredths of an MPa pressure increase would have been observed, while at a hydraulic conductivity of $10^{-12} \mathrm{~m} / \mathrm{s}$, the pressure would have increased by a few tenths of an MPa. If the test-zone compressibility was less than the value assumed for these simulations, then the simulations shown in Figure 7-27 would be representative of proportionally lower hydraulic conductivities. Considering that no pressure buildup at all was observed, we might conclude that the hydraulic conductivity of the relatively pure halite around $\mathrm{C} 2 \mathrm{HO} 3$ is less than $10^{-14} \mathrm{~m} / \mathrm{s}$. This may be a conservatively high upper bound on the hydraulic conductivity around $\mathrm{C} 2 \mathrm{H} 03$, considering the responses observed during testing of the $\mathrm{C} 2 \mathrm{H} 01-\mathrm{B}$ guard zone, which had an interpreted hydraulic conductivity of $1.4 \times 10^{-14} \mathrm{~m} / \mathrm{s}$ (Figure $7-14$ ).

Finiey (personal communication) has attempted to measure brine inflow to 10 -cm-diameter holes drilled horizontally into map unit 9 from Room D (see Figure 5-4). Over a monitoring period of more than three years, no observable brine inflow to the holes has been 


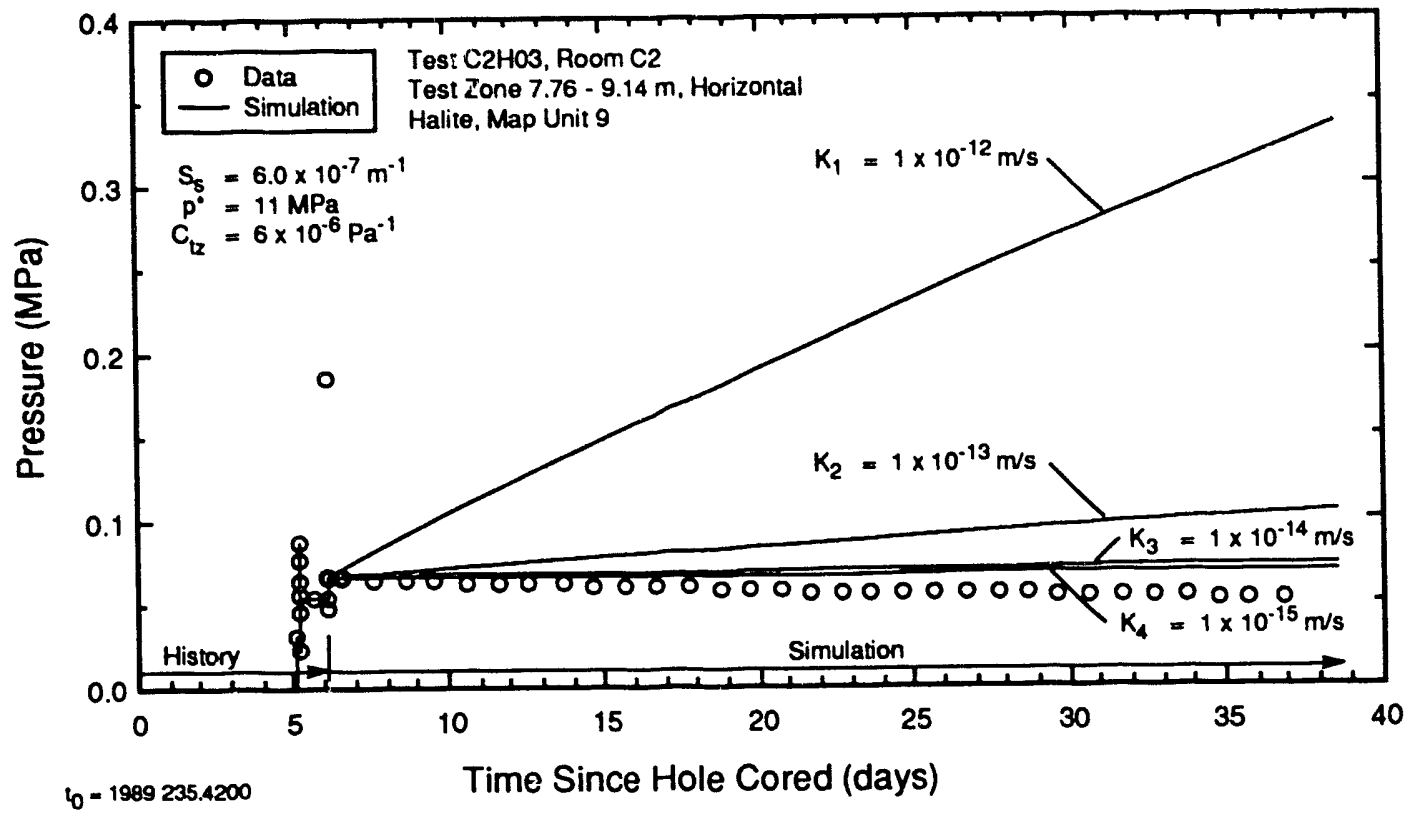

TRI-6344-581-0

Figure 7-27. Simulated Test-Zone Fluid-Pressure Response in Borehole C2H03 Using a Formation Pore Pressure of $11 \mathrm{MPa}$, a Test-Zone Compressibility of $6 \times 10^{-6} \mathrm{~Pa}^{-1}$, and Varying Hydraulic Conductivity.

detected, providing further indication of small or nonexistent permeability in the pure halite of map unit 9.

The simulations discussed above are highly speculative and are only presented in an attempt to give an upper bound on the hydraulic conductivity of relatively pure halite, based on an underlying assumption that map unit 9 has some permeability and pore pressure. When similar hydraulic behavior is encountered in future test holes, additional testing will be performed to try to address questions about the presence or absence of pore pressure and permeability more directly.

7.1.5.2 Guard Zone. Figure 7-26 shows that the fluid pressure in the guard zone of $\mathrm{C}_{2} \mathrm{H} 03$ decreased from 0.101 MPa to $0.092 \mathrm{MPa}$ during the first 15 days of the shut-in period, and was then stable for the next 15 days. The absence of a buildup response precludes any quantitative evaluation of formation hydraulic properties. The discussion and qualitative evaluation of the test-zone response presented in Section 7.1.5.1 applies equally well to the guard-zone response.

7.1.6 N4P50. Borehole N4P50 was drilled in the North 1420 drift in December 1988. One test tool was installed in December, but was removed 18 days later because of suspected problems with electrical connections. A second test tool was installed on January 6,1989 , and the test and guard zones were shut in on January 12,1989 . The test zone for both installations included anhydrite " $c$ " and clay B (Figure 7-28). The second tool had to be removed from the hole on February 6, 1989 because of construction activity nearby. Due to the length of the construction period, borehole N4P50 was later abandoned.

Figure 7-29 shows the fluid-pressure buildups observed in the test and guard zones in N4P50. The testzone data give only an indication of a relatively rapid 


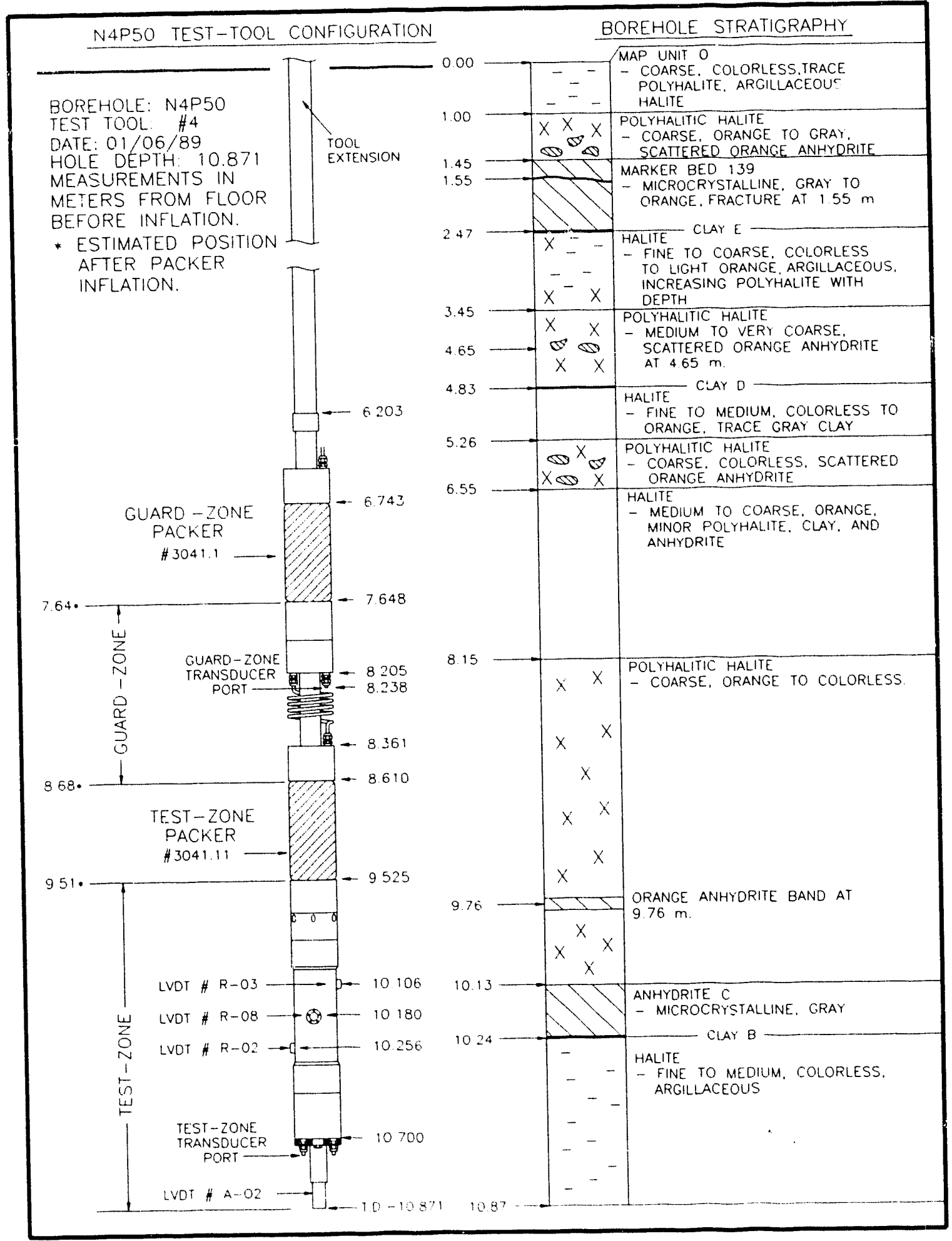

Figure 7-28. Configuration of Multipacker Test Tools $\# 3$ and $\# 4$ for Permeablilty Testing in Borehole N4P50. 


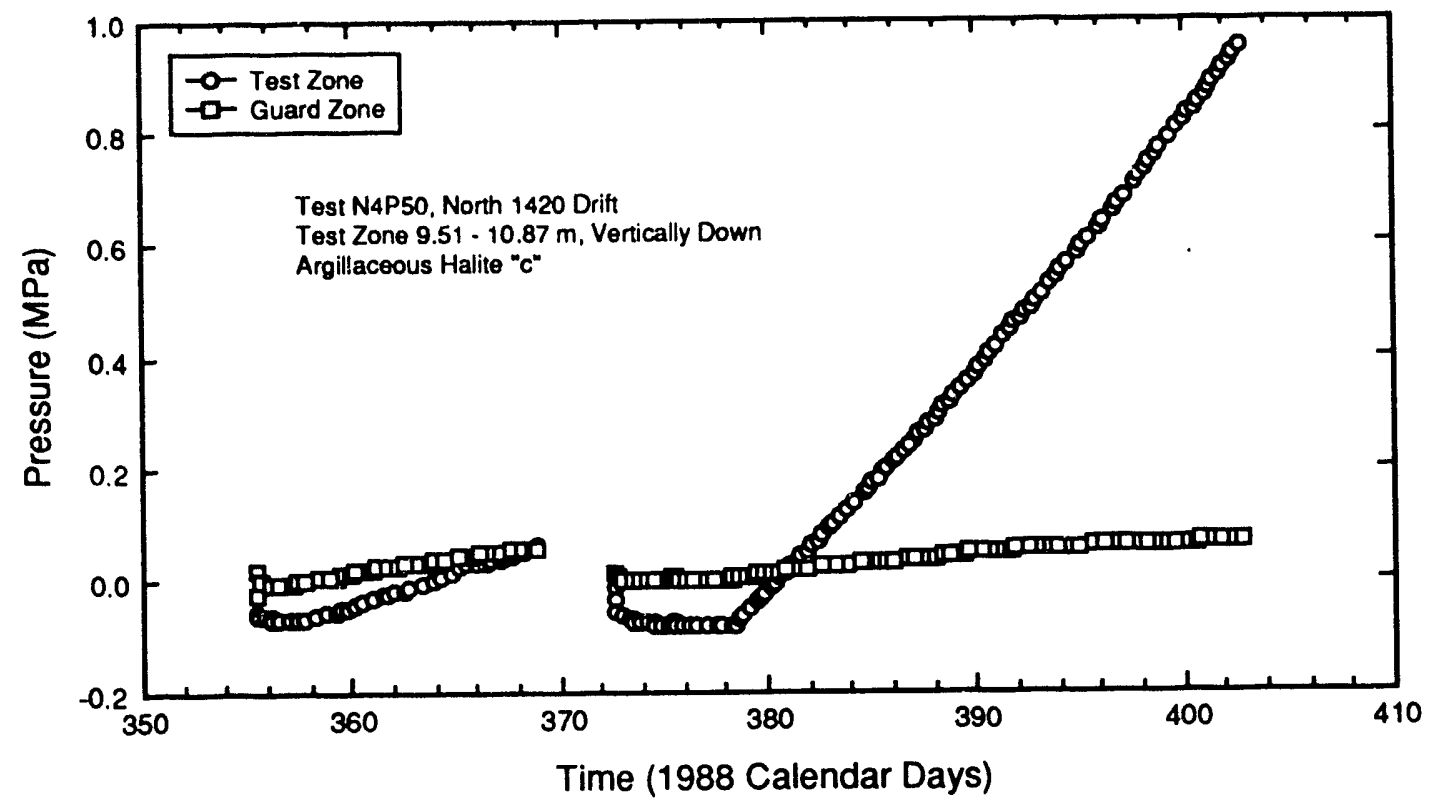

TRI-\$34-582-0

Figure 7-29. Test- and Guard-Zone Fluld-Pressure Data from N4P50 Testing.

fluid-pressure buildup following shut-in; no pressure stabilization was achieved. The guard-zone data show a slower rate of pressure rise. No pulse tests were conducted in N4P50. The available fluid-pressure data are not sufficient to allow quantitative interpretation of formation parameters.

7.1.7 L4P51-A. Borehole L4P51 was drilled ver.ically downward into the floor of Room L4 in October 1989 (Section 5.3). Because the hole was later deepened to allow testing of anhydrite "c," the testing performed with the original hole configuration is given an " $A$ " suffix. The test-tool configuration for the L4P51-A testing allowed monitoring of Marker Bed 139 in the guard zone, and underlying halite, polyhalitic halite, and clay $D$ in the test zone (Figure 7-30).

Figure 7-31 shows a plot of the fluid-pressure data from the test and guard zones collected during the L4P51-A testing. The testing sequence in the test zone consisted of an initial buildup period followed by two pulse-withdrawal tests. A constant-pressure flow test was conducted in the guard zone beginning March 1, 1990 (1989 Calendar Day 425). That test will be discussed and interpreted in a subsequent report. Interpretations of the pulse-withdrawal tests in the test zone, and discussion of the fluid pressures observed in the guard zone during those tests, are presented below.

7.1.7.1 Test Zone. The initial pressure buildup in L4P51-A produced a non-characteristic buildup curve (Figure 7-31) similar to those described for the $\mathrm{C} 2 \mathrm{H} 01-\mathrm{B}, \mathrm{C} 2 \mathrm{H} 101-\mathrm{C}$, and $\mathrm{C} 2 \mathrm{HO} 2$ test zones in Sections 7.1.2.1, 7.1.3.1, and 7.1.4.1. The same factors that could have caused the compressibility of the test zone to be dependent on pressure in those cases might also have been operative in this case, with the exception that all of the aluminum test-tool components used during earlier testing had been replaced with stainless steel components for the L4P51-A testing, thereby eliminating the pctential for gas 


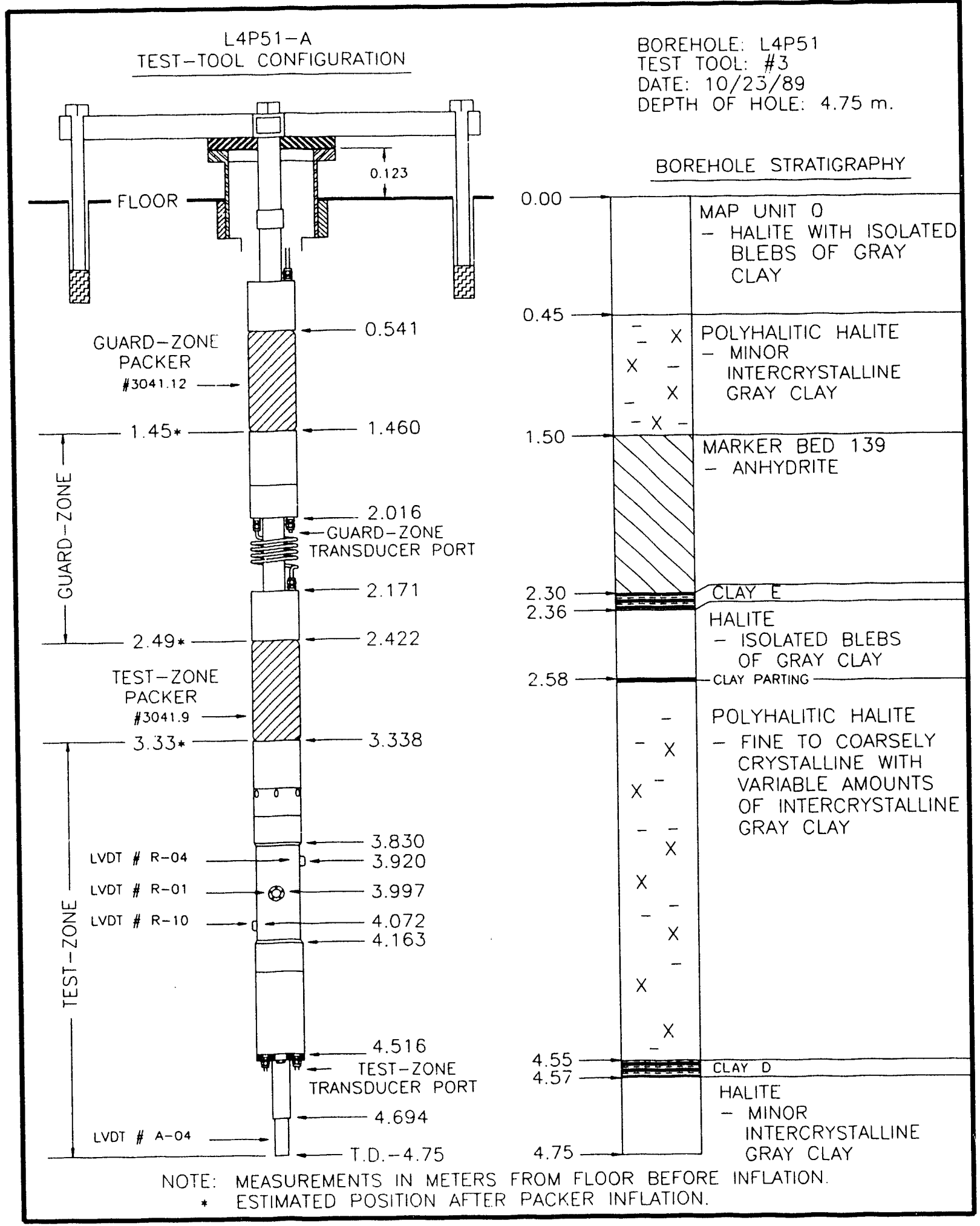

Figure 7-30. Configuration of Multipacker Test Tool \#3 in Borehole L4P51 for L4P51-A Testing. 
generation through aluminum corrosion. The testzone compressibilities calculated for the two pulse withdrawals, $7.01 \times 10^{-10}$ and $7.31 \times 10^{-10} \mathrm{~Pa}^{-1}$ (Table 6$3)$, are only slightly higher than the estimated compressibility of the test-zone brine, $3.1 \times 10^{-10} \mathrm{~Pa}^{-1}$. No free gas was observed during the pulse withdrawals, although the brine withdrawn degassed visibly in the collection vessel (Saulnier et al., 1991).

During the L4P51-A testing, each successive pressure buildup appeared to be trending towards a lower pressure than the previous buildup (Figure 7-31). This pattern of response is typically observed during depletion of a finite reservoir. Therefore, a zero-flow condition was used for the external boundary of the model for the L4P51-A simulations. The distance to this boundary was one of the parameters fitted during test interpretation.

Figure 7-32 shows the best-fit model simulation of the L4P51-A pulse-withdrawal tests along with the observed fluid-pressure data from the test zone. The data from the time of penetration of the center of the test zone by drilling to the first pulse withdrawal were included as specified-pressure history, as were the data collected during the first minutes following each pulse withdrawal. The specified parameters used to simulate the two pulse-withdrawal tests were a formation thickness of $1.42 \mathrm{~m}$, a specific storage of $1.3 \times 10^{\text {. }}$ $7 \mathrm{~m}^{-1}$, and a test-zone compressibility of $7.16 \times 10^{-10}$ $\mathrm{Pa}^{-1}$. The fitted parameters were a hydraulic conductivity of $4.5 \times 10^{-14} \mathrm{~m} / \mathrm{s}$ (permeability of $6 \times 10^{-21} \mathrm{~m}^{2}$ ), a formation pore pressure of $2.75 \mathrm{MPa}$, and a distance to the zero-flow boundary of $2.0 \mathrm{~m}$. Additional simulations showing the sensitivity of the best-fit model to slight changes in hydraulic conductivity, formation pore pressure, specific storage, test-zone compresssibility, and distance to the zero-flow boundary, as well as to the presence or absence of test-zonevolume and temperature compensations, are presented in Section 7.2.
The apparent depletion response observed during the L4P51-A testing is puzzling. No reason is known for permeability to disappear over a distance of a few meters. Therefore, other factors in addition to a zeroflow boundary that could cause an apparent depletion response during hydraulic testing should also be considered.

The rock surrounding the WIPP excavations should be continually losing pressure to the excavations. In addition, open boreholes throughout the WIPP underground facility should be causing depressurization of all strata they penetrate. Depressurization from either of these sources could, at least locally, be observable on the time scale of our testing. A continuous depressurization superimposed on the formation response to the testing could have produced a composite response similar to that observed.

In this particular case, the test zone was less than one meter below Marker Bed 139. The guard-zone-pressure monitoring during the L4P51-A testing showed that the pressure in Marker Bed 139 was only 0.2 to $0.3 \mathrm{MPa}$ (Figure 7-31). Thus, a significant pressure gradient was present between the test zone and MarkerBed 139. Flow from the interval spanned by the test zone to Marker Bed 139 could have resulted in a loss of pressure from the test-zone interval. If this process were in fact operative, however, we would expect to see a continual decline in the test-zone pressure with time as the depressurization continued. Continued monitoring of the test-zone pressure for a period of three months during testing in the guard zone showed little or no net depressurization (Figure 7-31). After recovering from the second pulse-withdrawal test to a peak pressure of $2.24 \mathrm{MPa}$, the test-zone pressure did decline slightly, to $2.18 \mathrm{MPa}$, over a period of approximately 40 days. However, the simulation indicates that the pressure decreased from 2.75 MPa when the borehole was first drilled io 


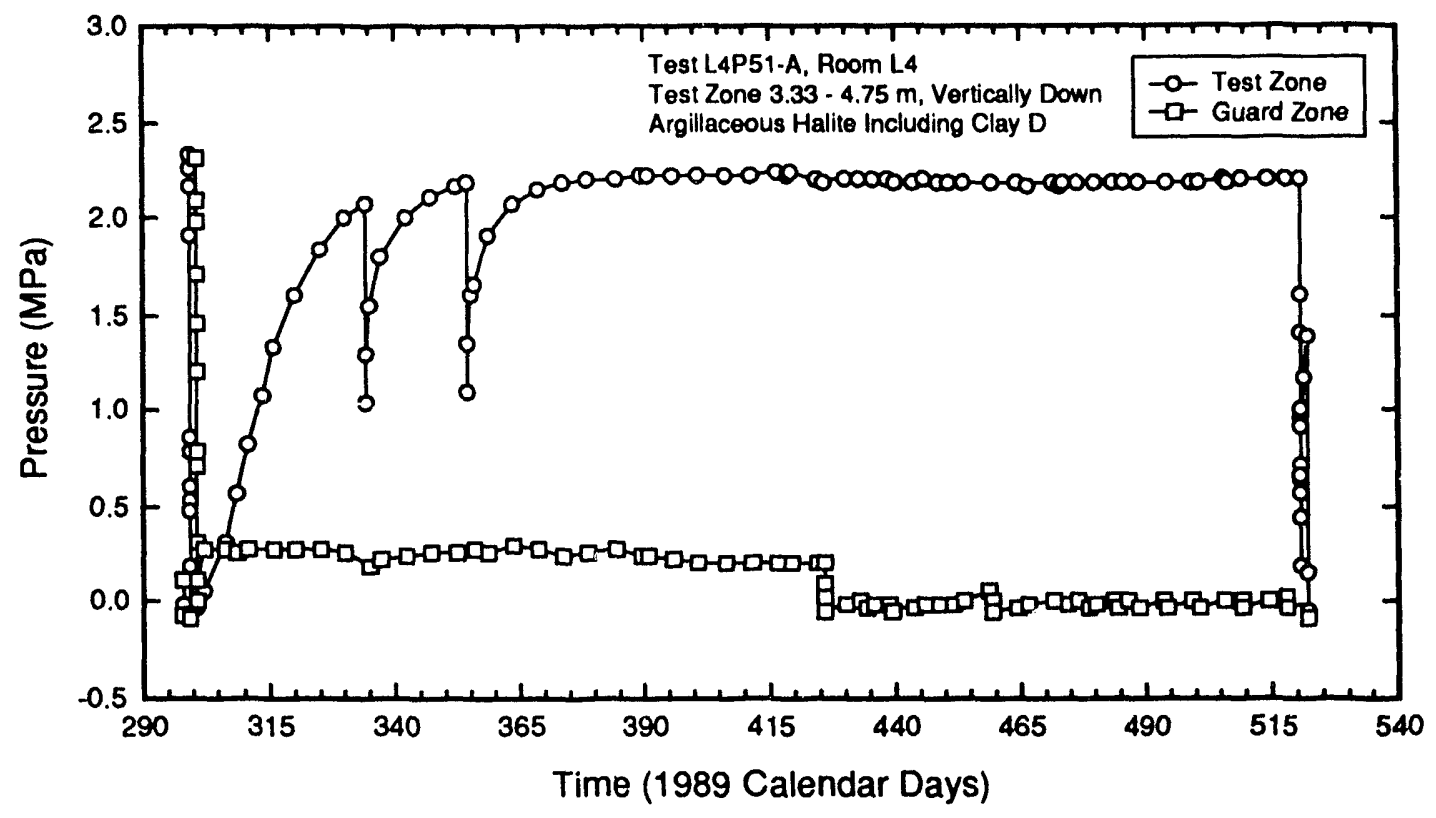

TRI.6344.583-0

Figure 7-31. Test- and Guard-Zone Fluid-Pressure Data from L4P51-A Testing.

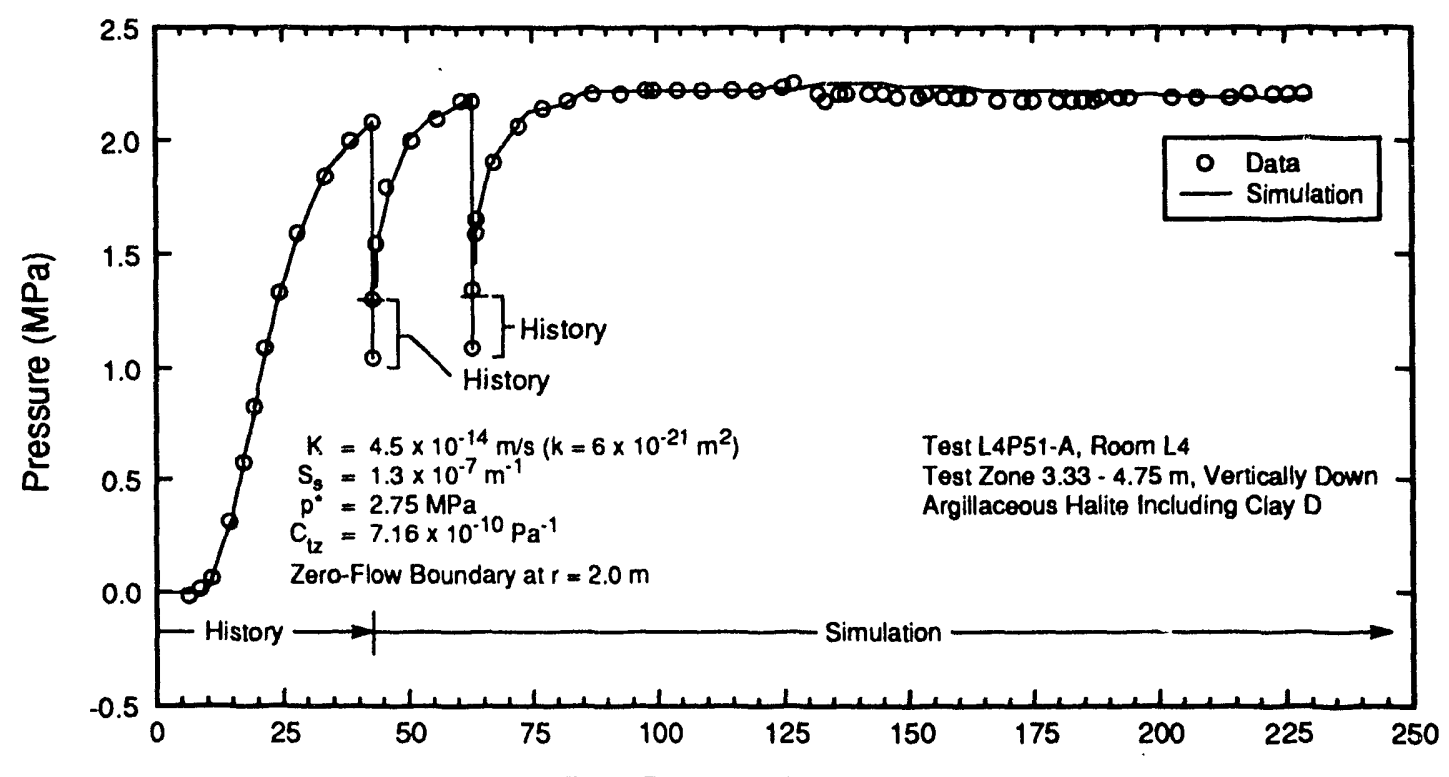

'0 - 1989291.5859

Time Since Hole Cored (days)

TRI-6344.584-0

Figure 7-32. Best-Fit Model Simulation of the Test-Zone Fluld-Pressure Response During L4P51-A Testing. 
2.24 MPa about 130 days later, when the pressure peaked following the second pulse withdrawal. If this depressurization had continued linearly for the next 40 days, the pressure would have dropped to about 2.08 MPa, not 2.18 MPa. Moreover, over the following 60 days, the test-zone pressure did not drop at all, but rose to approximately $2.21 \mathrm{MPa}$. Continuous loss of pressure from the test-zone interval to Marker Bed 139 does not, therefore, appear to be a plausible explanation for the pressure depletion observed during the L4P51-A testing.

The nearest open borehole to L4P51 is N4P50, $20 \mathrm{~m}$ away (Figure 5-1). The potential for depressurization of a test interval by leakage into a hole $20 \mathrm{~m}$ away should be much less than the potential for leakage into a relatively underpressurized stratum only one meter above the test interval. Leakage into N4F50 should also have resulted in a continuing depressurization at L4P51, which was not observed. Thus, depressurization by leakage into borehole N4P50 also does not appear to be a plausible explanation for the apparent pressure depletion of the L4P51-A test interval.

If no external pressure sink caused the pressure depletion, the cause may lie in the rock itself. The apparent zero-permeability boundary could be explained if most of the brine in communication with the hole was contained within discontinuous clay stringers. The brine in these stringers could be depleted relatively rapidly, and recharged slowly (if at all) by brine contained within halite or by brine contained w!'hin other clay stringers with low-permeability connections to those depleted. Alternatively, stress changes around a borehole could create a ring of increased permeability, surrounded by lower permeability material. In this case, the high-permeability ring could depressurize faster than the surrounding material could recharge it. If the basic concept of a finite inner permeable region surrounded by an outer region of lower (or nonexistent) permeability is correct, we should be able to obtain at least temporary pressure stabilization at successively higher levels by performing a series of pulse injections on the interval. This procedure will be attempted at the next opportunity.

The rise in the test-zone fluid pressure observed over the last 50 to 60 days of monitoring could have been caused by either or both of two factors. First, the pressure rise could have been caused by borehole closure compressing the fluid in the test zone. Problems with O-ring compression (see Section D.2 of Appendix $D$ ) rendered the radial LVDT data from L4P51-A unreliable in evaluating borehole deformation early in the testing period, but the late-time closure indicated by the LVDTs (Figure D-2) is believed to be at least qualitatively reliable. Second, the fluid pressure could have increased due to slow recharge of the depleted volume of rock from surrounding lower permeability material.

7.1.7.2 Guard Zone. The guard zone during the L4P51-A testing included Marker Bed 139, clay E, and a few centimeters of halite above and below (Figure 7-30). After the guard zone was shut in on October 27, 1989 (Calendar Day 300), the fluid pressure stabilized quickly at about $0.28 \mathrm{MPa}$. The guardzone pressure decreased slowly during the testing in the test zone, reaching about $0.20 \mathrm{MPa}$ on March 1 , 1990 (1989 Calendar Day 425). On that date, a constant-pressure flow test was initiated in the guard zone. That test will be discussed and interpreted in a subsequent report.

Fluid pressures of up to $10 \mathrm{MPa}$ have been observed in Marker Bed 139 at other locations where the marker bed is farther removed from the excavations than in Room L4 (boreholes $\mathrm{C} 2 \mathrm{H} 01$ and $\mathrm{C} 2 \mathrm{H} 02$, and Peterson et ai. [1987]). The low observed pressure in L4P51 of only $0.28 \mathrm{MPa}$ and subsequent decrease may be 
related to a general and on-going depressurization of Marker Bed 139 under the room, possibly through fractures developing in the DRZ around the room.

7.1.8 SOP01. Borehole SOPO1 was drilled vertically downward in the floor of the South 1300 drift. Figure 733 shows the configuration of the test tool in S0P01 and indicates the lengths and stratigraphic locations of the guard and test zones. The test zone included halite and polyhalitic halite underlying Marker Bed 139 and clay D. At this location, clay $D$ is approximately one $\mathrm{cm}$ thick (Appendix C). The guard zone included all but the upper few centimeters of Marker Bed 139, and a few centimeters of the underlying halite.

Figure 7-34 is a plot of the test- and guard-zone fluidpressure data collected by the DAS during the monitoring period. The testing sequence in the test zone consisted of an initial buildup period fo "iowed by two pulse-withdrawal tests. Following tie second pulsewithdrawal test, the pressure in the test-zone was decreased during a gas-sampling exercise (Saulnier et al., 1991). Monitoring was terminated 11 days later. A pulse-withdrawal test was also attempted in the guard zone. Interpretations of the tests performed in S0P01 are presented below.

7.1.8.1 Test Zone. During both SOP01 pulse withdrawals, unknown quantities of gas were produced along with brine. Test-zone compressibilities were calculated only on the basis of the volumes of brine removed. The test-zone compressibilities calculated from the first and second pulse-withdrawal data were $1.47 \times 10^{-8}$ and $1.96 \times 10^{-8} \mathrm{~Pa}^{-1}$, respectively (Table 6-3). These values are nearly two orders of magnitude higher than the compressibility of brine, probably reflecting the presence of gas in the lost zone. The test tool used in SOP01 had aluminum components, which were found to be severely corroded when the tool was removed from the hole at the end of testing. Thus, as was the case in $\mathrm{C} 2 \mathrm{HO} 2$ (Section 7.1.4.1), hydrogen gas was probably generated as the corrosion occurred.

Figure 7-35 shows the best-fit model simulation of the SOP01 test response. Only the data from the time of drilling to the initial shut-in nine days later, as well as the data collected during the first minutes following the pulse withdrawals, were included as specified-pressure history. Because the initial buildup occurred at a continually decreasing rate similar to the ideal behavior shown on Figure 4-6, both the buildup and the recoveries from the pulse withdrawals were simulated. The simulation matches the observed data from the initial buildup period and from the second pulse-withdrawal test reasonably well, but deviates from the first pulse-withdrawal test data. During the first pulsewithdrawal test, a typical decreasing-slope curvature was observed for approximately the first 29 days of the test, followed by a relatively abrupt increase in slope. The reason for this change in behavior is unknown. Little weight was given, therefore, to the match between the data and the simulation of the first pulsewithdrawal test when determining the best-fit parameters.

The specified parameters for the simulation were a formation thickness of $1.43 \mathrm{~m}$, a specific storage of $1.1 \times 10^{-7} \mathrm{~m}^{-1}$, and a test-zone compressibility of $1.70 \times 10^{-8} \mathrm{~Pa}^{-1}$. The fitted parameters were a hydraulic conductivity of $6.1 \times 10^{-14} \mathrm{~m} / \mathrm{s}$ (permeabilitv of $8 \times 10^{-21} \mathrm{~m}^{2}$ ) and a formation pore pressure of 4.45 MPa. Additional simulations showing the sensitivity of the best-fit model to slight changes in hydraulic conductivity, formation pore pressure, specific storage, and test-zone compressibility, as well as to the presence or absence of test-zone-volume compensations and temperature compensations, are presented in Section 7.2. 


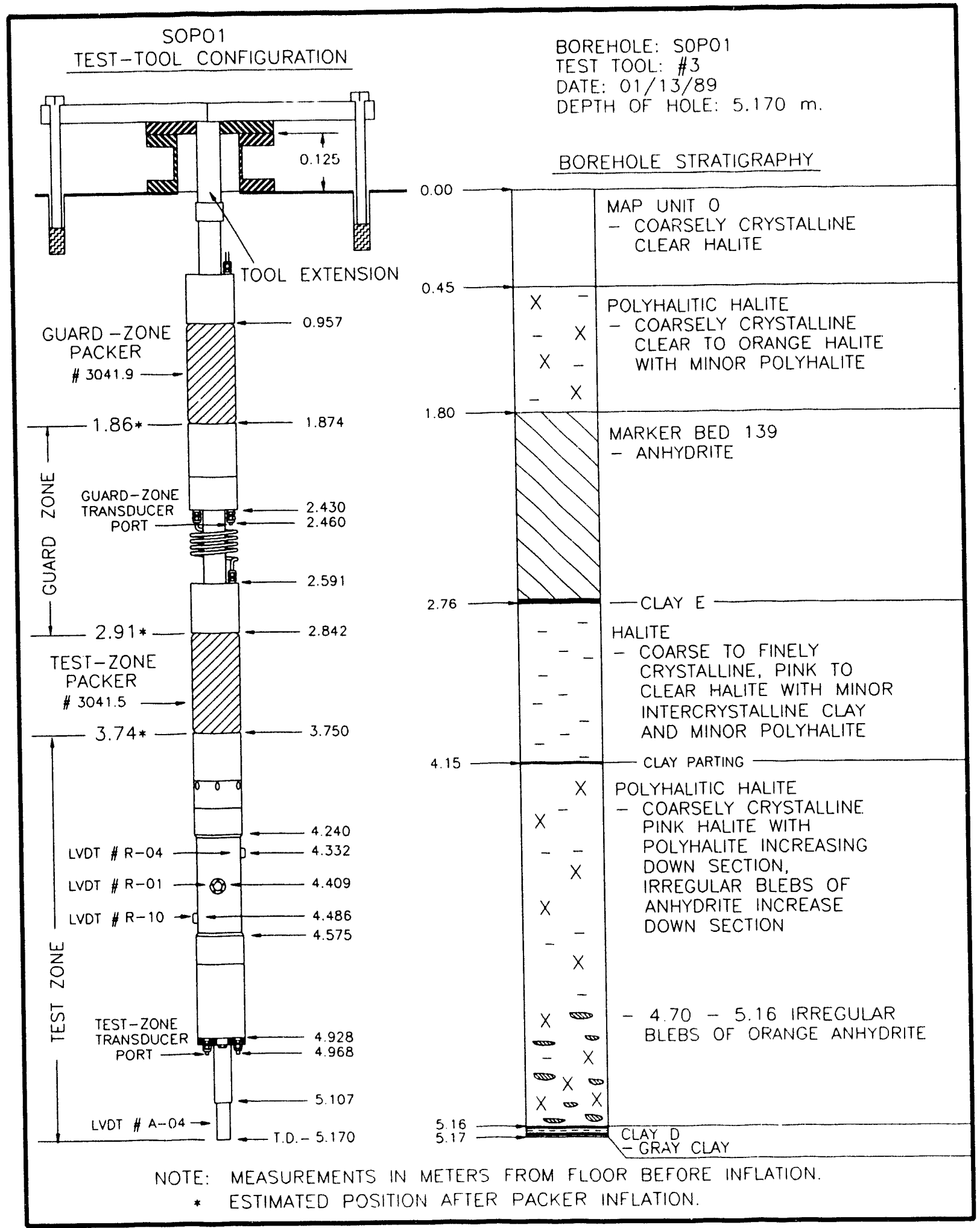

Figure 7-33. Configuration of Multipacker Test TCOl \#3 for Permeability Testing in Borehole SOP01. 


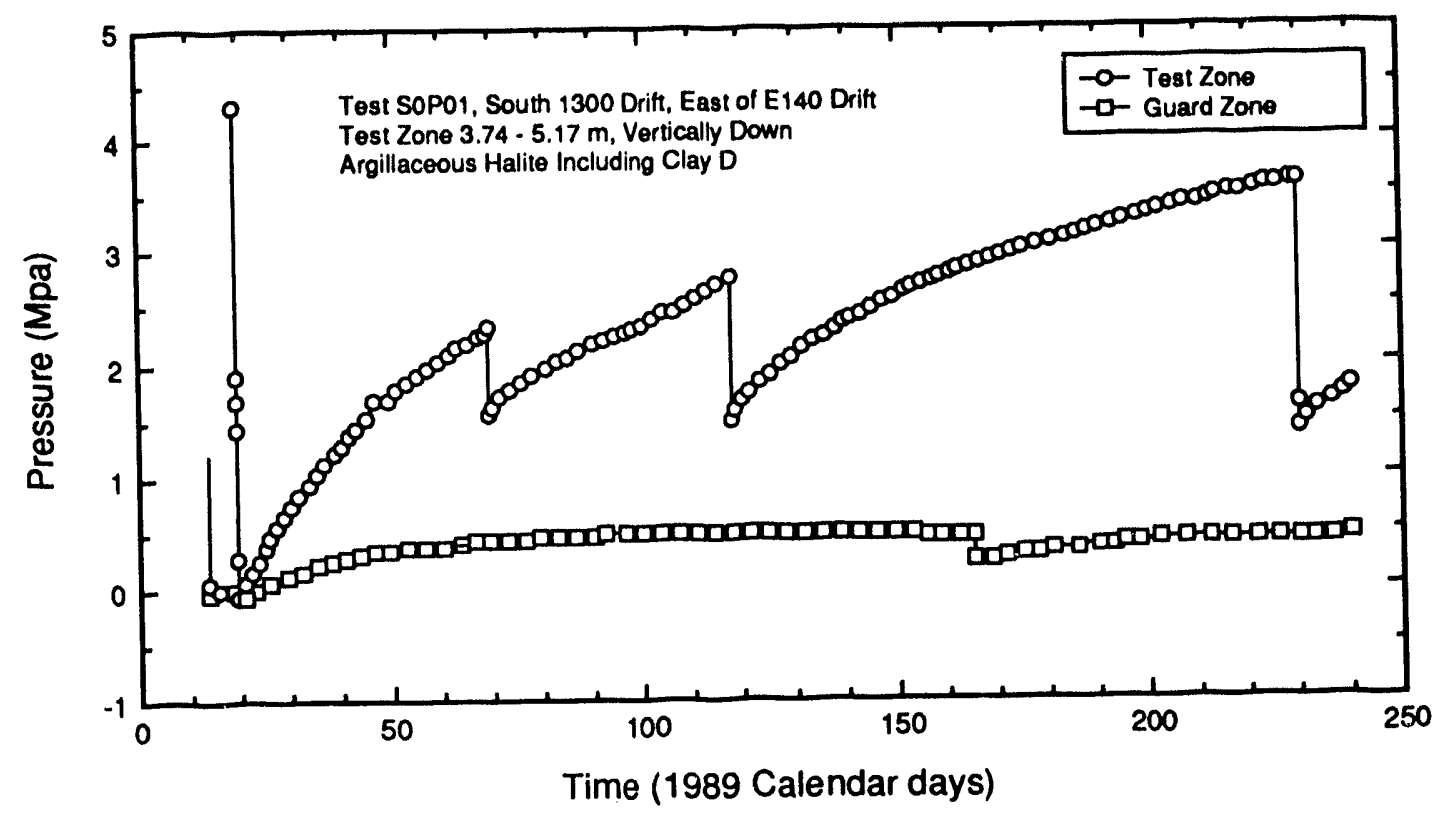

TRI-6394-585-0

Figure 7-34. Test- and Guard-Zone Fluld-Pressure Data from SOPO1 Testing.

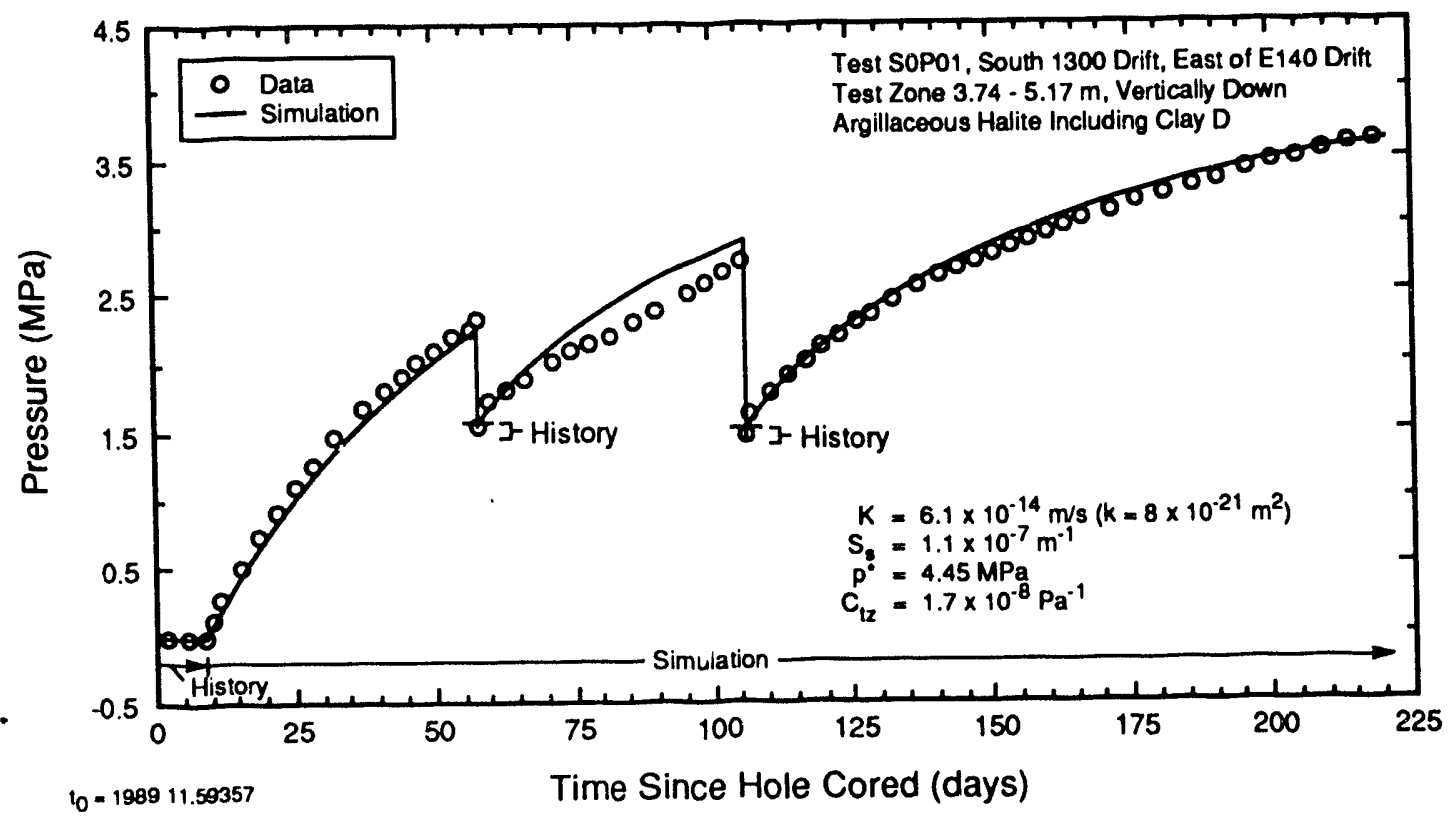

Figure 7-35. Best-Fit Model Simulation of the Test-Zone Fluld-Pressure Response During SOP01 Testing. 
The well-test-analysis model was used to examine the radius of influence of the SOP01 testing. Figure 7-36 shows simulated pressures at different radial distances from the borehole throughout the entire testing period. The longest duration, highest magnitude response was caused by the initial open-hole and buildup periods. The simulated effects of this depressurization had propagated to a distance of more than $8 \mathrm{~m}$ from the hole by the end of the monitoring period. The effects of the individual pulse tests can be seen as minor changes in the slopes of the pressure curves to a distance of at least $2 \mathrm{~m}$ from the hole. In the case of the 2-m pressure curve, these changes in slope occur 5 to 10 days after the pulses.

7.1.8.2 Guard Zone. The fluid pressures measured in the guard zone (Marker Bed 139) during the SOPO1 testing are shown plotted in Figure 7-37. The initial buildup period was followed by a pulsewithdrawal test. The behavior shown is anomalous in the sense that the pressure-recovery curves exhibit relatively abrupt decreases in slope, causing flattening of the curves. During the initial buildup period, the fluid pressure appeared to stabilize at about $0.49 \mathrm{MPa}$, and then dropped to about $0.46 \mathrm{MPa}$ for an unknown reason. Following the pulse withdrawal, the fluid pressure rose and stabilized at about $0.44 \mathrm{MPa}$ for several waeks before starting to rise again.

The pulse-withdrawal period for the SOP01 guardzone test lasted about seven minutes (Saulnier et al., 1991). During the first two minutes, $7.3 \mathrm{~cm}^{3}$ of brine were withdrawn, but little or no pressure decrease was noted. During the next five minutes, only an unmeasured amount of gas was produced, and the pressure dropped from 0.46 to $0.23 \mathrm{MPa}$. When the test tool was removed from the hole at the end of testing, the aluminum mandrel within the guard zone was found to be severely corroded. Thus, the gas observed may have been largely hydrogen, as was observed in $\mathrm{C} 2 \mathrm{HO} 2$ (Section 7.1.4.1).

Data are not available to allow calculation of the guardzone compressibility at the time of the pulse withdrawal. The guard-zone compressibility also likely changed during the testing period, as gas was generated by corrosion of aluminum. As a result of this uncertainty in the guard-zone compressibility, no definitive interpretation can be made of the test data. Simulations of the test can be performed, however, using a theoretical maximum value of guard-zone compressibility. The hydraulic conductivity estimated from these simulations should represent an upper bound on the actual value. The theoretical maximum compressibility of the SOP01 guard zone is the compressibility of an idea! gas at the pressure measured in the guard zone. The compressibility of an ideal gas is given by the inverse of the absolute pressure of the gas (Craft and Hawkins, 1959). At the end of the pulse withdrawal, the guard-zone pressure in SOP01 was $0.23 \mathrm{MPa}(0.33 \mathrm{MPa}$ absolute pressure). The theoretical maximum compressibility of the guard zone, therefore, was $3.0 \times 10^{-6} \mathrm{~Pa}^{-1}$.

Figure 7-37 shows a simulation of the SOP01 guardzone test response using the guard-zone compressibility value determined above. The data from the time of penetration of the midpoint of the guard zone by drilling through the first minutes of the buildup period were included as specified-pressure history, as were the data collected when the pressure decreased for an unknown reason near the end of the buildup period. The data collected during the first $15 \mathrm{hr}$ after the pulse withdrawal, when little pressure buildup was observed, were also included as specified-pressure history in the simulations. In addition to the specified guard-zone compressibility, the simulation used specified values of $0.90 \mathrm{~m}$ for formation 


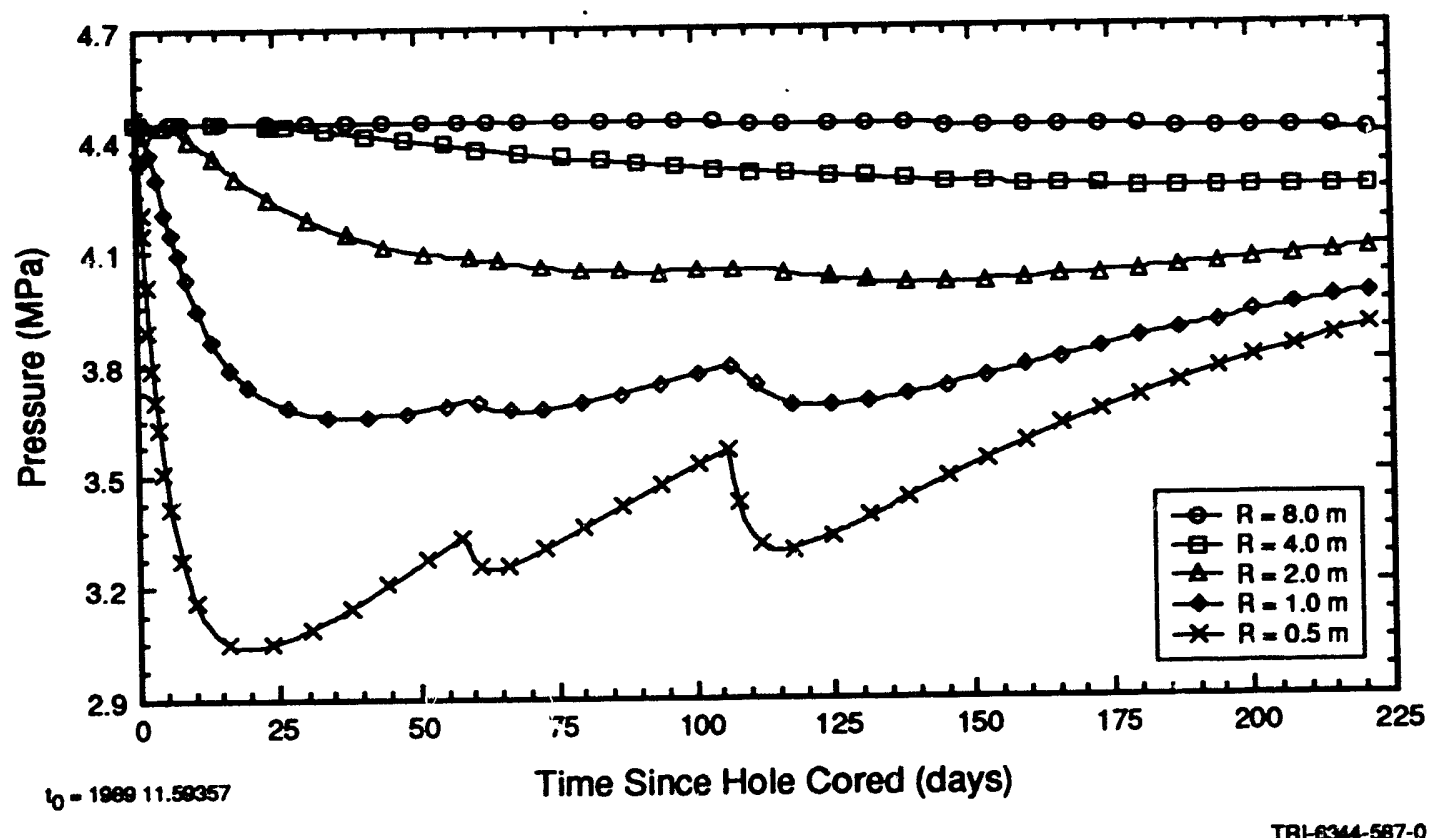

Figure 7-36. Simulated Formation Pore Pressures at Selected Radial Distances from the Test Zone During SOP01 Testing.

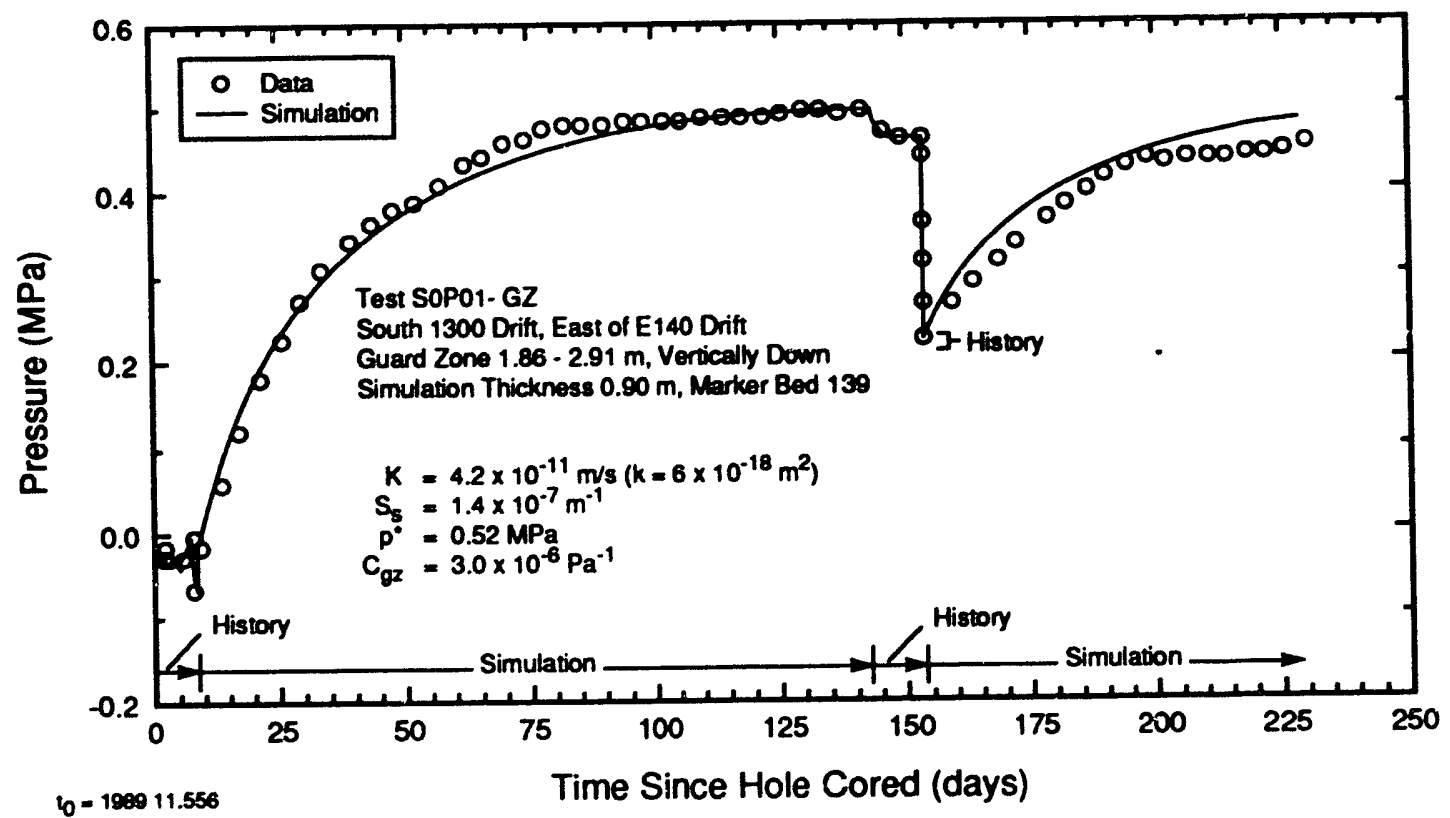

Figure 7-37. Best-Fit Model Simulation of the Guard-Zone Fluid-Pressure Response During SOP01 Testing. 
thickness and $1.4 \times 10^{-7} \mathrm{~m}^{-1}$ for specific storage. The fitted parameters were a hydraulic conductivity of $4.2 \times 10^{-11} \mathrm{~m} / \mathrm{s}$ (permeability of $6 \times 10^{-18} \mathrm{~m}^{2}$ ) and a formation pore pressure of $0.52 \mathrm{MPa}$.

As discussed above, the compressibility of the guard zone probably increased during the SOPO1 testing as hydrogen gas was generated by corrosion. Other gas may have exsolved from the formation brine or been supplied from the formation as an already separate phase during the testing. Thus, the assumption that the guard-zone compressibility could be represented by the compressibility of an ideal gas may have become increasingly valid as the test duration increased. However, the simulation shown in Figure 7-37 matches the observed data better during the initial shut-in buildup period than after the pulse withdrawal. Following the pulse withdrawal, the fluid pressure in the guario zone recovered relatively slowly compared to the rate at which it recovered following the initial shut in. The initial recovery following the pulse withdrawal was particularly slow, as little or no pressure increase was observed for 15 to $20 \mathrm{hr}$. Even after incorporating the first $15 \mathrm{hr}$ after the puise withdrawal as specifiedpressure history, the simulation still predicts a recovery faster than that observed. The curvature of the plot of the observed recovery data also differs from that predicted by the simulation, indicating that the model does not incorporate all of the processes actually acting on the guard zone.

In summary, the simulation of the SOP01 guard-zone test response was not completely successful. The interpreted hydraulic conductivity, $4.2 \times 10^{-11} \mathrm{~m} / \mathrm{s}$, may be reliable as an upper bound on the actual hydraulic . onductivity, but uncertainties remain about the role that gas generation and/or flow may have played in producing the observed fluid-pressure response. No interpretation was made of the possible radius of influence of the SOP01 guard-zone testing because it was considered to be too speculative in light of the uncertainties associated with the tests.

7.1.9 S1P71-A. Borehole S1P71 was drilled vertically downward into the floor of Room 7 in Waste Panel 1 in a depth of $4.55 \mathrm{~m}$ in November 1988 (Section 5.5). Because the hole was later deepened to allow additional testing, the testing performed with the original hole configuration is given an " $A$ " suffix. Figure 7-38 shows the configuration of the test tool in S1P71 during the S1P71-A testing and indicates the lengths and stratigraphic locations of the guard and test zones. The guard zone encompassed Marker Bed 139 and a few centimeters of the overtying halite, while the test zone included halite and polyhalitic halite below Marker Bed 139, as well as clay D.

Figure 7-39 is a plot of the test- and guard-zone fluidpressure data collected during the monitoring period. After achieving a successful pressure-tight test-tool installation on the third try (Saulnier et al., 1991), the testing sequence consisted of an initial pressurebuildup period followed by two pulse-withdrawal tests in the test zone. No pressure buildup was observed in the guard zone during the entire monitoring period. Two pulse-injection tests were attempted in the guard zone, but in both cases the induced pressure dissipated cormpletely as soon as the guard zone was shut in.

7.1.9.1 Test Zone. During the S1P71-A testing, each successive pressure buildup appeared to be trending towards a lower pressure than the previous buildup (Figure 7-39), similar to the behavior observed at L4P51-A (see Section 7.1.7.1). Therefore, a zero-flow condition was used for the external boundary of the model during the S1P71-A simulations. The distance to this boundary was one of the parameters fitted during test interpretation. 


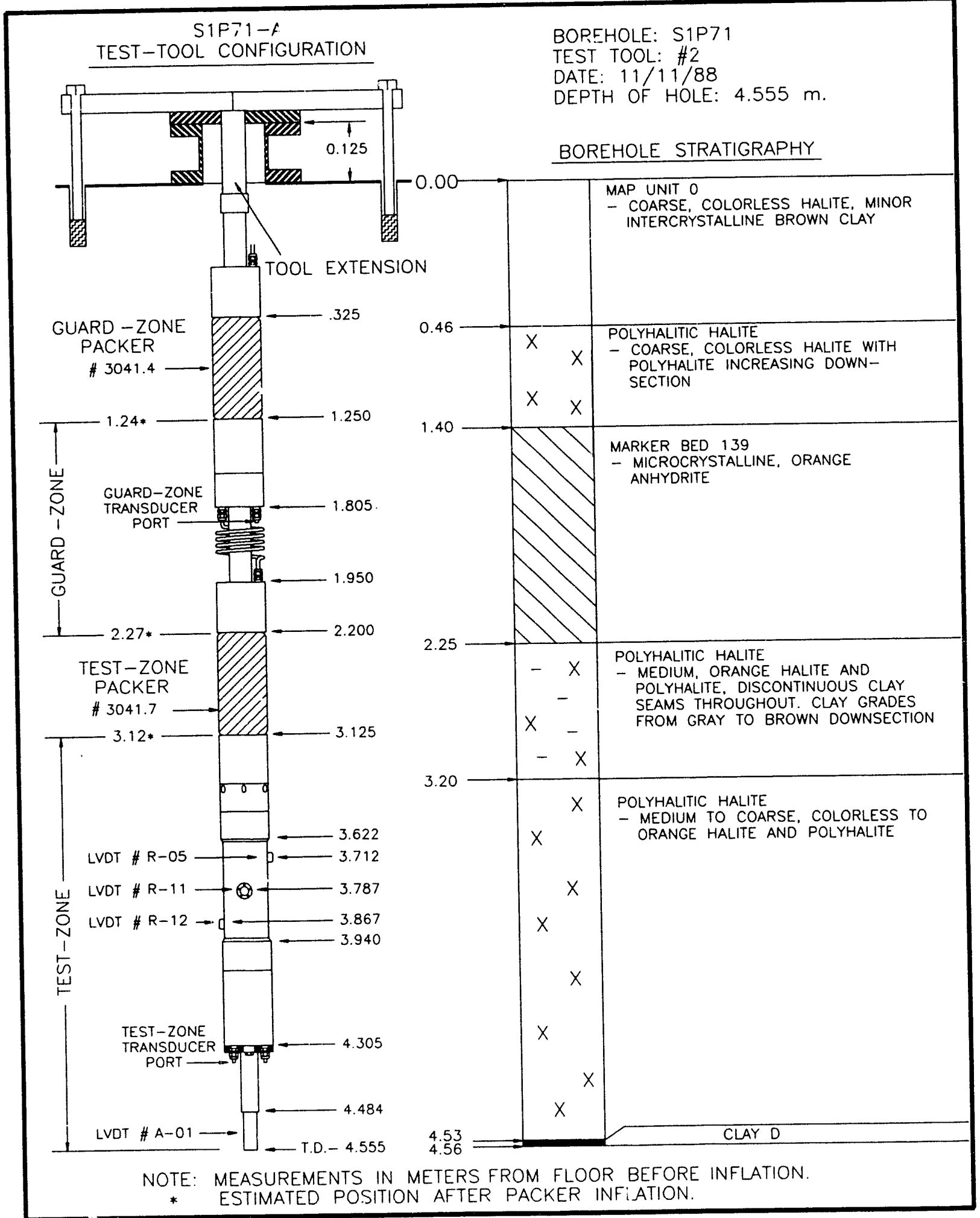

Figure 7-38. Configuration of Multipacker Test Tool \#2 in Borehole S1P71 for S1P71-A Testing. 


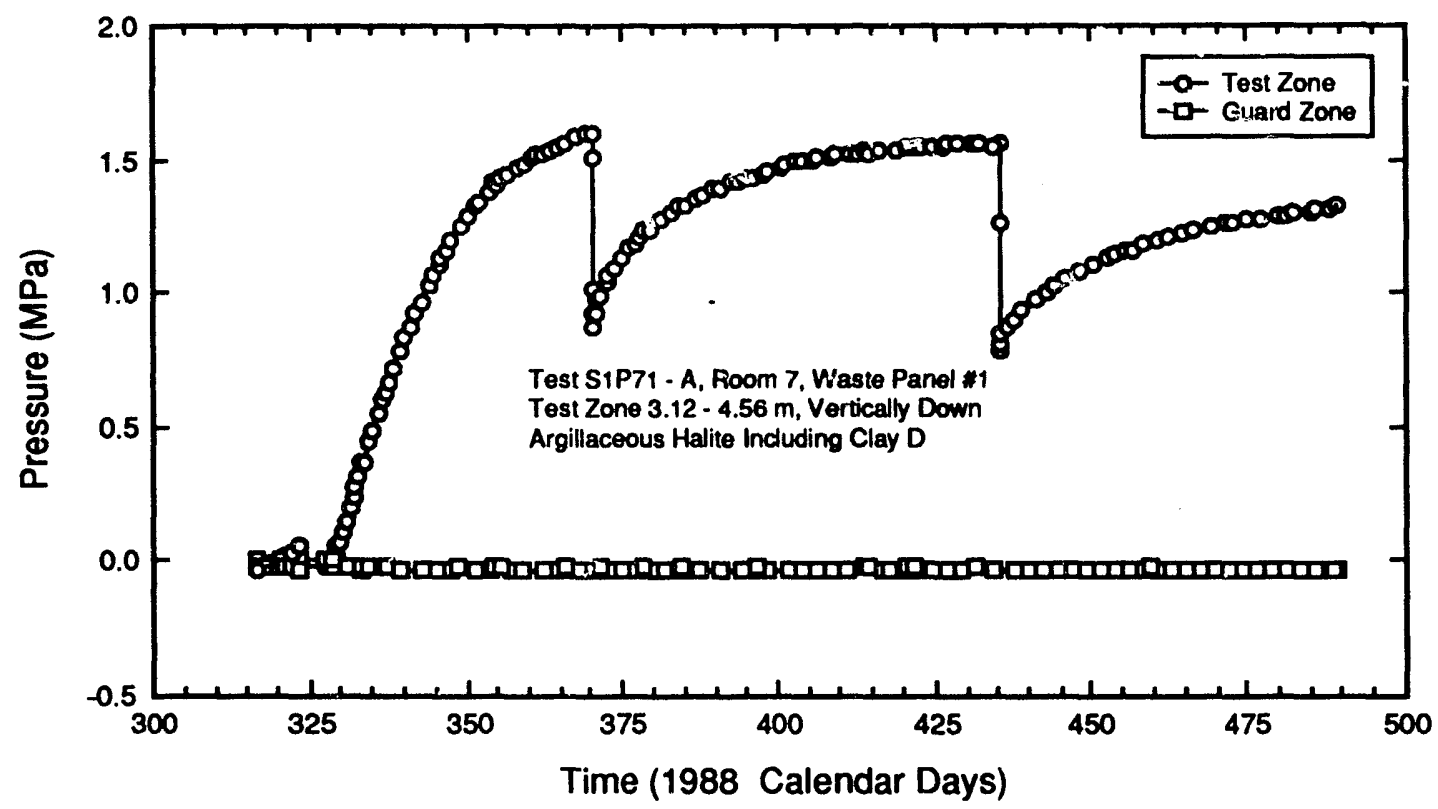

TRI-6344-589-0

Figure 7-39. Test- and Guard-Zone Fluld-Pressure Data from S1P71-A Testing.

Even though the test-zone compressibilities calculated from the first and second pulse-withdrawal data were high $\left(2.89 \times 10^{-8} \mathrm{~Pa}^{-1}\right.$ and $5.31 \times 10^{-8} \mathrm{~Pa}^{-1}$, Table 6$3)$, the pressure buildup following the initial shut in displayed the ideal decreasing-rate behavior shown in Figure 4-6. Therefore, the initial buildup period was simulated along with the puls?-withdrawal tests, rather than being included as a period of specified-pressure history.

Figure 7-40 shows the best-fit model simulation of the S1P71-A pulse-withdrawal tests along with the observed fluid-pressure data froril the test zone. The data from the time of penetration of the midpoint of the test zone by drilling to the shut in for the initial buildup period were included as specified-pressure history, as were the data collected during the first minutes following the pulse withdrawals. The buildup period and two pulse-withdrawal tests were simulated using a specified formation thickness of $1.44 \mathrm{~m}$, a specific storage of $1.5 \times 10^{-7} \mathrm{~m}^{-1}$, and a test-zone compressibility of 3.92 $x 10^{-8} \mathrm{~Pa}^{-1}$. The fitted parameters were a hydraulic conductivity of $4.0 \times 10^{-13} \mathrm{~m} / \mathrm{s}$ (permeability of $5 \times 10^{-20}$ $\mathrm{m}^{2}$ ), a formation pore pressure of $2.95 \mathrm{MPa}$, and a distance to the zero-flow boundary of $2.8 \mathrm{~m}$. Additional simulations showing the sensitivity of the best-fit model to slight changes in hydraulic conductivity, formation pore pressure, specific storage, test-zone compressibility, and distance to the zero-flow boundary, as well as to the presence or absence of test-zone-volume compensations, are presented in Section 7.2.

7.1.9.2 Guard Zone. No pressure buildup was obsenss $d$ in the S1P71-A guard zone following shut-in; the zone remained at atmospheric pressure throughout the testingperiod in thetestzone(Figure 7-39). Pulse-injection tests were attempted in the guard zone in S1P71 on two separateoscasions. The first testwas aitemptedon May 3 , 1989 (1988 Calendar Day 489) at the end of the testing period in the test zone. The second test was attempted on 


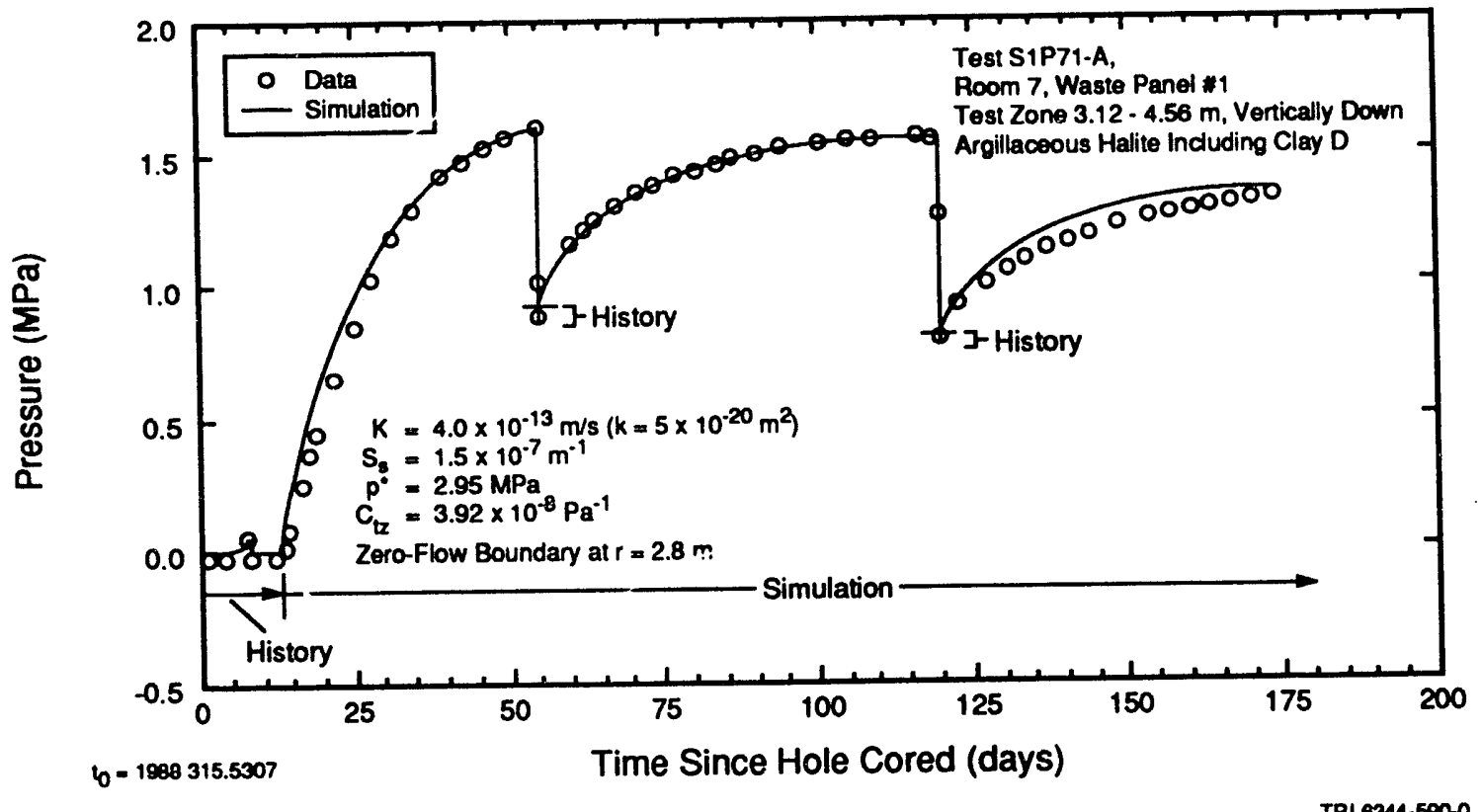

Figure 7-40. Best-Fit Model Simulation of the Test-Zone Fiuld-Pressure Response During S1P71-A Testing.

July6, 1989 (1988Calendar Day553) afterthetest toolhad been removed from the borehole, leak tested, and reinstalled in the hole. In each case, two liters of brine were injected into the guard zone in an attempt to create a pressure differential between the guard zone and the surrounding rock. Neither of these tests was successful because the injection pressure dissipated immediately upon the guard zone being shut in (Saulnier et al., 1991). Stormont (1990a) concluded, based on examination of extensometer, inclinometer, and gas-flow measurements, that vertical separations almost always occur within Marker Bed 139 beneath rooms the size of Room 7 in Waste Panel 1. These separations resull in depressurization of the markerbedandhighpermeabilities. Theoccurrence of this type of separation is consistent with our observations during the attempted testing of Marker Bed 139 in the S1P71-A guard zone.

\subsection{Sensitivity Analyses}

Our first objective in test interpretation was to define the values of the fitted parameters (hydraulic conduc- tivity, formation pore pressure, and, in some cases, distance to a zero-flow boundary) that combined with the specified parameters to produce the model simulations that most closely matched the observed data. Our approach to this problem was to investigate a matrix of values for the fitted parameters while holding the specified parameters fixed, and to select the combination of fitted parameters that subjectively provided the best match to the observed data.

Our second objective was to evaluate the sensitivity of the modeling results to the values selected for both the fitted and specified parameters. This was accomplished by individually varying the parameters hydraulic conductivity, formation pore pressure, distance to a boundary (when relevant), specific storage (which includes formation porosity and compressibility as well as brine density and compressibility), and test-zone compressibility to show the effects that these variations had on the simulations. No sensitivity analysis was performed for the specified parameter test-zone 
thickness, because thickness was always known to within a few percent, and uncertainty in this parameter results in almost linear, inverse uncertainty in hydraulic conductivity. Additional sensitivity analyses were performed to evaluate the effects of, and need for, testzone-volume and temperature compensations. These sensitivity analyses provide a measure of the uncertainty in the fitted parameters.

7.2.1 HYDRAULIC CONDUCTIVITY. The sensitivities of the best-fit simulations to slight changes in hydraulic conductivity are shown in Figures 7-41 through 7-48. Unit changes within the order of magnitude of the best-fit value (e.g., changing $2.5 \mathrm{x}$ $10^{-14} \mathrm{~m} / \mathrm{s}$ to $1.5 \times 10^{-14} \mathrm{~m} / \mathrm{s}$ and $3.5 \times 10^{-14} \mathrm{~m} / \mathrm{s}$ ) generally resulted in noticeably poorer fits to the observed data, particularly for hydraulic conductivities less than $10^{-13} \mathrm{~m} / \mathrm{s}$. In the cases of the simulation of the C2H01-A testing (Figure 7-41) and the simulation of the C2H01-C testing of Marker Bed 139 (Figure 7-44), which showed the highest hydraulic conductivities of any test intervals discussed in this report, changes in hydraulic conductivity of about half an order of magnitude are needed to degrade the matches between the simulations and the observed data noticeably.

7.2.2 FORMATION PORE PRESSURE. The sensitivities of the best-fit simulations to $0.1-\mathrm{MPa}$ changes in the formation pore pressure are shown in Figures 7-49 through 7-56. In all cases, the changes in formation pore pressure resulted in observably different simulations, showing formation pore pressure to be a very sensitive parameter.

7.2.3 DISTANCE TO A BOUNDARY. For the simulations of the L4P51-A and S1P71-A tests, which included zero-flow boundaries, the sensitivities of the results to the distances to the boundaries were evaluated. Figures 7-57 and 7-58 show the effects on the simulations of $0.1-\mathrm{m}$ changes in the distance to the boundary. As might be expected, the simulations are faily sensitive to this distance because it is one of the parameters controlling the volume of fluid contained within the confines of the zero-flow boundary.

7.2.4 SPECIFIC STORAGE. To define appropriate ranges over which to evaluate sensitivities to specific storage, the estimated uncertainties in formation elastic moduli and porosity and brine density and compressibility were used. The estimated uncertainty ranges for the drained bulk and shear moduli of the different rock types tested are given in Table 6-1. A range of 22.8 to $24.0 \mathrm{GPa}$ was used for the bulk modulus of halite solids (Carmichael, 1984). The other estimated uncertainty ranges were 0.001 to 0.03 for halite and anhydrite porosity, 0.20 to 0.40 for claystone porosity, 1.20 to $1.25 \mathrm{~kg} / \mathrm{L}$ for brine density, and $2.9 \mathrm{x}$ $10^{-10}$ to $3.3 \times 10^{-10} \mathrm{~Pa}^{-1}$ for brine compressibility.

The uncertainty range for the specific storage of halite was calculated using end-membervalues of the ranges presented above in Eq. 6-2. The minimum specific storage calculated was about $2.8 \times 10^{-8} \mathrm{~m}^{-1}$, and the maximum value was about $3.6 \times 10^{-7} \mathrm{~m}^{-1}$. While these values may reasonably encompass the possible range for the specific storage of intact halite, they are probably too low to be representative of fractured halite.

Walsh (1965) showed that the compressibility of rock increases when cracking or microfracturing occurs. This effect can be quantified by comparing compressional-wave velocities through intact and fractured rock. Compressional-wave velocities decrease when rocks fracture. Compressional-wave velocity is related to the factor $\alpha$ given in Eqs. 6-1 and 6-3 by (Green and Wang, 1990):

$$
v_{p}=1 / \sqrt{ }(\alpha \rho)
$$




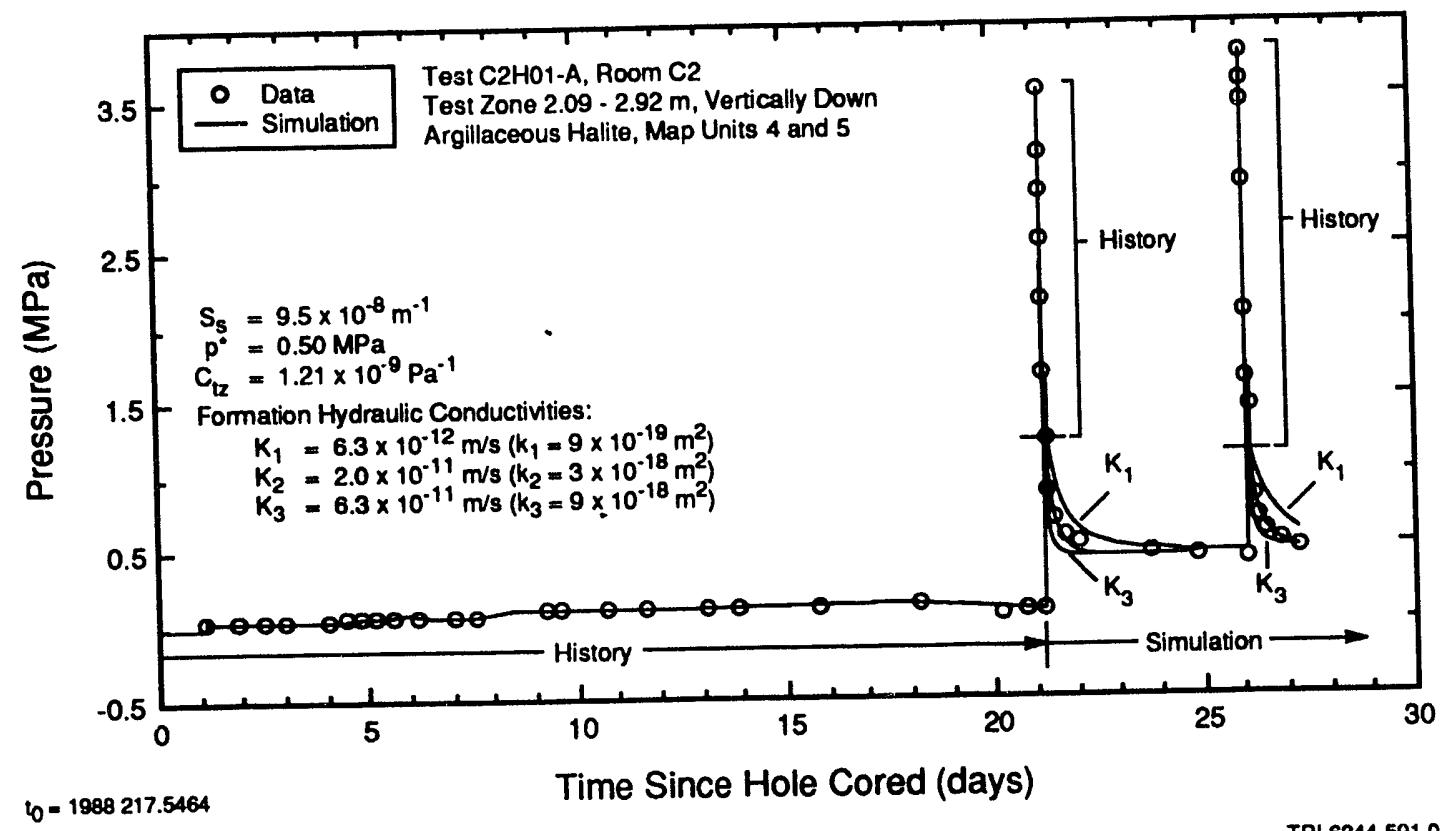

Figure 7-41. Simulation of the Test-Zone Fluid-Pressure Response During C2H01-A Testing Showing the Simulation's Sensitivity to Hydraulic Conductivity.

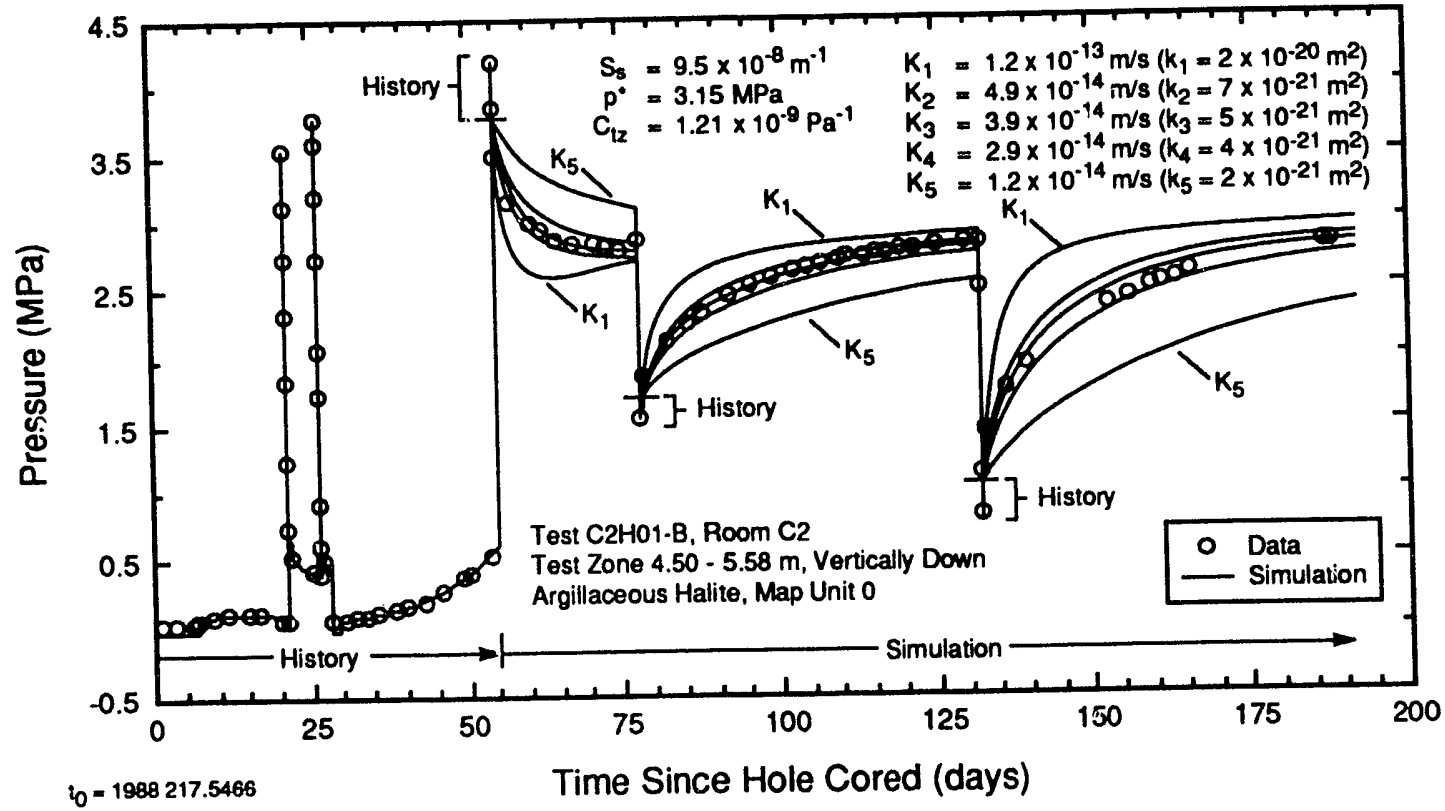

Figure 7-42. Simulation of the Test-Zone Fluid-Pressure Response During C2H01-B Testing Showing the Simulation's Sensitivity to Hydraulic Conductivity. 


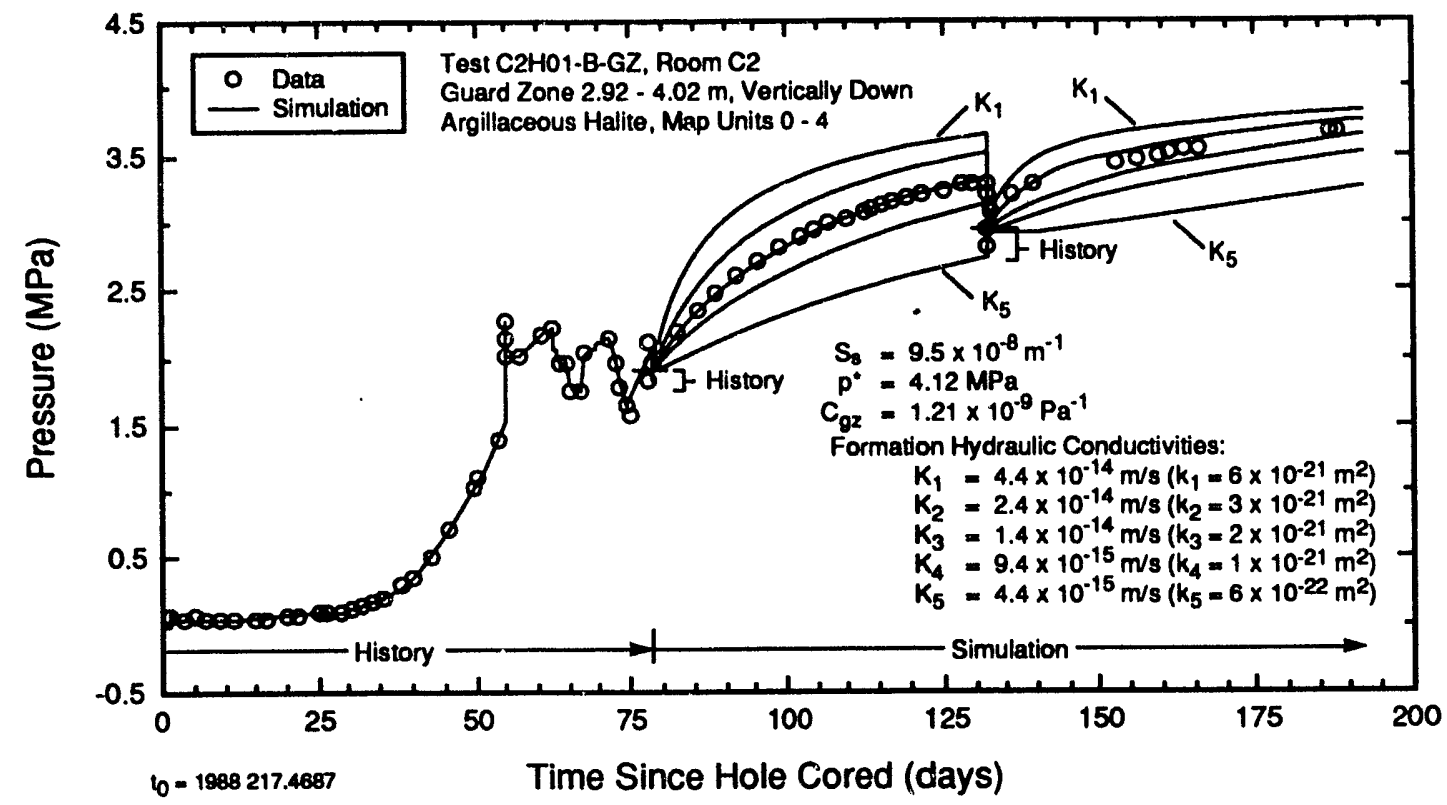

TRI-6344-742-0

Figure 7-43. SImulation of the Guard-Zone Fluld-Pressure Response During C2H01-B Testing Showing the Simulation's Sensitivity to Hydraulic Conductivity.

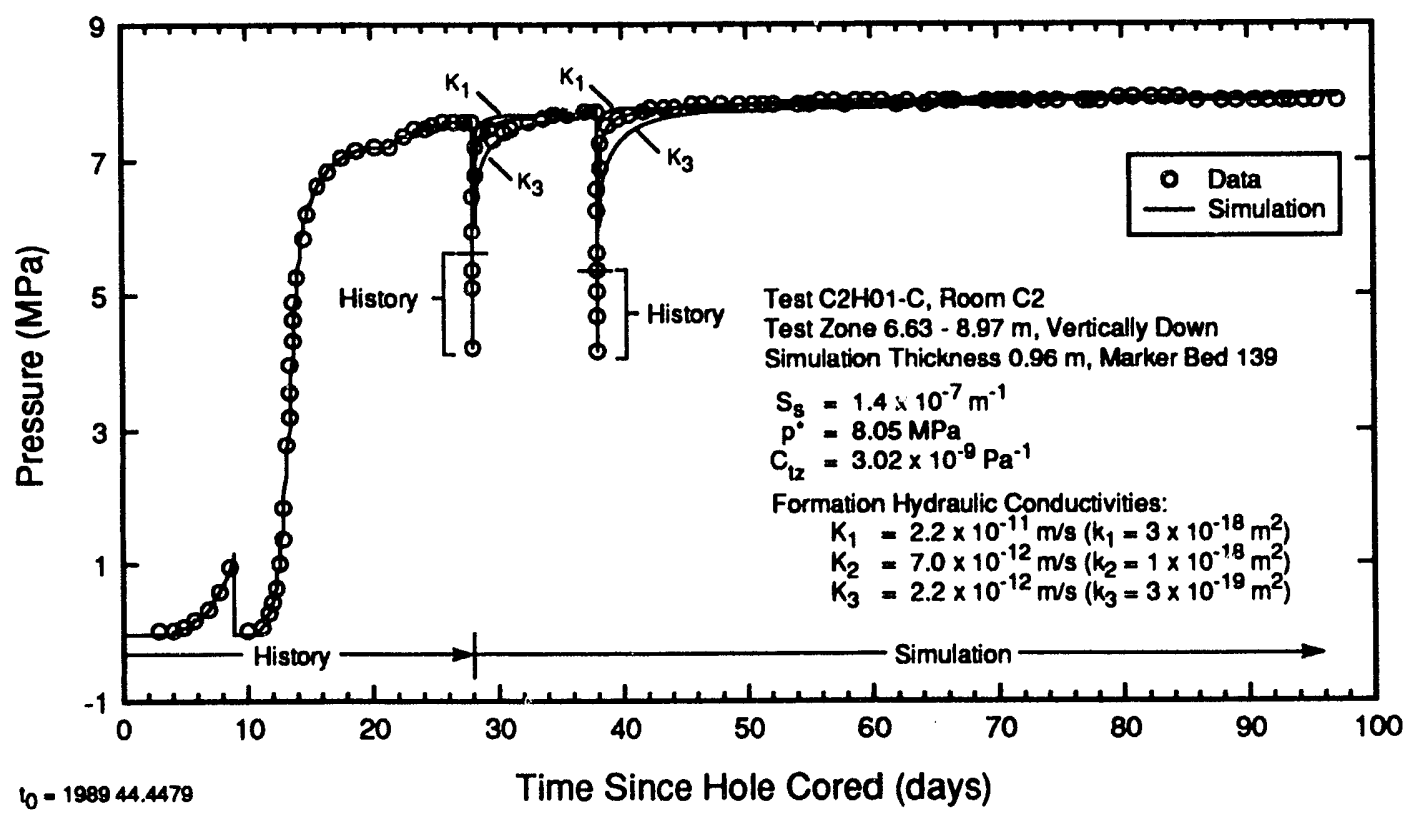

TRI-6344-594-0

Figure 7-44. Simulation of the Test-Zone Fluid-Pressure Response During C2H01-C Testing Showing the Simulation's Sensitivity to Hydraulic Conductivity. 


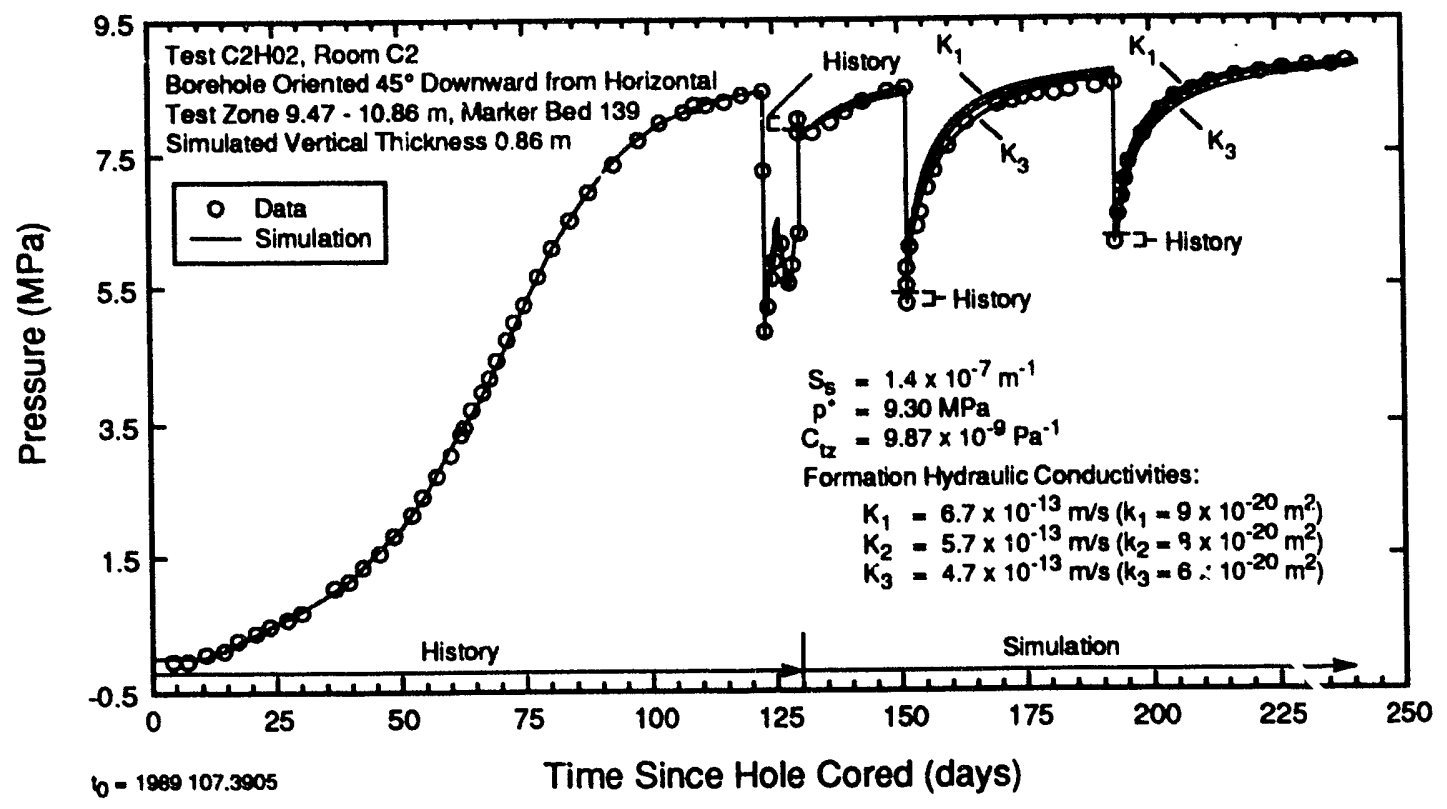

TRI-6344-595-0

Figure 7-45. Simulation of the Test-Zone Fluld-Pressure Response During C2H02 Testing Showing the Simulation's Sensitivity to Hydraulic Conductivity.

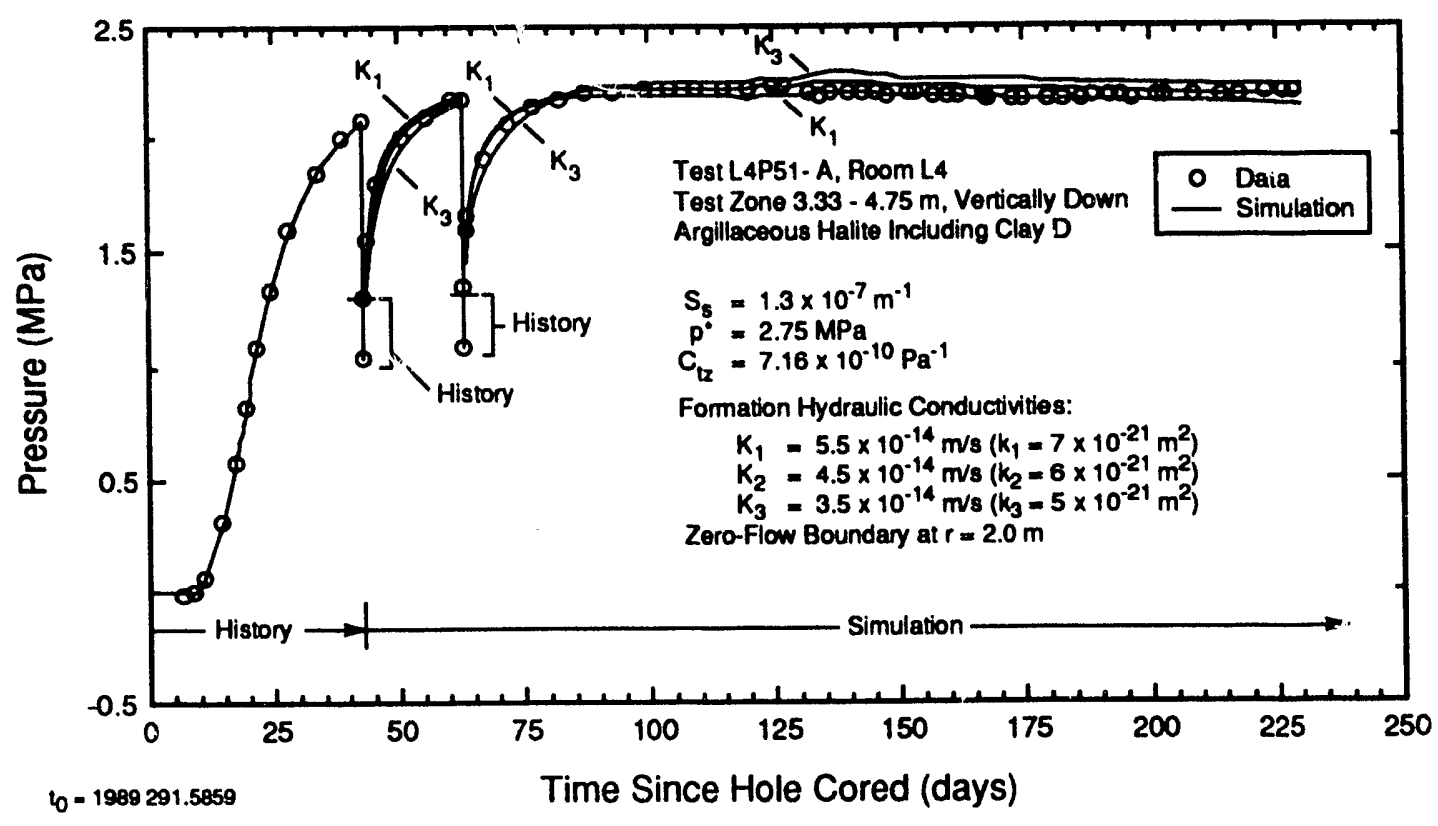

Figure 7-46. Simulation of the Test-Zone Fluid-Pressure Response During L4P51-A Testing Showing the Simulation's Sensitlvity to Hydraulic Conductivity. 


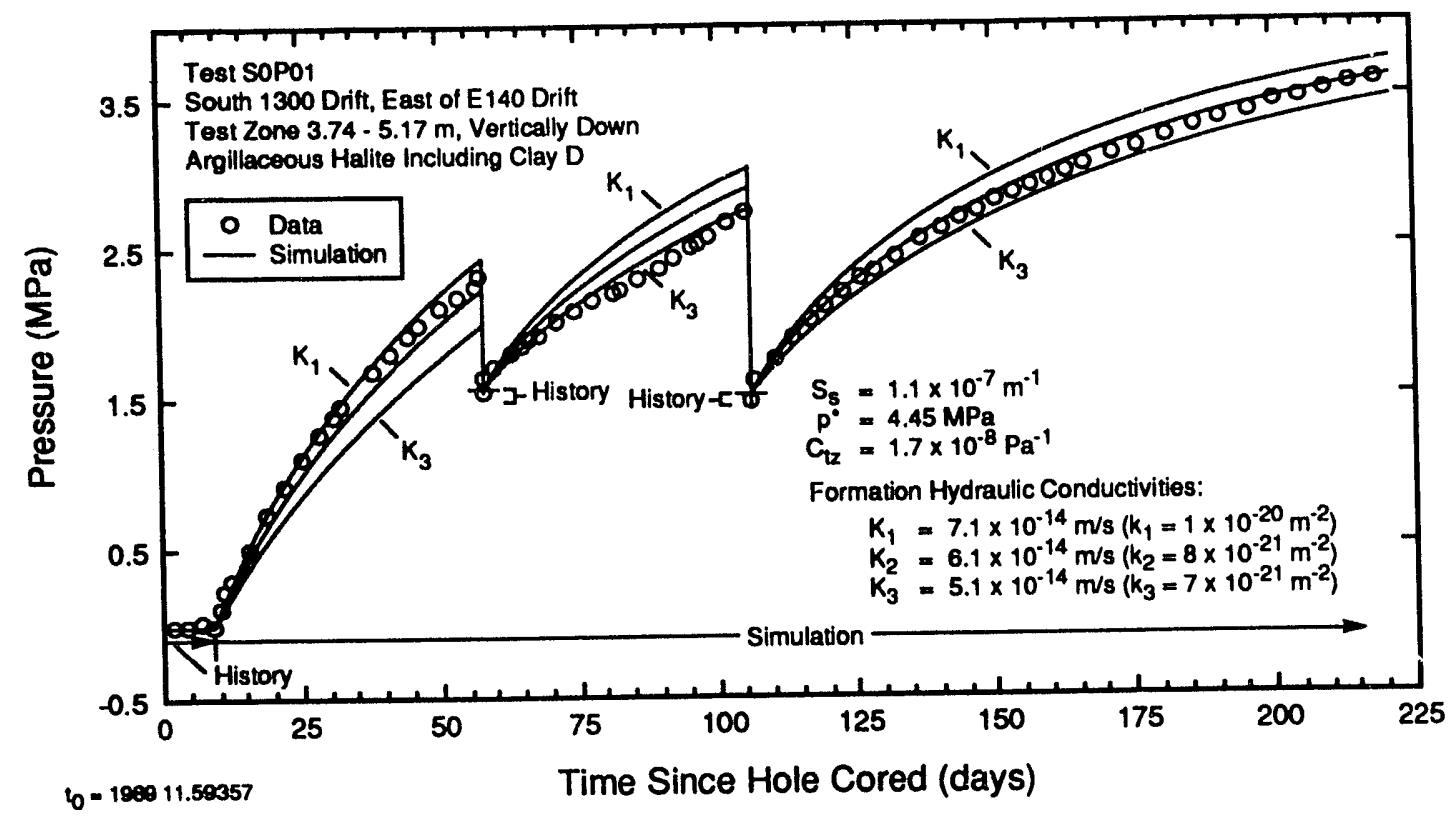

Figure 7-47. Simulation of the Test-Zone Fluld-Pressure Response During SOP01 Testing Showing
the Simulation's Sensitivity to Hydraulic Conductivity.

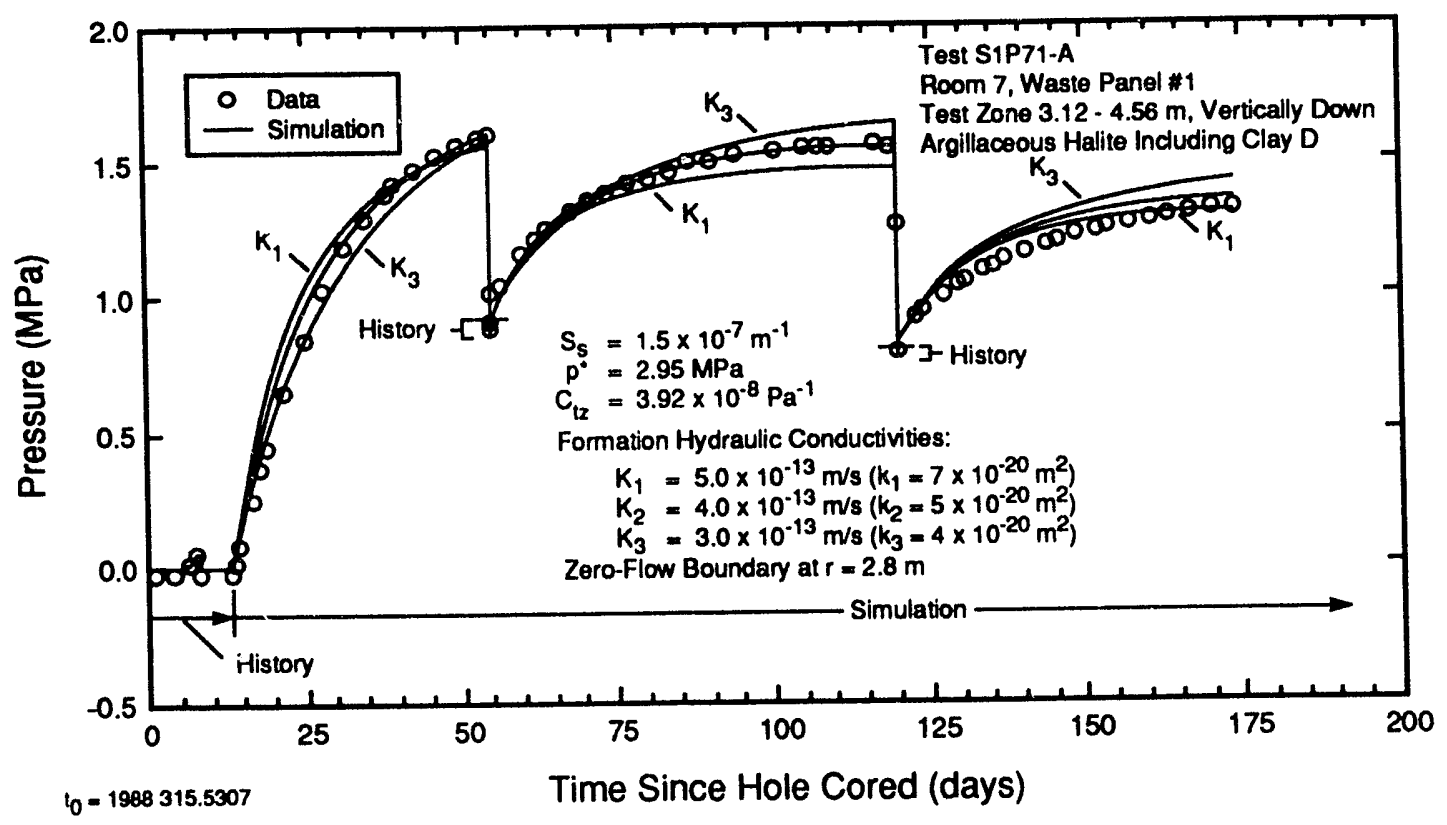

Figure 7-48. Simulation of the Test-Zone Fluid-Pressure Response During S1P71-A Testing Showing the Simulation's Sensitivity to Hydraulic Conductivity. 


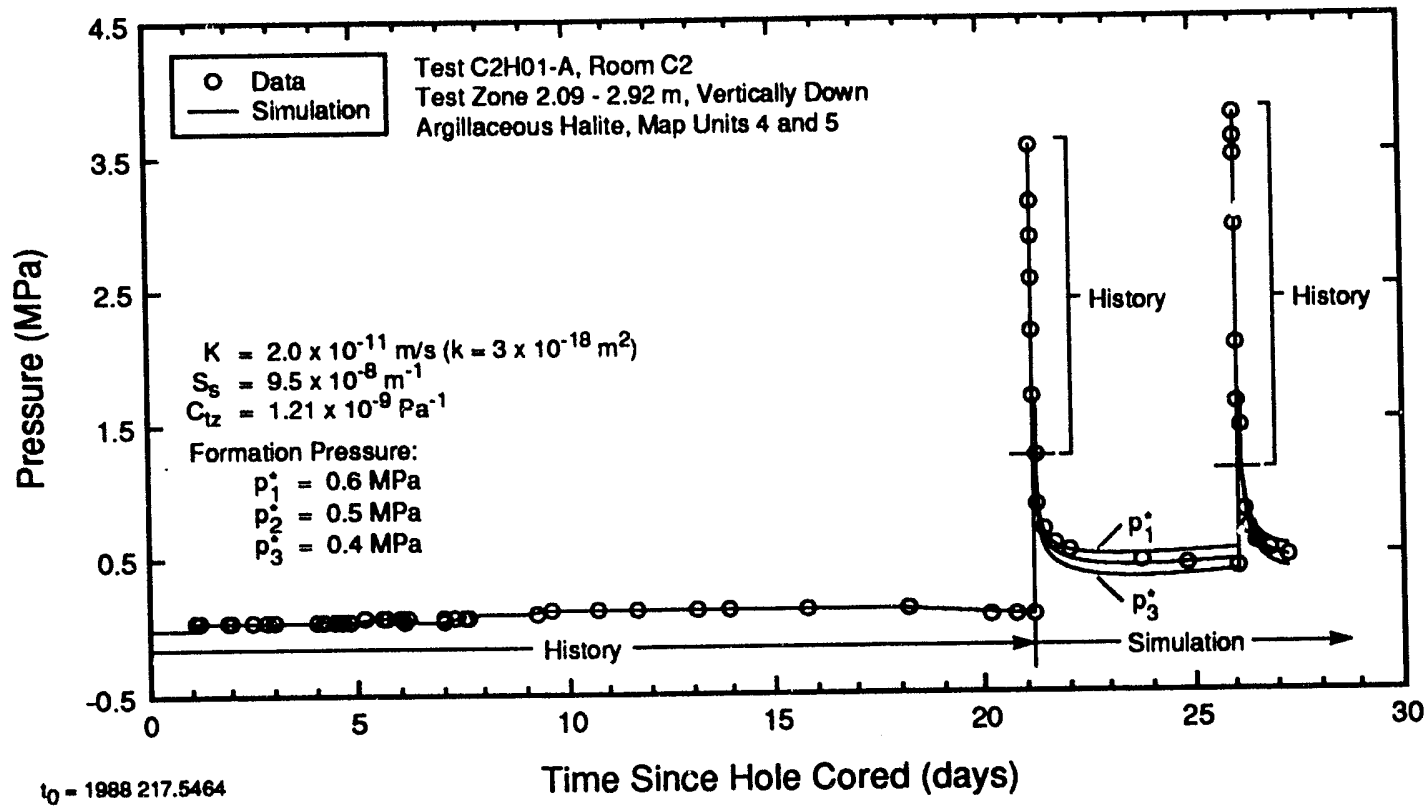

TRL6344-5990

Figure 7-49. Simulation of the Test-Zone Fluld-Pressure Response During C2H01-A Testing Showing the Simulation's Sensitivlty to Formation Pore Pressure.

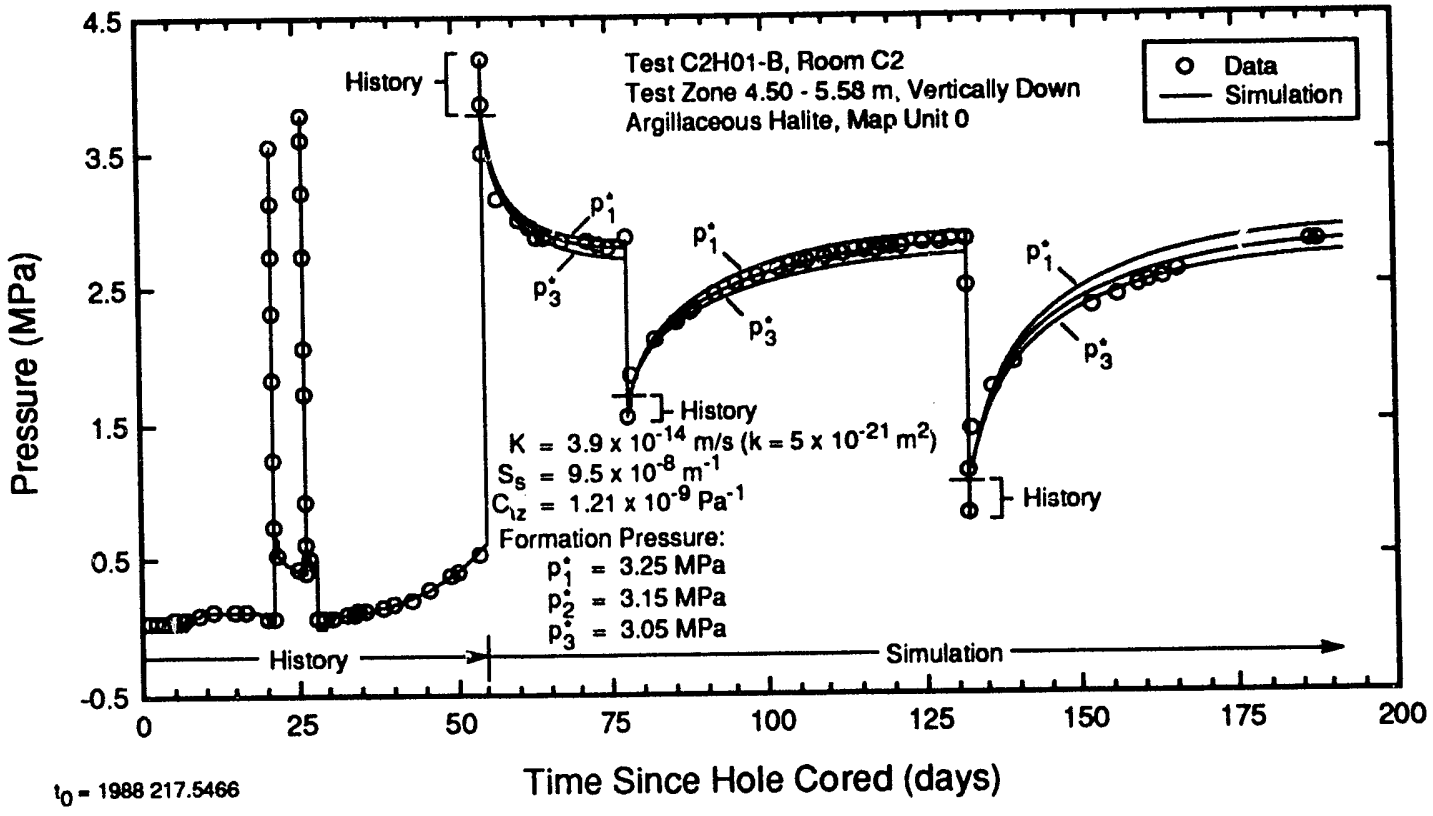

Figure 7-50. Simulation of the Test-Zone Fluid-Pressure Response During C2H01-B Testing Showing the Simulation's Sensitivity to Formation Pore Pressure. 


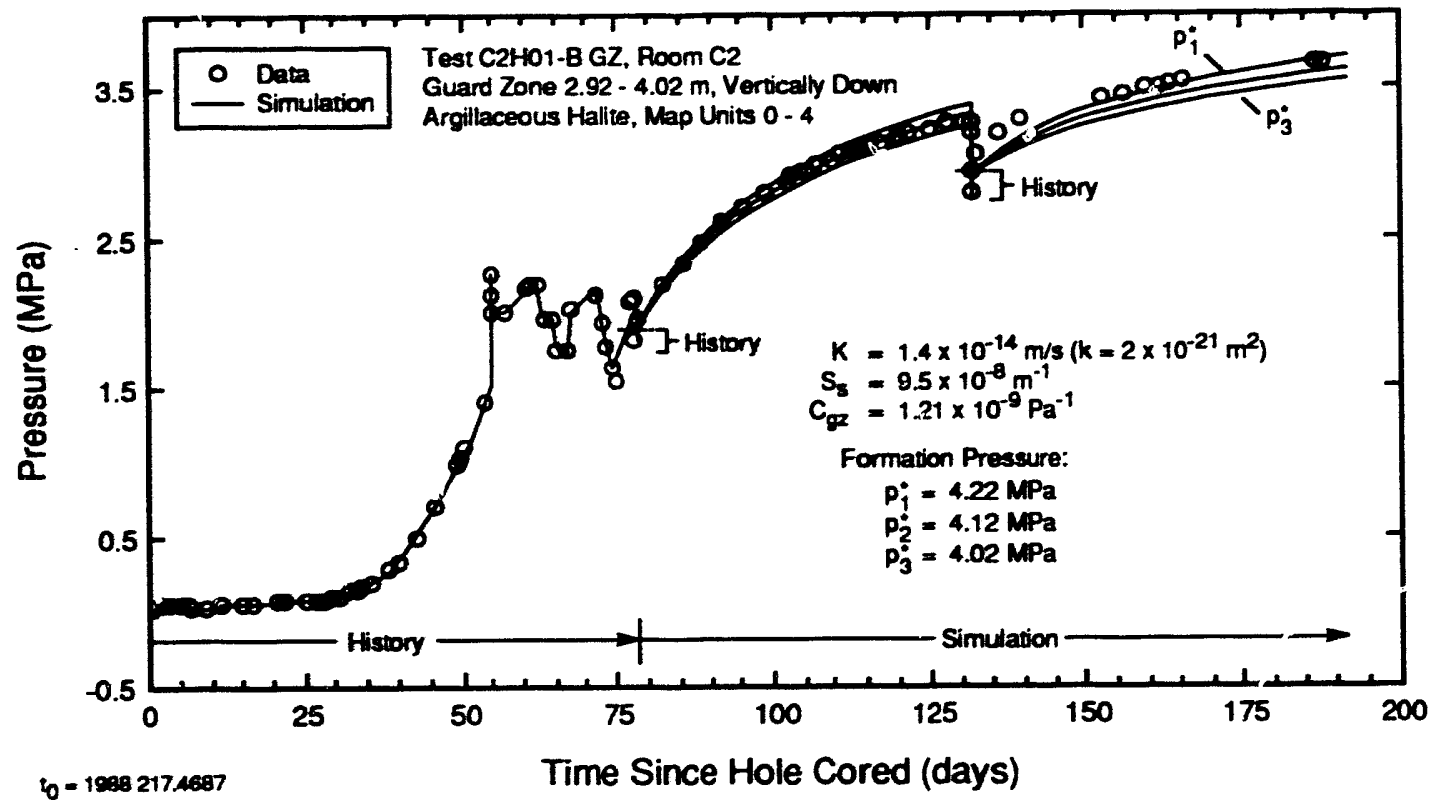

TR1-634-601-0

Figure 7-51. Simulation of the Guard-Zone Fluid-Pressure Response During C2H01-3 Testing Showing the Simulation's Sensitivity to Formation Pore Pressure.

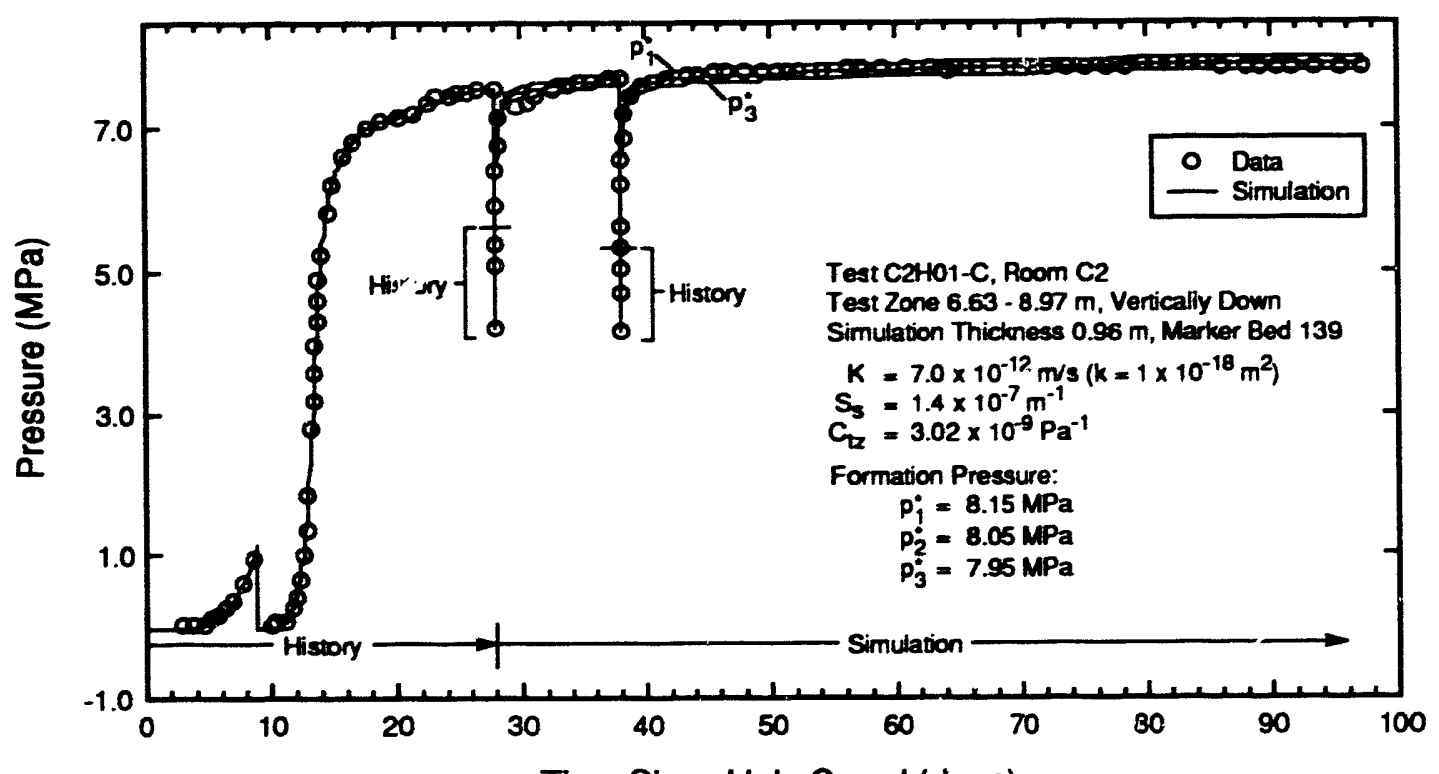

$0=19004.4479$

Time Since Hole Cored (days)

TRI-634-602-0

Figure 7-52. Simulation of the Test-Zone Fluid-Pressure Response During C2H01-C Testing Showing the Simulation's Senstivity to Formation Pore Pressure. 


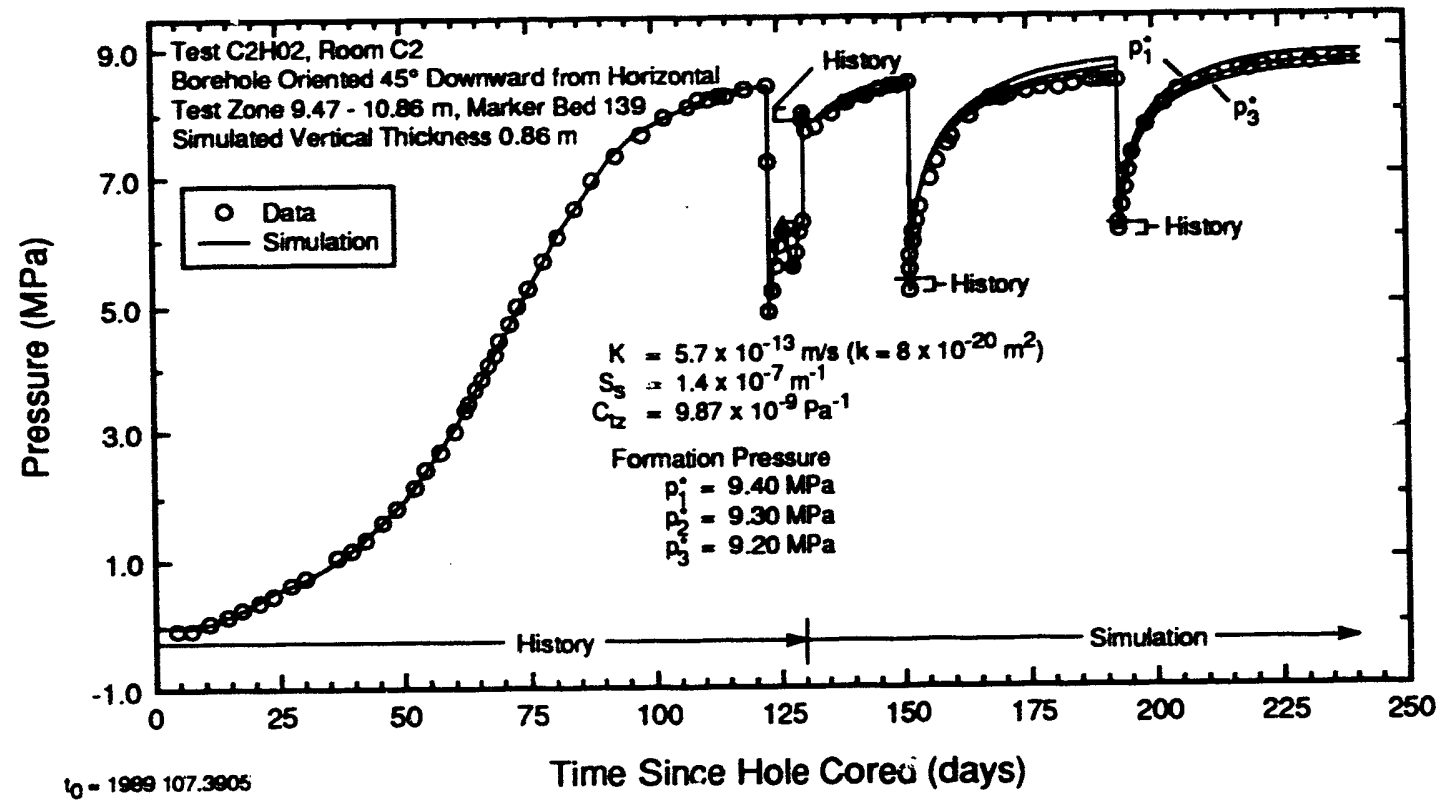

Figure 7-53. Simulation of the Test-Zone Fluld-Pressure Response During C2H02 Testing Showing the Simulation's Sensitivity to Formation Pore Pressure.

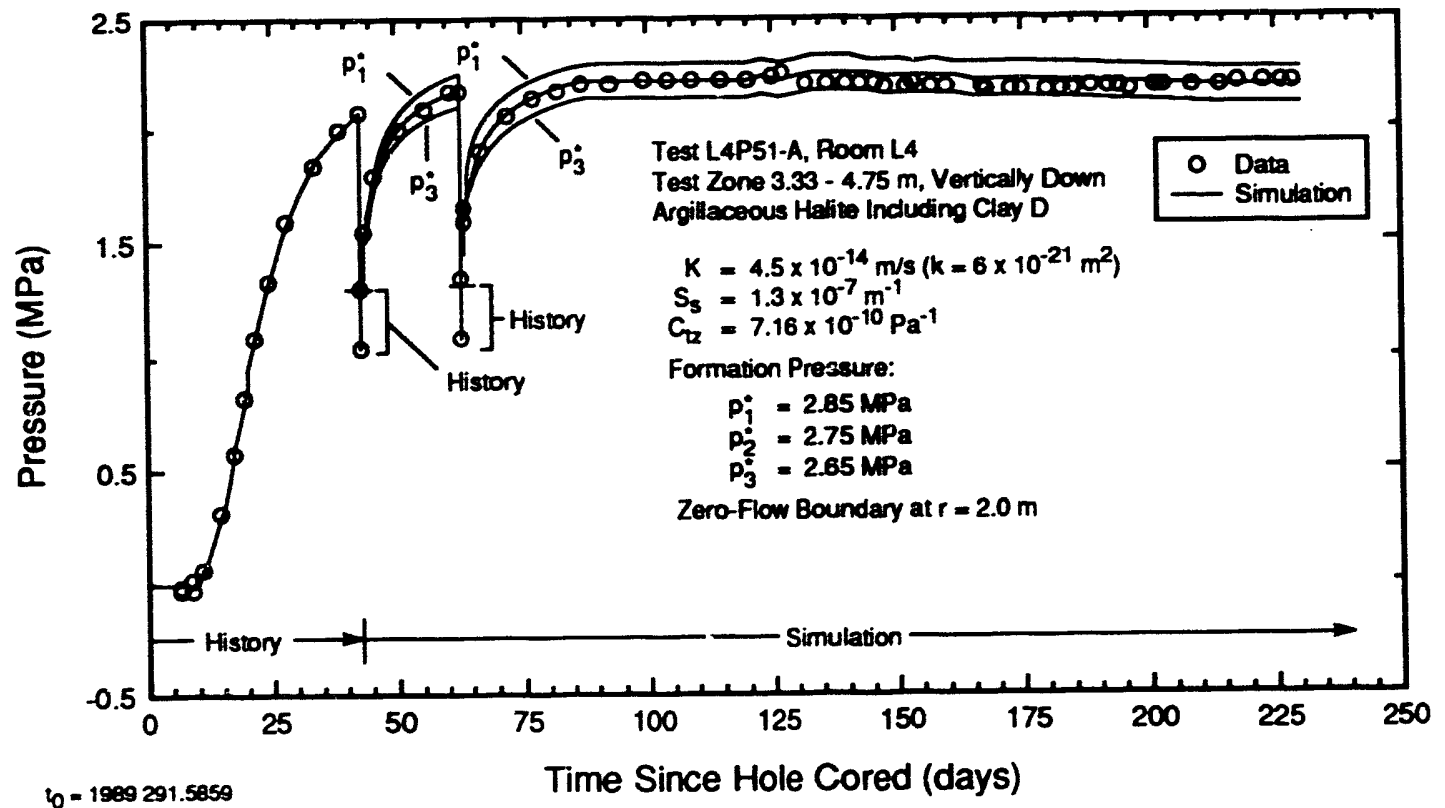

TR16344604-0

Figure 7-54. Simulation of the Test-Zone Fluid-Pressure Response During L4P51-A Testing Showing the Simulation's Sensitivity to Formation Pore Pressure. 


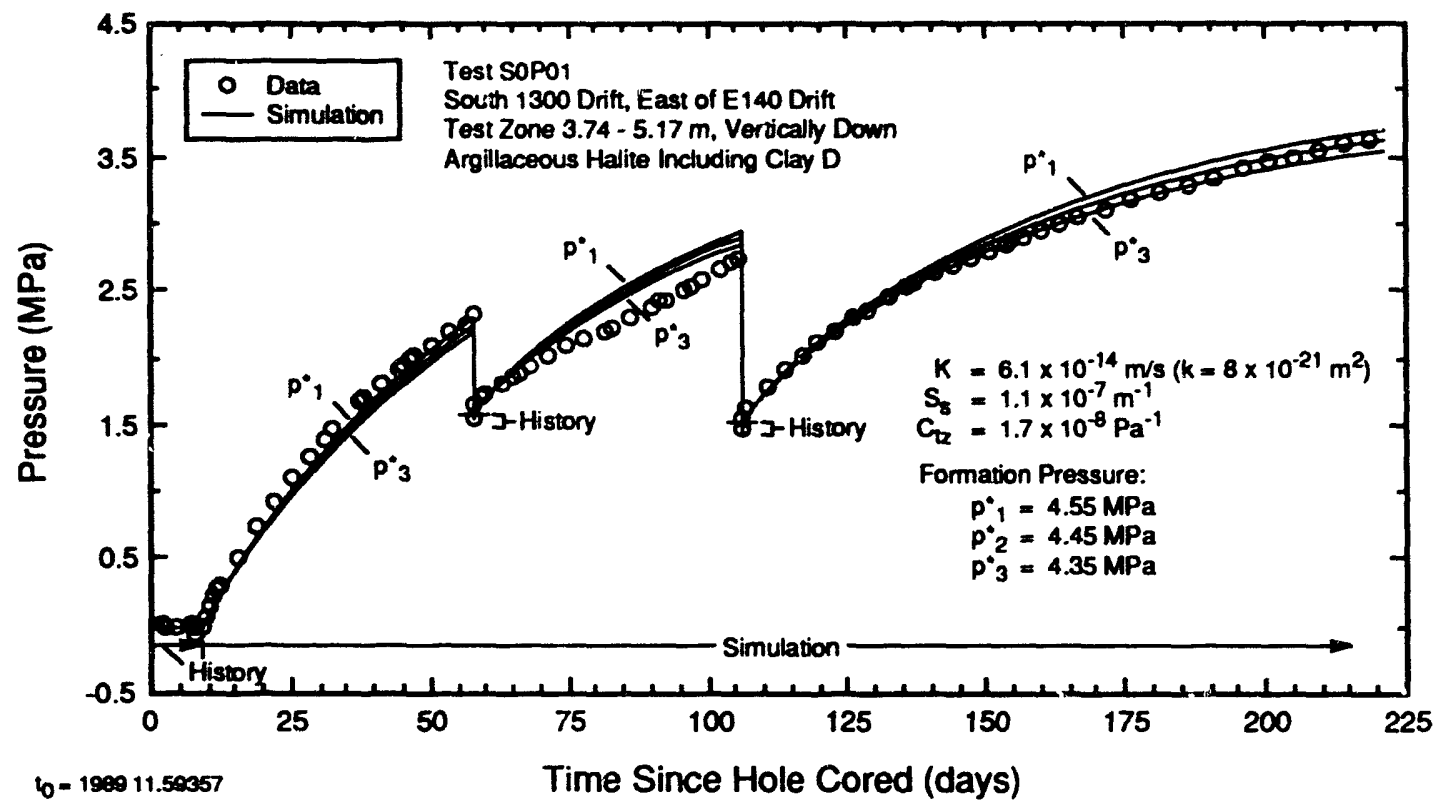

TRI-6344-605-U

Figure 7-55. Simulation of the Test-Zone Fluid-Pressure Response During SOP01 Testing Showing the Simulation's Sensitivity to Formation Pore Pressure.

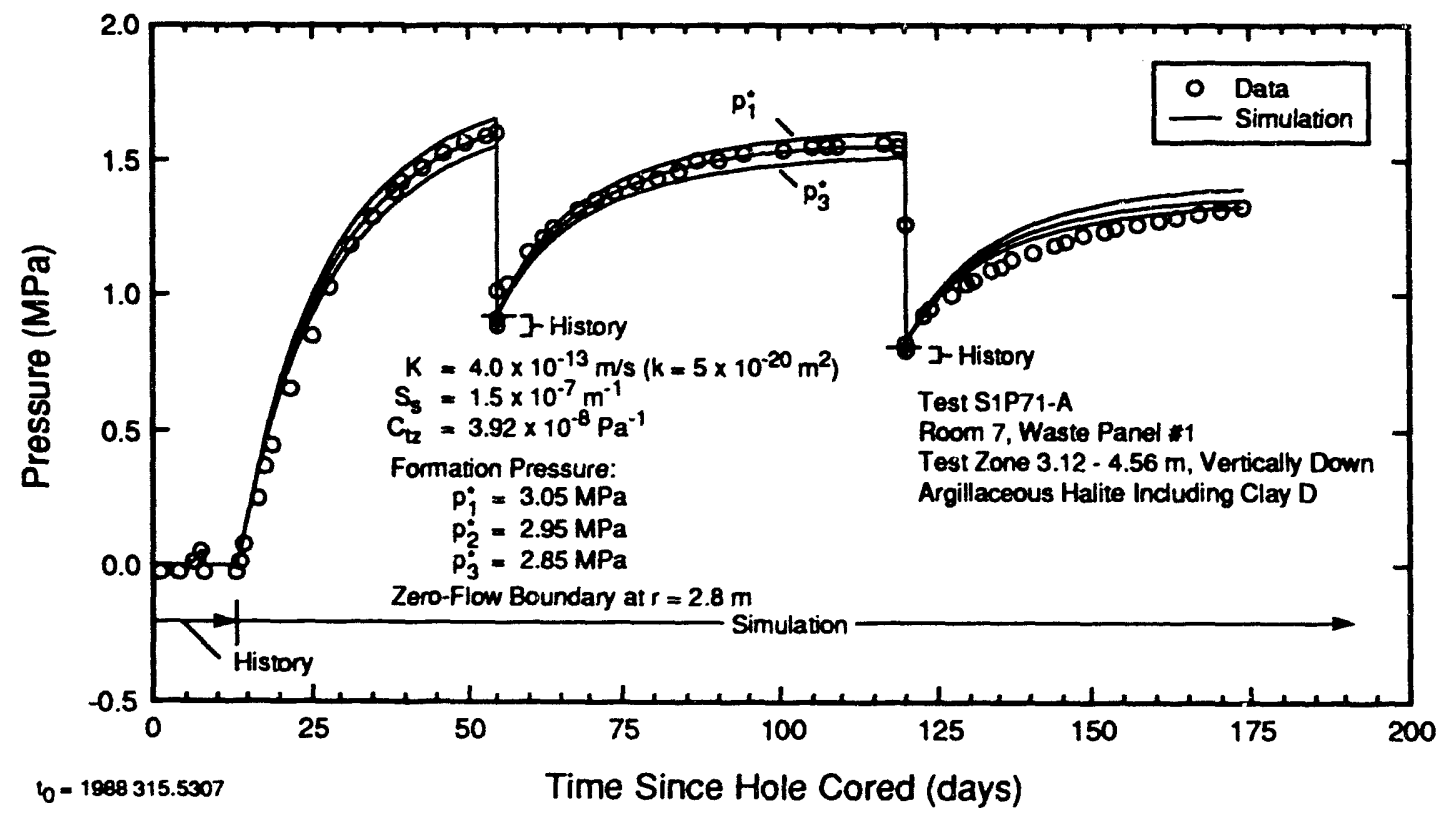

TRI-6344-606-0

Figure 7-56. Simulation of the Test-Zone Fluid-Pressure Response During S1P71-A Testing Showing the Simulation's Sensitivity to Formation Pore Pressure. 


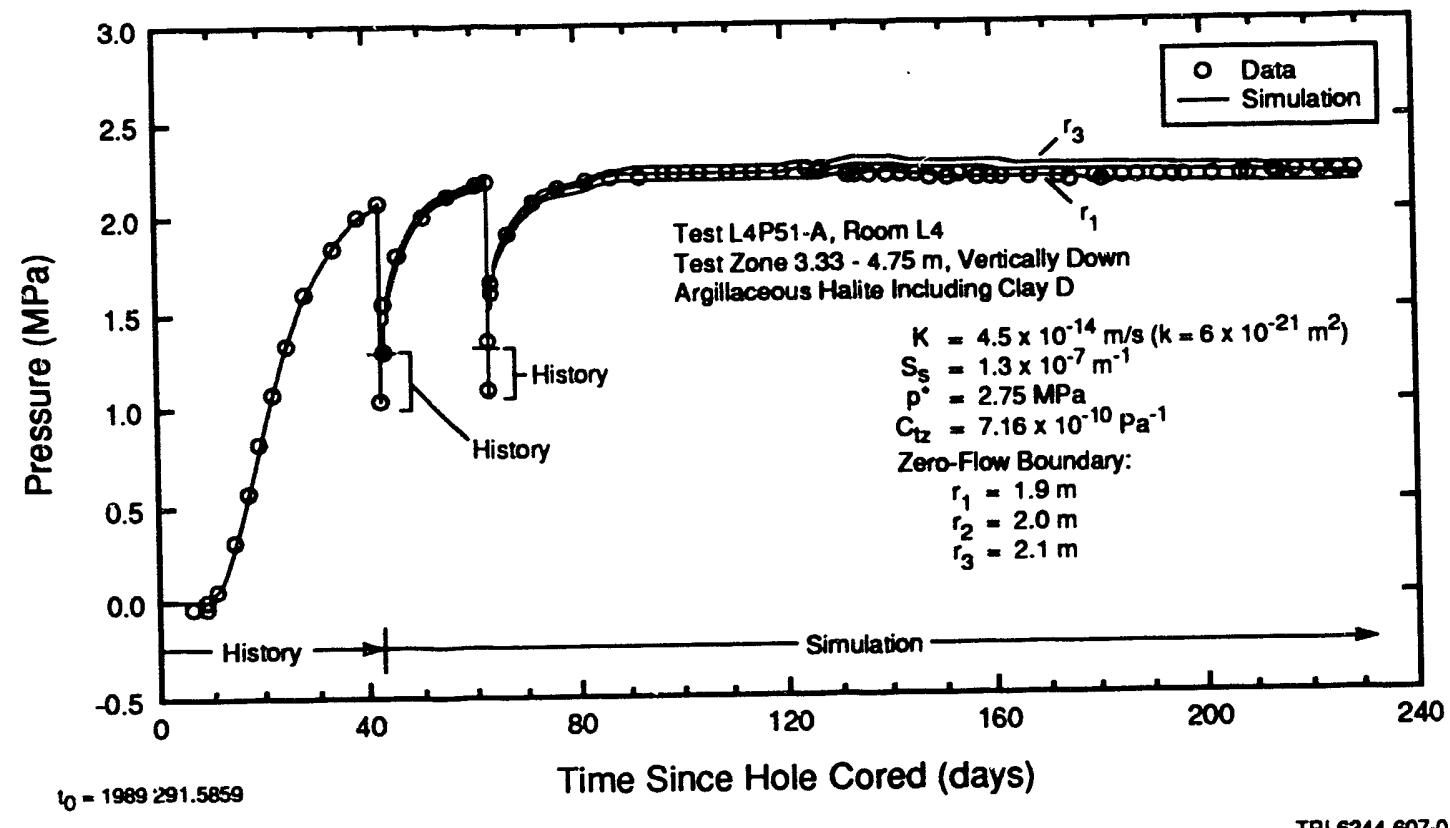

Figure 7-57. Simulation of the Test-Zone Fluld-Pressure Response During L4P51-A Testing Showing the Simulation's Sensitivity to Distance to the Zero-Flow Boundary.

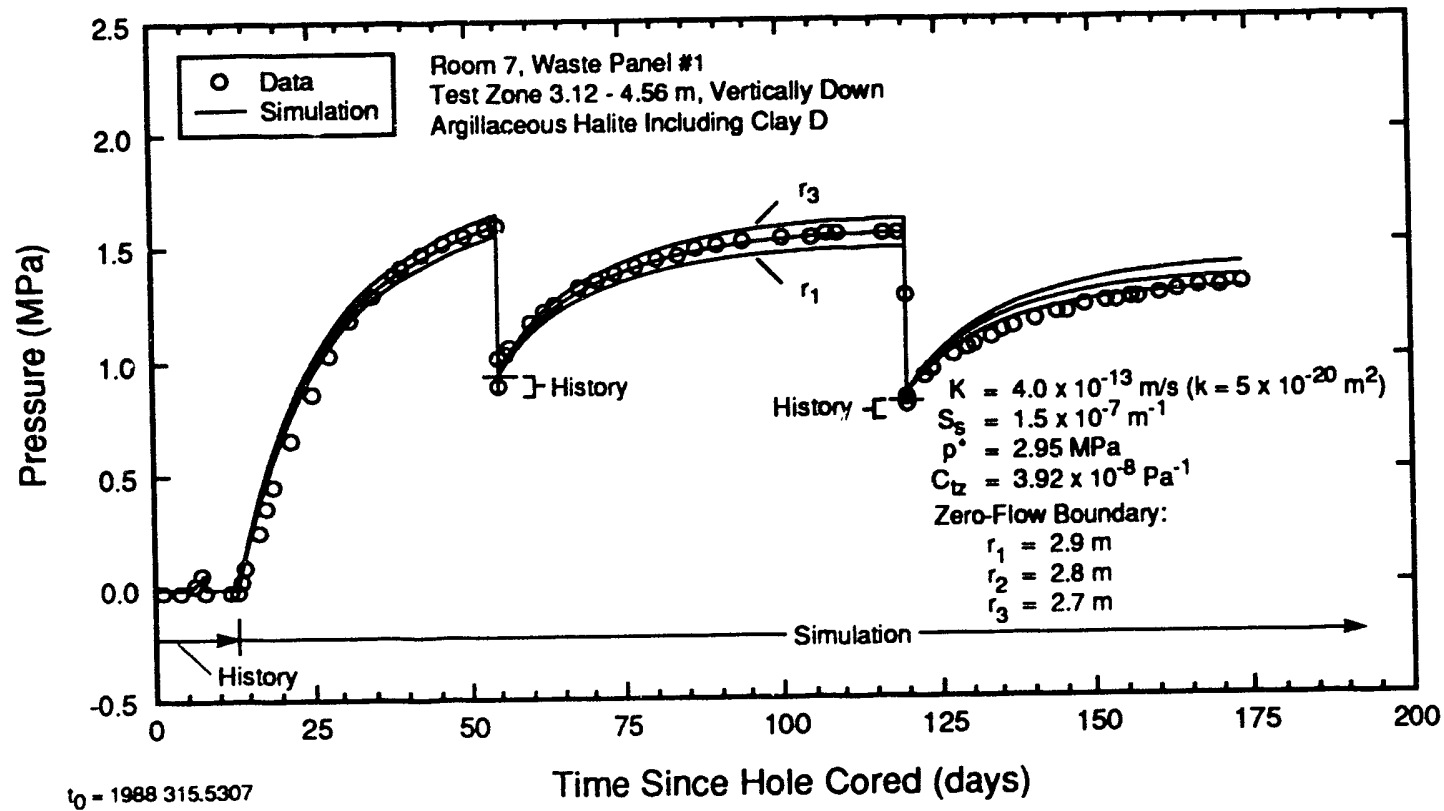

Figure 7-58. Simulation of the Test-Zone Fluid-Pressure Response During S1P71-A Testing
Showing the Simulation's Sensitivity to Distance to the Zero-Flow Boundary. 
where:

$v_{p}=$ compressional-wave velocity

$\alpha=$ uniaxial compressibility given by Eq. 6-3

$\rho=$ rock density

Brodsky (1990) reported decreases in comiuressionalwave velocities in the laboratory of up to eleven percent in Salado halite specimens at one percert axial strain. Ibrahim et al. (1989) reported in situ decre:ases in compressional-wave velocities of up to aboul 50 percent within about 1.5 m of WIPP excavations. A50 percent decrease in $V_{p}$ in Eq. 7-1 translates to a fourfold increase in $\alpha$. Thus, specific storage might also increase by about this factor as a result of microfracturing around the WIPP excavations. ACcordingly, the maximum value of specific storage of halite considered in the sensitivity calculations was $1.4 \times 10^{-8} \mathrm{~m}^{-1}$.

The uncertainty range for the specific storage of anhydrite was calculated using end-member values of the ranges presented above in Eq. 6-1. Specific storage was calculated to range from a low of about $9.7 \times 10^{-8} \mathrm{~m}^{-1}$ to a high of about $2.5 \times 10^{-7} \mathrm{~m}^{-1}$. To account for the effects of fracturing on anhydrite compressibility, the maximum value of specific storage to be considered in sensitivity calculations was increased to $1.0 \times 10^{-6} \mathrm{~m}^{-1}$.

The uncertainty range for the specific storage of claystone was calculated using end-member values of the ranges presented above in Eq. 6-1. Specific storage was calculated to range from a low of about 1.7 $\times 10^{-6} \mathrm{~m}^{-1}$ to a high of about $5.6 \times 10^{-6} \mathrm{~m}^{-1}$.

The sensitivities of the best-fit simulations to the estimated uncertainties in specific storage are shown in Figures 7-59 through 7-66. In general, the simulations are about as sensitive to the uncertainty in specific storage as they are to the unit changes within the order of magnitude of the best-fit value of hydraulic conductivity presented in Figures 7-41 through 7-48, or to the 0.1-MPa changes in formation pore pressure presented in Figures 7.49 through 7-56. However, the simulations of the L4P51-A and S1P71-A tests (Figures 7-32 and 7-40, respectively), which include zerroflow boundaries, are highly sensitive to specific storage because that parameter governs the amount of brine releasable from storage within the zero-flow boundary.

To evaluate which of the fitted parameters was most sensitive to the uncertainty in specific storage, the L4P51-A and S1P71-A tests were resimulated to obtain the best fit to the data using the end-member values of specific storage as specified parameters. The SOP01 tests were also resimulated using the lower end-member value of specific storage for comparison purposes.

Figures 7-67 and 7-68 show the simulations that best matched the L4P51-A test data when specificstorage values of $1.5 \times 10^{-6} \mathrm{~m}^{-1}$ and $5.2 \times 10^{-8} \mathrm{~m}^{-1}$, respectively, were specified. Compared to the simulation with the base-case value of specitic storage of $1.3 \times 10^{-7} \mathrm{~m}^{-1}$ (Figure 7-32), the estimated hydraulic conductivity and formation pore pressure changed only slightly. For the high-specific-storage case (Figure 7-67), hydraulic conductivity decreased from $4.5 \times 10^{-14}$ to $3.0 \times 10^{-14} \mathrm{~m} / \mathrm{s}$ and formation pore pressure increased from 2.75 to $2.85 \mathrm{MPa}$. For the low-specific-storage case (Figure 7-68), hydraulic conductivity decreased to $4.0 \times 10^{-14} \mathrm{~m} / \mathrm{s}$ and formation pore pressure increased from 2.75 to $2.88 \mathrm{MPa}$. The parameter that proved to be most sensitive to specific storage was the distance to the zero-flow boundary. For the high-specific-storage case, the distance to the boundary decreased from 2.00 to $0.52 \mathrm{~m}$, while for the low-specific-storage case, it increased to $2.65 \mathrm{~m}$. 


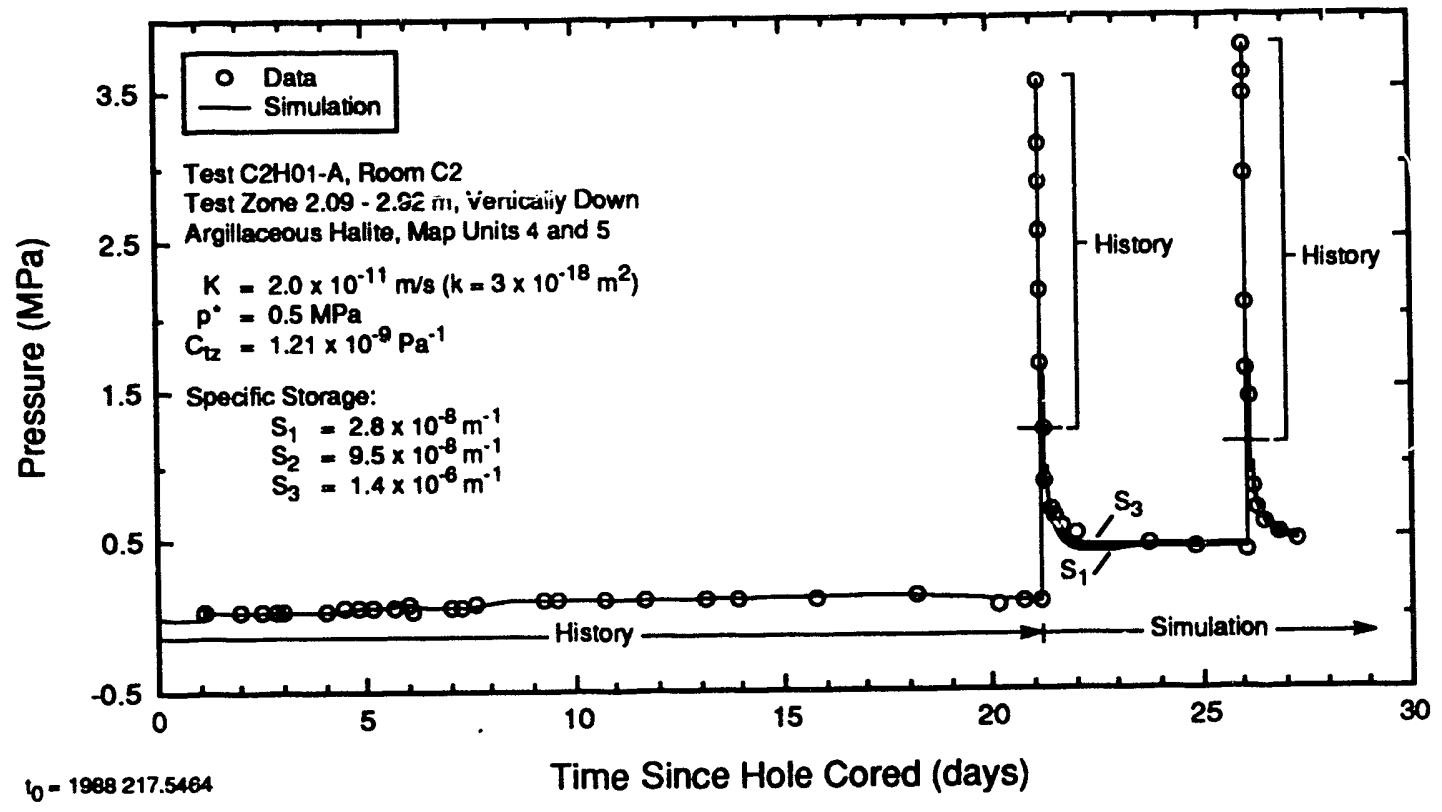

TRI-6344-609-0

Figure 7-59. Simulation of the Test-Zone Fluld-Pressure Response During C2H01-A Testing Showing the Simulation's Sensitivity to Specific Storage.

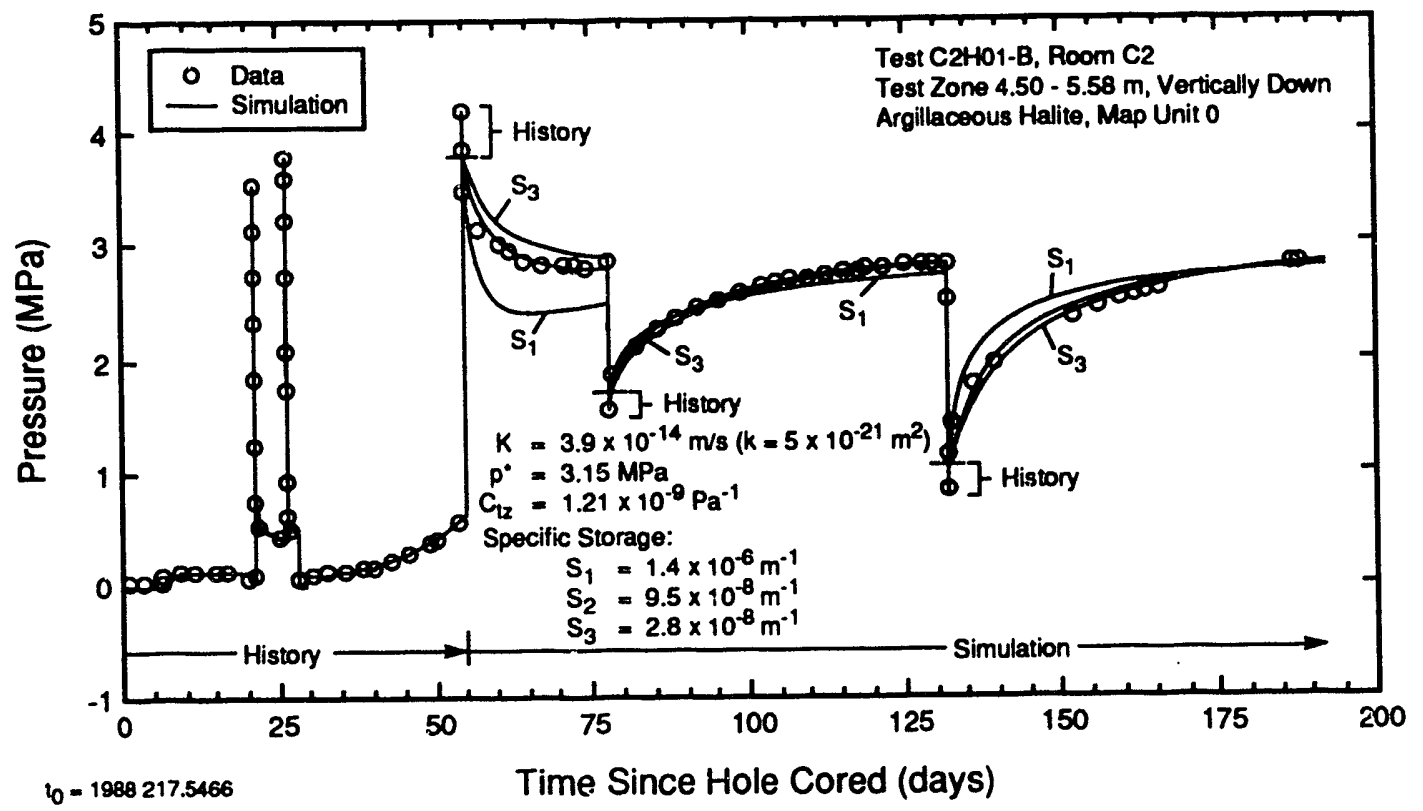

Figure 7-60. Simulation of the Test-Zone Fluid-Pressure Response During C2H01-B Testing Showing the Simulation's Sensitivity to Specific Storage. 


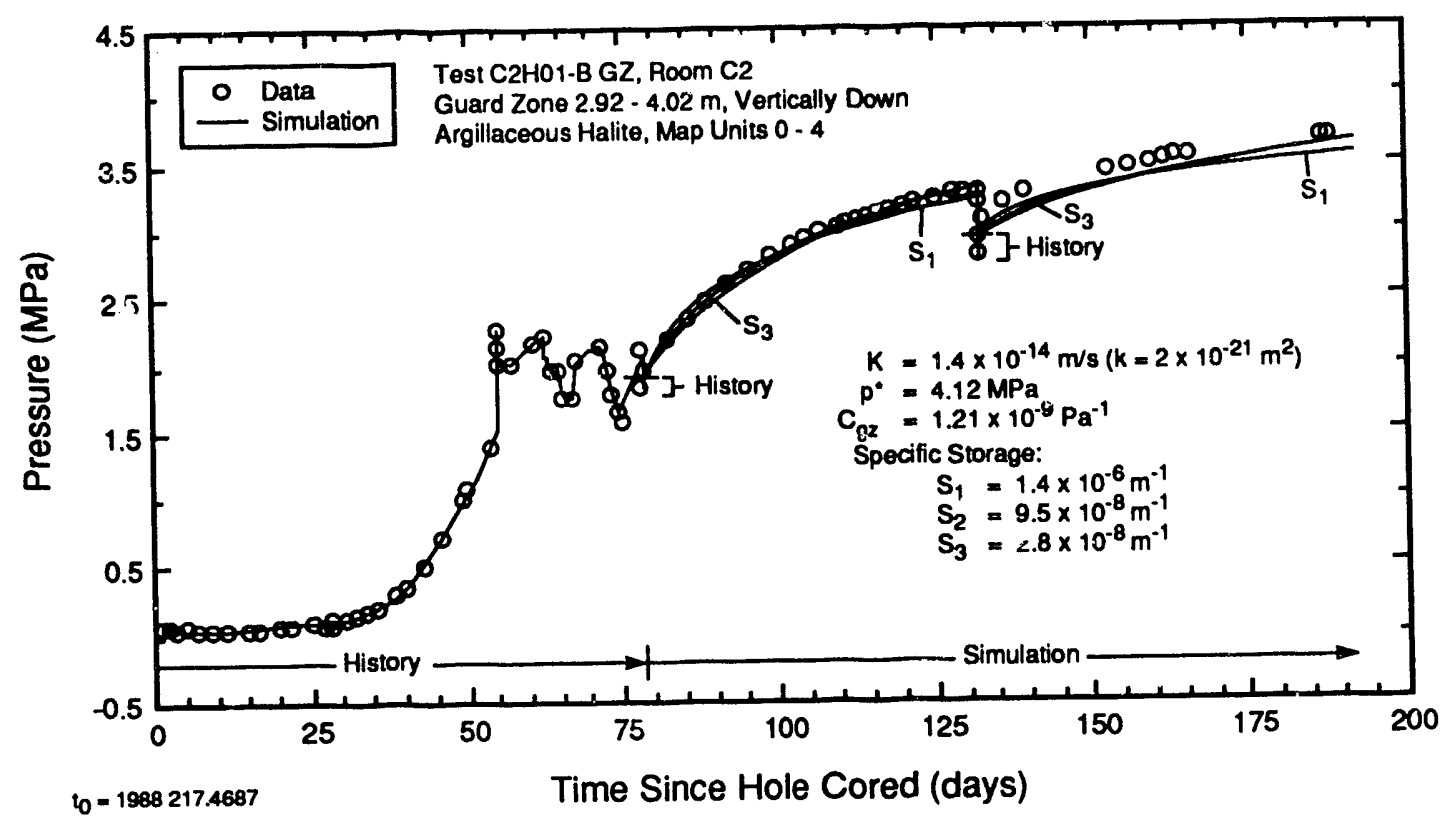

Figure 7-61. Simulation of the Guard-Zone Fluid-Pressure Response during C2H01-B Testing Showing the Simulation's Sensitivity to Specific Storage.

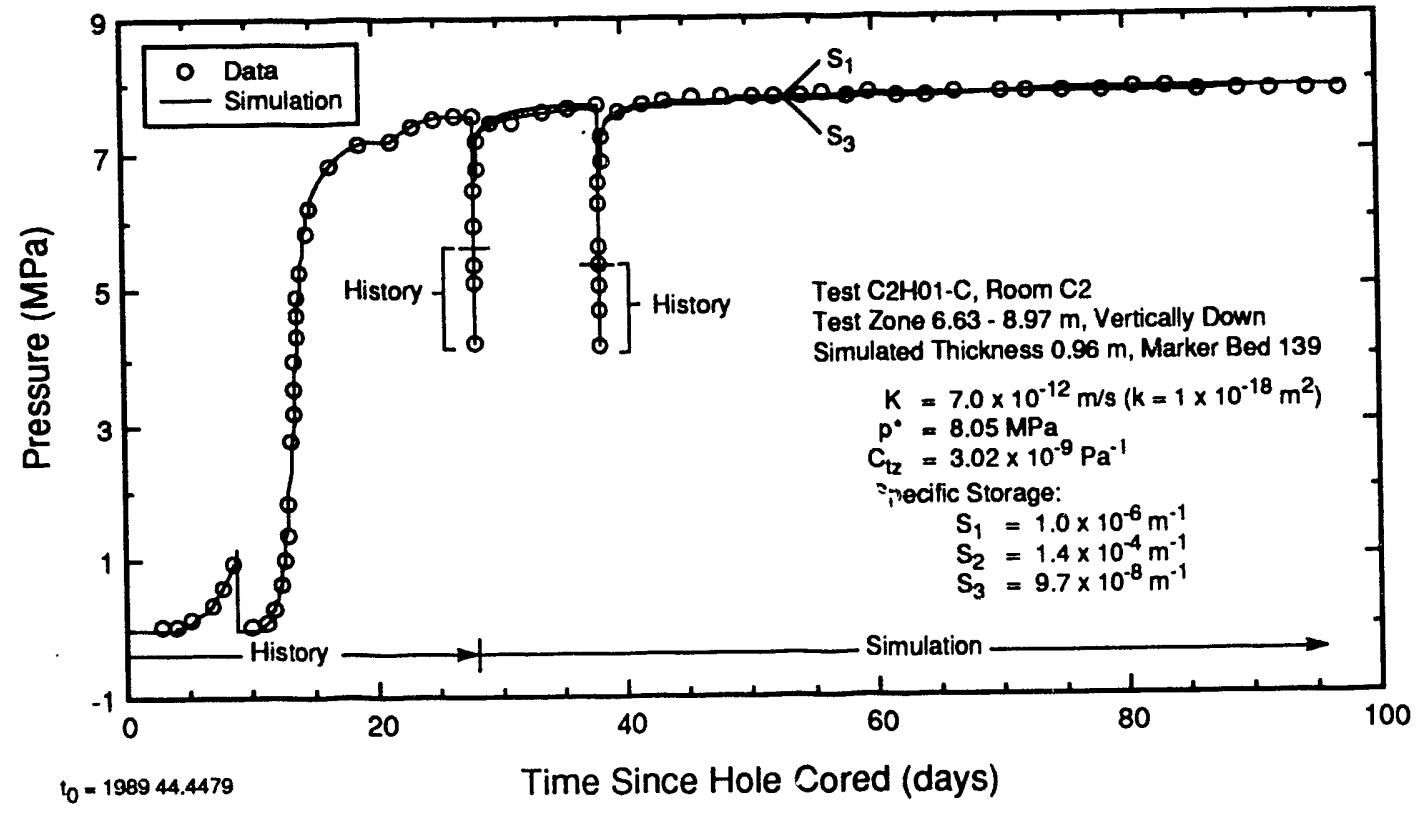

Figure 7-62. Simulation of the Test-Zone Fluid-Pressure Response during C2H01-C Testing Showing the Simulation's Sensitivity to Specific Storage. 


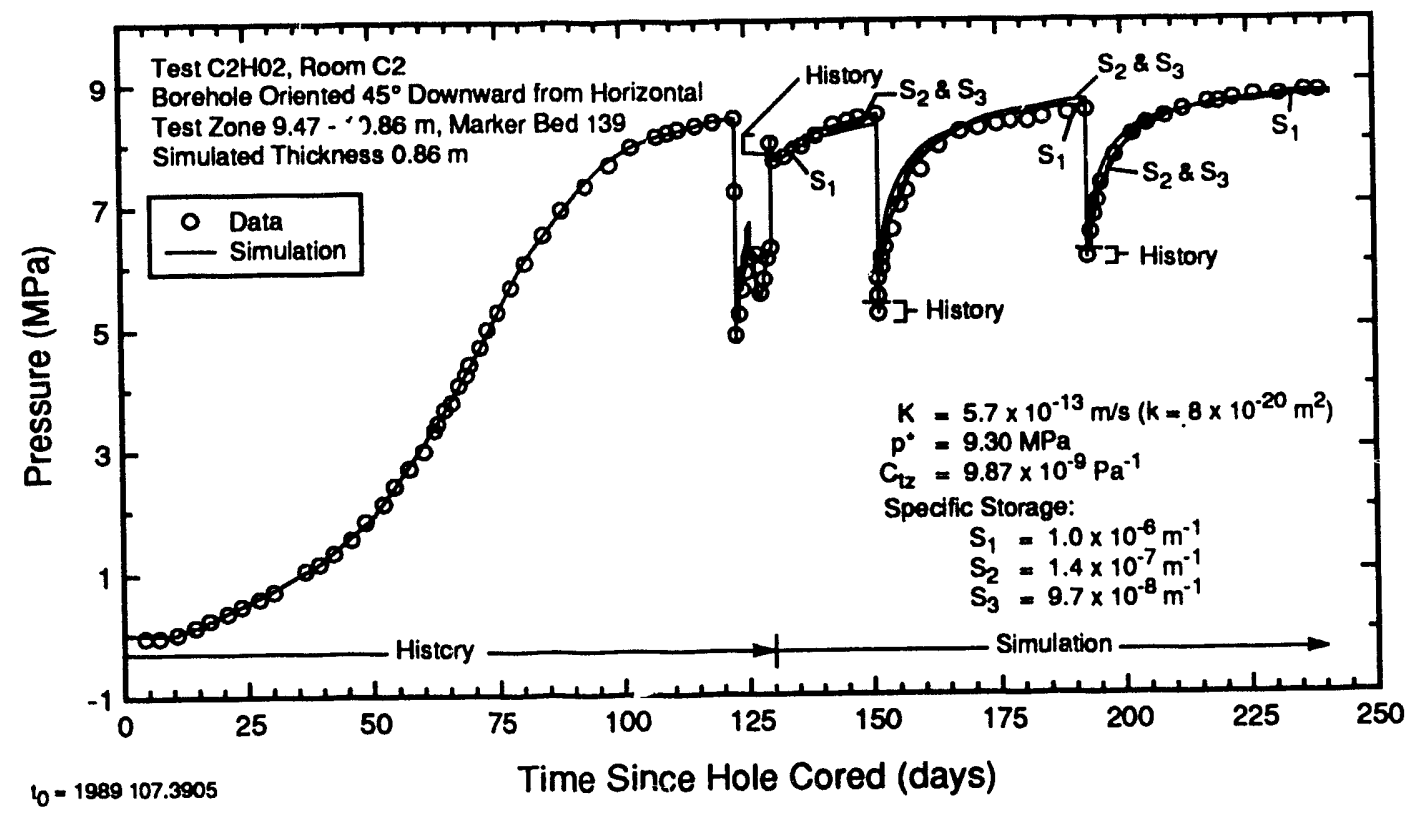

TRI-6344-613-0

Figure 7-63. Simulation of the Test-Zone Fluid-Pressure Response During C2H02 Testing Showing the Simulation's Sensitivity to Specific Storage.

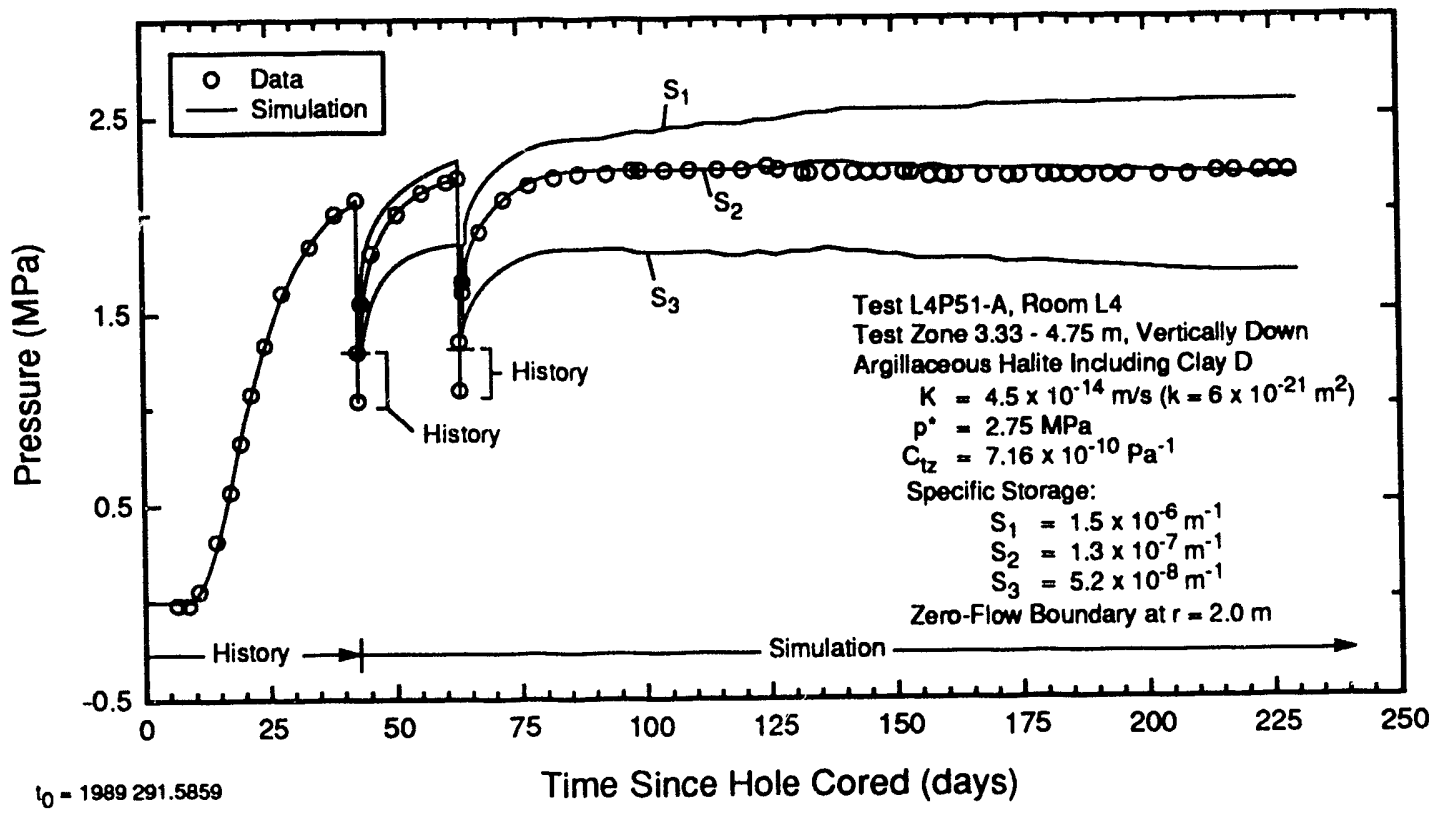

TRI-6344-614-0

Figure 7-64. Simulation of the Test-Zone Fluid-Pressure Response During L4P51-A Testing Showing the Simulation's Sensitivity to Specific Storage. 


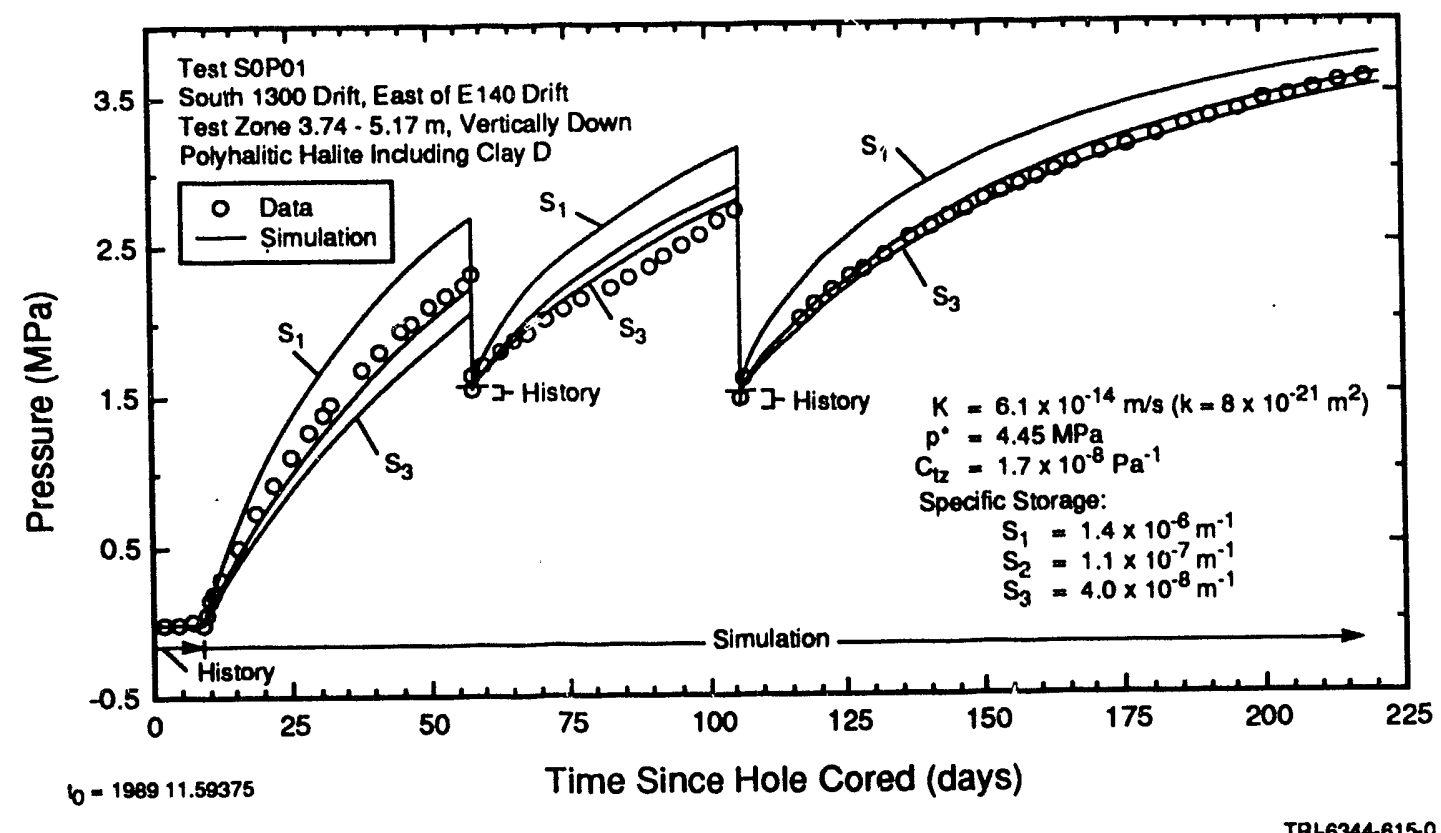

Figure 7-65. Simulation of the Test-Zone Fluid-Pressure Response During SOP01 Testing Showing the Simulation's Sensitivity to Specific Storage.

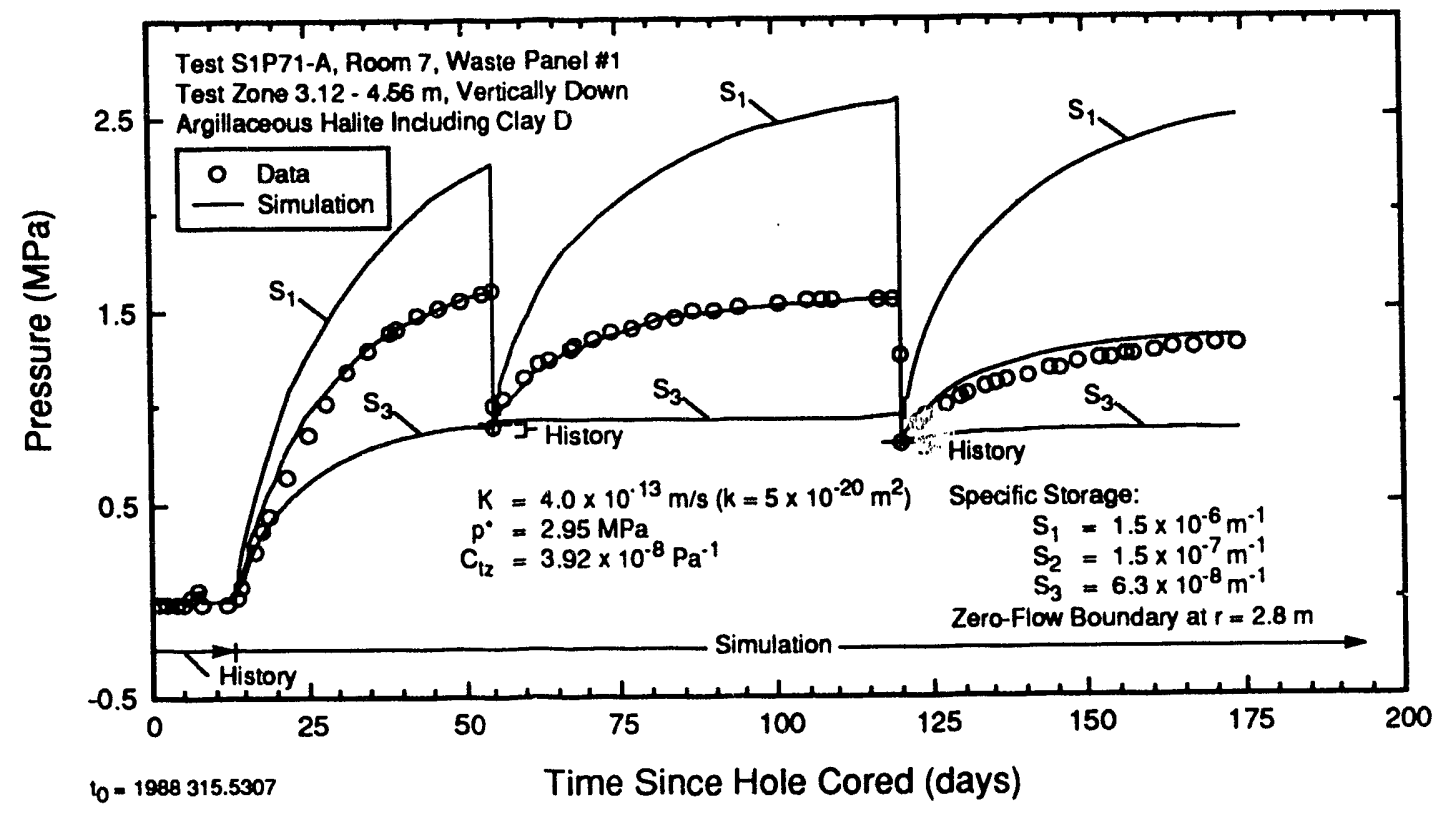

Figure 7-66. Simulation of the Test-Zone Fluid-Pressure Response During S1P71-A Testing Showing the Simulation's Sensitivity to Specific Storage. 


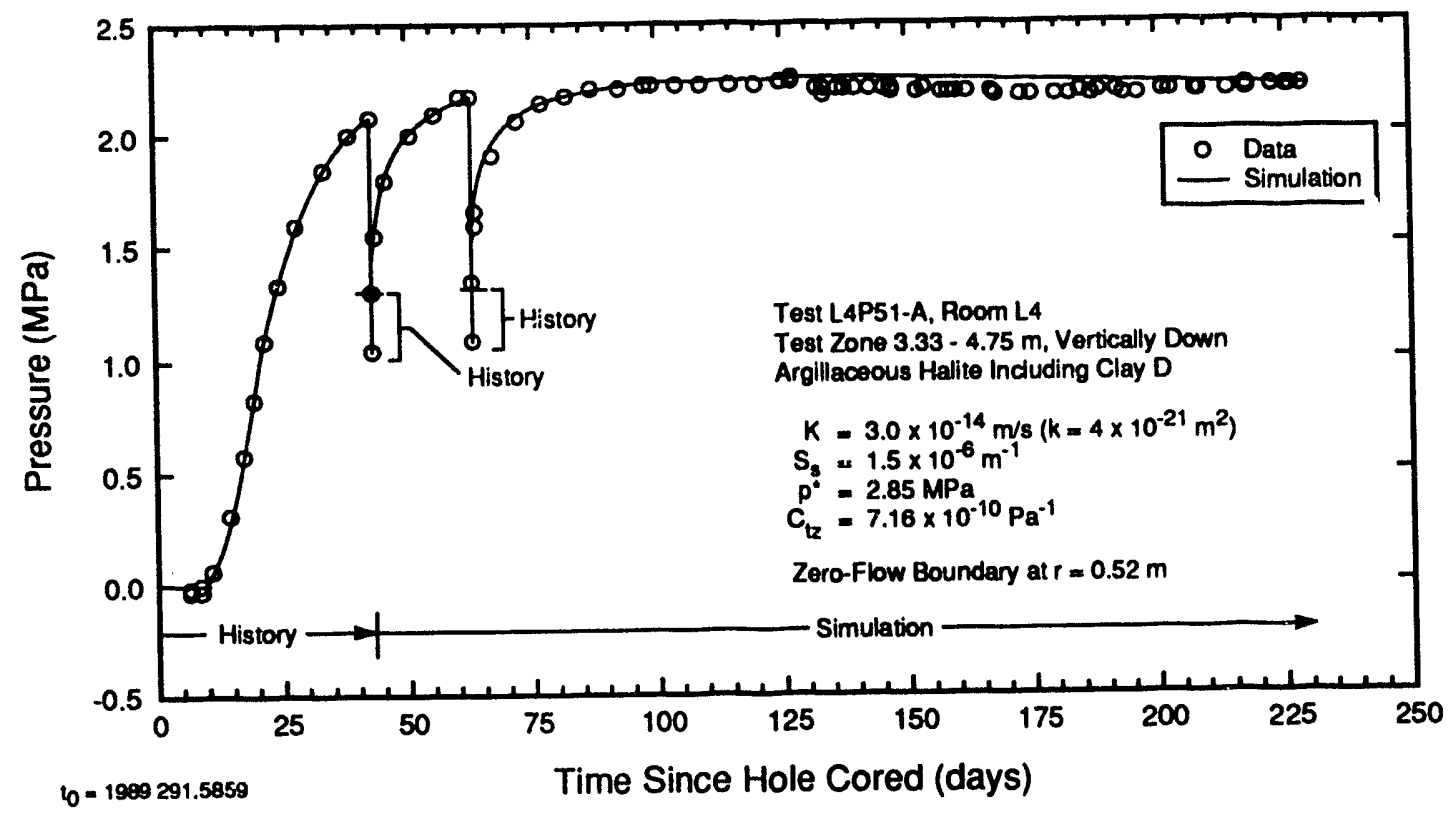

TRI-6344-617-0

Figure 7-67. Best-Fit Model Simulation of the Test-Zone Fluid-Pressure Response During L4P51-A Testing Using the Maximum Estimated Value for Specific Storage.

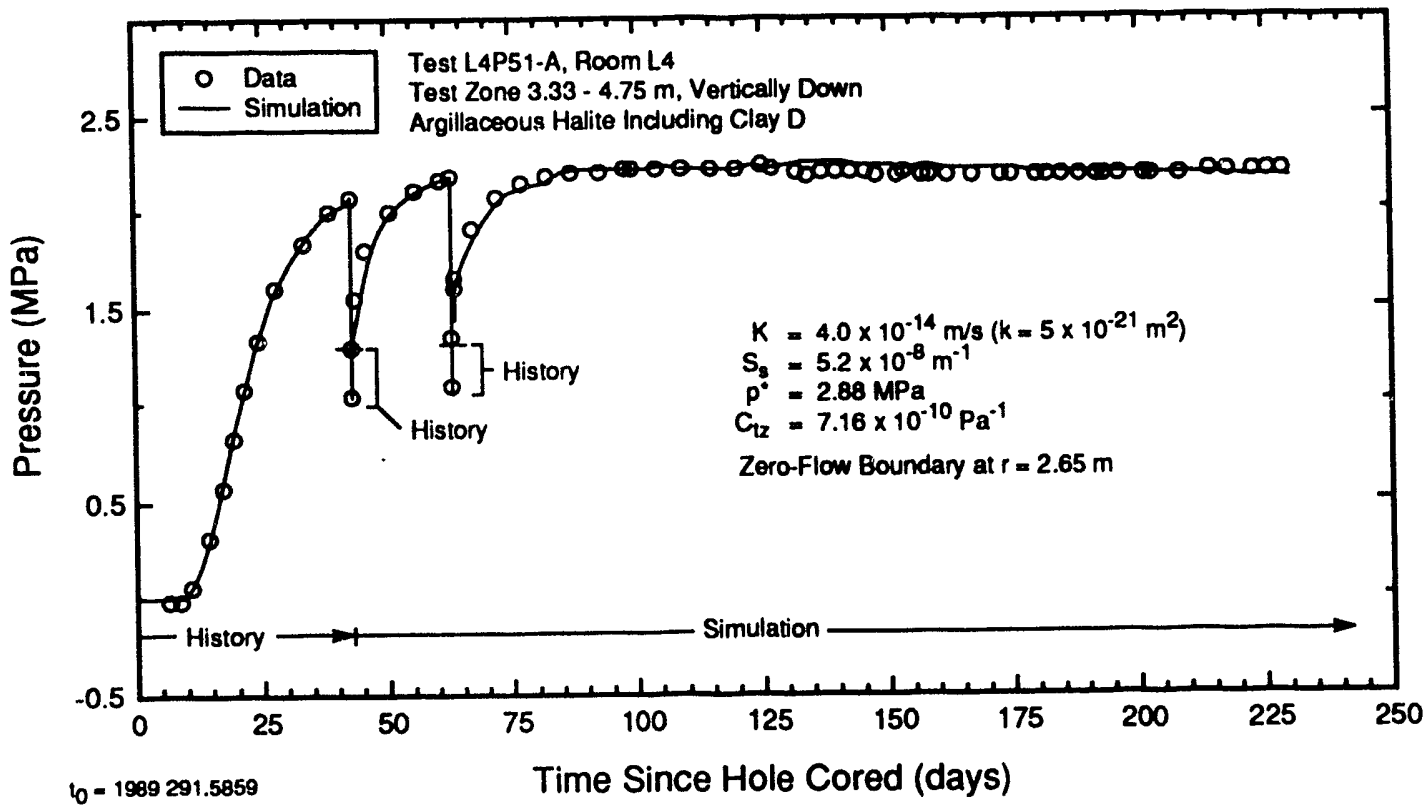

Figure 7-68. Best-Fit Model Simulation of the Test-Zone Fluld-Pressure Response During L4P51-A Testing Using the Minimum Estimated Value for Specific Storage. 
Figure 7-69 shows the simulation that best matched the S1P71-A test data when specific storage was decreased from its base-case value of $1.5 \times 10^{-7} \mathrm{~m}^{-1}$ to $6.3 \times 10^{-8} \mathrm{~m}^{-1}$. The estimated hydraulic conductivity decreased slightly from $4.0 \times 10^{-13}$ to $3.1 \times 10^{-13} \mathrm{~m} / \mathrm{s}$, and formation pore pressure increased from 2.95 to $3.50 \mathrm{MPa}$. The distance to the zero-flow bourdary changed by a greater percentage, increasing fium 2.80 to $3.57 \mathrm{~m}$. No simulation of the S1P71-A test data using a specific storage of $4.7 \times 10^{-7} \mathrm{~m}^{-1}$ is shown because a simulation using an even more extreme value is presented below.

Figure 7-70 shows the simulation that best matched the SOP01 test data when spesific storage was decreased to $4.0 \times 10^{-8} \mathrm{~m}^{-1}$ from its base-case value of $1.1 \times 10^{-7} \mathrm{~m}^{-1}$. Compared to the base-case simulation (Figure 7-35), hydraulic conductivity increased from $6.1 \times 10^{-14}$ to $6.6 \times 10^{-14} \mathrm{~m} / \mathrm{s}$, while formation pore pressure was unchanged. Figure 7-71 shows that the radius of influence of the testing increased as a result of the decrease in specific storage, when compared with the base-case radial pressures shown in Figure 7-36.

McTigue et al. (1989) have suggested that the effects of deformation and creep might result in an apparent specific storage as much as three orders of magnitude greater than a specific storage calculated using Eqs. 6-1 or 6-2. Accordingly, attempts were made to fit the responses observed during the SOP01 and S1P71-A testing using a capacitance $\left(S_{s} / \rho, g\right)$ of $3.4 \times 10^{9} \mathrm{~Pa}^{-1}$ (McTigue, 1989), which produces a specific-storage value of about $4.1 \times 10^{-5} \mathrm{~m}^{-1}$.

A good match was obtained to the SOP01 data (Figure 7-72) by decreasing the hydraulic conductivity from $6.1 \times 10^{-14}$ to $6.0 \times 10^{-15} \mathrm{~m} / \mathrm{s}$, and increasing the formation pore pressure from 4.45 to $6.40 \mathrm{MPa}$, relative to the best-fit simulation that employed the base case value of specific storage of $1.1 \times 10^{-7} \mathrm{~m}^{-1}$ (Figure 7-35). As a result of increasing the specific storage by over two orders of magnitude, the calculated radius of influence of the SOPO1 testing decreased significantly. Figure 7-73 shows that the radius of influence of the entire SOP01 testing sequence assuming high specific siorage was only about $20 \mathrm{~cm}$, or only about $15 \mathrm{~cm}$ past the wall of the borehole, compared to a radius of influence of over 8 $m$ using the base-case value of specific storage (Figure 7-36). The effects of the individual pulses are only observed out to a radial distance of about $9 \mathrm{~cm}$, about $4 \mathrm{~cm}$ past the wall of the borehole. This result is not surprising, because the pressure distribution in a porous medium is controlled by the hydraulic diffusivity $\left(K S_{S}\right)$. Between the base-case simulation and the high-specific-storage simulation, the SOP01 hydraulic diffusivity decreased from $5.5 \times 10^{-7} \mathrm{~m}^{2} / \mathrm{s}$ to $1.5 \times$ $10^{-10} \mathrm{~m}^{2} / \mathrm{s}$.

The best fit obtained to the S1P71-A data using the high specific-storage value of $4.1 \times 10^{-5} \mathrm{~m}^{-1}$ (Figure 7 . 74) matched the data almost as well as the basecase simulation, which used a specific storage of 1.5 $\times 10^{-7} \mathrm{~m}^{-1}$ (Figure 7-40). Relative to the base-case simulation, hydraulic conductivity was decreased from $4.0 \times 10^{-13}$ to $9.0 \times 10^{-14} \mathrm{~m} / \mathrm{s}$, formation pore pressure was increased from 2.95 to $3.50 \mathrm{MPa}$, and the distance to the zero-flow boundary was decreased from 2.80 to $0.115 \mathrm{~m}$ for the high-specific-storage simulation. A distance of $0.115 \mathrm{~m}$ to the zero-flow boundary implies that only an annulus of rock around the borehole about $6 \mathrm{~cm}$ thick contributed to the observed response.

The physical processes that may contribute to specific storage in halite are uncertain. However, we can draw conclusions from the SOP01 simulations with low and high values of specific storage (Figures 7-70 and 7-72, respectively) as to how uncertainty in specific storage 


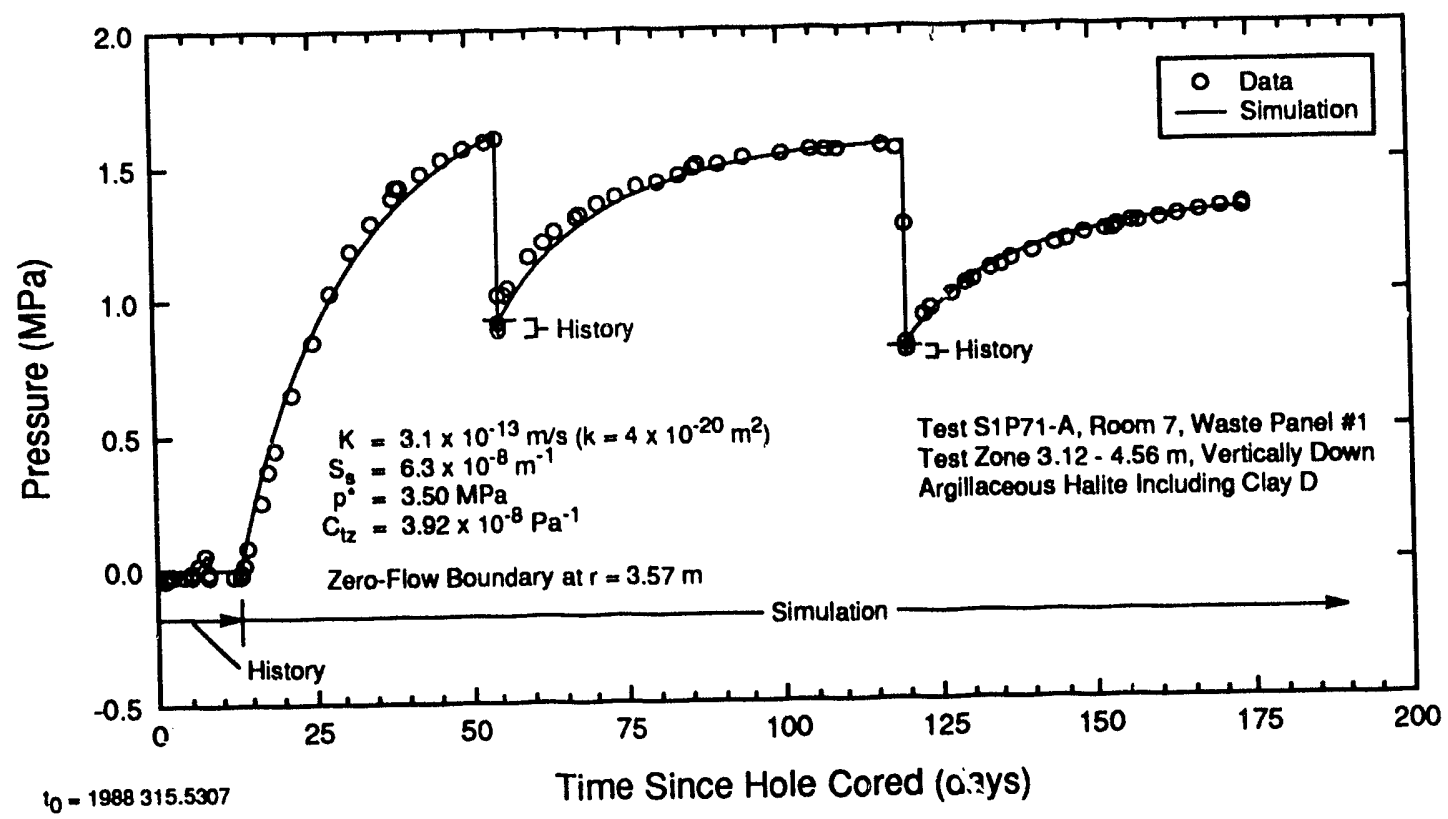

TRl-6344-619-0

Figure 7-69. Best-Fit Model Simulation of the Test-Zone Fluld-Pressure Response During S1P71-A Testing Using the Minimum Estimated Value for Specific Storage.

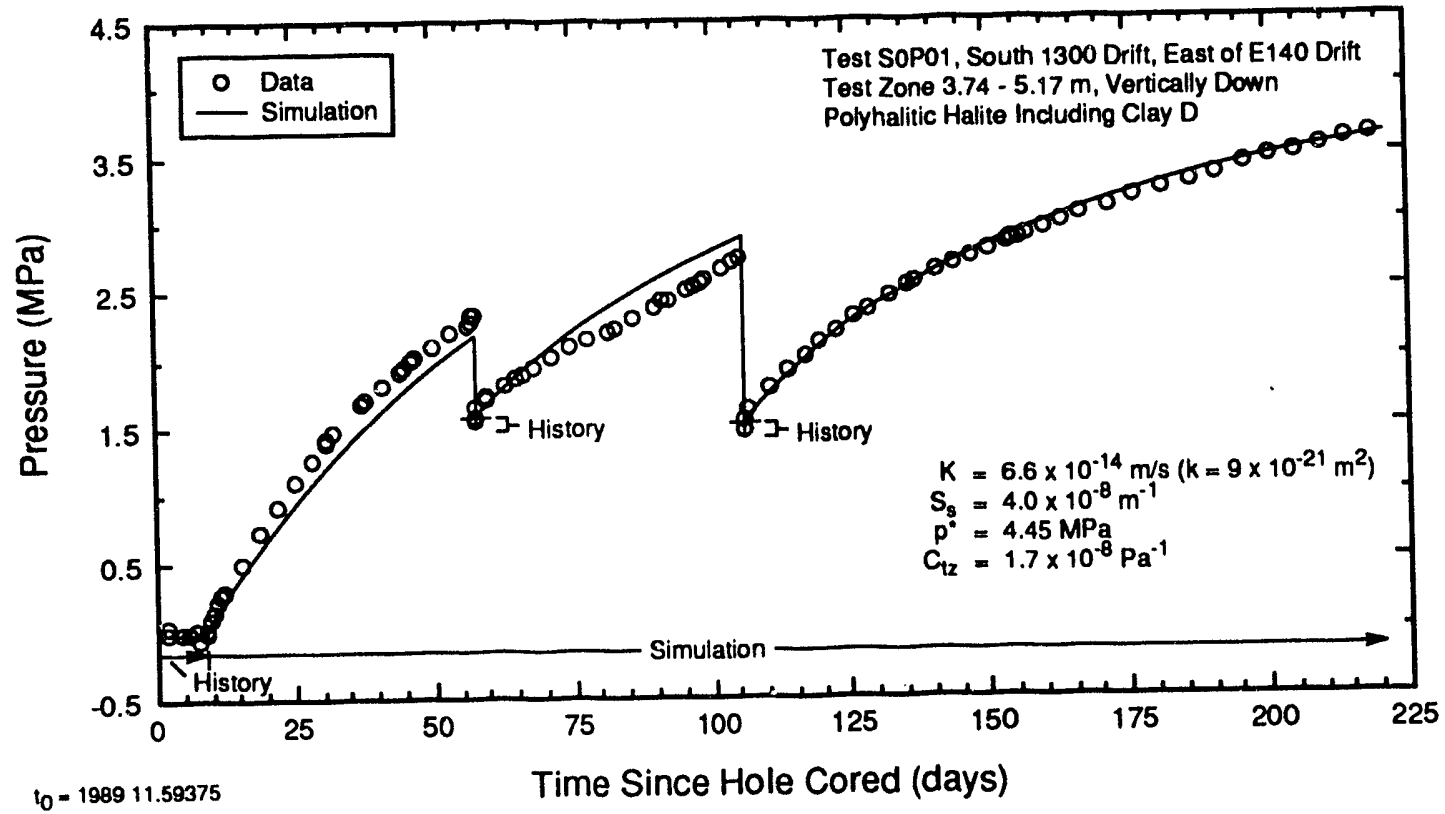

Figure 7-70. Best-Fit Model SImulation of the Test-Zone Fluid-Pressure Response During SOP01 Testing Using the Minimum Estimated Value for Specific Storage. 


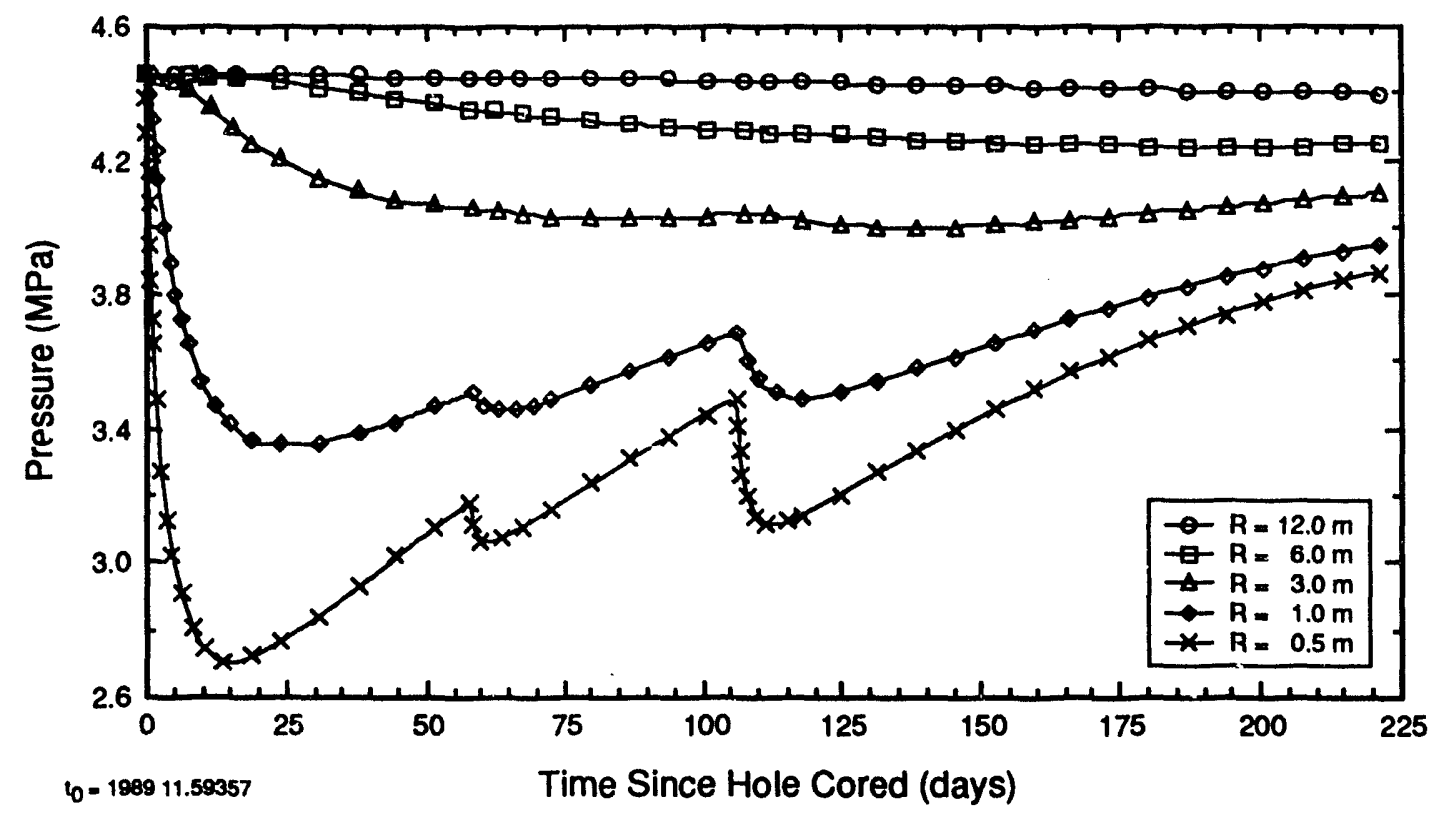

Figure 7-71. Simulated Formation Pore Pressures at Selected Radial Distances from the Test Zone During SOP01 Testing Using the Minimum Estimated Value for Specific Storage.

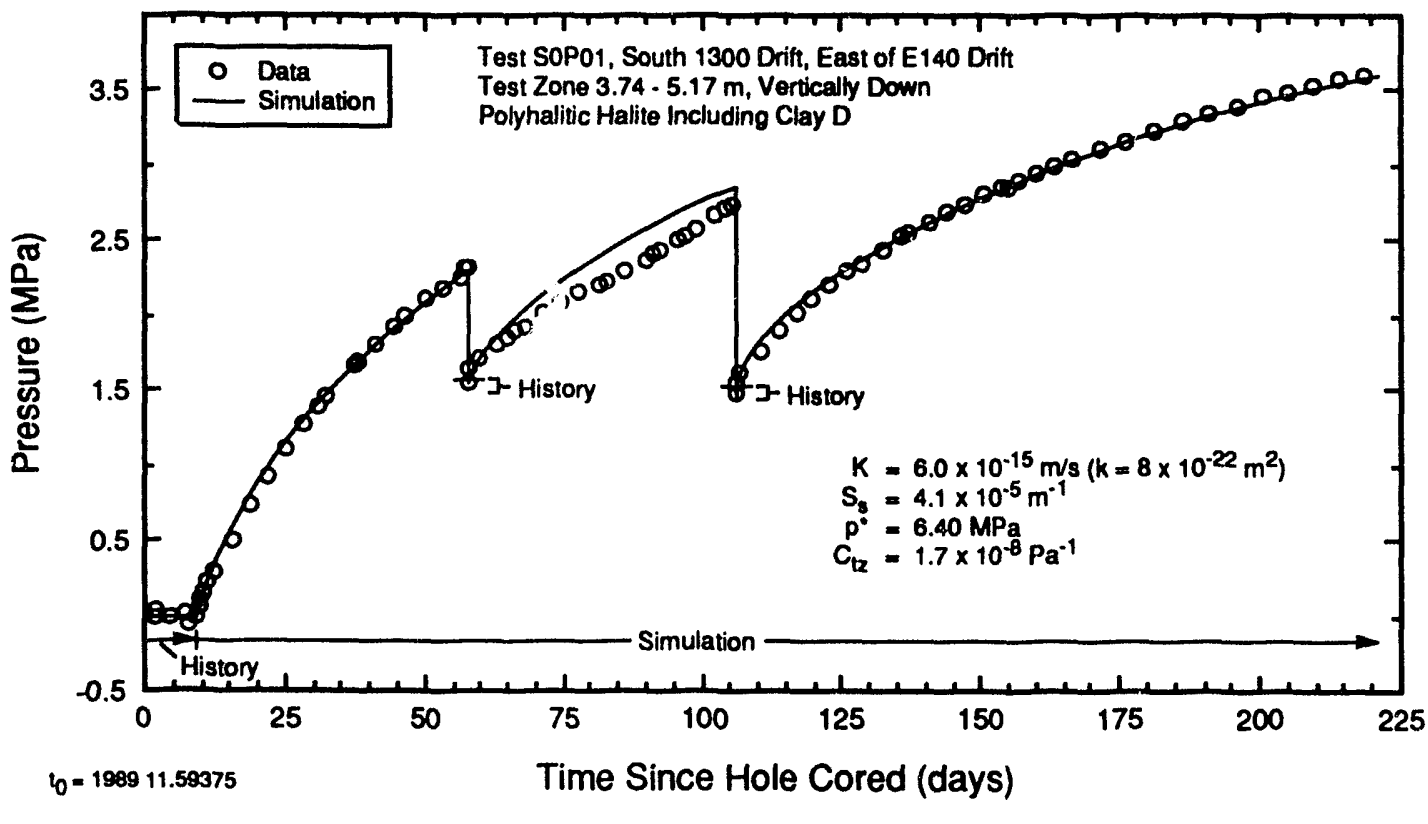

Figure 7-72. Best-Fit Model Simulation of the Test-Zone Fluid-Pressure Response During SOP01 Testing Using a Specific Storage of $4.1 \times 10^{-5} \mathrm{M}^{-1}$. 


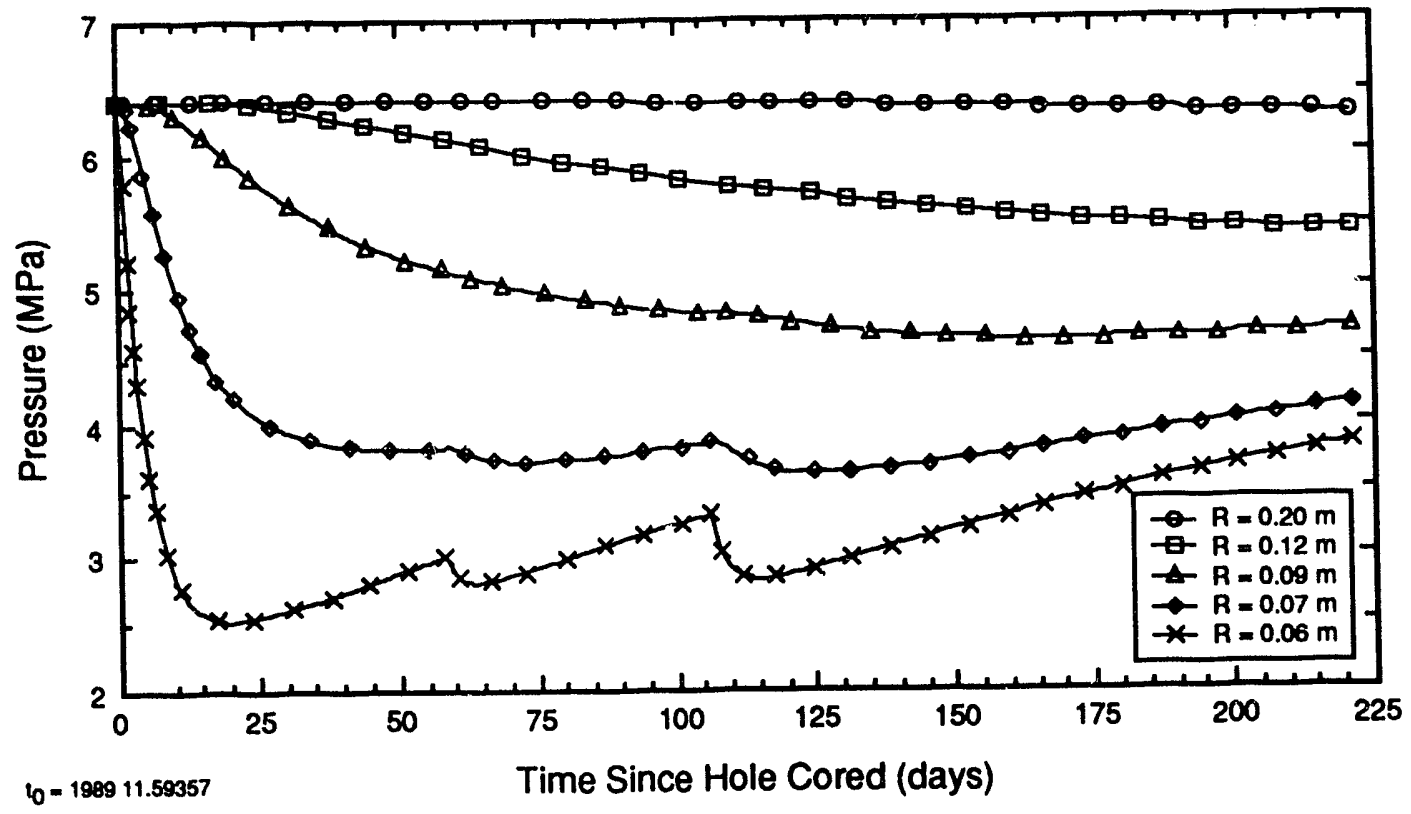

TR1-6344-623-0

Figure 7-73. Simulated Formation Pore Pressures at Selected Radlal Distances from the Test Zone During SOP01 Testing Using a Specific Storage of $4.1 \times 10^{-5} \mathrm{M}^{-1}$.

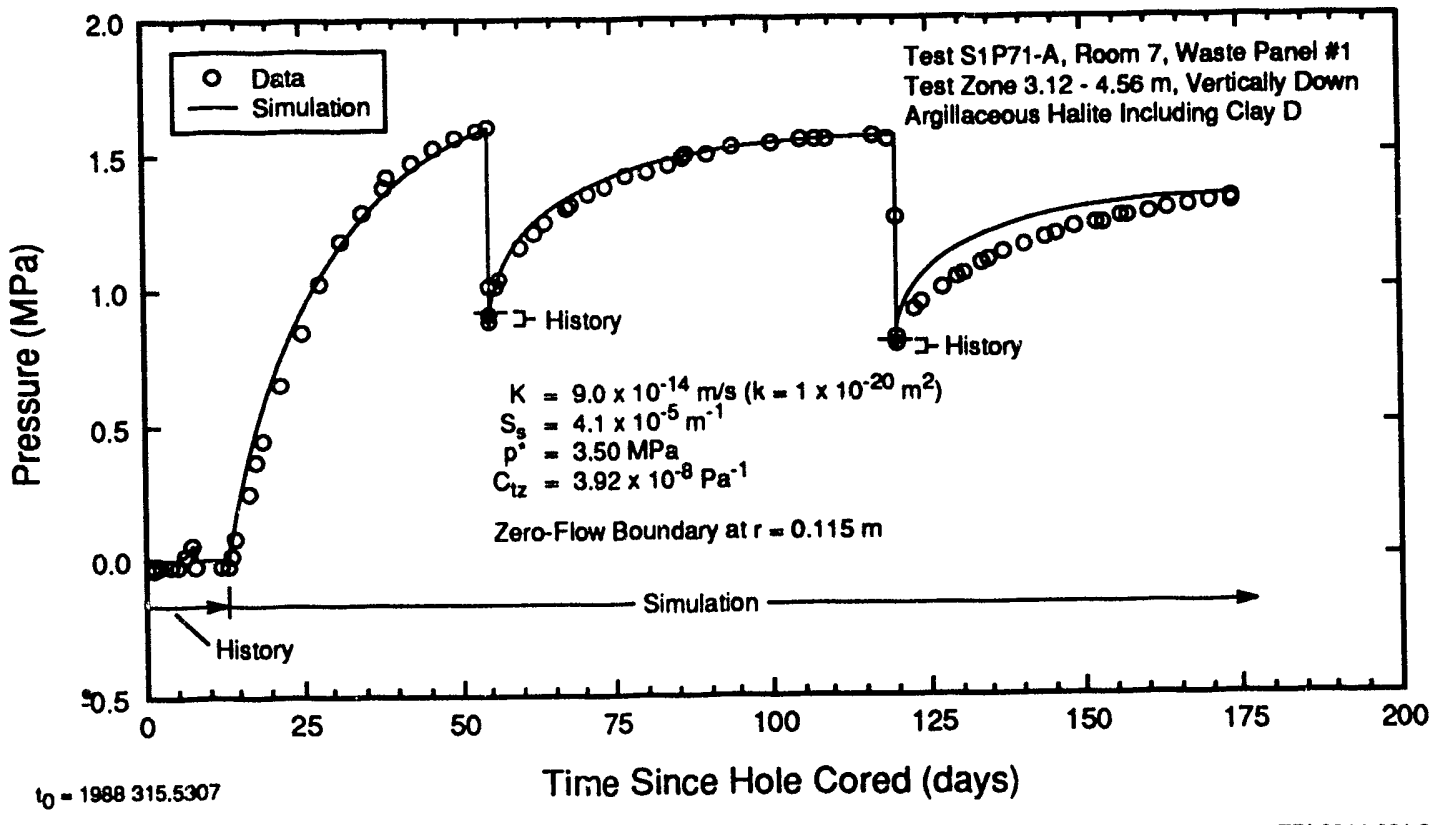

Figure 7-74. Best-Fit Model Simulation of the Test-Zone Fluld-Pressure Response During S1P71-A Testing Using a Speclfic Storage of $4.1 \times 10^{-5} \mathrm{M}^{-1}$. 
affects estimates of other parameters. With respect to base-case values of specific storage, which assume pore deformation is caused only by changes in vertical effective stress, the inclusion of other mechanisms of pore deformation that increase specific storage will serve to decrease estimates of hydraulic conductivity and increase estimates of formation pore pressure. Inctusion of factors that decrease specific storage will increase estimates of hydraulic conductivity and decrease estimates of formation pore pressure. In the case of the SOPO1 simulations, varying specific storą̧e over three orders of magnitude caused best-fit hydraulic-conductivity values to vary over only one order of magnitude. In the case of simulations involving zero-flow boundaries, however, the effects of changes in specific storage on hydraulic conductivity and formation pore pressure are more difficult to predict because of the added influence of the boundary. In all cases, estimates of radii of influence or distances to zero-flow boundaries decrease as specific storage increases, because the volume of rock affected by a test is roughly inversely proportional to hydraulic diffusivity.

7.2.5 TEST-ZONE COMPRESSIBILITY. A value for test-zone compressibility was calculated for each pulse withdrawal except for the first one during the C2H01-B testing (Table 6-3). The base-case value used in the simulations of a particular testing sequence was the log-average of all available values from that testing sequence. Figures 7-75 through 7-82 show the sensitivities of the best-fit simulations to the values of test-zone compressioility calculated from the individual pulse-withdrawal data. When only one value of test-zone compressibility was available for a particular testing sequence, as for $\mathrm{C} 2 \mathrm{H} 01-\mathrm{B}$, the sensitivity calculations were performed using values of test-zone compressibility about half an order of magnitude higher and lower than the single calculated value. Also, because no values of test-zone compressibility were available for the $\mathrm{C} 2 \mathrm{H} 01-\mathrm{A}$ and $\mathrm{C} 2 \mathrm{H} 01-\mathrm{B}-\mathrm{GZ}$ sequences, sensitivity to test-zone compressibility for these sequences was evaluated using the same range of values as was used for the $\mathrm{C} 2 \mathrm{H} 01-\mathrm{B}$ testing sequence.

Changing test-zone compressibility by half an order of magnitude for the $\mathrm{C}_{2} \mathrm{HO}-\mathrm{A}, \mathrm{C} 2 \mathrm{HO1}-\mathrm{B}$, and C2H01-B-GZ simulations (Figures 7-75, 7-76, and 7-77, respectively) causes the simulations to change about as much as is caused by a change in hydraulic conductivity of half an order of magnitude (Figures 7 . 41, 7-42, and 7-43), as expected. The change in the $\mathrm{C} 2 \mathrm{H} 01-\mathrm{A}$ simulation (Figure 7-75) was comparable to that caused by a $0.1-\mathrm{MPa}$ change in formation pore pressure ( igure 7-49), while the changes in the $\mathrm{C} 2 \mathrm{H} 01-\mathrm{B}$ and $\mathrm{C} 2 \mathrm{H} 01-\mathrm{B}-\mathrm{GZ}$ simulations were greater than those caused by $0.1-\mathrm{MPa}$ pressure changes (Figures 7-50 and 7-51, respectively). In the case of $\mathrm{C} 2 \mathrm{H} 01-\mathrm{C}$ (Figure 7-78), the uncertainty in test-zone compressibility has little effect on the simulations (separate simulation lines are not resolvable on the figure) because of the inclusion of a relatively high value of hydraulic conductivity. In the cases of $\mathrm{C} 2 \mathrm{HO} 2$ and L4P51-A (Figures $7-79$ and $7-80$, respectively), the ranges in calculated testzone compressibilities are small, and the simulations employing the different values differ correspondingly little. The uncertainty in test-zone compressibility for SOP01 changes the simulation (Figure 7-81) about as much as does a unit change within the order of magnitude of the best-fit value of hydraulic conductivity (Figure 7-47), and a little more than does a $0.1-\mathrm{MPa}$ change in formation pore pressure (Figure 7-55). The uncertainty in test-zone compressibility for S1P71-A changes the simulation (Figure 7-82) slightly more than do the standard changes in hydraulic conductivity (Figure 7-48), formation pore pressure (Figure 7-56), and distance to the zero-flow boundary (Figure 7-58). 


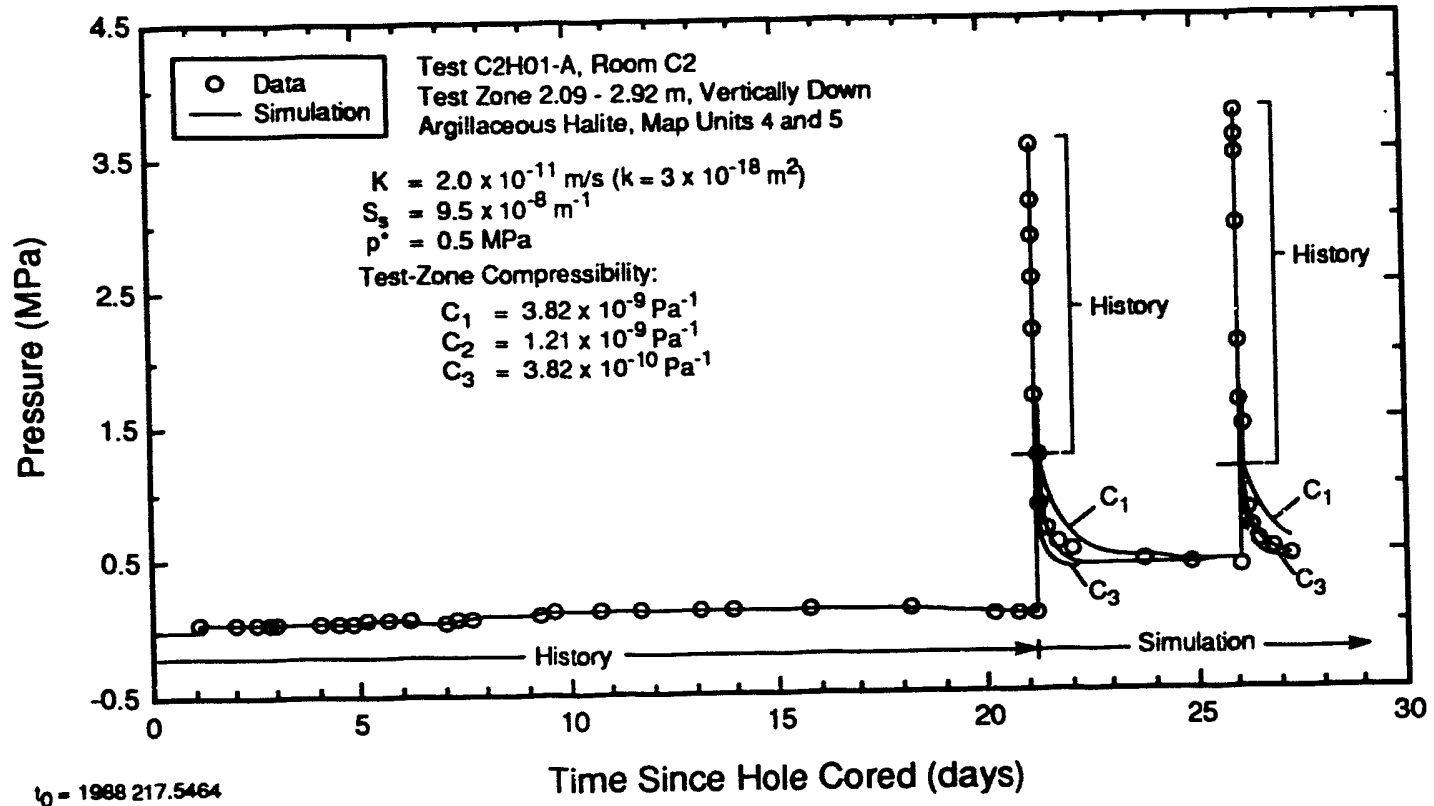

TR1-6344-625-0

Figure 7-75. Simulation of the Test-Zone Fluid-Pressure Response During C2H01-A Testing Showing the Simulation's Sensitivity to Test-Zone Compressibility.

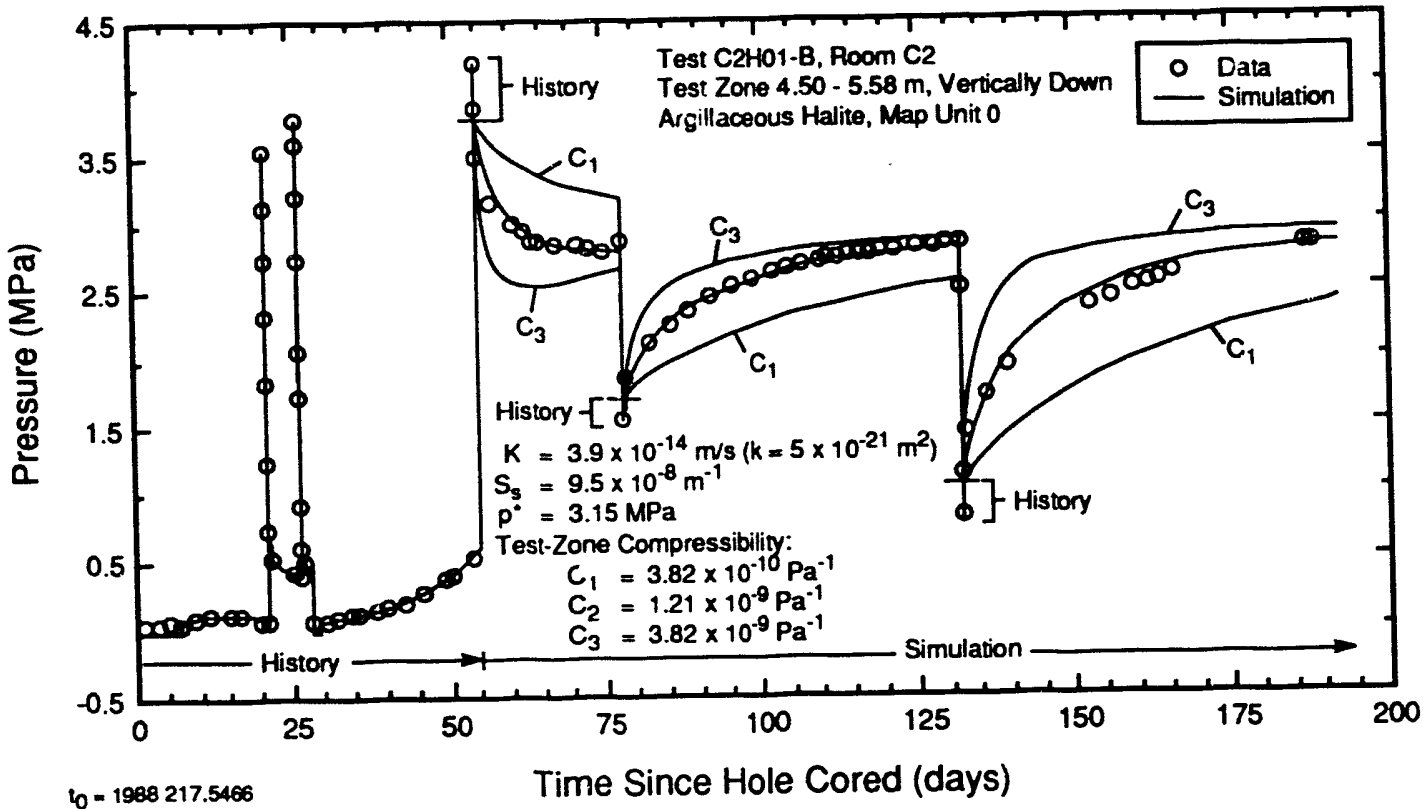

Figure 7-76. Simulation of the Test-Zone Fluid-Pressure Response During C2H01-B Testing Showing the Simulation's Sensitivity to Test-Zone Compressibility. 


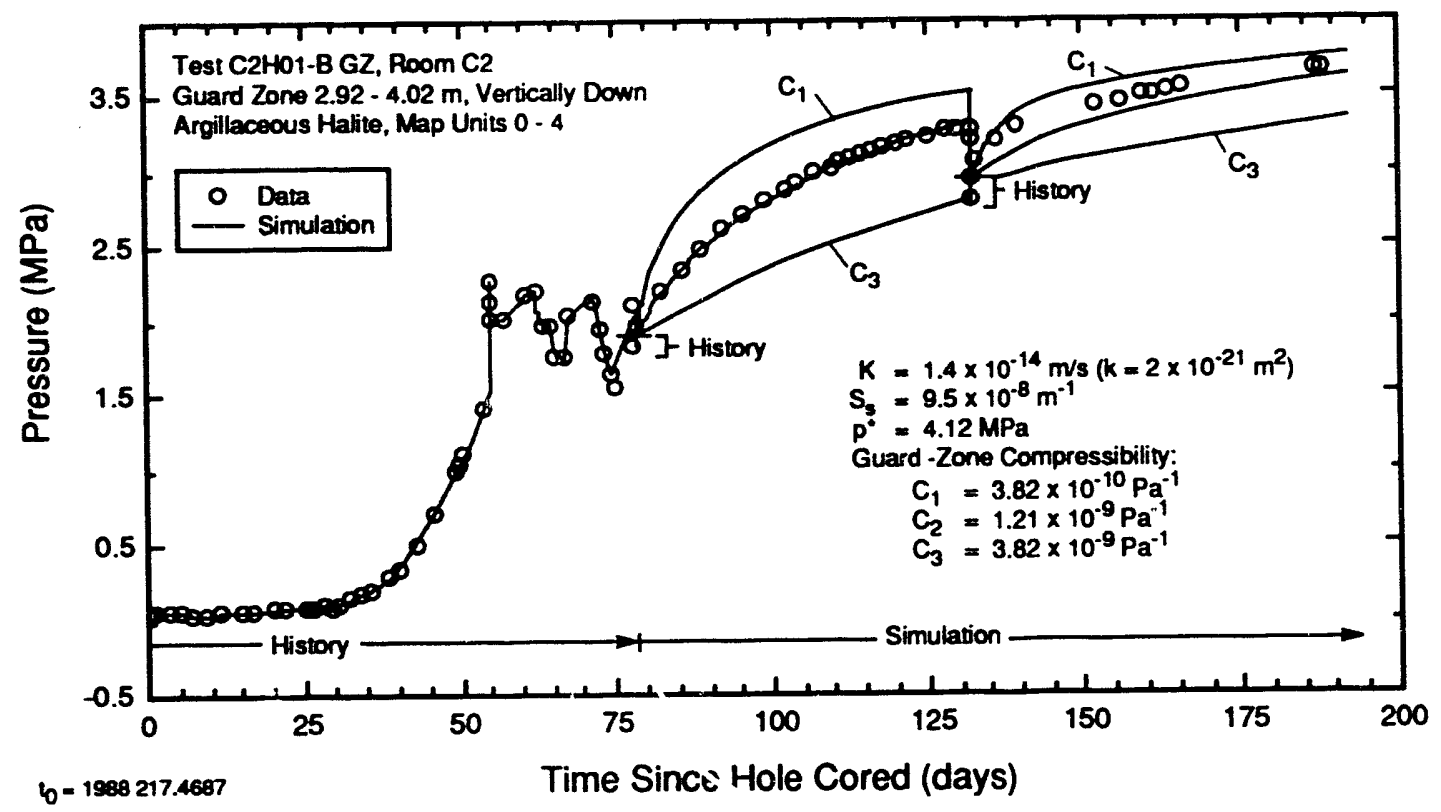

TR1-6344-697-0

Figure 7-77. Simulation of the Guard-Zone Fluid-Pressure Response During C2H01-B Testing Showing the Simulation's Sensitivity to Guard-Zone Compressibility.

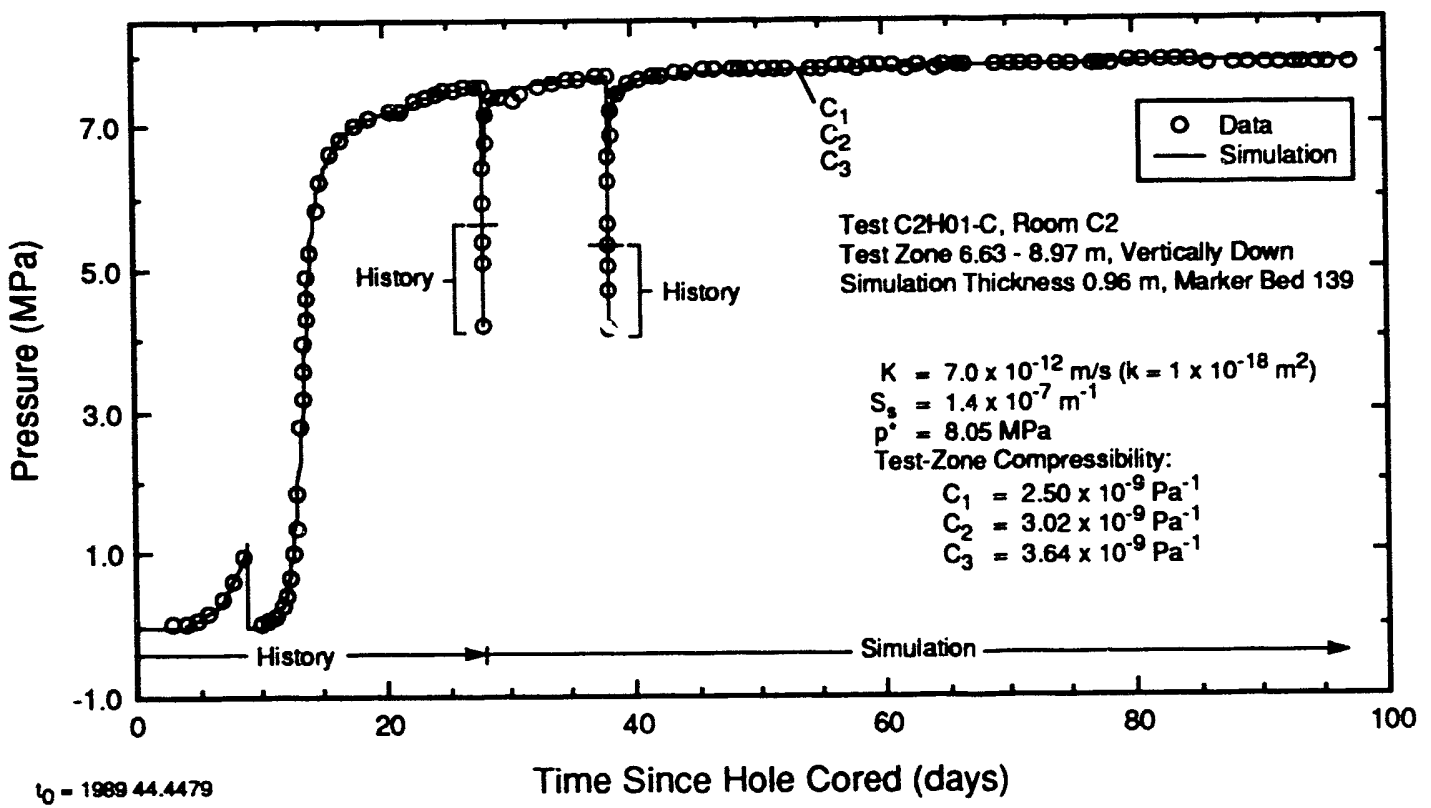

TA16344-628-0

Figure 7-78. Simulation of the Test-Zone Fluid-Pressure Response During C2H01-C Testing Showing the Simulation's Sensitivity to Test-Zone Compressibility. 


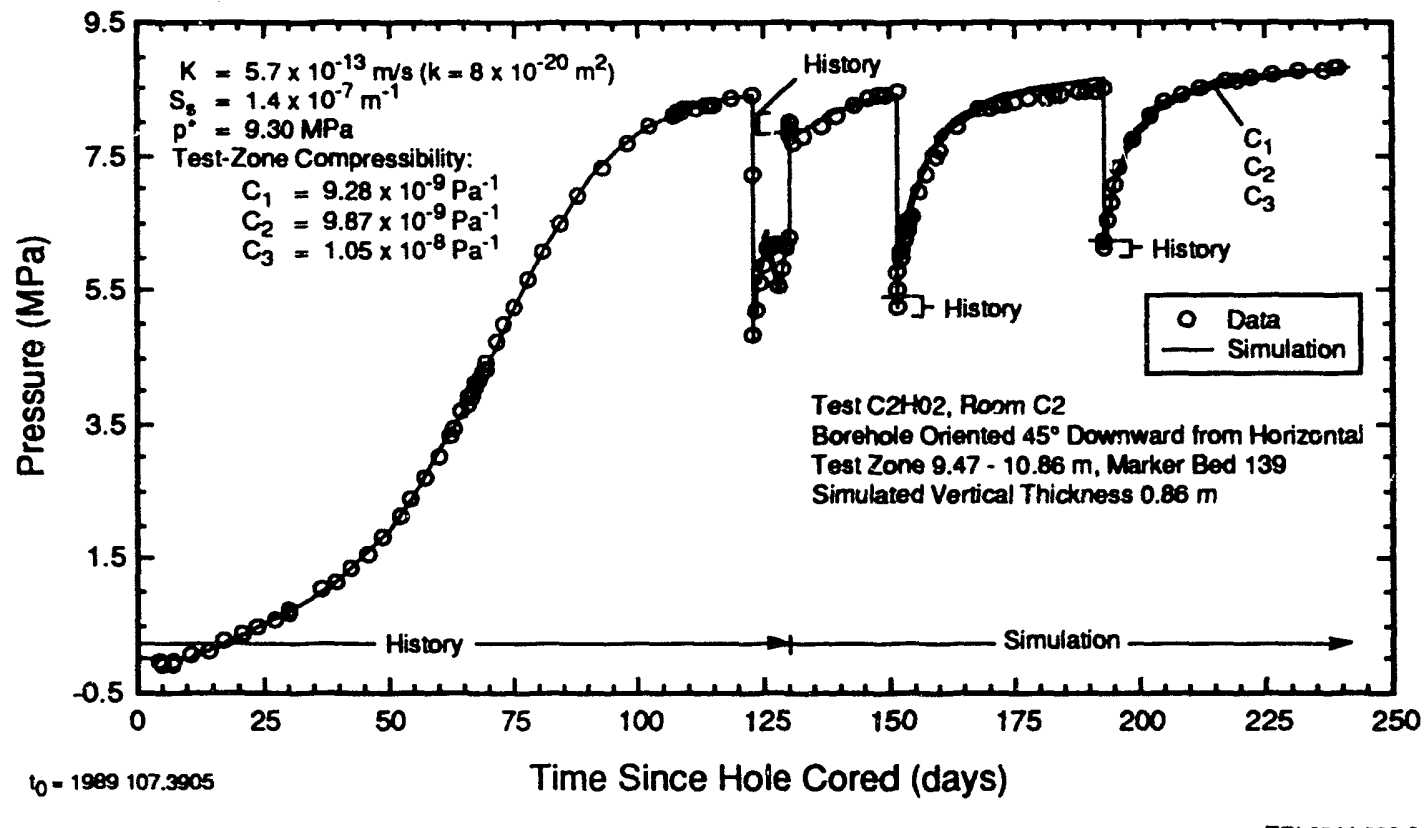

TRL6344-6290

Figure 7-79. Simulation of the Test-Zone Fluid-Pressure Response During C2H02 Testing Showing the Simulation's Sensitivity to Test-Zone Compressibility.

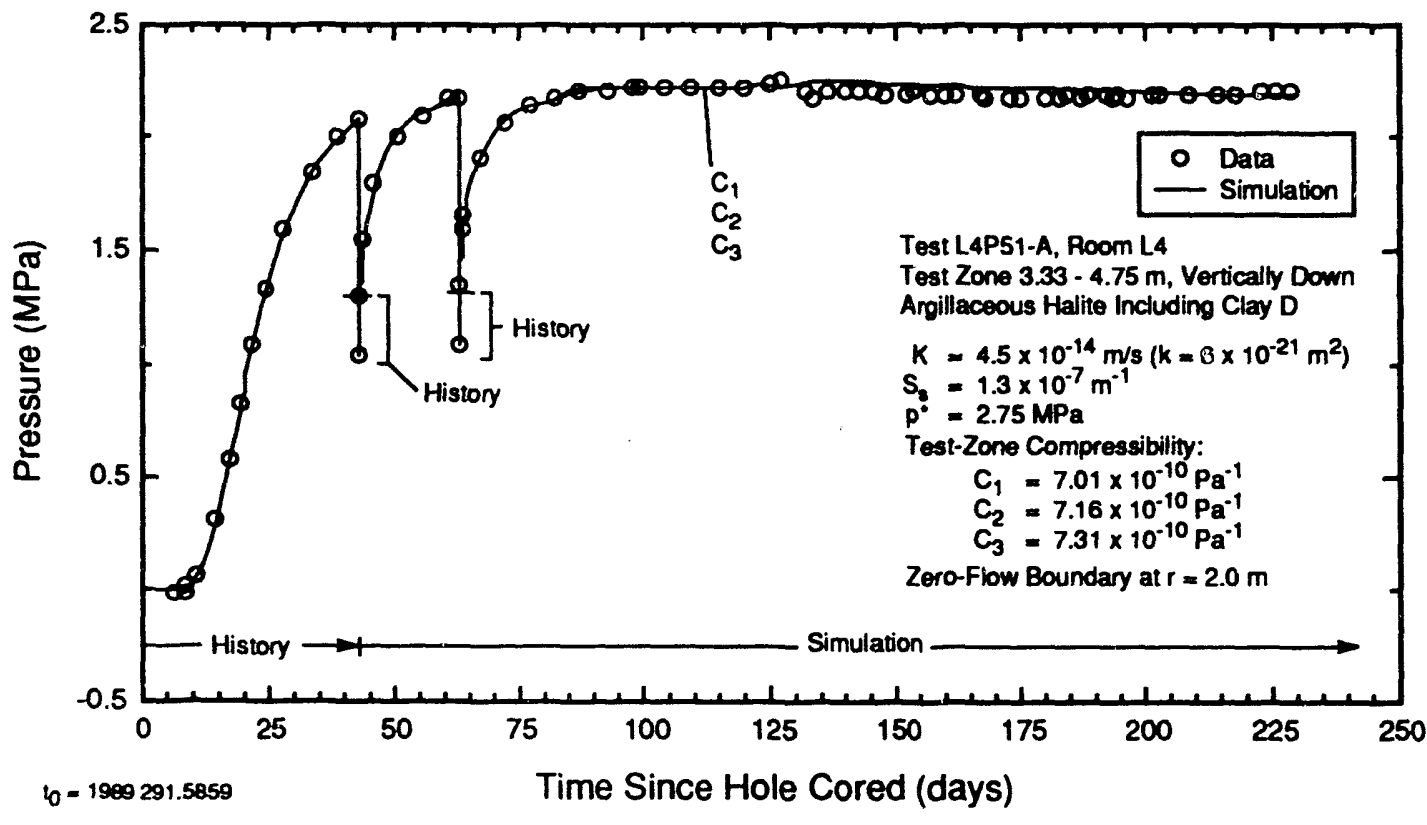

Figure 7-80. Simulation of the Test-Zone Fluid-Pressure Response During L4P51-A Testing Showing the Simulation's Sensitivity to Test-Zone Compressibility. 


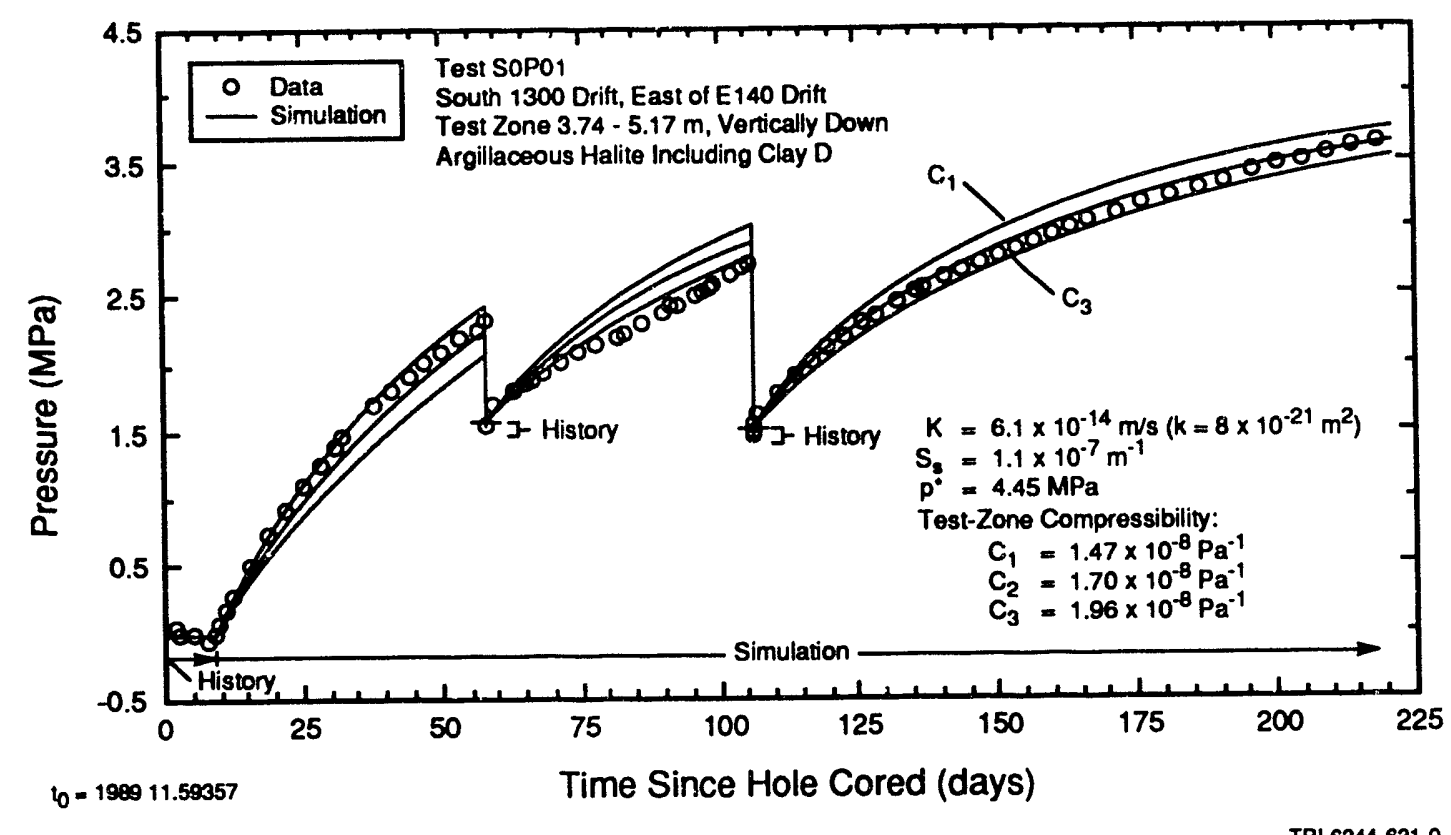

Figure 7-81. Simulation of the Test-Zone Fluid-Pressure Response During SoP01 Testing Showing the Simulation's Sensitivity to Test-Zone Compressibility.

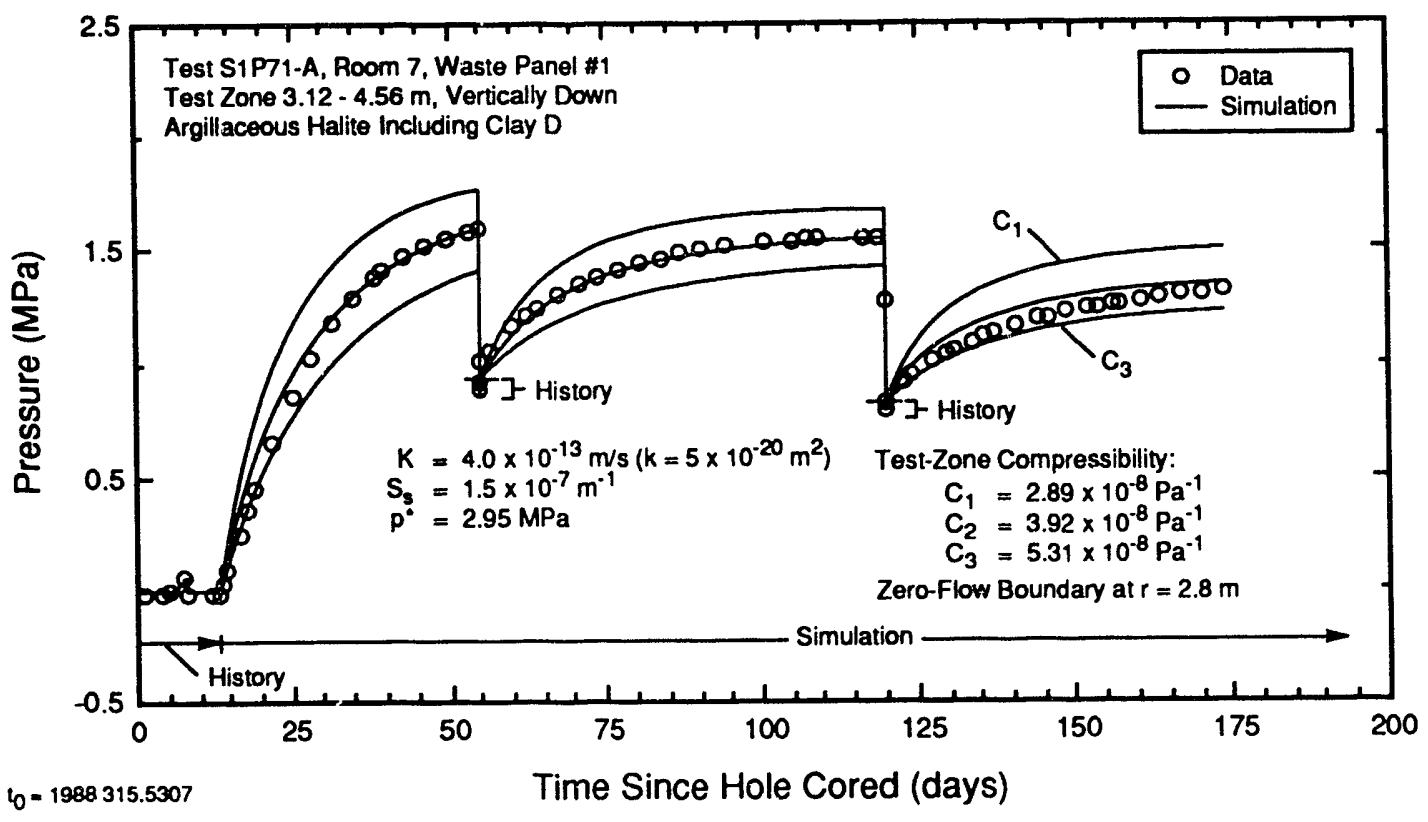

Figure 7-82. Simulation of the Test-Zone Fluid-Pressure Response During S1P71-A Testing Showing the Simulation's Sensitivity to Test-Zone Compressibility. 
Test-zone compressibility was among the most uncertain of the specified parameters. As discussed in Section 6.5 , the estimation of test-zone compressibility did not take into consideration potential non-linearities and time-varying factors such as changes in the brine/ gas ratio in the test zone, nor did it include gas volumes released during pulse withdrawals. Accordingly, the sensitivity analyses discussed above may not have fully examined the true ranges of uncertainty in testzone compressibility for the different tests.

\subsubsection{TEST-ZONE-VOLUME COMPENSATIONS.}

The sensitivities of the best-fit simulations to the inclusion or exclusion of time-varying test-zonevolume compensations are shown in Figures 7-83 through 7-90. These figures compare the best-fit simulations obtained with test-zone-volume compensations with simulations obtained using exactly the same values for the specified and fitted parameters, but without test-zone-volume compensations. In general, the presence or absence of test-zonevolume compensations makes little difference in the simulations. The one notable exception is L4P51-A (Figure 7-88). The test-zone-volume compensation had a significant influence on the L4P51-A simulation for two reasons: 1) the simulation includes a zero-flow boundary, so volume changes within the borehole represent a larger fraction of the total volume considered in the model than in the simulations with no boundaries; and 2) the calculated testzone compressibility was lower during the L4P51-A tests than during any other tests, causing any volume changes that occurred to have a larger eifect on pressure. In contrast, the other simulation that included a zero-flow boundary, that of the S1P71-A tests (Figure 7-90), used the highest calculated test-zone compressibility of any test. This high compressibility apparently acted to minimize the effects of volume changes on test-zone pressure.
7.2.7 TEMPERATURE COMPENSATIONS. The largest test-zone-temperature fluctuations observed to date during the Salado permeability-testing program (about $i^{\circ} \mathrm{C}$ ) occurred during the L4P51-A and SOP01 testing (Saulnier et al., 1991). The sensitivities of the best-fit simulations of these two tests to the presence or absence of temperature compensations are shown in Figures 7-91 and 7-92. These figures compare the best-fit simulations obtained with temperature compensations with simulations obtained using exactly the same values for the fitted and specified parameters, but without temperature compensations. In both cases, the effects of temperature compensations appear to be insignificant, even though test-zone compressibilities in the two cases differ by about 1.4 orders of magnitude.

\subsubsection{SUMMARY OF SENSITIVITY ANALYSES.} The following conclusions can be drawn from the sensitivity analyses. The fitted parameters (hydraulic conductivity, formation pore pressure, and distance to azero-flowboundary where applicable) canbe changed individually very little without degrading the matches between the simulations and the observed data. If two or more parameters are changed simultaneously, however, the ranges of values that produce acceptable simulations widen. Within the context of the overall model conceptualization and subject to the estimations made of the possible ranges of values of the specified parameters, the hydraulic-conductivity values provided by the modeling appear to be reliable to within about \pm one-half order of magnitude, and formation pore pressure estimates appear to be reliable within about $\pm 0.5 \mathrm{MPa}$. These uncertainties may be quantified more accurately by future analyses. Estimates of the distance to a zero-flow boundary are highly sensitive to the assumed value of specific storage. In most cases, test-zone-volume compensations have negligible effect on the interpreted parameters. 


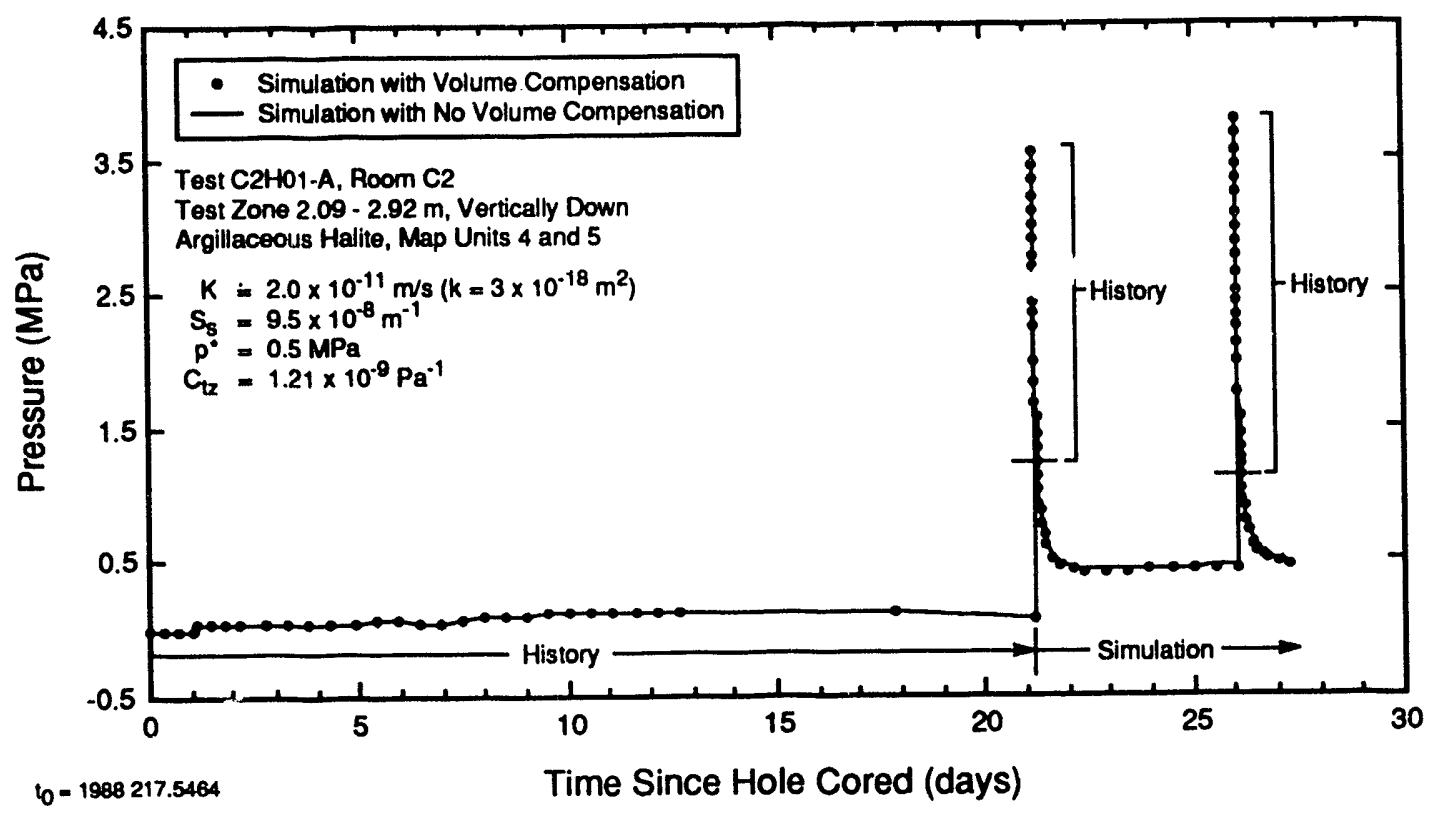

TRI-6344-633-0

Figure 7-83. Simulation of the Test-Zone Fluid-Pressure Response During C2H01-A Testing Showing the Simulation's Sensitivity to Test-Zone-Volume Compensation.

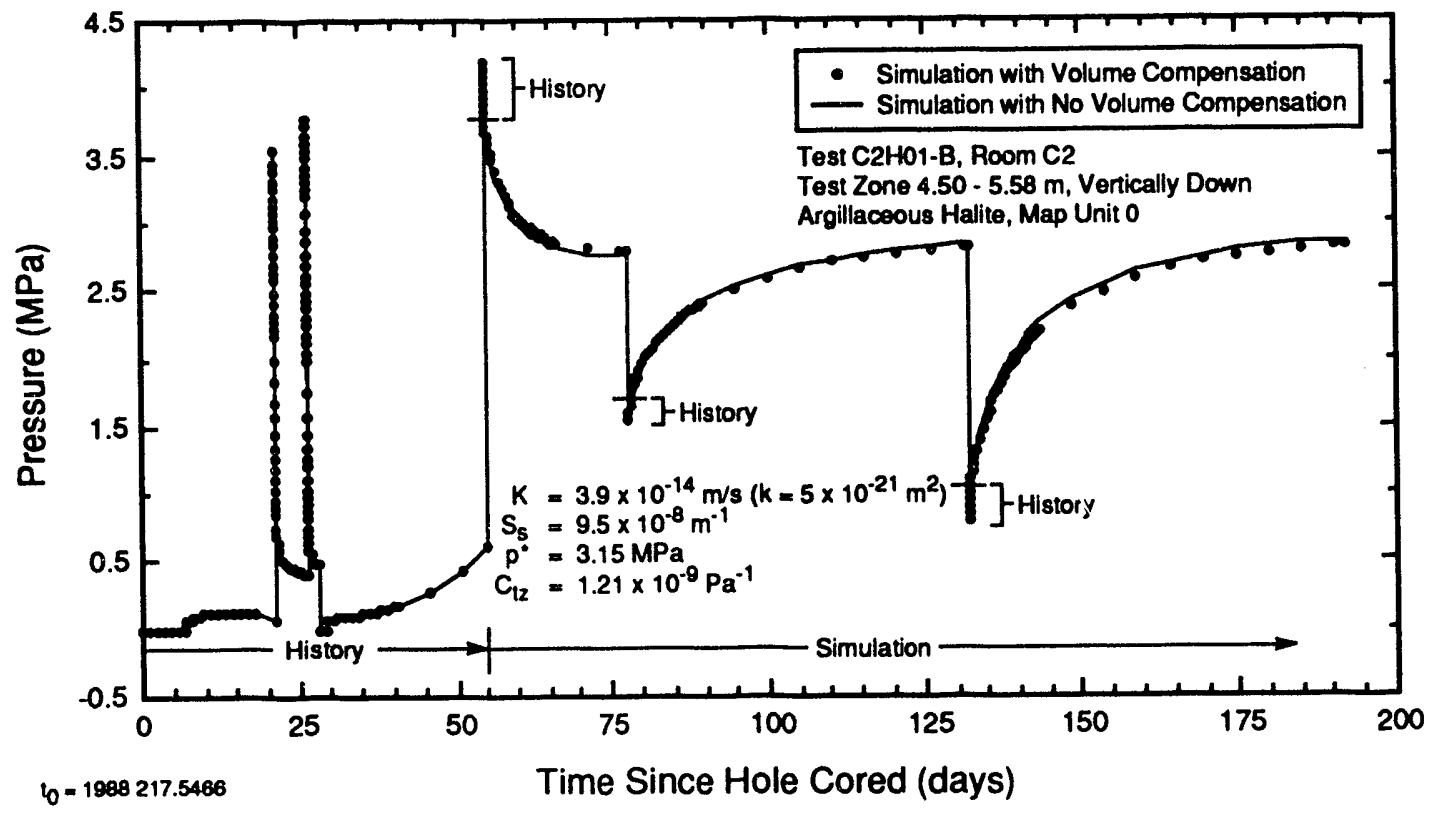

Figure 7-84. Simulation of the Test-Zone Fluld-Pressure Response During C2H01-B Testing Showing the Simulation's Sensitivity to Test-Zone-Volume Compensation. 


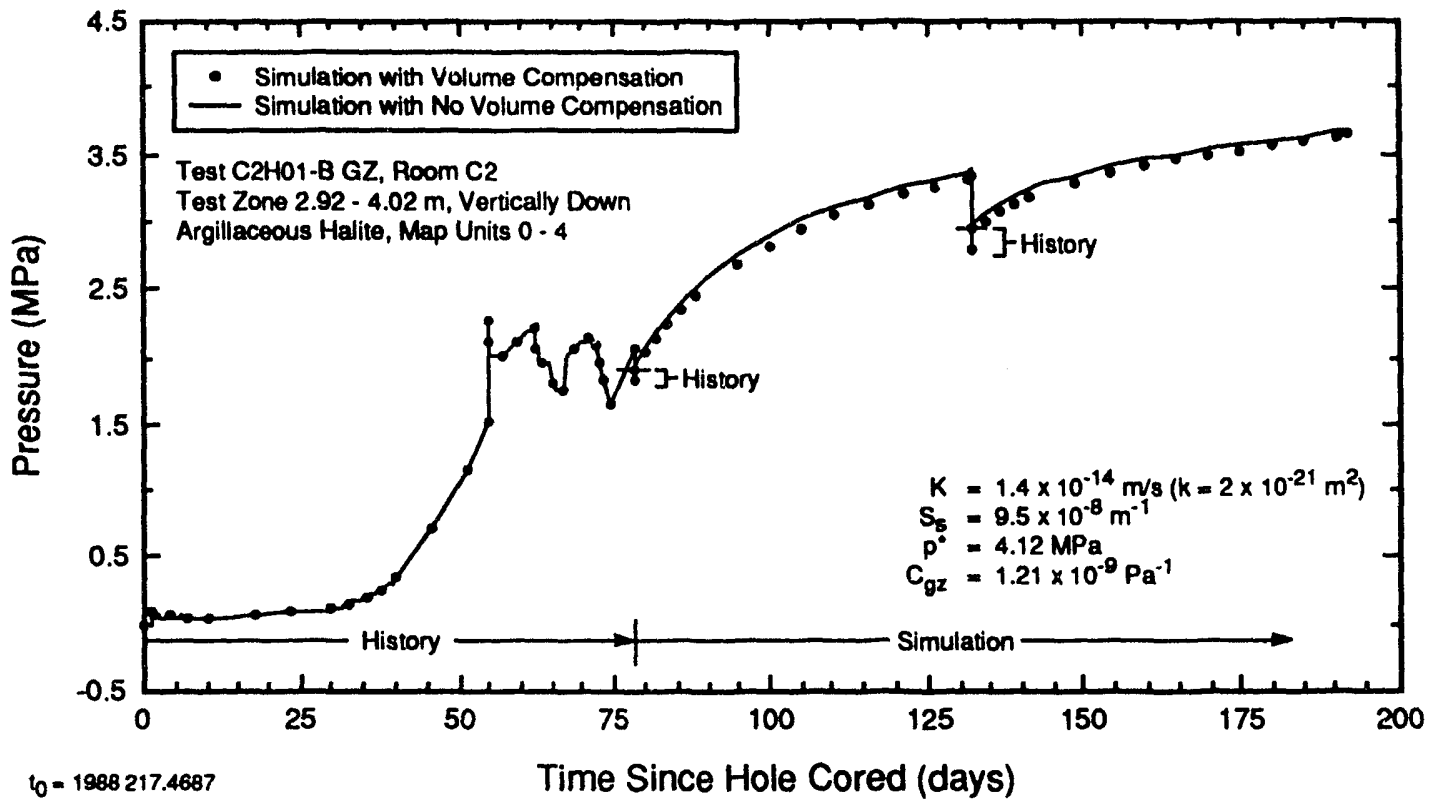

TR1-6344-635-0

Figure 7-85. Simulation of the Guard-Zone Fluid-Pressure Response During C2H01-B Testing Showing the Simulation's Sensitivity to Guard-Zone-Volume Compensation.

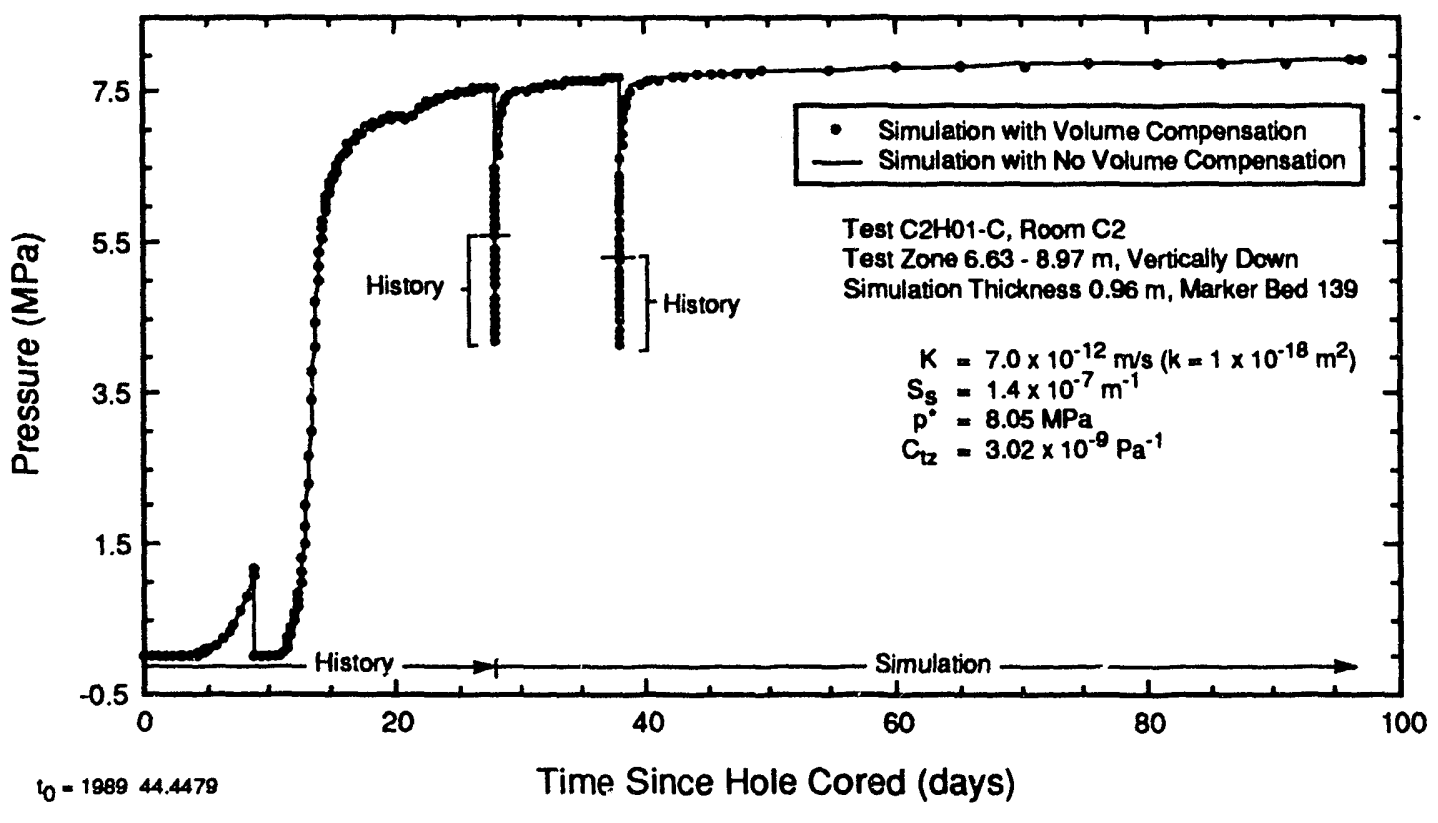

Figure 7-86. Simulation of the Test-Zone Fluld-Pressure Response During C2H01-C Testing Showing the Simulation's Sensitivity to Test-Zone-Volume Compensation. 


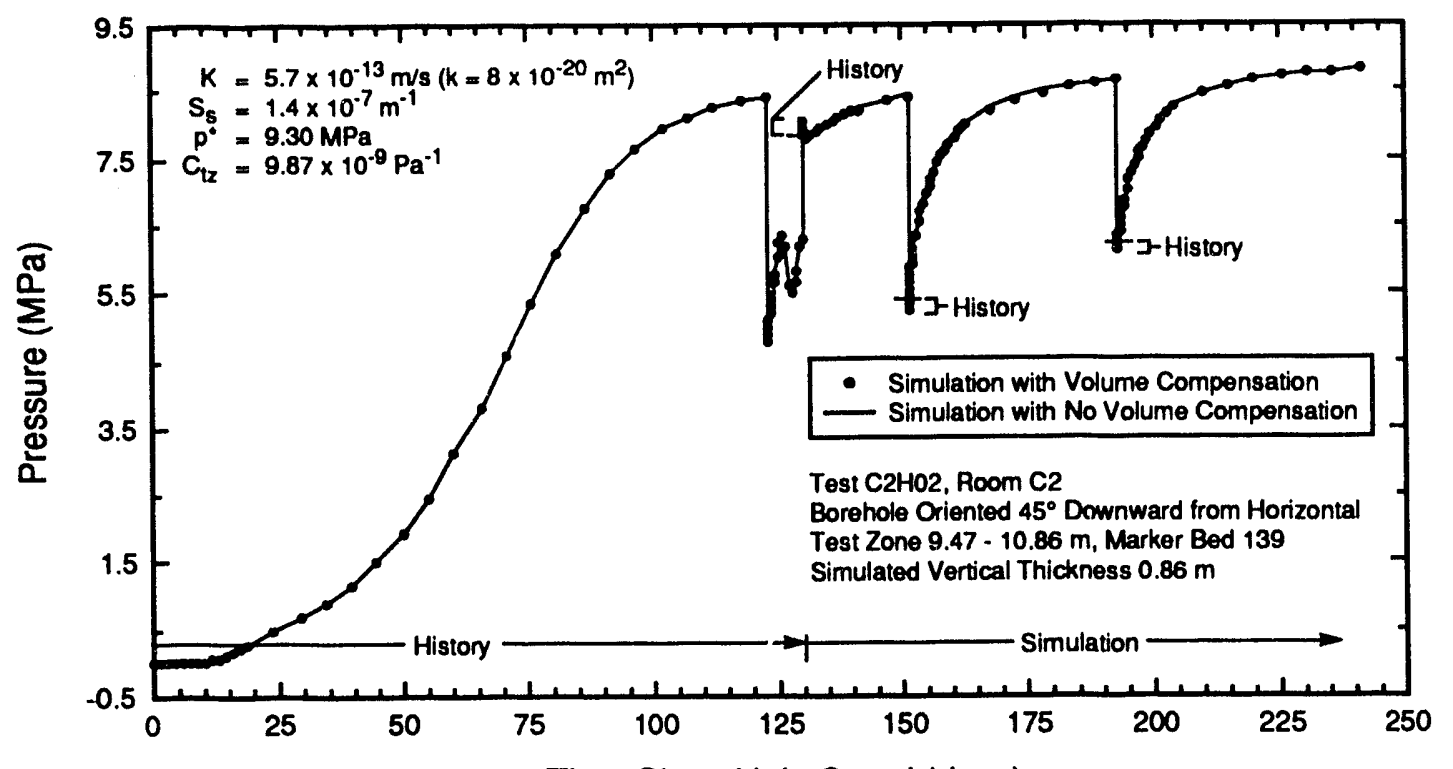

to -1989107.3905

Time Since Hole Cored (days)

TR1-6344-637-0

Figure 7-87. Simulation of the Test-Zone Fluld-Pressure Response During C2H02 Testing Showing the Simulation's Sensitivity to Test-Zone-Volume Compensation.

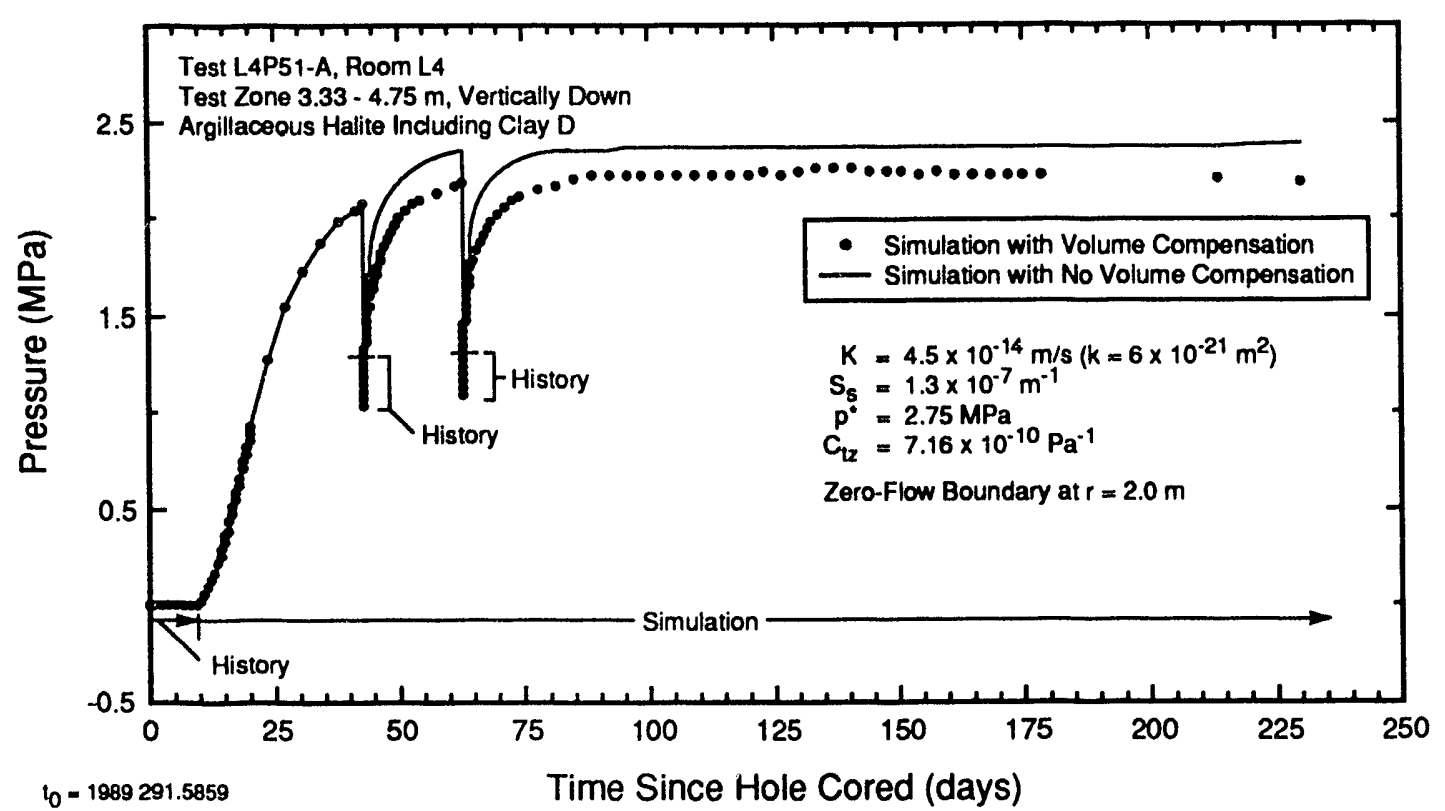

TRI-6344-638-0

Figure 7-88. Simulation of the Test-Zone Fluid-Pressure Response During L4P51-A Testing Showing the Simulation's Sensitivity to Test-Zone-Volume Compensation. 


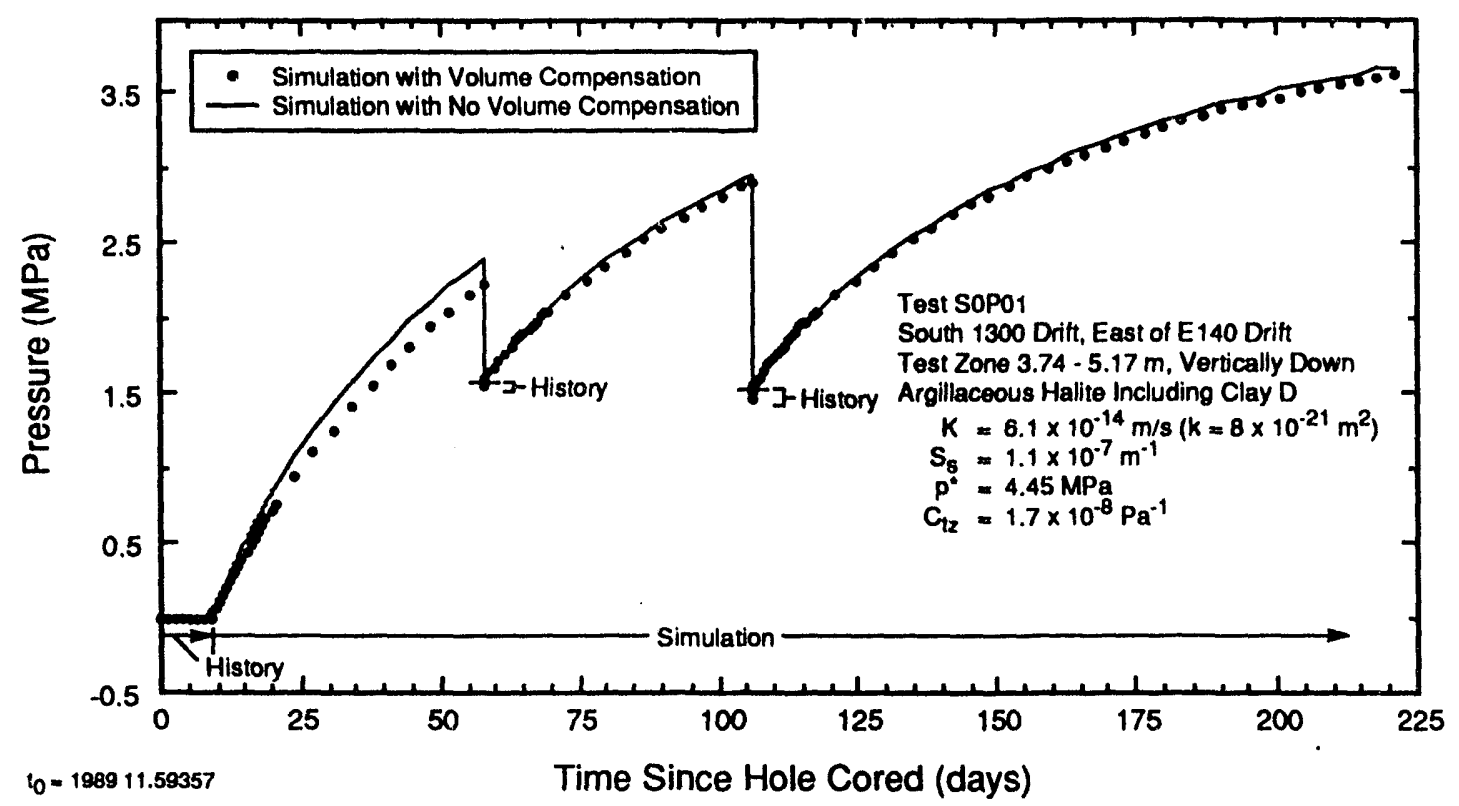

TRI-6344-639-0

Figure 7-89. Simulation of the Test-Zone Fluid-Pressure Response During SOP01 Testing Showing the Simulation's Sensitivity to Test-Zone-Volume Compensation.

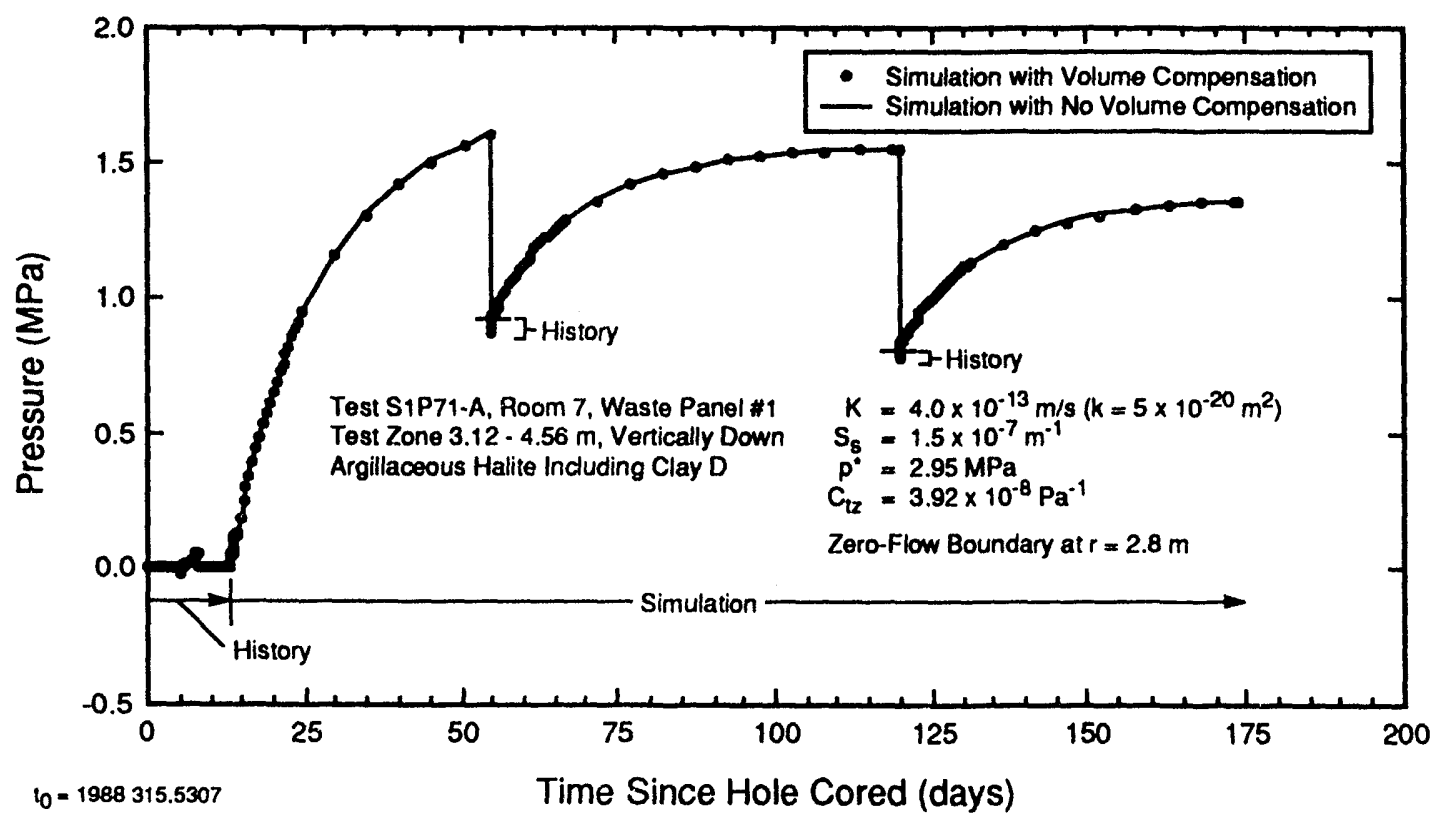

Figure 7-90. Simulation of the Test-Zone Fluid-Pressure Response During S1P71-A Testing Showing the Simulation's Sensitivity to Test-Zone-Volume Compensation. 


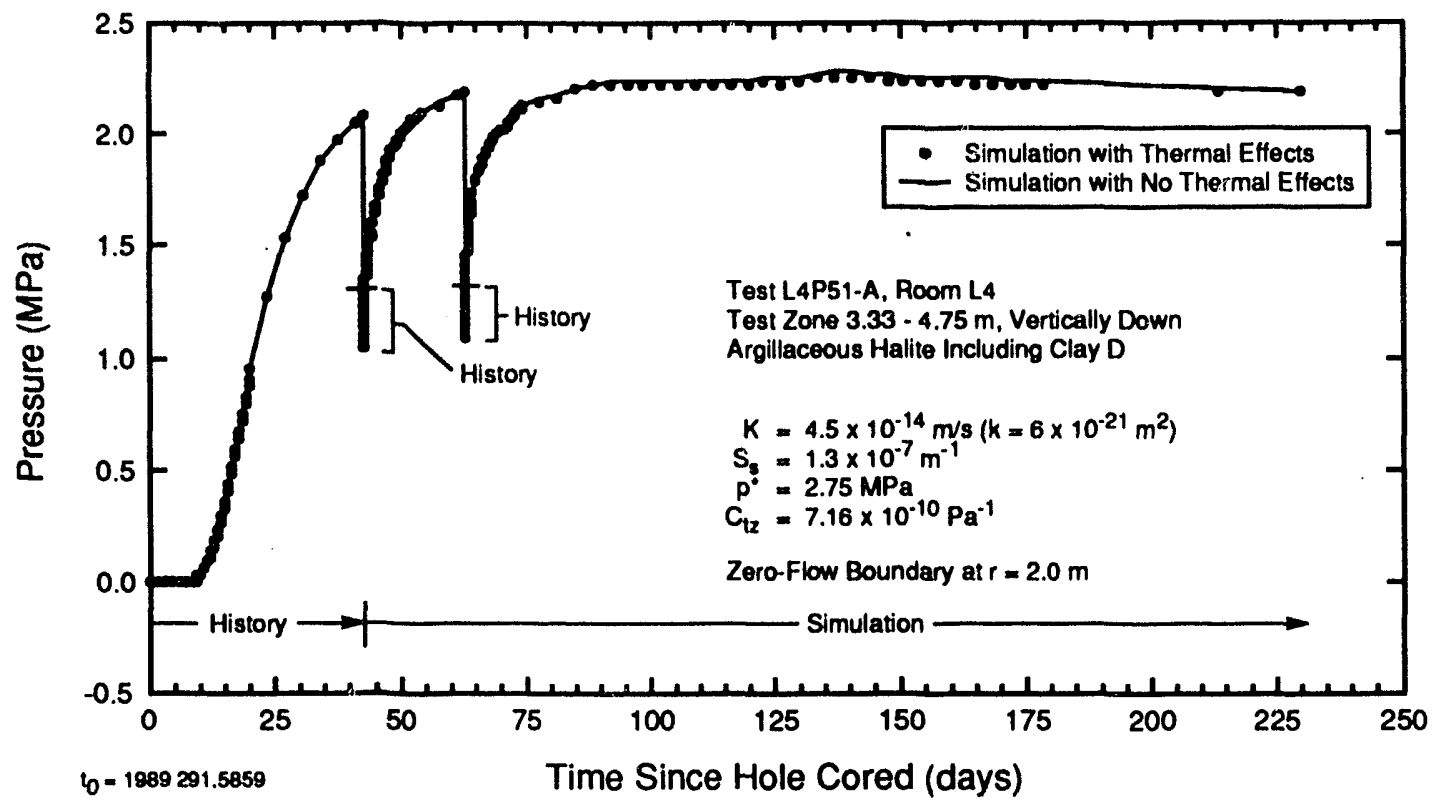

TR1-6344-641-0

Figure 7-91. Simulation of the Test-Zone Fluid-Pressure Response During L4P51-A Testing Showing the Simulation's Sensitivity to Temperature Compensation.

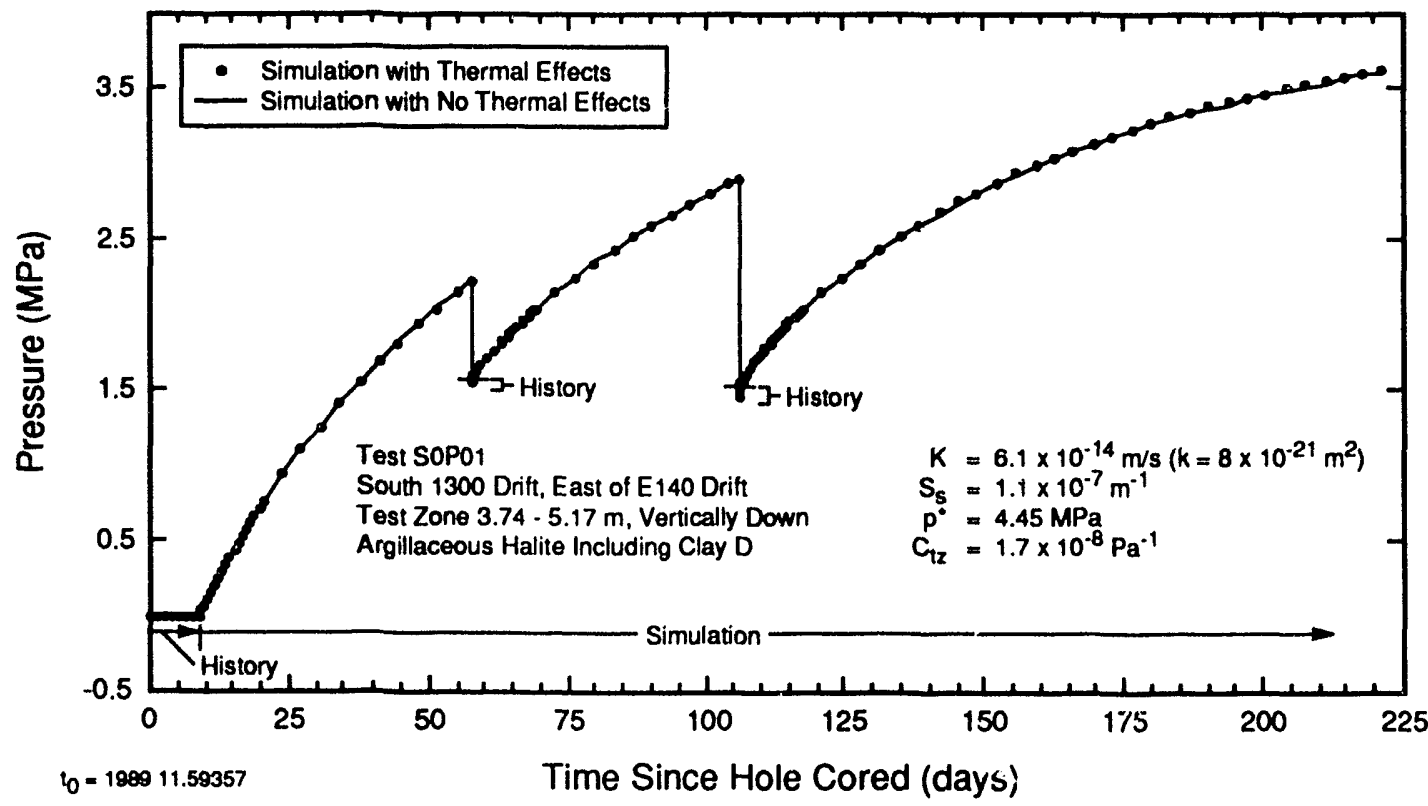

TRI-6344-642.0

Figure 7-92. Simulation of the Test-Zone Fluid-Pressure Response During S0P01 Testing Showing the Simulation's Sensitivity to Temperature Compensation. 
Temperature fluctuations in the tested zones were either of too low magnitude or occurred too slowly to affect the simulations significantly.

\subsection{Discussion of Results}

The number of tests discussed in this report is too small to allow firm conclusions to be drawn about the overall hydraulic properties and behavior of the Salado Formation on a repository or regional scale. However, the data can be examined for apparent relationships between various factors, with the expectation that future testing will either substantiate or invalidate the hypothesized relationships. Possible relationships, and other general summary observations about the testing, are presented below.

\subsubsection{EFFECTSOF DISTURBED-ROCKZONE. Cre-} ation of an underground opening in rock causes both immediate and long-term changes in the mechanical and hydraulic properties of the surrounding rock. Dilatation of the rock around an opening may occur immediately after excavation. Dilatation is the result of grain-boundary readjustment and intragranular microcracking, especially close to the excavation face, which could increase permeability and porosity. Increases in porosity would increase specific storage and, at least temporarily, decrease the formation pore pressure, while increases in permeability would enhance fluid drainage towards the low-pressure excavation, again decreasing the formation pore pressure.

A redistribution of stress also occurs around any underground opening in rock because the opening creates a surface of decreased stress. Brady and Brown (1985) state that stress redistribution around a circular opening in linearly elastic rock in an isotropic stress field extends to a distance from the center of the opening of about five times the radius of the opening (using a stress change of $\pm 5 \%$ from the undisturbed value as a criterion). Within this five-radii region, radial stresses are lower relative to the far-field undisturbed stress, and tangential stresses are higher. The difference between the radial stress and the tangential stress determines the magnitude of what is referred to as the deviatoric stress. The largest amount of stress redistribution, and hence the highest deviatoric stress, occurs within one radius of the opening. If several openings lie within each others' radii of influence, or if the rock response is inelastic (plastic), stress-field perturbations may go beyond the distance of five times the radius of an individual opening. Wawersik and Stone (1989) reported that an isotropic stress field in rock salt at the WIPP, representative of conditions unaffected by the presence of an excavation, was encountered only at distances greater than $50 \mathrm{~m}$ from WIPP Rooms 1 through 4 (Figure 5-1).

Deviatoric stress resulting from stress redistribution around an opening induces shear strain in the rock mass. Because rock salt experiences time-dependent deformation (creep) under deviatoric stresses, straining could theoretically continue for as long as the opening exists. The resulting differential movement within the rock mass may lead to fracturing at various scales. Permeability can be related to the amount of macro- and/or micro-fracturing present at any given time. Inasmuch as strain and microfracturing might accumulate for the lifetime of the opening, permeability might increase with time.

Holcomb (1988), Borns and Stormont (1988), and others have studied the types and processes of deformation occurring around the WIPP excavations. Borns and Stormont (1988) considered the following processes to be of potential importance to the WIPP: Rectangular openings in rock are unstable, and arcuate fracture systems, concave towards the openings, develop around the openings to convert the rectangular openings to more stable circular or elliptical forms. The fracture systems 
define the external boundary of what can be considered to be the "active" opening (Mraz, 1980). The rock between the surface of the active opening and the actual excavation face can become decoupled from the host rock along a shear plane. Rock near the excavation face can also experience brittle failure because it is unconfined (and therefore fails at a lower strai// than confined rock) and undergoes high rates of S'rain. Shear may also occur along planes of weakriess close to the excavation, such as along clay seams or anhydrite interbeds (Brady and Brown, 1985). Extension fractures may develop parallel to the excavation faces.

Because of the changes that can occur in the rock around an excavation, the affected volume of rock is sometimes referred to as a disturbed-rock zone (DRZ). Borns and Stormont (1988) and Stormont (1990b) report evidence for measureable changes in mechanical and hydraulic properties in the rock around the WIPP excavations extending to distances between one and five meters from the excavationface. Holcomb (1988) reported changes in compressional-wave attenuation, and to a lissser degree velocity, which he attributed to an incre.nse in fracture porosity, to a distance of at least three meters from the face of a newiy excavated room.

All of the testing discussed in this report was performed in intervals where stress redistribution must have occurred as a result of excavation of the WIPP facility. Furthermore, all test intervals except for those of $\mathrm{C}_{2} \mathrm{H} 01-\mathrm{C}, \mathrm{C}_{2} \mathrm{HO2}$, and $\mathrm{C}_{2} \mathrm{HO} 3$ extended no farther than $5.6 \mathrm{~m}$ from a room or drift, and were within about two room radii of the openings. Thus, the interpreted hydraulic properties presented in this report may not be representative of undisturbed rock, but may reflect permeability and porosity enhancement and depressurization within the DRZ around the WIPP facility.
Possible effects of the DRZ on the observed test responses are discussed below.

\subsubsection{Comparison of Results from} L4P51-A, S0P01, and S1P71-A. The L4P51-A, S0P01, and S1P71-A tests involved essentially the same strata within the test and guard zones. Thus, differences in the hydraulic properties interpreted from these tests might be related to differences in the DRZ at these locations. According to Borns and Stormont (1988) and Stormont (1990a), a wider excavation tends to have a more developed DRZ than a narrower excavation of the same age, and an older excavation tends to have a more developed DRZ than a younger excavation of the same size. Hydraulic properties within the DRZ may also vary with position over the width of a single drift or room (Borns and Stormont, 1988; Stormont, 1990a). The L4P51 and S1P71 boreholes are in rooms $10.1 \mathrm{~m}$ wide, while SOP01 is in a drift that is only $6.1 \mathrm{~m}$ wide. However, SOP01 is in the $\$ 1300$ drift, which was 4.5 years old when testing began, whereas the rooms containing L4P51 and S1P71 were only about eight months old when testing began at those locations. As a result, the three tests do not provide ideal, controlied-experiment conditions in which only one variable is altered between experiments. We may not, therefore, be able to separate the effects of excavation age and size.

Whether or not the hydraulic properties at SOP01 are significantly different from those at L4P51 and S1P71, the hydraulic properties at the latter two locations might be expected to be similar because of similar room ages and sizes. However, the estimated hydraulic conductivities of the test-zone intervals of L4P51-A and S1P71-A differ by an order of magnitude (4.5 $\mathrm{x}$ $10^{-14} \mathrm{~m} / \mathrm{s}$ vs. $4.0 \times 10^{-13} \mathrm{~m} / \mathrm{s}$, respectively), while that for SOP01 is intermediate $\left(6.1 \times 10^{-14} \mathrm{~m} / \mathrm{s}\right)$. The estimated 
formation pore pressures, however, are similar for L4P51-A and S1P71-A (2.75 and 2.95 MPa, respectively), while that at SOP01 is considerably higher (4.45 MPa). L4P51-A and S1P71-A are also similar in that both sets of tests showed apparent zero-flow boundaries 2 to $3 \mathrm{~m}$ from the borehole, while no boundary effects were observed during the testing of SOP01. Marker Bed 139 was isolated in the guard zones of these holes. The highest guard-zone pressure (0.52 MPa) was observed in SOP01. The guardzone pressure in L4P51-A decreased from 0.3 to $0.2 \mathrm{MPa}$ during testing, and no pressure above atmospheric was observed in the S1P71-A guard zone. Why the test-zone interval of S1P71-A should have a higher formation pore pressure than that of L4P51-A, while the opposite is true of the guard-zone intervals is unknown.

In summary, the lowertest-and guard-zone pressures in L4P51-A and S1P71-A relative to S0P01 might be related to increased disturbance resulting from their being in a larger excavation, as might the higher hydraulic conductivity of the S1P71-A test-zone interval. If true, this would indicate that the age of an excavation is less important than its size in determining the degree of disturbance in the rock surrounding the excavation. Stormont (1990a) reached the same conclusion from examination of extensometer measurements, inclinometer measurements, and gas-flow measurements made in boreholes drilled from different size rooms. The low hydraulic conductivity of the L4P51-A test-zone interval, however, is not in accord with this hypothesis. In addition, we have difficulty reconciling the concept of increased disturbance with the apparent zero-flow boundaries around L4P51 and S1P71. If disturbance increases permeability and allows pressure to escape, we would not expect to observe zero-flow boundaries. Additional testing will be required before more definitive conclusions can be drawn about the relationship between an excavation's age and size and the hydraulic properties within the DRZ.

7.3.1.2 Comparison of Results from C2H01-C and $\mathrm{C2}_{2}$ HO2. Another location where the DRZ may have had some influence on the hydraulic properties observed in Marker Bed 139 is in Room C2. Hole C2H01, drilled vertically downward into the flbor of the room, is thought to have encounteredone ormorefractures inMarkerBed 139 that contributed to the relatively high hydraulic conductivity $\left(7.0 \times 10^{-12} \mathrm{~m} / \mathrm{s}\right)$ observed at that location. The hydraulic conductivity of Marker Bed 139 was bwer $\left(5.7 \times 10^{-13} \mathrm{~m} / \mathrm{s}\right)$ at hole $\mathrm{C} 2 \mathrm{H} 02$, which was drilled under the rib of the room at a $45^{\circ}$ angle. The pore pressure in Marker Bed 139 was higher at $\mathrm{C} 2 \mathrm{HO} 2(9.30 \mathrm{MPa}$ ) than at $\mathrm{C} 2 \mathrm{H} 01(8.05 \mathrm{MPa})$. These observations are consistent with disturbance $\mathrm{di}$ rectly under the room creating fractures in Marker Bed 139, or allowing existing fractures to open, causing an increase in permeability and decrease in pore pressure compared to the relatively undisturbed conditions under the rib of the room. These observations therefore suggest that the $D R Z$ beneath Room $\mathrm{C} 2$ extends at least to a depth of $7 \mathrm{~m}$, the depth of Marker Bed 139.

\subsubsection{Relationship Between Hydraulic} Conductivity and Distance from an Excavation. All other things being equal, we would expect to observe an inverse relationship between hydraulic conductivity and distance from an excavation because of the relationship between deviatoric stress and fracturing ( $\mathrm{Sec}$ tion 7.3.1). Figure 7-93 shows a plot of the interpreted hydraulic conductivities of the different test intervals versus the distances from the centers of those intervals to the excavations from which they were drilled. With respect to the tests of halite intervals, no consistent correlation is observed between hydraulic conductivity and distance from an excavation. The test interval closest to an excavation, that of $\mathrm{C}_{2} \mathrm{HO} 1-\mathrm{A}$, had 
a hydraulic conductivity imore than an order of magnitude higher than that of any other halite interval, but the hydraulic conductivities of the other five intervals lie within a two-order-of-magnitude range with no apparent relationship to distance from an excavation.

The lack of an observed correlation between halite hydraulic conductivity and distance from an excavation may be due to natural heterogeneity, a statistically inadequate amount of data, and/or other factors such as excavation size, excavation age, mineralogy, and other sedimentological differences having a larger influence on hydraulic "onductivity than distance from an excavation. Alters ntively, the absence of a correlation between rydraulic conductivity and distance from an excavation may reflect the existence of a timevarying inelastic deviatoric stress fieid in rock salt (Wawersik and Stone, 1989). That is, time variation in properties may mask distance variation in properties.

With respect to the tests of Marker Bed 139, hydraulic conductivity does appear to increase with increasing proximity to an excavation (Figure 7-93). This observation, however, is based on only three data points. Additional data will be required to place this conclusion on a firmer basis.

The two highest hydraulic conductivities indicated on Figure $7-93$ are from the two shallowest test intervals, the S0P01 guard zone and the C2H01-A test zone. The guard zone for the S1P71-A testing was even shallower (1.25 to $2.20 \mathrm{~m}$ deep; Figure 7-38), and the apparent hydraulic conductivity of Marker Bed 139 in that interval was also relatively high (see Section 7.1.9.2). The simulations of the $\mathrm{C}_{2} \mathrm{H} 01-A$ tests and the SOP01 guard-zone tests produced the worst fits to the observed data of all the tests (Figures 7-3 and 7-37, respectively). The poor fits may be the result of discrepancies between the model assumption of radial flow in a homogenecus medium and actival flow con- ditions in the DRZ close to the excavations. Specifically, flow within portions of the DRZ may be nonradial and dominated by fractures of limited extent. Within two or three meters of an excava ion, therefore, excavation effects may have created a DRZ in which permeabilities are relatively high and nonradial flow conditions may exist. Beyond three meters, permeabilities are lower and radial-flow models can duplicate the observed test responses.

\subsubsection{Relationship Between Formation} Pore Pressure and Distance from an Excavation. All other things being equal, we would expect to observe higher formation pore pressures as distance from an excavation increases. Figure 7-94 shows a plot of interpreted formation pore pressures versus the distances from the centers of the corresponding test intervals to the excavations from which they were drilled. Considering the data from halite intervals and Marker Bed 139 intervals together, a general trend of increasing formation pore pressure with distance from an excavation is evident. However, if only the data from the halite intervals are considered (i.e., exclude SOP01-GZ, $\mathrm{C}_{2} \mathrm{H}_{01-C}$, and $\mathrm{C}_{2} \mathrm{HO2}$ ), the trend is less clear. This is probably due in part to the sparsity of data, particularly over a wide range of distances from the excavations. Otherfactors, however, such as timevarying inelastic deviatoric stress fields, must also have an influence on the formation pore pressures within the halite intervals.

The two lowest formation pore pressures shown on Figure 7-94 are from the two shallowest test intervals, the $\mathrm{C} 2 \mathrm{H} 01-\mathrm{A}$ test zone (assuming the contributing zone was 2.09 to $2.92 \mathrm{~m}$ deep) and the SOP01 guard zone. Two shallower isolated intervals, the $\mathrm{C} 2 \mathrm{H} 01-\mathrm{A}$ guard zone ( 0.50 to $1.64 \mathrm{~m}$ deep) and the S1P71-A guard zone (1.24 to $2.27 \mathrm{~m}$ deep), were apparently at atmospheric pressure only. As discussed in Section 7.3.1.3, these intervals may be within distuhed zones 


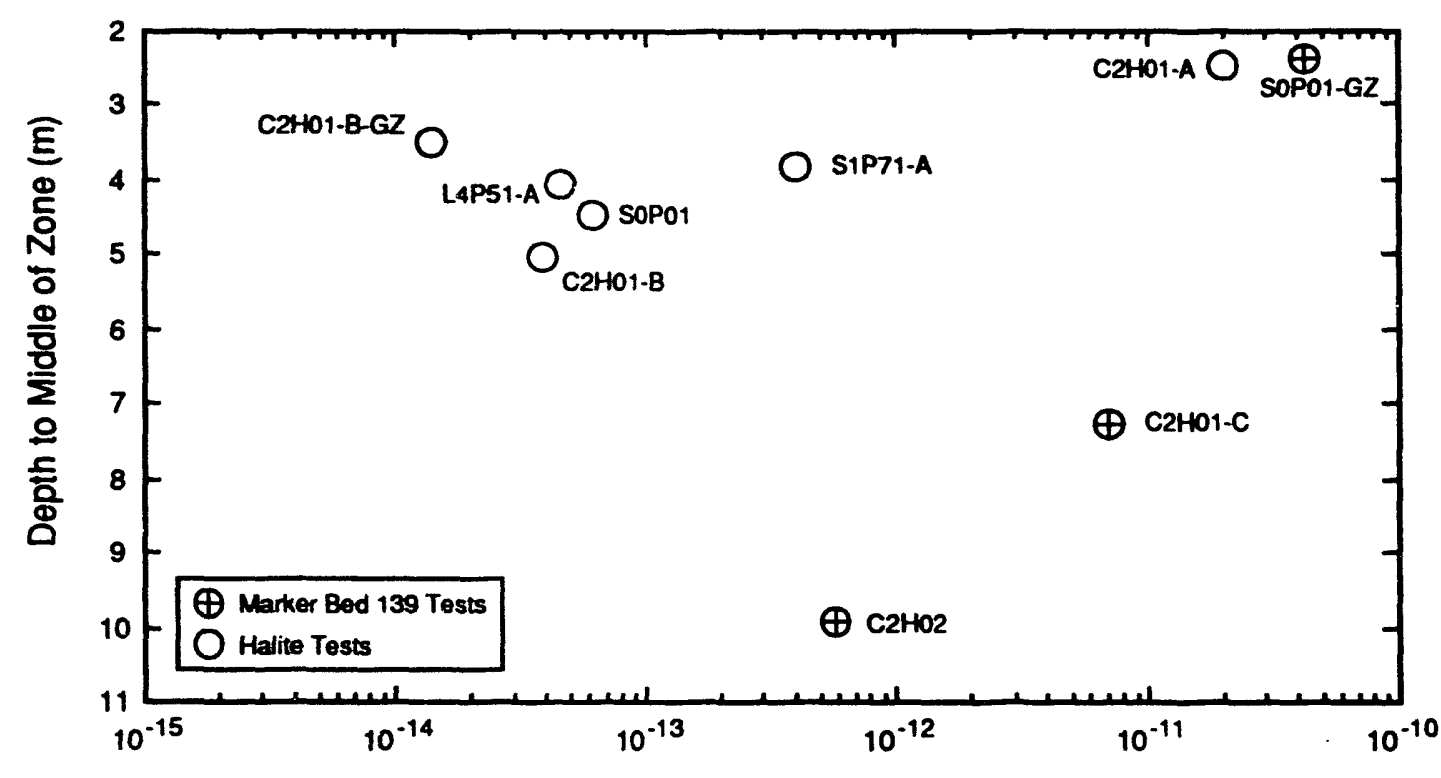

Hydraulic Conductivity (m/s)

TRI-634-643-0

Figure 7-93. Interpreted Hydraulic Conductivities Versus Distances From Excavations to the Centers of Tested Intervals.

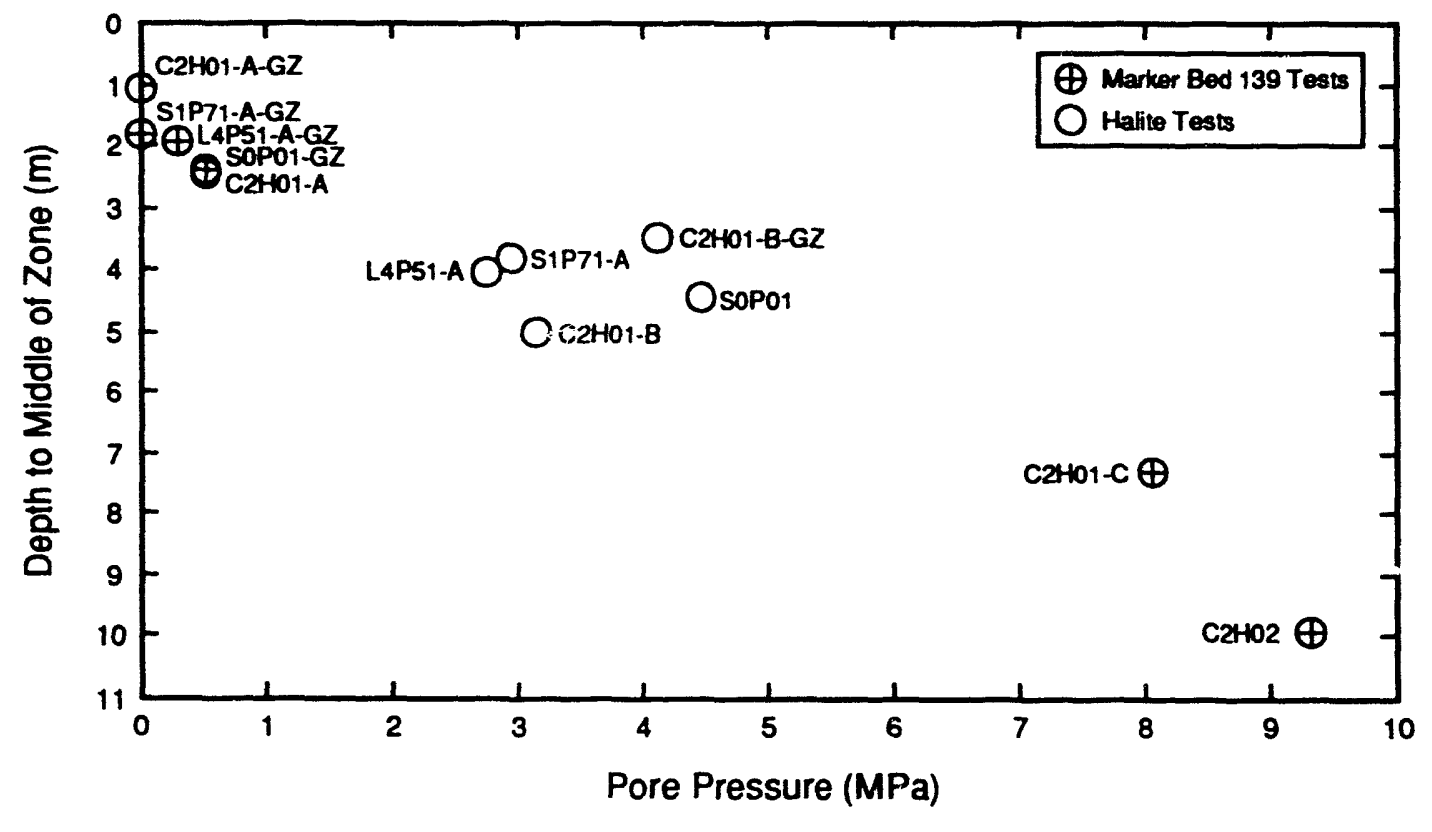

Figure 7-94. Interpreted Formation Pore Pressures Versus Distances From Excavations to the Centers oi Tesied intervais. 
around their respective excavations in which permeabilities have increased and formation pore pressures have decreased. Observations of atmospheric pressure in the guard zones of $\mathrm{C} 2 \mathrm{H} 01-\mathrm{A}$ and S1P71-A probably reflect the extreme condition of direct fracture connection between the isolated intervals and the overlying excavations. Beyond about three meters' depth, the rock appears to be sufficiently intact to contain pressures of several MPa.

\subsubsection{EFFECTS OF MINERALOGY ON HYDRAU-} LIC PROPERTIES. Keeping in mind possible influences of the DRZ, two conclusions can be drawn concerning mineralogy anci hydraulic properties. First, the anhydrite of Marker Bed 139 (including the underlying clay E) appears to have an intrinsically higher hydraulic conductivity than halite. The hydraulic conductivity of Marker Bed 139 was greater at all locations where it was tested than the hydraulic conductivity of all the halite intervals tested, with the exception of the halite interval in $\mathrm{C} 2 \mathrm{H} 01-\mathrm{A}$. This halite interval, however, is believed to be significantly disturbed by its proximity to the excavation, and not at all representative of undisturbed halite. In general, Marker Bed 139 had a hydraulic conductivity one to two orders of magnitude higher than that of halite.

Second, impure halite, containing trace amounts of clay and in some cases polyhalite, appears to be more permeable than pure halite. This conclusion is less certain than the previous conclusion, because test data from pure halite are available from only one hole, $\mathrm{C} 2 \mathrm{H} 03$. Nevertheless, the complete lack of an observable pressure response in $\mathrm{C} 2 \mathrm{H} 03$, when contrasted with the unambiguous responses observed in all impure-halite test intervals, indicates that the hydraulic conductivity of pure halite must be lower than that of impure halite. As the testing program continues, additional data will be collected to support or refute this conclusion.
No conclusions can as yet be drawn concerning the amount of clay that must be present to influence hydraulic conductivity significantly. The test intervals containing clay $D$, an areally persistent clay seam or group of clay stringers up to $2 \mathrm{~cm}$ thick, had hydraulic conductivities only slightly higher than intervals containing less continuous clay impurities. Additional testing combined with quantitative determinations of clay contents are needed to evaluate the influence of clay on hydraulic conductivity.

7.3.3 RADIUS OF INFLUENCE OF TESTING. The radius of influence of a hydraulic test depends on the specific storage of the formation being tested: the lower the specific storage, the greater the radius of influence. Assuming base-case values of specific storage (Table 6-2), the individual pulse tests discussed in this report had radii of influence ranging from about 1 to $10 \mathrm{~m}$ (Table 7-1). The pressure disturbances caused by hole drilling and entire testing sequences extended to distances between 4 and $35 \mathrm{~m}$ from the boreholes, except in the cases of the L4P51-A and S1P71-A testing which appeared to encounter zeroflow boundaries 2 to $3 \mathrm{~m}$ from the holes. In general, the individual tests of polyhalitic and argillaceous halite had radii of influence on the order of $2 \mathrm{~m}$. The tests of Marker Bed 139 in holes $\mathrm{C}_{2} \mathrm{H} 01$ and $\mathrm{C}_{2} \mathrm{HO} 2$ had individual radii of influence of about $5 \mathrm{~m}$. For both the halite and Marker Bed 139 intervals, these radii are great enough to provide confidence that the test results are representative of formation properties beyond possible damaged zones associated with the boreholes. However, if the maximum specific-storage values considered possible, which are thought to represent extreme conditions within the $D R Z$, are applicable, the radii of influence of the tests could be on the order of 1 m or less. Attempts will be made in the future to measure specific storage directly to resolve uncertainties about the radii of influence of testing. 
As discussed in Section 6.2, the model used for test interpretation assumes no vertical flow in the formation. Any vertical flow associated with these tests would tend to decrease the horizontal radius of influence of the tests. Thus, the radii of influence presented in this report should be considered as maximum values.

\subsubsection{EVALUATION OF POROUS-MEDIUM AS-} SUMPTION. The interpretations presented in this report are predicated on an assumption that the Salado Formation is a porous medium. That is, we have assumed that the Salado contains a continuous network of interconnected pores that provides for continuous pore-pressure gradients and permeability. Some of the tests we have conducted can be easily interpreted under this assumption, whereas others cannot. The responses observed during tests of Marker Bed 139 where it should be relatively undisturbed by the excavations ( $\mathrm{C} 2 \mathrm{H} 01-\mathrm{C}$ and $\mathrm{C} 2 \mathrm{H} 02$ ) appear to be well represented by a porousmedium model. The responses to the $\mathrm{C} 2 \mathrm{H} 01-\mathrm{B}$ (both test zone and guard zone) and SOP01 tests of impure halite are also well represented by a porousmedium model. The L4P51-A and S1P71-A tests of impure halite, however, provide indications of a limited interconnected pore volume, while the $\mathrm{C} 2 \mathrm{H} 03$ test of pure halite showed no apparent permeability or pore pressure at all. The responses observed during the $\mathrm{C} 2 \mathrm{H} 01-\mathrm{A}$ and SOP01-GZ tests are thought to be heavily influenced by the $D R Z$ and gas generation, respectively, and provide little insight into the adequacy of a porous-medium model.

The only location at which the continuity of the porepressure gradient can be evaluated at more than two points is borehole $\mathrm{C} 2 \mathrm{H} 01$. The three sets of tests performed in that hole resulted in six different intervals being isolated. During the $\mathrm{C} 2 \mathrm{H} 01-\mathrm{A}$ tests, the guard zone extended from 0.50 to $1.64 \mathrm{~m}$ deep and the test zone extended from 2.09 to $5.58 \mathrm{~m}$ deep. As discussed in Section 7.1.1.1, the responses observed in the $\mathrm{C} 2 \mathrm{H} 01-\mathrm{A}$ test zone are thought to represent only the interval from 2.09 to (at most) 2.92 m deep; that is, not the portions of the $\mathrm{C} 2 \mathrm{H} 01-\mathrm{A}$ test interval later included in the $\mathrm{C} 2 \mathrm{H} 01-\mathrm{B}$ test and guard zones, which showed significantly different responses. During the C2H01-B tests, the guard zone was from 2.92 to 4.02 $\mathrm{m}$ deep and the rest zone was from 4.50 to $5.58 \mathrm{~m}$ deep. During the $\mathrm{C} 2 \mathrm{H} 01-\mathrm{C}$ tests, the guard zone extended from 4.75 to 5.79 m deep, while the test zone extended from 6.63 to $8.97 \mathrm{~m}$ deep, and included Marker Bed 139 from 6.80 to $7.76 \mathrm{~m}$ deep. As discussed in Section 7.1.3.2, no formation-pore-pressure estimate was obtained from the $\mathrm{C} 2 \mathrm{H} 01-\mathrm{C}$ guardzone data.

Figure 7-95 shows the formation pore pressures interpreted for each of the five intervals in $\mathrm{C}_{2} \mathrm{H} 01$ plotted as a function of depth. With the exception of the pressure from the $\mathrm{C} 2 \mathrm{H} 01-\mathrm{B}$ test-zone interval, the plot shows pressures increasing with depth below the excavation. The pressure from the $\mathrm{C} 2 \mathrm{H} 01-\mathrm{B}$ test-zone interval is anomalous in that it is lower than the pressures both above and below. This observation casts doubt on the existence of a continuous pore-pressure gradient below Room C2 and, by extension, on the concept of continuous interconnected porosity. Alternatively, timedependent deformation processes and vertical heterogeneity in the mechanical properties of the rock might combine to produce transient pressure gradients that appear anomalous. Even if porosity is not continuously interconnected across bedding, however, it may still be interconnected within a single bed or map unit. Further investigation into the existence of continuous pore-pressure gradients both within individual beds and across bedding is being carried out as part of the Room Q tests at the WIPP (Nowak et al., 1990). 


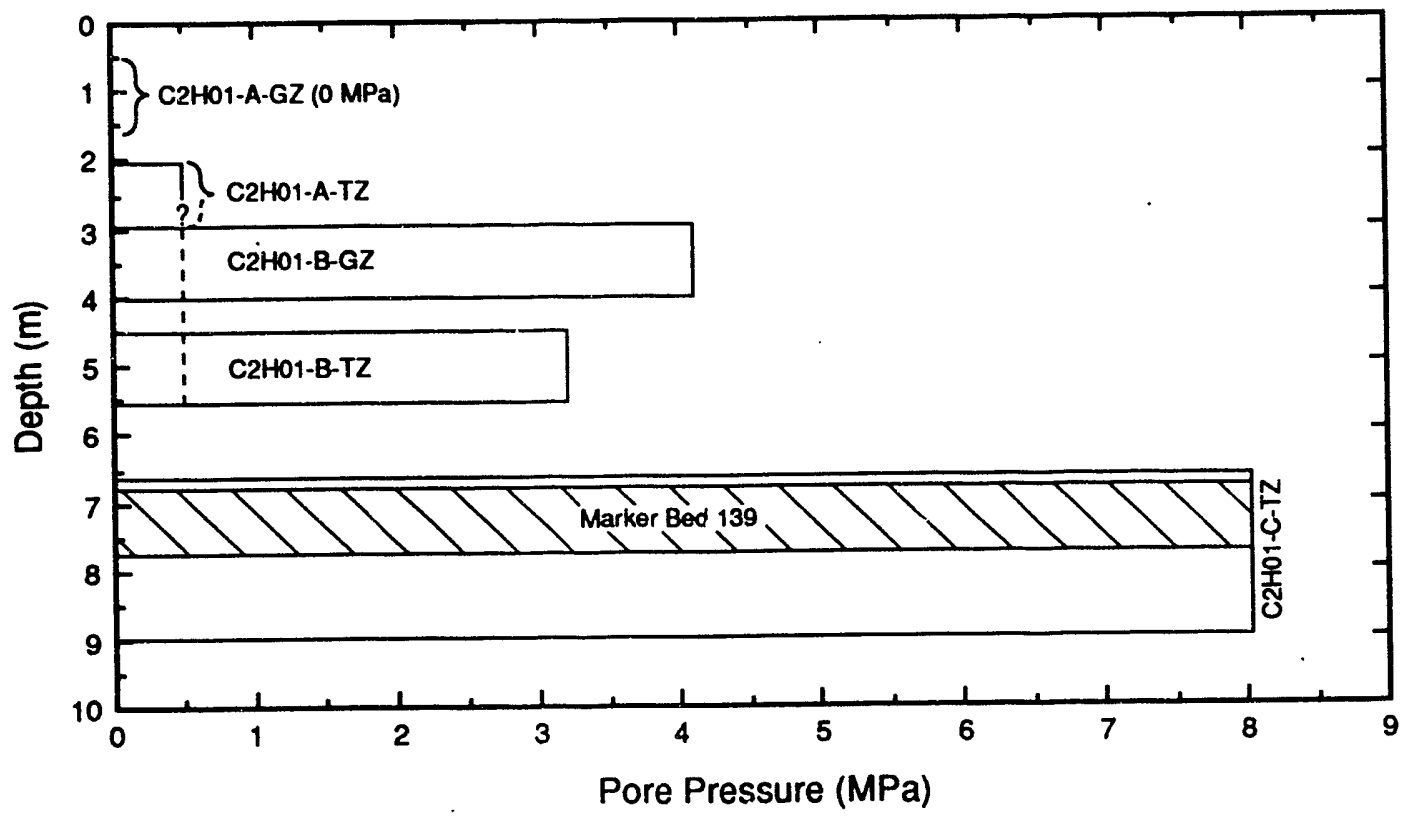

TRI-6344-645-0

\section{Figure 7-95. Interpreted Formation Pore Pressures Versus Depths Below Excavation for the Tested Intervals in Borehole C2HO1.}

Thus, the interpreted results of the Salado permeability tests conducted to date are inconclusive with respect to the question of whether or not continuous interconnected porosity exists within the Salado. No evidence contradicts the concept of continuous interconnected porosity within Marker Bed 139. Within halite, however, two tests provide indications of porosity being interconnected only on the scale of about two to three meters, while others show continuous interconnected porosity to distances of at least four meters from the boreholes. Moreover, while the tests of the $\mathrm{C} 2 \mathrm{H} 01-\mathrm{B}$ test zone and guard zone showed no radial restrictions to porosity (or permeability), the formation pore pressures interpreted for those intervals indicate that porosity may be limited vertically (across bedding) at that location. Additional testing to be performed over the next several years should help resolve questions about the porous nature of bedded halite. 


\section{SUMMARY AND CONCLUSIONS}

This report presents interpretations of hydraulic tests conducted in bedded evaporites of the Salado Formation from 1988 through early 1990. Tests were conducted on ten intervals in six boreholes drilled from the underground WIPP facility. A summary of the test-interpretation results and conclusions about the hydraulic properties and behavior of the Salado Formation are presented below.

\subsection{Results of Testing}

The first objective of the hydraulic tests was to estimate the permeabilities of different stratigraphic intervals in the Salado Formation around the WIPP facility. Pressure-pulse tests were successfully conducted in five stratigraphic intervals. Interpreted hydraulic conductivities range from $1.4 \times 10^{-14}$ to $2.0 \times 10^{-11} \mathrm{~m} / \mathrm{s}$ for halite intervals, and from $5.0 \times 10^{-13}$ to $<4 \times 10^{-11} \mathrm{~m} / \mathrm{s}$ for anhydrite Marker Bed 139. Testing of an interval of relatively pure halite was unsuccessful because no pressure response was observed. Sensitivity analyses suggest our uncertainty in estimated hydraulic-conductivity values is about \pm one-half order of magnitude in all cases.

The second objective of the testing program was to estimate formation pore pressures within different stratigraphic intervals around the WIPP facility. No pressure above atmospheric was observed in isolated intervals within two meters of the WIPP excavations. Estimated pore pressures beyond two meters from the excavations ranged from 0.5 to $9.3 \mathrm{MPa}$. The highest pore pressures, 8.05 and $9.30 \mathrm{MPa}$, were estimated from tests performed in Marker Bed 139. Sensitivity analyses show our uncertainty in estimated formation pore pressures to be on the order of about $\pm 0.5 \mathrm{MPa}$.

The third objective of the tests was to determine whether or not hydraulic boundaries would be encountered in the Salado on the scale of testing. Tests of five of the intervals had interpreted radii of influence ranging from about 4 to $35 \mathrm{~m}$, with no indications of hydraulic boundaries. Tests of two intervals showed apparent zero-flow boundaries at distances of 2.0 and $2.8 \mathrm{~m}$ from the boreholes. Two other tests, conducted in intervals 2 to $3 \mathrm{~m}$ from the excavations, showed hydraulic behavior not well represented by a radial-flow model. This behavior may have been related to limited fracturing within a disturbed-rock zone around the excavations.

The fourth objective was to define the distance(s) to which the presence of the WIPP facility has affected hydraulic properties and formation pore pressures in the surrounding rock. Hydraulic conductivity and pore pressure appear to be most affected within 2 to $3 \mathrm{~m}$ of the facility. The interpreted hydraulic conductivity of a halite interval within this zone was two orders of magnitude higher than the hydraulic conductivity of any other halite interval. The hydraulic conductivity of Marker Bed 139 also appears to be higher within several meters of an excavation than it is at greater distances. However, the distance beyond which the hydraulic conductivity of either halite or Marker Bed 139 is completely unaffected by the presence of the excavations cannot be determined with the data currently available. Formation pore pressures within $3 \mathrm{~m}$ of the excavations are low, ranging from atmospheric to $0.5 \mathrm{MPa}$. Pore pressures beyond $3 \mathrm{~m}$ of the excavations are variable, ranging from about 2.7 to 9.3 MPa. The observation that lower pore pressures are observed in halite up to $6 \mathrm{~m}$ from the excavation than in Marker Bed 1396.8 to $10.7 \mathrm{~m}$ from the excavation suggests that the halite has been depressurized by flow towards the excavation and/or by creation of new pore space by rock deformation. No data are as yet available to 
define formation pore pressures in the total absence of axcavation effects.

The database from permeability tests of the Salado is not currently large enough to allow us to achieve our fifth objective, which was to differentiate between different mechanisms/models of brine flow through evaporites. One possibility is that continuous, albeit slow, flow occurs through evaporites in response to continuous porepressure gradients as it does through other porous media. A second possibility proposed by McTigue et al. (1989) is that flow only occurs after initially isolated pores are interconnected by shear deformation around an opening. Once the pores are interconnected, brine in the pores that had been at a pressure approaching lithostatic can flow towards the pressure sink represented by the opening, with creep then closing the pores and thereby helping to maintain the flow. The hydraulic behaviors observed during the Salado permeability testing program to date cannot be uniquely ascribed to either mechanism of brine flow. This is due, in part, to uncertainty as to whether or not any of the tested intervals discussed in this report were sufficiently far from the excavations to be unaffected by deviatoric stress resulting from the excavations. The two possible mechanisms of brine flow discussed above are also not necessarily mutually exclusive. Deformation and creep could act simply to enhance already-existing flow.

\subsection{Future Testing Plans and Con- siderations}

While this report was being prepared, tests of nine additional intervals were initiated. These include tests of Marker Bed 139 (L4P51-A guard zone, S1P72, SCP01 [Figure 5-1]), anhydrite " $\mathrm{C}$ " (S1P71-B and L4P51-B), map unit 0 and/or the polyhalitic halite between map unit 0 and Marker Bed 139 (S1P72 guard zone and SCP01 guard zone), halite between clay $D$ and anhydrite " $C$ " (L4P51-B guard zone), and Marker Bed 138
(S1P73-B). Other tests are planned to examine the hydraulic properties of anhydrites "a," "b," and "c," Marker Beds 138, 139, and 140, various clay seams/stringers, and other map units near the WIPP disposal horizon. However, efforts will be made to perform these new tests at greater distances from the excavations than were the tests discussed in this report. Testing at greater distances from the excavations should provide information on hydraulic properties and behavior beyond the range of potential excavation effects.

The new tests will not consist solely of pulsewithdrawal tests, but will also include pulseinjection tests, constant-pressure flow tests, and cross-hole interference tests. The need for pulseinjection tests was shown by the tests of $\mathrm{C}_{2} \mathrm{HO}_{3}$, L4P51-A, and S1P71-A. When conditions of little or no pressure buildup are observed, as they were at $\mathrm{C} 2 \mathrm{H} 03$, pulse-injection tests will allow us to differentiate between simple depressurization and extremely low (zero?) permeability. When apparent zero-flow boundaries are encountered, pulse-injection tests will be performed to attempt to increase the pressure in the test interval and counteract the apparent depletion effects of the pulse withdrawals. The behavior we observe should indicate whether or not we are truly dealing with a small, finite volume of fluid.

Where preliminary pulse-test interpretation indicates hydraulic conductivities on the order of $10^{-13} \mathrm{~m} / \mathrm{s}$ or higher, constant-pressure flow tests will also be performed. Constant-pressure flow tests are insensitive to test-zone compressibility and will allow confirmation of pulse-test interpretations and evaluation of potential errors in the pulsetest analyses. Flow tests may also provide additional information on the presence or absence of free gas at different testing locations.

The radii of influence obtained from the interpretation of the tests of Marker Bed 139 in boreholes 
$\mathrm{C}_{2} \mathrm{HO}_{1}$ and $\mathrm{C} 2 \mathrm{HO} 2$ indicate that cross-hole interference testing between holes 5 to $10 \mathrm{~m}$ apart may be feasible in Marker Bed 139. Interference tests allow reliable determination of the value of specific storage, whereas single-hole pressurepulse tests, in practice, do not. An interference test would probably take the form of a constantpressure flow test at one hole, while monitoring the pressure response at one or more nearby holes.

Testing in horizontal holes will be avoided in the future. The inability to remove all entrapped air from test zones in horizontal holes results in unacceptable uncertainty in the test-zone compressibility. Tests of the map units within the wastedisposal horizon will be performed in holes angled upward or downward enough to allow complete filling of the test zones with brine.

Future test-interpretation efforts will include the use of other types of numerical models to address factors not considered in this report, such as partialpenetration effects, the nature of the flow field around an inclined borehole, pressure-dependent test-zone compressibility, two-phase flow, and creep. Factors potentially affecting specific storage in halite will also be studied in greater depth Depending upon the results of these efforts, some of the test interpretations presented in this report could be modified.

\subsection{Conclusions}

The tests discussed in this report have demonstrated that the hydraulic properties of bedded evaporites can be determined from in situ hydrogeologic testing. Hydraulic conductivities of evaporites are low (10-14 to $10-11 \mathrm{~m} / \mathrm{s})$ when compared to those of most other water-bearing rock types, but they can be estimated using techniques and equipment specifically designed for low-permeability media. Questions remain, however, as to the nature and degree of interconnected porosity and permeability naturally present in halite. Hydraulic conductivities were found to increase, and formation pore pressures decrease, with increasing proximity to the underground excavations. Whether or not any of the tests can be considered to be unaffected by rock response to the excavations (deviatoric stress) is as yet unknown. This question can probably only be resolved by testing at greater distances from the excavations to establish the distance beyond which hydraulic properties remain relatively constant. A comparison of the hydraulic behaviors observed within and beyond the region influenced by deviatoric stress should provide insight into the mechanisms affecting brine flow through evaporites. 


\section{REFERENCES}

Bechtel National, Inc. 1985. Quarterly Geotechnical Field Data Report, September 1985, DOE-WIPP 218 (Carlsbad, NM: US DOE).

Bechtel National, Inc. 1986. Interim Geotechnical Field Data Report, Fall 1986, DOE-WIPP 86-012 (Carlsbad, NM: US DOE).

Black, S.R., Newton, R.S., and Shukla, D.K., editors. 1983. Results of Site Validation Experiments, Waste Isolation Pilot Plant (WIPP) Project, Southeastern New Mexico, Volume II, TME 3177 (Albuquerque, NM: US DOE).

Borns, D.J. 1985. Marker Bed 139: A Study of Drillcore From a Systematic Array, SAND85-0023 (Albuquerque, NM: Sandia National Laboratories).

Borns, D.J., and Stormont, J.C. 1988. An Interim Report on Excavation Effect Studies at the Waste Isolation Pilot Plant: The Delineation of the Disturbed Rock Zone, SAND87-1375 (Albuquerque, NM: Sandia National Laboratories).

Brady, B.H.G., and Brown, E.T. 1985. Rock Mechanics for Underground Mining (London: George Allen \& Unwin), $527 \mathrm{p}$.

Bredehoeft, J.D., and Papadopulos, S.S. 1980. "A Method for Determining the Hydraulic Properties of Tight Formations," Water Resources Research 16(1):233-238.

Brodsky, N.S. 1990. Crack Closure and Healing Studies in WIPP Salt Using Compressional Wave Velocity and Attenuation Measurements: Test Methods and Results, SAND90-7076 (Albuquerque, NM: Sandia National Laboratories).

Carmichael, R.S., editor. 1984. CRC Handbook of Physical Properties of Rocks, Volume III (Boca Raton, FL: CRC Press), $340 \mathrm{p}$.

Cinco, H., Miller, F.G., and Ramey; H.J., Jr. 1975. "IJnsteady-State Pressure Distribution Created By a Directionally Drilled Well," J. Pet. Tech. 27:1392-1400.

Craft, B.C., and Hawkins, M.F. 1959. Applied Petroleum Resservoir Engineering (Englewood Cliffs, NJ: Prentice-Hall, Inc.), 437 p.

Cygan, R.T. 1991. The Solubility of Gases in NaCl Brıne and a Critical Evaluation of Available Data, SAND90-2848 (Albuquerque, NM: Sandia National Laboratories).

Deal, D.E., Abitz, R.J., Belski, D.S., Case, J.B., Crawley, M.E., Deshler, R.M., Drez, P.E., Givens, C.A., King, R.B., Lauctes, B.A., Myers, J., Niou, S., Pietz, J.M., Roggenthen, W.M., Tyburski, J.R., and Wallace, 
M.G. 1989. Brine Sampling and Evaluation Program 1988 Report, DOE/WIPP 89-015 (Carlsbad, NM: US DOE).

Deal, D.E., Case, J.B., Deshler, R.M., Drez, P.E., Myers, J., and Tyburski, J.R. 1987. Brine Sampling and Evaluation Program Phase II Report, DOENIPP 87-010 (Carlsbad, NM: US DOE).

Desai, C.S., and Varadarajan, A. 1987. "A Constitutive Model for Quasi-Static Behavior of Rock Salt," J. Geophys. Res. 92(B11):11,445-11,456.

Domenico, P.A. 1972. Concepts and Models in Groundwater Hydrology (New York: McGraw-Hill), 405 p.

Ea:lougher, R.C., Jr. 1977. Advances in Well Test Analysis. Monograph Volume 5 (Dallas, TX: Soc Pet Eng of AIME), $264 \mathrm{p}$.

Freeze, R.A., and Cherry, J.A. 1979. Groundwater (Englewood Cliffs, NJ: Prentice-Hall Inc.), 604 p.

Gevantman, L.H., editor. 1981. Physical Properties Data for Rock Salt. NBS Monograph 167 (Washington, DC: National Bureau of Standards), $288 \mathrm{p}$.

Green, D.H., and Wang, H.F. 1990. "Specific Storage as a Poroelastic Coefficient," Water Resources Research 26(7):1631-1637.

Hantush, M.S. 1964. "Hydraulics of Wells," in Chow, V.T., editor, Advances in Hydroscience (New York: Academic Press) 1:281-432.

Hantush, M.S. 1966. "Analysis of Data from Pumping Tests in Anisotropic Aquifers," J. Geophys. Res. $71(2): 421-426$.

Holcomb, D.J. 1988. "Cross-Hole Measurements of Velocity and Attenuation to Detect a Disturbed Zone in Salt at the Waste Isolation Pilot Plant," in Cundall, P.A., Sterling, R.L., and Startield, A.M., editors, Key Questions in Rock Mechanics: Proceedings of the 29th U.S. Symposium, University of Minnesota, Minneapolis, 13-15 June 1988 (Rotterdam: A.A. Balkema), pp. 633-640.

Holt, R.M., and Powers, D.W. 1990. Geologic Mapping of the Air Intake Shaft at the Waste Isolation Pilot Plant, DOE/WIPP 90-051 (Carlsbad, NM: US DOE).

Hsieh, P.A., Neuman, S.P., and Simpson, E.S. 1983. Pressure Testing of Fractured Rocks--A Methodology Employing Three-Dimensional Cross-Hole Tests, NUREG/CR-3213 (Washington, DC: US NRC).

Ibrahim, A.W., Borns, D.J., and Jung, Y. 1989. "Mapping Fractures in Salt with the Seismic Method," SEG Abstracts 59(1):252-254. 
Jensen, A.L. 1990. Borehole Closure and Test Zone Volume Determination Program for BrinePermeability Test Results Within the Waste Isolation Pilot Plant Underground Facility, SAND90-0228 (Albuquerque, NM: Sandia National Laboratories).

Jones, C.L., Bowles, C.G., and Bell, K.G. 1960. Experimental Drill Hole Logging in Potash Deposits of the Carlsbad District, New Mexico. USGS Open-File Rpt 60-84 (Washington, DC: US GPO), 25 p.

Krieg, R.D. 1984. Reference Stratigraphy and Rock Properties for the Waste Isolation Pilot Plant (WIPP) Project, SAND83-1908 (Albuquerque, NM: Sandia National Laboratories).

McTigue, D.F. 1989. "Observations on Brine Flow Mechanisms in WIPP Repository Salt Based on Data from a Room D Borehole." Memorandum to Distribution, March 15, 1989, Division 1511, Sandia National Laboratories, Albuquerque, NM.

McTigue, D.F., Finley, S.J., and Nowak, E.J. 1989. "Brine Transport in Polycrystalline Salt: Field Measurements and Model Considerations," Eos Transactions 70(43):1111.

Mraz, D. 1980. "Plastic Behavior of Salt Rock Utilized in Designing a Mining Method," CIM Bulletin 73:11123.

Neuzil, C.E. 1982. "On Conducting the Modified 'Slug' Test in Tight Formations," Water Resources Research 18(2):439-441.

Nowak, E.J., McTigue, D.F., and Beraun, R. 1988. Brine Inflow to WIPP Disposal Rooms: Data, Modeling, and Assessment, SAND88-0112 (Albuquerque, NM: Sandia National Laboratories).

Nowak, E.J., Finley, S.J., and Howard, C.L. 1990. Implementation of Initial Tests in the Brine Inflow Room (Room Q) of the Waste Isolation Pilot Plant, SAND90-0611 (Albuquerque, NM: Sandia National Laboratories).

Palciauskas, V.V., and Domenico, P.A. 1989. "Fluid Pressures in Deforming Porous Rocks," Water Resources Research 25(2):203-213.

Perry, R.H., and Chilton, C.H., editors. 1973. Chemical Engineers' Handbook, Fifth Edition (New York: McGraw-Hill).

Peterson, E.W., Lagus, P.L., and Lie, K. 1987. WIPP Horizon Free Field Fluid Transport Characteristics, SAND87-7164 (Albuquerque, NM: Sandia National Laboratories).

Pfeifle, T.W., Mellegard, K.D., and Senseny, P.E. 1983. Preliminary Constitutive Properties for Salt and Nonsalt Rocks From Four Potential Repository Sites, ONWI-450 (Columbus, OH: Battelle Memorial Institute). 
Pfeifle, T.W., and Senseny, P.E. 1981. Elastic-Plastic Deformation of Anhydrite and Polyhalite as Determined From Quasi-Static Triaxial Compression Tests, SAND81-7063 (Albuquerque, NM: Saridia National Laboratories).

Pickens, J.F., Grisak, G.E., Avis, J.D., Belanger, D.W., and Thury, M. 1987. "Analysis and Interpretation of Borehole Hydraulic Tests in Deep Boreholes: Principles, Model Development, and Applications," Water Resources Research 23(7):1341-1375.

Powers, D.W., and Hassinger, B.W. 1985. "Synsedimentary Dissolution Pits in Halite of the Permian Salado Formation, Southeastern New Mexico," J. Sed. Pet. 55(5):769-773.

Powers, D.W., Lambert, S.J., Shaffer, S.-E., Hill, L.R., and Weart, W.D., editors. 1978. Geological Characterization Report, Waste Isolation Pilot Plant (WIPP) Site, Southeastern New Mexico, 2 volumes, SAND78-1596 (Albuquerque, NM: Sandia Laboratories).

Saulnier, G.J., Jr., and Avis, J.D. 1988. Interpretation of Hydraulic Tests Conducted in the Waste-Handling Shaft at the Waste Isolation Pilot Plant (WIPP) Site, SAND88-7001 (Albuquerque, NM: Sandia National Laboratories).

Saulnier, G.J., Jr., Domski, P.S., Palmer, J.B., Roberts, R.M., Stensrud, W.A., and Jensen, A.L. 1991. WIPP Salado Hydrology Program Data Report \#1, SAND90-7000 (Albuquerque, NM: Sandia National Laboratories).

Skokan, C.K., Pfeifer, M.C., Keller, G.V., and Andersen, H.T. 1989. Studies of Electrical and Electromagnetic Methods for Characterizing Salt Properties at the WIPP Site, New Mexico, SAND87-7174 (Albuquerque, NM: Sandia National Laboratories).

Stensrud, W.A.: Bame, M.A., Lantz, K.D., Cauffman, T.L., Palmer, J.B., and Saulnier, G.J., Jr. 1988. WIPP Hydrology Program, Waste Isolation Pilot Plant, Southeastern New Mexico, Hydrologic Data Report \#6, SAND87-7166 (Albuquerque, NM: Sandia National Laboratories).

Stormont, J.C. 1990a. "Discontinuous Behaviour Near Excavations in a Bedded Salt Formation," Int. J. Mining and Geological Engineering 8:35-56.

Stormont, J.C. 1990b. Summary of 1988 WIPP Facility Horizon Gas Flow Measurements, SAND89-2497 (Albuquerque, NM: Sandia National Laboratories).

Teufel, L.W. 1981. Mechanical Properties of Anhydrite and Polyhalite in Quasi-Static Triaxial Compression, SAND81-0858 (Albuquerque, NM: Sandia National Laboratories).

Touloukian, Y.S., Judd, W.R., and Roy, R.F. 1981. Physical Properties of Rocks and Minerals. McGrawHill/Cindas Data Series of Material Properties, Y.S. Touloukian and C.Y. Ho, editors, Volume II-2, 548 p. 
U.S. Department of Energy. 1983. Quarterly Geotechnical Field Data Report, October 1983, WIPP-DOE177 (Albuquerque, NM: US DOE).

Van Sambeek, L.L. 1987. Thermal and Thermomechanical Analyses of WIPP Shatt Seals, SAND87-7039 (Albuquerque, NM: Sandia National Laboratories).

Walsh, J.B. 1965. "The Effect of Cracks on the Compressibility of Rock," J. Geophys. Res. 70(2):381389.

Wawersik, W.R., and Hannum, D.W. 1980. "Mechanical Behavior of New Mexico Rock Salt in Triaxial Compression Up to $2000^{\circ}$ C," J. Geophys. Res. 85:891-900.

Wawersik, W.R., arid Stone, C.M. 1989. "A Characterization of Pressure Records in Inelastic Rcck Demonstrated by Hydraulic Fracturing Measurcments in Salt," Int. J. Rock Mech. Min. Sci. \& Geomech. Abstr. 26(6):613-627.

Weast, R.C., editor. 1983. CRC Handbook of Chemistry and Physics, 64th Edition (Boca Raton, FL: CRC Press).

Westinghouse Electric Corporation. 1989. Geotechnical Field Data and Analysis Report, July 1987-June 1988, Volume il, DOEMIPP 89-009 (Carlsbad, NM: US DOE).

Westinghouse Electric Corporation. 1990. Geotechnical Field Data and Analysis Report, July 1988-June 1989, Volume II, DOEMIIPP 90-006 (Carlsbad, NM: US DOE). 


\section{APPENDIX A}

\section{SUMMARY OF SURFACE-BASED HYDRAULIC TESTING OF THE SALADO FORMATION}

From 1976 to 1985 , a number of hydraulic tests of the Salado Formation were performed in boreholes drilled from the surface. Most of these tests were intended as reconnaissance tests to try to find evidence of high permeabilities and pressures, rather than as tests to measure the expected low permeability of halite. As a result, little effort was expended trying to establish optimal conditions for testing of lowpermeability media. Drillstem tests (DSTs), air-injection tests, and/or pressure-pulse iests were performed in boreholes ERDA-9, ERDA-10, AEC-7, AEC-8, Cabin Baby-1, DOE-2, and WIPP-12, but none provided data that could be reliably interpreted to yield formation permeability and/or pressure values.

In 1976, ten DSTs were attempted in borehole ERDA-9 of Salado intervals ranging in thickness from 11.6 to $76.5 \mathrm{~m}$ (Griswold, 1977). The purpose of the tests was to look for evidence in the Salado Formation of geopressured brine flow such as had been observed in the Castile Formation at the ERDA-6 borehole (Griswold, 1977). Accordingly, no effort was made to optimize conditions for testing of very low permeability (< 10-15 m2; 1 milliDarcy [mD]) media. Three of the DSTs were unsuccessful, as one or both packers failed to establish a pressure-tight seat in the borehole. Halliburton Services, the company that performed the DSTs, reported permeability values from fivf of the tests (Sigmon, 1976). One of these five tests, and a sixth test, were also interpreted by Sipes, Williams, and Aycock, Inc., the contractor hired to oversee the DSTs. The seventh test was considered uninterpretable because the buildup data provided evidence only of afterflow (wellbore storage) (Sigmon, 1976; Griswold, 1977).

The permeabilities interpreted from the six DSTs in ERDA-9 have since appeared in Griswold (1977), Lambert and Mercer (1978), and Mercer (1987) without critical evaluation. Examination of the interpretations presented by Sigmon (1976) reveals that no flows into the well occurred during ine DST flow periods. Nevertheless, the buildup data were fitted to type curves, and the time matches between the data and the type curves were used incorrectly to estimate permeabilities. Standard DST buildup analysis (Earlougher, 1977) requires that a flow rate be measured during a flow period. This flow rate is used along with the pressure match between the data and a type curve to calculate permeability. The time match is only used with the permeability obtained from the pressure match to calculate the wellbore-storage coefficient of the well. The time match alone provides no information on permeability. Thus, the permeability values presented by Sigmon (1976) from the ERDA-9 DSTs are invalid. The DST interpretations of Sipes, Williams, and Aycock, Inc., also relied on invalid type-curve-matching procedures and on invalid Horner analyses because no flows were observed during those tests. Without flow data, the ERDA9 DSTs simply cannot be interpreted to provide estimates of permeability.

Even though invalid interpretations of the ERDA-9 DSTs were reported, the deficiencies of the tests were recognized by the parties involved. Quoting Griswold (1977), "... we must conclude that the drill-stem test did not adequately test the formation. This is not an operational fault of the technique we used, but rather an indication that extremely long shut-in times (perhaps a month or more) will be required. Such times are not realistic for conducting active drilling operations. Therefore, the only conclusion that can be drawn 
from the 10 drill-stem tests is that no signiticant amount of fluid is present in the Salado. Definitive tests as to what trace amounts are present and under what pressures must be determined by other means ..."

DSTs were attempted over two intervals of the Salado in borehole AEC-7 in 1979 (Sandia and D'Appolonia, 1983a), over one interval of the Salado in borehole AEC-8 in 1976 (Sandia and D'Appolonia, 1983b), and over two Salado intervals in borehole ERDA-10 in 1977 (Sandia and D'Appolonia, 1983c), but no interpretable results were obtained from any of these tests. Although pressure buildups were usually observed when the intervals were shut in, no flows into the wells were observed during the DST flow periods, which typically lasted one hour or less.

Air-injection tests of two $30.5-\mathrm{m}$ intervals of the Salado were attempted in June 1979 in borehole AEC-7 (Peterson et al., 198i). Peterson et al. (1981) interpreted these tests by assuming that the pores in the Salado were dry, containing only gas at atmospheric pressure. This assumption has since been found to be invalid, as the Salado pores appear, from testing performed in the WIPP underground, to be saturated with brine at pressures of up to $11 \mathrm{MPa}$. The fluid that had been in the AEC-7 borehole since it was drilled was evacuated 28 days before the air-injection testing began, which may have resulted in partial desaturation of the rock around the hole. The true saturation state and pressure distribution around the AEC-7 borehole at the time of the air-injection tests cannot now be determined, however, and hence the tests cannot be reinterpreted to provide reliable permeability values.

In 1983, DSTs and a slug test were attempted on a 597.5-m interval of the Salado in borehole Cabin Baby1 (Beauheim et al., 1983). From a Horner analysis of the second DST buildup period, Beauheim et al. (1983) reported a maximum average permeability of the interval of $9 \times 10^{-21} \mathrm{~m}^{2}(9 \mathrm{nD})$. This value was reported as a maximum because it was derived from the final slope of a Horner buildup curve that was continuing to steepen at the end of the DST, and permeability is inversely proportional to the slope of such a curve. Later observations of shut-in pressures at the Cabin Baby-1 wellhead revealed that pressures had indeed risen higher than the value predicted from extrapolation of the final slope observed during the DST, confirming that the permeability value reported was an overestimate. Beauheim et al. (1983) also reported a Salado permeability value of $8 \times 10^{-20} \mathrm{~m}^{2}(80 \mathrm{nD})$ based on a poor fit between the slug-test data from Cabin Baby-1 and a type curve. This permeability value is also likely an overestimate, because the type-curve interpretation failed to take into account the transient pressure conditions existing before the slug test began. The recovery response observed during the slug test actually represented a superposition of recovery responses from the earlier DSTs and other wellbore conditions in addition to the slug test itself, and therefore was more rapid, leading to a higher interpreted permeability, than it would have been had the slug test been the only stress on the system. Thus, the testing at Cabin Baby-1 provided only poorly defendable upper bounds on the permeability of the Salado.

In 1985, a DST and pressure-pulse tests were attemp.ted over two Salado intervals in borehole DOE-2 (Beauheim, 1986). The DST was performed over a 34.7- $\mathrm{m}$ interval of the Salado that included Marker Beds 138 and 139. The test-interval pressure was given nearly $21 \mathrm{hr}$ to stabilize before testing began, but this proved to be an inadequate period. The DST consisted of a 21 -minute flow period followed by a 23.3.hr buildup period. From a بorner analysis of the buildup data, Beauheim (1986) estimated a maximum average permeability of the interval of $3 \times 10^{-19} \mathrm{~m}^{2}(300 \mathrm{nD})$. This value was reported as a 
maximum because the Homer buildup curve was continuing to steepen at the end of the monitoring period. Two pressure-pulse tests were attempted over a 626.4-m interval of the Salado in DOE-2. The tests were preceded by a 15-hr pressure-stabilization period. Attempted type-curve interpretation of these tests failed because the two data sets provided inconsistent estimates of the static formation pressure and fit the type curves poorly. Therefore, no defendable estimates of permeability were obtained from the pulse tests. In summary, the testing at DOE-2 resulted only in an overestimate of the permeability of one interval. Both the DST and pulse tests at DOE-2 provided qualitative indications that carefully controlled permeability tests of the Salado would require testing durations on the order of weeks to months.

DSTs were also performed over four Salado intervals in borehole WIPP-12 in 1985 (Beauheim, 1987). The primary purpose of the tests was to identify the source(s) of high pressures observed at the WIPP-12 wellhead, not to provide data for quantitative permeability analysis. Thus, no attempt was made to allow test-interval pressures to stabilize before beginning the DSTs, and all tests were terminated while the buildup curves (on a Horner plot) were continuing to steepen. No attempt has been made to derive permeability values from these tests because the test clata are unsuitable for that purpose. However, the responses observed during the WIPP-12 testing provided additional qualitative indications that a permeability test of the Salado would require a testing duration on the order of weeks to months.

Following the DOE-2 and WIPP-12 testing, we concluded that the time periods required for successful permeability testing of the Salado rendered surface-based testing in deep boreholes unfeasible. Economic considerations involving the costs of deep drilling and maintaining necessary equipment at remote surface sites for long periods of time, and technical difficulties that had been encountered, such as a lack of good packer seats and numerous equipment failures, contributed to this conclusion. Thus, all future hydraulic testing of the Salado was planned to be conducted in the underground WIPP facility, where access to the formation at the facility horizon could be easily obtained, and where tests could be started and conducted more economically with more control over the mechanics of testing and equipment. 


\section{REFERENCES}

Beauheim, R.L. 1986. Hydraulic-Test Interpretations for Well DOE-2 at the Waste Isolation Pilot Plant (WIPP) Site, SAND86-1364 (Albuquerque, NM: Sandia National Laboratories).

Beauheim, R.L. 1987. Interpretations of Single-Well Hydraulic Tests Conducted At and Near the Waste Isolation Pilot Plant (WIPP) Site, 1983-1987, SAND87-0039 (Albuquerque, NM: Sandia National Laboratories).

Beauheim, R.L., Hassinger, B.W., and Klaiber, J.A. 1983. Basic Data Report for Borehole Cabin Baby-1 Deepening and Hydrologic Testing. WTSD-TME-020 (Albuquerque, NM: US DOE).

Earlougher, R.C., Jr. 1977. Advances in Well Test Analysis. Monograph Volume 5 (Dallas, TX: Soc Pet Eng of AIME), $264 \mathrm{p}$.

Griswold, G.B. 1977. Site Selection and Evaluation Studies of the Waste Isolation Pilot Plant (WIPP), LoS Medaños, Eddy County, NM, SAND77-0946 (Albuquerque, NM: Sandia Laboratories).

Lambert, S.J., and Mercer, J.W. 1978. Hydrologic Investigations of the Los Medaños Area, Southeastern New Mexico, 1977, SAND77-1401 (Albuquerque, NM: Sandia Laboratories).

Mercer, J.W. 1987. Compilation of Hydrologic Data From Drilling the Salado and Castile Formations Near the Waste Isolation Pilot Plant (WIPP) Site in Southeastern New Mexico, SAND86-0954 (Albuquerque, NM: Sandia National Laboratories).

Peterson, E.W., Lagus, P.L., Broce, R.D., and Lie, K. 1981. In Situ Permeability Testing of Rock Salt, SAND81-7073 (Albuquerque, NM: Sandia National Laboratories).

Sandia National Laboratories and D'Appolonia Consulting Engineers, 1983a. Basic Data Report for Drillhole AEC 7 (Waste Isolation Pilot Plant - WIPP), SAND79-0268 (Albuquerque, NM: Sandia National Laboratories).

Sandia National Laboratories and D'Appolonia Consulting Engineers, 1983b. Basic Data Report for Drillhole AEC 8 (Waste Isolation Pilot Plant - WIPP), SAND79-0269 (Albuquerque, NM: Sandia National Laboratories).

Sandia National Laboratories and D'Appolonia Consulting Engineers, 1983c. Basic Data Report for Drillhole ERDA 10 (Waste Isolation Pilot Plant - WIPP), SAND79-0271 (Albuquerque, NM: Sandia National Laboratories).

Sigmon, J.E. 1976. Letter on ERDA-9 Drillstem Testing Analysis to John Keesey, Sipes, Williams, and Aycock: Inc. Midland: Texas; dated August 9. 1976. 


\section{APPENDIX B \\ STRATIGRAPHIC UNITS (MAP UNITS) NEAR THE WIPP \\ FACILITY HORIZON}




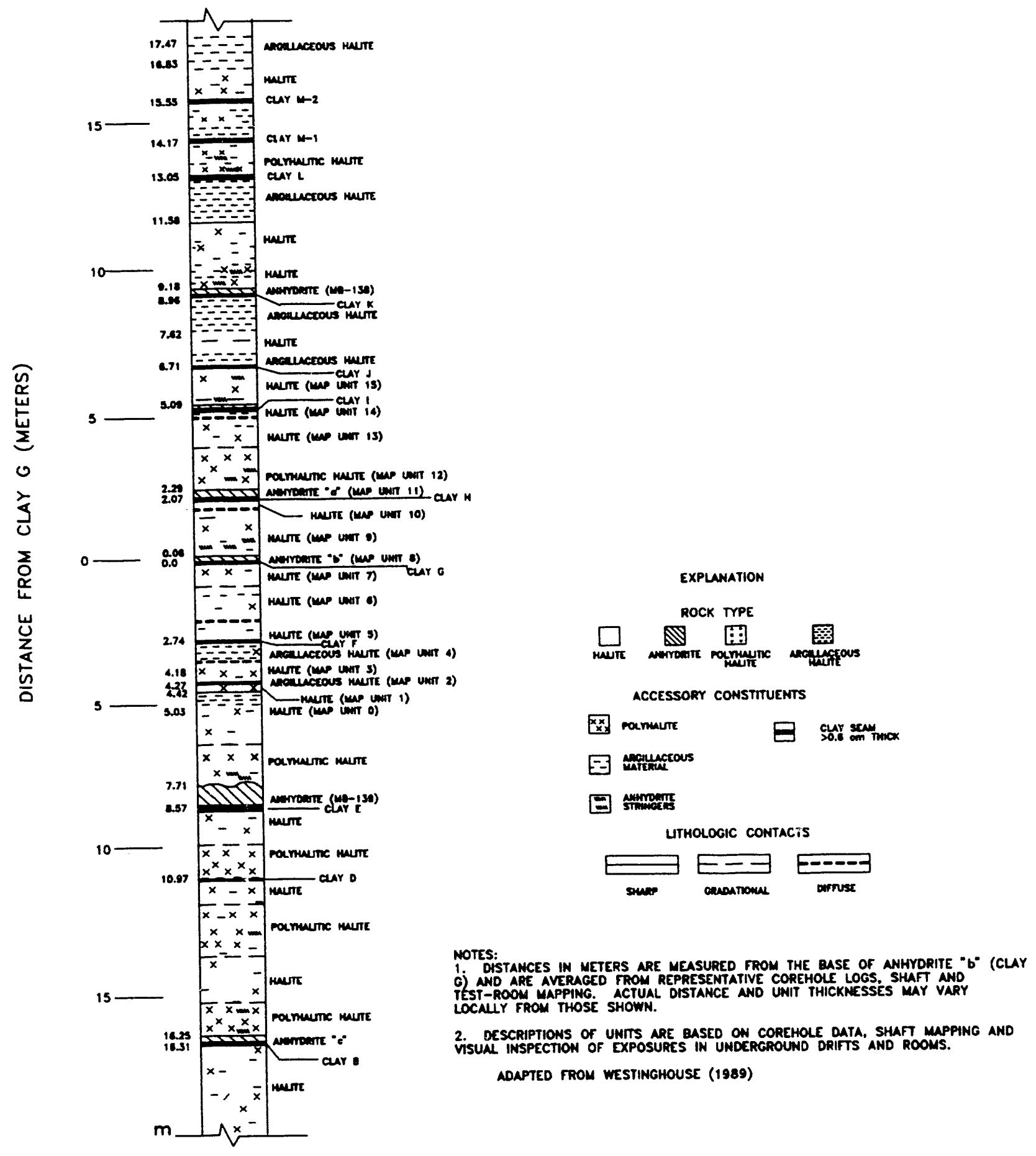

Figure B-1. Detalled Stratigraphy Near the WIPP Underground Facllity. 
Table B-1

\section{Description of Generalized Stratigraphy*}

\begin{tabular}{|c|c|c|}
\hline $\begin{array}{l}\text { Approximate } \\
\text { Distance From } \\
\text { Clay G (Meters) }\end{array}$ & Stratigraphic Unit & Description \\
\hline 16.8 to 17.5 & Argillaceous halite & $\begin{array}{l}\text { Clear to moderate brown, medium to coarsely crystalline. }<1 \text { to } \\
3 \% \text { brown clay. Intercrystalline and discontinuous breaks. In } \\
\text { one core hole, consists of a } 2.54 \text { centimeter thick clay seam. } \\
\text { Unit can vary up to } 1.2 \text { meters in thickness. Contact with lower } \\
\text { unit is gradational. }\end{array}$ \\
\hline 14.2 to 16.8 & Halite & $\begin{array}{l}\text { Clear to moderate reddish orange and moderate brown, } \\
\text { coarsely crystalline, some medium. } \leq 1 \% \text { brown clay, locally } \\
\text { argillaceous (clays } M-1 \text { and } M-2 \text { ). Scattered anhydrite stringers } \\
\text { locally. }\end{array}$ \\
\hline 13.0 to 14.2 & Polyhalitic halite & $\begin{array}{l}\text { Clear to moderate reddish orange, some moderate brown, } \\
\text { coarsely crystalline. }<1 \text { to } 3 \% \text { polyhalite. None to } 1 \% \text { brown } \\
\text { and some gray clay. Scattered anhydrite locally. Contact with } \\
\text { unit below is fairly sharp. }\end{array}$ \\
\hline 11.6 to 13.0 & Argillaceous halite & $\begin{array}{l}\text { Clear to moderate brown, medium to coarsely crystalline, some } \\
\text { fine. }<1 \text { to } 5 \% \text { brown clay. Locally contains } 10 \% \text { clay. } \\
\text { Intercrystalline and scattered breaks. Locally contains partings } \\
\text { and seams. Contact with lower unit is gradational based on } \\
\text { increased clay content. Average range of unit is } 11.6 \text { to } 13.0 \\
\text { meters above clay G but does vary from } 10.3 \text { to } 14.0 \text { meters. }\end{array}$ \\
\hline 10.4 to 11.6 & Halite & $\begin{array}{l}\text { Clear to moderate brown, some moderate reddish brown, } \\
\text { coarsely crystalline, some fine and medium. } \leq 1 \% \text { brown clay, } \\
\text { trace gray clay locally. Scattered breaks. Locally argillaceous. } \\
<1 \% \text { polyhalite. Contact with unit below is gradational based on } \\
\text { clay and polyhalite content. }\end{array}$ \\
\hline 9.2 to 10.4 & Halite & $\begin{array}{l}\text { Clear to moderate reddish orange, coarsely crystalline. }<1 \text { to } \\
3 \% \text { polyhalite. Commonly polyhalitic. Scattered anhydrite } \\
\text { stringers with anhydrite layers up to } 1.27 \text { centimeters thick } \\
\text { locally. Scattered brown clay locally. Contact with MB-138 } \\
\text { below is sharp. }\end{array}$ \\
\hline 9.0 to 9.2 & Anhydrite (MB-138) & $\begin{array}{l}\text { Light to medium gray, microcrystalline. Partly laminated. } \\
\text { Scattered halite growths. Clay seam } \mathrm{K} \text { found at base of unit. }\end{array}$ \\
\hline 7.6 to 9.0 & Argillaceous halite & $\begin{array}{l}\text { Clear to moderate brown, some light moderate reddish orange. } \\
\text { Medium to coarsely crystalline. }<1 \text { to } 3 \% \text { brown clay, some } \\
\text { gray. Locally up to } 5 \% \text { clay. Clay is intercrystalline with scat- } \\
\text { tered breaks and partings present. }<1 / 2 \% \text { dispersed polyhalite. } \\
\text { Contact with lower unit is gradational based on clay content. } \\
\text { Upper contact with clay K is sharp. }\end{array}$ \\
\hline
\end{tabular}

"From Geotechnical Field Data and Analysis Report, Vol. II, Westinghouse, 1989. 


\section{Description of Generalized Stratigraphy (Continued)}

Approximate

Distance From

Clay G (Meters)

7.0 to 7.6

Halite

6.4 to 7.0

5.1 to 6.4

4.8 to 5.1

3.5 to 4.8

Halite (map unit 13)

2.3 to 3.5

2.1 to 2.3

1.7102 .1

0.1 to 1.7

Argillaceous halite (clay J)

Halite (map unit 15)

Halite (map unit 14)

Polyhalitic halite

(map unit 12)

Anhydrite

("a" - map unit 11)

Halite (map unit 10)

Halite (map unit 9)
Clear, some light moderate brown, coarsely crystalline. $<1 / 2 \%$ brown clay. Contact with clay $\mathrm{J}$ below varies from sharp to gradational depending if clay $\mathrm{J}$ is a distinct seam or merely an argillaceous zone.

Usually consists of scattered breaks or argillaceous zone containing $<1$ to $3 \%$ brown clay. In C\&SH shaft, it is a 1.27 centimeiers thick brown clay seam.

Clear, coarsely crystalline, scattered medium. Up to $1 \%$ dispersed polyhalite and brown clay. Scattered anhydrite. Lower contact is sharp with clay 1 .

Clear to grayish orange-pink, coarsely crystalline, some medium. $<1 / 2 \%$ dispersed polyhalite. Scattered discontinuous gray clay stringers. Clay $I$ is along upper contact. Contact with lower unit is diffuse.

Clear to moderate reddish orange and moderate brown, medium to coarsely crystalline, some fine. $\leq 1 \%$ brown clay, locally up to $3 \%$. Trace of gray clay. Scattered discontinuous breaks. $<1 \%$ dispersed polyhalite and polyhalite blebs. Contact with unit below is gradational based on clay and polyhalite content.

Clear to moderate reddish orange, coarsely crystalline. $\leq 1$ to $3 \%$ dispersed polyhalite and polyhalite blebs. Scattered anhydrite stringers. Contact is sharp with unit below.

Light to medium gray, light brownish gray and sometimes light moderate reddish orange. Microcrystalline. Halite growths within. Partly laminated. Clear, coarsely crystalline halite layer up to 5.1 centimeters wide, found within exposures in waste experimental area. Thin gray clay seam $\mathrm{H}$ at base of unit.

Clear to moderate reddish orange/brown, fine to coarsely crystalline. $\leq 1 \%$ brown and/or gray clay and dispersed polyhalite. Discontinuous clay stringers locally. Contact with lower unit is diffise based on crystal size and varying amounts of clay and polyhalite.

Clear to light moderately reddish orange, coarsely crystalline, some medium. None to $<1 \%$ polyhalite. Trace of gray clay locally. Scattered anhydrite stringers. Contact with unit below is sharp. 


\section{Description of Generalized Stratigraphy (Continued)}

\section{Approximate \\ Distance From \\ Clay G (Meters)}

0.0 to 0.1

0.0 to -0.7

-0.7 to -2.1

-2.1 to -2.7

-2.7 to -3.5

-3.5 to -4.2

-4.2 to -4.3

-4.3 to -4.4

-4.4 to -6.7
Stratigraphic Unit

Anhydrite

("b" - map unit 8)

Halite (map unit 7)

Halite (map unit 6)

Halite (map unit 5)

Argillaceous halite (map unit 4)

Halite (map unit 3)

Argillaceous halite (map unit 2)

Halite (map unit 1)

Halite (map unit 0)
Light to medium gray, microcrystalline anhydrite. Scattered halite growths. Thin gray clay seam $G$ at base of unit.

Clean to light/medium gray, some moderate reddish orange/ brown. Coarsely crystalline, some fine and medium. $\leq 1 \%$ brown and gray clay. Locally up to $2 \%$ clay. $<1 \%$ dispersed polyhalite. Upper contact is sharp with clay G. Contact with lower unit is gradational.

Clear, some moderate reddish orange, coarsely crystalline, some fine to medium locally. $<1 / 2 \%$ gray clay and polyhalite. Contact with lower unit gradational and/or diffuse.

Clear, coarsely crystalline. $<1 / 2 \%$ gray clay. Contact with lower unit usually sharp with clay $F$.

Clear to moderate brown and moderate reddish brown, coarsely crystalline. $<1 \%$ polyhalite. $<1$ to $5 \%$ argillaceous material; predominantly brown, some gray, bcally. Intercrystalline and discontinuous breaks and partings common in upper part of unit. Decreasing argillaceous content downward. Contact with lower unit is gradational.

Clear to moderate reddish orange, coarsely crystalline. $\leq 1 \%$ dispersed polyhalite and polyhalite blebs. Locally polyhalitic. Scattered gray clay locally. Contact with lower unit is sharp.

Moderate reddish brown to medium gray, medium to coarsely crystalline. $<1$ to $3 \%$ argillaceous material. Contact with lower unit is usually sharp.

Light reddish orange to moderate reddish orange, medium to coarsely crystalline. $\leq 1 \%$ dispersed polyhalite. Contact with lower unit is sharp.

Clear to moderate reddish orange/brown, moderate brown and grayish brown. Medium to coarsely crystalline. $<1$ to $5 \%$ argillaceous material. Predominantly brown, some gray, intercrystalline argillaceous material and discontinuous breaks and partings. Upper 0.6 meters of unit is argillaceous halite decreasing in argillaceous material content downward. None to $<1 \%$ polyhalite. Contact with lower unit is gradational based on polyhalite content. 


\section{Description of Generalized Stratigraphy (Continued)}

\begin{tabular}{lll}
\hline $\begin{array}{c}\text { Approximate } \\
\text { Distance From } \\
\text { Clay G (Meters) }\end{array}$ Stratigraphic Unit & Description \\
\hline
\end{tabular}

-6.7 to $-7.7 \quad$ Polyhalitic halite

-7.7 to -8.6

Anhydrite (MB-139)

-8.6 to $-9.5 \quad$ Halite

-9.5 to $-11.0 \quad$ Polyhalitic halite

-11.0 to $-11.5 \quad$ Halite

-11.5 to $13.0 \quad$ Polyhalitic halite

-13.0 to $14.4 \quad$ Halite

-14.4 to $-16.2 \quad$ Polyhalitic halite

-16.2 to $-16.3 \quad$ Andydrite ("c")
Clear to moderate reddish orange. Coarsely crystalline, some medium locally. $<1$ to $3 \%$ polyhalite. Scattered anhydrite. Scattered gray clay locally. Contact with lower unit (MB-139) is sharp, but commonly irregular and undulating. Trace of gray locally present along this contact.

Moderate reddish orange/brown to light and medium gray, microcrystalline anhydrite. "Swallowtail" pattern, consisting of halite growths within anhydrite, common in upper part of unit. Locally, hairline, clay-filled, low-angle fractures found in lower part of unit. Thin halite layer common close to lower contact. Clay seam $E$ found at base of unit. Upper contact is irregular, undulating and sometimes contains $<0.16$ centimeters gray clay.

Clear to moderate reddish orange, and light gray. Coarsely crystalline, some fine and medium. $\leq 1 \%$ polyhalite and intercrystalline gray clay. Contact with lower unit is gradational based on increased polyhalite content.

Clear to moderate reddish orange, coarsely crystalline. $<1$ to $3 \%$ polyhalite. Contact with bwer unit is usually sharp along clay D.

Clear to moderate reddish orange, some light gray. Medium to coarsely crystalline. $\leq 1 \%$ polyhalite and gray clay. Contact with lower unit is gradational based on increased polyhalite content.

Clear to moderate reddish orange/brown, coarsely crystalline. $<1$ to $3 \%$ polyhalite. Trace of clay locally. Scattered anhydrite locally. Contact with lower unit is gradational, based on decreased polyhalite content.

Clear to moderate reddish orange, medium to coarsely crystalline. $<1 \%$ dispersed polyhalite. $<1 \%$ brown and/or gray clay. Contact with lower unit is gradational and/or diffuse.

Clear to moderate reddish orange. Coarsely crystalline with some medium sometimes present close to lower contact. $<1$ to $3 \%$ polyhalite. Scattered anhydrite especially common close to anhydrite " $c$ ". Lower contact is sharp with anhydrite "c".

Light to medium gray, microcrystalline anhydrite. Scattered halite growths. Faintly laminated locally. Clay seam B found at baise of unit. 


\section{Description of Generalized Stratigraphy (Concluded)}

\section{Approximate Distance From Clay G (Meters)}

-16.3 to $-20.0 \quad$ Halite

-11.5 to 13.0

Polyhalitic halite

-13.0 to -14.4

Halite

\section{Description}

Clear to medium gray and moderate brown. Medium to coarsely crystalline, some fine locally. $\leq 1 \%$ polyhalite, locally polyhalitic. $<1$ to $3 \%$ clay, both brown and gray. Intercrystalline clay with discontinuous breaks and partings. Zones of argillaceous halite found within unit. Seams of clay mixed with halite crystals present locally. Upper contact of this unit is sharp with clay B.

Clear to moderate reddish orange/brown, coarsely crystalline. $<1$ to $3 \%$ polyhalite. Trace of clay bcally. Scattered anhydrite locally. Contact with lower unit is gradational, based on decreased polyhalite content.

Clear to moderate reddish orange, medium to coarsely crystalline. $<1 \%$ dispersed polyhalite. $<1 \%$ brown and/or gray clay. Contact with lower unit is gradational and/or diffuse. 


\title{
APPENDIX C
}

\section{CORE LOGS}

\author{
$\mathrm{C} 2 \mathrm{H} 01$ \\ $\mathrm{C} 2 \mathrm{HO} 2$ \\ $\mathrm{C} 2 \mathrm{HO} 3$ \\ N4P50 \\ L4P51-A \\ S0P01 \\ S1P71-A
}




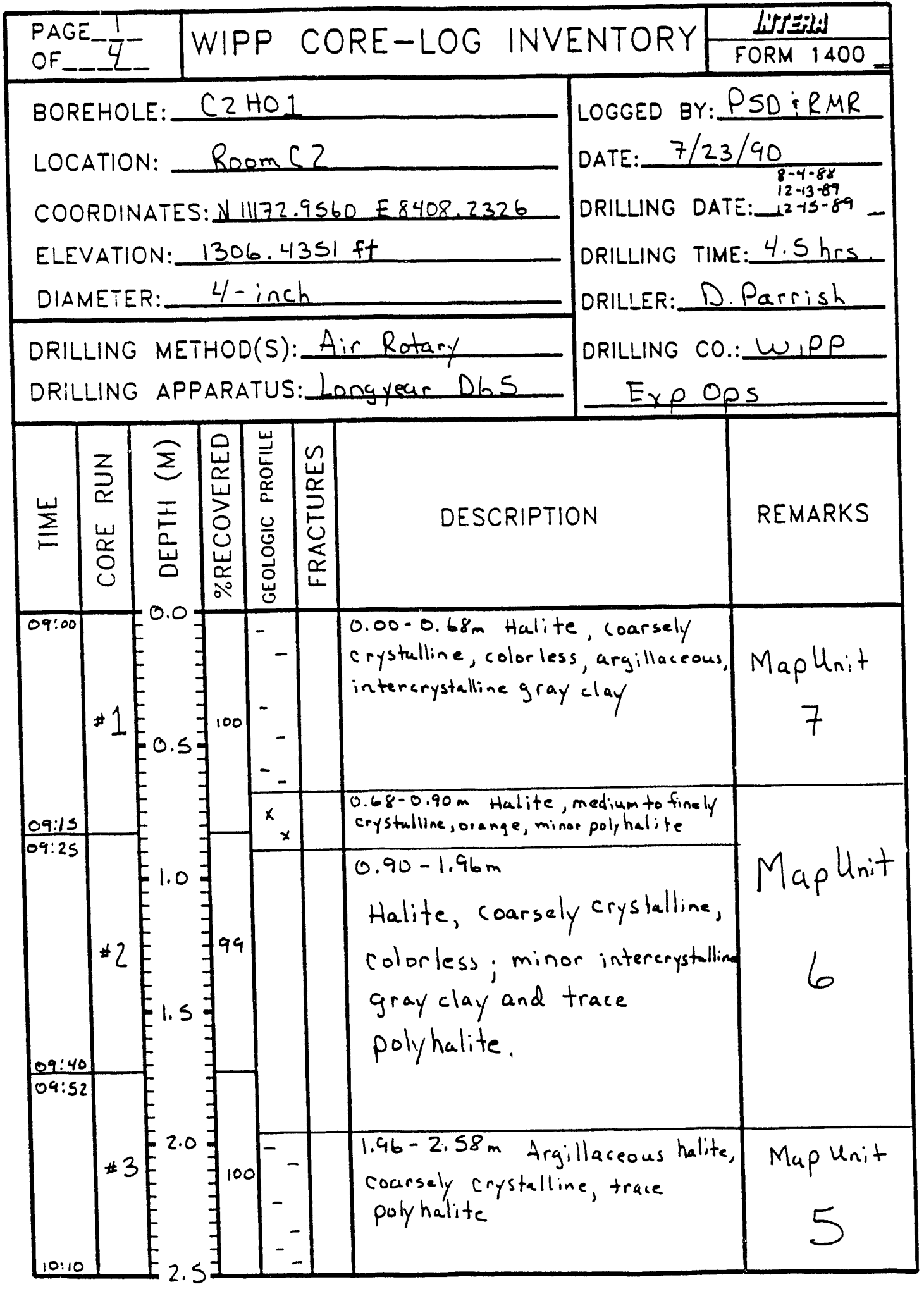




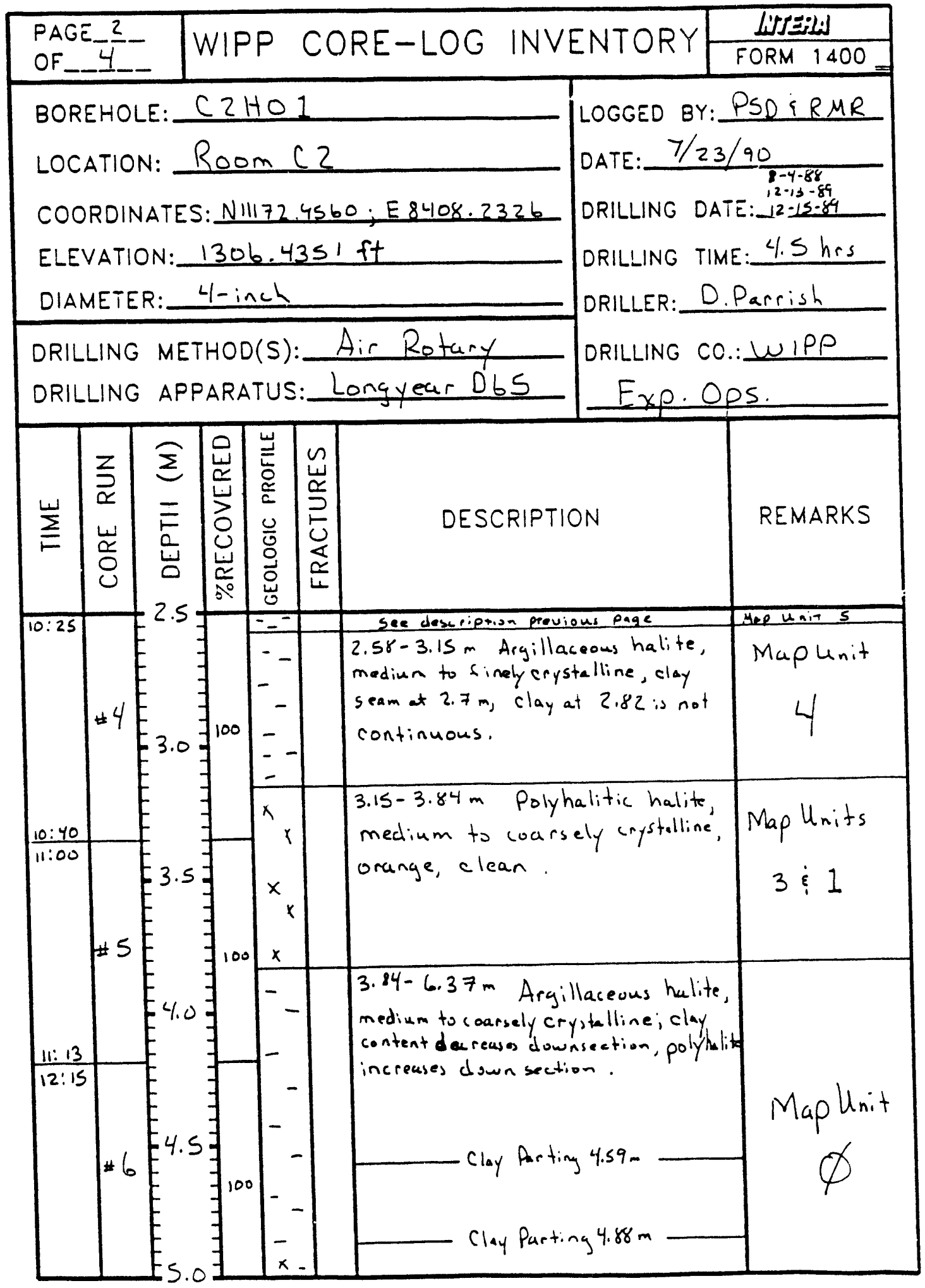




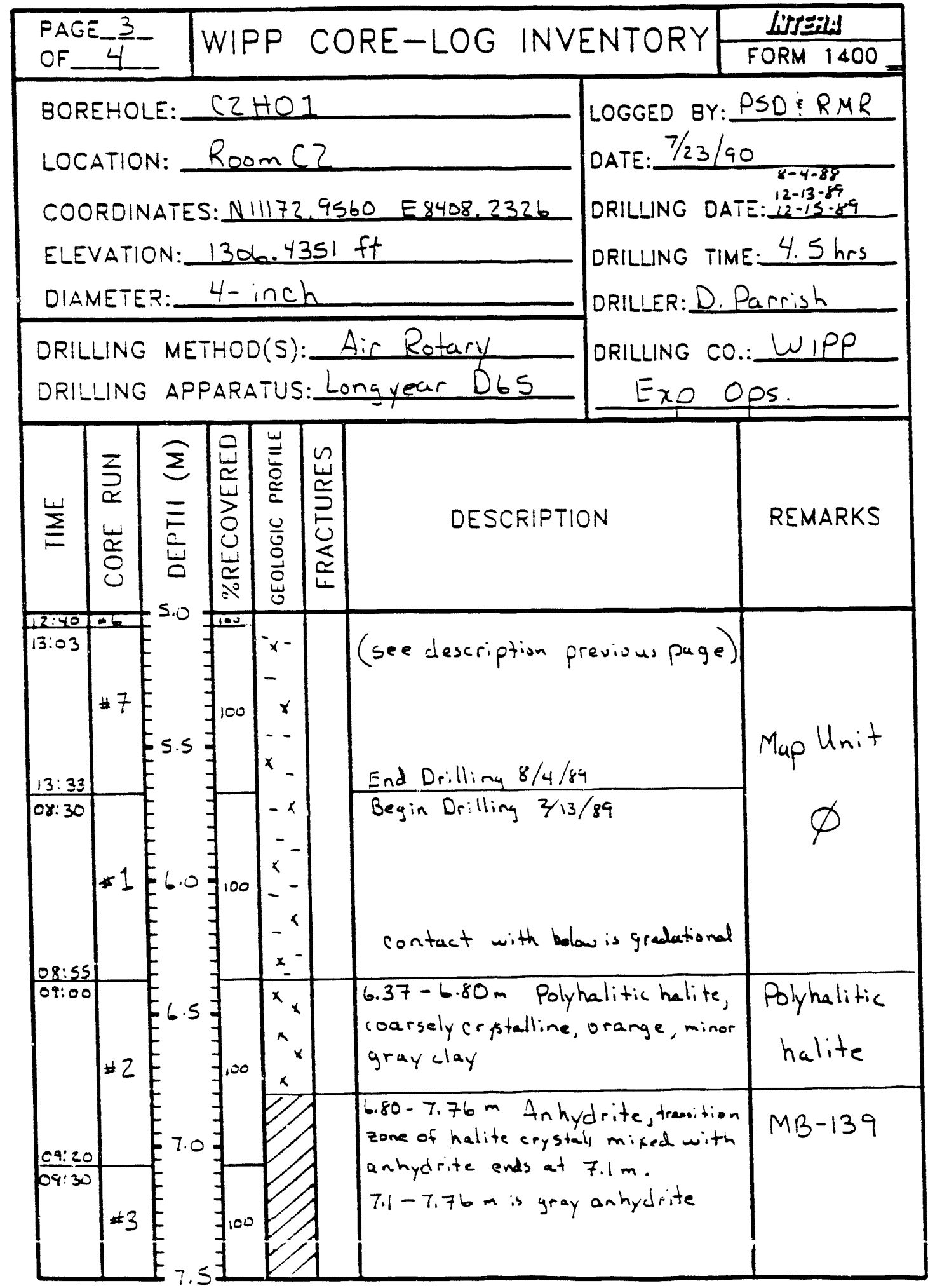




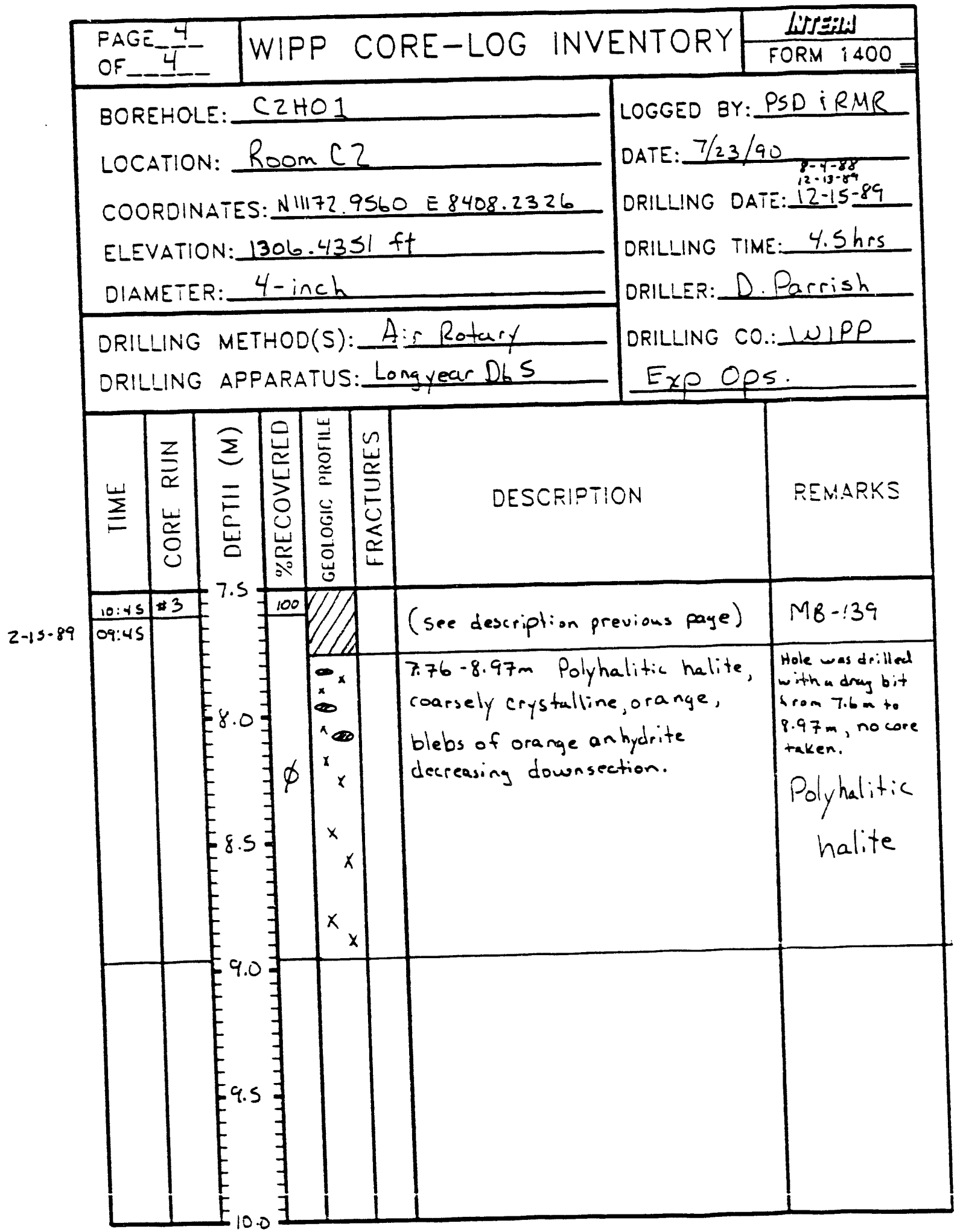




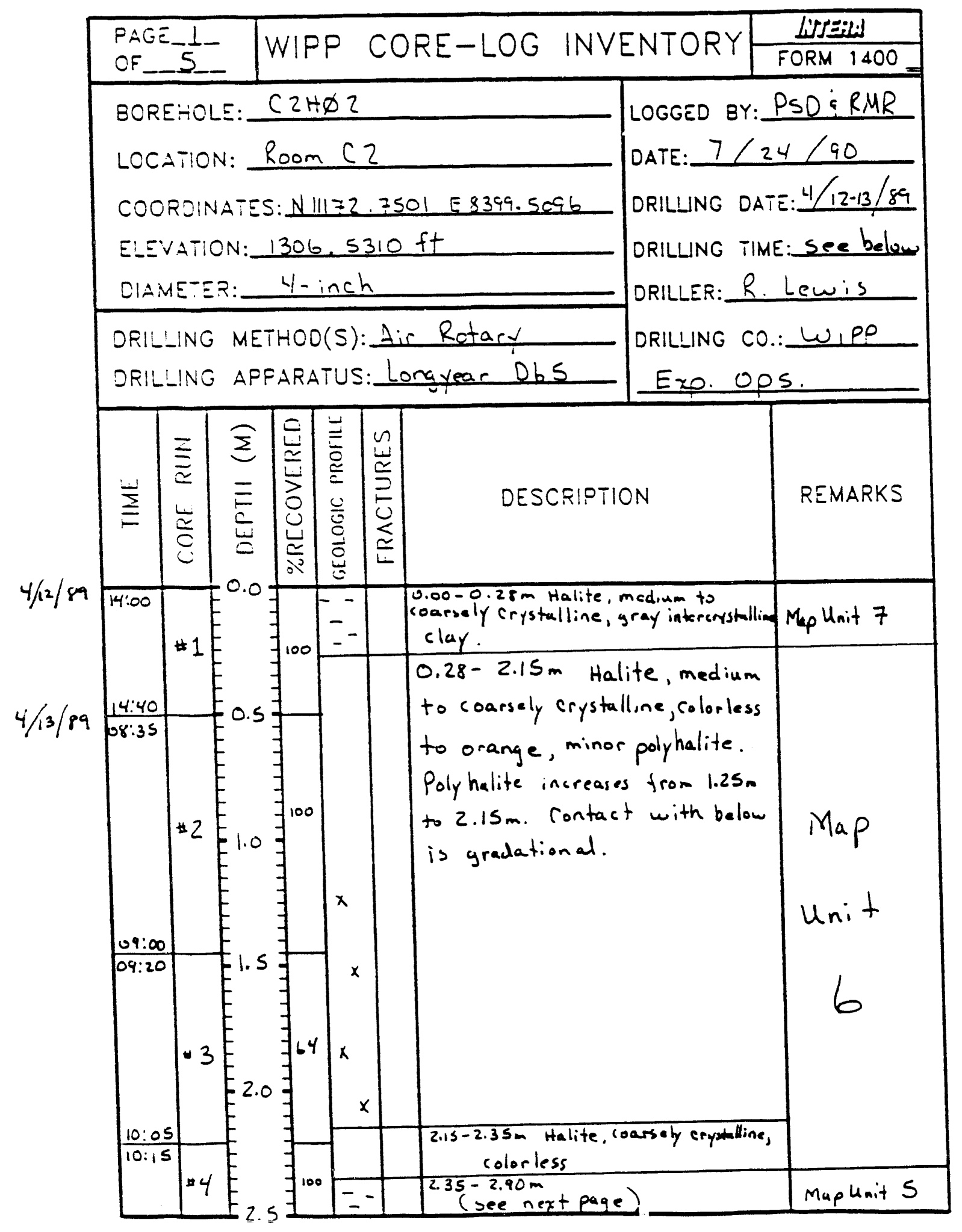




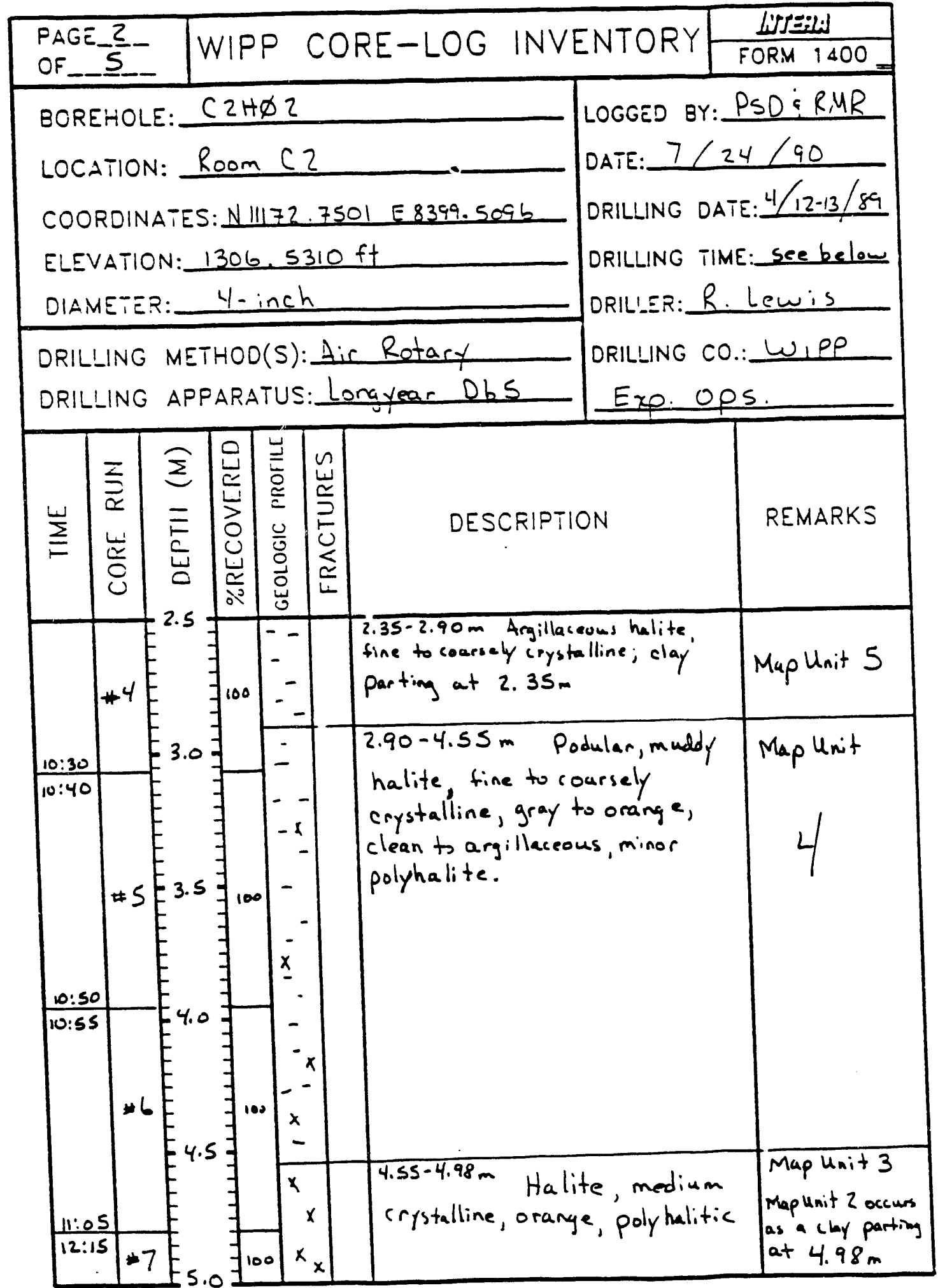




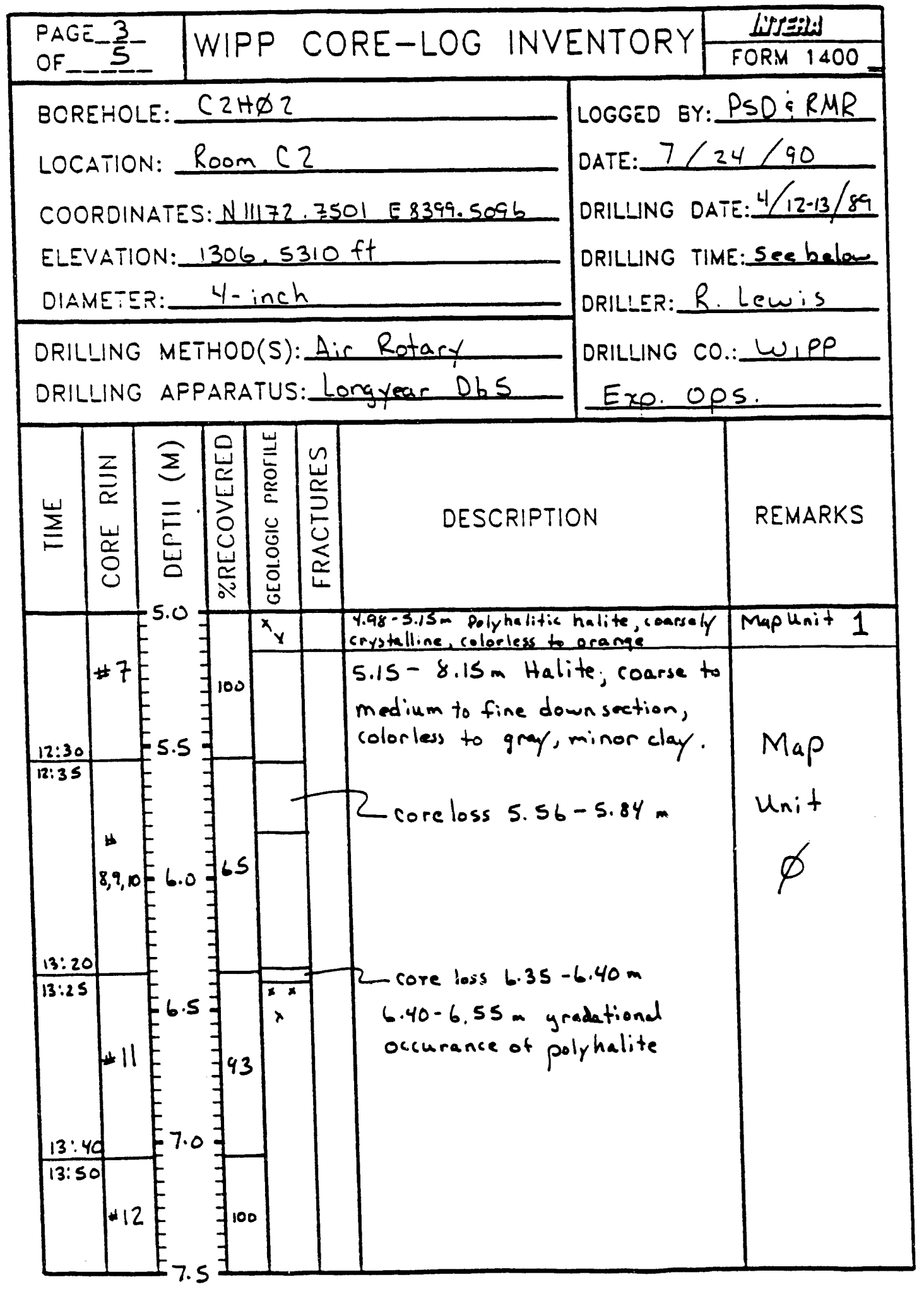




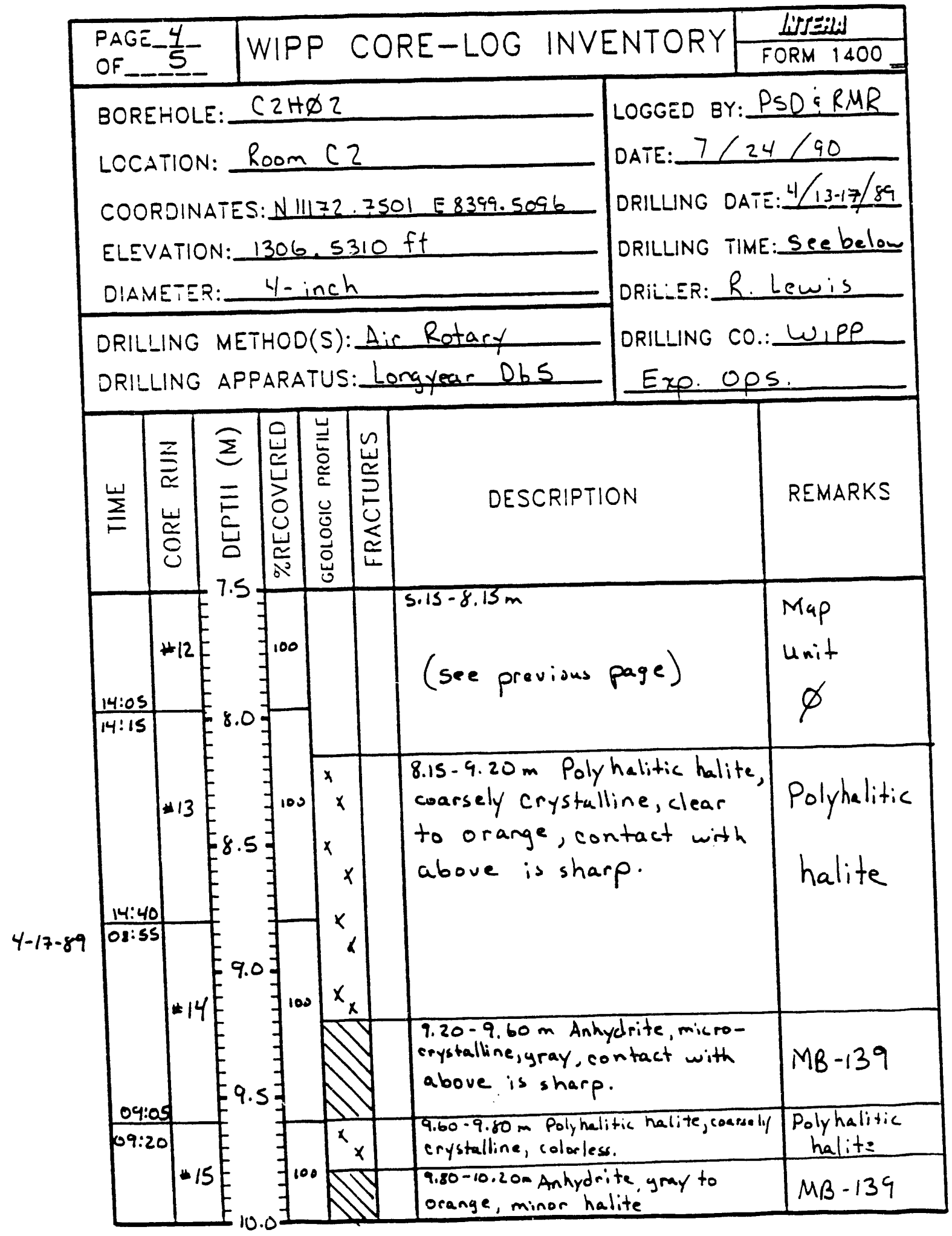




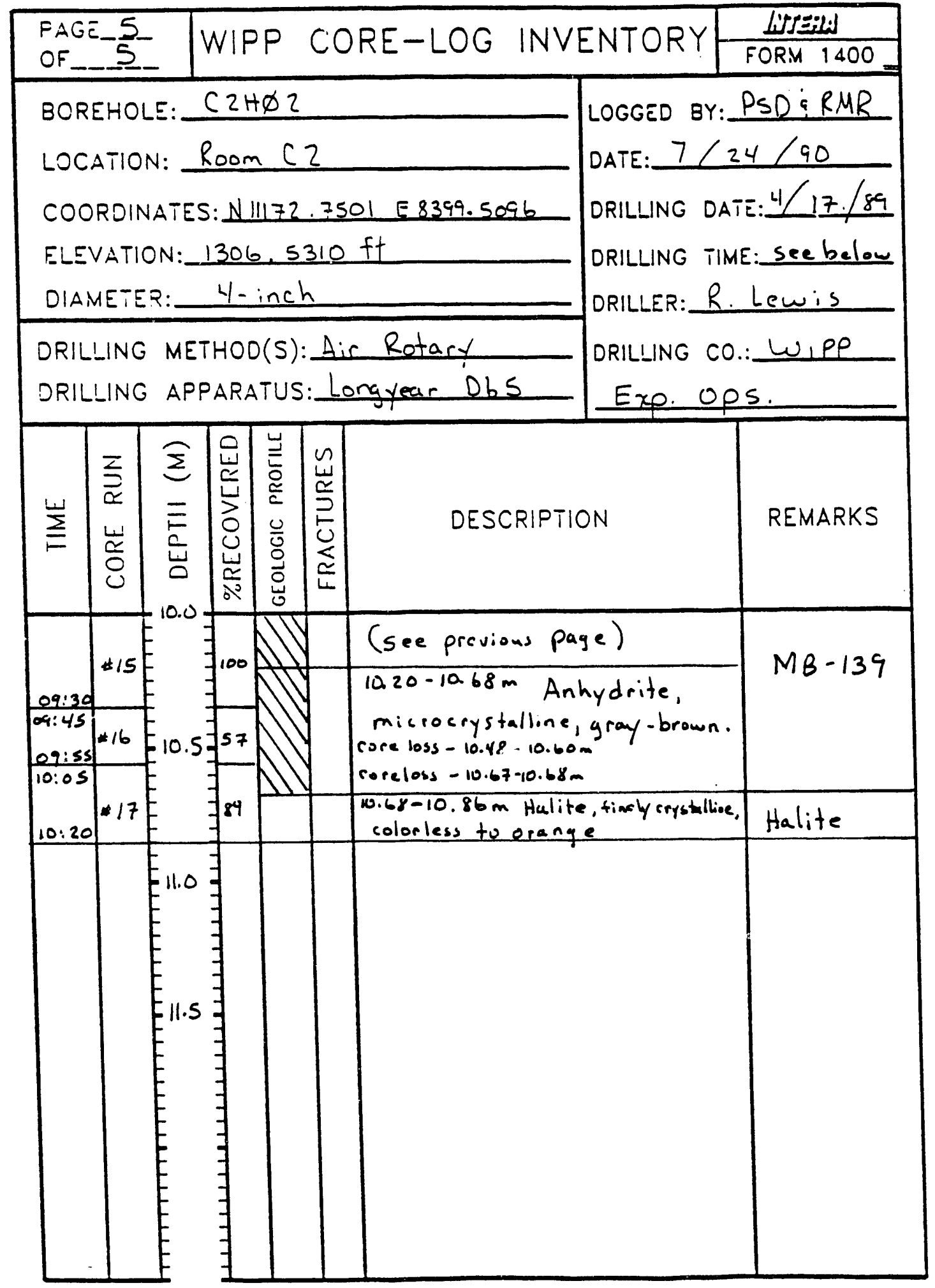




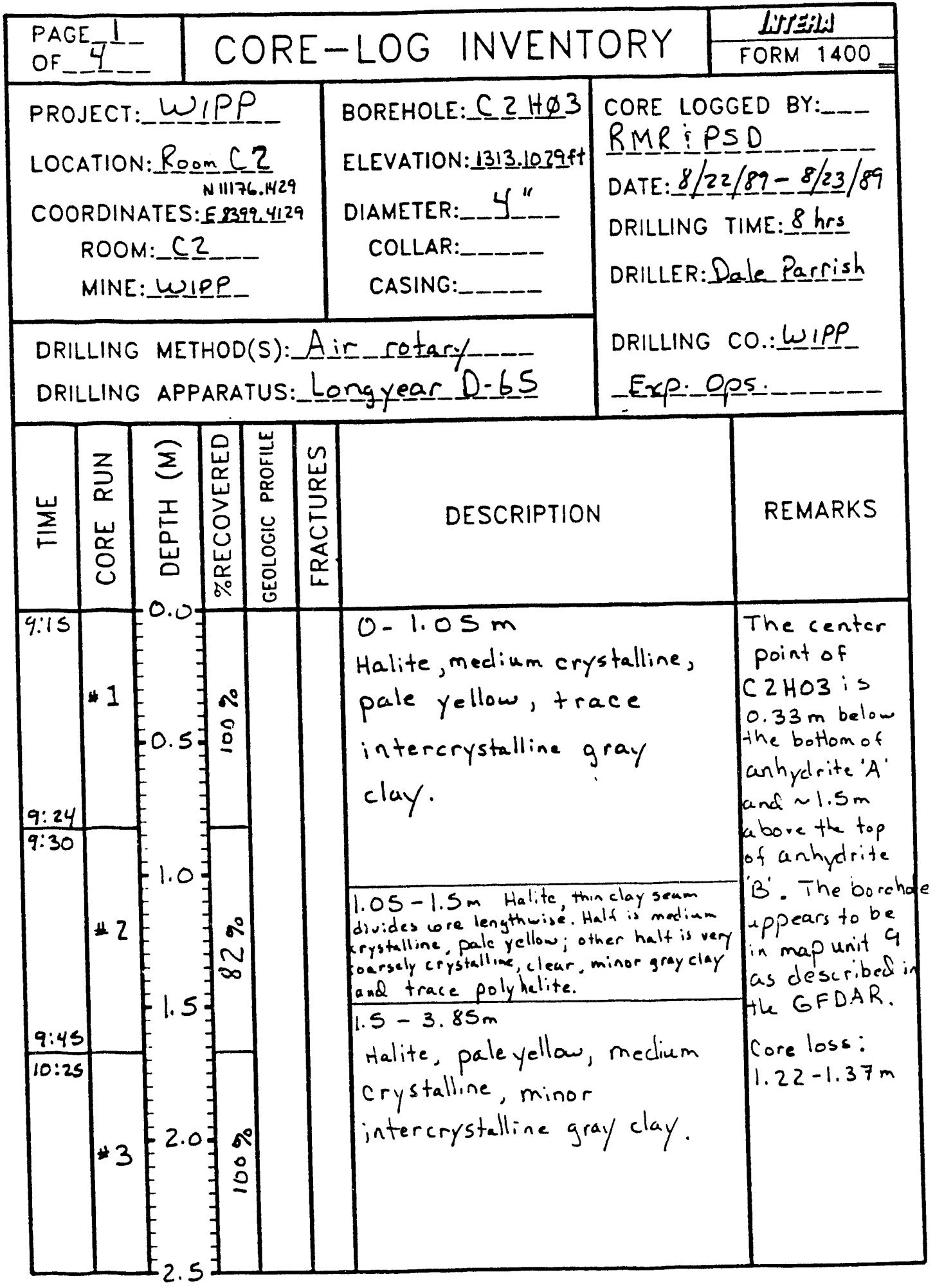




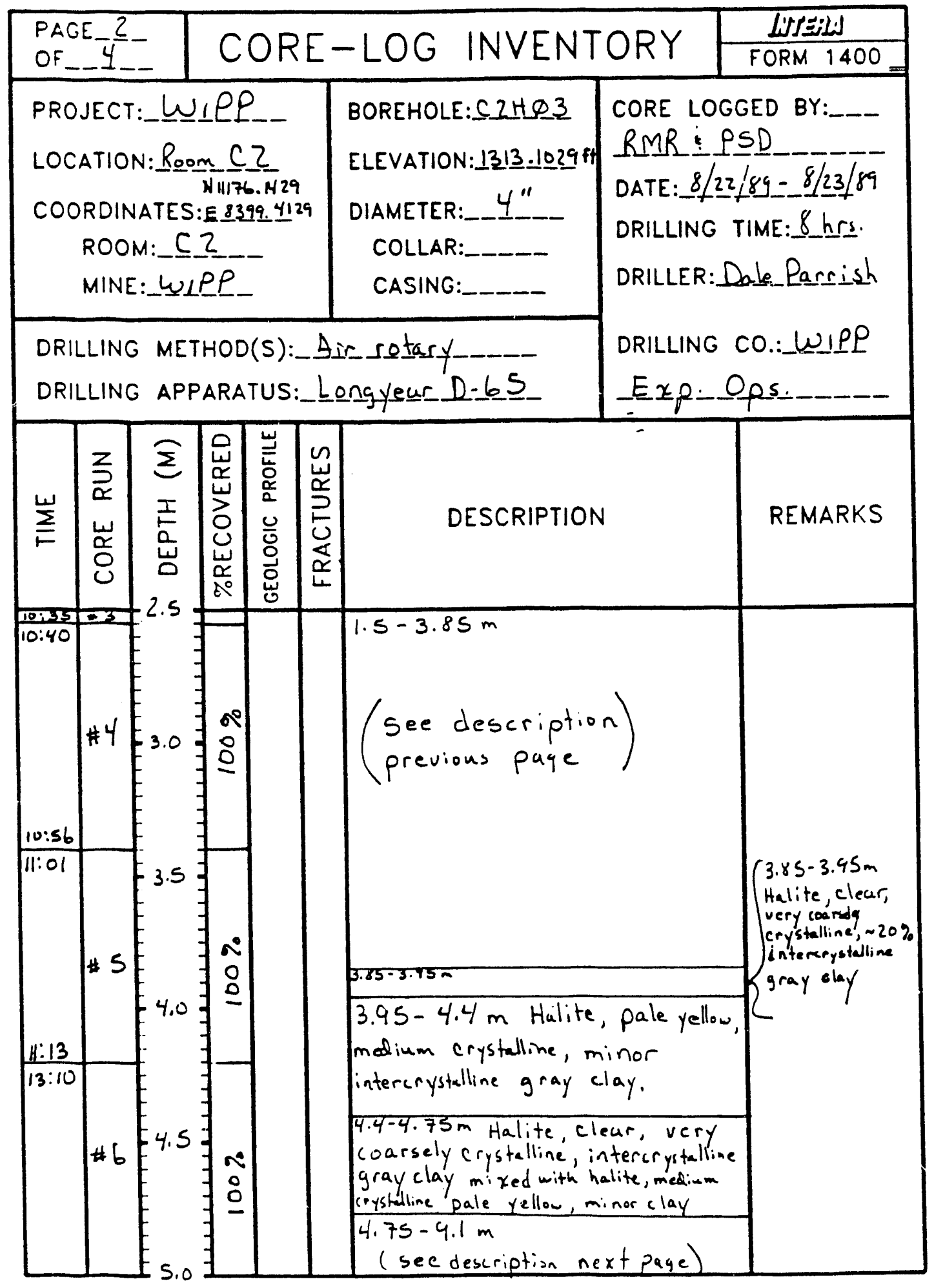




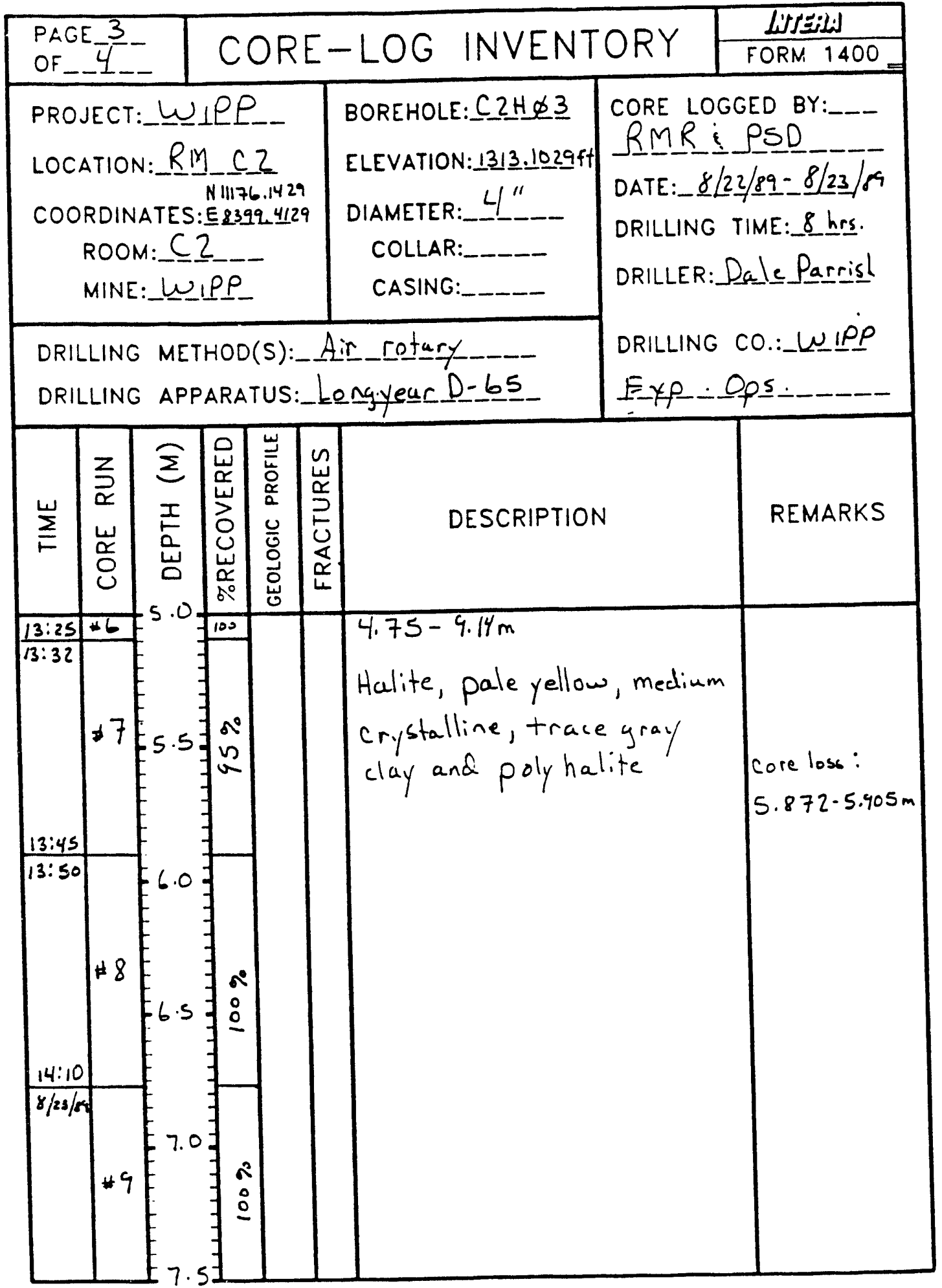




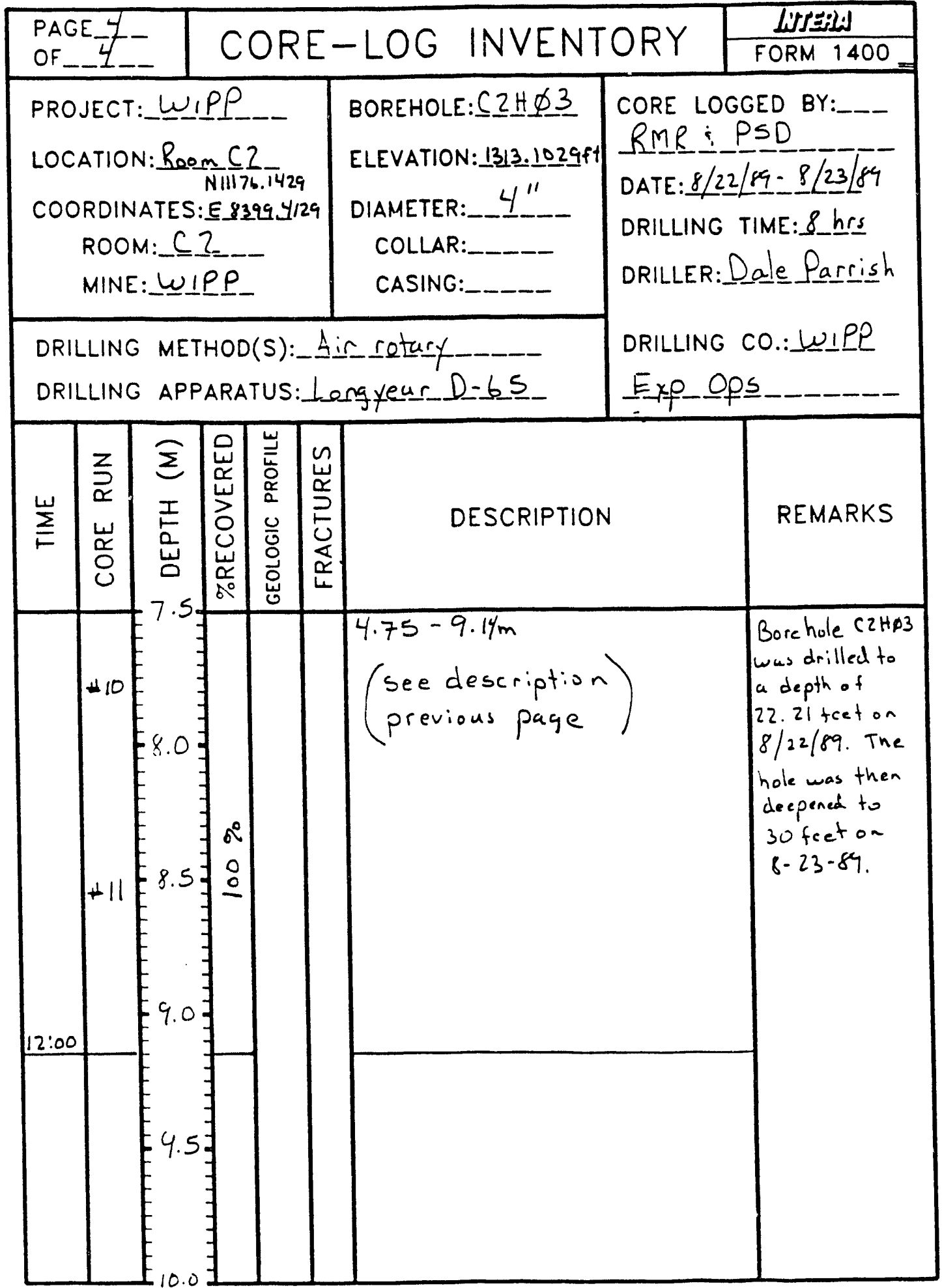




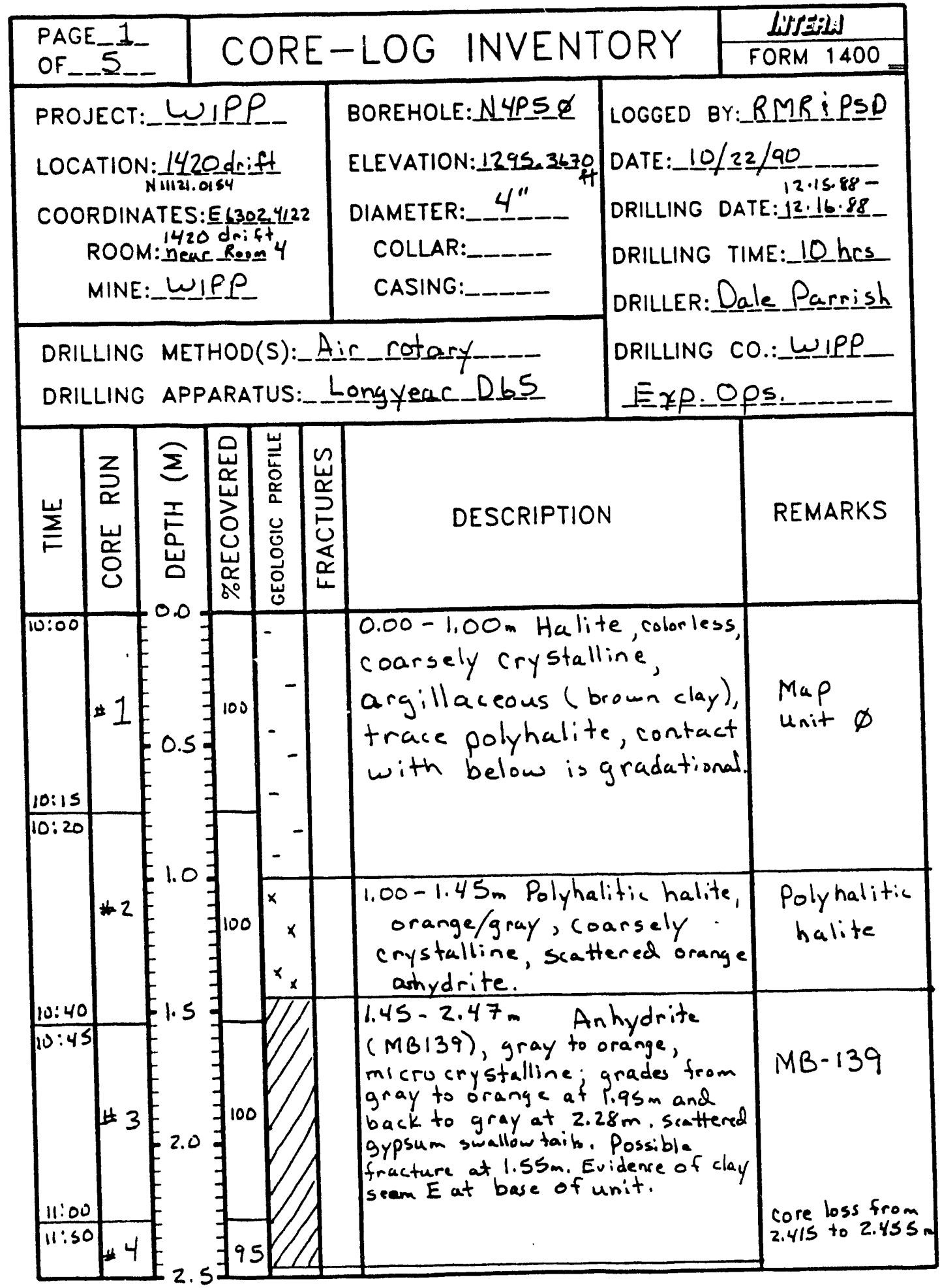




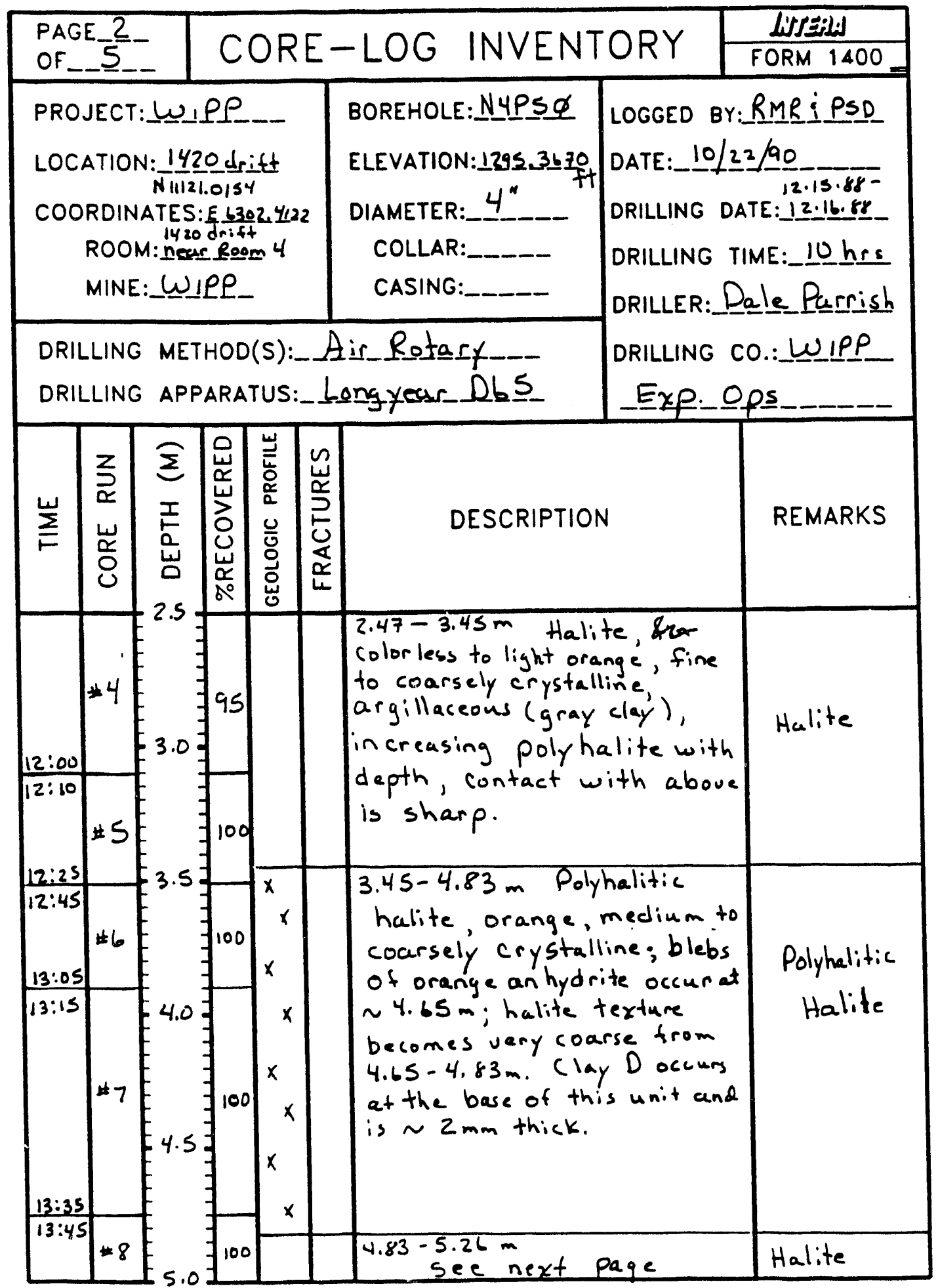




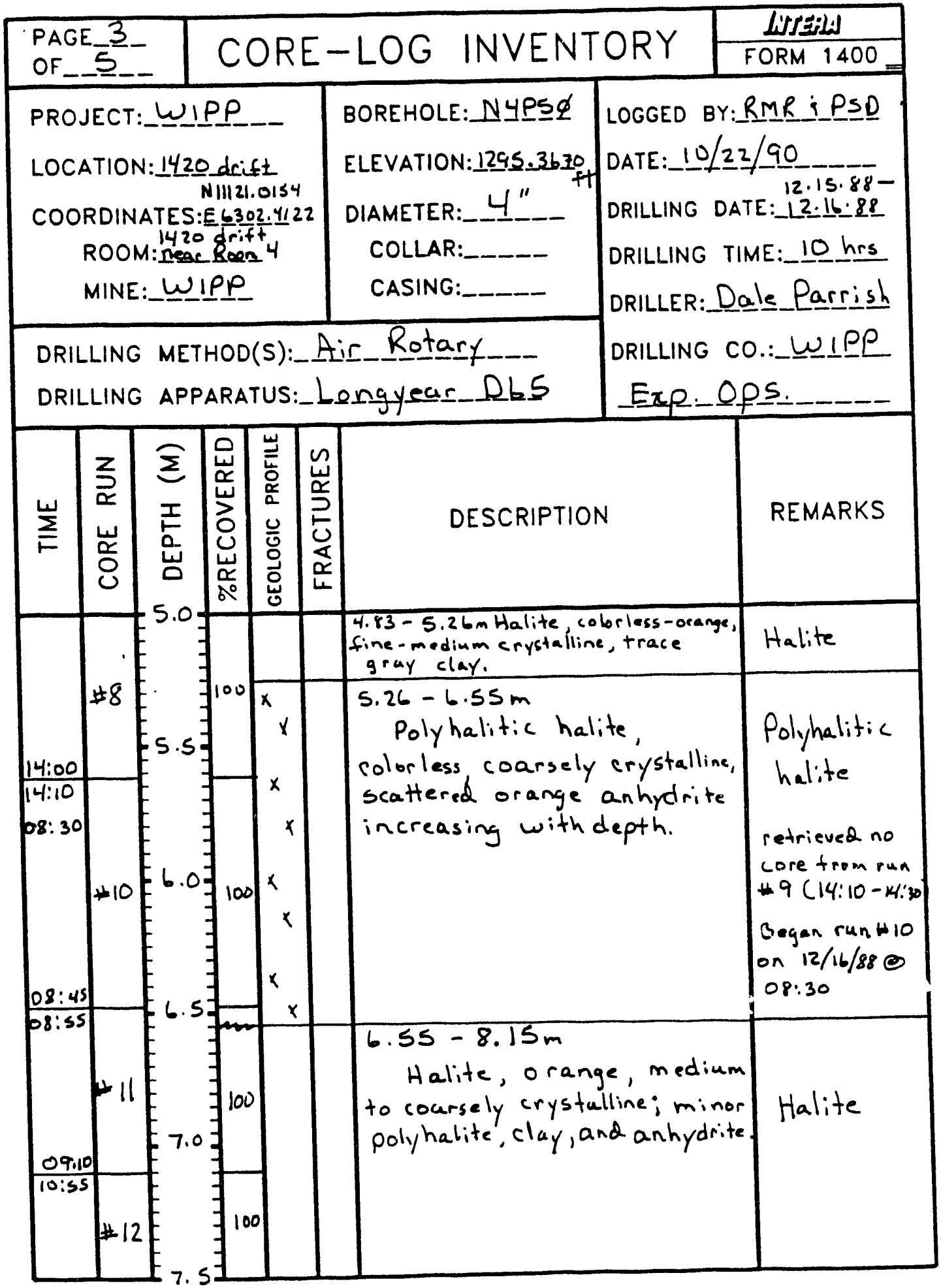




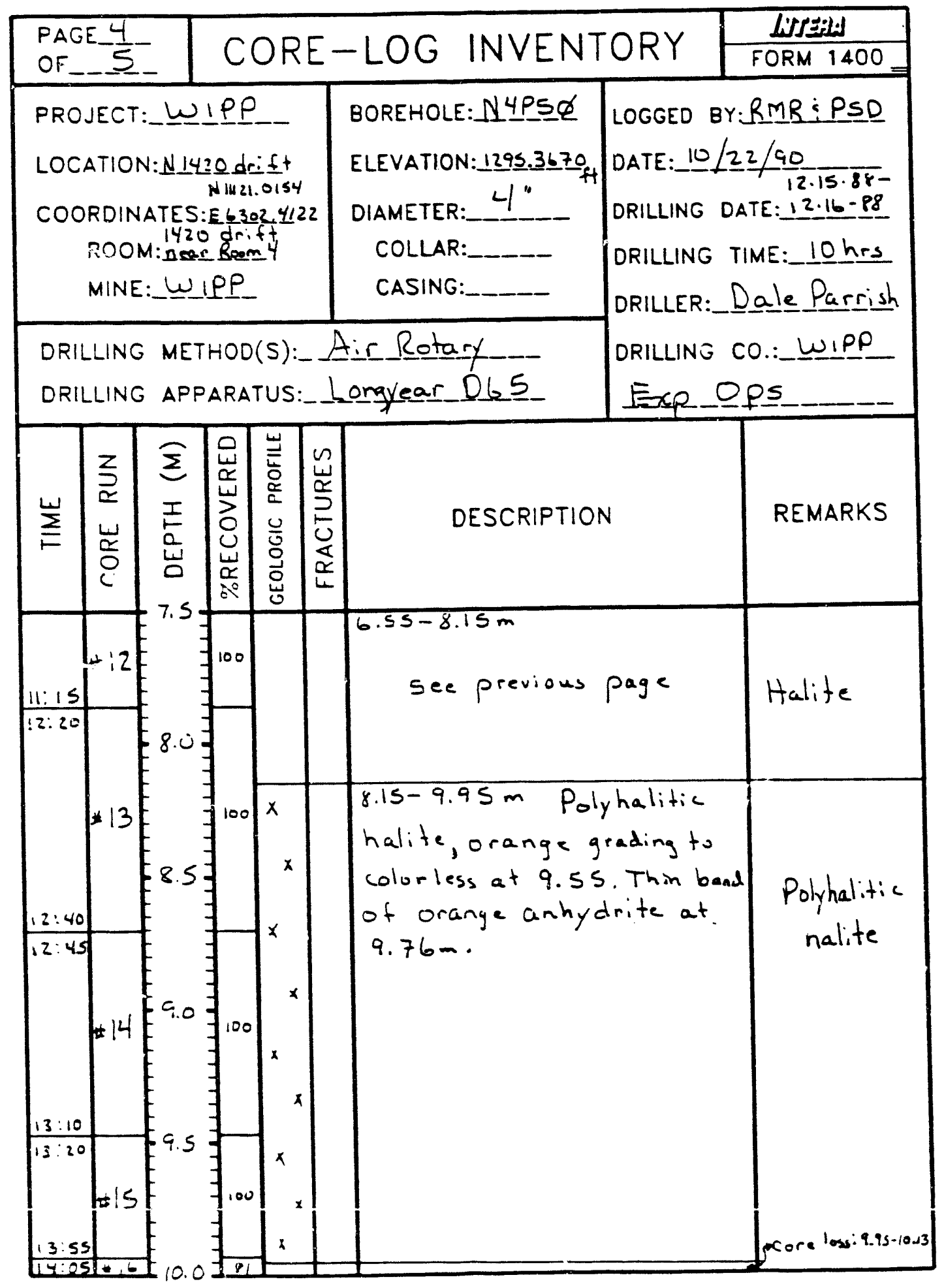




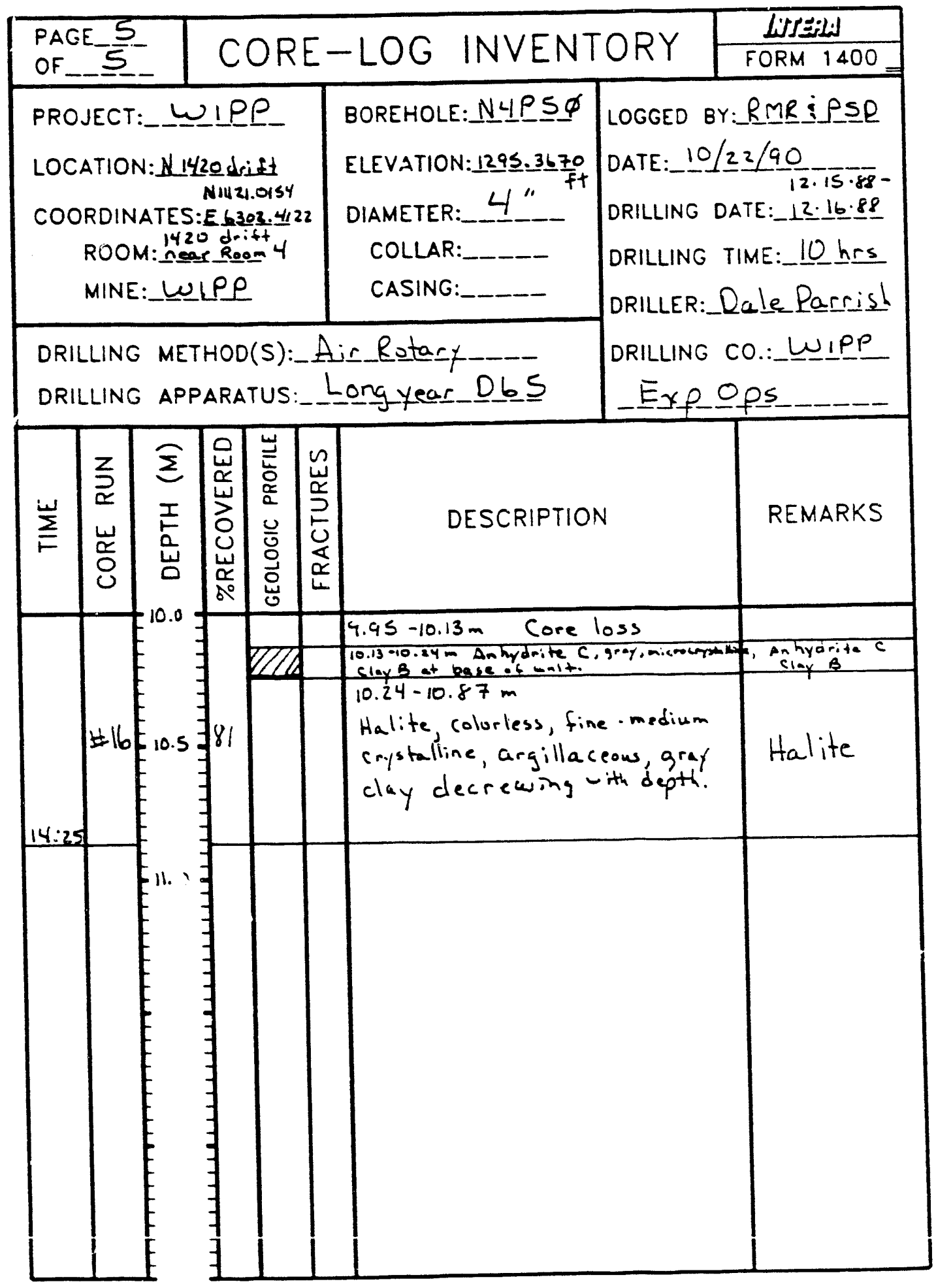




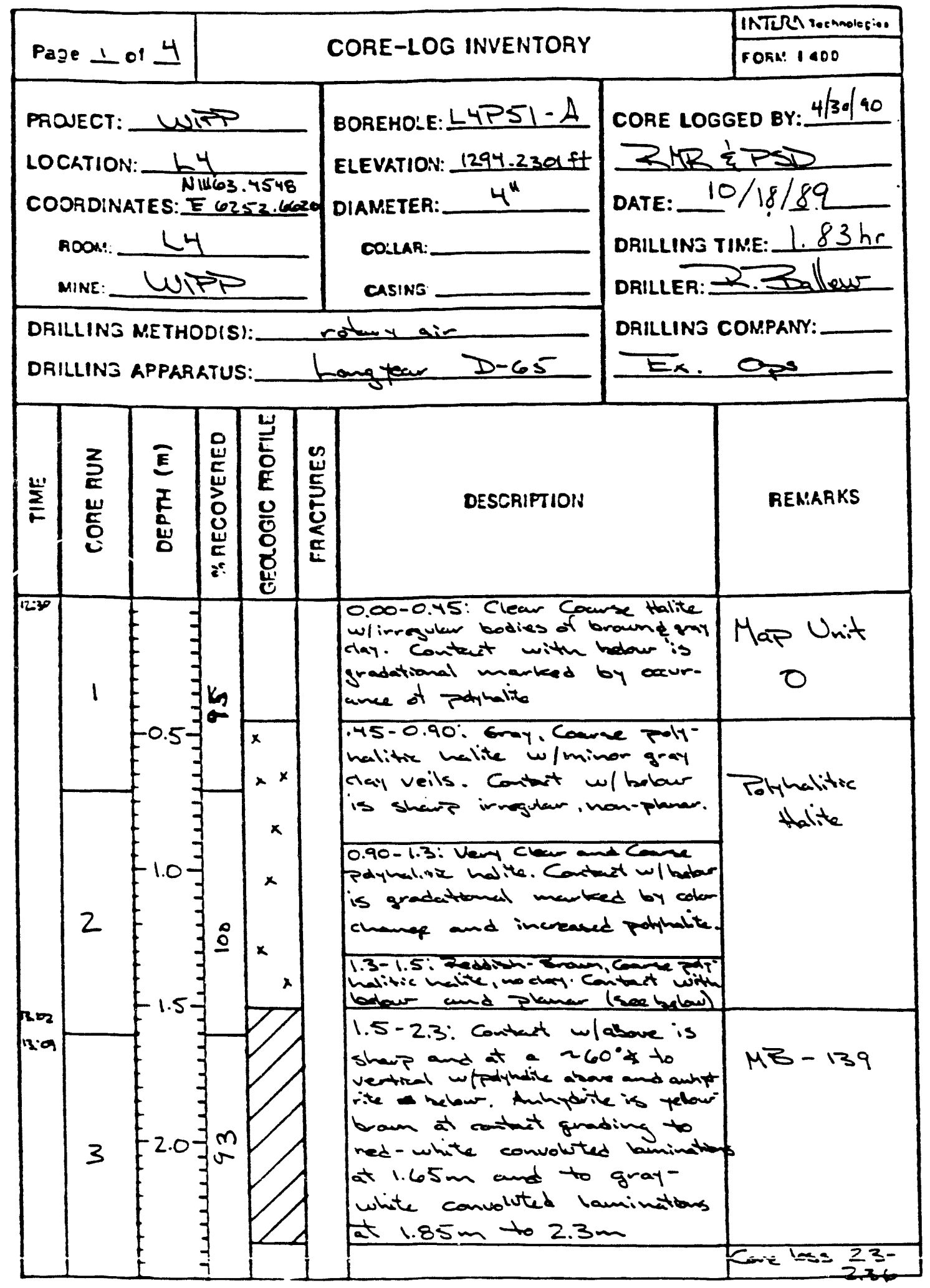




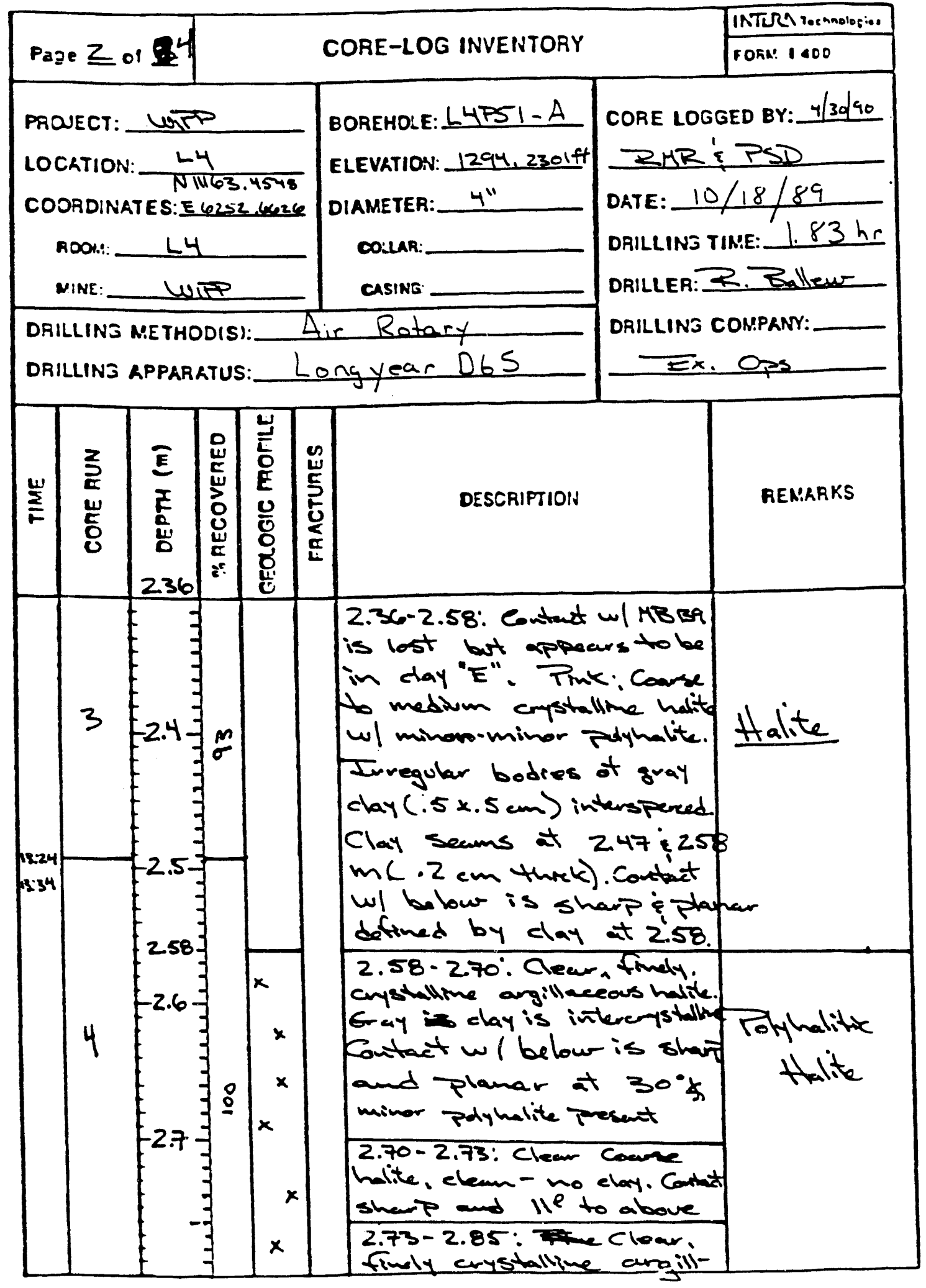




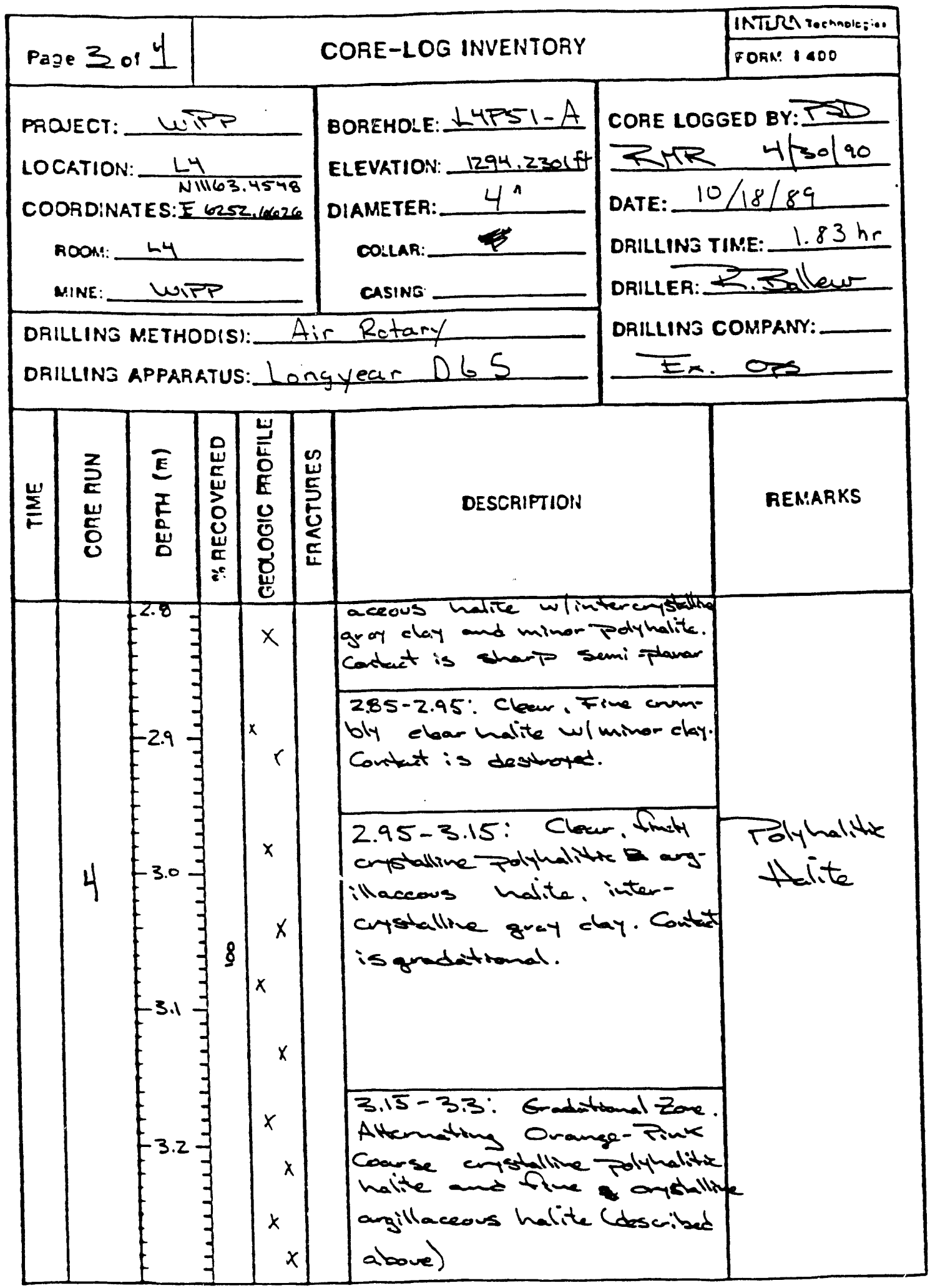




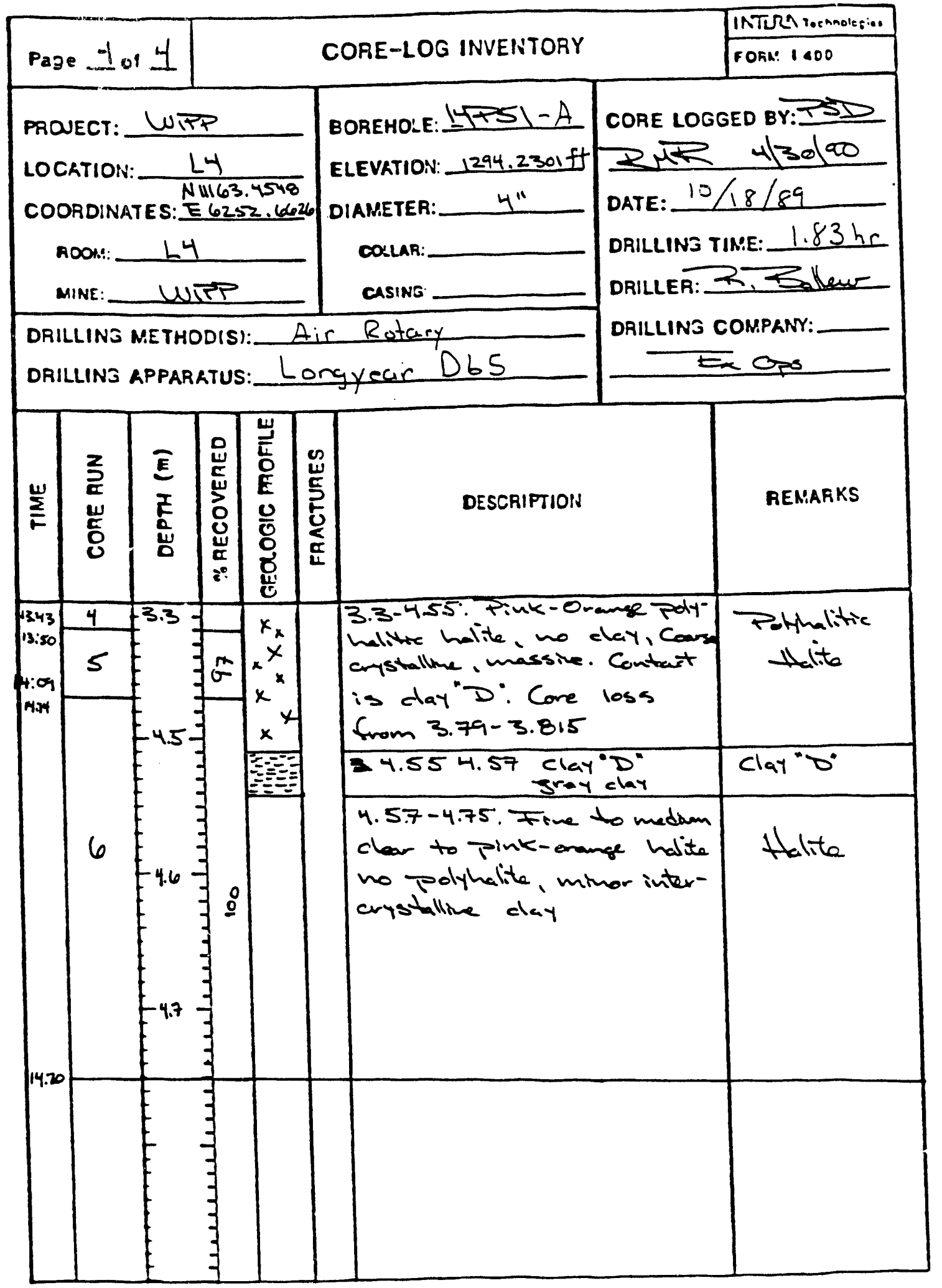




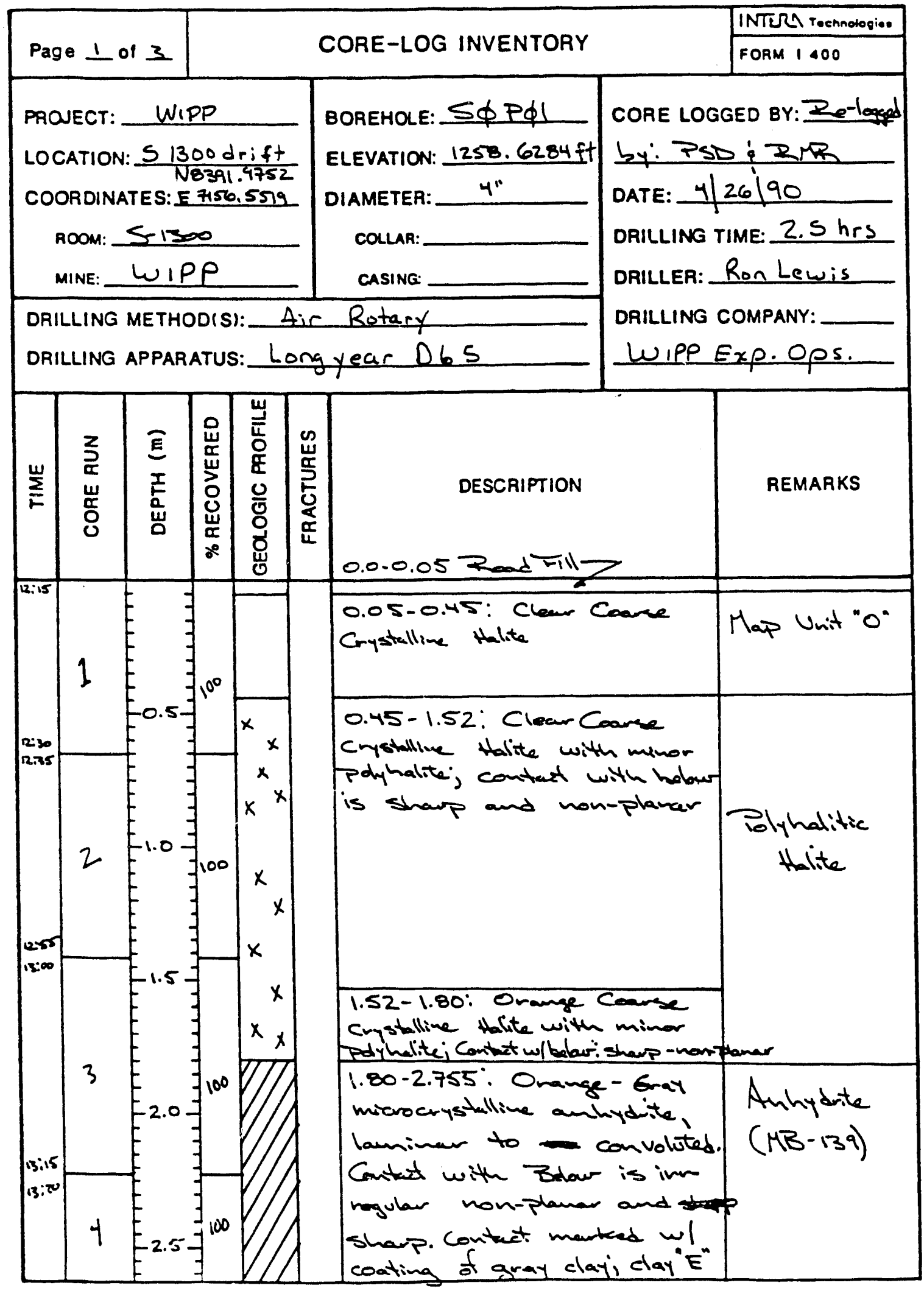




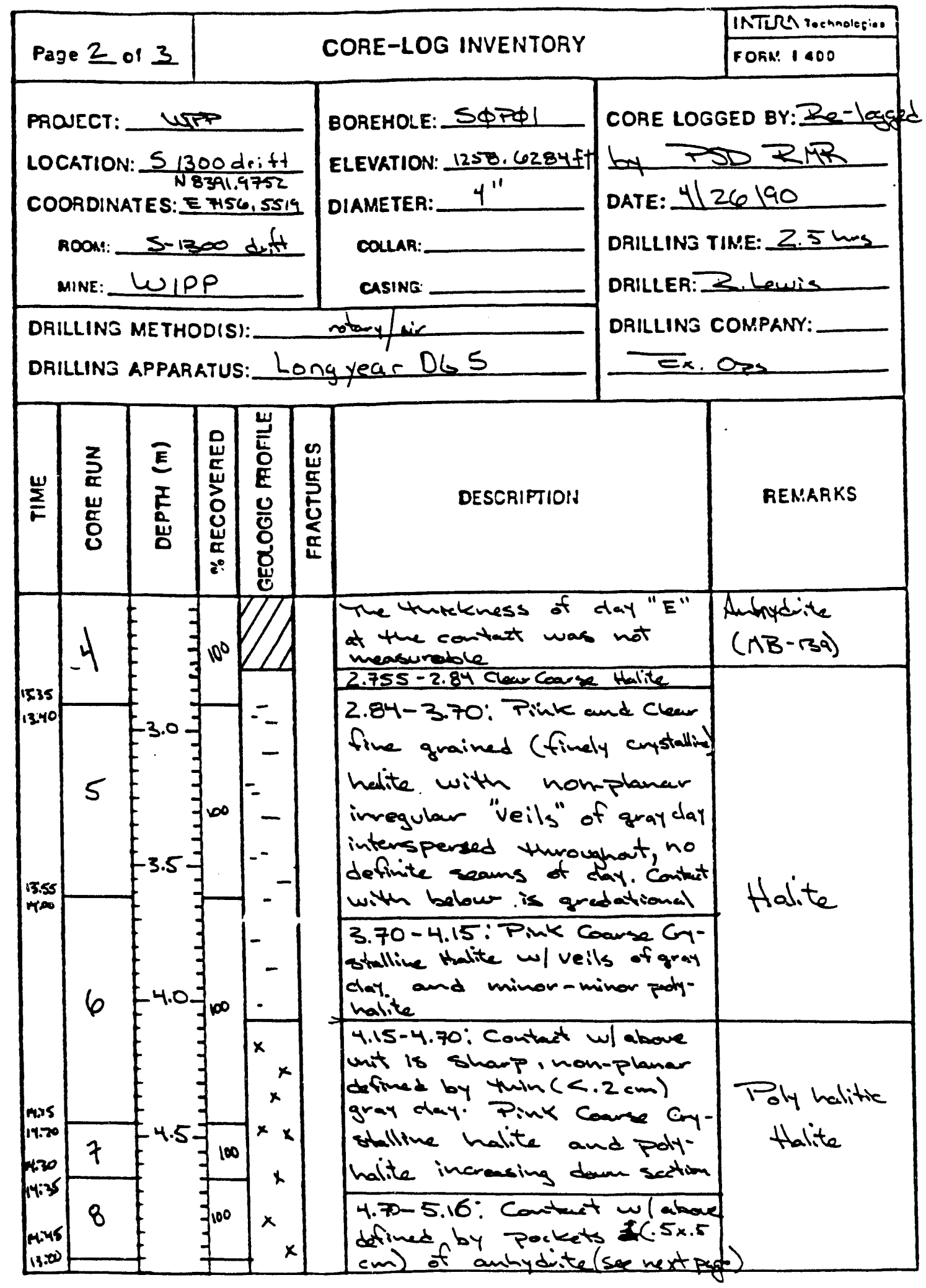




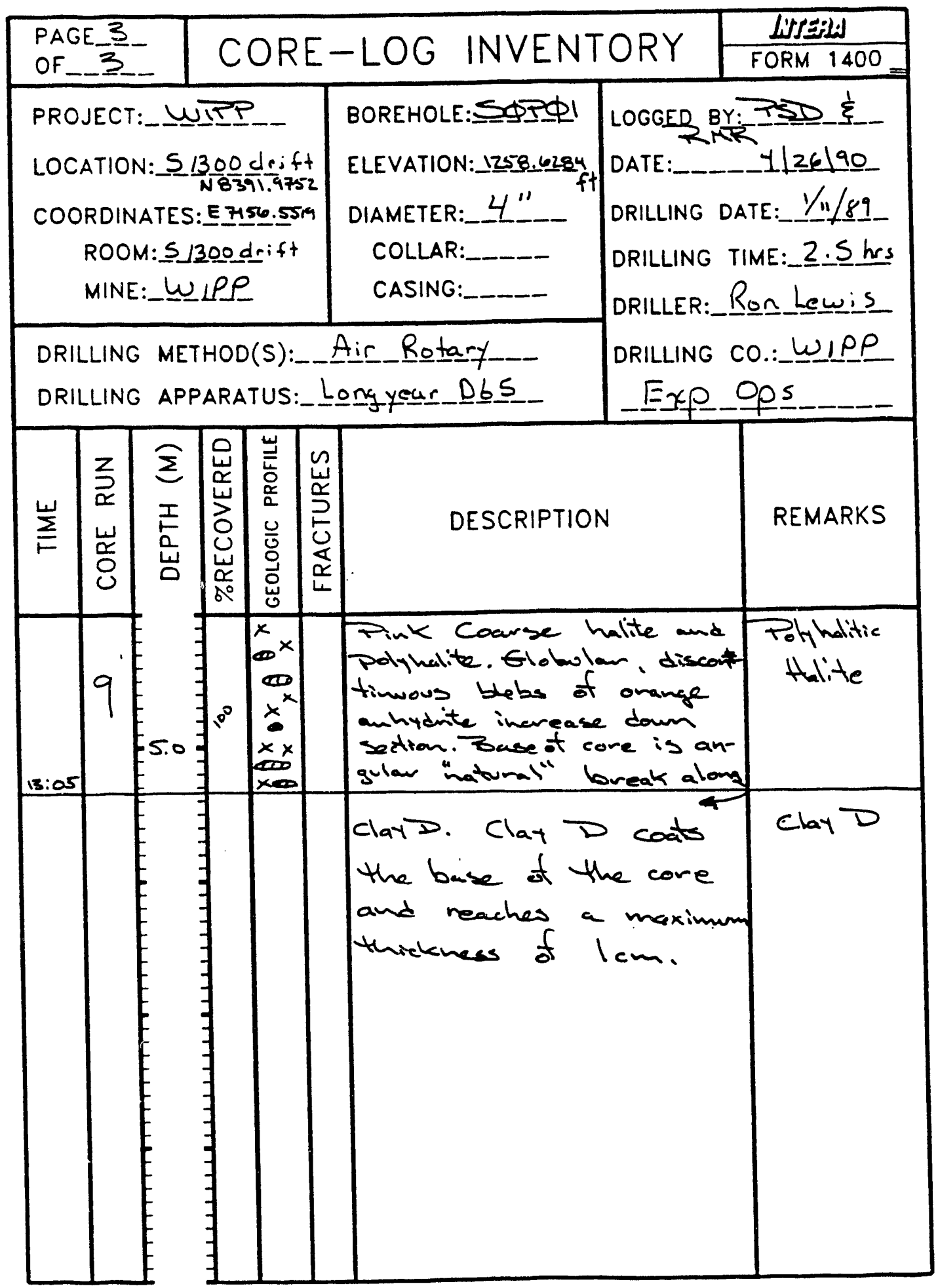




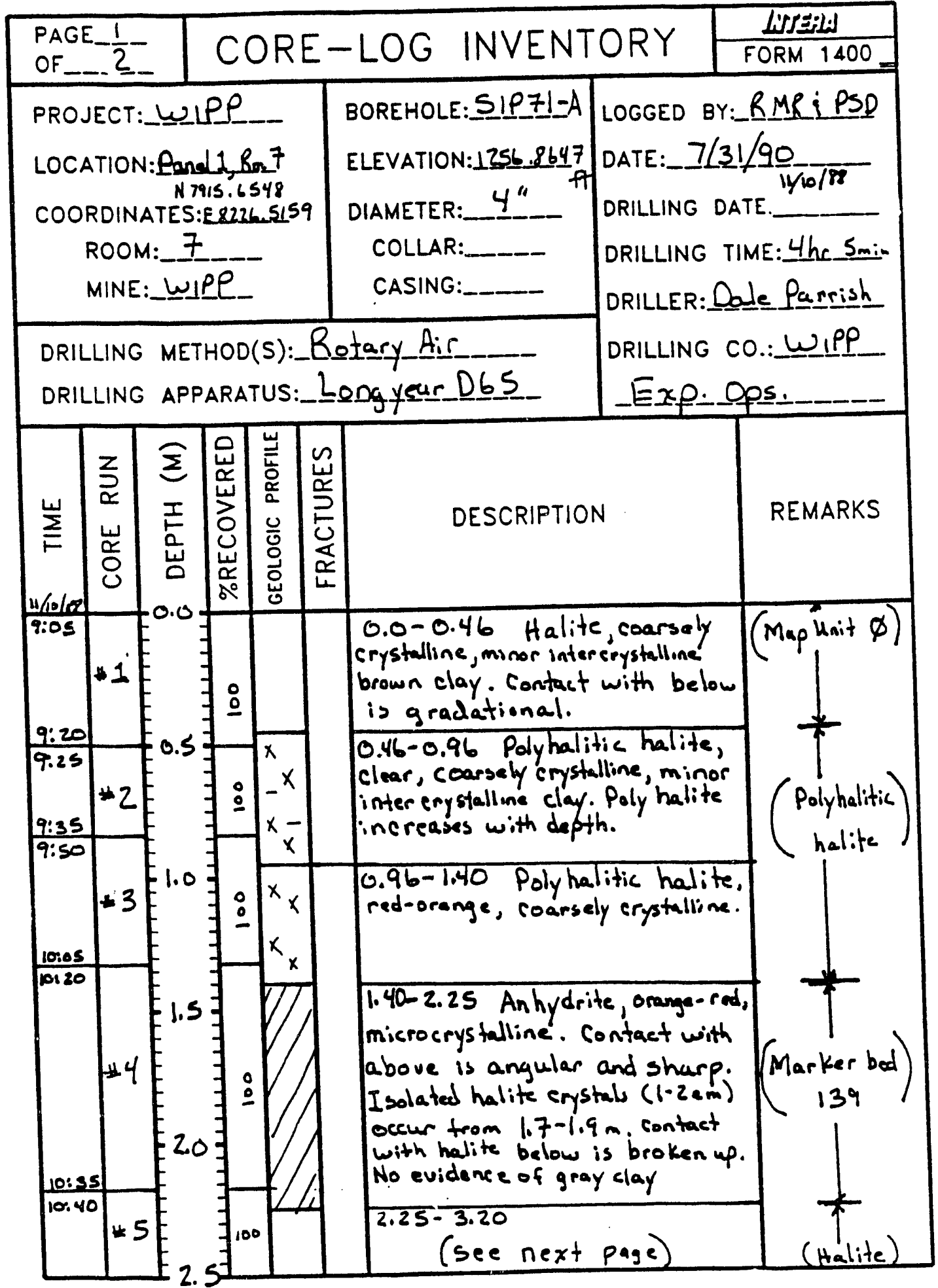




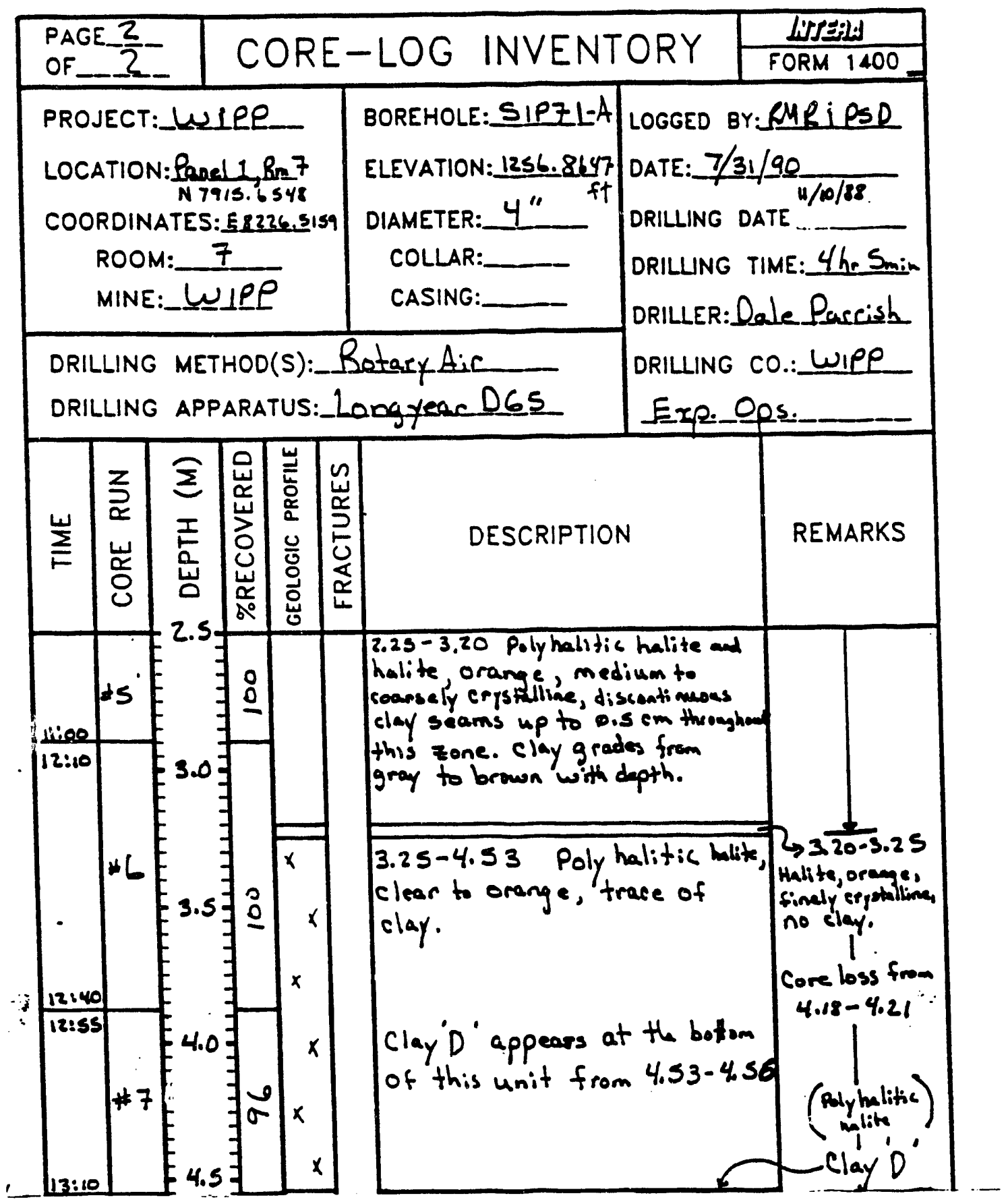




\section{APPENDIX D}

\section{FACTORS AFFECTING TEST-ZONE COMPRESSIBILITY}

Section 6.5 briefly describes a number of factors which potentially affect test-zone compressibility $\left(C_{12}\right)$.

1) non-packer test-tool-componenicompressibility - The volumes of various metal components of the test tool vary in response to changes in test-zone pressure.

2) borehole compressibility - The radius of the borehole varies in response to applied test-zone pressure.

3) axial test-tool movement - The test tool has a tendency to move into and out of the borehole in response to applied test-zone pressure.

4) test-zone-packerdeformation - The packer-inflation-pressure data indicate that the packer volume changes during testing. These changes can be assumed to affect the test-zone volume also.

5) entrapped/created gas in the testzone - Gas was observed during the venting of some test zones during pulse withdrawals. A separate gas phase in the test zone would affect $C_{t z}$.

6) creep closure of the borehole - Halite and argillaceous halite are considered to undergo inelastic steadystate creep in underground openings (Krieg, 1984' van Sambeek, 1987). Therefore, creep closure may potentially cause borehole-volume changes.

Factors 1,2 , and 3 above can be quantified in ter $m s$ of changes in the test-zone volume and therefore can be compensated for in the test analysis. Sections D.1, D.2, and D.3 discuss the mechanisms associated with factors 1,2 , and 3 , and present the equations used to calculate the volume changes associated with each factor.

Sections D.4 through D. 6 discuss possible causes of factors 4,5 , and 6 . Section D. 6 shows that the impact of creep closure is most likely insignificant.

\section{D.1 Non-Packer-Related Tool Compressibility.}

All parts of the multipacker test tool in contact with the test-zone fluid can undergo pressure-related expansion and contraction. Figures 3-1 and 3-2 show typical test-tool configurations, with Figure 3-2 showing the multipacker test tool equipped with radial and axial LVDTs. The components of interest are:the test-zone-packer fixed-end sub, spacers, swivel mechanism, radial-LVDT carrier, transducer/vent-line feed-through carrier, the fixed and moving portions of the axial LVDT, and the transducer and test-zone vent lines. The total test-toolvolume change due to these test-tool components can be written as:

$$
\Delta \mathrm{V}_{\mathrm{tool}}=\Delta \mathrm{V}_{\mathrm{tc}_{1}}+\Delta \mathrm{V}_{\mathrm{tc}_{2}}+\ldots+\Delta \mathrm{V}_{\mathrm{tc}}+\Delta \mathrm{V}_{\mathrm{tube}}
$$

where:

$$
\begin{aligned}
& \Delta V_{\text {tool }}=\text { total volume change due to test-tool components } \\
& \Delta V_{\text {tin }}=\text { volume change due to tool component } n \\
& \Delta V_{\text {tube }}=\text { volume change attributable to tubing }
\end{aligned}
$$

With the exception of the transducer/vent lines, each of the test-tool components mentioned above can be assumed to behave as a thick-walled vessel under uniform external radial pressure and zero longitudinal pressure (i.e., the vessel is free to extend in the axial direction). The application of external pressure will cause 
the external radius of the vessel to decrease and the length of the vessei to increase. The component's volume change attributable to an applied external pressure can be calculated as follows (Young, 1989):

$$
\Delta r_{0}=-\frac{P r_{0}}{E}\left[\frac{r_{0}^{2}+r_{i}^{2}}{r_{0}^{2}-r_{i}^{2}}-v\right]
$$

and

$$
\Delta L=-\frac{P v L}{E}\left[\frac{2 r_{0}^{2}}{r_{0}^{2}-r_{i}^{2}}\right]
$$

where:

$$
\begin{aligned}
& r_{0}=\text { external radius of vessel } \\
& \Delta r_{0}=\text { change in external radius } \\
& r_{1}=\text { internal radius of vessel } \\
& P \quad=\text { applied external pressure } \\
& E \quad=\text { modulus of elasticity } \\
& v \quad=\text { Poisson's ratio } \\
& L \quad=\text { length of vessel } \\
& \Delta L=\text { change in length of vessel }
\end{aligned}
$$

Therefore,

$$
\Delta V_{t c_{n}}=\pi\left[r_{0}^{2} L-\left(r_{0}+\Delta r_{0}\right)^{2}(L+\Delta L)\right]
$$

The expansion or contraction of the transducer/vent tubing lines can be calculated assuming the lines are thickwalled vessels under uniform internal radial pressure where an increase in pressure causes the internal radius of the tubing to increase and the length to decrease. The appropriate formulae (Young, 1989) are as follows:

and

$$
\Delta r_{i}=\frac{P r_{i}}{E}\left[\frac{r_{0}^{2}+r_{i}^{2}}{r_{0}^{2}-r_{i}^{2}}+v\right]
$$

$$
\Delta L_{\text {tube }}=\frac{P V L_{\text {tube }}}{E}\left[\frac{2 r_{i}^{2}}{r_{0}^{2}-r_{i}^{2}}\right]
$$

where:

$$
\begin{aligned}
& \Delta \mathrm{L}_{\text {1ube }}=\text { change in tubing length } \\
& \Delta \mathrm{r}_{i}=\text { change in internal radius of tubing lines } \\
& \mathrm{L}_{\text {tube }}=\text { total length of tubing }
\end{aligned}
$$

Therefore,

$$
\Delta V_{\text {tube }}=\pi\left[\left(r_{i}+\Delta r_{i}\right)^{2}\left(L_{\text {tube }}+\Delta L_{\text {tube }}\right)-r_{i}^{2} L_{\text {tube }}\right]
$$

Changes in test-tool and tubing volume were calculated for each test-tool configuration used in the permeability testing by applying Equations D-2 through D-4 for each tool component, and Equations D-5 through D-7 for all 
tubing. Component geometry data are found on test-tool-installation diagrams and from field measurements. Values of $E$ and $v$ are found in Young (1989) and are listed below along with the associated materials:

\begin{tabular}{lcc}
\multicolumn{1}{c}{$\begin{array}{c}\text { Modulus of } \\
\text { Material }\end{array}$} & $\begin{array}{c}\text { Elasticity (Pa) } \\
\text { Stainless Steel }\end{array}$ & Poisson's Ratio \\
Aluminum & $1.93 \times 10^{11}$ & 0.27 \\
& $6.90 \times 10^{10}$ & 0.30
\end{tabular}

Total test-tool volume changes were determined by applying the equations for each tool component and tubing length and summing the cumulative volume change for a range of applied pressures encompassing the pressure variation encountered during testing (0 to $15 \mathrm{MPa})$. Volume change versus applied pressure displayed an essentially linear relationship for this pressure range.

Therefore:

$$
\Delta \mathrm{V}_{\text {tool }}=\mathrm{C}_{1001} \mathrm{P}
$$

where:

$$
C_{\text {bol }}=\text { test-tool volume-change constant }
$$

The $C_{1001}$ constants calculated for the tests analyzed in this report are as follows:

\begin{tabular}{lll}
\multicolumn{1}{c}{ Test } & \multicolumn{1}{c}{ Tool \# } & $\begin{array}{c}C_{\text {1ool }} \text { Test-Tool } \\
\text { Volume Constant }\end{array}$ \\
\cline { 2 - 2 } C2H01-A & MPT \#1 & 0.25 \\
C2H01-B & MPT \#1 & 0.25 \\
C2H01-B(GZ) & MPT \#1 & 0.20 \\
C2H01-C & MPT \#5 & 0.44 \\
C2H02 & MPT \#4 & 0.09 \\
C2H02(GZ) & MPT \#4 & 0.09 \\
C2H03 & MPT \#5 & 0.08 \\
N4P50 & MPT \#3, MPT \#4 & 0.09 \\
L4P51-A & MPT \#3 & 0.08 \\
SOP01 & MPT \#3 & 0.08 \\
S0P01(GZ) & MPT \#3 & 0.14 \\
S1P71-A & MPT \#2 & 0.08
\end{tabular}

The test-tool volume constants indicate that volume changes due to the expansion and contraction of the test tool and the injection'withdrawal tubing result in a maximum of about $30 \%$ or less of the total volume compensation. The full effect of all volume-compensation factors is illustrated in the test-analysis figures in Section 7 that show model simulations with and without volume compensation.

\section{D.2 Borehole Compressibility.}

The three radial LVDTs on the multipacker test tools indicated that changes in radius occurred during the testing periods. The radial-LVDT responses consistently indicated that the apparent borehole radius increased with increased test-zone pressure, and decreased during the pressure reductions caused by the pulse withdrawals.

Test-zone volume-compensation data were to be derived directly from the observed radial-LVDT responses, after adjusting the observeo data for the radial expansion/compression of the radial-LVDT transducer carrier. However, during the compliance tests conducted in the steel and stainless-steel chambers (see Section 4.1), 
discrepancies were noted between the radial-LVDT data and the calculated response of the steel chamber. The observed LVDT displacement was $0.015 \mathrm{~cm}$ greater than the calculated chamber-wall expansion plus the calculated test-tool compression. Figure D-1 shows that the O-ring used to seal part of the radial-LVDT housing could be subject to a maximum of $0.051-\mathrm{cm}$ compression with increasing external pressure on the test tool churing shut-in and test conditions. The relative movement associated with $O$-ring compression would produce a radialLVDT response indicating borehole expansion. Unfortunately, the actual magnitude of this movernent during testing could not be quantified. As a result, the actual change in borehole radius could not be determined from the radial-LVDT data.

Figure D-2 is a plot of the test-zone pressure in L4P51-A along with the radius calculated from the radial-LVDT data. Figure D-2 shows that for approximately the first 90 days after borehole coring, the radius changes indicated by the LVDT data appeared to parallel changes in test-zone pressure. After approximately 90 days, however, when the radial-LVDT O-rings were presumably fully compressed, the radial-LVDT data indicated borehole closure while the test-zone pressure remained relatively constant.

The procedure used to quantify borehole-radius changes for volume compensation was based on the equation used to evaluate the effect of compression of the walls of an underground, pressurized cylindrical opening. The equation used was that developed for a pressurized borehole in rock as given in Jaeger $(1979$, Sec. 10.3.2) as follows:

$$
\Delta r_{b}=P C_{r} r_{b}(1+v)
$$

where:

$$
\begin{aligned}
& \Delta r_{b}=\text { change in borehole radius due to applied pressure } \\
& P=\text { applied intemal borehole pressure } \\
& C_{r}=\text { rock compressibility } \\
& r_{b}=\text { initial borehole radius } \\
& v \quad=\text { Poisson's ratio }
\end{aligned}
$$

For a typical borehole radius and a representative formation compressibility of $2.5 \times 10^{-11} \mathrm{~Pa}^{-1}$, the change in borehole radius was approximately $1.6 \times 10^{-4} \mathrm{~cm} / \mathrm{MPa}$. Borehole-radius change yields a test-zone-volume change as follows:

$$
\Delta V_{r a d}=\pi\left[\left(r_{b}+\Delta r_{b}\right)^{2}-r_{b}^{2}\right] L_{t}
$$

where:

$$
\begin{array}{ll}
\Delta V_{\text {rad }} & =\text { test-zone-volume change due to change in borehole radius } \\
L_{D} & =\text { test-zone length }
\end{array}
$$

The relationship between volume change and pressure can be approximated as:

where:

$$
\Delta V_{r a d}=C_{r a d} P
$$

$$
C_{\text {rad }}=\text { test-specific borehole-radius-change volume constant }
$$

A rock compressibility of $2.5 \times 10^{-11} \mathrm{~Pa}^{-1}$, derived from data in Touloukian et al. (1981) and Krieg (1984), was used to develop $C_{\text {rad }}$ for each test. The value of Poisson's ratio used in the calculations was 0.25 , a value representative of Salado Formation halite (Krieg, 1984; Van Sambeek, 1987). The values of $C_{\text {rad }}$ developed for each test analyzed in this report are as follows: 


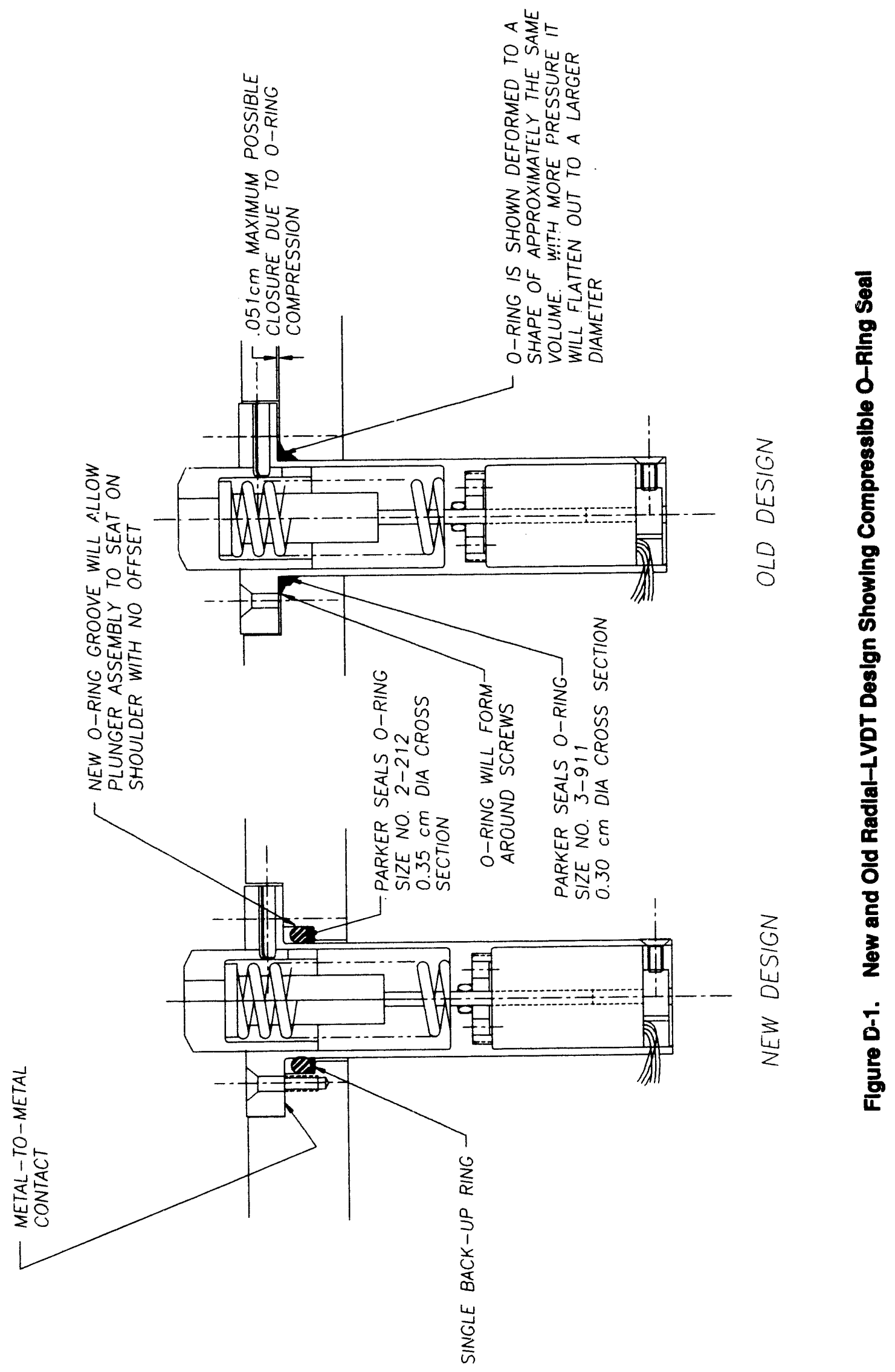




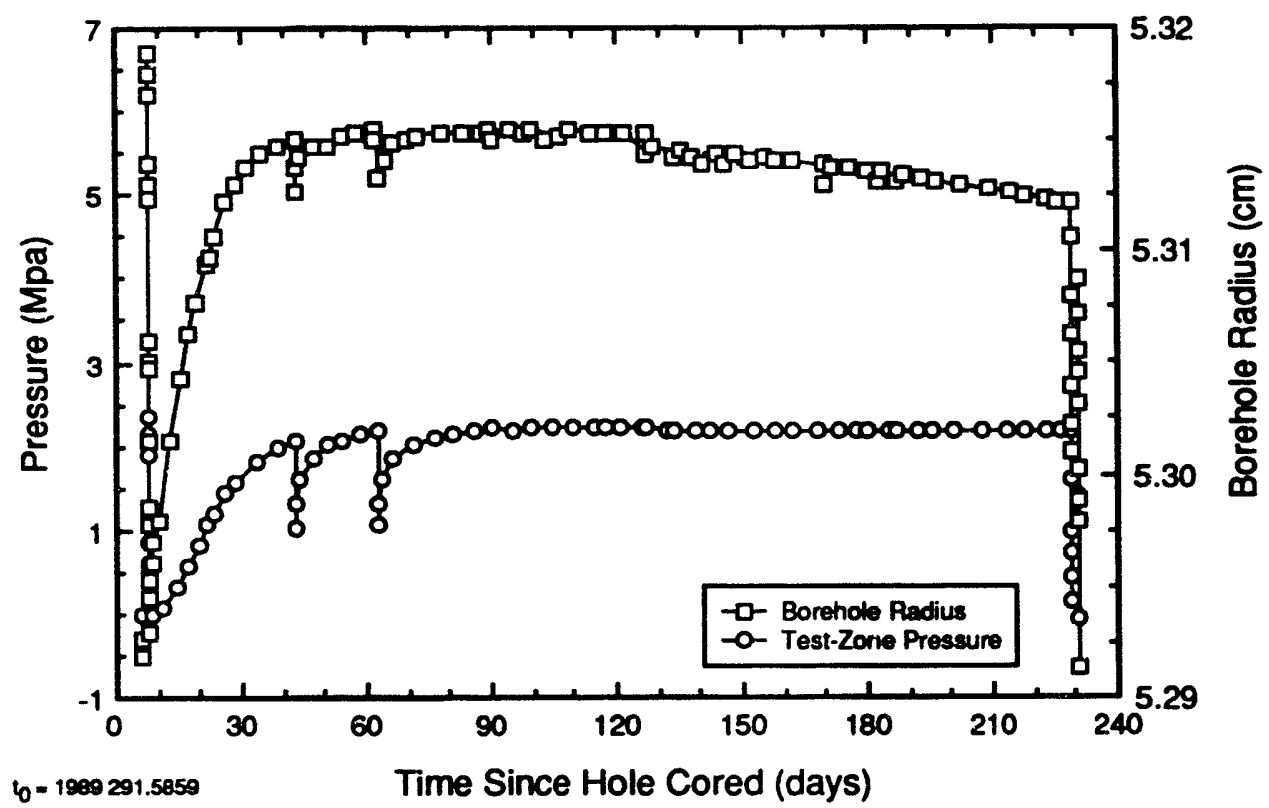

TRL-634-646-0

Figure D-2. Test-Zone Pressure and Borehole Racius During L4P51-A Testing.

Test

C2H01-A
C2H01-B
C2H01-B(GZ)
C2H01-C
C2H02
C2H02(GZ)
C2H03
N4P50
L4P51-A
SOP01
SOP01(GZ)
S1P71-A

IoOH\#

MPT \#1

MPT \#1

MPT \#1

MPT \#5

MPT \#4

MPT \#4

MPT \#5

MPT \#3, MPT \#4

MPT \#3

MPT \#3

MPT \#3

MPT \#2

\author{
$\mathrm{C}_{\text {rod }}$ Borehole \\ Volume Constant
}

1.83

0.54

0.55

1.25

0.78

0.54

0.75

0.80

0.78

0.75

0.55

0.77

These values of $C_{\text {red }}$ represent average values for the lithologies in the different test boreholes. The values of $\mathrm{C}_{\mathrm{rad}}$ indicate that the changes in borehole volume in response to changes in fluid pressure are the largest factors in the total volume compensation used in the simulations of the individual tests. The full effect of all volume compensation factors is illustrated in the test-analysis figures in Section 7.2 which show model simulations with and without voll me compensation.

\section{D.3 Axial Test-Tool Movement.}

The multipacker test tools were retained in the test boreholes by bolting a steel tie-down bar or a square-tube steel cross across the top of the tool mandrels, or by bolting a flange attached to the mandrels to the $0.51-\mathrm{m}$ long 
borehole collars which were cemented in place for every test borehole except $\mathrm{C} 2 \mathrm{H} 01$ and S1P71-A. However, while these fastening procedures were adequate for safety, they reduced but did not eliminate movement of the test tool.

The axial-LVDT responses indicated axial test-tool movement during all tests. This axial movement had two apparent causes. First, the test tools appeared to exhibit piston-like behavior in response to pressure changes in the boreholes. The test tools moved slowly out of the boreholes during buildup periods, and retracted into the boreholes at a much quicker rate during pulse withdrawals (Figure D-3). This axial movement is thought to be limited to the mandrel and other solid test-tool components. The packer element is not believed to actually slide in the hole, but to only flex slightly as the solid fest-tool components move up or down in the hole. The second factor that contributes to the apparent movement of the test tool is closure of rooms/drifts. As measured by multipoint extensometers in the WIPP underground (e.g., Westinghouse, 1990), the relative motion caused by creep closure decreases with increasing distance from an excavation, causing boreholes drilled from the excavation to elongate. With the tool anchored to the floor of the roomdrift, room closure tends to pull the test tool away from the bottom of the borehole. On the time scale of the tests discussed in this report, room closure should cause hole elongation at relatively constant rates of up to about one crn/yr (Westinghouse, 1990).

Axial test-tool movement causes changes in the test-zone volume. The total volume change associated with axial test-tool movement consists of packer intrusionextrusion relative to the test zone, test-tool-body movement, and axiafLVDT actuator-rod movement. The volume change due to axial test-tool movement is illustrated in Figure D-4, and is given by the following equation:

$$
\Delta V_{\text {ax }}=\Delta V_{\text {peacker }}+\Delta V_{\text {body }}-\Delta V_{\text {actuatior }}
$$

where:

$$
\begin{array}{ll}
\Delta V_{\text {ax }} & =\text { volume change due to axial test-tool movement } \\
\Delta \mathbf{V}_{\text {podor }} & =\text { packer intrusion/extrusion volume change } \\
\Delta \mathbf{V}_{\text {body }} & =\text { test-tool-body volume change } \\
\Delta \mathrm{V}_{\text {eaumor }} & =\text { axial-LVDT actuator-rod volume change }
\end{array}
$$

Packer intrusion into the test zone is difficult to express analytically without simplifying assumptions. The surface of the deformable packer element is assumed to form a straight line from the packer end-sub to the borehole wall. The packer element at the wall is assumed to be fixed at this point. Using these assumptions, as illustrated on Figure D-4, the change in test-tool volume due to packer intrusionvextrusion and test-tool-body movement can be combined and expressed as:

$$
\Delta V_{\text {packer }}+\Delta V_{\text {body }}=\Delta L_{a x} \frac{\pi}{3}\left[r_{b}^{2}+r_{e s}^{2}+r_{b} r_{e s}\right]
$$

where:

$$
\begin{array}{ll}
r_{o s} & =\text { packer end-sub radius } \\
r_{b} & =\text { borehole radius } \\
\Delta L_{a x} & =\text { change in axial position of the test tool }
\end{array}
$$

The final term in Equation D-12, $\Delta \mathrm{V}_{\text {equaror }}$, is expressed as:

$$
\Delta \mathrm{V}_{\text {equenor }}=\Delta \mathrm{L}_{2 \mathrm{x}} \pi \mathrm{r}^{2} \text { actuator }
$$

where:

$$
r_{\text {saumor }}=\text { radius of axial-LVDi actuator rod }
$$




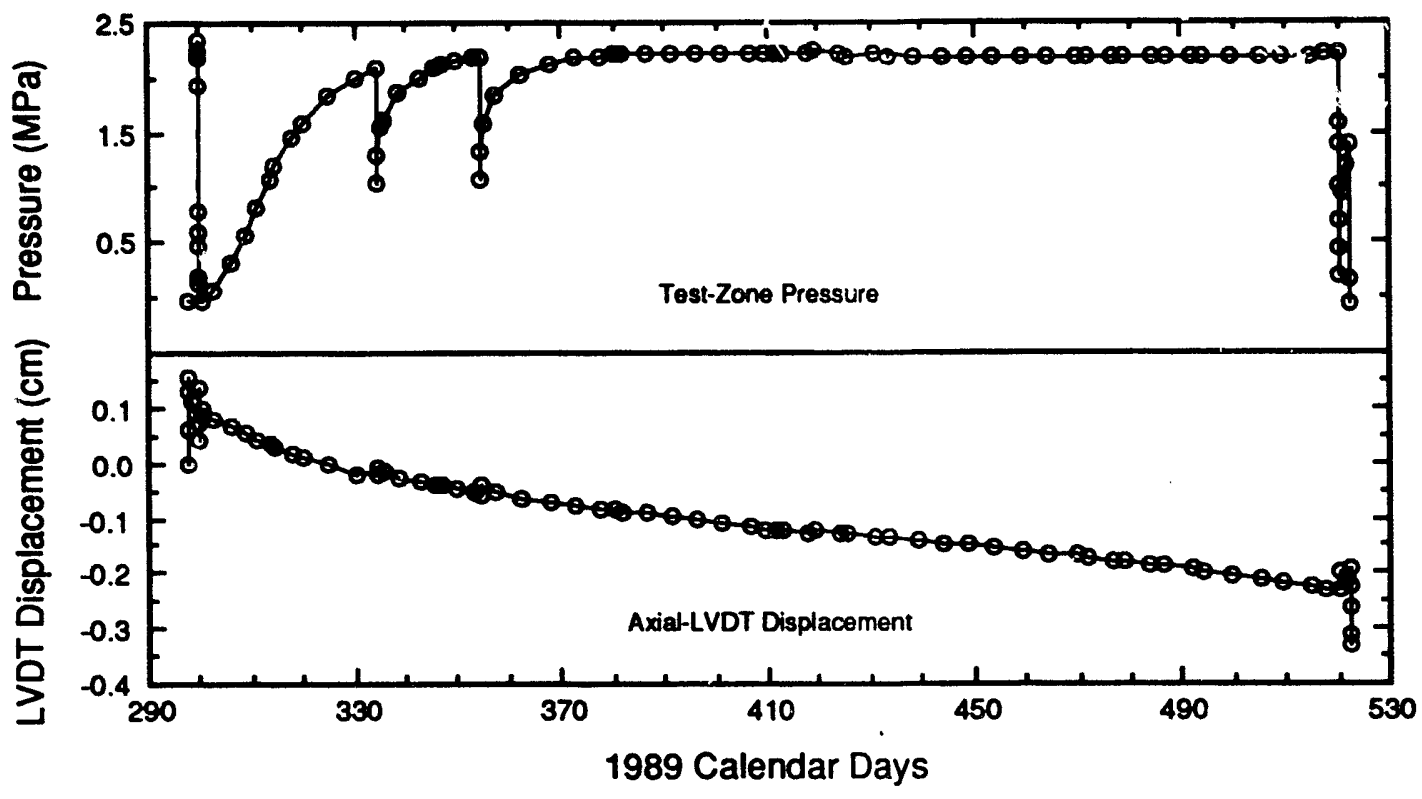

TR1-6344-647-0

Figure D-3. Test-Zone-Pressure and Axial-LVDT Data During L4P51-A Testing.

If all test-specific constant values are substituted into Equations D-13 and D-14, Equation D-12 can be expressed as:

$$
\Delta \mathrm{V}_{\mathrm{ax}}=\mathrm{C}_{\mathrm{ax}} \Delta \mathrm{L}_{\mathrm{ax}}
$$

where:

$$
\mathrm{C}_{\mathrm{ax}}=\text { test-specific axial test-tool-movement volume constant }
$$

In Equation D-15, the borehole radius is considered to be constant because the minor changes in radius determined from Equation D-9 were determined to have a negligible influence on the calculated volume change $\Delta \mathrm{V}_{\mathbf{2 x}}$.

\section{D.4 Test-Zone-Packer Deformation.}

The inflation pressures of the test- and guard-zone packers are monitored and recorded by the DAS during permeability testing. The data show that the packer-inflation pressures do not remain constant throughout the tests. Figures D-5 through D-13 show the packer-inflation pressures during each test. Assuming that the packers are not leaking, these changes in packer-inflation pressure indicate that the enclosed volume of the packer must be changing. If the intemal packer volume is changing, the extemal volume is most likely changing, which can be expected to affect the test-zone volume, and in turn, affect the test-zone compressibility.

The packer-inflation-pressure responses indicate both transient and long-term behavior. In transient behavior, the packer reacts quickly to pressure events in the test zone such as pulse withdrawals and injections. A pulse injection causes an increase in packer-inflation pressure while a withdrawal causes a decrease. Following an event which changes the initial packer-inflation pressure, the packer-inflation pressure immediately changes toward the pre-event pressure. This type of behavior reflects the expected elastic properties of the packer element. 


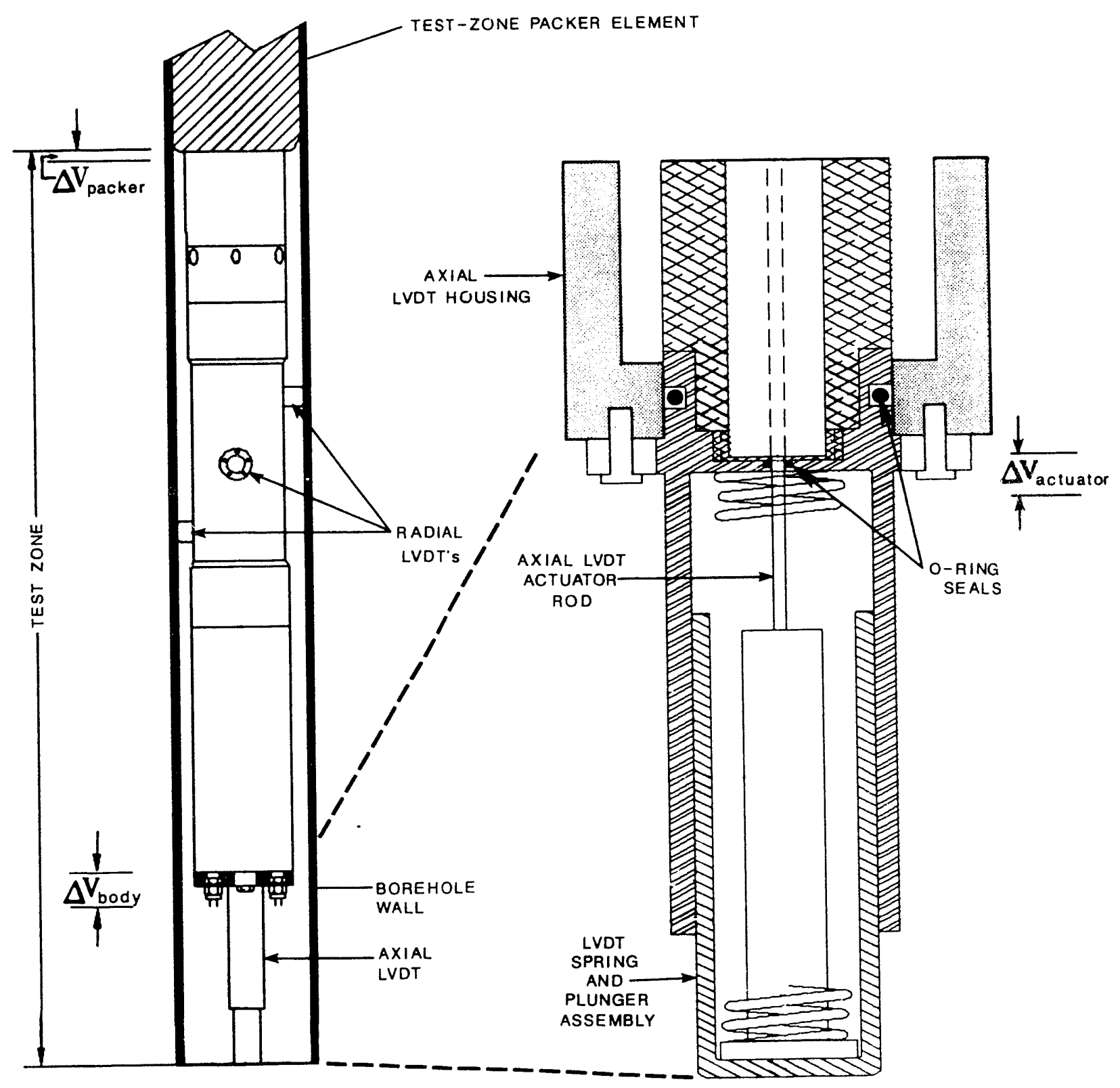

Figure D-4. Test Zone and Axial LVDT Showing Elements Contributing to Volume Change. 


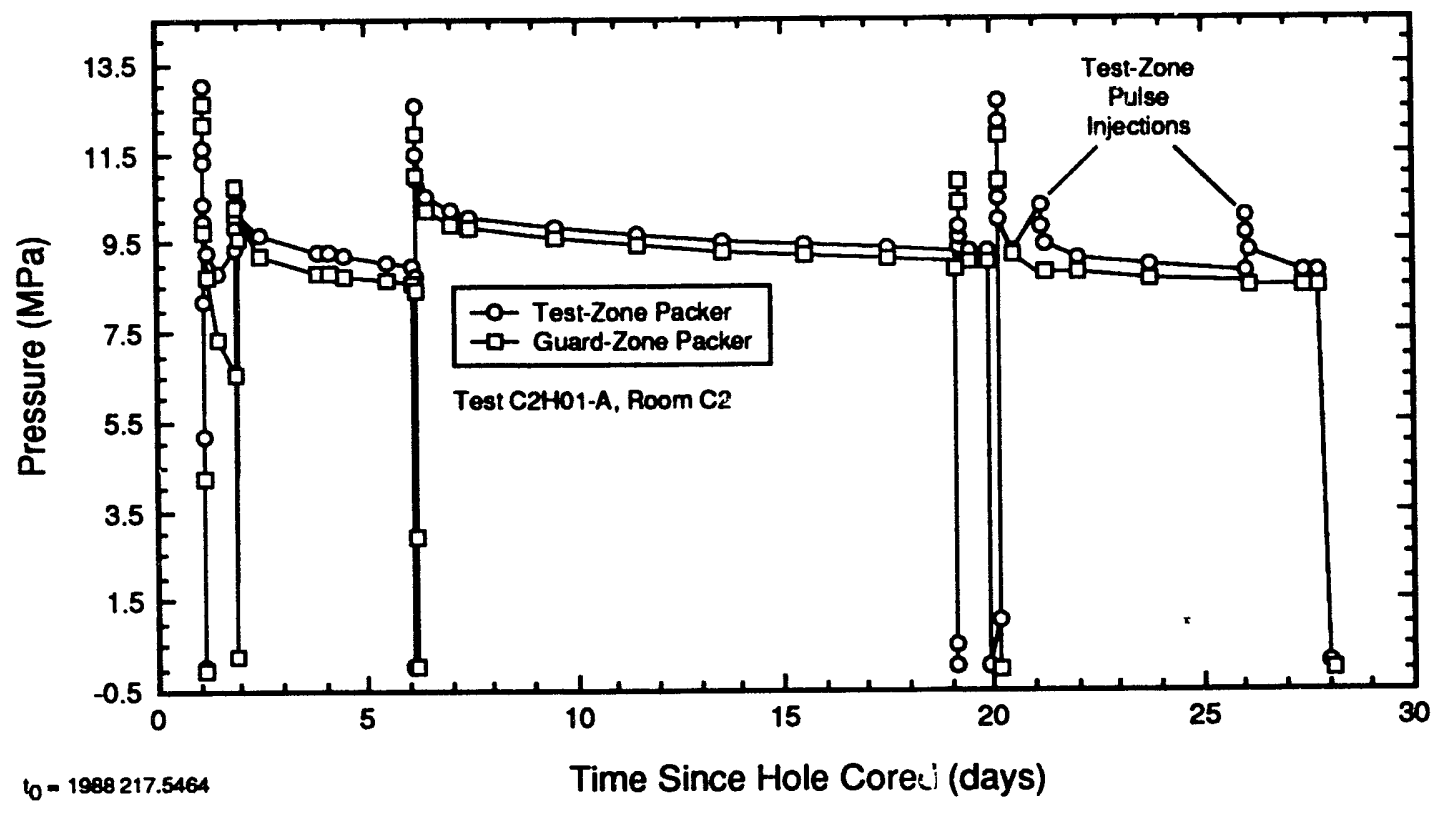

TR1-6344-648-0

Figure D-5. Test- and Guard-Zone Packer-Inflation Pressures During C2H01-A Testing.

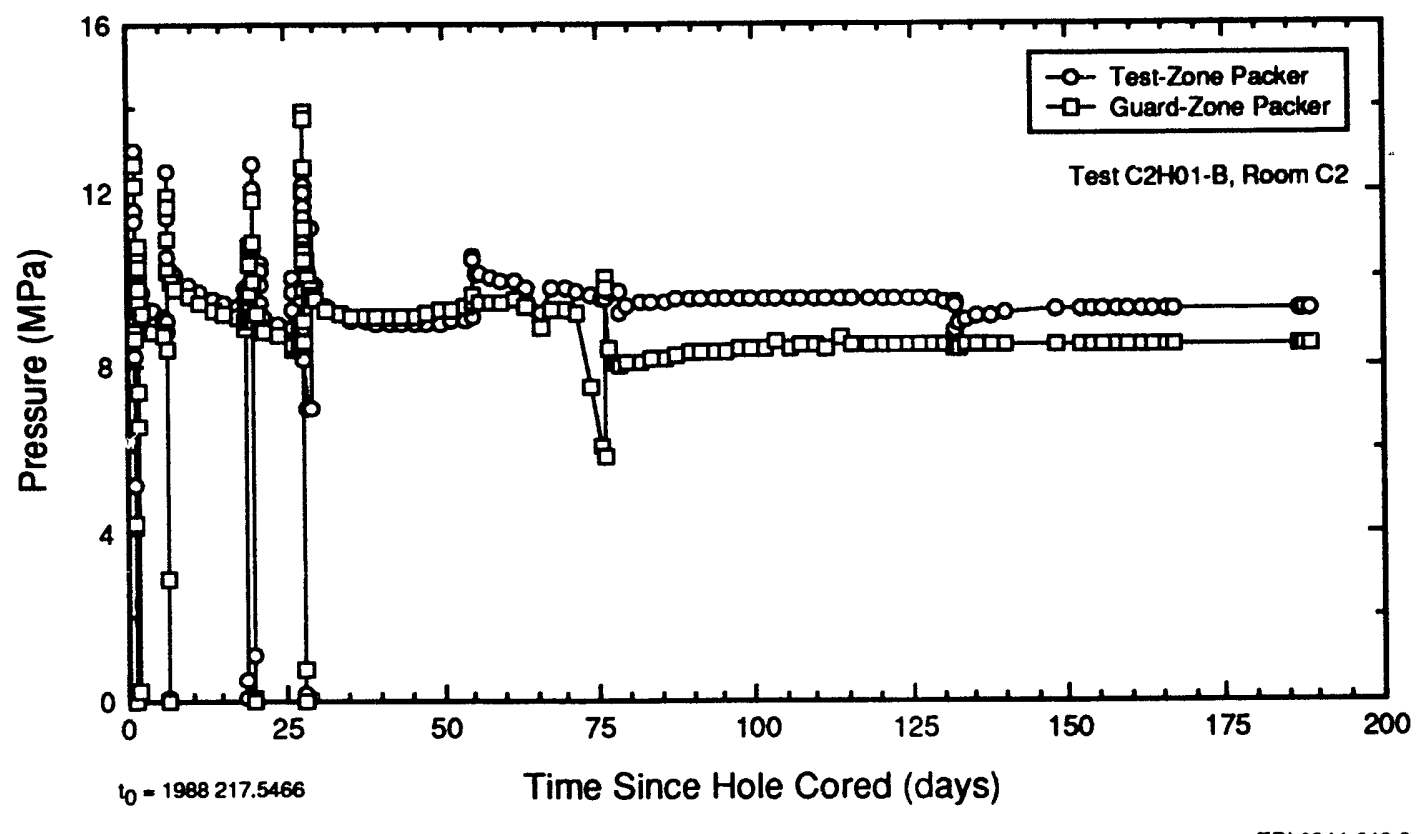

Figure D-6. Test- and Guard-Zone Packer-Inflation Pressures During C2H01-B Testing. 


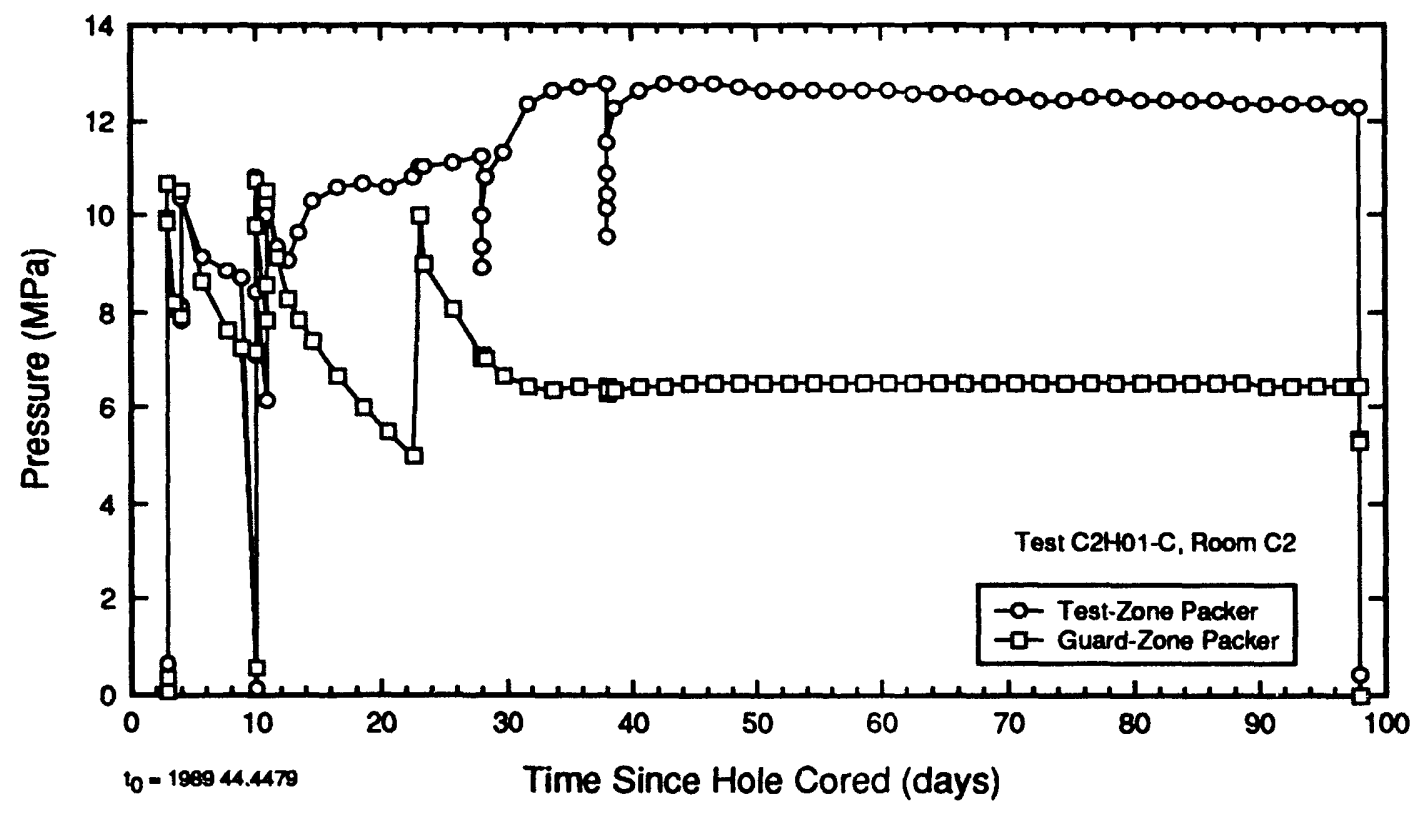

TRI-6344-650-0

Figure D-7. Test- and Guard-Zone Packer-Inflation Pressures During C2H01-C Testing.

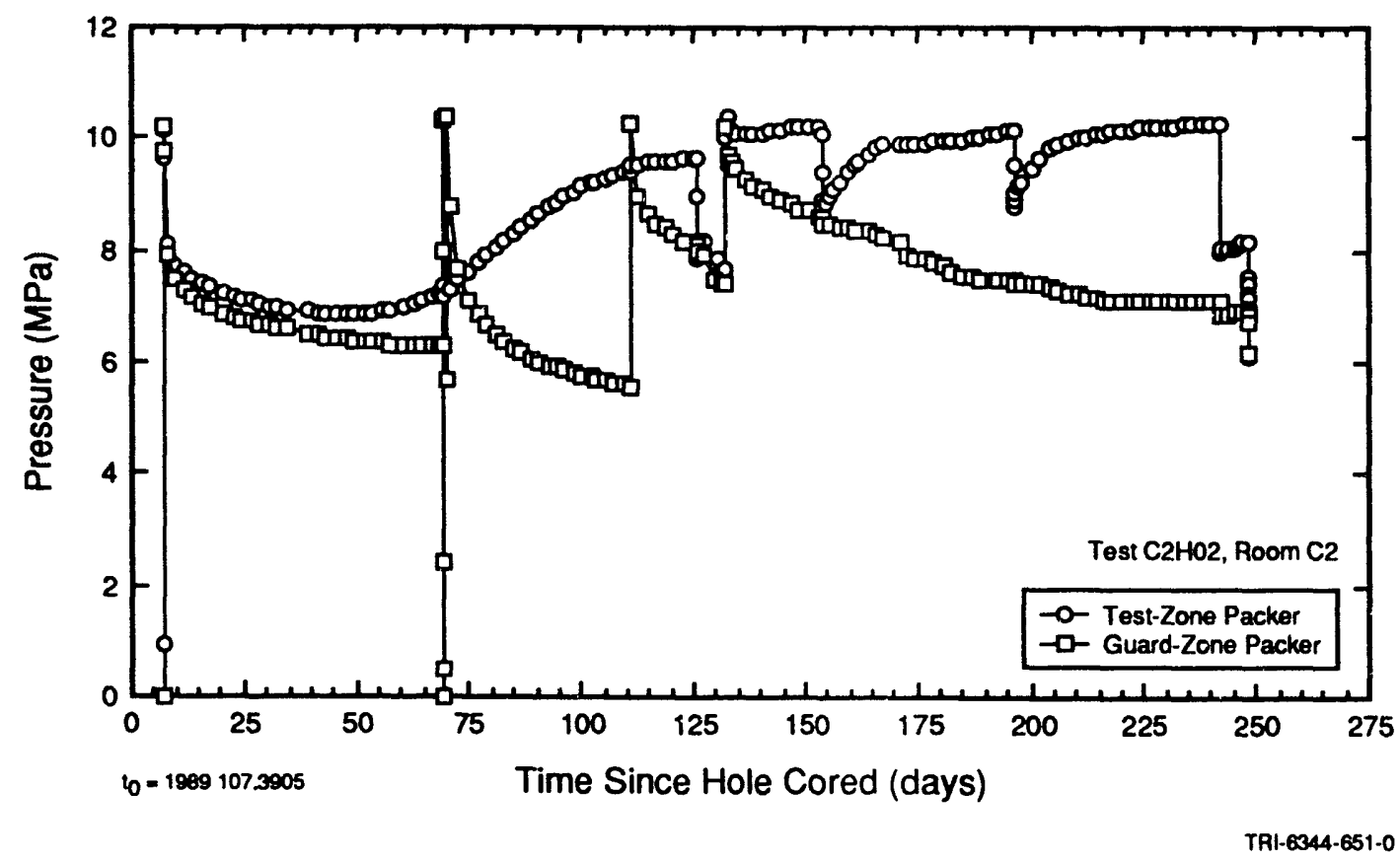

Figure D-8. Test- and Guard-Zone Packer-Inflation Pressures During C2H02 Testing. 


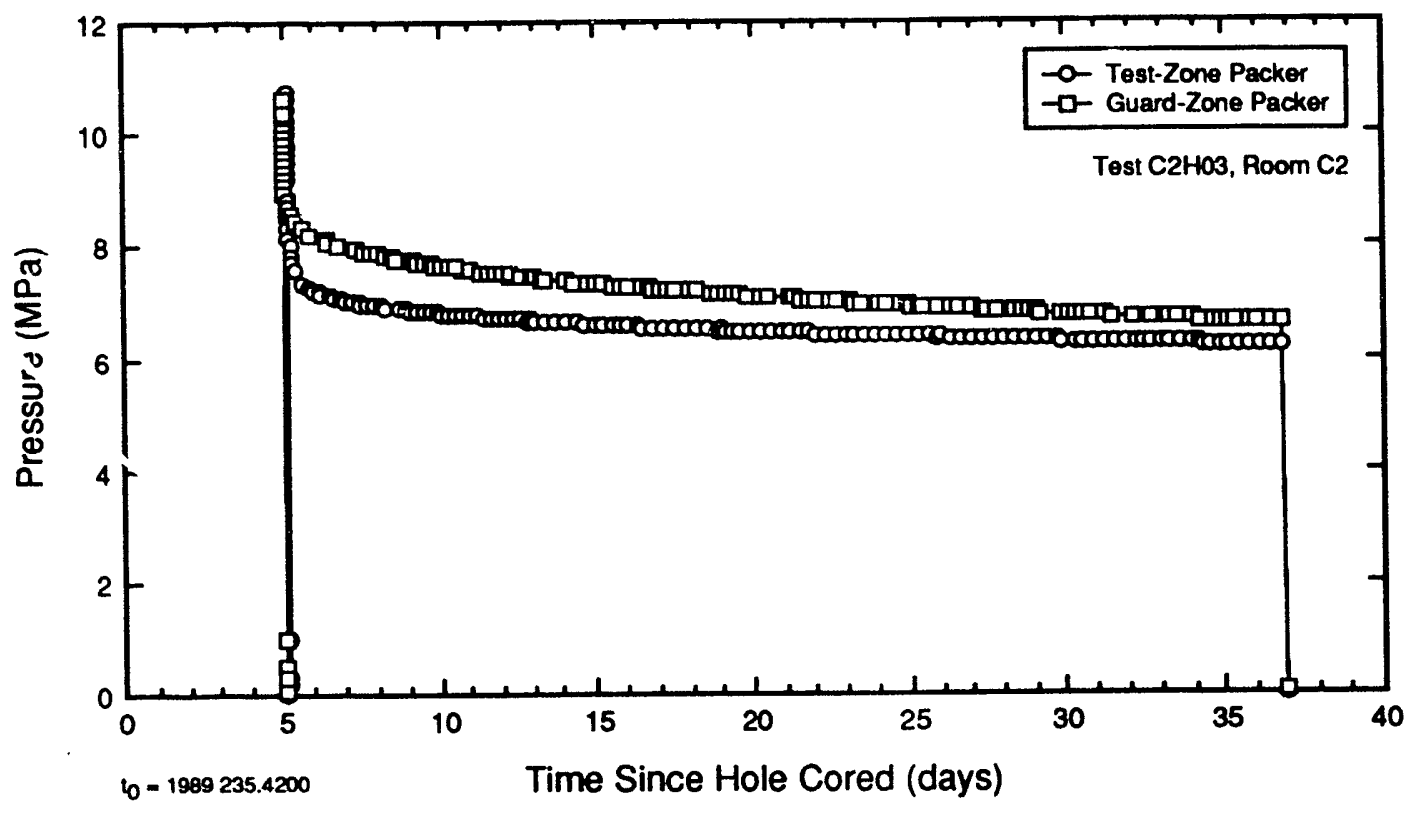

TRI-6344-652-0

Figure D-9. Test- and Guard-Zone Packer-Inflation Pressures During C2H03 Testing.

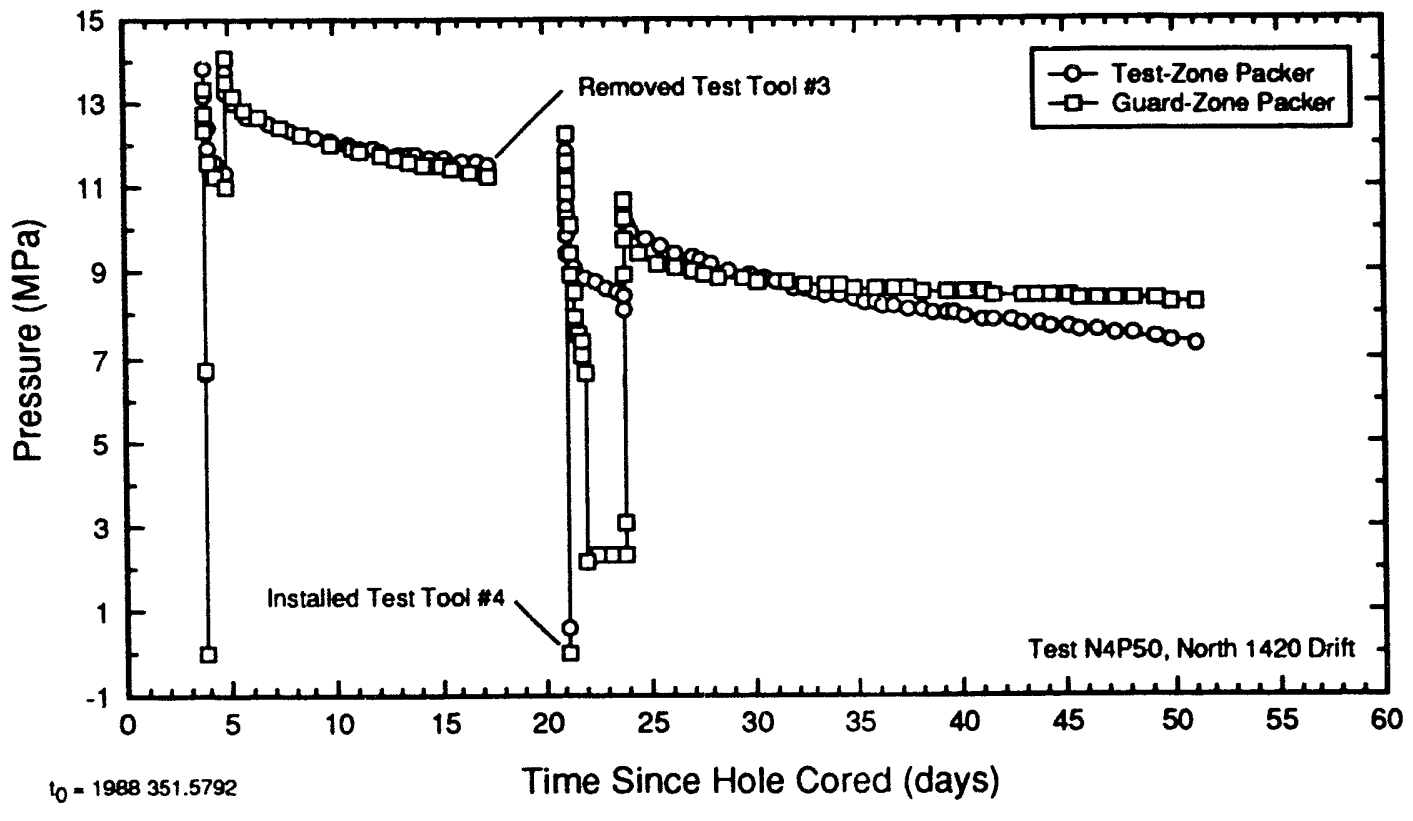

Figure D-10. Test- and Guard-Zone Packer-Inflation Pressures During N4P50 Testing. 


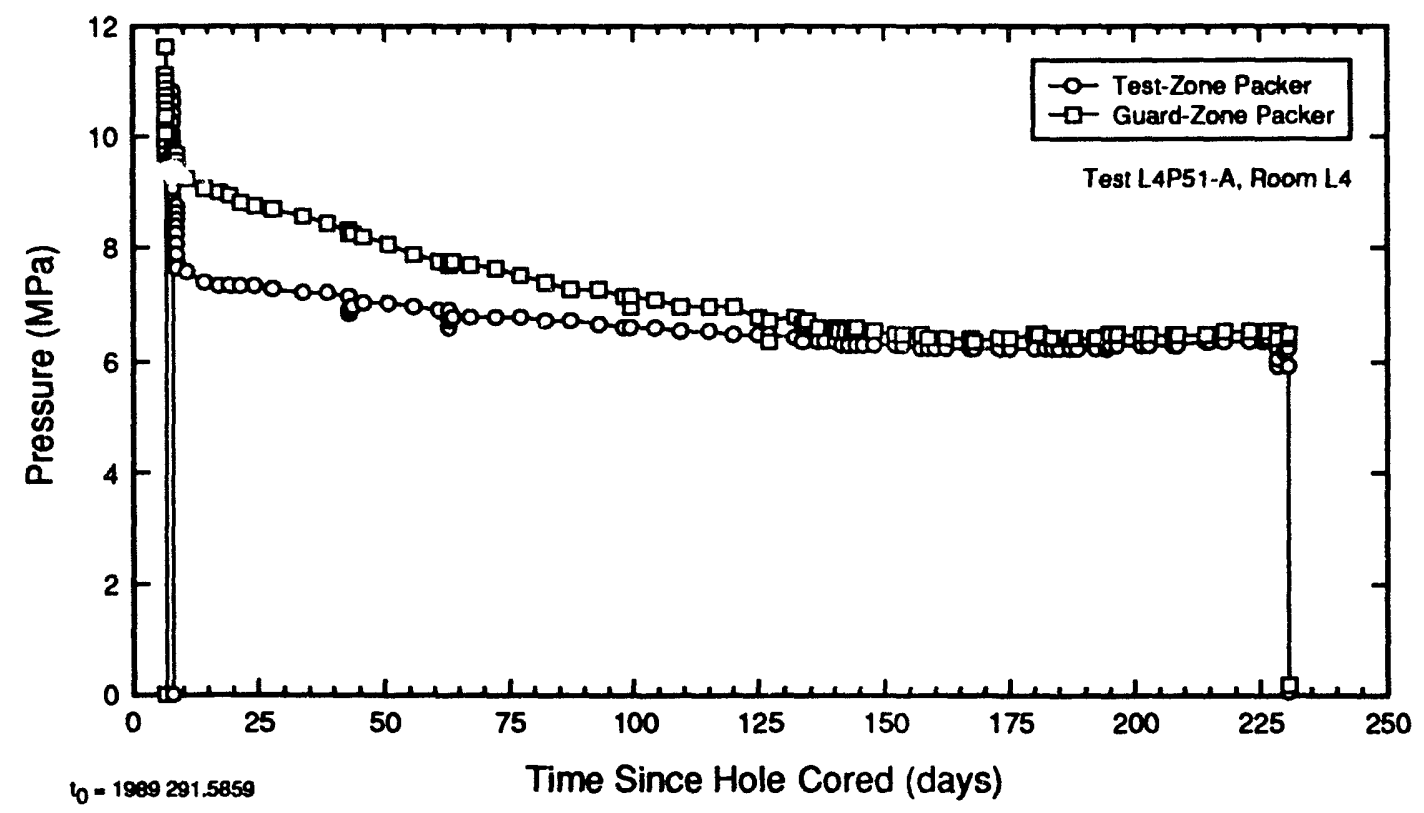

TRI-6344-654-0

Figure D-11. Test- and Guard-Zone Packer-Inflation Pressures During L4P51-A Testing.

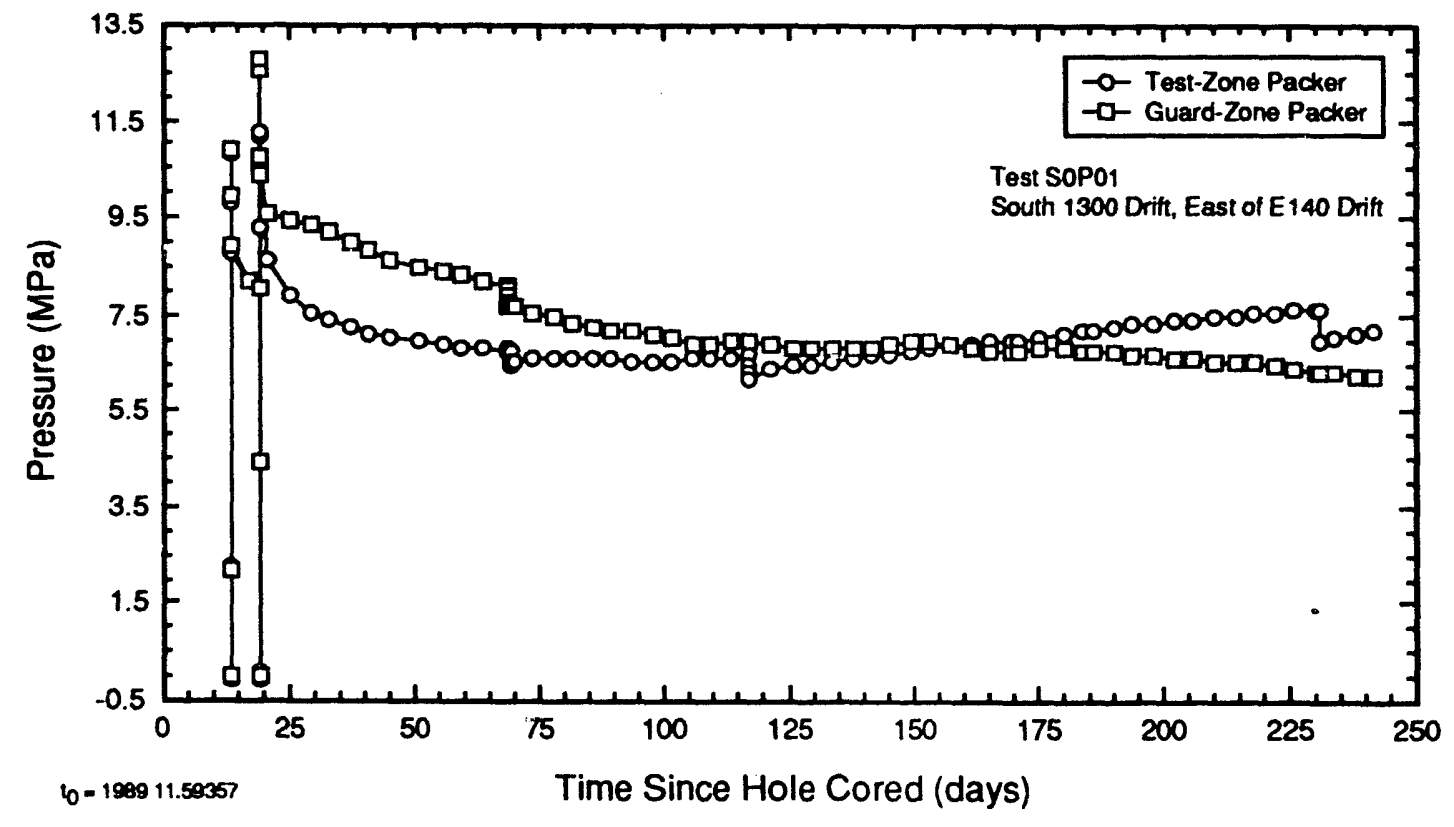

Figure D-12. Test- and Guard-Zone Packer-Inflation Pressures During SOP01 Testing. 


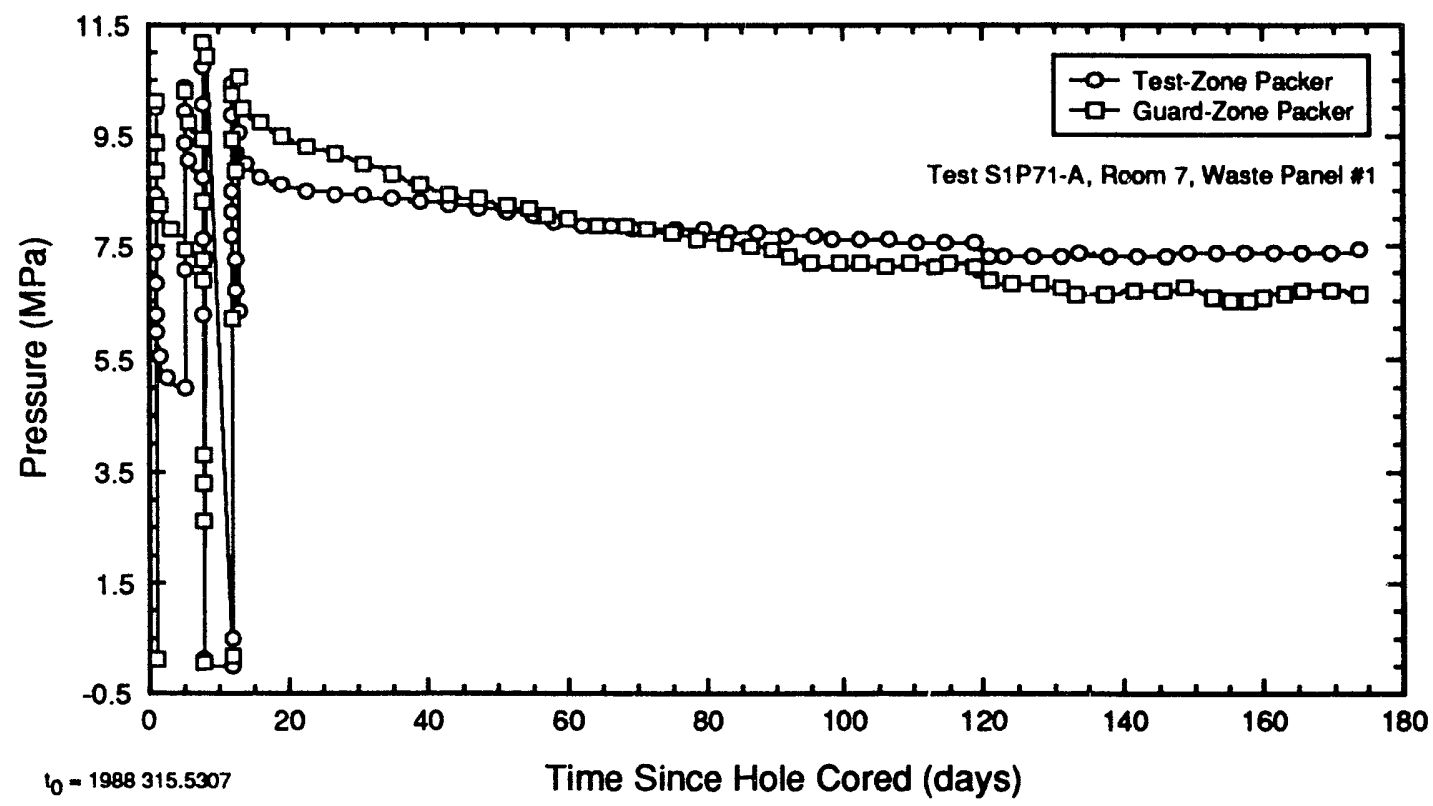

TR1-6344-656-0

Figure D-13. Test- and Guard-Zone Packer-Inflation Pressures During S1P71-A Testing.

Long-term packer-inflation-pressure responses are more difficult to characterize and explain. In most of the permeability tests, packer-inflation pressure continuously decreased during the majority of the test periods, although at a decreasing rate as the tests progressed. The decrease in packer-inflation pressure indicates that the packer volume is continually increasing, perhaps as a result of a creep-like behavior in the packer element. This behavior was confirmed by observing packer-pressure responses during compliance testing. During compliance tests, 10 to $20 \%$ reductions in packer-inflation pressures typically occurred during the first 24 to 48 hours after inflation. After increasing the packer-inflation pressures to compensate for these initial reductions, the continued reductions in packer-inflation pressures were significantly less.

During some permeability tests, particularly in $\mathrm{C} 2 \mathrm{H} 01-\mathrm{B}$ and $\mathrm{C} 2 \mathrm{H} 02$, the relative changes in the test-zone packer-inflation pressure were similar to the test-zone fluid-pressure responses, and the two pressures began tracking each other as shown on Figures D-14 (C2H01-C) and D-15 (C2H02). Figure D-14 shows that in C2H01$C$, the test-zone pressure and the test-zone-packer's inflation pressure synchronously increased and decreased in response to zone pressure buildup and pulse withdrawals. The test-zone pressure and test-zone packerinflation pressure also increased together during an increase in the guard-zone-packer's inflation pressure on the 23rd day after coring the test hole. Similar behavior was also observed in $\mathrm{C} 2 \mathrm{H} 02$ during the latter part of the testing period, when the test-zone-packer's inflation pressure was about i.5 MPa greater than the test-zone pressure. As shown on Figure D-15, the test-zone-packer's inflation pressure began decreasing after the initial shut in, and then began increasing as the test-zone pressure began to build up. Both these tests exhibited testzone pressures of about $8 \mathrm{MPa}$, which is about twice the fluid pressure observed in the test and guard zones of the other tests described in this report. Apparently, the lower pressure differentials between the test-zone packers and the test zones in $\mathrm{C}_{2} \mathrm{H} 01-\mathrm{C}$ and $\mathrm{C}_{2} \mathrm{H} 02$ caused the test-zone-packers' inflations pressures to be more sensitive to fluid-pressure changes in the test zones than during the other tests.

The actual mechanism causing the synchronous pressure changes in the test-zone pressures and the testzone-packers' inflation pressures could be as follows. Decreases in test-zone pressure, as occurs during pulse 


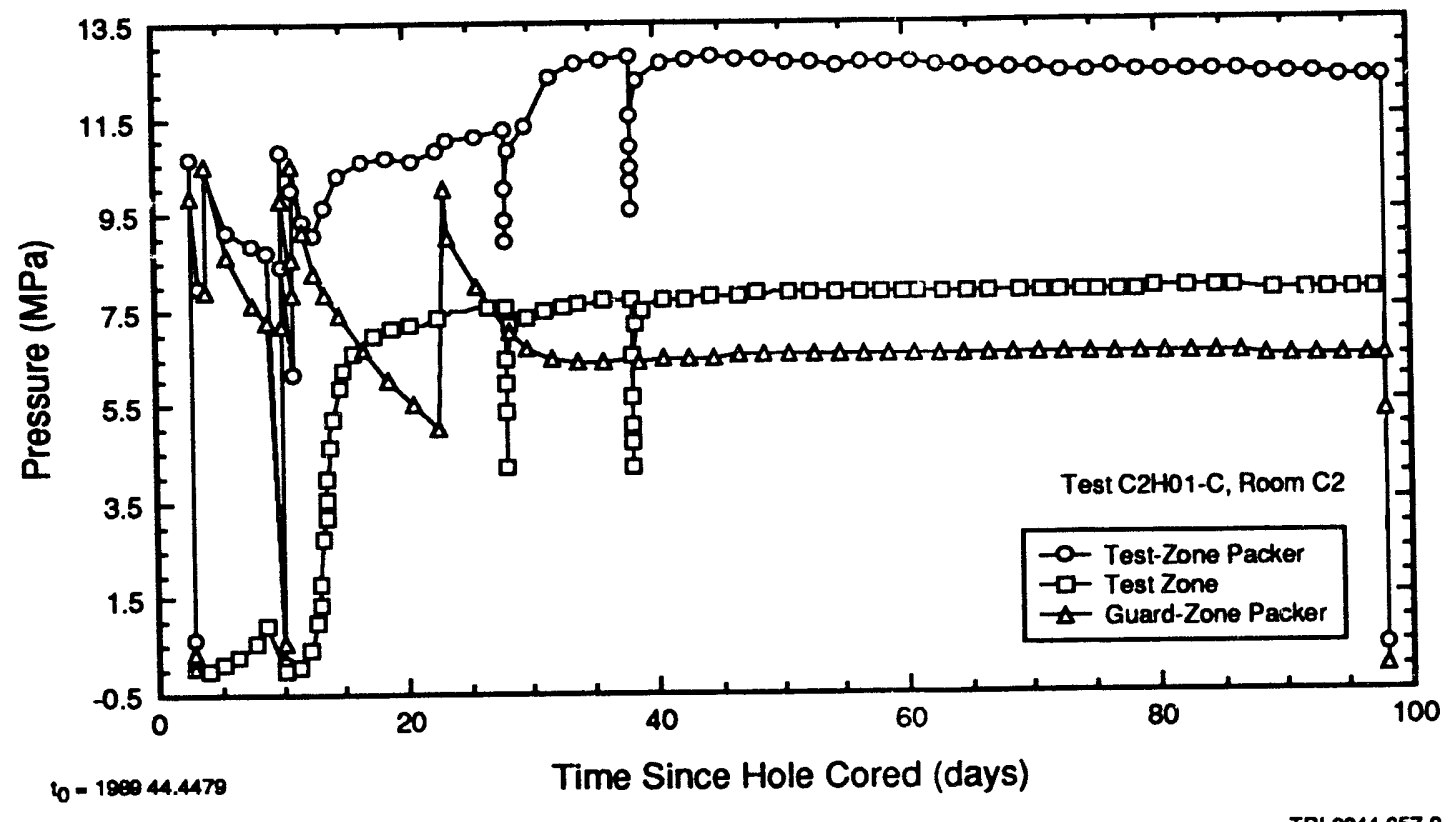

Figure D-14. Test-Zone Pressure and Test-Zone and Guard-Zone Packer-Inflation Pressures During C2H01-C Testing.

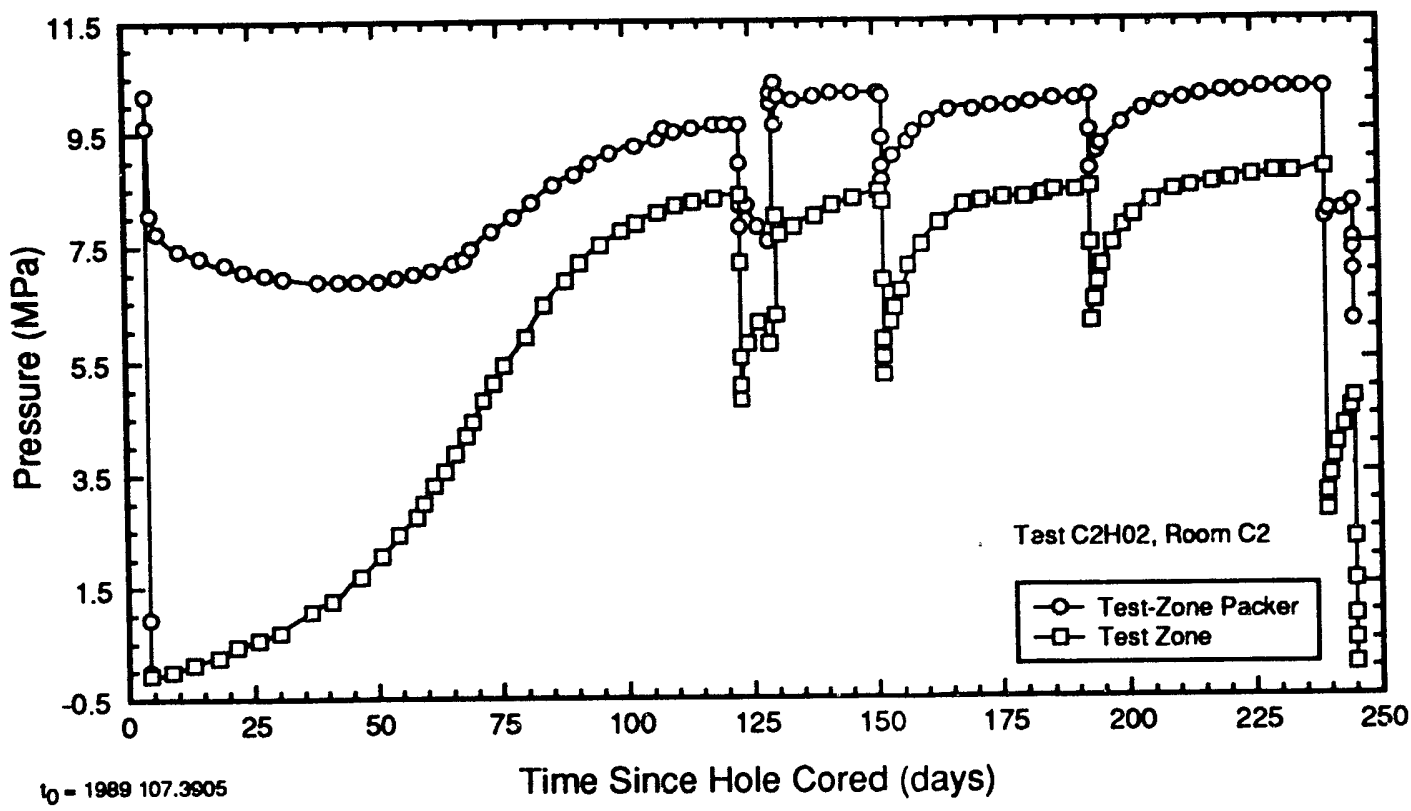

Figure D-15. Test-Zone Pressure and Test-Zone Packer-Inflation Pressure During C2H02 Testing. 
withdrawals, could decrease the external pressure on the packer element, causing an expansion of the packer element and a consequeit decrease in the packer's inflation pressure. Conversely, increases in the test-zone pressure would increase the extemal pressure on the packer element, reducing the internal volume of the packer element, thus causing an increase in the packer's inflation pressure. No evidence of leakage of test-zone pressure across the packer to the guard zone was observed in any of the tests.

Expansion of the packer elements during pulse withdrawals implies that the volumes withdrawn during the pulse withdrawals are greater than the volume changes in the test zones. Overestimates of the test-zone-volume changes result in overestimates of test-zone compressibility as calculaicd by Equation 6-9. Inasmuch as decreases in packer-inflation pressures were observed curing all pulse withdrawals, all of the test-zonecompressibility values presented in Table 6-3 may be slightly high.

Apart from the parallel behavior of the test-zone and packer-inflation pressures observed during testing in $\mathrm{C}_{2} \mathrm{H} 01-\mathrm{C}$ and $\mathrm{C}_{2} \mathrm{HO} 2$, the short- and lorig-tern changes in packer-inflation pressure indicate that a "packercompressibility factor" may be important in the test analyses. Unfortunately, insufficient data are available to incorporate such a factor in the test analyses by means of a volume-change mechanism such as that discussed in Sections D. 1 through D.3. The uncertainty in the specific internal volume of the packer systems used in each test, the quantity of entrapped gas either dissolved or present as a separate phase in the packers, the unknown nature of the elasticity of the packer elements, and the compressibility of the packer-inflation fluid make accurate determination of the changes in the internal volume of the packer system impossible.

The permeability tests analyzed for this report were conducted with packers filled by direct inflation using an intensifier pump. No attempt was made to purge the packers of air or fluid before inflation. The air in the packers before inflation was probably entrapped during the inflation process. This air may have been dissolved in the inflation fluid after the pressure was raised to 8 to $12 \mathrm{MPa}$ or may have still been present as a separate pha:?. The fluid volume used to inflate a typical packer was measured to be $2330 \pm 20 \mathrm{~cm}^{3}$. After observing a number of compliance tests in the stainless-steel compliance-testing chamber, packer-inflation procedures were modified to include complete draining and vacuum evacuation of the $\mathrm{ps}$ *kers before inflating packers for permeability-testing installations. Usirig these procedures, a typical packer inflation required approximately $2650 \mathrm{~cm}^{3}$ of fluid, about $300 \mathrm{~cm}^{3}$ more than the amount required when the packer was not completely evacuated. The absence of air, either as a separate phase or dissolved, probably reduces the compressibility of the packer system. Data from compliance and permeability tests performed after using these packer-inflation procedures will be presented in subse fuent reports.

Even if internal volume changes of a typical packer system could be determined exactly, the correlation between the intemal volume and external impact on the fluid-pressure responses of isolated test zones is problematic. For example, would a change in packer-inflation ressure resulting in a calculated $2 \mathrm{~cm}^{3}$ increase in internal packer-system volume yield a $1 \mathrm{~cm}^{3}$ decrease ir the test-zone volume and a $1 \mathrm{~cm}^{3}$ decrease in the guard-zone volume or would the change yield a $2 \mathrm{~cm}^{3}$ de rease in the test-zone volume alone? The presence of a sliding end-sub on the test-zone packer further complicates volume determinations. The guard-zone end of the testzon packer is designed to slide during packer infl ition/deflation to reduce the amount of stretching of the packer elerr ent. We do not know whether or not movemel $!$ of the sliding end-sub occurs at any other time except during packer inflation.

The compressibility of the synthetic material of the packer element is another potential component of packersystem compressibility. However, because the packer-element compressibility is difficult to quantify, its effect on test-zone volume is also difficult to assess. The area of the packer element in contact with the test-zorie fluid is approximately $43 \mathrm{~cm}^{2}$. The actual volume changes due to expansion or contraction of the packer-element material can only be determined through laboratory testing. The relatively small area of this material subject to test-zone pressure indicates that the effect of changes in the volume of packer-element material is likely to be insignificant. 


\section{D.5 Gas in the Test Zone.}

Gas was noted during some pulse withdrawals (Table 6-3). Four potential gas sources are: air entrapped in the test-zone during test-tool installation; gas generated by the reaction of the metal tool components with the test-zone brine; ga's exsolved from the formation fluid under the lower pressure in the isolated borehole intervals; and gas generated by anaerobic bacterial degradation of possible hydrocarbons in the tesi-zone fluid.

\section{D.5.1 ENTRAPPED AIR.}

In $\mathrm{C} 2 \mathrm{H} 01-\mathrm{B}, \mathrm{C} 2 \mathrm{H} 02$, SOP01, and S1P71-A, a significant quantity of air may have been introduced into the test zone as a result of the test-tool installation procedures. To prevent the fluid displaced during test-tool installation from overflowing the top of the test tool and wetting the electrical elements in the test-tool mandrel, the test tool was installed in a dry borehole and the packers were inflated. Brine was then pumped into the test and guard zones through the vent lines. The quantity of entrapped air was probably reduced in boreholes $\mathrm{C} 2 \mathrm{H} 01-\mathrm{B}$ and SOP01 because the packers were deflated to adjust the test-tools' positions after filling the test and guard zones. After adjusting the test tools' positions, the packers were then re-inflated and the test and guard zones were shut in.

The testing equipment and test-tool installation procedures for later tests were modified to reduce the possibility of entrapped air. Specifically, these modiftcations were:

1) the upper mandrel of the test tool was modified to be a sealed hollow tube to prevent overflow and entry of borehole fluid;

2) forvertically downward and downward-angled boreholes, the test boreholes are filled with fluid, and that fluid is circulated through the transducer lines and vent lines before inflating the test-zone packer to ensure that all air has been purged from these lines;

3) drainage/filling ports were added to the void spaces in the test-tool radial-LVDT connectors (swivels) to ensure that the void spaces in the swivel are filled with brine when the tool is installed in brine-filled boreholes;

4) in horizontal or vertically upwards holes where the test zones cannot be filled with brine before packer inflation, the test zones are placed under vacuum pressure, the test-zone vent lines are extended from the feed-through plug to the highest elevation possible, and the test zones are filled through the transducer lines until fluid flows from the vent lines;

5) horizontally flat surfaces on the test tool were rounded to minimize the possibility of trapping air bubbles on the test tool during test-tool installation.

The effectiveness of 2) and 5) was visually confirmed by installing the tool in a length of translucent PVC and/ or LEXAN casing before and after these modifications and examining the surface of the test-zone portion of the test tool to see where air bubbles had been eliminated by the modifications. This procedure was also used to determine the optimum placement of the vent line for procedure 4).

Including the effect of entrapped air in the test zone in the test analyses would require modification of the analysis model to incorporate a non-linear two-phase boundary condition in the test zone. A simplified version of the boundary condition would assume that the fluid and gas phases were immiscible, while a more representative implementation would allow dissolving/exsolving of gas in the test-zone fluid.

\section{D.5.2 TOOL COMPONENT/BRINE REACTION}

The early versions of the multipacker test tool consisted of packers and LVDT carriers with stainless-steel components and anodized aluminum end subs and spacers. When the test tools were removed from test boreholes after two to eight months of testing, the aluminum parts were observed to have undergone significant corrosion. Corrosion of metals by brine in the absence of oxygen results in the production of metal oxides or hydroxides and hydrogen gas. A gas sample collected from the test zone of borehole $\mathrm{C} 2 \mathrm{H} 02$ at the end of testing 
was analyzed and found to contain $91 \%$ hydrogen (Saulnier et al., 1991). Subsequently, aluminum components of the test tools were replaced with stainless steel, which exhibits much greater resistance to corrosion.

The following table lists the materials used in the test tools for each test analyzed in this report and notes the severity of corrosion indicated in the post-test examination of the test tools.

\begin{tabular}{llll} 
Test & Tool\# & Material & \multicolumn{1}{c}{ Corrosion } \\
C2H01-A & MPT \#1 & SS & None \\
C2H01-B & MPT \#1 & SS & None \\
C2H01-C & MPT \#5 & Al, SS & Minor Al Pitting \\
C2H02 & MPT \#4 & Al, SS & Severe Al Pitting \\
C2H03 & MPT \#5 & SS & None \\
N4P50 & MPT \#3, MPT \#4 & Al, SS & Minor Al Pitting \\
L4P51-A & MPT \#3 & SS & None \\
SOP01 & MPT \#3 & Al, SS & Severe Al Pitting \\
S1P71-A & MPT \#2 & Al, SS & Al Pitting
\end{tabular}

The conversion to completely stainless steel test-tools should prevent gas generation by brine corrosion. However, if gas generation through brine/tool reaction continues to occur, the inclusion in the analysis model of the effects of generated gas on the fluid-pressure responses would require modifying the analysis model to include both a method for including the effects of non-linear two-phase behavior in the test-zone, as discussed in D.5.1, and a time-varying gas-generation term.

\section{D.5.3 FORMATION GAS}

Gas dissolved in the formation fluid may be exsolving due to the reduced formation pore pressures in the vicinity of the borehole and in the test zone itself following drilling of the boreholes and/or pulse withdrawals. Few data are available as to the dissolved gas content of in situ WIPP brines (Lappin et al., 1989).

If gas is being produced from the formation, gas introduced to the test zone will have a similar impact on testzone compressibility as the other potential gas sources identified. However, unlike the other gas sources, the formation gas will also involve two-phase behavior in the formation and will require that the formation be simulated as a two-phase system. The presence of a free gas phase in the formation would cause test interpretations to underestimate formation permeability when test-zone fluid-pressure responses are analyzed with a single-phase model.

Scoping calculations to address the possibility of formation-gas exsolution will be presented in subsequent reports. If the calculations indicate that two-phase behavior significantly affects the estimated formation permeability, some of the tests in this report may be reanalyzed using a two-phase approach.

\section{D.5.4 BACTERIAL GAS PRODUCTION}

Gas could potentially be produced by anaerobic bacterial degradation of hydrocarbons in the test-zone brine. Experiments are currently being planned to assess the likelihood of this possibility, and to determine methods for reducing or eliminating bacterial gas production. If bacterial gas production cannot be eliminated, bacterial gas could potentially be included in future test analyses if the analysis model was modified as described in Section D.5.1.

\section{D.6 Creep Closure.}

Halite and argillaceous halite are considered to undergo inelastic steady-state creep in underground or enings (Krieg, 1984; Van Sambeek, 1987). Potential borehole-volume changes due to creep closure were evaluated according to the rate equation:

$$
\frac{d v}{d t}=-\Lambda_{c} v
$$


where $\Lambda_{c}$ is the steady-state strain rate in the reference secondary creep law (Van Sambeek, 1987) or:

$$
\Lambda_{c}=A_{c} e^{\frac{-Q_{c}}{R T}} \Delta \sigma^{n_{c}}
$$

where:

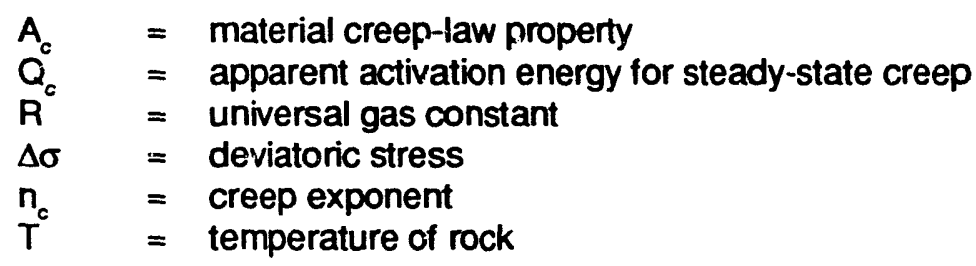

Creep ciosure was calculated for a typical test borehole in salt using the fci.'owing values for the constants in Equation D-17 (Senseny et al., 1985):

$$
\begin{array}{ll}
A_{c} & =2 \times 10^{-3} \mathrm{MPa}^{-n_{c}} / \mathrm{s} \\
\Delta \sigma & =16 \mathrm{MPa} \\
n_{c} & =5.3 \\
Q_{c} / R & =9810^{\circ} \mathrm{K} \\
T & =303^{\circ} \mathrm{K}
\end{array}
$$

The calculations showed that creep-caused radius changes of from 0.01 to $0.06 \mathrm{~mm}$, corresponding to volume changes of $3.14 \times 10^{-4}$ to $1.13 \times 10^{-2} \mathrm{~cm}^{3} / \mathrm{m}$, would occur after 120 days in a fluid-filled borehole pressurized to $3 \mathrm{MPa}$. Changes significant enough to alter test simulations would occur after several hundred days, or longer than a typical permeability test. This amount of creep closure is much less than increases in volume that were estimated for the compression of the test tool and borehole walls due to pressure buildup in the isolated test intervals. Therefore, a creep-closure term was not included in the volume compensation used in the testinterpretation simulations. Measured creep closure will be included in future volume compensations as more reliable radial-LVDT data become available. 


\section{REFERENCES}

Jaeger, C. 1979. RockMechanics and Engineering, Second Edition (Cambridge: Cambridge University Press), $523 \mathrm{pp}$.

Krieg, R.D. 1984. Reference Stratigraphy and Rock Properties forthe Waste Isolation Pilot Plant (WIPP) Project, SAND83-1908 (Albuquerque, NM: Sandia National Laboratories).

Lappin, A.R., Hunter, R.L., Garber, D.P., and Davies, P.B., ‘ditors. 1989. Systems Analysis, Long-Term Radionuclide Transport, and Dose Assessments, Waste Isolation Pilot Plant (WIPP), Southeastern New Mexico; March 1989, SAND89-0462 (Albuquerque, NM: Sandia National Laboratories).

Saulnier, G.J., Jr., Domski, P.S., Palmer, J.B., Roberts, R.M., Stensrud, W.A., and Jensen, A.L. 1991. WIPP Salado Hydrology Program Data Report \#1, SAND90-7000 (Albuquerque, NM: Sandia National Laboratories).

Senseny, P.E., Pfeifle, T.W., and Mellegard, K.D. 1985. Constitutive Parameters for Salt and Nonsalt Rocks from the Detten, G. Friemel, and Zeeck Wells in the Palo Duro Basin, Texas, BMI/ONWI-549 (Columbus, OH: Battelle Memorial Institute).

Touloukian, Y.S., Judd, W.R., and Roy, R.F., editors. 1981. Physical Properties of Rccks and Minerals. McGrawHill/Cindas Data Series on Material Properties, Volune II-2, 548 pp.

Van Sambeek, L.L. 1987. Thermal and Thermomechanical Analyses of WIPP Shaft Seals, SAND87-7039 (Albuquerque, NM: Sandia National Laboratories).

Westinghouse Electric Corporation. 1990. Geotechnical Field Data and Analysis Report, July 1988-June 1989, Volume II, DOEMIPP 90-006 (Carlsbad, NM: US DOE).

Young, W.C. 1989. Roark's Formulas for Stress and Strain, Sixth Edition (New York: McGraw-Hill), 763 pp. 


\section{DISTRIBUTION:}

U. S. Department of Energy (5)

Office of Civilian Radioactive Waste

Management

Office of Geological Repositories

Forrestal Building

Washington, DC 20585

Deputy Director, RW-2

Associate Director, RW-10

Office of Program Administration and Resources Management

Associate Director, RW-20

Office of Facilities Siting and De:yalopment

Associate Director, RW-30

Office of Systems Integration and Regulations

Associate Director, RW-40

Office of External Relations and Policy

U. S. Department of Energy (3)

Albuquerque Operations Office

P.O. Box 5400

Albuquerque, NM 87185

J. E. Bickel

R. Marquez, Director

Public Affairs Division

U. S. Department of Energy/AL

Attn: National Atomic Museum Librarian

P.O. Box 5400

Albuquerque, NM 87185

U. S. Department of Energy (6)

WIPP Project Office (Carlsbad)

P.O. Box 3090

Cartsbad, NM 88221
A. Hunt
V. Daub
R. Batra
J. Carr
R. Becker
D. Blackstone

U. S. Department of Energy

Research \& Waste Management Division

P.O. BoxE

Oak Ridge, TN 37831

W. R. Bibb, Director

U. S. Department of Energy

Richland Operations Office

Waste Management Division

P.O. Box 550

Richland, WA 99352

R. F. Guercia

U. S. Department of Energy (6)

Office of Environmental Restoration and Waste

Washington, DC 20585

J. Lytle -- EM30

M. Frei -- EM34(3)

M. Duff --. EM34

C. Frank --- EM50

U. S. Department of Energy (2)

Idaho Operations Office

Fuel Processing and Waste

Management Division

785 DOE Place

Idaho Falls, ID 83402

U. S. Department of Energy

Savannah River Operations Office

Defense Waste Processing Facility

Project Office

P.O. Box A

Aiken, SC 29802

W. D. Pearson

U. S. Environmental Protection Agency (2)

Office of Radiation Programs (ANR460)

Washington, DC 20460

M. Cotton

R. Clark 
U. S. Nuclear Regulatory Commission (4)

Division of Waste Management

Mail Stop 623SS

Washington, DC 20555

J. Bunting, HLEN 4H3OWFN

R. Ballard, HLGP 4H3OVWFN

J. Philip

NRC Library

U. S. Geological Survey (2)

Water Resources Division

Suite 200

4501 Indian School, NE

Albuquerque, NM 87110

New Mexico Institute of Mining and

Technology (3)

Environmental Evaluation Group

7007 Wyoming Blvd., NE, Suite F-2

Albuquerque, NM 87109

R. H. Neill, Director

NM Department of Energy \& Minerals

P.O. Box 2770

Santa Fe, NM 87501

K. LaPlante, Librarian

New Mexico State Engineers Office

District II, $909 \mathrm{E}$. Second

P.O. Box 1717

Roswell, NM 88201

A. Mason

NM Environmental Improvement Division 1190 St. Francis Dr.

Santa Fe, NM 87503

Deputy Director

U. S. Geological Survey

Conservation Division

P.O. Box 1857

Roswell, NM 88201

W. Melton
New Mexico Bureau of Mines and Mineral Resources (2)

Socorro, NM 87801

F. E. Kottolowski, Director

J. Hawley

U. S. Geological Survey

431 National Center

Reston, VA 22092

C. E. Neuzil

Battelle Pacific Northwest

Laboratories

Battelle Boulevard

Richland, WA 99352

Library

Bechtel Inc. (2)

P.O. Box 3965

45-11-B34

San Francisco, CA 94119

E. Weber

H. Taylor

Westinghouse Electric Corporation (5)

P.O. Box 2078

Carlsbad, NM 88221

Library
A. L. Trego
R. F. Cook
R. Richardson
R. F. Kehrman

INTERA Inc. (12)

6580 Austin Center Blvd., \#300

Austin, TX 78731

G. E. Grisak

J. F. Pickens

G. J. Saulnier (5)

J. D. Avis

G. A. Freeze

M. Reeves

T. L. Cauffman

Library 
INTERA Inc. (2)

8100 Mountain Rd. PI., NE

Albuquerque, NM 87110

D. T. Upton

A. M. LaVenue
INTERA Inc. (5)

P.O. Box 2123

Carlsbad, NM 88221

W. A. Stensrud

M. D. Fort

R. A. Roberts

J. B. Palmer

T. F. Dale

IT Corporation (2)

P.O. Box 2078

Carisbad, NM 88221

D. Deal

IT Corporation (4)

5301 Central Ave., NE

Suite 700

Albuquerque, NM 87108

R. F. McKinney

M. E. Crawley

R. M. Holt

J. Myers

RE/SPEC, Inc.

P.O. Box 725

Rapid City, SD 57709

Library

RE/SPEC, InC.

P.O. Box 14984

Albuquerque, NM 87191

Library

S-Cubed

P.O. Box 1620

La Jolla, CA 92038

E. Peterson

University of Arizona

Department of Nuclear Engineering

Tucson, AZ 85721

J. G. McCray
University of Wisconsin-Madison

Department of Geology and Geophysics

1215 W. Dayton St.

Madison, WI 53706

H. F. Wang

The Pennsylvania State University

Materials Research Laboratory

University Park, PA 16802

D. Roy

Texas A\&M University

Center of Tectonophysics

College Station, TX 77840

J. Handin

South Dakota School of Mines

Dept. of Geology and Geological Engineering

Rapid City, SD 57701

W. M. Roggenthen

University of New Mexico (2)

Geology Department

Albuquerque, NM 87131

M. Campana

Library

New Mexico Tech (4)

Department of Geoscience

Socorro, NM 87801

J. Wilson

F. Phillips

C. S. Chen

R. S. Bowman

Argonne National Laboratory 9700 South Cass Avenue

Argonne, IL 60439

D. Hambeley

Los Alamos National Laboratory

Los Alamos, NM 87545

B. Erdal, CNC-11 
Brookhaven National Laboratory

Associated Universities, Inc.

Upton, NY 11973

P. W. Levy, Senior Scientist

Center for Nuclear Waste Regulatory

Analysis

Southwest Research Institute

6220 Culebra Rd.

San Antonio, TX 78228-0510

P. K. Nair

National Academy of Sciences, WIPP Panel:

Dr. Charles Fairhurst, Chairman

Department of Civil and Mineral Engineering

University of Minnesota

500 Pillsbury Dr., SE

Minneapolis, MN 55455

Dr. Frank L. Parker

Department of Environmental and Water Resources Engineering

Vanderbilt University

Nashville, TN 37235

Dr. John O. Blomeke

3833 Sandy Shore Drive

Lenoir City, TN 37771

Dr. John D. Bredehoeft

Western Region Hydrologist

Water Resources Division

U. S. Geological Survey (M/S 439)

345 Middlefield Road

Menlo Park, CA 94025

Howard Adler

Oak Ridge Associated Universities

Medical Sciences Division

P.O. Box 117

Oak Ridge, TN 37831-0117

Dr. Fred M. Ernsberger

250 Old Mill Road

Pittsburgh, PA 15238

\author{
Dr. Rodney C. Ewing \\ Department of Geology \\ University of New Mexico \\ 200 Yale, NE \\ Albuquerque, NM 87131 \\ Dr. Leonard F. Konikow \\ U.S. Geological Survey \\ MS 431
}

Reston, VA 22092

B. John Garrick

Pickard, Lowe, and Garrick, Inc.

Sulte $\mathbf{4 0 0}$

4590 MacArthur Blvd.

Newport Beach, CA 92660-2027

Jeremiah O'Driscoll

Jody Inc.

505 Valley Hill Dr.

Atlanta, GA 30350

Dr. Christopher G. Whipple

Electric Power Research Institute

3412 Hillview Avenue

Palo Alto, CA 94303

Dr. Peter B. Meyers, Staff Director

National Academy of Sciences

Committee on Radioactive Waste

Management

2101 Constitution Avenue

Washington, DC 20418

Dr. Geraldine Grubs: Staff Officer

National Academy of Sciences

Board on Radioactive Waste

Management

GF456

2101 Constitution Avenue

Washington, DC 20418

Hobbs Public Library

509 N. Ship Street

Hobbs, NM 88248

M. Lewis, Librarian 
New Mexico Tech

Martin Speere Memorial Library

Campus Street

Socorro, NM 87810

Southwest Collection

New Mexico State Library

325 Don Gaspar

Santa Fe, NM 87503

N. McCallan

Zimmerman Library

University of New Mexico

Albuquerque, NM 87131

Z. Vivian

WIPP Public Reading Room

Atomic Museum

Kirtland East AFB

Albuquerque, NM 87185

G. Schreiner

WIPP Public Reading Room

Carlsbad Municipal Library

101 S. Halagueno St.

Carlsbad, NM 88220

L. Hubbard, Head Librarian

Dr. Thomas Sahr

New Mexico Water Resources Institute

New Mexico State University

Box 3167

Las Cruces, NM 88003-3167

Mr. Leonard Slosky

Slosky and Associates

Suite 1400

Bank Western Tower

1675 Tower

Denver, CO 80202

Mr. Newal Squyres

Holland \& Hart

P.O. Box 2527

Boise, ID 83701
Dr. Arthur Kubo

Vice President

BDM International, Inc.

7915 Jones Branch Drive

McLean, VA 22102

Mr. Robert Bishop

Nuclear Management Resources Council

Suite $\mathbf{3 0 0}$

1776 I Street, NW

Washington, DC 20006-2496

British Nuclear Fuels, PLC

Risley, Warrington, Cheshire

WA3 6AS 1002607 GREAT BRITAIN

D. R. Knowles

Institut für Tieflagerung (4)

Theodor-Heuss Strasse 4

D-3300 Braunschweig

FEDERAL REPUBLIC OF GERMANY

K. Kuhn

Bundesanstalt für

Geowissenschaften

und Rohstoffe

Postfach 510153

D-3000 Hannover 51

FEDERAL REPUBLIC OF GERMANY

$M$. Langer

Hahn-Meitner Institut für

Kernforschung

Glienicker Strasse 100

100 Berlin 39

FEDERAL REPUBLIC OF GERMANY

W. Lutze

Bundesministerium für Forschung und Technologie

Postfach 200706

D-5300 Bonn 2

FEDERAL REPUBLIC OF GERMANY

Rolf-Peter Randl 


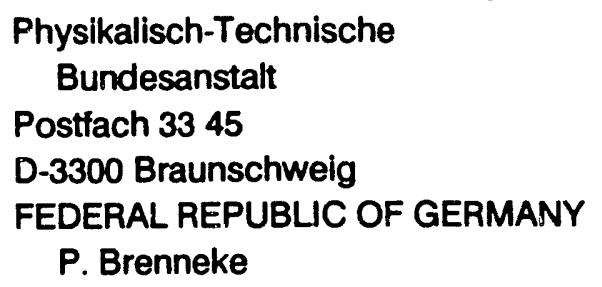

Kernforschung Karisruhe

Postfach 3640

D-7500 Karlsruhe

FEDERAL REPUBLIC OF GERMANY

K. D. Closs

Japan Atomic Energy Research Institute

Tokai-Muri, Naka-Gun

Ibaraki-Ken 319-11, JAPAN

Shingo Tashiro

Svensk Kărnbränsleforsorjning $A B$

Project KBS

Karnbranslesakerhet

Box 5864

S-102 48 Stockholm, SWEDEN

F. Karlsson

Svensk Kärnbrănslehantering $A B$

Box 5864

S-102 48 Stockholm, SWEDEN

K.-E. Almén

Atomic Energy of Canada, Ltd. (3)

Whiteshell Nuclear Research

Establishment

Pinewa, Manitoba, CANADA

ROE 1LO

P. Haywood

C. C. Davison

D. Stevenson
Studiecentrum Voor Kernenergie

Centre D'Energie Nucleaire

SCK/CEN

Boeratang 200

B-2400 Mol, BELGIUM

A. Ronne

Agence Nationale pour la Gestion des

Déchets Radioactifs

Route du Panorama Robert Schuman

B.P. 38

92.266 Fontenay-aux-Roses

Cedex, FRANCE

L. Dewiere

Ontario Hydro Research Lab (2)

800 Kipling Avenue

Toronto, Ontario, CANADA

M8Z 5S4

D. K. Mukerjee

A. T. Jakubick

Centre D'Etudes Nucleaires

De La Vallee Rhone

CEN/NALRHO

S.D.H.A. BP 171

30205 Bagnols-Sur-Ceze, FRANCE

C. Sombret

OECD Nuclear Energy Agency

Division of Radiation Protection and Waste Management

38, Boulevard Suchet

75016 Paris, FRANCE

J-P Olivier

Netherlands Energy Research

Foundation ECN (2)

3 Westerduinweg

P.O. Box 1

1755 ZG Petten, THE NETHERLANDS

T. Deboer, Mgr.

L. H. Vons 
Nationale Genossenschaft für die

Lagerung Radioaktiver Abfälle (2)

Parkstrasse 23

CH-5401 Baden, SWITZERLAND

S. Vomvooris

M. Thury

Sveriges Geologiska AB

Pusterviksgatan 2

S-413 01 Goteborg, SWEDEN

A. Winberg

National Institue of Public Health and Environmental Protection (2)

Antonie von Leeuwenhoeklaan 9

P.O. Box 1

3720 BA Bilthoven, THE NETHERLANDS

S. M. Hassanizadeh

P. Glasbergen

Environment Canada

National Water Research nstitute

Canada Centre for Inland Lakes

867 Lakeshore Road

P.O. Box 5050

Burlington, Ontario

L7R 4A6 CANADA

K. S. Novakowski

Technical Research Center of Finland Nuclear Engineering Laboratory

P.O. Box 169

SF-00181 Helsinki, FINLAND

V. Tahassalo

University of British Columbia

Department of Geological Sciences

Vancouver, British Columbia

V6T IW5 CANADA

R. A. Freeze

ANDRA

31 Rue de la Federation

75015 Paris, FRANCE

D. Alexandre, Deputy Director
Oak Ridge National Laboratory

Building 2001

Ecological Sciences Information

Center

P.O. Box X

Oak Ridge, TN 37830

C. S. Fore

National Ground Water

Information Center

6375 Riverside Drive

Dublin, $\mathrm{OH} 43017$

J. Bix

University of California (j)

Lawrence W. Berkeley Laboratory

Berkeley, CA 94720

K. Karasaki

C. F. Tsang

J. C. S. Long

Utrecht University (2)

Institute of Earth Sciences

HPT Lab/Dept. of Geology

Budapestlaan 4

P.O. Box 80.021

3508 TA Utrecht, THE NETHERLANDS

C. J. Peach

C. J. Spiers

Kansas Geological Survey

University of Kansas

1930 Constant Avenue, Campus West

Lawrence, KS 66046

J. Butler

Roswell Public Library

301 N. Pennsylvania Avenue

Roswell, NM 88201

N. Langstori

U. S. Geological Survey (2)

Water Resources Division

345 Middlefield Rd.

Menlo Park, CA 94025

P. A. Hsieh

A. F. Moench 
Texas A\&M University

Department of Geology

College Station, TX 77843

P. A. Domenico

Pannell Library

New Mexico Junior College

Lovington Highway

Hobbs, NM 88240

R. Hill

Government Publications Dept.

General Library

University of New Mexico

Albuquerque, NM 87131

Savannah River Laboratory (6)

Aiken, SC 29801

N. Bibler

E. L. Albenisius

M. J. Plodinec

G. G. Wicks

C. Jantzen

J. A. Stone

Savannah River Plant

Building 704-S

Aiken, SC 29808

R. G. Baxter

Arthur D. Little, Inc.

Acorn Park

Cambridge, MA 01240-2390

C. R. Hadlock

University of Arizona

Department of Hydrology

Tucson, AZ 85721

S. P. Neuman

Golder Associates (2)

4104 148th Avenue NE

Redmond, WA 98052

T. W. Doe

C. Voss
SAIC

10260 Campus Point Drive

San Diego, CA 92121

H. R. Pratt

SAIC

Suite 1250

160 Spear St.

San Francisco, CA 94105

M. B. Gross

SAIC

101 Convention Center Dr.

Las Vegas, NV 89109

G. Dymmel

Thomas Brannigan Library

106 W. Hadley St.

Las Cruces, NM 88001

D. Dresp, Head Librarian

L. Lehman and Associates, Inc.

1103 W. Burnsville Parkway

Suite 209

Minneapolis, MN 55337

L. Lehman

D. W. Powers

Star Route Box 87

Anthony, TX 79821 
Sandia Internal:

$\begin{array}{ll}1510 & \text { J. W. Nunziato } \\ 1511 & \text { D. F. McTigue } \\ 1514 & \text { C. M Stone } \\ 1520 & \text { C. W. Peterson } \\ 3141 & \text { S. A. Landenberger (5) } \\ 3145-1 & \text { C. L. Ward, for DOE/OSTI (8) } \\ 3151 & \text { G. C. Claycomb (3) } \\ 6000 & \text { D. Hartley } \\ 6232 & \text { W. R. Wawersik } \\ 6253 & \text { N. R. Warpinski } \\ 6300 & \text { T. O. Hunter } \\ 6310 & \text { T. E. Blejwas } \\ 6311 & \text { A. L. Stevens } \\ 6312 & \text { F. W. Bingham } \\ 6313 & \text { L. E. Shephard } \\ 6314 & \text { L. S. Costin } \\ 6315 & \text { F. B. Nimick } \\ 6316 & \text { R. P. Sandoval } \\ 6340 & \text { W. D. Weart } \\ 6340 & \text { S. Y. Pickering } \\ 6341 & \text { R. C. Lincoln }\end{array}$

6341

6342

6342

6342

6342

6343

6344

6344

6344

6344

6344

6344

6344

6344

6345

6345

6346

6346

9325

9333

8523-2

8524
Sandia WIPP Central Files (5)

D. R. Anderson

P. Vaughn

M. G. Marietta

R. P. Rechard

T. M. Schultheis

E. D. Gorham

R. L. Beauheim

P. B. Davies

S. J. Finley

S. M. Howarth

A. L Jensen

T. F. Corbet

S. W. Webb

B. M. Butcher

F. T. Mendenhall

R. E. Finley

J. R. Tillerson

L. J. Keck

J. W. Mercer

Central Technical Files (1)

J. A. Wackerly (SNLL Library) 

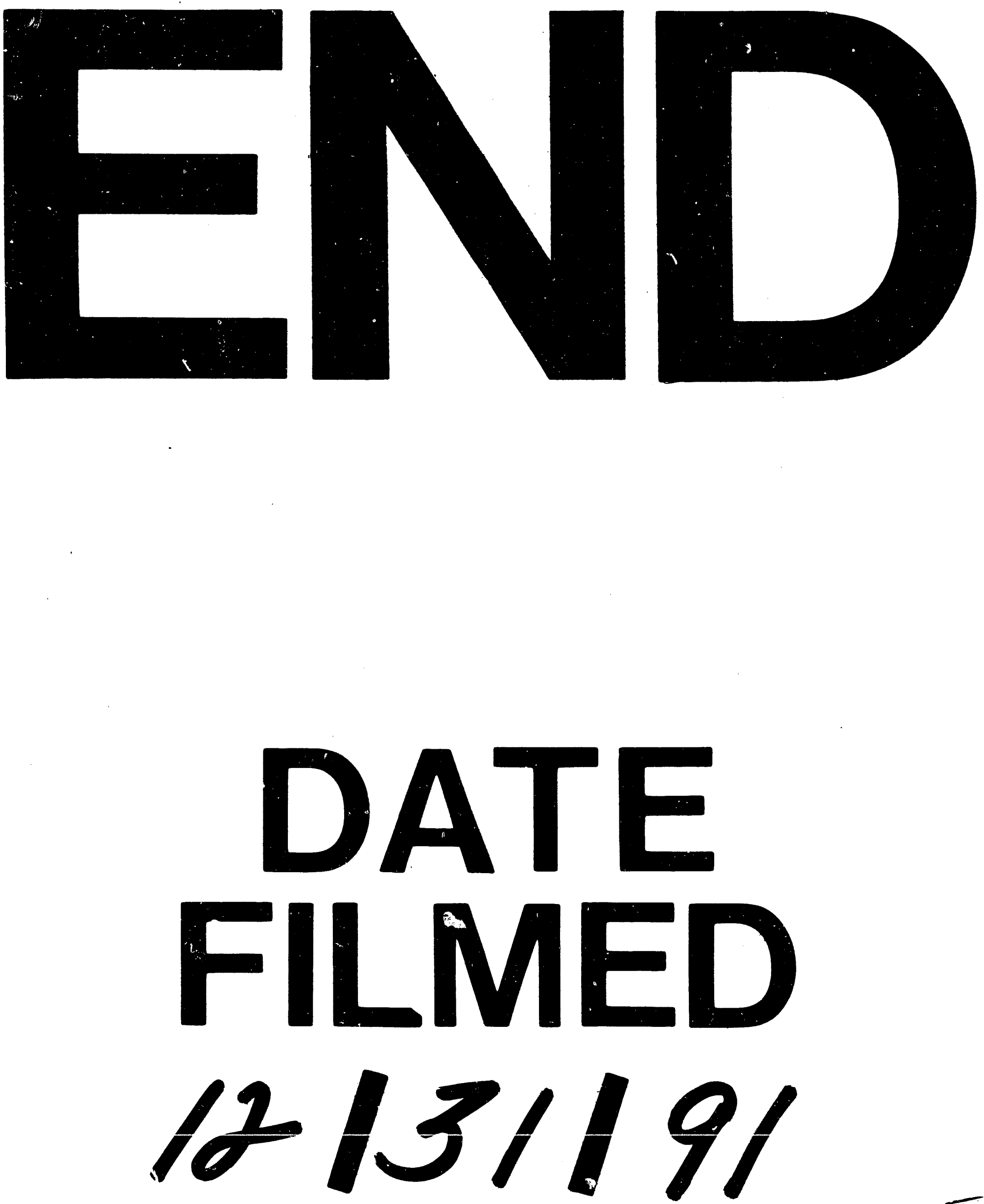
